\title{
DISSERTATION
}

\section{THREE ESSAYS ON HEALTH AND LABOR OUTCOMES}

\author{
Submitted by \\ Ian Michael Breunig \\ Department of Economics
}

\author{
In partial fulfillment of the requirements \\ For the Degree of Doctor of Philosophy \\ Colorado State University \\ Fort Collins, Colorado
}

Spring 2011

Doctoral Committee:

Advisor: David Mushinski

Martin Shields

Stephan Weiler

Sammy Zahran 
Copyright by Ian Breunig 2011

All Rights Reserved 


\section{ABSTRACT OF DISSERTATION}

\section{THREE ESSAYS ON HEALTH AND LABOR OUTCOMES}

This dissertation is composed of three essays which examine the effects of health on labor market outcomes. Chapter 1 reviews the literature on health and the labor market. It also emphasizes the inherent endogeneity of health when included in models for labor market outcomes. It goes on to highlight the empirical methods most often used to accommodate that endogeneity.

In chapter 2, I use 2000 to 2007 data from the Medical Expenditure Panel Survey (MEPS) to examine the role of health status in decisions to transition to self-employment. Much of the past literature has incorporated health status in models for self-employment in a perfunctory fashion. I account for unobserved heterogeneity and endogenous initial conditions using a discrete factor random effects model. Three hypotheses for the direct effect of health on the self-employment decision are put forth. The indirect effect that health may have in determining one's valuation of health insurance coverage is controlled for in the model. Regression results indicate that individuals who experience any sort of functioning limitation, or who report relatively poorer health, are more likely to transition to self-employment over wage-employment, holding all else constant. Although the magnitude of the impact of health status varies between two sub-groups of the population studied. 
Chapter 3 examines the extent to which a spouse's ill-health influences the labor supply decisions of the older men and women. Spouses' ill-health is likely to affect their partner's labor supply decision in off-setting ways. I control for the income effect due to the increase in the probability of an ill spouse to leave the labor force. Therefore, my estimates reflect the direct impact of a spouse's ill-health on the partner's labor supply decision through its effect on the partner's reservation wage. However, it is likely that spouses' earnings are endogenous in these models due to unobserved characteristics common to husbands and wives. I find that the estimated effect of a wife's ill health on their partner's labor supply decision is dependent on whether I instrument the spouse's earnings. I also find that the estimated effect of husbands' and wives' ill health on their partners'labor supply decision is dependent on the health measure used in the models. 


\section{ACKNOWLEDGEMENTS}

I would first like to thank my family, particularly my wife, Amber Hackstadt, and parents, Jeffrey and Viola Breunig, for their longstanding support of my academic pursuits. I would also like to thank my friends and colleagues at Colorado State University for their guidance and general interest regarding my work.

Thank you to my advisors as well as the other faculty and staff of the Department of Economics at Colorado State University for their continued guidance and support during my pursuit of a degree. I'd most like to thank Dr. David Mushinski for not only all of the hard work and time he has spent in editing multiple drafts of this dissertation but also for the valuable mentor that he has become over the years.

I'd also like to thank Professors William Weber and Bruce Domazlicky at Southeast Missouri State University for inspiring me to continue my studies in Economics after receiving my undergraduate degrees.

Last, but in no way the least, thank you to the Ewing Marion Kauffman Foundation, for their financial support during the writing of this dissertation. The value of their support far exceeded any monetary gain. 
This research was funded in part by the Ewing Marion Kauffman Foundation. The contents of this publication are solely the responsibility of Ian Breunig. 


\section{TABLE OF CONTENTS}

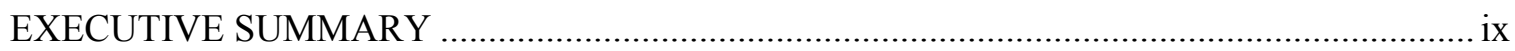

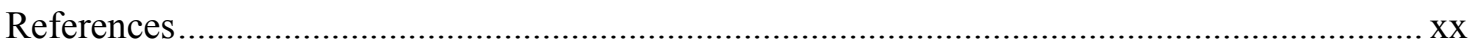

CHAPTER I: The Endogenous Nature of Health in Models for Labor Market Outcomes ............. 1

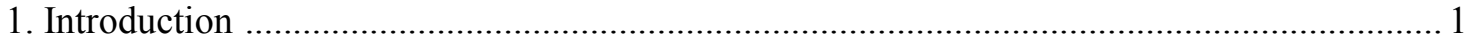

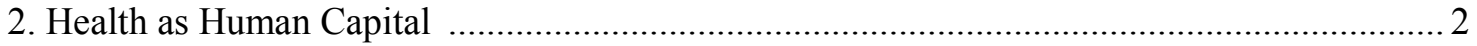

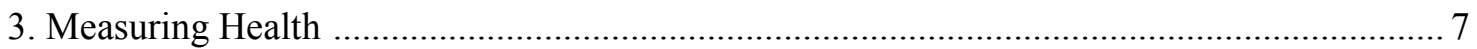

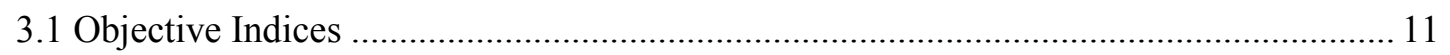

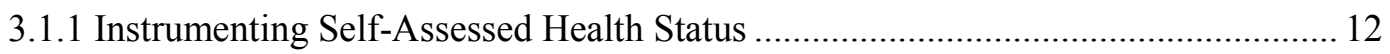

3.1.2 Summary Dichotomous Indicators and Summary Indices ................................... 13

3.1.3 Principal Component Analysis and Summary Indices Supplied by Data Sets ........ 14

4. Methods for Estimating Health Effects on Labor Market Outcomes ................................... 19

4.1 Two-Stage versus Full Information Maximum Likelihood Estimation ......................... 20

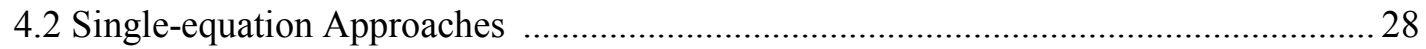

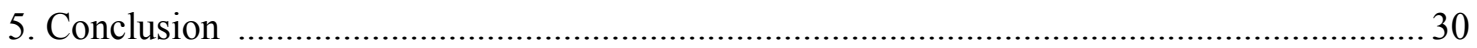

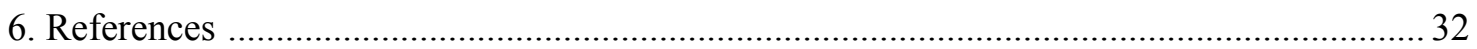

CHAPTER II: The Impact of Health on the Self-Employment Decision ..................................... 36

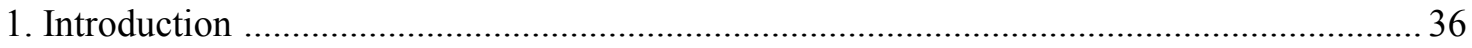

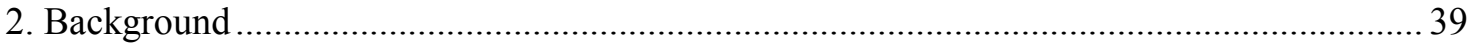

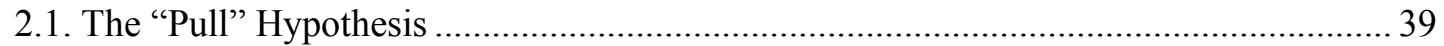

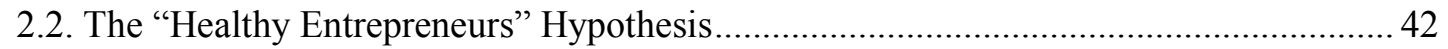

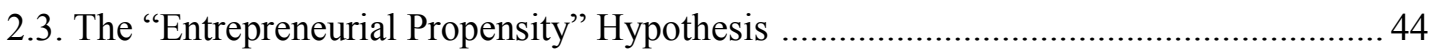

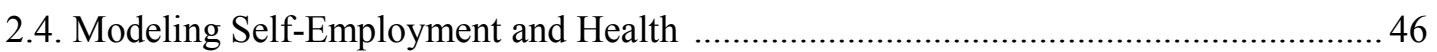

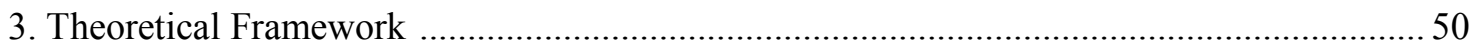

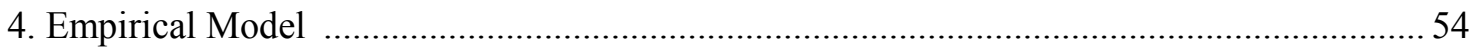

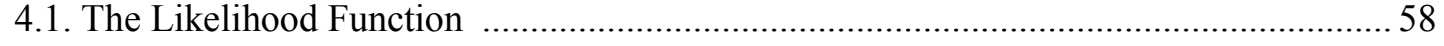

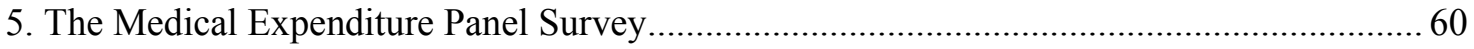

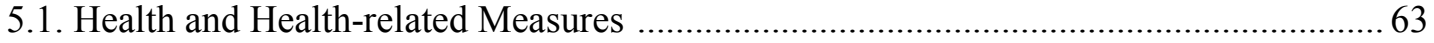




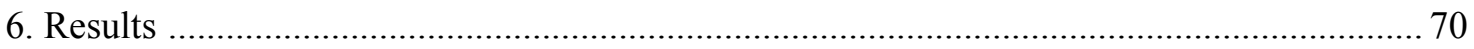

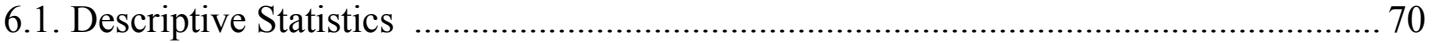

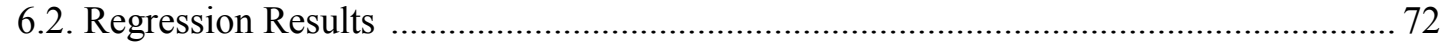

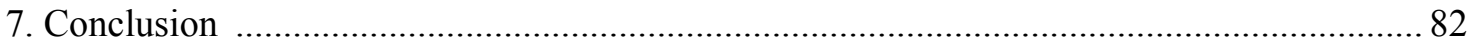

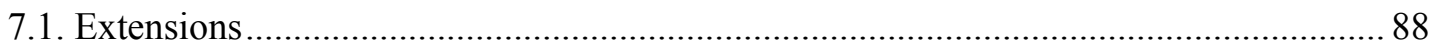

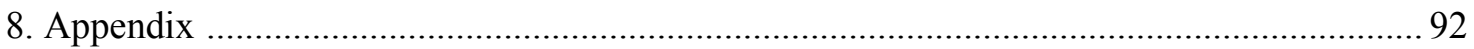

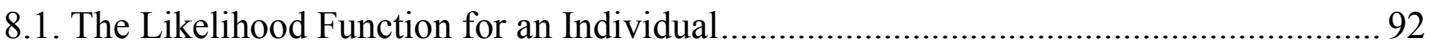

8.2. Assumptions Regarding Discrete Factor Components of the Econometric Model ....... 93

8.3. Description of Other Covariates in the Regression Analysis ......................................... 94

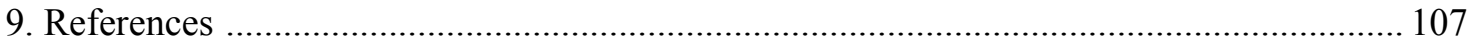

CHAPTER III: Measuring the Effect of a Spouse's Health on the Labor Supply of Older Workers: Further Evidence ............................................................................. 112

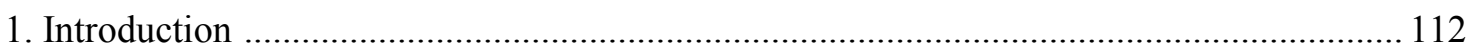

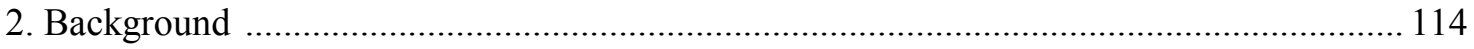

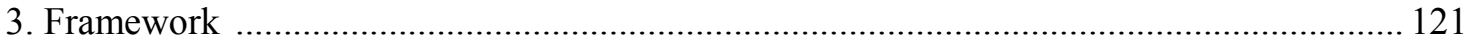

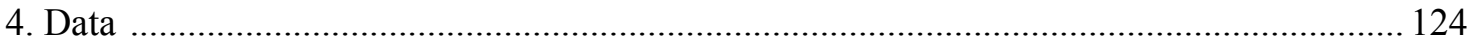

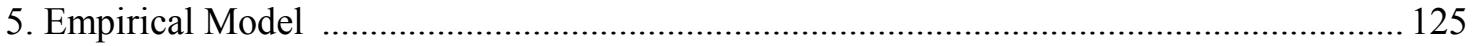

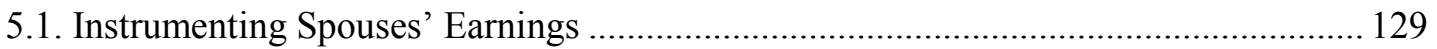

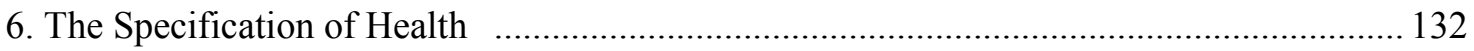

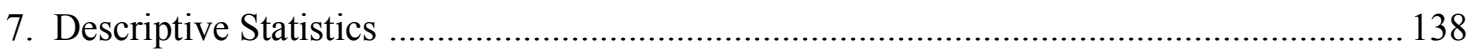

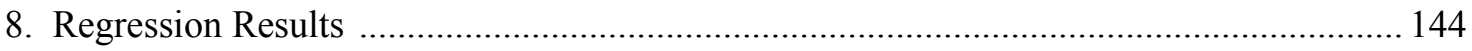

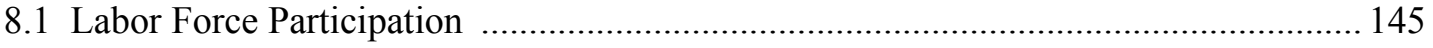

8.1.1 Symmetry of Husbands and Wives Regarding Labor Force Participation ............ 156

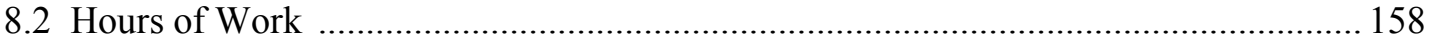

8.2.1 Symmetry of Husbands and Wives Regarding Hours of Work ............................ 162

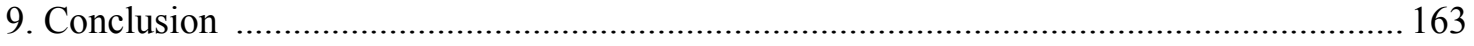

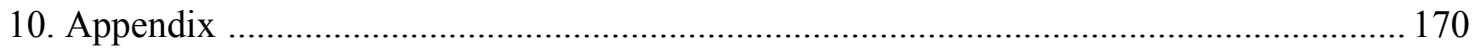

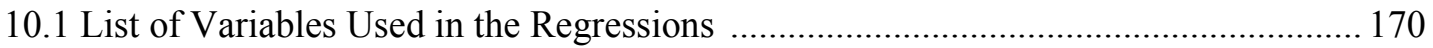

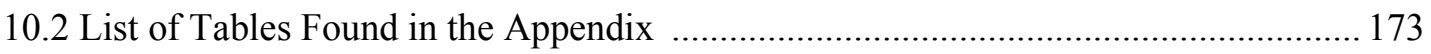

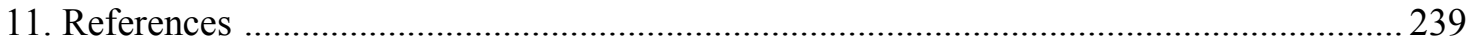




\section{EXECUTIVE SUMMARY}

This dissertation is composed of three essays which examine the effects of health on labor market outcomes. ${ }^{1}$ Chapter 1 reviews the literature on health and the labor market. It also emphasizes the inherent endogeneity of health when included in models for labor market outcomes. It goes on to highlight the empirical methods most often used to accommodate that endogeneity. Chapter 2 explores three hypotheses concerning the role of health status in an individual's decision to transition into self-employment. It goes beyond the well-documented "job-lock" phenomenon which emphasizes the role of health as a factor in the demand for employer sponsored health insurance ("ESI") which may be a potential barrier to employment transitions. Chapter 3 examines the extent to which a spouse's ill-health influences the labor supply decisions of older men and women. Although contextually different from models of own-health and own labor supply, similar concerns regarding the possible endogeneity of health measures discussed in Chapter 1 still arise when dealing with a spouse's health in models for own labor supply decisions.

Chapter 1 discusses the endogenous nature of health in models of labor market decisions by individuals. Grossman (1972; 1999) and Michael (1973) expand the human capital theory approach to the treatment of health in labor models to treat health as both a

\footnotetext{
${ }^{1}$ Page references in brackets refer to pages of this dissertation.
} 
consumptive and investment commodity that determines household utility. In theory, modeling the individual's choice of health jointly with their labor market decisions requires a more complex understanding of the relationship between health and work. For instance, while earnings are partly determined by investments in health capital, the stock of health today depends on past and current investments in health which, in turn, depend on past and current earnings. If treated exogenously in labor decision models health may potentially be a significant source for bias. Moreover, one's employment may have direct effects on one's health, although the direction of impact is ambiguous [pp. 4-5].

Accurate measurement of health has been a great concern since the onset of the empirical literature regarding health and labor market outcomes. No consensus has been reached regarding indicators for health which fully capture an individual's capacities or abilities as they pertain to work. Studies have traditionally used self-assessed measures ("SAH") as a proxy for health. The primary objection to the use of these measures is not that they are poorly correlated with true underlying health status, but that under - or over - reporting by the individuals is correlated with the error in the equation for the labor market outcome being estimated [pp. 7-9]. "Objective" indicators for "disability" or for overall health may also suffer from problems similar to that of $\mathrm{SAH}$, but there is greater concern over the extent to which theses measures can fully capture the multiple dimensions of health that determine an individual's ability or willingness to work. Whether a single indicator is included in models to proxy for health status, multiple indicators are included, or several objective indicators are selected to construct an 
objective index, ${ }^{2}$ estimates may still suffer from omitted variable bias and measurement error [pp. 9-11].

The empirical methods for addressing the endogeneity of health have consisted largely of two-stage techniques or simultaneous estimation of a system of equations in a full-information maximum likelihood ("FIML") context. While two-stage methods are computationally tractable and produce consistent estimates, they are not efficient because they do not account for the potential correlation between the error terms of the labor and health equations. Two-stage methods only provide a partial test for endogeneity. FIML estimators, on the other hand, tend to be sensitive to the parametric assumptions imposed in the underlying model and the validity of exclusion restrictions across equations [pp. 21-22]. A number of studies use either, or both, of these techniques to investigate the relationship between labor outcomes and health among multiple demographic groups. In general, the results support the case for endogeneity [pp. 22-28].

Chapter 2 explores three alternative hypotheses for the role of health in the decision to transition into self-employment. The "Pull" hypothesis [pp. 40] focuses on the non-pecuniary benefits of self-employment. The greater flexibility in hours of work or the work-environment allows for those in poor health to make the accommodations necessary to mitigate the labor market impact of any limitations to work they may face. Self-employment may also be a viable employment alternative for individuals who face systematic discrimination in regards to their ill-health or disability. The "Healthy

\footnotetext{
${ }^{2}$ See pages 12-18 for discussion on the merits of various methods for constructing objective indices to use as proxies for health status in labor models. These include instrumentation of self-assessed health with objective indicators [pp. 12-13], summary dichotomous indicators and cursory summary indexes [pp. 13-14], principle component analysis or factor analysis techniques [pp. 14-17], and summary indexes supplied by micro-data sets, often constructed by a source external to the agency administering the data set, from psychometric methods by experts in the field [pp. 17-18].
} 
Entrepreneurs" hypothesis [pp. 42] suggests that we may observe relatively healthy individuals select into self-employment since it usually implies longer hours and greater responsibility hence it is typically more physically and mentally demanding (Georgellis et al, 2005; Rees and Shah, 1986). The "Entrepreneurial Propensity" hypothesis [pp. 44] relies on claims that individuals possess particular psychological traits that predispose them to entrepreneurship (i.e., "entrepreneurial spirits"). These traits may be correlated with a healthy lifestyle. In this case, we may not observe any significant relationship between health and self-employment if these unobservable characteristics are sufficiently controlled for.

I utilize panels five through eleven (2000-2007) of the Medical Expenditure Panel Survey data set (MEPS) to investigate the effects of health on the propensity to transition into self-employment from wage-employment and non-employment. The general working-age population (18-60) was investigated in order to generate a more comprehensive profile of the health status of individuals who transition to selfemployment. MEPS proves to be convenient for cross-sectional studies on health, health insurance ("HI"), and a variety of labor outcomes [pp. 59-61]. I use FIML procedures, in a multinomial logit (MNL) context, to estimate a system of simultaneous equations which model an individual's transition decision [pp. 53-56]. This framework is consistent with the theoretical framework for job turnover that is commonly found in the labor market literature. Health is incorporated in a manner that is consistent with the models for household production of health developed by Grossman (1972; 1999) and Michael (1973) [pp. 50-53]. Thus, health status at the time of the transition is treated as endogeneous; as is initial employment status and the spouse's employment status. Reduced form 
equations for initial health status and initial employment status make up the remaining equations of the system.

It is likely that the same unobserved characteristics of individuals that determine the transition decision have also determined the initial health status and initial employment status. To control for unobserved heterogeneity a common random effect term, $\mu$, is incorporated into all equations. Instead of assuming a particular distribution for $\mu$ I model it using the discrete factor method proposed by Mroz (1999) in which we assume that the unobserved heterogeneity factor has a discrete distribution with a fixed number of points of support. The points of support of the distribution, the factor loadings, and the probabilities of the points of support are jointly estimated with all other parameters of the model. This econometric approach (1) models explicitly unobserved heterogeneity and (2) controls for potential endogeneity due to the presence of initial conditions [pp. 56-59]. The econometric model has the added benefit of separating different sub-groups within a sample, based on unobserved heterogeneity, so that differences between these sub-groups regarding the marginal impacts of health may be revealed. Further still, if I were to find evidence for only one point of support in my model this implies that no unobserved heterogeneity is present and that the "Entrepreneurial Propensity" hypothesis may be rejected.

Two groups of individuals from the general population were identified (Group 1 and Group 2). Group 2 can be characterized as (1) more likely to report "good" health and less likely to report any physical limitation, (2) more likely to be wage employed than non-employed, and (3) more likely to transition from wage employment to alternative wage employment and, more importantly, to self-employment. The calculated 
probabilities indicate that this sub-group is at least twice as likely as their counterparts to transition to self-employment from wage employment. Unobserved heterogeneity did not seem to be a significant factor in explaining transitions to self-employment if initially non-employed (given a transition into the workforce). A comparison of the estimated coefficients of the health status variables from my econometric model and a model that does not control for unobserved heterogeneity suggested that, for transitions from wage employment, the predicted bias was present in the non-heterogeneity model; therefore, we cannot reject the Entrepreneurial Propensity hypothesis.

Although it need not be the case that the Healthy Entrepreneurs and the Pull hypotheses are mutually exclusive, estimates of the marginal effects for self-reported overall health and the presence of any physical limitation both provide evidence in support of the Pull hypothesis. The statistical significance of the coefficient estimates suggests that the latter health measure has a more distinct effect on the self-employment decision. The calculation of the marginal effects shows that, as the average individual in Group 1 moves from a "good" health status to a less than "good" health status, he or she is between $0.18 \%$ and $0.34 \%$ more likely to transition from wage employment to selfemployment, depending on the presence of any limitation. The worker is $0.51 \%$ to $0.67 \%$ more likely to make the same transition if they report the presence of any limitation. A similar individual moving from a state of good health with no physical limitation to poorer health and any limitation is $0.85 \%$ more likely to enter self-employment.

For an otherwise average individual in Group 2, the marginal effect of less than "good" health on the wage to self-employment transition is between $0.40 \%$ and $0.57 \%$. For any limitation the marginal impact is between $1.19 \%$ and $1.36 \%$. As the individual 
moves from a "good" health status and no limitation to a state of less than "good" health and any limitation, the probability of transitioning increases by $1.75 \%$.

No statistically valid inferences can be made regarding the marginal impact of health status and limitations on transitions to self-employment from non-employment. However, unlike the sub-sample of initially wage-employed individuals, estimates for non-employed individuals are conditional upon a transition to either wage or selfemployment. Therefore we interpret the statistical insignificance of most of the covariates to mean that other factors not explained by the model and which tend to be uncorrelated with self-assessed health and physical limitations may be more important to determining whether a non-employed individual who enters the work-force chooses selfemployment over wage-employment. This does not conflict with, nor support, previous literature regarding these types of transitions. Moreover, the statistical insignificance of the heterogeneity factor in the transitions from non-employment suggests that the unobservable characteristics that may impact the decision to transition from nonemployment may differ from those which affect the transition from wage employment.

Chapter 3 examines the extent to which a spouse's ill-health influences the labor market decisions of older women and men. Overall, the impact of spousal health status on labor supply is theoretically ambiguous and may differ across wives and husbands according to different characteristics between them. Because poor health increases the probability that an individual will withdraw from the labor-market (causing the total income of the household to decrease), a spouse may increase his or her market-time due to the income effect and due to the rise in demand for costly market-provided medical care or, in a related fashion, due to the increase in value placed on ESI. On the other 
hand, spouses may substitute non-market time for market-time in order to care for their partner or spend more time with them.

Siegel (2006) studies the average impact of a husband's ill-health on the labor supply of wives. She controls for the husband's earnings to estimate the direct impact of his ill-health on his wife's reservation wage. Unlike prior studies, Siegel treats husbands' earnings as endogenous since there are likely to be unobserved characteristics common to both spouses. She tests and controls for endogeneity by using instrumental variable (IV) techniques. Key findings from this study were that husbands' health increases the probability of wives' labor force participation but decreases her hours of work. Estimates depend, however, on the specification for health as well as whether endogeneity of husbands' earnings are controlled for. However, the finding that estimates depend on the measure of health used is consistent with the review in Chapter 1 of this dissertation. Recent literature addresses the symmetry (or asymmetry) between husbands and wives regarding the labor market response to a spouse's ill-health (Blau, 1998; Blau and Riphahn, 1999; Coile, 2004). Blau and Kahn (2007) find that married women's labor supply elasticities are continually becoming more and more like married men's [pp. 118]. Thus, it may be true that men and women's labor market responses to spousal health have also become more symmetrical over this period and that I should observe similar effects of spouses' health on the labor supply of older men and women.

This essay replicates Siegel's methodology [pp. 120-122 and pp. 124-127]. However, it investigates the impact of spousal health on both men and women's labor supply. I use a larger, more recent data set [MEPS, panels 5-11] than that of Siegel [the National Retirement Survey, 1992]. This allows me to not only test for the robustness of 
Siegel's findings in general but also for the robustness of her results over the decade since her data was obtained. Furthermore, by examining the labor supply decisions of both husbands and wives, I will be able to examine the symmetry between their labor market behaviors with regard to their spouse's health. ${ }^{3}$

Similar to Siegel's findings, I find that the estimated effect of a spouse's ill-health on the other's labor supply depends on the measurement used to proxy for their health status. I also find that, although the direction of impact does not change, the magnitudes of the coefficients on these health measures depend on whether we control for the possible endogeneity of the spouse's earnings in these models. However, while Siegel found that the exogeneity assumption of husbands' earnings could not be rejected when modeling women's labor force participation but should rejected when modeling their hours of work, I use slightly different (but equally valid) instruments for spouses' earnings to determine that husbands' earnings could be treated as exogenous in our models for both the participation and hours of work of wives, while the exogeneity assumption on wives' earnings should be rejected when modeling both the participation and hours of work of men.

I find that the ill-health of a spouse is estimated to increase the propensity for older women and men to participate in the labor force when health is measured by a more objective measure for disease status - a health conditions index - and a more comprehensive objective measure of health, the Physical Component Summary - a comprehensive index for an individual's health computed using Principle Component Analysis on a pre-designed questionnaire . I also found this relationship holds when we

\footnotetext{
${ }^{3}$ Differences between HRS and MEPS prevented me from estimating a model that is the same as Siegel (2006).
} 
use an indicator for a work-limitation to proxy for the functional status of the spouse. Moreover, the magnitude of the marginal impact of the work-limit measure was quite large in comparison to the other measures, and it remained fairly steady over various specifications for health and across some extensions of the model that were used to test for the possibility of the "error-in-variables" problem [see pp. 134].

I control for a spouse's earnings and its possible endogeneity in the model, thereby controlling for the negative impact that a spouse's ill-health may have on household income and the resulting labor market response of the other spouse. I also control for the employment status of the spouse. I find that a spouse's ill-health decrease men and women's reservation wages. This may be in order to pay for unusually high medically-related expenses or to obtain or retain health insurance often tied to employment. It may also be the case that the presence of a spouse complements a person's leisure time and the ill-health of a spouse decreases this complementary effect.

Furthermore, when I compare the estimated marginal impacts of a spouse's health between men and women's propensity for employment I find only weak evidence that men are more responsive to their wives' poor health than are women to their husband's ill-health. The more subjective, and therefore possibly endogenous, self-assessed measure for wives' health is statistically significant only in the model for men's labor force participation, while the coefficients for all other measures were statistically indistinguishable between men and women.

When I model the individuals' hours of work as a function of their spouses' health I find no statistically significant effects when health is measured by an indicator for a work-limitation and the other more objective indices. Although statistically insignificant, 
the signs on the coefficients show that both older men and women tend to work a greater number of hours per week when their spouse reports a poorer health status. On the other hand, I find a statistically significant marginal impact of wives' self-assessed health on husbands' hours of work. However, the sign of the coefficient on the measure indicates that an older husband tends to decrease, rather than increase, his hours of work as his wife moves from excellent health to a lower health status. It remained statistically distinguishable from the effect of husbands' self-assessed health on women's hours of work when we modeled men and women's hours of work jointly. Again, I find evidence for some degree of asymmetry between the men and women's labor supply responses to their spouse's ill-health when measured using self-assessed health, but no evidence when I use the other measures included in our model. It may be the case that husbands are lesslikely than wives to take on the role of caregiver when their spouse falls into ill-health and more likely to respond through the provision of formal care or maintenance. Or, it may be that the complementarity effect of a wife's presence during a husband's leisure time [see pp. 117] tends to decrease as her health decreases, and that this does not occur to the same extent for women. 


\section{References}

Blau, D.M. (1998) "Labor Force Dynamics of Older Married Couples," Journal of Labor Economics, 16(3), pp. 595-629.

Blau, D.M. and R.T. Riphahn (1999) "Labor Force Transitions of Older Married Couples in Germany.” Labour Economics, 6, pp. 229-251.

Blau, F.D. and L.M. Kahn (2007) "Changes in Labor Supply Behavior of Married Women: 1980-2000," Journal of Labor Economics, 25(3), pp. 393-438.

Coile, C.C. (2004) “Health Shocks and Couples' Labor Supply Decisions,” NBER Working Paper 10810. National Bureau of Economic Research: Cambridge, MA.

Georgellis, Y., J.G. Sessions, and N. Tsitsianis (2005) "Self-Employment Longitudinal Dynamics: A Review of the Literature," Economic Issues, 10(2).

Grossman, M. (1972) "On the Concept of Health Capital and the Demand for Health," Journal of Political Economy, 80(2), pp. 223-255.

Grossman, M. (1999) "The Human Capital Model of the Demand for Health," NBER Working Paper 7078. National Bureau of Economic Research: Cambridge, MA.

Michael, R. (1973) "Education in Nonmarket Production," Journal of Political Economy, 81, pp. 306-327.

Mroz, T.A. (1999) "Discrete Factor Approximations in Simultaneous Equation Models: Estimating the Impact of Dummy Endogenous Variables on a Continuous Outcome," Journal of Econometrics, 92, pp. 233-274.

Rees, H. and A. Shah (1986) "An Empirical Analysis of Self-Employment in the U.K.," Journal of Applied Econometrics, 1(1), pp. 95-108.

Siegel, M.J. (2006) "Measuring the Effect of Husband's Health on Wife's Labor Supply," Health Economics, 15, pp. 579-601. 


\section{CHAPTER I}

\section{The Endogenous Nature of Health in Models for Labor Market Outcomes}

\section{Introduction}

The first chapter of this dissertation provides an overview for understanding the complexities of incorporating measures for health into labor market models. Health status has often been analogized to other forms of human capital. It is true that individuals' capacity for productive activity in the home or in the labor market is, to a large extent, determined by the extent to which they are physically or mentally able to perform the tasks required of household duties or their chosen employment. However, it is also true that individuals may choose their occupation based on the earnings that they expect to receive given their perceived health status. Alternatively, individuals may make labor market decisions in a manner that maximizes their ability to afford the medical care or health-related leisure activities necessary to achieve some level of health. The latter explanation views health as a household commodity whose consumption is maximized simultaneously with other consumptive commodities and leisure, given some budget constraint. Section 2 of this chapter discusses the literature regarding the inherent endogeneity of health in labor market models.

Additional complication arises from the fact that "health" is a multi-dimensional concept which is difficult to capture with any one measure, however constructed. We will see how relying on individuals to provide an accurate assessment of their own health 
is not always optimal. On the other hand, relying on a single physician-diagnosed indicator of a particular dimension of health cannot adequately define one's overall health status. Section 3 addresses the concern over the measurement of health and puts forth several alternative measures for doing so.

Several empirical methods have been used in the health and labor literature to address these difficulties, the most prevalent of which will be highlighted in section 4 . The methodology employed in the remainder of this dissertation will be consistent with the methods discussed in sections 3 and 4, and several references will be made to this chapter throughout the dissertation.

\section{Health as Human Capital}

Conventional approaches to modeling the relationship between health and labor market outcomes analogize health to other forms of human capital. Assuming that an individual's wage rate is related to his or her marginal productivity of labor, wages depend on the individual's level of work effort and their level of skills. Skill levels are determined by level of innate ability as well as levels of investment in human capital, which depend on the individual's marginal rate of return on investment and marginal cost of financing. In this light, increases in human capital only increase earnings, thus it would be a simple task to use existing models such as those put forth by Becker (1967) and BenPorath (1967) for an individual's optimal level of education. Since poor health is likely to be detrimental to work performance and productivity, wages will be positively correlated with health status, or people in poor health will be less likely to be employed under established wages. Furthermore, since economic factors such as wages (the 
opportunity cost of leisure) and non-employment income determine labor supply

decisions, and poor health lowers these factors, human capital theory predicts that poor health will also be negatively related to the probability of labor force participation (Chirokos and Nestel, 1984). ${ }^{4}$

The human capital theory approach to the treatment of health in labor models was extended by Grossman (1972) and Michael's (1973) models of household production of commodities such as health. These models acknowledge that health is both a consumptive and investment commodity and, unlike other forms of human capital which do not necessarily depreciate, the large initial stock of health must be continually replenished through the sacrifice of time and monetary resources. Thus, while earnings are partly determined by investments in health capital, the stock of health today depends on past (and current) investments in health which, in turn, depend upon past (and current) earnings. ${ }^{5}$

In Grossman's model, health does not affect an individual's productivity but determines the amount of time that the individual can spend earning income and producing non-market commodities. The variation of individuals' inputs of medical services and time into the production of health will vary according to the opportunity costs of the time lost to poor health. Michael suggests a similar result; however, his

\footnotetext{
${ }^{4}$ Several other theories exist to justify the direct impact of health on labor outcomes. For instance: (1) deterioration in one's health may alter the relative utility derived from income and leisure - most prevalent in the retirement and disability literatures; (2) Poor health may raise the value of non-market time to care for one's health; and (3) poor health may decrease life expectancy thereby changing the time horizon in which economic decisions are made; among others (Dwyer and Mitchell, 1999; Cai and Kalb, 2006; Grossman, 1972).

${ }^{5}$ In other words, "the demand for health should rise with the wage rate as the rate of return to health investment increases with wage; on the other hand, better health should raise market productivity and hence wages" (Lee, 1982).
} 
model views poor health as shifting the household production functions for market and non-market goods to less efficient levels rather than simply impacting the productive ("non-sick") time available. As a result, opportunity costs of time and the production mix of commodities are changed, which leads to changes in the mix of market and nonmarket work (Chirikos and Nestle, 1984).

Both models illustrate that, in theory, modeling the interaction between health and labor market outcomes requires a more complex understanding of the relationship between health status and labor decisions. For instance, human capital theory suggests that poor health will reduce earnings and labor force participation, but it could also be argued that lower earnings associated with poor health may increase labor supply due to the income effect. The rise in demand for health services associated with poor health may also require an individual to work more (Cai and Kalb, 2006). On the whole, health capital cannot be treated exogenously when modeling labor market decision making. Rather, it must be treated as a choice variable (Currie and Madrian, 1999).

Other justifications for the endogenous treatment of health in labor models beyond those based in human capital theory - are also present across the literature. These tend to assert that labor market activities may have a direct effect on individual's health, although the direction of the impact is ambiguous. In general, it may be the case that exogenous changes in the workplace environment, wages, and health insurance coverage can affect the probability of job-related injury, stress and risk-taking behaviors, alter the opportunity costs of investments in health capital, or change the returns to health (Currie and Madrian, 1999). ${ }^{6}$ 
Additionally, social interactions at work or self-esteem, identity, and personal fulfillment from labor effort may benefit health (Leung and Wong, 2002; Jones, 2005). Stress and poor working environment can worsen health (Leung and Wong, 2002; Jones, 2005; Cai and Kalb, 2006). Increased income may lead to improvements in housing, diet, and healthcare (Baker et al, 2004; Jones, 2005). Alternatively, boredom, inaction, or lower incomes from non-participation can contribute to deterioration of health (Bound, 1991; Cai and Kalb, 2006). Regardless of the empirical validity regarding evidence for these effects, the possibility further suggests that health measures should be treated as endogenous (Currie and Madrian, 1999). ${ }^{7}$

The bond between employment and health insurance ("HI") in the United States implies that current and prospective labor market participants are faced with simultaneous choices regarding their health, health insurance, and employment statuses. ${ }^{8}$ Labor force participation and other occupational choices can be particularly important for persons with health problems or dependents with health problems. For instance, employer sponsored health insurance (“ESI”) is often only offered by firms to its full-

\footnotetext{
${ }^{6}$ For a partial survey of the literature see the background discussion within Ross and Mirowski (1995) and Ruhm (2000, 2003); Bardasi and Fransesconi (2004) cites multiple surveys documenting evidence of the relationship between unemployment and personal well-being (p1673), and provide recent evidence of the effects of atypical employment on individual well-being in Britain (see also Virtanen et al (2005)).

${ }^{7}$ Currie and Madrian (1999, p. 3313) claim that much of the validity of the evidence from this literature remains contentious due to lack of consideration for the endogeneity of employment status, the ad hoc nature of specification for models, or the choice of health measures used.

${ }^{8}$ As opposed to most industrialized countries, the culture and historical circumstances of the U.S. has led to an environment in which nearly 55 percent of the population is covered by insurance linked to their own or their spouse's employment. The remaining fraction of the population that is covered either relies upon various public assistance programs that were designed to cover those with "weaker" or zero attachment to the labor market (approximately 26\%), or purchases coverage from the private market for insurance $(5 \%)-$ often at greater premiums than what they would obtain from an employer. A smaller fraction of the population simply remains uninsured (16\%) (Kaiser Commission, 2007).
} 
time employees. As a result, higher demand for health insurance by less healthy workers may induce a willingness to work more labor hours than they would otherwise provide so that they may reach the 35-40 hour per week threshold that often qualifies the individual for ESI coverage. Furthermore, it is obvious that any ESI-related impediment to the mobility of labor from less-productive jobs to productivity-enhancing labor activities (“job-lock") can inhibit potential earnings and, in turn, can influence the amount of labor to supply. ${ }^{9}$ Evidence has suggested that workers with higher expected family medical costs will sort into jobs that offer health insurance (higher valued coverage) and those with lower preferences for coverage will sort into jobs that lack health insurance (lower valued coverage) (Monheit and Vistnes, 1999, 2006; Bhattacharya and Vogt, 2006). Further still, the interaction of the demand and supply for ESI may influence the wage rates of those who choose to participate. Employees may be willing to accept lower wages in exchange for lower HI costs while employers may or may not pass on all of the costs to the employee. ${ }^{10}$

\footnotetext{
${ }^{9}$ The phenomenon known in the economic literature as "job-lock" refers to the tendency for workers who value their current ESI coverage to be less likely to change jobs if they are faced with alternatives of inferior coverage or barriers to obtaining a new policy. The costs of ESI coverage is prohibitively high for some firms compared to others - see O'Brien (2003). For example, smaller firms face difficulties in obtaining and maintaining employee health insurance that larger firms do not. While approximately $97 \%$ of large firms offer some form of coverage to its workforce, only $61 \%$ of small firms (those with fewer than 50 employees) do (AHRQ, 2006).

Further still, firms could benefit most by having all or most of its employees covered under plans with standard minimum benefits, but the quality and variety of plan choices offered by each employer will ultimately reflect their specific business strategy (O'Brien, 2003). As a result, there may be considerable variation in co-payments, deductibles, and the type of medical care covered, pre-existing-condition exclusions may exclude families from coverage under a new plan, and new plans may only allow access to approved medical facilities which may not include a family's current doctor (Madrian, 2006).

${ }^{10}$ Evidence for "compensating differentials" remains surprisingly weak; in fact, some studies have found that ESI coverage is actually associated with higher wages (see O'Brian, 2003) - probably attributable to these being "better jobs", or due to benefits accruing to employers that are not yet accounted for in the empirical research (O’Brien, 2003).
} 
The implications of obtaining HI through employment are (1) health may have direct effects upon labor market outcomes and indirect effects via insurance demand, (2) to the extent that health insurance coverage affects health outcomes, labor decisions may also indirectly affect one's health status through the link between insurance provision and employment status ${ }^{11}$, and (3) to the extent that ESI impacts wage levels, this adds another dimension to the relationship between wages and health investments described above.

\section{Measuring Health}

Accurate measurement of health has always been a great concern in the empirical literature regarding health and labor market outcomes. Chirikos (1981) has defined health to be "that bundle of physical and mental capacities affecting the ability to perform primary and secondary social role responsibilities." No consensus has been reached regarding an indicator for health which captures these capacities or abilities as they pertain to work.

Due to cost considerations, most early large scale household surveys only included self-assessed measures of overall health or self-reported disabilities. So, for want of better measures, numerous studies used self-assessed measures (SAH) as a proxy for health - see Bound (1991) or Currie and Madrian (1999). While several studies suggested that SAH are highly correlated with the unobserved true health status (Bound, 1991; Currie and Madrian, 1999), several others documented a variety of reasons to suggest that the use of these measures may introduce selection bias when incorporated into labor market models or may be highly correlated with other economic variables.

\footnotetext{
${ }^{11}$ The evidence to this effect also remains contentious due to empirical issues (Hadley, 2003; Levy and Meltzer, 2001).
} 
Several authors have expressed concern that individuals may assess and report their health status in a manner that socially or legally justifies their current or prospective labor force status - this is often referred to as the "justification hypothesis." For instance, people who have reduced hours of work or withdrawn from the labor force may be more likely to report poor health or disability if it is seen as a socially accepted reason for nonparticipation (Stern, 1989; Bound, 1991; Baldwin et al, 1994). Since disability or early retirement benefits are often available to people deemed incapable of work, the economic incentives for reporting work-limiting disabilities grow (Parsons, 1982; Chirikos and Nestle, 1984; Chirikos, 1993; Sickles and Taubman, 1986; Stern, 1989; Bound, 1991; Currie and Madrian, 1999; Kreider, 1999; Au et al, 2004).

There is also no reason to suspect that self-assessments should be entirely comparable across all individuals (Bound, 1991). Perceptions and knowledge about health can influence one's self-assessment of health in systematic ways (Dow et al, 1997). Dow et al (1997) explicitly show that exposure to the health care system can greatly influence self-reporting of health status. Use of health care services can be influenced by a number of factors, including education, income, employment, and health insurance status. As long as people with higher earnings or insurance have greater access to health care they will be more likely to be diagnosed with conditions and hence more likely to report them (Currie and Madrian, 1999). Lee (1982) provides evidence that people with higher education tend to provide overly optimistic reports of their health status compared to those with less education. Stern $(1989$, p. 362) cites evidence that some respondents may simply not understand the wording of the questionnaire, and Baker et al (2004) find considerable error in self-reporting across specific disabilities. 
Finally, individuals with work-limiting chronic conditions may choose jobs with requirements or environments accommodating to those conditions and, therefore, will be less likely to report that their health does limit their chosen work (Currie and Madrian, 1999). One corollary to this is that the search behavior of individuals seeking suitable jobs can influence the extent to which debilitating conditions reduce wages and earnings. Individuals with higher earnings may engage in more job search, while those with lower earnings may forgo search, favoring disability compensation instead. Thus, differences in work effort across individuals with similar health problems may systematically vary with economic status (Chirikos and Nestle, 1984).

For these reasons, researchers have expressed great skepticism about the reliability of self-reported health status and have turned to more "objective" indicators to proxy for health status. ${ }^{12}$ Greater investments in the construction of comprehensive micro-datasets for public policy research have led to the availability of a variety of types of objective measures. In addition to $\mathrm{SAH}$, other measures consist of indicators for health limitations on the ability to perform work-related tasks; functional limitations related to activities of daily living ("ADLs"); the presence of physician-diagnosed chronic or acute conditions; utilization of medical care; clinical assessments for such behavioral conditions like alcoholism or mental health; nutritional status (height, weight, Body Mass Index (“BMI")); and expected future mortality (Currie and Madrian, 1999). While the use of one or more of these measures to proxy for health status may reduce problems related to the endogeneity of SAH discussed above, these measures have

\footnotetext{
${ }^{12}$ The primary objection to the use of self-reported measures is not that they are poorly correlated with true underlying health status, but that under or over reporting by the individual is correlated with the error in the equation for the labor outcome estimated (Bound, 1991).
} 
shortcomings. The multiple dimensions of one's "health status" deems any one indicator insufficient to capture the full extent to which a person may be limited by their health in their capacity or willingness to work, unless the investigator is focused upon the effects of the specific condition in question. Including multiple indicators of health status in a model for labor outcomes can increase its explanatory power a great deal (Currie and Madrian, 1999; Bound et al, 1999). However, to the extent that the included measures do not fully capture the dimensions of health that determine an individual's ability or willingness to work, the model will still suffer from omitted variable bias - this is often referred to in the literature as "measurement error" (Parsons, 1982; Bound, 1991). ${ }^{13}$ The same can be said for any objective indicator for health, whether it is single-dimensional or a comprehensive measure obtained from some multivariate construct, as discussed below. Moreover, by using several indicators as explanatory variables there will be no obvious way to quantify the marginal effects of changes in health status on the outcomes of interest, and since several of the measures will likely be collinear to some degree this will complicate the interpretation of the estimated coefficients further (Bound et al 1999).

Furthermore, the use of "objective" indicators for either disability or for overall health may also suffer from problems similar to that of SAH in that they may not be fully comparable across the survey population and therefore may not provide unambiguous evidence of differences in health levels. Comparability may only be achieved if the character of health conditions is accounted for concomitant with social, occupational, environmental, and other individual-specific factors. For instance, measures for

\footnotetext{
${ }^{13}$ A related concern in the health and labor literature is the "error-in-variables" problem. This occurs when the chosen measures for health proxies for some unintended effect of health on the labor outcome, unrelated to the capacity or ability for work or daily living.
} 
functional limitations on work or daily living make no allowance for the adaptive behaviors of individuals over time; individuals with a given limitation may be perfectly capable of performing the tasks required by their jobs. In general, job or other social responsibilities are evaluated by the individual through unknown means in the absence of an explicit reference point. Thus, the relationships under study may be obscured (Chirikos and Nestle, 1981; Kreider, 1999). Bound (1991) argues that inferences in labor supply models using objective health indicators may be more misleading than those using self-reported measures. ${ }^{14}$

\subsection{Objective Indices}

In response to the objections pertaining to SAH and "objective" measures for health, several researchers have attempted to alleviate problems of measurement error, endogeneity ("error in variables"), and comparability by using more comprehensive "summary" indices. Inevitably, the index of choice - its method for its construction and the vector of covariates used - is subject to evaluation by the author and will depend on the particular relationship between health and the labor outcome that he or she wishes to estimate. Hence, several different indices can be found throughout the vast literature on health and labor. In this section I categorize the various indices found in the literature based on their method of construction and discuss their comparative advantages and deficiencies.

\footnotetext{
${ }^{14}$ Taken from Kreider (1999, p. 759).
} 


\subsubsection{Instrumenting Self-Assessed Health Status}

Stern's (1989) two-stage approach for constructing an unbiased measure of health has substantially influenced the literature on health and labor market outcomes. In an effort to test for the presence and magnitude of the endogeneity of self-reported disability and health status measures Stern used three tests: (1) a two stage IV approach; (2) a MLE approach; and (3) a Hausman test. Test (1) is of particular importance for this section. ${ }^{15}$ The two-stage approach involves the estimation of two reduced form equations for participation and self-reported health status, respectively, and the subsequent use of each of their predicted outcomes in the structural equation for the other. ${ }^{16}$ To the extent that the numerous objective indicators available in the data are exogenous in the labor force participation decision, the predicted probability of $\mathrm{SAH}$ as a function of medical conditions, functional limitations, and selected demographics constitutes a health measure that is "purged" of the inherent biases associated with self-assessment and measurement error.

Because Stern's method is computationally simple it is attractive to researchers. Bound (1991) expands upon Stern's research while specifically addressing some concerns over the IV technique. A first concern is that we must assume that the financial incentives which affect labor market behavior have no impact on their self-reported health. If this assumption is incorrect, as many have suggested, then estimates of these financial incentives on the labor outcome will be understated. Second, inclusion of demographic or economic variables in predicting the health status of an individual

\footnotetext{
${ }^{15}$ See Stern (1989) for a detailed description of all tests.

${ }^{16}$ The results of Stern's investigation will be discussed in the next section as well. Only the formation of a "purged" measure of health stock is of importance here.
} 
depends upon whether they are believed to capture differences in health status or in reporting behavior. They should be included if the former is true and excluded if the latter is true. However, it is plausible that these variables may capture both types of differences. Lastly, the results of the estimation rely on the specification for the health equation that is used to instrument self-assessed health; each specification implies something different about the structure of the measurement errors involved in the proxies. As a consequence, any comparisons of the results from different specifications are difficult and generalizations for the effects of health cannot be made. Bound (1991), and later, Bound et al $(1999,2008)$, also uses objective indicators for health to essentially instrument the endogenous health-limitation and/or SAH measures but turns to simultaneous estimation of a latent health model to address the concerns above.

\subsubsection{Summary Dichotomous Indicators and Summary Indices ${ }^{17}$}

Several other methods for constructing health indices use objective information available within the data set but do not rely upon regression techniques to formulate a measure of "health". The simplest of these methods is the construction of either (1) binary indicators, where the indicator equals one for the presence of any physical $/$ mental limitation or acute/chronic condition from a set that is specified by the researcher and zero otherwise, or (2) summary indices, where the value of the indicator grows sequentially as the individual reports an additional limitation or condition included in the

\footnotetext{
${ }^{17}$ Other objective indexes have been created from, for example, mortality experience (Anderson and Burkhauser (1984), Parsons (1980, 1982), Loprest et al (1995), and Bound (1991) - see Currie and Madrian (1999) for references), or total amt of illness in year (Boskin (1977) and Burkhauser (1979) - see Bazolli (1985) for references). However, results based on these indicators have been heavily criticized (Chirikos, 1993; Bazzoli, 1985; Bound, 1991), and these will be left out of the discussion here.
} 
set previously specified by the researcher. One obvious advantage of summary indices is that the number of potential explanatory variables is collapsed into one or few indicators, thereby eliminating problems with the interpretation of variable coefficients and multicollinearity. It is not clear that these methods capture true health status. The implicit assumption for (1) would be that all limitations or conditions in the specified set are equal in severity and have the same effect as the others, and that a person who experiences more than one limitation has the same level of well-being as those who experience only one. For (2), the implicit assumption would be that all conditions are equal in severity and that the individual's level of well-being decreases in a monotonic fashion as one more condition is indicated. ${ }^{18}$ A more plausible and less ambiguous index that comes closer to the ordinary, intuitive definition of health would be one that incorporates ranks (or weights) for limitations or conditions by level or degree of severity according to the residual or chronic departure from "normal" physiological and psychological functioning (Chirikos and Nestle, 1981).

\subsubsection{Principal Component Analysis and Summary Indices Supplied by Data Sets ${ }^{19}$}

A logical extension of the more cursory summary measures above is Principal Component Analysis (PCA), or its close relative, Factor Analysis (FA). Fundamentally,

\footnotetext{
${ }^{18}$ The count index may not be all bad. Dwyer and Mitchell (1999) and Siegel (2006) utilize a count index and acknowledge that it does not count for severity of conditions, however, they claim that since these conditions are not likely to be independent, people with more severe conditions tend to score higher in the index; severity is picked up by co-morbidity. Furthermore, Kaplan et al (1976) conducts a test for construct validity of their comprehensive index of well-being and shows that well-being does diminish in a monotonic fashion with the incremental increases of the count indicator they constructed.

${ }^{19}$ A variety of techniques for scaling underlying health and disability besides factor analysis exist (for instance, see Glaser and Grundy (2002)) however, to the extent that these are not the most prevalent in the literature they will be overlooked in this study.
} 
PCA/FA are simply another, although more computationally intensive, method for creating an index that reduces or transforms several components in the data in a linear fashion so that they are organized and arranged in a way that facilitates their use (Chirikos and Nestle, 1981). PCA/FA constructed indices incorporate relative weights for each component, based upon their "importance" (or unimportance) in explaining the health status of an individual relative to others in the sample. To the extent that the results reflect the underlying epidemiological relationship and "rank" (weight) the items by their severity, such indices ("factors") could prove superior to the summation indices discussed above.

Use of these analyses may be rationalized by appealing to epidemiological evidence that the relative frequencies of impairments show a pattern of inverse relationships between severity of impairments and frequency of reports (Chirikos and Nestle, 1981), and that those with more severe conditions tend to report multiple ones. PCA/FA first uses the frequency distribution of the items in a set of variables across a sample of individuals to determine the correlation among the responses on each item. A PCA of the correlation matrix of all components yields factors where the loading of each item in a factor is its "weight" on that factor. The percentage of total variation in frequencies explained by a factor is viewed as the "importance" of that factor and the weights of its components indicate the contribution of each variable to the "common" variance. Several factors may be identified by the analysis, but eigenvalue tests are typically used to determine which factors and factor components contribute significantly 
to the variance in frequencies, and those that contribute the least are typically deemed "unimportant" and dropped from the analysis accordingly. ${ }^{20}$

CPA/FA analysis can be criticized due to its subjective nature. Numerous alternative patterns may emerge from the same correlation matrix of the data being analyzed, and the number of factors taken from the analysis is a subjective decision of the analyst. Nonetheless, one hopes to arrive at a specification that seems to (1) be plausible and consistent with a priori knowledge, (2) be reliable (in that it is composed of the variance associated with the true score of health as opposed to random error), and (3) demonstrate constructive validity (the scores should be interpretable, should exhibit some expected level of correlation with other measured relationships, and be more closely related with similar variables than with those more distantly related) (Kaplan et al, 1976). Kaplan et al (1976) argue that while factor methods are valuable as a statistical or data reduction technique among highly correlated independent variables, they are inappropriate for constructing an outcome or dependent variable. In brief, they raise the following objections:

- The PCA/FA method "subtly substitutes variation in frequency for variation in social importance. Items that are checked rarely or are poorly correlated with other items in a given population may receive very low weights on all factors, or may even yield an independent factor with a very low eigenvalue regardless of how important they may be...low levels of function are not frequent but are very important when they do occur, so such items should be retained."

\footnotetext{
${ }^{20}$ The preceding paragraphed borrows heavily from a brief description of the PCA/FA procedure in Kaplan et al (1976).
} 
- The correlation structures can vary significantly across different populations according to different frequencies of occurrences across populations.

- A comprehensive health status measure must not only reflect frequencies of occurrences but also social preferences (perceptual impacts on one's health) for the conditions in a set; factor analysis does not offer a means for combining the two.

Although PCA/FA methods for the construction of an index have been used in the past in the health and labor literature (Grossman and Benham (1974), Nagi (1976), Berkowitz (1978), Chirikos and Nestle (1981, 1982, 1984) - see Chirikos and Nestel (1984) for these references; Johnson and Lambrinos (1985), Baldwin and Johnson (1994) - see Currie and Madrian (1999) for references) this author finds that they have rarely been used since Stern (1989) and Bound (1991) published their respective works. Perhaps the methods demonstrated in Stern (1989) and Bound (1991) prove to be superior to the use of objective indices - although this is doubtful since most studies include the cursory summary measures discussed in the previous subsection as a test for endogeneity - or, more likely, its advantages over other more cursory summary measures are outweighed by the costs associated with the computational intensity required. With respect to the latter, contemporary data sets often include additional, comprehensive measures for health constructed by outside experts using psychometric methods on a range of variables which were obtained for the specific purpose of the matter at hand. Depending on the psychometric method used on the related variables, each summary measure can potentially yield differing results; therefore the researcher should obviously look to outside sources for the construct validity of these measures and comparisons of their performance against other alternatives, or conduct such tests themselves (Ware et al, 
1995). ${ }^{21}$ However, to the extent that these measures have been validated and included in professionally designed micro-data sets on this basis, and due the computational efficiency that these measures can provide, their use as objective indicators for true underlying health or impairment has grown in popularity and may prove valuable for future studies in the health and labor field.

Some examples for comprehensive summary measures used in past studies are the General Health Questionairre (GHQ, 12-point measure) (Bardasi and Francesconi, 2004), Fillenbaum-Maddox Health Index (Bazzoli, 1985), and the Health Utilities Index Mark 3 (HUI3) (Au et al, 2004). ${ }^{22}$ The Medical Expenditure Panel Survey (MEPS) data used throughout this dissertation includes two aggregate summary measures - Physical Component Summary (PCS) and Mental Component Summary (MCS) - constructed from individual responses to SF-12 questions (directly available in the data) and computed using an algorithm derived from factor-analytic methods and described in the manual for SF-12 (Ware et al, 2002). ${ }^{23}$ The PCS will be mentioned again in the next chapters.

\footnotetext{
${ }^{21}$ Kaplan (1976) summarizes the three basic types of validity that a comprehensive health index should demonstrate: criterion, content, and construct.

${ }^{22}$ Additional scales, created by the user following guidelines laid out in previous studies, have also been used: for instance, an 11-point scale developed by Katz et al (1963) and Spector et al (1987) (see Dwyer and Mitchell, 1999 for references); a weighted score for disability found in Grundy and Glaser (1997) (see Parker and Rougier, 2004 for references); and a CESD depression index or depressive symptom scale found in Ettner (1997) and Ruhm (1992) (see Currie and Madrian (1999) for references).

${ }^{23}$ Also see Ware et al (1995) for validity tests on the same measures (PCS/MCS) constructed from the SF36 questionnaire embedded in the Medical Outcomes Study.
} 


\section{Methods for Estimating Health Effects on Labor Market Outcomes}

The discussion above has shown that incorporating health into models for labor market outcomes introduces several sources for endogeneity. It has also shown that the manner in which the health of an individual is measured can introduce further sources for bias. The following discussion will highlight the empirical techniques most often undertaken in the health and labor literature in order to correct for the bias. Keep in mind that the purpose of this section is not to provide any sort of meta-analysis across studies but to put forth evidence that justifies concern over the endogeneity of health measures in labor models. $^{24}$

A straightforward approach to estimating the effects of health across labor outcomes is to treat an indicator of health status as exogenous. In fact, much of the literature to date has done just this - see Chirikos (1993) or Currie and Madrian (1999). This method is fine if health is exogenous; models can be consistently estimated using OLS or other conventional techniques. As Currie and Madrian (1999, p. 3313) explain, "this may not be an unreasonable assumption given that current health depends on past decisions and on habits that may be very difficult to break, and the fact that individuals often have highly imperfect information about the health production function at the time these decisions are made."

Chirikos's (1993) early review of the health and labor literature documents the empirical evidence accumulated in the prior two decades where many (but not all) of these studies appeared less concerned with the possible endogeneity of health. In

\footnotetext{
${ }^{24}$ For a comprehensive overview of estimates for the effects of health on various labor market outcomes see Currie and Madrian (1999).
} 
general, his review concludes that, consistent with economic theory, "health matters," at least to some extent, in the determination of virtually every labor market outcome, and

"In virtually every case, impaired health exacts some toll by either restricting the ability of individuals to engage in market work or shifting their preferences for time spent in the labor market, reducing the wages of workers in poor health, and/or changing the labor market behavior of other persons in the household of the health-impaired individual. This conclusion is generally invariant to sociodemographic characteristics, occupational or industrial attachment, or the type of physical or mental health condition." (Chirikos, 1993, p. 301)

Thus, omitted variable bias is guaranteed to plague any labor model which does not incorporate health. ${ }^{25}$ The passage above suggests that various economic outcomes that are related to the labor market are partially determined by health (e.g. wages or insurance status). When these economic outcomes are included with health measures in models for other labor outcomes (e.g. labor force participation or labor hours) the coefficient on the health variable may understate its true effect if the reciprocal effect of health on the economic outcomes is assumed not to exist; the indirect effects of health will not be accounted for (Chirikos and Nestle, 1984).

\subsection{Two-Stage versus Full Information Maximum Likelihood Estimation}

Despite the controls for endogeneity by some of the more recent studies, there is general agreement overall that health and wages or labor supply measures are positively correlated. The possibility of endogeneity merely suggests that continual research is

\footnotetext{
${ }^{25}$ As discussed above, omitted variable bias is not guaranteed to disappear with the inclusion of a proxy for health either; it must also be measured appropriately with respect to the capacity for an individual to work.
} 
needed to explore the direction of the causality, and that exact estimates of the effects of health must be taken with caution.

Nearly all of the data available to explore the relationship between labor outcomes and health is non-experimental. ${ }^{26}$ If health and labor outcomes are endogenous, this implies that the errors associated with the observed labor and health statuses are correlated and separate estimation of each without consideration for such correlation will not give consistent estimates. As a result, the methods that focus on the joint determination of health - health capital and/or self-assessed health - and employment have largely consisted of (1) two-stage methods, where all exogenous variables are used to estimate multiple reduced form equations in the first stage then structural equations are estimated in the second stage by using the predicted values from the first, and (2) simultaneous estimation of a system of equations utilizing full information maximum likelihood (FIML) which explicitly takes into account the correlation structure between the respective errors.

One significant advantage of the two-stage method is its computational tractability over FIML techniques. This is especially true for models where the indicator for health takes on a polychotomous form (Cai and Kalb, 2006; Stern, 1989; Lee, 1982). However, while two-stage estimation produces consistent parameter estimates it does not take into account the potential correlation between the error terms of the labor and health equations and is therefore not efficient. FIML methods explicitly account for correlation

\footnotetext{
${ }^{26}$ Dow et al (1997) do obtain two experimental data sets; the RAND Health Insurance Experiment, and the Indonesian Resource Mobilization Study (IRMS). The former is well known in the health literature. The IRMS involved an exogenous increase in the price of public health services for a set of randomly chosen treatment areas in two provinces of the country. The experimental design of the data is used to eliminate endogeneity between health and health care prices. The prices and other exogenous determinants of health are included in OLS estimations on reduced form equations for labor supply and wages. Heterogeneity is controlled for using differences-in-differences.
} 
such that the results are consistent and efficient (Sickles and Taubman, 1986). A further advantage that FIML methods have over two-stage procedures is that they provide a true test for exogeneity by measuring the joint significance of the coefficients on the variables and the correlation parameter, whereas two-stage approaches can only provide coefficient estimates for each equation and therefore only provide a partial test for endogeneity (Stern, 1989; Cai and Kalb, 2006).

Despite deficiencies of the two-stage approach, the two-stage approach can be more robust to misspecification of the disturbance. One concern is that results from FIML are sensitive to the normality assumption imposed and the validity of exclusion restrictions across the equations (Stern, 1989; Currie and Madrian, 1999). Concerning the latter, Currie and Madrian use the examples of Lee (1982) and Haveman et al (1994) to discuss at length how exclusion restrictions are often arbitrarily decided and can result not only in differing estimates across studies for the effects of health on wages or hours worked but also for the effects of other variables included in the model that may be related to health. For example, despite previous studies that find a strong positive relationship between education and health, both studies find that the effect of education on health is substantially reduced when simultaneous equation methods are used.

With some exceptions, the case for endogeneity between labor outcomes and health or self-reported health has been supported by studies that use either method. ${ }^{27}$ Lee (1982) simultaneously estimates a system of equations for log wage and health capital.

\footnotetext{
${ }^{27}$ I have studied more articles than this review will lead the reader to believe, but have purposely grouped those that treat health in only a perfunctory fashion with the studies alluded to in the very beginning of this section - treating health as exogenous and providing some evidence of impact. I don't feel that these studies will add much to the discussion here. Additionally, there is a large literature investigating the effects of economic determinants on the reporting bias of self-assessed measures that does not follow the multiple-equation framework discussed here. These have been left out for brevity.
} 
He first estimates the model using a polychotomous, self-assessed measure of health, and then estimates the model a second time using more a more objective indicator of selfreported work limitations. His particular approach both accounts for the possible endogeneity of health and wages and allows the testing for measurement error in the two indicators. He concludes that (1) education and race significantly affect the perceptions of health in self-evaluations; and (2) that wages and health are "strongly" jointly dependent, both having positive effects on the other.

Haveman et al (1994) simultaneously estimate a three-equation model for health, hours worked, and wages utilizing panel data. They assume that self-reported limitations to work are an objective measure of one's health and conclude that (1) hours worked has no significant effect on health, but (2) the type of work an individual engages in can influence health status, and (3) prior health limitations negatively affect both work time and wages, where wages and work time are positively related. Most importantly, Haveman et al note that simultaneous estimation of the three equations can significantly change the nature of the work time-health relationship. When estimated separately the results suggest a strong influence of hours worked on health, but when estimated simultaneously evidence for this causality disappears. Furthermore, the magnitude for several coefficients across the three equations changes substantially when estimated simultaneously.

A number of studies investigate the relationship between disability and labor force participation using both two-stage estimation and MLE to explore the possibly endogenous relationship between the two outcomes (Stern, 1989; Baldwin et al, 1994; Leung and Wong, 2002; Cai and Kalb, 2006). In general, two-stage estimation and 
maximum likelihood estimation (MLE) can come to quite different results regarding the effects of one outcome on the other, however most studies agree that the exogeneity assumption between the two should be rejected. Stern (1989) and Cai and Kalb (2006) find that when using either method, health has an unambiguously positive effect on labor force participation, but the results are not as clear for the causality in the other direction. Two-stage estimates in both studies reveal no significant effect of participation on disability; thus, two-stage estimates alone would suggest that the exogeneity assumption should not be rejected. Exogeneity can be rejected according to the MLE results. Both studies find positive and significant coefficients for participation in the disability equation - much bigger in magnitude than that of two-stage estimates - with significant, negative correlation coefficients. ${ }^{28}$ The opposite signs for the two coefficients make it difficult to predict the direction of the bias if disability were not treated as endogenous in models for labor participation. Interestingly, though, the positive coefficient is opposite of the expected sign if "justification" were present, suggesting that other sources for endogeneity must be present, such as stress or bad work conditions. As mentioned earlier, the differing results regarding exogeneity across these two methods could be due to the two-stage method's inability to conduct joint tests on the variable and correlation coefficients, or due to its lower efficiency.

Baldwin et al (1994) also use the two-stage approach to estimate the recursive relationship between reported disability and labor force participation as well as reported

\footnotetext{
${ }^{28}$ Cai and Kalb (2006) separate their estimates across four subgroups divided by age and gender. While significant coefficients for participation were not found for either male subgroup, the joint test for exogeneity on both the variable and correlation coefficients rejected the exogeneity assumption across all subgroups. Stern conducts estimates across two different data sets, and finds MLE estimates to be insignificantly different from two-stage estimates for one, but not the other. This discussion pertains to the other.
} 
disability and wages. Relying on Stern (1989), these authors use predicted probabilities for disability status on objective health indicators and demographic variables to instrument for self-assessed disability in the second-stage participation or wage equation. Reduced form estimates for predicted employment were used as instruments in the second-stage estimation for disability while no reduced form estimate was needed for wage. The resulting coefficients on the instruments were significant, supporting the hypothesis that health and labor force participation are endogenous and health has a significant effect on predicted wages. The impact of reported disabilities on both participation and wages were negative as expected, however the predicted employment coefficients have a significant negative effect on male reporting and a positive one on female reporting. One explanation that the authors put forth is "that males face more social pressure than females to justify nonparticipation.” In either case, these results support the idea of "justification bias" in the self-reporting of disabilities and do not eliminate the possibility of other sources for bias in models for disability and participation.

Kreider's (1999) investigation into the prevalence of disability reporting bias uses MLE to estimate simultaneously a system of reduced form equations for labor force participation and health limits where the errors for each equation are allowed to be correlated with each other. The model takes on the form of a bivariate probit if the disability indicator is dichotomous and a trivariate probit when it is trichotomous. Like Stern (1989), Bound (1991), and others he attempts to control for justification bias related to the self-reporting of disabilities by instrumenting limitations with physician-diagnosed conditions. These are included along with behavioral indicators, occupation, and 
demographic characteristics in the reduced form equation for the limits to work due to health. The latent value for labor force participation is a function of the latent representation of health limits and exogenous determinants for income and participation. The estimated correlation coefficient between limitation and work is negative for both men and women, as is expected if unobserved factors influencing disability levels are correlated with the probability of work.

Leung and Wong (2002) demonstrate that "the endogeneity problem can be tackled by means of a simultaneous equations model without imposing any exclusion restrictions on the explanatory variables. ${ }^{29,}$ They too conclude that separate estimation of the two equations will produce misleading results. However, similar to Stern and Cai and Kalb's two-stage findings - most similar to Cai and Kalb's FIMLE for males - they find that joint estimation reveals "consistently that health is a significant positive determinant of employment, but employment has no significant impact on health.” An extensive literature examines the effects of health on the participation decisions of older individuals. The overall results from these studies indicate that improvements in health decrease the probability of retirement (see Currie and Madrian (1999) or Leung and Wong (2002) for a comprehensive but not exhaustive review). While the effects of health may be more pronounced among this cohort for obvious reasons similar endogeneity issues are of concern here. Bound (1991) uses both twostage IV methods and simultaneous estimation and concludes that endogeneity with

\footnotetext{
${ }^{29}$ See page 7 of their study for details of their estimation. They estimate a two-equation model for participation and health arguing that, while estimation of a larger system of equations to account for the endogeneity of income, insurance, of marital status with participation and health is feasible with their technique, the computational complexity of estimating larger systems is limiting with large data sets given their current computing power.
} 
respect to self-reported health measures is plausible. Anderson and Burkhauser (1985)

use bivariate logistic estimation for the two outcomes and find that the bivariate interaction term (correlation coefficient) reported by this model is negative and significant. This result holds whether using a dichotomous, self-reported indicator for limitations on work due to health or an arguably more objective indicator for health $-\mathrm{a}$ dichotomous variable for whether or not the individual died within ten years of the study.

On the other hand, Dwyer and Mitchell (1999) find no evidence that self-rated health measures are endogenously determined with labor supply. ${ }^{30}$ These authors (1) conducted separate OLS estimations of retirement age on SAH and self-reported disability, (2) instrumented for these measures using exogenous determinants, (3) conducted separate OLS estimations using three, more objective indices for health status and limitations ${ }^{31}$, and (4) instrumented for these measures using the same exogenous determinants. Their conclusion was based on Hausman-Wu tests for exogeneity which could not reject the hypothesis that the estimated effects of the health measures in (1) and (2) were equal and the estimates from (3) and (4) only differed slightly.

Au et al (2004) study the effects of health on older worker's retirement in Canada. The issue of "justification bias" was first tested "directly" by using an ordered logit model of SAH as a function of employment status and a comprehensive and arguably more objective health index constructed and made available by their data set (HUI3). A positive and significant effect of employment was found on SAH thereby further

\footnotetext{
${ }^{30}$ While several studies have indeed confirmed justification bias effects with SAH measures several other studies have come to similar conclusions as these authors - see Dwyer and Mitchell (1999, p. 174) for references (which include among others: Haveman et al (1989) and Stern (1989) as used in this paper).

${ }^{31}$ One of which is a "health condition index" similar to Stern's.
} 
supporting the notion of "justification bias" in these measures. Noting this, they explore the effects of health on employment by incorporating HUI3 and, alternatively, a predicted variable for "health stock" - estimated similar to Stern and others above - directly in the equation (as proxies for health). They also instrument SAH using either predicted estimates from the first test or similar estimates obtained with "health stock" substituted for HUI3. The effect of health on employment is consistently significant across all models. However the objective measures for health gave estimates very similar to those using instrumented SAH. The authors conclude that either SAH does not suffer from "justification bias" (at odds with their direct test) or that the "justification bias is outweighed by a counteracting attenuation bias caused by measurement error. ${ }^{32,}$

\subsection{Single-equation Approaches}

Recalling the previous discussion on health measures, some studies recognize the potential endogeneity of health measures in their labor model but instead attempt to circumvent the statistical procedures above and retain the assumption of exogeneity by using more objective, and therefore exogenous, measures as a proxy for health status. Bound (1991, p. 108) argued that "as long as these health proxies are not perfectly correlated with work capacity - the aspects of health that affect an individual's capacity for work - they will suffer from errors in variables problems," and "as long as the correlation between the proxy and actual health isn't close to perfect, the bias will be quite substantial." Furthermore, Bound (1991) put forth that measurement error of one's own health in models for labor force participation will tend to bias the coefficient on

\footnotetext{
${ }^{32}$ Bound (1991, p. 108): "With self-reported health measures we have biases working in opposite directions and, as such, they will have a tendency to cancel each other out."
} 
health downward and the coefficient of income upwards while the endogeneity of health will bias the coefficient on health upwards and the coefficient on income downwards. On the other hand, Bound optimistically asserts that "with self-reported health measures we have biases working in opposite directions and, as such, they will have a tendency to cancel each other out." Nonetheless, by treating health as exogenous but conducting estimation on both subjective measures which tend to be endogenous and objective measures which tend to suffer from measurement error, estimates for the range of relative importance of these variables can still be attained (Siegel, 2006). One concern with this approach however, is that if the direction of bias is not truly known and the researcher relies upon a priori expectations, the predictions for the "range" of relative importance should be taken with caution. Perhaps multiple estimations across alternatives for objective health indicators could provide more information on the extent of the respective bias.

Other researchers have constructed summary indices for physical and emotional impairments in an attempt to increase the correlation between the objective proxy and underlying health. ${ }^{33}$ Unlike self-assessed variables, these indices are supposedly exogenous and often continuous, so they may be especially useful for testing the impact of health status on labor outcomes. In a related manner, some have followed Stern's (1989) example to use specific health conditions to instrument self-assessed health (Dwyer and Mitchell, 1999; Bound, 1991; Kreider, 1999; Camplieti, 2002; Au et al, 2004), thereby creating an objective proxy for health - the variation in the predicted instrument should not be correlated with the error term of the primary equation - based

\footnotetext{
${ }^{33}$ See section 2 for detailed discussion.
} 
on linear regression techniques rather than PCA/FA. Again, however, Bound (1991) argues that Stern's IV approach does not completely solve the problem of endogenous self-assessed health since "it leaves unidentified the impact on [the outcome of interest] of any factors that also directly influence men's reports on their health. In particular this implies that in order to use [Stern's] technique to identify the impact on [the outcome of interest] of financial incentives, one must assume that men's reports on their health are insensitive to these incentives." If the assumption is incorrect, then Stern's IV approach will understate the impact of these financial incentives. Furthermore, Bound concludes that "in fact...using objective measures to instrument subjective ones may actually exacerbate the biases that occur when self-reported measures are used alone. ${ }^{34,}$ In general, if health measures are inherently endogenous with the outcome of interest, and this is not controlled for in accordance with the discussion above, the coefficient on any more objective health index may still suffer from bias.

\section{Conclusion}

We have seen that modeling health with labor market outcomes requires more than just a perfunctory incorporation of a measure of health into models for labor market behavior. We have also seen that thoughtful consideration of the relationship between health and labor market outcomes can lead to a variety of methods to control for the complexities that arise. No single method for measuring health and estimating its effects in labor market models has yet been consistently adopted by researchers in this field. It

\footnotetext{
${ }^{34}$ Kreieder (1999), discussed above, as well as Bound (1991) and Bound et al $(1998,2008)$ - see section 2 - did go beyond simply using instruments to control for measurement bias to also estimate simultaneously a system of equations to control for further endogeneity.
} 
may be the case that no one method could ever suffice for modeling the health and labor nexus. The particular method used by the researcher will most likely depend on the particular dimension of health that is most relevant to the question at hand (Currie and Madrian, 1999). Nevertheless, it is often the case that several alternative methods for determining a similar labor market outcome are used, and any person who seeks to gain insight from the health and labor market literature to date should keep in mind that, "estimates of the relationship between health and labor market outcomes vary widely and are sensitive to the identification assumptions employed" (Currie and Madrian, 1999). 


\section{References}

Au, D.W.H., T.F. Crossley and M. Schellhorn (2004) "The Effect of Health Changes and Long-Term Health on the Work Activity of Older Canadians," IZA Discussion Paper No. 1281.

Anderson, K.H. and R. Burkhauser (1985) "The Retirement-Health Nexus: A New Measure of an Old Puzzle," The Journal of Human Resources, 20(3), pp. 315330.

Baker, M., M. Stabile and C. Deri (2004) "What Do Self-Reported, Objective, Measures of Health Measure?” The Journal of Human Resources, 39(4), pp. 1067-1093.

Baldwin, M.L., L.A. Zeager and P.R. Flacco (1994) “Gender Differences in Wage Losses from Impairments: Estimates from the Survey of Income and Program Participation," The Journal of Human Resources, 29(3), pp. 865-887.

Bardasi, E. and M. Francesconi (2004) "The Impact of Atypical Employment on Individual Wellbing: Evidence From a Panel of British Workers," Social Science and Medicine, 58, pp. 1671-1688.

Bhattacharya, J. and W.B. Vogt (2006) "Employment and Adverse Selection in Health Insurance," NBER Working Paper No. 12430.

Becker, G.S. (1967) Human Capital and the Personal Distribution of Income: An Analytical Approach. W.S. Woytinsky Lecture No. 1. University of Michigan: Ann Arbor, MI.

Ben-Porath, Y. (1967) "The Production of Human Capital and the Life Cycle of Earnings," Journal of Political Economy, 75, pp. 353-367.

Bound, J. (1991) "Self-Reported Versus Objective Measures of Health in Retirement Models," The Journal of Human Resources, 26(1), pp. 106-138.

Bound, J., M. Schoenbaum and T. Waidmann (1995) "Race and Education Differences in Disability Status and Labor Force Attachment in the Health and Retirement Survey," Journal of Human Resources, 30, pp. 227-267.

Bound, J., M. Schoenbaum, T.R. Stinebrickner and T. Waidmann (1999) "The Dynamic Effects of Health on the Labor Force Transitions of Older Workers," Labour Economics, 6, pp. 179-202.

Bound, J., T. Stinebrickner and T. Waidmann (2008) "Health, Economic Resources and the Work Decisions of Older Men," Populations Studies Research Report 07-630, Population Studies Center: University of Michigan Institute for Social Research. 
Cai, L. and G. Kalb (2006) "Health Status and Labor Force Participation: Evidence from Australia," Health Economics, 15, pp. 241-261.

Campolieti, M. (2002) "Disability and the Labour Force Participation of Older Men in Canada," Labour Economics, 9, pp. 405-432.

Chirikos, T. N. (1993) "The Relationship Between Health and Labor Market Status," Annual Review of Public Health, 14, pp. 293-312.

Chirikos, T. N. and G. Nestel (1981) "Impairment and Labor Market Outcomes: A CrossSectional and Longitudinal Analysis," in Herbert S. Parnes, ed., Work and Retirement. The MIT Press: Cambridge, MA.

Chirikos, T.N. and G. Nestel (1984) "Economic Determinants and Consequences of SelfReported Work Disability,” Journal of Health Economics, 3, pp. 117-136.

Currie, J. and B.C. Madrian (1999) "Health, Health Insurance, and the Labor Market," in O. Ashenfelter and D. Card, eds., Handbook of Labor Economics, Volume 3. Elsevier Science: Amsterdam.

Dow, W., P. Gertler, R.F. Schoeni, J. Strauss and D. Thomas (1997) "Health Care Prices, Health and Labor Outcomes: Experimental Evidence," Working Paper Series 97-01. RAND: Santa Monica, CA.

Dwyer, D.S. and O.S. Mitchell (1999) "Health Problems as Determinants of Retirement: Are Self-rated Measures Endogenous?" Journal of Health Economics, 18, pp. 173-193.

Glaser, K. and E. Grundy (2002) "Class, Caring and Disability: Evidence from the British Retirement Survey," Aging and Society, 22, pp. 325-342.

Grossman, M. (1972) "On the Concept of Health Capital and the Demand for Health," Journal of Political Economy, 80(2), pp. 223-255.

Grossman, M. (1999) "The Human Capital Model of the Demand for Health," NBER Working Paper 7078. National Bureau of Economic Research: Cambridge, MA.

Hadley, J. (2003) "Sicker and Poorer - The Consequences of Being Uninsured: A Review of the Research on the Relationship between Health Insurance, Medical Care Use, Health, Work, and Income." Medical Care Research and Review, $60(2)$, supplement to 2003 , pp. 3-75.

Haveman, R., M. Stone and B. Wolfe (1994) "Market Work, Wages, and Men's Health," Journal of Health Economics, 13, pp. 163-182. 
Jones, M.K. (2005) "Disability and the Labour Market: A Review of the Empirical Evidence," WELMERC Discussion Paper No. 2005-03.

Kaiser Commission on Medicaid and the Uninsured/Urban Institute analysis of March 2007 CPS.

Kaplan, R. M., J.W. Bush and C.C. Berry (1976) "Health Status: Types of Validity and the Index of Well-being," Health Services Research, Winter, pp. 478-507.

Kreider, B. (1999) "Latent Work Disability and Reporting Bias," The Journal of Human Resources, 34(4), pp. 734-769.

Lee, L. (1982) "Health and Wage: A Simultaneous Equation Model with Multiple Discrete Indicators," International Economic Review, 23(1), pp. 199-221.

Leung, S.F. and C.T. Wong (2002) "Health Status and Labor Supply: Interrelationship and Determinants," Version of May 28, 2002, in mimeo, Hong Kong University of Science and Technology.

Levy, H. and D. Meltzer (2001). "What Do We Really Know About Whether Health Insurance Affects Health?" Paper presented at the Agenda Setting Meeting of the Coverage Research Institute, Ann Arbor, MI.

Michael, R. (1973) "Education in Nonmarket Production," Journal of Political Economy, 81, pp. 306-327.

Monheit, A.C. and J.P. Vistnes (1999) "Health Insurance Availability at the Workplace: How Important are Worker Preferences?" The Journal of Human Resources, 34(4), pp. 770-785.

Monheit, A.C. and J.P. Vistnes (2006) "Health Insurance Enrollment Decisions: Preferences for Coverage, Worker Sorting, and Insurance Take Up," NBER Working Paper No. W12429.

O’Brien, E. (2003) “Employers' Benefits from Workers' Health Insurance," The Milbank Quarterly, 81(1), pp. 5-43.

Parker, S.C. and J. Rougier (2004) "The Retirement Behaviour of the Self-Employed in Britain," Working Paper in Economics and Finance No. 04/08.

Parsons, D.O. (1982) "The Male Labour Force Participation Decision: Health, Reported Health, and Economic Incentives," Economica, 49(193), pp. 81-91.

Ross, C. and J. Mirowsky (1995) "Does Employment Affect Health?" Journal of Health and Social Behavior, 36, pp. 230-243. 
Ruhm, C. (2000) “Are Recessions Good for Your Health?” The Quarterly Journal of Economics, 115(2), pp. 617-650.

Ruhm, C. (2003) “Good Times Make You Sick," Journal of Health Economics, 22, pp. 637-658.

Sickles, R.C. and P. Taubman (1986) "An Analysis of the Health and Retirement Status of the Elderly," Econometrica, 54(6), pp. 1339-1356.

Siegel, M.J. (2006) "Measuring the Effect of Husband's Health on Wife's Labor Supply," Health Economics, 15, pp. 579-601.

Stern, S. (1989) "Measuring the Effect of Disability on Labor Force Participation," The Journal of Human Resources, 24(3), pp. 361-395.

Virtanen, P., J. Vahtera, M. Kivimaki, V. Liukkonen, M. Virtanen and J. Ferrie (2005) "Labor Market Trajectories and Health: A Four-Year Follow-up Study of Initially Fixed-Term Employees," American Journal of Epidemiology, 161(9), pp. 840-846.

Ware, J.E., M. Kosinski, D.M. Turner-Bowker and B. Gandek (October, 2002) "How to Score Version 2 of the SF-12(r) Health Survey,” QualityMetric, Inc., Lincoln, RI.

Ware, J.E., M. Kosinski, M.S. Bayliss, C.A. McHorney, W.H. Rogers, A. Raczek (1995) "Comparison of Methods for the Scoring and Statistical Analysis of SF-36 Health Profile and Summary Measures: Summary of Results from the Medical Outcomes Study," Medical Care, 33(4), pp. AS264-AS279. 


\section{CHAPTER II}

\section{The Impact of Health on the Self-Employment Decision ${ }^{35}$}

\section{Introduction}

Policy makers across developed economies have sought to foster economic growth through growth in self-employment. Entrepreneurship is often viewed as an avenue for alleviation of unemployment and poverty and a significant source for economic growth (Geogellis et al, 2005; Georgellis and Wall, 2005; Williams, 2004). The ability of small businesses to create new jobs has been highly publicized, as has their potential for restructuring stagnant industries and for spurring economy-wide innovation. Small businesses are seen as a viable employment alternative for displaced workers.

Models of entrepreneurial decision making have been routinely explored in recent decades and a list of important determinants of self-employment has been well established in the literature. As was made clear in the previous chapter, health status has been identified as having a significant impact on labor market outcomes. Omission of health status from an econometric model of wages and labor supply could bias parameter estimates. Its direct effect on outcomes has received relatively little attention in the selfemployment literature. Several studies have included variables for health in a

\footnotetext{
35 This research was funded in part by the Ewing Marion Kauffman Foundation. The contents of this publication are solely the responsibility of Ian Breunig.
} 
perfunctory fashion, while others have not included it in their models at all. Parker (2004) concludes that,

"...in summary, the association between self-employment and illhealth and disability is ambiguous. It is unclear at present what underlies the lack of agreement between the various empirical studies; but it would seem that there is ample scope for further research on this topic." (p. 76)

This chapter will examine the relationship between health status and the decision to enter into self-employment. Much of the past literature concerning self-employment has adopted cross-sectional models which examine the propensity to be self-employed at a given point in time. However, this type of approach tends to confound the determinants of the decision to enter employment and those of survival (Georgellis et al, 2005). Most recent studies tend to use longitudinal data to focus on the transitions into or out of selfemployment thereby focusing on the causes of self-employment rather than its consequences (Georgellis et al, 2005). Some studies have investigated the impact of older worker's health status on their propensity to transition into entrepreneurship before they retire; essentially treating self-employment as a "bridge" between wage-employment and retirement (Quinn, 1980; Fuchs, 1982; Zissimopoulos and Karoly, 2007; Giandrea, Cahill, and Quinn; 2008). Yet, little of the recent research has focused on the extent to which one's health status may influence decisions to enter self-employment in the general workforce.

Some endogeneity issues still remain when modeling job transitions and health status. Particularly, it may be the case that one's initial health status of an individual may have been partly determined by employment history therefore it may also have been determined according to the same decision process used in making transition decisions. This also implies that one's initial employment status may have been self-selected in part 
on the basis of factors that determined one's past health status. Moreover, the literature concerning self-employment identifies several key factors which may limit or, conversely, facilitate transitions to self-employment. However, reliable proxies for those factors are not always available in data sets. For example wealth, family history in entrepreneurship, or various personality traits may all contribute to the propensity for entrepreneurship but are not measured in data sets (see Georgellis et al. (2005) for a comprehensive survey of the various determinants of self-employment). If these unobserved characteristics correlated with individuals' current health status then a parameter estimate on a proxy for health might capture the effect of those characteristics on an individual's decision to become self-employed.

To mitigate these concerns and achieve unbiased estimates of the effect of health on the transition decision this study will adopt a discrete factor random effects model (DFM) to account for the potential confounding effect of unobserved heterogeneity on these estimates. The DFM I use also estimates simultaneously equations for initial employment status and initial health status. Hence, we can control for potential bias due to individuals sorting into initial employment status partly on the basis of past health and employment decisions. Another advantage of the DFM is that its discrete nature allows us to easily distinguish between groups of individuals on the basis of the unobserved heterogeneity which may be present in the sample. This allows us to examine the extent to which the marginal impact of health may vary across these sub-groups.

The next section presents the three hypotheses tested. Section three describes the theoretical framework from which I derive the empirical model. The empirical model is identified, and the details of the DFM are described in section four. Section five provides 
a brief description of the data - the Medical Expenditure Panel Survey (MEPS) - and the variables used in the study. This is followed by a discussion of descriptive statistics and the regression estimates. I conclude thereafter with a discussion of the implications of my findings and some possible extensions of my analysis.

\section{Background}

This section relates the self-employment literature to three hypotheses I consider regarding the effect of the health status of an employed or non-employed individual on their decision to transition to self-employment. In general, it may be the case that healthier individuals will select into self-employment since they will be most able to accommodate the more demanding work required of operating a business. I call this the "Healthy Entrepreneurs" hypothesis. Or, it may simply be that innate characteristics (or characteristics instilled during childhood) that predispose individuals to become entrepreneurs also predispose them to engage in a healthier lifestyle (the "Entrepreneurial Propensity" hypothesis). Conversely, it may be the case that less healthy individuals are pulled into self-employment due to its flexible work environment and schedule, among

other reasons (the "Pull" hypothesis). This section will conclude with support from prior research for the methodology employed in this study.

\subsection{The "Pull" Hypothesis}

The "Pull" hypothesis focuses on the non-pecuniary benefits of entrepreneurship. Despite the likelihood for lower earnings in self-employment, the persistence of significant levels of entrepreneurship has suggested that self-employment is associated 
with substantial non-pecuniary benefits (Hamilton, 2000). ${ }^{36}$ For example, it has been well documented that despite longer work hours, self-employment is believed to offer greater flexibility regarding the location and timing of work as well as the nature of the job (Quinn, 1980; Georgellis et al, 2005). To the extent that an individual with physical limitations will benefit from such flexibility, we would expect to see them enter entrepreneurship at a relatively greater rate. Likewise, the greater control over one's work environment afforded by self-employment allows one to make accommodations for any physical limitations that they face, thereby mitigating the labor market impacts of poor health (Borjas, 1986; Parker and Rougier, 2004; Jones, 2005; Zissimopoulos and Karoly, 2007). Other authors suggest that self-employment is one way in which people with physical disabilities who face discrimination by employers may come closer to realizing their earning potential (Fairlie and Meyer, 1996; Cowling and Taylor, 2001; Parker, 2003, 2004; Jones, 2005; Georgellis et al, 2005).

While there is some evidence supporting the Pull hypothesis, arguments supporting the hypothesis remain tentative since little empirical research has explored this issue. Survey evidence in some studies provides some support for these hypotheses. Schur and Kruse (2002) report higher rates of home working among the disabled. Data from the United States (Fredland and Little, 1981; Hamilton, 2000; Blanck et al, 2000) and the United Kingdom (Quinn, 1980; Curran and Burrows, 1989; Tanner, 1989; Cowling and Taylor, 2001; Boylan and Burchardt, 2002; Parker and Rougier, 2004) show that the self-employed are more likely to report the presence of a work-limiting disability

\footnotetext{
${ }^{36}$ Consistent with labor market studies, evidence shows that disabilities have a negative effect on the earnings of the self-employed, ceteris paribus - possibly due to less ability (although studies have also shown human capital characteristics to be less predictive of entrepreneurial earnings) or negative signaling sent to customers - see Evans and Leighton (1989), Rees and Shah (1986), and Gill (1988).
} 
relative to wage-earners. Using U.S. census data from 1980 and 1990, respectively, Borjas (1986) and Fairlie and Meyer (1997) each find a positive relationship between the presence of a work-limiting disability and the probability of being self-employed. On the other hand, Evans and Leighton (1989) use 1981 data from the National Longitudinal Survey to find no statistically significant relationship between reports of poor health and the probability of being self-employed. More interestingly, they also find no statistically significant effect of poor health when they model transitions into self-employment; as is the case in most other similar studies. ${ }^{37}$

A subset of the literature regarding transitions into self-employment focuses on older workers who may treat entrepreneurship as a "bridge" between wage-employment and retirement. The effects of health on labor decisions are expected to become more pronounced as individuals age. Retirement studies consistently show poor health to be a significant and positive predictor variable for exits from the workforce. The effect of poor health on transitions from wage-work to self-employment, however, remains ambiguous. Quinn (1980) and Fuchs (1982), using Retirement Survey (RS) data from the U.K., are two early studies on this subject. Contrary to Quinn's findings, Fuchs finds no evidence for the impact of health status or work limitations on transitions from wagework to self-employment among older workers. Zissimopoulos and Karoly (2007) come to the opposite conclusion using more recent data from the U.S. Health and Retirement Survey [1992-2000]. Giandrea, Cahill, and Quinn (2008) use the same data [1992-2004]

\footnotetext{
${ }^{37}$ The finding that there is a greater likelihood of self-employed individuals to report poorer health yet no statistical relationship between poor health and transitions to self-employment may suggest that workers have already sorted into jobs that provide the greatest utility with respect to their limiting conditions. Consequently, correlation between initial employment status and contemporaneous health status implies that health status may be endogenous in models for employment transitions and, if not addressed, this may bias estimates of the coefficient on health.
} 
to find that older individuals with poor health are significantly less likely to transition to self-employment than to exit the labor force; Parker and Rougier (2004) find similar results when using recent RS data.

Instead of focusing solely on transitioning to self-employment, Parker and Rougier (2004) contrast the retirement behavior of the self-employed and the wageemployed. Consistent with the retirement literature, they find that poor health significantly increases the probability of retirement for employees. But, consistent with the Pull hypothesis, they find health not to be a significant factor for the retirement of those who are self-employed. This contrasts with Quinn's (1980) earlier findings that poor health significantly reduced labor force participation rates among the older selfemployed in the U.S.

\subsection{The "Healthy Entrepreneurs" Hypothesis}

This hypothesis relies upon the fact that self-employment usually implies longer hours and greater responsibility hence it is typically more physically and mentally demanding (Georgellis et al, 2005; Rees and Shah, 1986). According to Parker (2004, p. 197), it has been well established that self-employed males work more hours per week on average than employees do, and self-employed who employ others put in the greatest hours per week of all. Stress is also greater on average for the self-employed (Dolinsky and Caputo, 2003; Parker, 2004). They have a greater tendency to do multiple jobs than employees (Parker, 2004). Furthermore, industries with the higher concentrations of selfemployment, such as construction or agriculture, can be inherently less-suited to those 
with physical limitations (Williams, 2004; Parker, 2004). ${ }^{38}$ Consequently, we should observe relatively healthy individuals selecting into entrepreneurship.

Rees and Shah (1986) and Gill (1988) provide evidence for a relationship between health and self-employment. Both authors estimate simultaneous equations for the probability of self-employment and earnings. They sought to eliminate the possibility of self-selection bias due to comparative advantages that self-employed individuals may have over wage earners - unobservable characteristics systematically related to both earnings and entrepreneurship. Rees and Shah use an indicator for health equal to one if a chronic condition is reported while Gill includes a dichotomous variable for the presence of a work-limiting condition. Their similar findings are particularly interesting. Poor health significantly increases the differential between the estimated earnings potential in self-employment and wage employment; supporting evidence that human capital characteristics matter less for self-employed earnings or that working-limitations may be better accommodated through self-employment. However, despite the increased earnings differential, the negative effect of poor health on the probability of being selfemployed is noticeably large; supporting the notion that the physical and mental demands of entrepreneurship may outweigh any pecuniary advantages.

Descriptive statistics from survey samples may be misleading. Holtz-Eakin et al (1996) report that people who transition into self-employment show slightly better health on average, as does Zissomopoulos and Karoly (2007). In their cross-country analyses Blanchflower (2000) and Fonseca et al (2007) also note that the probability of entrepreneurship appears to be higher for people in good health. However, excluding

\footnotetext{
${ }^{38}$ This also implies that one's occupation can cause disability and ill-health; providing another source for endogeneity in models for self-employment outcomes.
} 
those surveys noted under the previous hypothesis, the numerous other survey samples reviewed by this author show no significant difference in the proportion of people in good health between the self-employed and employees. Even the descriptive statistics offered in the Rees and Shah and Gill studies show no apparent difference. ${ }^{39}$ It is important to note here that "such simple statistics can conceal more than they reveal and make it all the more important to construct a comprehensive profile of the self-employed" (Rees and Shah, 1986, p. 96).

\subsection{The "Entrepreneurial Propensity" Hypothesis}

This hypothesis is based on the premise that health may not be the factor that influences the self-employment decision; rather we may observe healthier individuals transitioning into self-employment simply because particular personality traits that may be correlated with positive health outcomes are also positively correlated with entrepreneurial inclinations. A large body of literature has investigated the claims that some individuals possess particular psychological traits that predispose them to entrepreneurship. Though often unobservable due to limitations of data, these “entrepreneurial spirits" have been acknowledged by economists and some have attempted to control for or specifically investigate their effects by incorporating psychological variables in cross-sectional probit models of self-employment choice - see Parker (2004, pp.76-79) for discussion. After review, Parker (2004, p. 79) concludes that "psychological factors are neither necessary nor sufficient conditions for entrepreneurs or

\footnotetext{
${ }^{39}$ Perry and Rosen (2004) use probit regressions to find that no significant difference in the health status exists between these two groups. The results of their study are contentious, however, due to the limited sample size for those who transitioned and other arguable limitations of their analysis (Levy and Meltzer, 2001; Flaig, 2003).
} 
entrepreneurship," however, this in no way precludes the possibility of systemic effects of particular personality characteristics on the propensity for entrepreneurship. ${ }^{40}$

A review of the literature on entrepreneurial traits identifies four attributes associated with entrepreneurial behavior: need for achievement, internal locus of control, risk-taking propensity, and a tolerance for ambiguity (Beugelsdijk and Noorderhaven, 2005; Parker, 2004). The former two are of particular importance for this paper. Some have suggested that a key characteristic of successful entrepreneurs is the "need for achievement" rather than money, and that those with this trait will be more energetic entrepreneurs (Tucker, 1988). Such individuals also demonstrate pro-activeness, commitment to themselves and others, and desire feedback on their performance (McClelland, 1961). It is easy to imagine how all of these innate characteristics may also be correlated with individuals who either demonstrate a greater interest in their own health and well-being or experience relatively greater health as a byproduct of a more active lifestyle. A healthy lifestyle may also be correlated with people who demonstrate an "internal locus of control", which implies that the individual perceives that they have influence over outcomes through ability, effort, or skill such that their performance and resultant outcomes depend largely on their own actions rather than external factors (Beugelsdijk and Noorderhaven, 2005; Parker, 2004).

Furthermore, other studies characterize entrepreneurs as possessing a "Type A" personality, characterized by competitiveness, aggression, a striving for achievement, and impatience (Boyd, 1984). Beugelsdijk and Noorderhaven (2005) search for empirical evidence of traits that distinguish entrepreneurs from the general population and wage

\footnotetext{
${ }^{40}$ Note that "personality" traits may be inborn or inculcated during childhood through their environment and upbringing.
} 
earners. After controlling for endogeneity due to past experience and current employment status, they identify entrepreneurs as more individually oriented and consistently promoting ideals of individual responsibility and an ethic of working hard. All of the above personality traits may be associated with healthier outcomes such as a more aggressive pursuit of overall well-being, a more active lifestyle in general, or a concern for self-image.

\subsection{Modeling Self-Employment and Health}

Much of the empirical literature has adopted a straightforward method for modeling the decision to engage in entrepreneurship. A large majority of studies have employed single-equation Probit/Logit, or Multinomial Logit (MNL) models which are conditioned on a number of covariates that are commonly known to impact the entrepreneurship decision. ${ }^{41}$ Variables for human capital (e.g. education, job tenure, experience), demographic variables (e.g. age, race, ethnicity, marital status, number of children, location), economic variables (e.g. non-employment income, employment earnings, personal wealth, tax advantages), and employment variables (e.g. industry, occupation, union status) have all been shown to be key determinants. Health status has been included in some fashion by many, but not all, studies. This paper will utilize the MNL model to assess the probability of transitioning to self-employment as opposed to other alternatives (i.e. "no change" or "new wage job") from an initial wage employment or non-employment status. It will incorporate several of the covariates listed above and pay particular attention to the health status of the individual.

\footnotetext{
${ }^{41}$ Georgellis et al (2005) provides a thorough survey of studies that use longitudinal data to study selfemployment dynamics.
} 
Until recently, a majority of the literature concerning self-employment has adopted a cross-sectional framework which essentially examines the propensity to be self-employed at a given point in time (Georgellis et al, 2005). Although useful, such studies tend to confound the determinants of the decision to enter self-employment and those of survival (Georgellis et al, 2005). By using the longitudinal aspect of MEPS this study mitigates this concern and investigates the extent to which good health or poor health is a cause rather than a consequence of self-employment. ${ }^{42}$ However, endogeneity issues may still remain when modeling health and labor-market transitions. Much of the concern is attributed to the possibility of sorting by individuals over initial employment status based on past health - an individual's observed contemporary health status is expected to be highly correlated with past health status. We may suspect that relatively healthy individuals are more likely to be employed either due to increased labor supply (as a result of higher expected earnings relative to the expected income from public insurance programs) or increased labor demand due to greater expected productivity. Consequently, for transitions from employment, this self-selection may bias the coefficient on health upwards. To the extent that poor health partially causes nonemployment (Bardasi and Fransesconi, 2004) we would expect the estimates in transitions from non-employment to be biased downward.

\footnotetext{
${ }^{42}$ Evidence has shown that self-employment can lead to inferior health outcomes: (1) the physical and mental demands of self-employment can directly impact one's health (Williams, 2004; Dolinsky and Caputo, 2003; Haveman et al, 1994) - see Perry and Rosen (2004) for contrary evidence; (2) selfemployment leads to lower earnings on average (Hamilton, 2000; Georgellis et al, 2005), therefore, with respect to Grossman (1972), less resources are available for investments in health and inferior health outcomes can result over time. However, my sample will only consist of those with initial wage-earning or non-employment status therefore this will not be of great concern. It may be the case that some individuals classified as non-employed were previously self-employed, however, I suspect that the fraction of individuals in this category is minute and the detrimental effects of non-employment upon health will be controlled for in my model thereby alleviating this bias even further.
} 
Likewise, bias may also exist if one's past employment status directly impacts one's health. Regarding transitions from non-employment, studies have suggested that a history of long-term or frequent spells of unemployment can have negative impacts on health status (Bardasi and Fransesconi, 2004). Likewise, it has been shown that individuals with more unstable work histories are significantly more likely to enter selfemployment and be self-employed (Evans and Leighton, 1989; Knight and McKay, 2000). The resulting stress or inactivity can negatively affect one's health (Cai and Kalb, 2006), or lower income can result in decreased investment in household health (e.g. medical care, or poor nutrition and environment) (Grossman, 1972). Regarding transitions from employment, greater past earnings allows for greater investments in household health, and greater self-satisfaction from employment and positive externalities from a social environment can have positive impacts on health (Leung and Wong, 2002; Jones, 2005). ${ }^{43}$ Furthermore, the type of job held, the work environment, and whether one engages in shiftwork or daywork can impact one's health (Parkes, 1999). In particular, long term exposure to occupations that are physically demanding or relatively dangerous can result in diminished health. In turn, Parker (2004) notes that the latter types of occupations have higher concentrations of self-employment. Thus, this additional source for selection bias could introduce a downward bias on our estimates for the effects of health on the probability of transitions from employment. In general, without controlling for initial conditions of employment and health status, the impact of health on the probability of transitioning to self-employment from non-employment may

\footnotetext{
${ }^{43}$ See Chapter 1 for further discussion.
} 
be biased downward while the impact of health on transitions from employment is ambiguous. $^{44}$

People who are employed are far more likely to possess health insurance coverage in the U.S. However, whether health insurance coverage leads to greater health outcomes remains contentious in the literature (Levy and Meltzer, 2001). Noting that the selfemployed are less likely to hold health insurance, Perry and Rosen (2004) investigate whether self-employment results in worse conditions of health. No evidence for such an effect is apparent from their results. Furthermore, to account for the possibility of selfselection into self-employment on the part of healthier individuals, they also conduct a probit analysis of the probability of transitions by wage-earners into self-employment and find no significant effect on health. While their findings were robust across a variety of self-assessed and objective measures used to proxy for health status their somewhat casual analysis on a limited sample size suggests that further analysis is needed (Levy and Meltzer, 2001; Flaig, 2003). Regardless, as long as the possibility of a positive relationship between insurance coverage and health outcomes remains, it is reasonable to assume that one's initial health status will be further correlated with his or her initial employment status due to the predominance of employer sponsored health insurance (ESI) in the U.S.

To control for the possibility of selection bias, the model below will control for the individual's initial conditions by simultaneously estimating reduced form equations for his or her initial employment and health status, respectively, along with the primary

\footnotetext{
${ }^{44}$ To the extent that the non-employed's previous occupations can impact their initial health status, the effect of the bias may also be ambiguous for these transitions. Unfortunately, data limitations do not permit the observance of the characteristics of an individual's prior jobs.
} 
equations for transition decisions. Still, one final matter remains. The "entrepreneurial propensity" hypothesis discussed above suggests that seemingly unobservable personality traits may be positively correlated with both health status and our outcome. Furthermore, inevitable data limitations will not permit us to control for all the various determinants recognized by the entrepreneurship literature (e.g. various personality traits, family history, or wealth). In other words, despite controls for initial employment status, the variable for health may capture the impact of unobserved factors on an individual's employment decision. To alleviate the concern over unobserved heterogeneity I use a discrete factor random effects model (DFM) proposed by Mroz (1999) and formerly used by studies in the context of job turnover (Gilleskie and Lutz, 2002; Blau and Gilleskie, 2001a, 2001b; Blau, 1998; Mushinski, 2009) as well as in various other contexts (Cowell, 2006; Bigsten et al, 2004; Picone et al, 2003; Blau and Hagy, 1998).

\section{Theoretical Framework}

The empirical method for this paper is based on the framework laid out below. Assume that in a given period an individual's utility is dependent upon consumption of a composite commodity, $C$, and his or her health status, $H$. Health is a household commodity that is determined by a production function with inputs of medical care or other health-related goods and services that positively contribute to health, represented by $M$, as well as exogenous characteristics of the individual which may be correlated with health, $Z_{l}$. I assume that the utility function is strictly concave in both of its arguments. Similar to other forms of human capital, health can also be viewed as an investment commodity since it positively contributes to productivity. Hence an individual's total 
earnings from job status, $j$, can be represented by the function, $E_{j}\left(H\left(M, Z_{1}\right), Z_{2}\right)$, which is dependent upon health status as well as other human capital and demographic characteristics correlated with earnings, $Z_{2}$. Thus, in given period, conditional on job status, $j$, I assume that an individual undertakes the following utility maximization

$$
\max _{C, M} U_{j}\left(C, H\left(M, Z_{1}\right)\right)
$$

$$
\text { s.t. } \quad N+E_{j}\left(H\left(M, Z_{1}\right), Z_{2}\right)-P r=P_{c} C+b P_{m} M
$$

where $N$ represents unearned income, $P r$ is the premium associated with any health insurance coverage, $b$ is the fraction of total medical expenses paid out of pocket, and $P_{c}$ and $P_{m}$ are market prices for $C$ and $M$, respectively. Prices are taken as fixed. Depending on their insurance policy, an individual with health insurance coverage will pay some fraction of their total medical expenses $(0 \leq b<1)$ and may or may not be required to pay some positive premium amount $(\operatorname{Pr} \geq 0)$, as opposed to those with no insurance who pay no premium but also must pay the full amount of medical expenses $(b=1) .{ }^{45}$ The assumption of strict concavity of utility in health implies that the magnitude of the impact of health insurance coverage on utility will depend on the individual's state of health; less healthy individuals will value a given health insurance policy more than relatively healthier individuals. The total effect of insurance on utility will also depend on the income effect associated with the combination of a premium and out of pocket medically-related expenses $\left(b^{*} P_{M} * M\right)$ attributed to a given policy.

\footnotetext{
${ }^{45}$ Individuals may hold health insurance coverage through their own employer or employee union, their spouse's employer, a military veteran organization, or public assistance. Despite whether they hold ESI, if the firm employing an individual offers health insurance to its labor force, this may still impact the potential wage that the individual can receive from a job - due to the possible existence of a compensating wage differential within a firm or industry - or may still impact the individual's decision to transition from that job to another job or employment status. Thus, we should not assume that all individuals who are offered ESI will hold ESI, where being offered ESI is a characteristic included in the vector, $\mathrm{Z}_{2}$, and the holding of ESI determines the budget constraint that the individual is faced with.
} 
The individual will choose the employment alternative (job status) which maximizes their utility in a given period. Accordingly, the valuation of a given job status will depend on the difference between the individual's reservation wage and actual (or potential) wage in job status $j, W_{j i}$, as well as the individual's valuation of any nonpecuniary job-related benefits, $B_{j i}{ }^{46} W_{j i}$ is determined by such factors as health $\left(H_{i}\right)$, human capital (e.g. age, education levels, tenure at current job), demographic characteristics (e.g. age, race or ethnicity, gender), and labor demand factors (e.g. region, MSA residency, industry, union status), as well as whether they are married, if their spouse is employed, and the size of the family. Unearned income can be defined as all other household income net of own-earnings and would also impact the individual's reservation wage. The individual may value several benefits, $B_{j i}$, commonly supplied by full-time employers, e.g. paid vacation, sick leave, retirement (pension) plan, or the offer of ESI. We should expect that the holding of ESI through one's own or spouse's current employment, a public source, or other source will affect the valuation of a given job (let the vector $I_{j i}$ represent these characteristics). Finally, a number of unobservable attributes of the individual, $\eta_{i}$, will also play a role in the valuation of a given job or job status.

I represent the valuation of a given job status, $j$, by individual $i$ in period $t$ as

$$
V_{j i t}=g_{L}\left(W_{j i t}, B_{j i t}, H_{i t}, I_{j i t}, \eta_{i}\right)
$$

Let $V_{k i t+1}$ represent the individual $i$ 's valuation of job status $k$ in period $t+1$. The individual will only transition to a new job status $k$ if their expected present discounted

\footnotetext{
${ }^{46}$ Job-related benefits may partly determine levels of health since they may determine the amount of nonmarket time available which, hypothetically, determines levels of health-related leisure activities or amounts of paid "sick-time" (time allowed for recuperating from an illness) a person may experience.
} 
value (EPDV) of lifetime utility is greater than the EPDV of lifetime utility from remaining at job status $j$ in period $t+1$. Let $\bar{V}_{k}$ denote the present value of remaining in job status $k$ after the individual has transitioned to job status $k$ in period $t+1$. EPDV of lifetime utility consists of current period utility at job status $j$ plus the discounted expected value of holding job status $k$ in the subsequent period. The individual's EPDV of lifetime utility from transitioning from job status $j$ to job status $k$ can be expressed as

$$
\bar{V}_{j k i}=V_{j i t}+\beta \bar{V}_{k i}
$$

where $\beta$ is the discount factor. Thus, the individual will only transition when,

$$
\begin{aligned}
\bar{V}_{j k i} & >\bar{V}_{j j i} \\
\left(V_{j i t}+\beta \bar{V}_{k i}\right) & >\left(V_{j i t}+\beta \bar{V}_{j i}\right) \\
\bar{V}_{k i} & >\bar{V}_{j i}
\end{aligned}
$$

Assuming that the personal and job characteristics of one's current job status $j$ will not change from period $t$ to $t+1$, the individual's valuation between the two job statuses can be represented in the following manner

$$
L_{j k i t+1}=\left(V_{k i t+1}-V_{j i t+1} \geq 0\right)=g_{L}\left(W_{j k i}, B_{j k i}, H_{i}, I_{j k i}, \eta_{i}\right),
$$

where $W_{j k i}=W_{k i t+1}-W_{j i t+1}$, and $B_{j k i}, I_{j k i}$ are similarly defined. ${ }^{47}$ The characteristics of the alternative jobs are observed by the individuals (but not the econometrician) and they will choose the employment alternative that maximizes their EPDV of lifetime utility.

\footnotetext{
${ }^{47}$ An individual should not expect their health to immediately change with a change in job status, however, when comparatively valuing job alternatives he or she could calculate their expected health that may be achieved in the future based on their future income and various job characteristics. In either case, the impact of health on the valuation of a possible future job status will be dependent on their current health status, i.e. current health is the reference point from which expected health valuations are made; hence, $\mathrm{H}_{\mathrm{i}}$ is included in the comparative valuation equation and not $\mathrm{H}_{\mathrm{jki}}$.
} 


\section{Empirical Model}

My analysis will use the DFM to control for unobserved heterogeneity in the population that may influence both the transition decision and initial health status, and for the possible endogeneity of initial health status and initial employment status. The model will exclude variables for labor hours and earnings since these may be endogenous, but will instead rely on reduced form models to capture the effects of earnings and hours worked on the transition decision. Unfortunately, DFM can be quite computationally intensive and the time and computing costs grow rather quickly as the number of parameters to be estimated increases. Therefore, the specification of health will be restricted to two, more general, measures in lieu of a potentially more detailed specification for health that would be possible with MEPS. These two measures will be a subjective, self-assessed health measure which is intended to capture the individual's overall level of health and an objective indicator for the presence of any functional limitation in the year in which the transition occurs. If the estimated coefficients on the two measures are statistically significant, the direction of the impact of these two measures will provide support for one or both of the "Pull" hypothesis and the "Healthy Entrepreneur" hypothesis. If we find statistical support for the presence of unobserved heterogeneity in the model, this suggests that we cannot reject the "Entrepreneurial Propensity" hypothesis. The remainder of this section will describe the details of the DFM and the following section will describe the data.

Maximum likelihood is used to estimate simultaneously a system of equations that describes the individual's decision to transition to alternative employment from an initially wage employed or non-employed status. If the individual is initially employed 
they may (i) not transition, (ii) transition to alternative wage employment, or (iii)

transition to full-time self-employment. If they are initially non-employed, they may transition to wage employment or self-employment. I model each set of transitions using the MNL model. The possibility of bias due to self-selection into an initial employment status and endogeneity of initial health status requires the inclusion of reduced form logit equations for these factors into the empirical model (Heckman, 1981). ${ }^{48}$ To control for any unobserved heterogeneity that may be present a discretely distributed random effect component will be incorporated in the model. Since the unobservable variables may be common to all outcomes, we will allow this random effect to enter all equations, but our estimation will allow the impact of this common unobserved component to vary across all outcomes.

Letting $S_{i} \in\left\{W_{i}, B_{i}, H_{i}, I_{i}\right\}$ and linearizing the function $L_{j k i t+l}$ (and dropping the $t+1)$, the equation to be estimated is written as

$$
L_{j k i}\left(S_{i}, \mu\right)=S_{i} \beta_{j k}+\lambda_{j k} \mu+\varepsilon_{j k i}
$$

Unobservable characteristics that are systematically related to both initial health status and the valuation process of the transition decision are captured by the unobserved heterogeneity term, $\mu$; otherwise, they will be incorporated into the random error term, $\varepsilon_{\mathrm{jki}}$. The $\lambda_{\mathrm{jk}}$ represent factor loadings on the unobserved heterogeneity and will permit the

\footnotetext{
${ }^{48}$ We should also expect that the HI decision and a spouse's employment status are determined simultaneously and therefore endogenous within the model. Following the examples of Gilleskie and Lutz (2002) and Mushinski (2009), the endogeneity of spousal employment status will be controlled for by using instrumental variables as a proxy (spouse's age, and dummy indicators for the spouse's level of education). However, for computational efficiency, we will assume here that HI status will be exogenous to the decision. This study is not concerned with an accurate measure of "job-lock" (see, for example, Gilleskie and Lutz, 2002), only the adequate control for such an effect. Moreover, several of the covariates controlling for job characteristics will be assumed to be exogenous but are arguably endogenous, however, due to the large number of parameters already to be estimated by ML, each additional equation will add to the considerable difficulty of obtaining convergence with this maximum likelihood model. A later extension of this study could address these concerns.
} 
impact of the heterogeneity to vary across possible transitions. Assuming that the disturbances are independent and exhibit an extreme-value distribution, the probability of making a transition from employment state $j$ to employment state $k$, conditional on S and $\mu$, is the multinomial logit probability,

$$
P\left(V_{j k i}>V_{j k^{\prime} i}, k^{\prime} \neq k\right)=\frac{\exp \left(S_{i} \beta_{j k}+\lambda_{j k} \mu+\varepsilon_{j k i}\right)}{\sum_{k^{\prime} \epsilon K_{j}} \exp \left(S_{i} \beta_{j k^{\prime}}+\lambda_{j k^{\prime}} \mu+\varepsilon_{j k^{\prime} i}\right)}
$$

where $\mathrm{K}_{\mathrm{j}}$ is the set of employment alternatives from which individual $i$ with initial status $j$ might transition. For individuals whose initial employment state is wage employment, $\mathrm{K}_{\text {emp }}$ includes \{Same wage employment, New wage employment, Self-employment\}. For those whose initial employment state is non-employment, $\mathrm{K}_{\text {non-emp }}$ includes \{Wage employment, Self-employment\}. MNL models are unable to estimate equation parameters for all transitions, therefore for identification purposes I will assume that the parameters for wage-employment to same wage employment and non-employment to wage employment transitions are equal to zero so that parameters estimated will provide insight into the impact of the regressors on actual transitions from a given wage employment and on transitions to self-employment from non-employment.

Instead of assuming a particular distribution for $\mu$ I model it using the discrete factor method proposed by Mroz (1999), in which the unobserved heterogeneity factor iss assumed to have a discrete distribution with a fixed number of points of support. Using full-information maximum likelihood, the points of support of the distribution, factor loadings, probabilities of the points of support, and all other parameters of the model can be jointly estimated. If we find evidence for only one point of support in our model this implies that no unobserved heterogeneity is present and the standard MNL likelihood function is appropriate. 
One advantage of this method is that it can be adapted to a system of equations if needed. It need only be the case that the unobserved component is common to each equation. To avoid inconsistent parameter estimates, I account for the initial conditions of the individual by incorporating additional reduced form equations to be estimated jointly in the likelihood function (Heckman, 1981; Gilleskie and Lutz, 2002). The first equation must account for the initial employment state of the individual since it may have been predetermined according to the same decision process that is used in the transition equation. As Blau and Gilleskie (2001a, p. 40) note, “This implies that the initial employment status is self-selected in part on the basis of the permanent error components, the $\mu$ 's." Letting $\mathrm{E}_{i}$ equal one if an individual is wage-employed in the first period and equal zero if non-employed, the probability of wage employment is

$$
\begin{gathered}
P\left(E_{i}=1\right)=\Lambda\left(A_{i}^{E} \alpha+\lambda_{E} \mu\right)=\frac{\exp \left(A_{i}^{E} \alpha+\lambda_{E} \mu\right)}{1+\exp \left(A_{i}^{E} \alpha+\lambda_{E} \mu\right)}, \text { and } \\
P\left(E_{i}=0\right)=\left[1-P\left(E_{i}=1\right)\right]
\end{gathered}
$$

where $A_{i}^{E}$ is a vector of regressors particular to the employment equation and $\alpha$ and $\lambda_{E}$ are parameters to be estimated.

The remaining reduced form equations account for the possibility of endogenous initial health statuses. As discussed above, the initial health status of an individual may have been partly determined by employment history therefore it may also have been determined according to the same decision process as is used in making transition decisions. For ease of computation ${ }^{49}$, we will restrict the measures of health that are incorporated into the DFM to be dichotomous. Thus, we can model each as the following logit probability,

\footnotetext{
${ }^{49}$ See footnote 48 .
} 


$$
\begin{gathered}
P\left(H_{i}=1\right)=\Lambda\left(A_{i}^{H} \alpha+\lambda_{H} \mu\right)=\frac{\exp \left(A_{i}^{H} \alpha+\lambda_{H} \mu\right)}{1+\exp \left(A_{i}^{H} \alpha+\lambda_{H} \mu\right)}, \text { and } \\
P\left(H_{i}=0\right)=\left[1-P\left(H_{i}=1\right)\right]
\end{gathered}
$$

The remaining covariates in the model are all assumed to be exogenous. ${ }^{50}$ They will be described in more detail below.

\subsection{The Likelihood Function}

We assume that the unobserved heterogeneity term $(\mu)$ has a discrete distribution with a fixed number (L) of points of support $\left(\eta_{\ell}\right)$. The distribution of $\mu$ can be represented by ${ }^{51}$

$$
\operatorname{Pr}\left(\mu=\eta_{\ell}\right)=\pi_{\ell} \geq 0, \ell=1, \ldots, L \quad \text { and } \quad \sum_{\ell=1}^{L} \pi_{\ell}=1
$$

Let $\Theta=\{\beta, \lambda\}$ be the vector of parameters to be estimated in the model. We can represent the likelihood function of the model for an observation $i$ at a given point of support $\eta_{\ell}$ as $L_{i \ell}\left(\Theta \mid s_{\mathrm{i}}, \eta_{\ell}\right)^{52}$, and, unconditional on the permanent error components $\mu$, the likelihood function for that observation across all points of support is

$$
L_{i}\left(\Theta, \eta, \pi \mid s_{i}\right)=\sum_{\ell=1}^{L} \pi_{\ell} L_{i \ell}\left(\Theta \mid s_{\mathrm{i}}, \eta_{\ell}\right)
$$

where $\eta$ and $\pi$ are (Lx1) vectors of the points of support and their probabilities, respectively. Letting $\omega_{i}$ represent a weight associated with observation, $i$, the log likelihood function across all observations is

$$
\ln (L(\Theta, \eta, \pi \mid S))=\sum_{1}^{N} \omega_{i} \cdot \ln \left(L_{i}\left(\Theta, \eta, \pi \mid s_{i}\right)\right)
$$

\footnotetext{
${ }^{50}$ See footnote 48 .

${ }^{51}$ See the Appendix for the parameterization for the points of support.

${ }^{52}$ See the Appendix for the complete description of an individual's contribution to the likelihood function.
} 
As a final matter, I turn to identification of the structural parameters in the transition equations; I am less concerned with the identification of the parameters in the equations for the initial conditions. Identification is achieved both through the non-linear nature of the DFM and through exclusion restrictions. With regard to the latter, I chose to include variables that proxy for the individuals" "health behavior" within the two reduced forms for initial health status - an indicator for whether the individual smokes and the individual's Body Mass Index (BMI) - but not in the transition equations. This assumes that while smoking and obesity may impact one's health outcomes, we should not expect there to be systematic differences with respect to individuals' transition decision and therefore it will be independent of the decision to transition into wage or self-employment. I also include an indicator for past military experience in the reduced form equations for initial health status under the assumption that military experience may instill behaviors that positively contribute to one's health status over a lifetime but should not affect their transition decision from the initial period. ${ }^{53}$ Exclusion restrictions are of little importance regarding the reduced form equation for initial employment status since I am not interested in the structural parameters associated with this particular outcome. ${ }^{54}$

\footnotetext{
${ }^{53}$ It may be the case that, on average, veterans are more likely to possess personality traits that lead to a greater propensity for self-employment. However, regression analysis found no relationship between transitions from wage-employment or non-employment, but did find military experience to be a significant factor in determining health status. Similar tests found the same results regarding smoking and BMI.

${ }^{54}$ In a search for valid exclusion restrictions, however, an indicator for past military experience was tested but was insignificant in an individual model for initial employment. Regardless, the variable was included in the reduced form equations of the final, DFM model, but this did not have any impact on the estimates. Future work will search for other valid exclusion restrictions for the initial employment equation in order to assess whether my reliance on the non-linear nature of the DFM will suffice for identification of the full model. I considered variables for occupations as valid exclusion restrictions in the initial employment equation however I could not justify their inclusion in the employment equation and exclusion from the transition equations on theoretical grounds.
} 


\section{The Medical Expenditure Panel Survey}

Data are obtained from panels five through eleven [2000-2007] of the Household Component (HC) of the Medical Expenditure Panel Survey (MEPS). Each panel consists of a stratified sample of families who represent the civilian non-institutionalized population of the United States. ${ }^{55}$ They participate in five rounds of questionnaires over two calendar years. In addition to demographic characteristics and extensive information on employment, insurance, income, and family relations, MEPS includes a detailed set of variables on the health of each household. The number of observations in the several panels of MEPS overcomes a standard problem in the entrepreneurship literature, namely, a relatively low frequency of transitions to self-employment in the overall labor market.

This chapter will use the longitudinal aspect of each panel of MEPS to investigate the determinants of employment transitions between two rounds. ${ }^{56}$ The various determinants of employment transitions and, particularly, transitions to self-employment, have been well-documented throughout the labor and entrepreneurship literature. MEPS is adequate for such an analysis and has been used, to some extent, in the entrepreneurship literature (Perry and Rosen, 2004; Meer and Rosen, 2004; Mushinski, 2009; Kapur et al, 2008). Core questions pertaining to household, employment, occupational, and insurance status were collected in each round to monitor changes in

\footnotetext{
${ }^{55}$ MEPS is constructed from a complex survey design, so, some computationally intensive steps are needed in order to correctly estimate the variance-covariance matrices. Computation of the empirical model will be done with STATA which performs Linearized/robust variance estimation for user-written maximum likelihood estimators using complex survey data (StataCorp., 2007: p. 156).

${ }^{56}$ All variables are obtained from the $\left(\mathrm{t}^{\mathrm{th}}\right)$ round of a transition occurring between the $\left(\mathrm{t}^{\text {th }}\right)$ and $\left(\mathrm{t}^{\text {th }}+1\right)$ rounds, except for the indicator for any physical limitation ("ANY LIMIT") which indicates whether an individual has experienced any physical limitation in the year in which the employment transition took place. Justification for the use of this variable will be discussed below.
} 
status over the two-year period. The empirical model incorporates measures of job characteristics that may be associated with the value of being employed into the MNL equations for the initially wage-employed transitions. These include job tenure, and dummies for union coverage, paid vacation, paid sick leave, and the presence of a retirement or pension plan. ${ }^{57}$ Other variables included in the model that may influence the potential and reservation wages of the individuals are age, gender, education, race, Hispanic ethnicity, and family variables such as marital status, and the number ownchildren present in the household who are under 18 years of age and the number who are 18 years or older. Lastly, variables for labor demand include the industry in which the employed individuals work and the size of the firm at which they are initially employed. Regional dummies, MSA status, and dummies for the MEPS panel in which the individual participated are included in all transition equations. The variables for age, education, race and ethnicity, region, health behavior, marital status, and number of children are also included in the reduced form equations. The Appendix includes definitions and descriptive statistics of the regressors used in the analysis.

The sample is restricted to individuals who are full-time ( 35 or more hours per week) wage-employed or non-employed in the initial period. ${ }^{58}$ Furthermore, if initially employed, all individuals in the sample have remained at their initial employment over the five-round period, transitioned to a new full-time wage job, or transitioned to self-

\footnotetext{
${ }^{57}$ Again, despite the likely endogeneity of the job characteristics variables as well as insurance coverage, these will be assumed to be exogenous to lessen the computational burden of the DFM model. Future work will expand the model to control for such endogeneity.

${ }^{58}$ MEPS asks each individual who is categorized as non-employed why they are non-employed. From this information I was able to exclude those individuals who were non-employed at the time of the interview because they were already retired, were attending school full-time, or were waiting to start a new job already obtained.
} 
employment that requires twenty or more hours per week. The latter restriction is an effort to observe only individuals who have genuinely made the decision to transition from wage employment to self-employment. ${ }^{59}$ On the other hand, if initially nonemployed, all individuals in the sample have either transitioned to wage employment or transitioned to self-employment that requires twenty or more hours per week. Individuals who do not transition from non-employment over the five-round period are excluded since this study does not focus on determinants of non-employment, only the determinants of the decision to transition into self-employment over wage employment. Therefore, we will interpret the estimated coefficients for health in the non-employment equation as the effect of health on the probability of transitioning to self-employment over wage employment, given that the individual has chosen to transition into employment.

In order to assess the impact of health on decisions to enter into possibly "longterm" entrepreneurship our sample is further restricted to individuals between the ages of 18 and $60 .^{60}$ Several studies have investigated the aspect of self-employment that allows

\footnotetext{
${ }^{59}$ In each round MEPS asks participants to describe their "current main job" then follows with questions regarding other jobs they may hold simultaneously. Individuals were classified as self-employed only if self-employment was their "current main job". Inevitably, some individuals may have simply "lost" a fulltime wage job which they previously have classified as their "current main job" and simply reclassified some formerly "non-main" income generating activity as their new "current main job". By restricting the self-employment jobs to require twenty hours or more per week, I believe we can avoid counting those who are, in a general sense, non-employed but supplement their income with some sort of "part-time" revenue generating activity. If individuals who were previously full-time wage employed were also spending at least twenty hours per week at a second, "non-main", self-employment job, this job should not be designated as trivial. The hours per week requirement should not be restricted further since it is reasonable to believe that many seek self-employment opportunities due to its flexible work schedule.

${ }^{60}$ Some labor market studies have classified working aged adults to be 25 years or older and "older" workers to be greater than 55 years of age. If I were to restrict ages further than 18 to 60 years of age, say, to ages 25 to $55,9.75 \%$ of all transitions to self-employment would be dropped from the sample, thereby losing possibly valuable information regarding health status. Of the 548 transitions from wage employment to self-employment, 17 of them were by individuals less than 21 years old and 25 were between 56 and 60
} 
potential retirees to gradually transition into full retirement (Quinn , 1980; Fuchs, 1982;

Zissimopoulos and Karoly, 2007; Giandrea, Cahill, and Quinn, 2008; Parker and Rougier, 2004). The relatively "short-run" nature of these employment decisions may fundamentally differ from the self-employment decision by people who are not approaching eligibility for social security payments and Medicare coverage, and this study is not concerned with these types of decisions. This study will add to the sparse literature on the impact of health on self-employment decisions of the general labor force. Evidence does show that those who transition to self-employment are likely to be between ages 40 through 55 (Parker, 2004, pp. 70-71), however, my sample indicates that the age of those who transitioned to self-employment was normally distributed around a mean of 38 .

\subsection{Health and Health-related Measures}

The health status variables available in MEPS cover the spectrum of healthrelated variables (e.g. physical, mental/emotional, behavioral, self-assessed and physician diagnosed) found throughout the literature - see the discussion of health measures in chapter one. Several of the health measures are obtained in every other round, but the self-assessed health measure (SAH) - where individuals were asked to rate their health relative to other individuals their age as excellent, very good, good, fair, or poor - is obtained in all rounds and therefore represents the individuals' contemporaneous health status.

years of age. Of the 477 transitions from non-employment to self-employment, 21 of them were by individuals between 18 and 21 years of age and 37 were between 55 and 60 years of age. 
I use two variables to proxy for an individual's health status in my model. The first is a dichotomous variable equal to one if the individual assesses their health as excellent or very good ("Good" health) and zero otherwise ("Less than good" health) ${ }^{61}$ This transformation of the SAH variable provided in MEPS is based on the frequency of the categorical responses across the sample combined with the distribution of selected health indicators over the five categorical responses (Table 1). ${ }^{62}$ When used as a measure of the effect of own health on labor outcomes self-assessed measures may suffer from endogeneity bias leading to an overestimate of the effect of one's health relative to income (Chapter 1). However, this endogeneity bias is mitigated when we use the DFM to estimate models for good health and the transition decisions simultaneously and control for unobserved heterogeneity that may be correlated with both outcomes.

The second health measure used in the analysis (Any Limit) indicates individuals who have experienced any physical limitation in the year in with the employment transition took place. It aggregates the person's responses to questions that pertain to specific functional limitations, regardless of whether or not they hinder the person's ability to engage in productive work. ${ }^{63}$ Past labor supply studies have frequently used

\footnotetext{
${ }^{61}$ This was done for computational efficiency. Future work will relax such a stringent specification. Blau and Gilleskie (2001b) uses a similar specification although their study concerned retiree health insurance and is not focused specifically on individual health.

${ }^{62}$ Table 1 presents sample means for four five other proxies for health not included in the model: (1) two dichotomous indicators for experiencing any health condition or more than two function limitations; (2) two ordinal measures for the number of health conditions and the number of functional limitations; and (3) the Physical Component Summary (PCS) - a continuous index for overall health provided in MEPS. We see that for the sample of individuals who report "Good" health (as opposed to Excellent, Very Good, Fair, or Poor) the mean for each of the measures in (1) and (2) is greater than the overall sample means for each respective measure. Likewise, we see that the mean of each measure for individuals who report "Very Good" health is smaller than the overall sample mean for each of the measures. We see the opposite relationship regarding the PCS measure since it increases with the health status of the individual.
} 
indicators for whether the individual claims to have a "work-limiting" disability as a

proxy for the individual's capacity to work given the presence of one or more health

conditions. Due to its subjective nature, such a measure may suffer from endogeneity

when used to model the effect of own health on labor supply (Chapter one). For instance, a person may have a physical limitation of some sort but may not consider it "work

limiting" if they have sorted into a job that accommodates their limitation. Furthermore, "justification bias" may be present if social norms or legal definitions influence the person to claim a work-limiting disability (Chapter 1). The aggregate measure used here is arguably more objective since it is constructed from either yes or no responses to whether specifically-described physical conditions exist. On the other hand, compared to a "work-limiting" measure, Any Limit may suffer from a greater degree of measurement error to the extent that it is intended to proxy for the effect of one's physical functioning on the capacity or ability to work. ${ }^{64}$

\footnotetext{
${ }^{63}$ Any Limit was coded as equal to one if the individual reported the presence of any of the following physically-functioning limitations: (1) Instrumental Activities of Daily Living - needs help using the telephone, paying bills, taking medications, preparing light meals, doing laundry, or going shopping; (2) Activities of Daily Living - needs help with personal care such as bathing, dressing, or getting around the house; (3) Functional limitations - difficulty lifting 10 pounds, walking of 10 steps, walking 3 blocks, walking a mile, standing 20 minutes, bending or stooping, reaching overhead, using fingers to grasp; (4) Any limitations to work, housework, or school; and (5) Sensory limitations - any difficulty seeing (with the use of glasses or contacts, if needed) or any difficulty hearing (with the use of a hearing aid, if needed).

${ }^{64}$ In future work, I intend to use a proxy for an individual's functional status that is objective, therefore less likely to be endogenous than a more subjective "work-limiting" measure, but measured sufficiently finely in order to alleviate concerns of measurement error. The primary reason for using "Any Limit" in this study is that it provides a computational advantage over "Work Limit". Given the few observations for transitions from wage employment to self-employment relative to the other transitions, and the relatively small proportion of individuals who indicate the presence of a work limitation in the wage to self employment category, the DFM tends to attribute nearly all the variation in the probability of wage to self employment transition to the "Work Limit" variable once unobserved heterogeneity is controlled for. Consequently, the estimates for the other explanatory variables would not be reliable and the estimates for the factor loadings and the intercepts in this transition equation and the reduced form equation for "Work Limit" would also not be reliable. Using "Any Limit" increases the proportion of observations in this transition category who indicate the presence of a limitation to a level such that this problem is less likely to occur.
} 
Table 1. Means of alternative health measures by self-assessed health

\begin{tabular}{|c|c|c|c|c|c|c|c|c|c|}
\hline Health Measures & $\begin{array}{l}\text { No. of } \\
\text { Observations }\end{array}$ & $\begin{array}{l}\text { Sample } \\
\text { Mean }\end{array}$ & Excellent & $\begin{array}{l}\frac{\mathrm{d}}{\text { Very }} \\
\text { Good }\end{array}$ & Good & ss than & Poor & Good & $\begin{array}{l}\text { Less } \\
\text { than } \\
\text { Good }\end{array}$ \\
\hline Any Condition & 7752 & $23.7 \%$ & $12.5 \%$ & $21.0 \%$ & $32.6 \%$ & $48.4 \%$ & $62.7 \%$ & $17.0 \%$ & $36.7 \%$ \\
\hline$>2$ Functional Limitations & 1074 & $3.1 \%$ & $0.5 \%$ & $1.6 \%$ & $4.3 \%$ & $14.0 \%$ & $30.0 \%$ & $1.1 \%$ & $7.0 \%$ \\
\hline Number of Conditions & 32,622 & 0.30 & 0.19 & 0.33 & 0.54 & 0.89 & 1.31 & 0.19 & 0.50 \\
\hline Number of Functional Limits & 32,622 & 0.18 & 0.03 & 0.09 & 0.24 & 0.74 & 1.79 & 0.06 & 0.39 \\
\hline PCS & $29980 * *$ & 52.86 & 55.58 & 53.74 & 50.91 & 45.55 & 39.84 & 54.59 & 49.50 \\
\hline Any Limit & 4805 & $15.2 \%$ & $8.0 \%$ & $12.8 \%$ & $19.9 \%$ & $36.0 \%$ & $56.5 \%$ & $10.6 \%$ & $24.2 \%$ \\
\hline
\end{tabular}

Note: Total Number of observations $=32,622$

** Due to missing observations of PCS the total sample size shrinks to 29980 observations when using PCS.

Any Condition:

g

Equal to one if answered yes to "Have you ever been told by a doctor or other health professional that you've had (a/an) ...:” Heart problems \{Coronary Heart Disease, Angina, Heart Attack, any other kind\}, Stroke (or Ministroke), Emphysema, Arthritis, Asthma, Hypertension - rounds 3 and 5. The remaining conditions, Cancer and Diabetes, were ascertained each round within the "Conditions" section of the MEPS questionnaire and coded by the administrator using ICD-9-CM codes, these are relatively chronic conditions so should be treated as an "ever have" indicator like the former conditions.

Equal to one if three or more of the following functional limitations are present - difficulty lifting 10 pounds,

$>2$ Functional Limitations: difficulty walking up 10 steps, difficulty walking 3 blocks, difficulty walking a mile, difficulty standing 20 minutes, difficulty bending or stooping, difficulty reaching over head, difficulty using fingers to grasp - rounds 1,3 , and 5

Number of Conditions:

Total number of the conditions listed above.

Number of Functional Limits:

Total number of functional limitations listed above.

Any Limit:

Equal to one if any limitation present, zero otherwise (annual measure) - Described further in body of text

Physical Component Summary: $(P C S)$

An index for overall health constructed using principal component analysis on a series of 12 questions from the SF-

12 (trademarked) questionnaire - supplied by MEPS within the Self-Administered Questionnaire conducted in rounds 2 and 4 . Increases with health status. 
Table 2. Means of health variables conditional on the other

\begin{tabular}{|c|c|c|c|c|c|c|}
\hline \multirow[b]{2}{*}{$\begin{array}{l}\text { Health } \\
\text { Measures }\end{array}$} & \multirow[b]{2}{*}{$\begin{array}{l}\text { No. of } \\
\text { Obs. }\end{array}$} & \multirow[b]{2}{*}{$\begin{array}{l}\text { Sample } \\
\text { Mean }\end{array}$} & \multicolumn{4}{|c|}{ Conditional on } \\
\hline & & & Good & $\begin{array}{l}\text { Less } \\
\text { than Good }\end{array}$ & $\begin{array}{l}\text { Any } \\
\text { Limit }\end{array}$ & $\begin{array}{l}\text { No } \\
\text { Limit }\end{array}$ \\
\hline Good & 20408 & $66.1 \%$ & $100.0 \%$ & - & $46.0 \%$ & $69.7 \%$ \\
\hline Less than good & 12213 & $33.9 \%$ & -- & $100.0 \%$ & $54.0 \%$ & $30.2 \%$ \\
\hline Any Limit & 4805 & $15.2 \%$ & $10.6 \%$ & $24.2 \%$ & $100.0 \%$ & -- \\
\hline No Limit & 27817 & $84.8 \%$ & $89.4 \%$ & $75.8 \%$ & -- & $100.0 \%$ \\
\hline
\end{tabular}

Note: Total Number of observations $=32,622$

From Table 2, we see that 34 percent of the weighted sample reports being in less than good health and approximately 15 percent of the sample reports the presence of any limitation. Nearly 54 percent of individuals who report any limitation report as being in less than good health while only 24 percent of those in less than good health report any limitation present. The latter results suggest that these two measures report related but contain distinct information about health. For instance, the dichotomous measure for good health is more likely to capture the effect of one's disease status on the decision to transition to self-employment while the dichotomous Any Limit measure is more likely to capture the effect of functional limitations on that decision.

As a final matter, if we do not control for whether one holds employer sponsored health insurance (ESI) at their initial wage-job the estimated parameters for the health variables may understate or overstate the impact of health on the decision to transition from wage-employment relative to the value placed on health insurance coverage. In other words, if less than healthy individuals place a higher value on their current ESI coverage than healthier individuals, then, without controlling for whether the individual holds ESI, we would expect an upward bias on the estimated effect of Good health in the 
equations for transitioning from wage-employment; or a downward bias on the Any Limit coefficient. Fortunately, MEPS provides detailed information on the insurance status of households, which can be used to separate the direct effect of health status on the transition decision from the indirect effect it may have through the demand for insurance coverage. Table 3 shows the importance of including some sort of control for the "joblock" (or "entrepreneurship-lock") phenomenon. ${ }^{65}$ Individuals who chose to leave their current wage-employment for an alternative wage-job or self-employment are less likely to be insured and particularly less likely to be insured through their current employer. Those who transitioned to self-employment were more likely to be insured through their spouse's employer than those who remained in wage employment. For the initially nonemployed group, those who transitioned to self-employment were substantially more likely to be covered under a spouse's ESI however no more likely to be covered by some insurance source. To control for "job-lock", an indicator for whether one holds ESI will be included in the equations for transitions from wage employment, and one for holding health insurance from any other source will be included in all transition equations. An indicator for whether the working individual is offered ESI from their current employer is also included in the equations for the initially wage-employed. ${ }^{66}$

\footnotetext{
65 "Job-lock" refers to the barrier to job turnover posed by the non-transferability of ESI which a wageemployed individual may hold. "Entrepreneurship-lock" is analogous to job-lock but refers to the barrier of entry into self-employment due to the inferior coverage often associated with health insurance plans available to self-employed individuals.

${ }^{66}$ Gilleskie and Lutz (2002) point out that, if we measure job-lock as the effect of holding ESI on the propensity to transition from one's current employment, then a variable for the offer of ESI by an employer, regardless of whether one chooses to accept it, should be associated with positive job characteristics that reduce mobility. However, if the option of ESI holds some positive utility for an individual then the full job-lock effect is captured by the coefficients on both the holding ESI and the offer of ESI. I am not concerned with the unbiased estimate of the job-lock effect, only with the control for such an effect.
} 
Table 3. Means of health insurance status by employment transitions (percentages)

\begin{tabular}{lccc|cc}
\hline & \multicolumn{3}{c|}{ Initially Wage Employed } & \multicolumn{2}{c}{ Initially Non-Employed } \\
\cline { 2 - 6 } Variables & $\begin{array}{c}\text { No New } \\
\text { Wage }\end{array}$ & $\begin{array}{c}\text { To Self- } \\
\text { Employment }\end{array}$ & $\begin{array}{c}\text { To Wage } \\
\text { Job }\end{array}$ & $\begin{array}{c}\text { To Self- } \\
\text { Employment }\end{array}$ \\
\hline $\begin{array}{c}\text { No. of observations } \\
\text { (\% of sample) }\end{array}$ & 21,835 & 6,921 & 618 & 2,841 & 582 \\
& $(68.3 \%)$ & $(21.4 \%)$ & $(1.93 \%)$ & $(6.83 \%)$ & $(1.56 \%)$ \\
\hline HI Coverage & 89.0 & 69.8 & 69.6 & 45.6 & 45.8 \\
Holds ESI & 75.0 & 50.1 & 50.4 & -- & -- \\
Offered ESI & 85.6 & 60.5 & 55.7 & -- & -- \\
Holds Other HI & 17.8 & 22.0 & 22.3 & 40.2 & 40.8 \\
Spousal ESI & 14.3 & 12.6 & 16.6 & 14.4 & 24.5 \\
Public HI & 2.9 & 5.1 & 4.1 & 16.1 & 13.7 \\
Dependent of Other's & 0.9 & 4.7 & 1.7 & 10.8 & 3.7 \\
\hline \hline
\end{tabular}

Note: 'Holds Other HI' contains 'Spousal HI', 'Public HI', and 'Dependent of Other's HI'; some observations under the non-employed group were reported as being insured but did not indicate a source of own ESI, spouse's ESI, public HI, or other's HI - these were recorded as 'Holds Other HI' since the "insured" variable provided by MEPS was edited by adminstors to be consisted with overall responses to the survey. Note: If 'Holds ESI'=1, then 'Offered ESI'=1

Note: An individual may be covered by more than one type of health insurance policy

Further still, MEPS does not provide us the opportunity to control for potentially significant factors such as family or occupational history that an individual experienced (e.g. father/mother entrepreneurs, childhood health, work experience $)^{67}$ nor the innate characteristics of the individual that may influence their propensity to become entrepreneurs. The DFM model allows us to overcome limitations of the data. My discussion of the results below will illustrate how DFM allows us to draw inferences on whether these omitted variables may potentially bias estimates on the impact of health on the outcomes.

\footnotetext{
${ }^{67}$ See Parker (2004) or Georgellis et al (2005).
} 


\section{Results}

\subsection{Descriptive Statistics}

Table 4 presents the distribution of self-reported health and an indicator for one or more limitations over the five possible transition decisions. Among those individuals who are initially employed we see that only a slightly greater proportion of those who transition to self-employment report to be in good health relative to those who remained at their current job or transitioned to wage employment. For individuals who transitioned from non-employment, those who transitioned to wage employment instead of self employment reported better health. However, no statistically significant difference was found for the probability of being in good health between the three transitions from wage employment. Nor was there a statistically significant difference between the two transitions from non-employment. ${ }^{68}$ On the other hand, statistically significant differences in the probability of having any limitation were exhibited between the transitions to self-employment and wage employment from either initial employment status. ${ }^{69}$ Individuals who transitioned to self-employment were more likely to have a physical limitation than those who transitioned to wage-employment.

Table 5 presents an alternative perspective. It reports the proportion of individuals of a given health status who made each transition. A slightly greater proportion of individuals transitioned to self-employment given that they were in good

\footnotetext{
${ }^{68}$ The null hypothesis could not be rejected at the ten percent level.

${ }^{69}$ The difference is statistically significant at the ten percent level between those who transitioned from a wage job to self-employment and a wage job to a new wage job, and statistically significant at the one percent level for the transitions from non-employment.
} 
Table 4. Means of health measures by employment transitions (percentages)

\begin{tabular}{lccc|cc}
\hline & \multicolumn{3}{c|}{ Initially Wage Employed } & \multicolumn{2}{c}{ Initially Non-Employed } \\
\cline { 2 - 6 } Variables & $\begin{array}{c}\text { No } \\
\text { Transition }\end{array}$ & $\begin{array}{c}\text { To New } \\
\text { Wage Job }\end{array}$ & $\begin{array}{c}\text { To Self- } \\
\text { Employment }\end{array}$ & $\begin{array}{c}\text { To } \\
\text { Wage Job }\end{array}$ & $\begin{array}{c}\text { To Self- } \\
\text { Employment }\end{array}$ \\
\hline No. of observations & 21,835 & 6,921 & 548 & 2,841 & 477 \\
(\% of sample) & $(68.7 \%)$ & $(21.5 \%)$ & $(1.72 \%)$ & $(6.86 \%)$ & $(1.26 \%)$ \\
\hline Good Health & 67.2 & 66.1 & 68.4 & 57.0 & 52.1 \\
Less Than Good & 32.7 & 33.9 & 31.5 & 42.9 & 47.8 \\
Any Limit & 15.0 & 14.4 & 18.1 & 17.7 & 25.1 \\
No Limit & 85.0 & 85.6 & 81.9 & 82.3 & 74.9 \\
\hline \hline
\end{tabular}

Table 5. Distributions of employment transitions by health status (percentages)

\begin{tabular}{lcc|cc}
\hline & $\begin{array}{c}\text { Good } \\
\text { Health }\end{array}$ & $\begin{array}{c}\text { Less Than } \\
\text { Good Health }\end{array}$ & Any Limit & No limit \\
\hline $\begin{array}{c}\text { No. of observations } \\
\text { (\% of population sample) }\end{array}$ & $\begin{array}{c}20397 \\
(66.1 \%)\end{array}$ & $\begin{array}{c}12213 \\
(33.8 \%)\end{array}$ & $\begin{array}{c}4805 \\
(15.2 \%)\end{array}$ & $\begin{array}{c}27817 \\
(84.8 \%)\end{array}$ \\
\hline All Individuals & 66.1 & 33.8 & 15.2 & 84.8 \\
Given initial employment & & & & \\
No Transition & & & 75.1 & 74.7 \\
to New Wage Job & 75.0 & 74.2 & 22.6 & 23.5 \\
$\quad$ given transition & 23.1 & 24.0 & 90.8 & 93.0 \\
to Self-Employment & 92.4 & 93.1 & 2.28 & 1.80 \\
$\quad$ given transition & 1.91 & 1.79 & 9.16 & 7.12 \\
Given initial non-employment & 7.64 & 6.92 & & \\
to Wage Job & & & 79.3 & 85.7 \\
to Self-Employment & 85.6 & 83.0 & 20.7 & 14.3 \\
\hline \hline
\end{tabular}

Note: Given a transition from initial employment: $92.6 \%$ transitioned to wage and $7.4 \%$ transitioned to selfemployment

Note: Given initial non-employment: $84.5 \%$ transitioned to wage and $15.5 \%$ transitioned to self-

employment 
health rather than less than good health, while the opposite is true for those who were initially non-employed. However, these differences are statistically insignificant. On the other hand, regarding either initial employment status, a greater proportion of individuals with any limitation transitioned to self-employment than those with no limitation. ${ }^{70}$ Both perspectives provide little support for the "healthy entrepreneur" hypothesis but do show stronger support for the "Pull" hypothesis. As a final matter, the absolute differences in health status between the initial employment statuses (Table 4) suggest that it is important to account for potential bias due to the sorting of individuals into initial employment statuses according to health or, similarly, due to the impact that past employment status may have on the initial health statuses observed.

\subsection{Regression Results}

The transition equations and the equations for initial employment status and initial health status were estimated simultaneously using maximum likelihood since all equations depended on the same unobserved heterogeneity. ${ }^{71}$ Final estimates are derived

\footnotetext{
${ }^{70}$ This difference between the probability of transitioning to self-employment from initial non-employment given that you experienced any limitation or no limitation was statistically significant at the one percent level. This difference was not statistically significant $(\mathrm{P}|\mathrm{t}|>10 \%)$ for the probability of transitioning to selfemployment from wage employment. However, the probability of transitioning to self-employment from initial wage-employment, conditional on having transitioned from a current wage job ("to self-employment given transition"), was statistically significant at the ten percent level.

${ }^{71}$ Mroz (1999) observed that convergence to a local optimum rather than the global optimum is possible in discrete factor models. Due to the large number of parameters in the model a grid search for initial parameter values for the maximum likelihood procedure proved to be insufficient if not unfeasible. Instead the "brute force" technique identified in Bigsten, et al (2004) which was also adopted by Mushinski (2009) was used to guard against maximization toward a local optimum. This entails the following procedural steps: (1) take 50 bootstrap samples from the original sample and carry out 15 iterations from random starting values for each sample, (2) use the original sample to carry out 20 iterations using each of the 50 estimates as starting values, and (3) the parameter vectors associated with at least the 10 highest loglikelihoods are brought to an optimum and the one with the highest likelihood value is taken to be the maximum likelihood estimator.
} 
from a model with two points of support for the discrete distribution since a substantial improvement in the log-likelihood was exhibited by a two-factor model over a one-factor model (i.e. no unobserved heterogeneity) and models with three, four, and five points of support did not produce a notable improvement in the log-likelihood. ${ }^{72}$

Tables $6 \mathrm{a}$ and $6 \mathrm{~b}$ report estimates of the coefficients on the health variables and of the factor loadings and their corresponding probabilities, respectively (the full regression results are reported in the Appendix). ${ }^{73}$ Table 6 a also includes the estimated coefficients of the non-heterogeneity model (one point of support). The effects of health and any limitation are larger (as are the standard errors) with heterogeneity than without for transitions from initial wage-employment. This leads to the conclusion that accounting for unobserved heterogeneity and the possible endogeneity of initial wage employment, health, and any limitation increases the estimated impact of health on job turnover compared with no-heterogeneity results. ${ }^{74}$ Estimates for the transition from nonemployment to self-employment show little change. Turning briefly to the full regression results (located in the Appendix), I find that the model specification for the transitions from initial non-employment - variables that capture demographic and human capital

\footnotetext{
${ }^{72}$ To test the optimal number of points of support for the model the maximization procedure is run successively, each time adding a point of support. The "best fit" is achieved with the additional point of support does not notably increase the log likelihood. To guard against accepting too few points of support, additional points of support are added beyond the initial stopping point in order to see if these increase the likelihood significantly.

${ }^{73}$ All estimates use robust standard errors and are weighted by the person's respective longitudinal panel weight.

${ }^{74}$ To distinguish whether the observed bias in the parameters for health status is due to unobserved heterogeneity or due to endogeneity of initial conditions I must conduct further tests by estimating a DFM model without the inclusion of reduced forms for the initial conditions and compare the results to the full DFM model estimated here. I hope to conduct such a test in future work. Nonetheless, we can conclude from the results presented here that a model which controls for unobserved heterogeneity and endogeneity of initial conditions is superior to one that does not.
} 
Table 6a. Regression Results

\begin{tabular}{lccc|ccc}
\hline & \multicolumn{3}{c|}{ With Heterogeneity } & \multicolumn{2}{c}{ Without Heterogeneity } \\
\cline { 2 - 7 } Variables & $\begin{array}{c}\text { Wage } \\
\text { to Wage }\end{array}$ & $\begin{array}{c}\text { Wage } \\
\text { to SE }\end{array}$ & $\begin{array}{c}\text { Non-emp } \\
\text { to SE }\end{array}$ & $\begin{array}{c}\text { Wage } \\
\text { to Wage }\end{array}$ & $\begin{array}{c}\text { Wage } \\
\text { to SE }\end{array}$ & $\begin{array}{c}\text { emp to } \\
\text { SE }\end{array}$ \\
\hline Good & $-0.442^{* *}$ & -0.361 & 0.179 & -0.0170 & 0.0829 & 0.00502 \\
Health & $(0.186)$ & $(0.396)$ & $(0.375)$ & $(0.0448)$ & $(0.113)$ & $(0.132)$ \\
Any Limit & $0.569 * * *$ & $0.775^{* *}$ & -0.0347 & $0.135 * *$ & $0.313 * *$ & 0.104 \\
& $(0.149)$ & $(0.373)$ & $(0.323)$ & $(0.0566)$ & $(0.155)$ & $(0.171)$ \\
\hline \hline
\end{tabular}

Standard errors in parentheses: $* * * \mathrm{p}<0.01, * * \mathrm{p}<0.05,{ }^{*} \mathrm{p}<0.1$

Table 6b. Regression Results

\begin{tabular}{|c|c|c|c|c|c|c|}
\hline & \multicolumn{3}{|c|}{ Transitions } & \multicolumn{3}{|c|}{ Initial Conditions } \\
\hline & $\begin{array}{l}\text { Wage } \\
\text { to Wage }\end{array}$ & $\begin{array}{l}\text { Wage } \\
\text { to SE }\end{array}$ & $\begin{array}{l}\text { Non-emp } \\
\text { to SE }\end{array}$ & Employed & $\begin{array}{l}\text { Good } \\
\text { Health }\end{array}$ & Any Limit \\
\hline \multirow{2}{*}{$\begin{array}{l}\text { Factor } \\
\text { Loading }\end{array}$} & & & & & & \\
\hline & $\begin{array}{c}1.121 * * * \\
(0.337)\end{array}$ & $\begin{array}{c}1.186 \\
(0.918)\end{array}$ & $\begin{array}{c}-0.470 \\
(0.924)\end{array}$ & $\begin{array}{c}0.765 * * * \\
(0.116)\end{array}$ & $\begin{array}{c}1.965 * * * \\
(0.274)\end{array}$ & $\begin{array}{c}-2.046^{* * *} * \\
(0.255)\end{array}$ \\
\hline \multicolumn{2}{|c|}{ Probability Pt. $0=$} & $\begin{array}{l}0.39 * * * \\
(0.0182)\end{array}$ & \multicolumn{2}{|c|}{ Probability Pt.1 = } & $\begin{array}{l}0.61 * * * \\
(0.0182)\end{array}$ & \\
\hline
\end{tabular}

Standard errors in parentheses: $* * * \mathrm{p}<0.01,{ }^{* *} \mathrm{p}<0.05,{ }^{*} \mathrm{p}<0.1$

Note: Probabilities of points of support calculated using specification found in Appendix; standard errors for probabilities calculated using the delta method.

characteristics in addition to those of health - offers little explanation to why an individual might choose self-employment over wage-employment if they were initially non-employed. This may only suggest that the probability of transitioning to selfemployment or wage-employment given an entry or re-entry into the workforce may not be explained by the same determinants of the job-turnover. ${ }^{75,76}$

\footnotetext{
${ }^{75}$ Note that the unobserved heterogeneity factor included in the DFM only captures time-invariant heterogeneity that is common to all equations included in the model. Therefore, unobservable characteristics that may impact the decision to transition from non-employment may be different than those
} 
I will first focus on the results regarding the transitions to self-employment from initial wage employment. The multinomial logit estimates are consistent with the discussion of the descriptive statistics above. The estimated effect of having some sort of limitation on the probability of transitioning from wage-employment is positive and significant and the variable for any limitation has a slightly greater impact on the probability of transitioning to self-employment than on the transition to new wageemployment. The Good Health variable negatively impacts the probability of a job transition. This result is inconsistent with the Healthy Entrepreneurs hypothesis. Of course, it is statistically significant only in the wage job to new wage job transition equation. These results can be interpreted in a manner that provides support for the "pull" hypothesis. They suggest that an otherwise average worker in relatively better health is less likely to transition from their current job to self-employment, although their health may not strongly influence the decision. On the other hand, all else equal, a worker with any limitation is more likely to leave their current wage-employment and has a higher probability of entering into self-employment than a worker with no limitation.

The statistical significance of the factor loading in the transition from wage to new-wage employment suggests that unobserved heterogeneity has an impact on those transitions. Although the factor loading in the wage to self-employment equation is statistically insignificant its similar magnitude to the former, statistically significant, factor loading suggests that its influence on the probability of the self-employment

which affect the transition from wage employment. A model with two factors could capture such multidimensional heterogeneity.

\footnotetext{
${ }^{76}$ This may also provide an argument to test whether my specification for transitions from non-employment yields much explanatory power by dropping these transitions from the model and observing whether the log-likelihood substantially changes. This would require considerable computation (see footnote 74).
} 
transition should not be completely discounted - its relatively larger standard error could be a result of the relatively small proportion of the overall sample of individuals that we observe transitioning to self-employment (only $2 \%$ of the entire sample compared to $68 \%$ and $21.5 \%$ for no transition and wage transition, or $7.4 \%$ of all job transitions from an initial wage job). A positive sign on the loadings suggests that individuals at the larger point of support $(\mu=1)$ are more likely to make a transition from their current job. The probabilities of the points of support can be interpreted to suggest that nearly three-fifths of the nationally representative sample fall into the category of individuals defined by the larger point of support.

The statistical significance, magnitude, and signs of the factor loadings for the initial conditions equations allow us to contrast the group of individuals at point one with the group at point zero. The group at point one can be characterized as (1) more likely to report being in good health, (2) less likely to have any sort of limitation, and (3) more likely to be initially wage-employed than non-employed. This is consistent with the view of health as human capital.

In summary, there are one or more omitted variables from the model that may be positively correlated with both the overall health of individuals and their propensity to transition from current employment to self-employment. Because this interpretation is consistent with the "entrepreneurial propensity" hypothesis, the hypothesis cannot be rejected. Comparing the estimates of the heterogeneity model with the no-heterogeneity model, we see that, because of a positive correlation between an individual's health and variables that are typically omitted from such models (e.g. psychological, family background, risk-aversion, and wealth, among others), ignoring heterogeneity in a sample 
may result in an upward bias in estimates of the impact of health on employment transitions. For instance, the coefficient on "any limitation" substantially increases from 0.313 to 0.775 once we control for the heterogeneous group of individuals who are less likely to have any limitation but more likely to transition to self-employment. Likewise, despite statistical insignificance, the coefficient on "good health" is reduced from 0.083 to -0.363 in the self-employment transition equation once we control for heterogeneity.

The estimates for initially non-employed individuals should be interpreted in a slightly different manner than the estimates above because they are conditional upon a transition into the workforce. Contrary to the descriptive statistics in tables 2 and 3 above, the regression results indicate that overall health has little impact on whether individuals enter or re-enter the workforce via self-employment or wage-employment. Furthermore, the size of the standard errors prevents inferences regarding statistical significance and, thus, signs of these coefficients. The statistical insignificance and relatively small magnitude of the factor loading in this transition equation suggests that heterogeneity is not as important in these transitions.

The discussion so far has illustrated how the discrete nature of the DFM allows one to distinguish between groups of individuals in the population who may have different propensities to undertake entrepreneurial activities. Moreover, we can distinguish the relative economic importance of health in these groups by contrasting the marginal impact of self-assessed health and the presence of a physical limitation on the probability of transitioning to self-employment. For each point of support, Table $7 \mathrm{a}$ presents the probabilities of transitioning from wage-employment to self-employment of individuals who (1) report being in good health as opposed to less than good health, (2) 
Table 7a. Probabilities for transitions from employment*

\begin{tabular}{lcc}
\hline & Pt. 0 & Pt. 1 \\
\hline At Means of Both Measures & 0.61 & 1.66 \\
\hline Good Health & 0.55 & 1.52 \\
Not Good Health & 0.75 & 1.94 \\
Any Limitation & 1.11 & 2.76 \\
No Limitation & 0.55 & 1.51 \\
\hline Good Health \& No Limitation & 0.49 & 1.38 \\
Good Health \& Any Limitation & 1.00 & 2.57 \\
Not Good Health \& No Limitation & 0.68 & 1.78 \\
Not Good Health \& Any Limitation & 1.34 & 3.13 \\
\hline \hline
\end{tabular}

* Numbers reported are percentages

Table 7b. Marginal effects for transitions from employment*

\begin{tabular}{lrr}
\hline & Pt. 0 & Pt. 1 \\
\hline Good Health & -0.203 & -0.423 \\
Any Limit & 0.561 & 1.250 \\
Good Health (Given No Limitation) & -0.184 & -0.396 \\
Good Health (Given Any Limitation) & -0.338 & -0.565 \\
Any Limit (Given Good Health) & 0.512 & 1.188 \\
Any Limit (Given Not Good Health) & 0.666 & 1.357 \\
Not Good Health \& Any limitation & 0.851 & 1.753 \\
\hline
\end{tabular}

* Numbers reported are percentages; Marginal Effects are evaluated at the means of all covariates not being considered

report any physical limitation as opposed to having no limitation, and (3) who report neither, one or the other, or both. ${ }^{77}$ Table $7 \mathrm{~b}$ reports differences in the probabilities found in Table $7 \mathrm{a}$ - the marginal effects. The probabilities and marginal effects for all of the transitions are reported in the Appendix.

\footnotetext{
${ }^{77}$ All probabilities for transitions from wage-employment are calculated using the means of the other covariates conditional on initial employment.
} 
Comparing the probabilities of a transition to self-employment from wageemployment between individuals at point zero and point one in Table 7a shows that individuals at point one are nearly twice as likely to transition regardless of their state of health. For instance, an average employed individual in group one, who is in good health and with no limitation, has a $1.4 \%$ probability of transitioning compared to a $0.5 \%$ probability if that individual was in group zero. Turning to the marginal impacts of health and limitations in Table 7b, the results suggest that, for point zero, those individuals who report good health (less than good health) are between $0.18 \%$ and $0.34 \%$ less likely (more likely) to enter into self-employment, depending on the presence of any limitation. This group is $0.51 \%$ to $0.67 \%$ more likely - depending on their assessment of overall health - to enter into self-employment if they experience any physical limitation. At the extreme, individuals moving from a state of good health and no limitation to poorer health and any limitation are $0.85 \%$ more likely to enter self-employment.

The increased probability of entering self-employment due to poor health or limitations grows for individuals at point one. There is a decrease (increase) of between $0.40 \%$ and $0.57 \%$ in the probability of transitioning as an individual moves from less than good health to good health (good health to less than good health), and an increase in probability between $1.19 \%$ to $1.36 \%$ due to the presence of a limitation. Moving from a health status of good health and no limitation to one of less than good health and any limitation increases the probability of a self-employment transition by $1.75 \%$.

Turning to transitions from non-employment, the maximum likelihood results indicated that health and limitations yielded little explanatory power for the probability of entering self-employment over wage-employment given that the individuals entered the 
workforce, and heterogeneity does not seem to be of great concern. Consequently, any inferences based on the results found in Tables A2 or A4 should be treated with caution. Generally though, disregarding statistical insignificance, the estimates suggest that the group at the smaller point of support $(\mu=0)$ have a slightly greater proclivity towards selfemployment rather than the group at point one. ${ }^{78}$ Furthermore, contrary to individuals who transitioned from initial employment, those in better health and/or with no limitation have a higher probability of entering self-employment than their counterparts. The marginal impacts are stronger for the group at point zero than for point one.

To check for the robustness of the estimates above I re-estimated the model but excluded controls for health insurance coverage (e.g. Holds ESI, Offered ESI, Other HI, and Insured not specified) from all transition equations. The estimates for good health and any limitation are qualitatively similar and their interpretations remain the same. ${ }^{79}$ With respect to the "entrepreneurship-lock" literature mentioned above, it may also be valuable to contrast the marginal impact of health status on the decision to transition to self-employment from an initial wage-employed status between (1) individuals who are offered and subsequently hold ESI and (2) individuals who are not offered ESI. Gilleskie and Lutz (2002) argue that the combined effects of the offering and holding of ESI

\footnotetext{
${ }^{78}$ If we ignore the statistical insignificance of the factor loading in the non-employed transition equation and attempt to interpret the estimated probabilities as they are, the fact that the group at point one is more likely to enter self-employment if they are initially wage employed but less likely if they are initially nonemployed may seem contradictory. However, this outcome can be interpreted in a manner consistent with past literature regarding the "push" into self-employment from chronic or long-term non-employment, or the "misfit" hypothesis (see Parker, 2004) if we were to recognize that the group at point zero is also less likely than those at point one to be initially wage employed.

${ }^{79}$ The same steps described above, for computing the MLE and testing for the specification of the discrete factor, were conducted, only I used the 50 initial vectors from the second stage of finding initial starting values with the initial coefficient values for the insurance variables dropped. The model specification for unobserved heterogeneity remains the same - two points of support - but the likelihood value for these estimates suggests that controls for HI should not be excluded from the model explaining transitions.
} 
represent the total impact of job-lock on the individual's decision to leave their current employment given that the additional deterrence of leaving a "good job" is adequately controlled for by variables for pension, vacation days, and paid sick leave. We would expect to see that workers in relatively poorer health will be less likely to transition to self-employment if they hold ESI through their current employer since their expected valuation of their current health insurance coverage, hence their current job, will be greater than the valuation by workers who do not hold ESI nor have the potential to obtain coverage from their employer. Table 8 reports the differences in marginal effects of good health and any limitation for workers holding ESI and those who are not offered ESI. As expected, for either point of support, the negative marginal impact of "good" health on transitioning from wage-employment to self-employment and the positive marginal impact of having any limitation present are larger for individuals with no offer of ESI from their current employer, where the effect is more pronounced for the latter measure of health.

Table 8. Marginal effects of holding ESI at initial wage job*

\begin{tabular}{lrr}
\hline & Pt. 0 & Pt. 1 \\
\hline Good Health given Holds ESI & -0.258 & -0.442 \\
Good Health given no offer of ESI & -0.288 & -0.525 \\
& & \\
Any Limit given Holds ESI & 0.578 & 1.300 \\
Any Limit given no offer of ESI & 0.803 & 1.620 \\
\hline \hline * Numbers reported are percentages; Marginal Effects are evaluated at the \\
means of all covariates not being considered
\end{tabular}




\section{Conclusion}

This paper has addressed whether there exists a meaningful association between self-employment and health status. In doing so, it has avoided restricting the analysis to certain segments of the labor force such as older workers, or particular genders, races, or ethnicities. Moreover, transitions into self-employment from an initially wage-employed or non-employed status, across the general working-age population (18-60), were investigated in order to generate a more comprehensive profile of the health status of individuals who transition to self-employment. It has adopted an econometric approach which (1) models explicitly unobserved heterogeneity and (2) which controls for potential endogeneity due to the presence of initial conditions (Heckman, 1981). The econometric model has the added benefit of separating different sub-groups within a sample, based on unobserved heterogeneity, so that differences between these sub-groups regarding the marginal impacts of health may be revealed.

Given the differences between the data sources and the econometric methodology employed in this analysis and that of previous studies, it is difficult to compare their findings with those above. However, this paper considers three general hypotheses for the effects of health on the self-employment decision that can be extracted from the selfemployment literature. Thus, I compare their predicted outcomes to the results above. The "Healthy Entrepreneurs" hypothesis suggests that relatively healthier individuals will be most able to accommodate the more demanding work required of operating a business, therefore it predicts that individuals who report a "good" health status or are in better physical condition (e.g. report no physical limitations present) will tend to select into self-employment more often than their individuals in less than "good" health or have a 
limitation. The "Pull" hypothesis predicts the opposite outcome. It suggests that a flexible work environment and schedule associated with self-employment may be appealing to less healthy (physically restricted) individuals and this consideration may tend to outweigh any other employment considerations. Alternatively, self-employment may be a viable alternative for individuals who experience discrimination in the workplace or job market due to a physical ailment. Lastly, the "Entrepreneurial Propensity" hypothesis suggests that it may be the case that personal characteristics of individuals that may predispose individuals to become entrepreneurs - "entrepreneurial spirits" - may also predispose them to engage in a healthier lifestyle and therefore report better health outcomes. Ultimately, these unobservable traits may bias the estimations of the direct effect of health on the self-employment outcome upwards if left unattended in empirical models.

The capabilities of my econometric model allowed me to make an inference regarding the Entrepreneurial Propensity hypothesis. Two groups of individuals from the general population were identified (Group 1 and Group 2). Group 2 can be characterized as (1) more likely to report "good" health and less likely to report any physical limitation, (2) more likely to be wage employed than non-employed, and (3) more likely to transition from wage employment to alternative wage employment and, more importantly, to self-employment. The calculated probabilities indicate that this sub-group is at least twice as likely as their counterparts to transition to self-employment from wage employment. Unobserved heterogeneity did not seem to be a significant factor in explaining transitions to self-employment if initially non-employed (given a transition into the workforce). A comparison of the estimated coefficients of the health status 
variables from my econometric model and a model that does not control for unobserved heterogeneity suggested that, for transitions from wage employment, the predicted bias was present in the non-heterogeneity model; therefore, we cannot reject the Entrepreneurial Propensity hypothesis.

Although it need not be the case that the Healthy Entrepreneurs and the Pull hypotheses are mutually exclusive, estimates of the marginal effects for self-reported overall health and the presence of any physical limitation both provide evidence in support of the Pull hypothesis. The statistical significance of the coefficient estimates suggests that the latter health measure has a more distinct effect on the self-employment decision. The calculation of the marginal effects shows that, as the average individual in Group 1 (at point zero) moves from a "good" health status to a less than "good" health status, he or she is between $0.18 \%$ and $0.34 \%$ more likely to transition from wage employment to self-employment, depending on the presence of any limitation. The worker is $0.51 \%$ to $0.67 \%$ more likely to make the same transition if they report the presence of any limitation. A similar individual moving from a state of good health with no physical limitation to poorer health and any limitation is $0.85 \%$ more likely to enter self-employment.

For a similar individual in Group 2 (at point one), the marginal effect of less than "good" health on the wage to self-employment transition is between $0.40 \%$ and $0.57 \%$. For any limitation the marginal impact is between $1.19 \%$ and $1.36 \%$. Moving from a "good" health status and no limitation to a state of less than "good" health and any limitation, an individual's probability of transitioning increases by $1.75 \%$. 
No statistically valid inferences can be made regarding the marginal impact of health status and limitations on transitions to self-employment from non-employment. However, unlike the sub-sample of initially wage-employed individuals, estimates for non-employed individuals are conditional upon a transition to either wage or selfemployment. Therefore we interpret the statistical insignificance of most of the covariates to mean that other factors, not explained by the model and which tend to be uncorrelated with self-assessed health and physical limitations, must be more important to determining whether a non-employed individual who enters the work-force chooses self-employment over wage-employment. This does not conflict, nor support, previous literature regarding these types of transitions.

Moreover, the statistical insignificance of the heterogeneity factor in the transitions from non-employment suggests that the unobservable characteristics that may impact the decision to transition from non-employment may differ from those which affect the transition from wage employment. Future work might further test for whether unobserved heterogeneity, which may bias parameters on health, exists in the sample of transitions from non-employment by either estimating a separate model for these transitions or including a second factor to capture multi-dimensional heterogeneity in the overall sample.

Possible endogeneity of the characteristics of an individuals' initial wage job (e.g. those of tenure, job benefits, and union status) and insurance status were not controlled for due to computational costs. Future work could expand the model to include reduced form equations for these covariates in an attempt to gain further estimates. While the removal of indicators for insurance status from the model did not alter the conclusions 
above in any significant manner, other independent variables such as job tenure or marriage status may also be of concern. Furthermore, to facilitate inferences regarding the hidden composition of the heterogeneity factors, it may be beneficial to search further for possible proxies for the currently unobserved determinants which have been suggested by prior literature as partially explaining job turnover by individuals. For instance, the wealth of individuals may explain a substantial proportion of the heterogeneity observed in the estimates above.

While the prospect of more lucrative employment alternatives will certainly drive labor force transition decisions, and factors such as human capital characteristics (e.g. labor market experience, education levels, as well as the physical or mental capacity to work) and the access of capital will partially determine the available alternatives, it can also be the case that individuals base their labor supply decisions partially on jobsatisfaction or non-pecuniary advantages offered by certain employment alternatives. Recent evidence supports the notion that self-employment offers substantial nonpecuniary advantages (Georgellis et al, 2005). Economists are interested in whether these benefits are sufficient to offset some of the inherent costs that ventures into selfemployment often entail, such as forgone earnings in the wage and salary sector or costs tied to the uncertainty of success.

The results of this study suggest that certain non-pecuniary advantages which may be linked to individuals' health status may play a significant role in decisions to transition from wage employment to self-employment. The results above are reflective of the role that health plays in these decisions even after controlling for related factors which may have a more pecuniary effect, such as the possession of health insurance 
(observed) or household wealth (unobservable). They provide evidence that individuals in relatively poorer health have a greater propensity to leave wage-employment for selfemployment, all else equal. My findings have broader implications for a system of health insurance provision (such as that in the United States) where health insurance options differ across forms of employment (e.g., self employment and wage employment). Under these circumstances, an individual may choose a form of employment not because they would be economically most productive in it but because of the available health insurance in that form of employment. A mis-allocation of labor likely would result. My findings suggest that individuals with low health who prefer self-employment for its flexibility might stay in wage employment because their health insurance in wage employment is better. Thus, my findings support public policies which equalize health insurance options across forms of employment because those policies would remove any such inhibitions on transitions between forms of employment.

\subsection{Extensions}

The work presented in this chapter lends itself to several extensions which may prove valuable in understanding the breadth of the relationship between health status and self-employment. For one, while the number of observations for transitions to selfemployment was sufficient to draw inferences about the nature of those transitions, estimating the model for various sub-populations (e.g. single males or married males) may not prove to be fruitful since the number of observations transitioning to selfemployment would not be large. A similar problem arises if we attempt to estimate the model for the various occupations or industries that individuals who transition to self- 
employment started from or enter into. If this were possible, results may show that the "Healthy Entrepreneurs" hypothesis holds with regard to some industries or occupations while the "Pull Hypothesis" holds in others.

It would also be ideal to re-estimate the model using a larger variety of the health measures available within MEPS to get a better idea of the role of health in selfemployment decisions, but the small number of observations that transition to selfemployment and report a specific health status limits the ability to draw meaningful inferences regarding the national population. Nonetheless, it will be possible in future work to (1) disaggregate the dichotomous self-assessed health measure used in this analysis into four or five categories, (2) use a continuous, objective index - the Physical Component Summary - found in MEPS as an alternative for overall health status, and (3) attempt to gain more observations by incorporating panels released by MEPS in the future.

Secondly, my analysis restricted the sample to individuals who, had they transitioned to self-employment, reported working at least 20 hours per week at the new venture. I argue that this restriction alleviated our chances of including "non-genuine" transitions to self-employment among "genuine" transitions to self-employment. I consider "non-genuine" transitions to be (1) initially employed individuals who simply substituted some part-time, secondary source of income for their primary source of income had they "lost" their full-time wage job, or (2) initially non-employed people who have decided to supplement their income with some sort of "part-time" revenue generating activity. I arbitrarily decided that if wage employed individuals were simultaneously working 20 hours per week in self-employment, or if non-employed 
individuals began working 20 hours per week in a self-employed status, then this should not be designated as trivial.

On the other hand, it may be the case that some individuals enter into selfemployment gradually, working part-time and only choosing to be primarily selfemployed once their venture proves to be more lucrative than wage employment. Moreover, it is reasonable to believe that individuals choose self-employment due to its flexible work schedule. Health may play fundamentally different roles in these two employment strategies. This study may be extended by focusing on the impact of health on decisions made by people who enter into part-time self-employment. Contrasting the results with those found in this study may provide a clearer picture of the role(s) that health may play in self-employment decisions. Although, it would be difficult to decide how many hours of work constitutes "full-time" self-employment.

Similarly, it may be interesting to expand the set of possible transitions included in the analysis. For instance, including the possibility for non-employed individuals to remain non-employed would eliminate the conditionality imposed on the estimates above. Furthermore, the model above could be adapted to include transitions to small firms (ten or fewer employees) since Elfenbein et al (2008) have found that, among scientists and engineers, transitions to small firms involves the same type of entrepreneurial mindset as those who transition to self-employment. ${ }^{80}$

Lastly, this study focused only on the impact of health on the decision to transition into self-employment. The results support the Pull hypothesis; that certain nonpecuniary advantages of self-employment may be of value to individuals with physical

\footnotetext{
${ }^{80}$ This suggestion was contributed by my advisor, David Mushinski, and also suggested in his recent work on health insurance and transitions into, and out of, self-employment (Mushinski, 2009).
} 
limitations or individuals whose health conditions may require timely maintenance. These findings would be corroborated if we were to find that self-employed individuals who are in relatively poorer health are less likely to transition out of self-employment. On the other hand, if we were to witness a greater propensity to exit self-employment by those in poorer health this would provide support for the Healthy Entrepreneurs hypothesis. Barring "forced" exits from self-employment, estimations regarding the role of health status in decisions to exit self-employment may arguably provide stronger evidence for the Pull and Healthy Entrepreneurs hypotheses than do estimates on transitions into self-employment, since individuals will have revealed their employment preference based on information gathered during their venture. Parker and Rougier (2004) find that while poor health significantly increases the probability of retirement for older wage employees it was not a significant factor for the retirement of older selfemployed individuals. It may prove rewarding, however, to use the framework laid out in this study to examine the role of health in decisions to transition out of selfemployment by the general workforce. The Entrepreneurial Propensity hypothesis discussed in the analysis above may also hold when analyzing the role of health in decisions to transition from self-employment to wage employment. It may be that some individuals have personality traits more suited for self-employment in general or for any uncertainty associated with future returns to self-employment. Therefore these individuals may exhibit a greater propensity to remain self-employed despite more lucrative, or more certain, returns in the wage employment sector. As explained in the analysis above, these essentially unobservable personality traits may be positively correlated with health status. In this case, unobserved heterogeneity in the sample may 
dampen the estimated effect of good health on the probability of transitioning from selfemployment to wage employment and diminish the estimated effect of poorer health on the probability. The Discrete Factor Method may prove to be useful in dealing with the bias caused by unobserved heterogeneity in the sample. 


\section{Appendix}

\subsection{The Likelihood Function for an Individual}

The following likelihood representation is for a given observation, $i$. Thus the subscript, $i$, will be suppressed. The functions for the probabilities can be found in the body of the paper. The vector or regressors used in the equations for the transitions from wage employment is denoted $S_{\text {emp }}$. I denote the vector of regressors for transitions from non-employment as $S_{\text {non }}$. The parameter for a given point of support, $\ell \in L$, is represented as $\eta_{\ell}$, and the probability for that point of support is represented by $\pi_{\ell}$. Each initially employed individual chooses one of three possible transitions: (1) same wage job; (2) new wage job; or (3) self-employment. Each initially non-employed individual chooses to transitions to either (1) a wage job, or (2) self-employment. For example, the probability, at a given point of support, for the transition to self-employment from initial wage-employment is written as $P\left(y_{\text {self }}=1 \mid S_{\text {emp }}, \eta_{\ell}\right)$. Let A represent the vectors of regressors for the probabilities of the initial conditions. The probability that an individual is initially employed is $P\left(E=1 \mid A_{e m p}, \eta_{\ell}\right)$, and the probabilities that an observation reports good health and any limitation are $P\left(H_{\text {good }}=1 \mid A_{\text {good }}, \eta_{\ell}\right)$ and $P\left(H_{\text {anylim }}=1 \mid A_{\text {anylim }}, \eta_{\ell}\right)$, respectively. Thus, each observation's contribution to the likelihood is

$$
\begin{aligned}
& L\left(\Theta, \eta_{\ell}, \pi_{\ell} \mid S, A, L\right)= \\
& \sum_{\ell=1}^{L} \pi_{\ell}\left\{\begin{array}{c}
P\left(y_{\text {same wage }}=1 \mid S_{\text {emp }}, \eta_{\ell}\right) \cdot P\left(y_{\text {new wage }}=1 \mid S_{\text {emp }}, \eta_{\ell}\right) \cdot P\left(y_{\text {self }}=1 \mid S_{\text {emp }}, \eta_{\ell}\right) \\
\cdot P\left(y_{\text {wage }}=1 \mid S_{\text {non }}, \eta_{\ell}\right) \cdot P\left(y_{\text {self }}=1 \mid S_{\text {non }}, \eta_{\ell}\right) \\
\cdot P\left(E=1 \mid A_{\text {emp }}, \eta_{\ell}\right) \cdot P\left(H_{\text {good }}=1 \mid A_{\text {good }}, \eta_{\ell}\right) \cdot P\left(H_{\text {anylim }}=1 \mid A_{\text {anylim }}, \eta_{\ell}\right)
\end{array}\right\}
\end{aligned}
$$




\subsection{Assumptions Regarding Discrete Factor Components of the Econometric Model}

One identification issue raised by this distribution concerns the location and scale of the points of support (Mroz, 1999; Mushinski, 2009). The location of the distribution is arbitrary when each equation contains an intercept. To fix the location, we may set one of the points of support to zero (Mroz, 1999; Mushinski, 2009). The scale of the discrete factors is also arbitrary. Again, following Mroz and Mushinski’s examples, I will resolve this issue by restricting the range of the points of support to the unit interval. Therefore, the first point of support will equal zero $\left(\eta_{1}=0\right)$ and the last point of support will always be set to $1\left(\eta_{L}=1\right)$, and $\eta_{\ell} \in(0,1)$ for $\ell>2$. If there is only one point of support we obtain the standard multinomial logit likelihood function. Since my estimates suggested the presence of only two points of support, I will not discuss representation of the likelihood for more than two points of support.

Now, in the paper above we noted that the discrete distribution of the factors included throughout all equations can be described as

$$
\operatorname{Pr}\left(\mu=\eta_{\ell}\right)=\pi_{\ell} \geq 0, \ell=1, \ldots, L \quad \text { and } \quad \sum_{\ell=1}^{L} \pi_{\ell}=1 .
$$

To restrict the probabilities for each point of support to the unit interval and to ensure they sum to one, I will adopt the same parameterization as Mushinski (2009) who followed the example of Blau and Gilleskie (2001). Assume that the first (L-1) points of support follows the form of

$$
\pi_{\ell}=\frac{\exp \left(\gamma_{\ell}\right)}{1+\sum_{\ell=1}^{L-1} \exp \left(\kappa_{\ell}\right)}, \ell=1, \ldots, L-1
$$


and the $\mathrm{L}^{\text {th }}$ point of support equals

$$
\pi_{L}=\frac{1}{1+\sum_{\ell=1}^{L-1} \exp \left(\kappa_{\ell}\right)}
$$

where $\gamma_{\ell}$ are the parameters to be estimated.

\subsection{Description of Other Covariates in the Regression Analysis}

Holds ESI: dummy equals one if the employed individual is covered by employersponsored health insurance through their own job

Holds Other HI: dummy equals one if individual is covered by any insurance other than own-ESI (e.g. spouse's ESI, public insurance, or parent's insurance)

Other Ins: dummy equals one if individual is reported as insured but no particular type of insurance is reported (MEPS adjusts variables for consistency over all survey questionnaires, so if "insured" is indicated I did not want to lose this information).

Age and Spouse Age: their age in years

Male: Dummy equals one if individual is male; equals zero otherwise Less High School and Spouse Less HS: dummy equals one if individual did not obtain high school diploma or equivalent

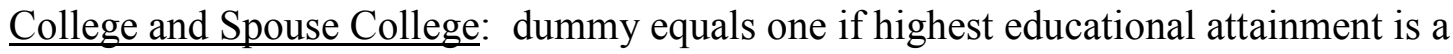
college degree

Professional and Spouse Professional: dummy equals one if highest educational attainment is greater than a college degree

Other Degree or Spouse Other Degree: dummy equals one if highest educational attainment is more than a high school diploma and less than college degree 
African American: dummy equals one if person is African American

Other Race: dummy equals one if person is neither African American or Caucasion Hispanic: dummy equals one if person's ethnicity is Hispanic (not exclusive of African American or Other Race)

No. of Children $<18$ : the number of own-children in the household less than 18 years of age

No. of Children $>=18$ : the number of own-children in the household greater than or equal to 18 years of age

Married: dummy equal to one if person is married

Midwest Region: dummy equals one if person lives in Census midwest region

South Region: dummy equals one if person lives in Census south region

West Region: dummy equals one if person lives in Census west region

MSA: dummy equals one if person resides within a Census metropolitan statistical area Tenure: the number of years a person has been employed at their present job

$\leq 1$ year Tenure: dummy equal to one if Tenure is less than one year

Paid Vacation: dummy equal to one if job includes paid vacation

Paid Sick Leave: dummy equal to one if job includes paid sick leave

Retirement Plan: dummy equal to one if job includes pension plan

Offer ESI: dummy equal to one if job offers at least one type of health insurance plan Union: dummy equal to one if person is member of a union

Small Firm: equal to one if job is at firm with less than or equal to 10 employees Midsize Firm: equal to one if job is at firm with greater than 10 employees but less than or equal to 50 employees 
Firm Missing: equal to one if size of firm is not reported

Industry $\mathrm{Ag} / \mathrm{Con}$ : dummy equals one if employed in agricultural, construction, or natural resources industries

Industry FIRE: dummy equals one if employed in Finance, Insurance, or Real Estate Industries

Industry Sales: dummy equals one if employed in Sales/Retail industries Industry Other: dummy equal to one if not employed in $\mathrm{Ag} / \mathrm{Con}$, FIRE, Sales industries, or by a Government

Panel 6: dummy equal to one if surveyed in Panel 6 of MEPS [1/1/2001 - 12/31/2002]

Panel 7: dummy equal to one if surveyed in Panel 7 of MEPS [1/1/2002 - 12/31/2003]

Panel 8: dummy equal to one if surveyed in Panel 8 of MEPS [1/1/2003 - 12/31/2004]

Panel 9: dummy equal to one if surveyed in Panel 9 of MEPS [1/1/2004 - 12/31/2005]

Panel 10: dummy equal to one if surveyed in Panel 10 of MEPS [1/1/2005 - 12/31/2006]

Panel 11: dummy equal to one if surveyed in Panel 11 of MEPS [1/1/2006 - 12/31/2007]

Military Experience: dummy equals one if person has ever served in the military (they

cannot be currently employed by military)

BMI: the individual's Body Mass Index

BMI Missing: dummy equal to one if BMI was not reported

Smoke: dummy equal to one if person is a habitual smoker 
Table A1. Means of the non-health covariates of the empirical model

\begin{tabular}{|c|c|c|c|c|c|c|c|c|}
\hline \multicolumn{9}{|c|}{ Percentages (unless discrete $\sim$ ) } \\
\hline \multirow[b]{2}{*}{ Variables } & \multirow[b]{2}{*}{ All Obs. } & \multirow[b]{2}{*}{ Employed } & \multirow[b]{2}{*}{$\begin{array}{c}\text { Non- } \\
\text { Employed }\end{array}$} & \multicolumn{5}{|c|}{ Transitions } \\
\hline & & & & $\begin{array}{c}\text { Same } \\
\text { Wage } \\
\text { Job } \\
\end{array}$ & $\begin{array}{c}\text { Wage } \\
\text { to Wage }\end{array}$ & $\begin{array}{l}\text { Wage } \\
\text { to SE }\end{array}$ & $\begin{array}{c}\text { Non-Emp } \\
\text { to Wage }\end{array}$ & $\begin{array}{c}\text { Non-Emp } \\
\text { to } \mathrm{SE}\end{array}$ \\
\hline Holds ESI & -- & 68.70 & -- & 75.00 & 50.10 & 50.40 & -- & -- \\
\hline Holds Other HI & 20.60 & 18.90 & 40.30 & 17.80 & 22.00 & 22.30 & 40.20 & 40.80 \\
\hline Insured & 81.01 & 84.14 & 45.62 & 88.99 & 69.80 & 69.60 & 45.59 & 45.79 \\
\hline Insured (type missing) & 2.34 & 1.92 & 7.07 & 1.51 & 3.10 & 3.68 & 7.14 & 6.73 \\
\hline Good Health & 66.10 & 67.00 & 56.30 & 67.20 & 66.10 & 68.40 & 57.00 & 52.10 \\
\hline Any Limit & 15.20 & 14.90 & 18.80 & 15.00 & 14.40 & 18.10 & 17.70 & 25.10 \\
\hline Age $\sim$ & 38.60 & 39.00 & 33.90 & 40.50 & 34.10 & 37.60 & 32.90 & 39.60 \\
\hline Male & 56.90 & 57.50 & 50.20 & 56.00 & 61.20 & 72.20 & 50.90 & 46.60 \\
\hline Less than High School & 10.90 & 9.74 & 23.60 & 8.84 & 12.60 & 10.10 & 24.10 & 20.70 \\
\hline High School Diploma & 50.48 & 50.01 & 55.80 & 48.65 & 54.55 & 47.39 & 55.86 & 55.45 \\
\hline College Degree & 20.20 & 21.10 & 10.90 & 21.90 & 18.20 & 25.00 & 10.90 & 10.80 \\
\hline Professional Degree & 9.53 & 10.10 & 3.19 & 11.20 & 6.75 & 8.60 & 2.72 & 5.72 \\
\hline Other degree & 8.50 & 8.74 & 5.69 & 9.15 & 7.43 & 8.81 & 5.52 & 6.65 \\
\hline White & 81.44 & 81.90 & 76.28 & 82.53 & 79.66 & 84.73 & 76.13 & 77.07 \\
\hline Black & 12.10 & 11.70 & 16.20 & 11.30 & 13.40 & 10.30 & 16.70 & 13.30 \\
\hline Other Race & 6.45 & 6.36 & 7.51 & 6.21 & 6.93 & 4.99 & 7.12 & 9.64 \\
\hline Hispanic & 14.20 & 13.40 & 23.10 & 12.60 & 15.80 & 12.50 & 24.10 & 18.10 \\
\hline$\#$ of own-children $<18 \sim$ & 0.74 & 0.74 & 0.78 & 0.75 & 0.69 & 0.83 & 0.77 & 0.82 \\
\hline$\#$ of own-children $>=18 \sim$ & 0.17 & 0.17 & 0.13 & 0.20 & 0.10 & 0.14 & 0.12 & 0.19 \\
\hline
\end{tabular}


Table A1 (continued). Means of the non-health covariates of the empirical model

\begin{tabular}{|c|c|c|c|c|c|c|c|c|}
\hline \multicolumn{9}{|c|}{ Percentages (unless discrete $\sim$ ) } \\
\hline \multirow[b]{2}{*}{ Variables } & \multirow[b]{2}{*}{ All Obs. } & \multirow[b]{2}{*}{ Employed } & \multirow[b]{2}{*}{$\begin{array}{c}\text { Non- } \\
\text { Employed } \\
\end{array}$} & \multicolumn{5}{|c|}{ Transitions } \\
\hline & & & & $\begin{array}{c}\text { Same } \\
\text { Wage } \\
\text { Job }\end{array}$ & $\begin{array}{c}\text { Wage } \\
\text { to Wage }\end{array}$ & $\begin{array}{l}\text { Wage } \\
\text { to SE }\end{array}$ & $\begin{array}{l}\text { Non-Emp } \\
\text { to Wage }\end{array}$ & $\begin{array}{c}\text { Non-Emp } \\
\text { to SE }\end{array}$ \\
\hline Married & 56.80 & 58.00 & 42.90 & 61.60 & 46.70 & 57.70 & 40.70 & 55.00 \\
\hline Spouse's Age* & 40.17 & 40.31 & 37.93 & 41.29 & 36.45 & 37.84 & 37.09 & 41.31 \\
\hline Spouse Less than HS* & 10.24 & 9.54 & 21.00 & 8.95 & 12.10 & 8.79 & 22.83 & 13.62 \\
\hline Spouse HS Diploma* & 47.96 & 48.06 & 46.47 & 47.85 & 49.20 & 45.61 & 44.87 & 52.92 \\
\hline Spouse College Degree* & 19.88 & 20.34 & 12.89 & 20.67 & 19.10 & 18.44 & 12.79 & 13.30 \\
\hline Spouse Professional Deg* & 9.49 & 9.66 & 6.85 & 9.99 & 7.75 & 15.21 & 6.39 & 8.68 \\
\hline Spouse Other Degree* & 9.23 & 9.45 & 5.75 & 9.73 & 8.32 & 9.41 & 5.30 & 7.57 \\
\hline Northeast & 18.08 & 18.25 & 16.19 & 19.11 & 15.82 & 14.12 & 15.98 & 17.34 \\
\hline Midwest & 22.50 & 22.80 & 19.20 & 23.60 & 20.20 & 21.90 & 19.70 & 16.50 \\
\hline South & 37.30 & 37.20 & 38.00 & 35.80 & 41.40 & 40.30 & 38.70 & 34.50 \\
\hline West & 22.20 & 21.80 & 26.60 & 21.50 & 22.60 & 23.70 & 25.70 & 31.60 \\
\hline MSA & 83.70 & 83.70 & 82.60 & 83.80 & 83.50 & 84.80 & 83.30 & 79.00 \\
\hline Tenure $($ years $) \sim$ & -- & 7.15 & -- & 8.56 & 2.92 & 3.40 & -- & -- \\
\hline$<1$ year tenure & -- & 9.23 & -- & 3.85 & 25.40 & 22.20 & -- & -- \\
\hline Paid Vacation & -- & 80.60 & -- & 85.90 & 65.10 & 64.00 & -- & -- \\
\hline Paid Sick Leave & -- & 70.50 & -- & 76.70 & 52.50 & 50.90 & -- & -- \\
\hline Retirement Plan / IRA & -- & 61.90 & -- & 68.90 & 41.40 & 38.40 & -- & -- \\
\hline Offered ESI & -- & 79.20 & -- & 85.60 & 60.50 & 55.70 & -- & -- \\
\hline Union & -- & 14.40 & -- & 17.20 & 6.13 & 4.61 & -- & -- \\
\hline Small Firm $(<10$ emps $)$ & -- & 16.60 & -- & 14.30 & 22.30 & 35.70 & -- & -- \\
\hline
\end{tabular}

* Mean conditional on being Married 
Table A1 (continued). Means of the non-health covariates of the empirical model

\begin{tabular}{|c|c|c|c|c|c|c|c|c|}
\hline \multicolumn{9}{|c|}{ Percentages (unless discrete $\sim$ ) } \\
\hline \multirow[b]{2}{*}{ Variables } & \multirow[b]{2}{*}{ All Obs. } & \multirow[b]{2}{*}{ Employed } & \multirow[b]{2}{*}{$\begin{array}{c}\text { Non- } \\
\text { Employed }\end{array}$} & \multicolumn{5}{|c|}{ Transitions } \\
\hline & & & & $\begin{array}{c}\text { Same } \\
\text { Wage } \\
\text { Job }\end{array}$ & $\begin{array}{l}\text { Wage } \\
\text { to Wage }\end{array}$ & $\begin{array}{l}\text { Wage } \\
\text { to SE }\end{array}$ & $\begin{array}{c}\text { Non-Emp } \\
\text { to Wage }\end{array}$ & $\begin{array}{c}\text { Non-Emp } \\
\text { to SE }\end{array}$ \\
\hline Large Firm ( $>50$ emps) & -- & 51.83 & -- & 55.92 & 40.31 & 32.43 & -- & -- \\
\hline Midsize Firm $(<=50$ emps $)$ & -- & 26.10 & -- & 24.70 & 30.30 & 27.50 & -- & -- \\
\hline Firm Size Missing & -- & 5.56 & -- & 5.14 & 7.00 & 4.43 & -- & -- \\
\hline Industry: Government & -- & 6.64 & -- & 7.99 & 2.62 & 2.93 & -- & -- \\
\hline Industry: Agric. / Const. & -- & 8.64 & -- & 7.32 & 12.10 & 17.60 & -- & -- \\
\hline Industry: FIRE & -- & 6.92 & -- & 7.22 & 6.14 & 4.63 & -- & -- \\
\hline Industry: Sales & -- & 13.10 & -- & 12.70 & 14.40 & 12.90 & -- & -- \\
\hline Industry: Other & -- & 64.60 & -- & 64.70 & 64.60 & 61.90 & -- & -- \\
\hline Panel 5 & 14.49 & 14.65 & 12.65 & 14.05 & 16.70 & 13.10 & 12.86 & 11.55 \\
\hline Panel 6 & 14.00 & 14.10 & 12.40 & 14.30 & 13.30 & 14.60 & 12.60 & 11.50 \\
\hline Panel 7 & 14.30 & 14.30 & 14.50 & 14.70 & 12.70 & 16.70 & 14.50 & 14.60 \\
\hline Panel 8 & 14.20 & 14.00 & 15.90 & 14.30 & 13.00 & 14.70 & 16.40 & 13.40 \\
\hline Panel 9 & 14.00 & 14.00 & 14.20 & 14.00 & 13.80 & 14.10 & 14.20 & 13.90 \\
\hline Panel 10 & 14.40 & 14.40 & 15.10 & 14.00 & 15.50 & 14.80 & 14.30 & 19.50 \\
\hline Panel 11 & 14.70 & 14.60 & 15.20 & 14.60 & 15.00 & 12.10 & 15.10 & 15.60 \\
\hline \multicolumn{9}{|l|}{ Reduced Form Identifiers } \\
\hline Military Experience & 9.33 & 9.66 & 5.58 & 9.66 & 9.52 & 11.50 & 5.81 & 4.33 \\
\hline Smoker & 22.43 & 21.67 & 31.01 & 19.27 & 28.35 & 34.25 & 30.49 & 33.81 \\
\hline Body Mass Index $(\mathrm{BMI}) \sim$ & 27.37 & 27.39 & 27.15 & 27.45 & 27.25 & 26.80 & 27.11 & 27.36 \\
\hline BMI Missing & 2.01 & 1.95 & 2.71 & 2.04 & 1.71 & 1.17 & 2.67 & 2.89 \\
\hline Observations & 32622 & 29304 & 3318 & 21835 & 6921 & 548 & 2841 & 477 \\
\hline
\end{tabular}


Table A2. Regression results

\begin{tabular}{|c|c|c|c|c|c|c|}
\hline \multirow[b]{2}{*}{ Variables } & \multicolumn{3}{|c|}{ Transitions } & \multicolumn{3}{|c|}{ Initial Conditions } \\
\hline & $\begin{array}{l}\text { Wage to } \\
\text { New Wage }\end{array}$ & Wage to SE & Non- to SE & Employed & Good Health & Any Limit \\
\hline \multirow{2}{*}{ Good Health } & $-0.442 * *$ & -0.361 & 0.179 & -- & -- & -- \\
\hline & $(0.186)$ & $(0.396)$ & $(0.375)$ & -- & -- & -- \\
\hline \multirow[t]{2}{*}{ Any Limit } & $0.569 * * *$ & $0.775 * *$ & -0.0347 & -- & -- & -- \\
\hline & $(0.149)$ & $(0.373)$ & $(0.323)$ & -- & -- & -- \\
\hline \multirow[t]{2}{*}{ Holds ESI } & $0.336 * * *$ & $1.051 * * *$ & -- & -- & -- & -- \\
\hline & $(0.0678)$ & $(0.222)$ & -- & -- & -- & -- \\
\hline \multirow[t]{2}{*}{ Offered ESI } & $-0.678 * * *$ & $-1.462 * * *$ & -- & -- & -- & -- \\
\hline & $(0.0701)$ & $(0.237)$ & -- & -- & -- & -- \\
\hline \multirow[t]{2}{*}{ Holds Other Insurance } & $0.235 * * *$ & 0.241 & -0.106 & -- & -- & -- \\
\hline & $(0.0587)$ & $(0.156)$ & $(0.149)$ & -- & -- & -- \\
\hline \multirow[t]{2}{*}{ Insured (type missing) } & -0.0997 & -0.221 & -0.356 & -- & -- & -- \\
\hline & $(0.140)$ & $(0.281)$ & $(0.302)$ & -- & -- & -- \\
\hline \multirow[t]{2}{*}{ Age (/100) } & $-3.954 * *$ & 5.306 & $18.70 * * *$ & $20.19 * * *$ & $-2.379 * *$ & $3.369 *$ \\
\hline & $(1.605)$ & $(3.287)$ & $(4.486)$ & $(1.637)$ & $(1.184)$ & $(1.753)$ \\
\hline \multirow[t]{2}{*}{ Age squared (/100) } & 0.171 & -0.639 & $-1.830 * * *$ & $-2.258 * * *$ & 0.00867 & 0.238 \\
\hline & $(0.200)$ & $(0.416)$ & $(0.575)$ & $(0.218)$ & $(0.148)$ & $(0.218)$ \\
\hline \multirow[t]{2}{*}{ Male } & $0.224 * * *$ & $0.669 * * *$ & -0.132 & $0.409 * * *$ & $0.228 * * *$ & $-0.178 * * *$ \\
\hline & $(0.0459)$ & $(0.127)$ & $(0.149)$ & $(0.0511)$ & $(0.0442)$ & $(0.0490)$ \\
\hline
\end{tabular}


Table A2 (continued). Regression results

\begin{tabular}{|c|c|c|c|c|c|c|}
\hline \multirow[b]{2}{*}{ Variables } & \multicolumn{3}{|c|}{ Transitions } & \multicolumn{3}{|c|}{ Initial Conditions } \\
\hline & $\begin{array}{l}\text { Wage to } \\
\text { New Wage }\end{array}$ & Wage to SE & Non- to SE & Employed & Good Health & Any Limit \\
\hline Less than High School & $\begin{array}{l}-0.266 * * * \\
(0.0991)\end{array}$ & $\begin{array}{l}-0.437 * * \\
(0.186)\end{array}$ & $\begin{array}{l}0.139 \\
(0.188)\end{array}$ & $\begin{array}{l}-0.650 * * * \\
(0.0633)\end{array}$ & $\begin{array}{l}-0.712 * * * \\
(0.0662)\end{array}$ & $\begin{array}{l}0.0733 \\
(0.0796)\end{array}$ \\
\hline College Degree & $\begin{array}{l}-0.00908 \\
(0.0674)\end{array}$ & $\begin{array}{l}0.542 * * * \\
(0.155)\end{array}$ & $\begin{array}{l}-0.238 \\
(0.255)\end{array}$ & $\begin{array}{l}0.654 * * * \\
(0.0795)\end{array}$ & $\begin{array}{l}0.589 * * * \\
(0.0636)\end{array}$ & $\begin{array}{l}-0.369 * * * \\
(0.0706)\end{array}$ \\
\hline Other degree & $\begin{array}{l}-0.0834 \\
(0.0898)\end{array}$ & $\begin{array}{l}0.233 \\
(0.218)\end{array}$ & $\begin{array}{l}0.00240 \\
(0.273)\end{array}$ & $\begin{array}{l}0.417 * * * \\
(0.101)\end{array}$ & $\begin{array}{l}0.226^{* * *} \\
(0.0649)\end{array}$ & $\begin{array}{l}-0.107 \\
(0.0780)\end{array}$ \\
\hline Professional Degree & $\begin{array}{l}-0.0558 \\
(0.0918)\end{array}$ & $\begin{array}{l}0.191 \\
(0.249)\end{array}$ & $\begin{array}{l}0.318 \\
(0.304)\end{array}$ & $\begin{array}{l}1.018 * * * \\
(0.137)\end{array}$ & $\begin{array}{l}0.678 * * * \\
(0.0822)\end{array}$ & $\begin{array}{l}-0.383 * * * \\
(0.0943)\end{array}$ \\
\hline African American & $\begin{array}{l}0.139 * * \\
(0.0599)\end{array}$ & $\begin{array}{l}-0.00703 \\
(0.159)\end{array}$ & $\begin{array}{l}-0.188 \\
(0.211)\end{array}$ & $\begin{array}{l}-0.311 * * * \\
(0.0673)\end{array}$ & $\begin{array}{l}-0.147^{*} \\
(0.0759)\end{array}$ & $\begin{array}{l}-0.573 * * * \\
(0.0776)\end{array}$ \\
\hline Other Race & $\begin{array}{l}0.00899 \\
(0.0890)\end{array}$ & $\begin{array}{l}-0.480^{* *} \\
(0.226)\end{array}$ & $\begin{array}{l}0.274 \\
(0.238)\end{array}$ & $\begin{array}{l}-0.338 * * * \\
(0.0926)\end{array}$ & $\begin{array}{l}-0.556 * * * \\
(0.0884)\end{array}$ & $\begin{array}{l}-0.168 * \\
(0.0972)\end{array}$ \\
\hline Hispanic & $\begin{array}{l}-0.153 * * \\
(0.0665)\end{array}$ & $\begin{array}{l}-0.430 * * \\
(0.168)\end{array}$ & $\begin{array}{l}-0.265 \\
(0.166)\end{array}$ & $\begin{array}{l}-0.232 * * * \\
(0.0660)\end{array}$ & $\begin{array}{l}-0.300 * * * \\
(0.0600)\end{array}$ & $\begin{array}{l}-0.591 * * * \\
(0.0871)\end{array}$ \\
\hline$\#$ of own-children $<18$ & $\begin{array}{l}-0.0126 \\
(0.0225)\end{array}$ & $\begin{array}{l}0.0803 \\
(0.0503)\end{array}$ & $\begin{array}{l}-0.0177 \\
(0.0626)\end{array}$ & $\begin{array}{l}-0.124 * * * \\
(0.0241)\end{array}$ & $\begin{array}{l}-- \\
--\end{array}$ & -- \\
\hline$\#$ of own-children $>=18$ & $\begin{array}{l}-0.0211 \\
(0.0531)\end{array}$ & $\begin{array}{l}0.0458 \\
(0.118)\end{array}$ & $\begin{array}{l}-0.0812 \\
(0.121)\end{array}$ & $\begin{array}{l}-0.0177 \\
(0.0561)\end{array}$ & $\begin{array}{l}-- \\
--\end{array}$ & $\begin{array}{l}-- \\
--\end{array}$ \\
\hline Married & $\begin{array}{l}-0.0260 \\
(0.116)\end{array}$ & $\begin{array}{l}0.302 \\
(0.241)\end{array}$ & $\begin{array}{l}0.139 \\
(0.281)\end{array}$ & $\begin{array}{l}0.300 * * * \\
(0.0551)\end{array}$ & $\begin{array}{l}0.130 * * * \\
(0.0432)\end{array}$ & $\begin{array}{l}-0.521 * * * \\
(0.0495)\end{array}$ \\
\hline
\end{tabular}


Table A2 (continued). Regression results

\begin{tabular}{|c|c|c|c|c|c|c|}
\hline \multirow[b]{2}{*}{ Variables } & \multicolumn{3}{|c|}{ Transitions } & \multicolumn{3}{|c|}{ Initial Conditions } \\
\hline & $\begin{array}{l}\text { Wage to } \\
\text { New Wage }\end{array}$ & Wage to SE & Non- to SE & Employed & Good Health & Any Limit \\
\hline \multirow[t]{2}{*}{ Spouse's Age (/100) } & -0.135 & -0.730 & 0.193 & -- & -- & -- \\
\hline & $(0.287)$ & $(0.636)$ & $(0.700)$ & -- & -- & -- \\
\hline \multirow[t]{2}{*}{ Spouse Less than HS } & -0.0541 & -0.273 & $-0.586^{* * *}$ & -- & -- & -- \\
\hline & $(0.0932)$ & $(0.222)$ & $(0.210)$ & -- & -- & -- \\
\hline \multirow[t]{2}{*}{ Spouse College Degree } & 0.0297 & -0.0706 & -0.117 & -- & -- & -- \\
\hline & $(0.0756)$ & $(0.189)$ & $(0.278)$ & -- & -- & -- \\
\hline \multirow[t]{2}{*}{ Spouse Professional Deg. } & -0.0110 & $0.701 * * *$ & 0.0273 & -- & -- & -- \\
\hline & $(0.126)$ & $(0.249)$ & $(0.354)$ & -- & -- & -- \\
\hline \multirow[t]{2}{*}{ Spouse Other Degree } & -0.106 & 0.0135 & 0.172 & -- & -- & -- \\
\hline & $(0.108)$ & $(0.268)$ & $(0.418)$ & -- & -- & -- \\
\hline \multirow[t]{2}{*}{ Midwest } & -0.0331 & 0.224 & -0.267 & 0.116 & 0.0354 & $0.352 * * *$ \\
\hline & $(0.0736)$ & $(0.204)$ & $(0.221)$ & $(0.0979)$ & $(0.0710)$ & $(0.0906)$ \\
\hline \multirow[t]{2}{*}{ South } & 0.0844 & 0.210 & -0.224 & 0.0607 & -0.0318 & $0.440 * * *$ \\
\hline & $(0.0725)$ & $(0.178)$ & $(0.203)$ & $(0.0675)$ & $(0.0654)$ & $(0.0798)$ \\
\hline \multirow[t]{2}{*}{ West } & 0.0262 & 0.226 & 0.137 & -0.133 & -0.0931 & $0.474 * * *$ \\
\hline & $(0.0857)$ & $(0.186)$ & $(0.198)$ & $(0.0870)$ & $(0.0839)$ & $(0.0936)$ \\
\hline \multirow[t]{2}{*}{ MSA } & 0.0598 & $0.243 * *$ & $-0.290^{*}$ & 0.0705 & 0.00888 & $-0.211 * * *$ \\
\hline & $(0.0558)$ & $(0.121)$ & $(0.165)$ & $(0.0698)$ & $(0.0543)$ & $(0.0657)$ \\
\hline \multirow[t]{2}{*}{ Tenure (years) $(/ 100)$} & $-10.57 * * *$ & $-9.737 * * *$ & -- & -- & -- & -- \\
\hline & $(0.592)$ & $(1.372)$ & -- & -- & -- & -- \\
\hline
\end{tabular}


Table A2 (continued). Regression results

\begin{tabular}{|c|c|c|c|c|c|c|}
\hline \multirow[b]{2}{*}{ Variables } & \multicolumn{3}{|c|}{ Transitions } & \multicolumn{3}{|c|}{ Initial Conditions } \\
\hline & $\begin{array}{l}\text { Wage to } \\
\text { New Wage }\end{array}$ & Wage to SE & Non- to SE & Employed & Good Health & Any Limit \\
\hline \multirow[t]{2}{*}{$<1$ Year of Tenure } & $1.143 * * *$ & $1.085 * * *$ & -- & -- & -- & -- \\
\hline & $(0.0771)$ & $(0.174)$ & -- & -- & -- & -- \\
\hline \multirow[t]{2}{*}{ Tenure Missing } & $-0.676^{* * *}$ & -1.061 & -- & -- & -- & -- \\
\hline & $(0.247)$ & $(0.754)$ & -- & -- & -- & -- \\
\hline \multirow[t]{2}{*}{ Paid Vacation } & $-0.190 * * *$ & -0.135 & -- & -- & -- & -- \\
\hline & $(0.0533)$ & $(0.162)$ & -- & -- & -- & -- \\
\hline \multirow[t]{2}{*}{ Paid Sick Leave } & $-0.317 * * *$ & $-0.429 * * *$ & -- & -- & -- & -- \\
\hline & $(0.0516)$ & $(0.134)$ & -- & -- & -- & -- \\
\hline \multirow[t]{2}{*}{ Retirement Plan } & $-0.138 * * *$ & $-0.388 * *$ & -- & -- & -- & -- \\
\hline & $(0.0460)$ & $(0.166)$ & -- & -- & -- & -- \\
\hline \multirow[t]{2}{*}{ Union } & $-0.496 * * *$ & $-0.818 * * *$ & -- & -- & -- & -- \\
\hline & $(0.0620)$ & $(0.260)$ & -- & -- & -- & -- \\
\hline \multirow[t]{2}{*}{ Small Firm $(<10$ emps $)$} & $0.162 * * *$ & $0.793 * * *$ & -- & -- & -- & -- \\
\hline & $(0.0566)$ & $(0.163)$ & -- & -- & -- & -- \\
\hline \multirow[t]{2}{*}{ Midsize Firm $(<=50$ emps) } & $0.197 * * *$ & $0.329 * *$ & -- & -- & -- & -- \\
\hline & $(0.0515)$ & $(0.131)$ & -- & -- & -- & -- \\
\hline \multirow[t]{2}{*}{ Firm Size Missing } & 0.0743 & -0.118 & -- & -- & -- & -- \\
\hline & $(0.0827)$ & $(0.308)$ & -- & -- & -- & -- \\
\hline \multirow[t]{2}{*}{ Industry: Agric. / Const. } & $0.672 * * *$ & $0.888 * *$ & -- & -- & -- & -- \\
\hline & $(0.140)$ & $(0.374)$ & -- & -- & -- & -- \\
\hline
\end{tabular}


Table A2 (continued). Regression results

\begin{tabular}{|c|c|c|c|c|c|c|}
\hline \multirow[b]{2}{*}{ Variables } & \multicolumn{3}{|c|}{ Transitions } & \multicolumn{3}{|c|}{ Initial Conditions } \\
\hline & $\begin{array}{l}\text { Wage to } \\
\text { New Wage }\end{array}$ & Wage to SE & Non- to SE & Employed & Good Health & Any Limit \\
\hline \multirow[t]{2}{*}{ Industry: FIRE } & $0.526 * * *$ & 0.116 & -- & -- & -- & -- \\
\hline & $(0.134)$ & $(0.417)$ & -- & -- & -- & -- \\
\hline \multirow[t]{2}{*}{ Industry: Sales } & $0.594 * * *$ & 0.423 & -- & -- & -- & -- \\
\hline & $(0.126)$ & $(0.360)$ & -- & -- & -- & -- \\
\hline \multirow[t]{2}{*}{ Industry: Other } & $0.681 * * *$ & $0.606^{*}$ & -- & -- & -- & -- \\
\hline & $(0.114)$ & $(0.325)$ & -- & -- & -- & -- \\
\hline \multirow[t]{2}{*}{ Panel 6} & $-0.284 * * *$ & 0.0690 & -0.00502 & -- & -- & -- \\
\hline & $(0.0839)$ & $(0.198)$ & $(0.263)$ & -- & -- & -- \\
\hline \multirow[t]{2}{*}{ Panel 7} & $-0.388 * * *$ & 0.106 & 0.0894 & -- & -- & -- \\
\hline & $(0.0856)$ & $(0.213)$ & $(0.258)$ & -- & -- & -- \\
\hline \multirow[t]{2}{*}{ Panel 8} & $-0.283 * * *$ & 0.0371 & -0.137 & -- & -- & -- \\
\hline & $(0.0886)$ & $(0.192)$ & $(0.266)$ & -- & -- & -- \\
\hline \multirow[t]{2}{*}{ Panel 9} & $-0.175 * *$ & 0.0129 & 0.0939 & -- & -- & -- \\
\hline & $(0.0870)$ & $(0.229)$ & $(0.262)$ & -- & -- & -- \\
\hline \multirow[t]{2}{*}{ Panel 10} & -0.0813 & 0.0224 & 0.397 & -- & -- & -- \\
\hline & $(0.0879)$ & $(0.211)$ & $(0.252)$ & -- & -- & -- \\
\hline \multirow[t]{2}{*}{ Panel 11} & $-0.148^{*}$ & -0.172 & 0.172 & -- & -- & -- \\
\hline & $(0.0825)$ & $(0.226)$ & $(0.253)$ & -- & -- & -- \\
\hline \multirow[t]{2}{*}{ Military } & -- & -- & -- & 0.0550 & $-0.174 * * *$ & $0.254 * * *$ \\
\hline & -- & -- & -- & $(0.112)$ & $(0.0661)$ & $(0.0816)$ \\
\hline
\end{tabular}


Table A2 (continued). Regression results

\begin{tabular}{|c|c|c|c|c|c|c|c|}
\hline \multirow[b]{2}{*}{ Variables } & & \multicolumn{3}{|c|}{ Transitions } & \multicolumn{3}{|c|}{ Initial Conditions } \\
\hline & & $\begin{array}{l}\text { Wage to } \\
\text { New Wage }\end{array}$ & Wage to SE & Non- to SE & Employed & Good Health & Any Limit \\
\hline \multirow{2}{*}{\multicolumn{2}{|c|}{ BMI }} & -- & -- & -- & -- & $-0.765 * * *$ & $0.491 * * *$ \\
\hline & & -- & -- & -- & -- & $(0.0510)$ & $(0.0583)$ \\
\hline \multirow{2}{*}{\multicolumn{2}{|c|}{ BMI Missing }} & -- & -- & -- & -- & $-2.632 * * *$ & $1.478 * * *$ \\
\hline & & -- & -- & -- & -- & $(0.193)$ & $(0.245)$ \\
\hline \multirow{2}{*}{\multicolumn{2}{|c|}{ Smoker }} & -- & -- & -- & -- & $-0.582 * * *$ & $0.474 * * *$ \\
\hline & & -- & -- & -- & -- & $(0.0649)$ & $(0.0537)$ \\
\hline \multirow{2}{*}{\multicolumn{2}{|c|}{ Constant }} & 0.0437 & $-5.755 * * *$ & $-5.348 * * *$ & $-2.389 * * *$ & $2.601 * * *$ & $-3.642 * * *$ \\
\hline & & $(0.350)$ & $(0.838)$ & $(0.813)$ & $(0.288)$ & $(0.319)$ & $(0.416)$ \\
\hline \multirow{2}{*}{\multicolumn{2}{|c|}{ Factor Loading }} & $1.121 * * *$ & 1.186 & -0.470 & $0.765 * * *$ & $1.965 * * *$ & $-2.046 * * *$ \\
\hline & & $(0.337)$ & $(0.918)$ & $(0.924)$ & $(0.116)$ & $(0.274)$ & $(0.255)$ \\
\hline Gamma $=$ & -0.439 & Probability Pt.1= & $61 \% * * *$ & \multirow{2}{*}{\multicolumn{4}{|c|}{${ }^{\wedge}$ Pseudo Log-Likelihood $=1.186 \times 10^{9}$}} \\
\hline & $(0.320)$ & & $(0.0182)$ & & & & \\
\hline
\end{tabular}

Standard errors in parentheses: $* * * \mathrm{p}<0.01, * * \mathrm{p}<0.05, * \mathrm{p}<0.1$

Note: Probabilities of points of support calculated using specification found in in Appendix; standard errors calculated using the delta method.

$\wedge$ : Pseduo Log-likelihood is computed due to complex survey design (since each observation is weighted to represent the national population each individual's contribution to the likelihood is quite large, hence, a 10 digit Pseudo Log-likelihood value. 
Table A3. Probabilities for Transitions*

\begin{tabular}{|c|c|c|c|c|c|c|c|c|c|c|}
\hline & \multicolumn{2}{|c|}{ No Transition } & \multicolumn{2}{|c|}{ Wage to Wage } & \multicolumn{2}{|c|}{ Wage to SE } & \multicolumn{2}{|c|}{ Non-emp to Wage } & \multicolumn{2}{|c|}{ Non-emp to SE } \\
\hline & Pt. 0 & Pt. 1 & Pt. 0 & Pt. 1 & Pt. 0 & Pt. 1 & Pt. 0 & Pt. 1 & Pt. 0 & Pt. 1 \\
\hline Good Health & 91.37 & 77.47 & 8.08 & 21.01 & 0.55 & 1.52 & 83.38 & 88.92 & 16.62 & 11.08 \\
\hline Not Good Health & 87.25 & 68.97 & 12.00 & 29.08 & 0.75 & 1.94 & 85.72 & 90.56 & 14.28 & 9.44 \\
\hline Any Limitation & 84.81 & 64.44 & 14.08 & 32.81 & 1.11 & 2.76 & 84.80 & 89.92 & 15.20 & 10.08 \\
\hline No Limitation & 90.91 & 76.46 & 8.54 & 22.04 & 0.55 & 1.51 & 84.35 & 89.61 & 15.65 & 10.39 \\
\hline Good Health \& No Limitation & 92.03 & 78.95 & 7.48 & 19.67 & 0.49 & 1.38 & 83.28 & 88.85 & 16.72 & 11.15 \\
\hline Good Health \& Any Limitation & 86.58 & 67.66 & 12.42 & 29.77 & 1.00 & 2.57 & 83.76 & 89.19 & 16.24 & 10.81 \\
\hline Not Good Health \& No Limitation & 88.18 & 70.79 & 11.14 & 27.43 & 0.68 & 1.78 & 85.64 & 90.51 & 14.36 & 9.49 \\
\hline Not Good Health \& Any Limitation & 80.66 & 57.51 & 18.00 & 39.36 & 1.34 & 3.13 & 86.06 & 90.80 & 13.94 & 9.20 \\
\hline
\end{tabular}

* Numbers reported are percentages

Table A4. Marginal effects for transitions*

\begin{tabular}{|c|c|c|c|c|c|c|c|c|c|c|}
\hline & \multicolumn{2}{|c|}{ No Transition } & \multicolumn{2}{|c|}{ Wage to Wage } & \multicolumn{2}{|c|}{ Wage to SE } & \multicolumn{2}{|c|}{ Non-Emp to Wage } & \multicolumn{2}{|c|}{ Non-Emp to SE } \\
\hline & Pt. 0 & Pt. 1 & Pt. 0 & Pt. 1 & Pt. 0 & Pt. 1 & Pt. 0 & Pt. 1 & Pt. 0 & Pt. 1 \\
\hline Good Health & 4.12 & 8.50 & -3.92 & -8.08 & -0.20 & -0.42 & -2.34 & -1.65 & 2.34 & 1.65 \\
\hline Any Limit & -6.10 & -12.02 & 5.53 & 10.77 & 0.56 & 1.25 & 0.45 & 0.32 & -0.45 & -0.32 \\
\hline Good Health (Given No Limitation) & 3.85 & 8.15 & -3.66 & -7.76 & -0.18 & -0.40 & -2.35 & -1.66 & 2.35 & 1.66 \\
\hline Good Health (Given Any Limitation) & 5.91 & 10.15 & -5.58 & -9.58 & -0.34 & -0.57 & -2.30 & -1.61 & 2.30 & 1.61 \\
\hline Any Limit (Given Good Health) & -5.46 & -11.29 & 4.95 & 10.10 & 0.51 & 1.19 & 0.48 & 0.34 & -0.48 & -0.34 \\
\hline Any Limit (Given Not Good Health) & -7.52 & -13.28 & 6.86 & 11.93 & 0.67 & 1.36 & 0.42 & 0.29 & -0.42 & -0.29 \\
\hline Not Good Health \& Any limitation & -11.37 & -21.44 & 10.52 & 19.69 & 0.85 & 1.75 & 2.77 & 1.95 & -2.77 & -1.95 \\
\hline
\end{tabular}

* Numbers reported are percentages; Marginal Effects are evaluated at the means of all covariates not being considered. 


\section{References}

AHIP Center for Policy and Research (March, 2009). Small Group Health Insurance in 2008. Washington, D.C.

Bardasi, E. and M. Francesconi (2004) "The Impact of Atypical Employment on Individual Wellbeing: Evidence From a Panel of British Workers,' Social Science and Medicine, 58, pp. 1671-1688.

Beugelsdijk, S. and N. Noorderhaven (2005) "Personality Characteristics of SelfEmployed; An Empirical Study,” Small Business Economics, 24, pp. 159-167.

Bigsten, A., P. Collier, S. Dercon, M. Fafchamps, B. Gauthier, J.W. Gunning, A. Oduro, R. Oostendorp, C. Pattillo, M. Soderbom, F. Teal, and A. Zeufack (2004) "Do African Manufacturing Firms Learn From Exporting?" The Journal of Development Studies, 40(3), pp. 115-141.

Blanck, P.D., L.A. Sandler, J.L. Schmeling, and H.S. Schwartz (2000) "The Emerging Workforce of Entrepreneurs with Disabilities: Preliminary Study of Entrepreneurship in Iowa." Iowa Law Review, 85, pp. 1583-1668.

Blanchflower, D.G. (2000) "Self-Employment in OECD Countries," Labour Economics, 7, pp. 471-505.

Blau, D.M. (1998) "Labor Force Dynamics of Older Married Couples," Journal of Labor Economics, 16(3), pp. 595-629.

Blau, D.M. and D.B. Gilleskie (2001a) "The Effect of Health on Employment Transitions of Older Men," Worker Wellbeing in a Changing Labor Market, 20, pp. 35-65.

Blau, D.M. and D.B. Gilleskie (2001b). "Retiree Health Insurance and the Labor Force Behavior of Older Men in the 1990s," The Review of Economics and Statistics, 83(1), pp. 64-80.

Blau, D.M. and A.P. Hagy (1998) "The Demand for Quality in Child Care," The Journal of Political Economy, 106(1), pp. 104-146.

Borjas, G.J. (1986) “The Self-Employment Experience of Immigrants.” The Journal of Human Resources, 21(4), pp. 485-506.

Boyd, R.L. (1984) "Type A Behavior, Financial Performance and Organizational Growth in Small Business Firms," Journal of Occupational Psychology, 57, pp. 137-140.

Boylan, A. and T. Burchardt (2002) "Barriers to Self Employment for Disabled People," Report for the Small Business Service, October 2002. 
Cai, L. and G. Kalb (2006) "Health Status and Labor Force Participation: Evidence from Australia." Health Economics, 15, pp. 241-261.

Cowell, A.J. (2006) "The Relationship Between Education and Health Behavior: Some Empirical Evidence,” Health Economics, 15, pp. 125-146.

Cowling, M. and M. Taylor (2001) "Entrepreneurial Women and Men: Two Different Species?” Small Business Economics, 16, pp. 167-175.

Curran, J. and R. Burrows (1989) "National Profiles of the Self-Employed," Employment Gazette, 97, pp. 376-385.

Currie, J. and B.C. Madrian (1999) "Health, Health Insurance, and the Labor Market," in O. Ashenfelter and D. Card, eds., Handbook of Labor Economics, Volume 3. Elsevier Science: Amsterdam. pp. 3309-3416.

DeCicca, P. (2007) "Health Insurance Availability and Entrepreneurship: Evidence from New Jersey," Paper presented at ERIU Summer Research Conference, Ann Arbor, MI.

Dolinsky, A.L. and R.K. Caputo (2003) "Health and Female Self-Employment," Journal of Small Business Management, 41(3), pp. 233-241.

Elfenbein, D.W., B.H. Hamilton, and T.R. Zenger (2008) “The Entrepreneurial Spawning of Scientists and Engineers: Stars, Slugs, and the Small Firm Effect," Working paper series, Social Science Research Network.

Evans, D.S. and L.S. Leighton (1989) "Some Empirical Aspects of Entrepreneurship," The American Economic Review, 79(3), pp. 519-535.

Fairlie, R.W. and B.D. Meyer (1996) "Ethnic and Racial Self-employment: Differences and Possible Explanations," The Journal of Human Resources, 31, pp. 643-669.

Fairlie, R.W., K. Kapur, and S.M. Gates (2008) "Is Employer-Based Health Insurance a Barrier to Entrepreneurship?" Working Paper WR-637-EMKF. RAND Institute for Civil Justice: Santa Monica, CA.

Flaig, G. (2003) "Comments: Insurance and the Utilization of Medical Services among the Self-Employed," in S. Cnossen and H. Sinn, eds., Public Finance and Public Policy in the New Century. The MIT Press: Cambridge, MA. pp. 397-401.

Fonseca, R., P. Michaud, and T. Sopraseuth (2007) "Entrepreneurship, Wealth, Liquidity Constraints and Start-up Costs,” IZA Discussion Paper No. 2874. 
Fredland, J.E. and R.D. Little (1981) "Self-Employed Workers: Returns to Education and Training," Economics of Education Review, 1(3), pp. 315-337.

Fuchs, V.R. (1982) "Self-Employment and Labor Force Participation of Older Males," The Journal of Human Resources, 17(3), pp. 339-357.

Georgellis, Y., J.G. Sessions, and N. Tsitsianis (2005) "Self-Employment Longitudinal Dynamics: A Review of the Literature," Economic Issues, 10(2).

Georgellis, Y. and H.J. Wall (2005) "Gender Differences in Self-Employment," International Review of Applied Economics, 19(3), pp. 321-342.

Giandrea, M.D., K.E. Cahill, J.F. Quinn (2008) "Self-Employment Transitions Among Older Workers with Career Jobs," U.S. Bureau of Labor Statistics.

Gill, A.M. (1988) "Choice of Employment Status and the Wages of Employees and the Self-Employed: Some Further Evidence," The Journal of Applied Econometrics, 3(3), pp. 229-234.

Gilleskie, D.B. and B.F. Lutz (2002) “The Impact of Employer-Provided Health Insurance on Dynamic Employment Transitions," The Journal of Human Resources, 37(1), pp. 129-162.

Grossman, M. (1972) "On the Concept of Health Capital and the Demand for Health," The Journal of Political Economy, 80(2), pp. 223-255.

Gumus, G. and T.L. Regan (2009) "Self-Employment and the Role of Health Insurance," IZA Discussion Paper No. 3952.

Hamilton, B.H. (2000) "Does Entrepreneurship Pay? An Empirical Analysis of the Returns to Self-Employment," The Journal of Political Economy, 108(3), pp. 604-631.

Haveman, R., M. Stone, and B. Wolfe (1994) "Market Work, Wages, and Men's Health," The Journal of Health Economics, 13, pp. 163-182.

Heckman, J.J. (1981) “The Incidental Parameters Problem and the Problem of Initial Conditions in Estimating a Discrete Time-Discrete Data Stochastic Process," in C.F. Manski and D. McFadden, eds., Structural Analysis of Discrete Data With Econometric Implications. MIT Press: Cambridge, MA. pp. 179-195.

Holtz-Eakin, D., J.R. Penrod, and H.S. Rosen (1996) "Health Insurance and the Supply of Entrepreneurs," Journal of Public Economics, 62, pp. 209-235. 
Jones, M.K. (2005) "Disability and the Labour Market: A Review of the Empirical Evidence," WELMERC Discussion Paper No. 2005-03.

Kapur, K., J.J. Escarce, M.S. Marquis, and K.I. Simon (2008) "Where Do the Sick Go? Health Insurance and Employment in Small and Large Firms," Southern Economic Journal, 74(3), pp. 644-664.

Knight, G. and S. McKay (2000) "Lifetime Experiences of Self-employment," Labor Market Trends, 108, pp. 470-472.

Leung, S.F. and C.T. Wong (2002) "Health Status and Labor Supply: Interrelationship and Determinants," Version of May 28, 2002, in mimeo, Hong Kong University of Science and Technology.

Levy, H., and D. Meltzer (2001) "What Do We Really Know About Whether Health Insurance Affects Health?" Paper presented at the Agenda Setting Meeting of the Coverage Research Institute, Ann Arbor, MI.

McClelland, D. (1961) The Achieving Society. Van Nostrand Reinhold: Princeton, NJ.

Meer, J. and H.S. Rosen (2004) "Insurance and the Utilization of Medical Services," Social Science and Medicine, 58, pp. 1623-1632.

Mushinski, D. (2009) "The Role of Employer Sponsored Health Insurance in Individual Decisions to Become Entrepreneurs," Unpublished Paper (Colorado State University).

Mroz, T.A. (1999) "Discrete Factor Approximations in Simultaneous Equation Models: Estimating the Impact of Dummy Endogenous Variables on a Continuous Outcome," Journal of Econometrics, 92, pp. 233-274.

Parker, S.C. (2003) "The Distribution of Wealth of Older Self-Employed Britons," Fiscal Studies, 24(1), pp. 23-43.

Parker, S.C. (2004) The Economics of Self-Employment and Entrepreneurship. Cambridge University Press: Cambridge, UK.

Parker, S.C. and J. Rougier (2004) "The Retirement Behaviour of the Self-Employed in Britain,” Working Paper in Economics and Finance No. 04/08.

Parkes, K.R. (1999) "Shiftwork, Job Type, and the Work Environment as Joint Predictors of Health Outcomes," Journal of Occupational Health Psychology, 4, pp. 256-268. 
Perry, C.W. and H.S. Rosen (2004) "The Self-Employed Are Less Likely to Have Health Insurance Than Wage Earners. So What?" in D. Holtz-Eakin and H.S. Rosen, eds., Public Policy and the Economics of Entrepreneurship. The MIT Press: Cambridge, MA. pp. 23-57.

Picone, G.A., F.A. Sloan, S. Chou, and D.H. Taylor, Jr. (2003) "Does Higher Hospital Cost Imply Higher Quality of Care?" The Review of Economics and Statistics, 85(1), pp. 51-62.

Quinn, J.F. (1980) "Labour-Force Participation Patterns of Older Self-Employed Workers," Social Security Bulletin, 43, pp. 17-28.

Rees, H. and A. Shah (1986) "An Empirical Analysis of Self-Employment in the U.K.," Journal of Applied Econometrics, 1(1), pp. 95-108.

Schur, L. and D. Kruse (2002) "Non-standard Work and Arrangements and Disability Income," Report to the Disability Research Institute, University of Illinois Urbana-Champagn, August 2002.

StataCorp (2007) Stata Survey Data Reference Manual, Release 10. StataCorp LP: College Station, TX

Tanner, S. (1998) “The Dynamics of Male Retirement Behavior," Fiscal Studies, 19, pp. 175-196.

Tucker, I.B. (1988) "Entrepreneurs and Public-Sector Employees: The Role of Achievement Motivation and Risk in Occupational Choice," Journal of Economic Education, 19, pp. 259-168.

Wellington, A.J. (2001) "Health Insurance Coverage and Entrepreneurship," Contemporary Economic Policy, 19(4), pp. 465-478.

Williams, D.R. (2004) "Youth Self Employment: Its Nature and Consequences," Small BusinessEconomics, 23, pp. 323-336.

Winfree, P.L. (2009) "Does Employer-sponsored Health Insurance Reduce Job Mobility? How the Health Insurance System Influences the Likelihood of Changing Jobs and Becoming Self-employed," Unpublished Manuscript. Available at: http://ssrn.com/abstract=1350031.

Zissimopoulos, J.M. and L.A. Karoly (2007) "Transitions to Self-employment at Older Ages: The Role of Wealth, Health, Health Insurance and Other Factors," Labour Economics, 14, pp. 269-295. 


\section{CHAPTER III}

\section{Measuring the Effect of a Spouse's Health on the Labor Supply of Older Workers: Further Evidence}

\section{Introduction}

The impact of spousal health status on labor supply is theoretically ambiguous. A decline in a spouse's health and their withdrawal from the labor force is likely to affect their partner's labor-leisure tradeoff in opposite ways. Since formal medical care is costly, the partner may substitute non-market time for market time in order to care for or spend more time with their spouse. On the other hand, the partner may substitute market time for non-market time to pay for costly market-provided medical care, to replace lost income, or due to the increase in value placed on employer-provided medical insurance (Blau, 1998). An understanding of the factors affecting older individuals' allocation of time to market-work and caregiving may have significant implications for the demands of costly formal care at older ages, and can contribute to our understanding of the effects of contemporary long-term care policies on the demands for these services (Siegel, 2006).

Siegel (2006) explores the effects of a decline of a husband's health on the wife's allocation of time between the labor market and non-market activities among older couples. She notes that previous studies have not sought to disentangle the effect of a husband's poor health on a wife's reservation wage from the offsetting income effect of his ill health. Hence, she argues that by controlling for the husband's earnings in models for labor force participation and hours of work, we can estimate the effects of the 
husband's ill-health on the wife's propensity to provide care at home or to purchase care in the market. Moreover, Siegel recognizes that husbands' earnings are likely to be endogenous in this model if there are unobserved characteristics common to both husbands and wives. She tests for the presence of endogeneity using instrumental variable (IV) techniques. Her key findings are that a husband's poor health significantly increases the probability of a wife's labor force participation but decreases her hours of work. Estimates of the impact depend, however, on the specification of health as well as whether the endogeneity of husband's earnings was controlled for in the model.

This paper re-examines Siegel's findings using a larger and more recent data set drawn from several panels of the Medical Expenditure Panel Survey (MEPS) spanning the years 2000-2007. It goes further to examine whether the relationship between a husband's ill health and a wife's labor force participation can be analogized to that of a wife's ill health and the husband's participation decision. The presence of underlying differences in characteristics or past labor market experience may or may not lead to differences between older men and women in their propensities for care giving or for the provision of formal care for their spouses. A few important differences between Siegel's data set [The Health and Retirement Survey (1992), or "HRS"] and my data set limit comparisons of our estimates. Despite these differences, our findings together should provide further insight on the importance of controlling for the endogeneity of a spouse's earnings on their counterpart's labor decisions and reemphasize the appropriateness of using the various health measures which can be found in contemporary micro-data sets to explore the possible range of estimates for the impact of health in similar studies. 
Section two summarizes the findings of Siegel (2006) and contrasts her findings with those of similar studies. It goes on to discuss more recent literature that has inspired this author to expand upon Siegel's (2006) investigation to examine the reciprocal relationship that may exist between older husbands and wives. Section three briefly describes a framework which incorporates a spouse's health status into the labor market decision process made by the other spouse. Siegel (2006) lays out this framework for us. Section four describes the data and section five lays out the methodology employed to obtain estimates for the effects of spousal health on the labor supply decisions of older individuals. The remainder of the paper presents and interprets the results.

\section{Background}

Siegel (2006) finds that a husband's ill health is likely to increase the wife's probability of employment when health is measured by an index of physical functioning, and that a wife whose husband has a heart condition is also more likely to work. Since she controls for a spouse's earnings, thereby controlling for the income effect, Siegel concludes that, on average, a wife will decrease her reservation wage in response to a husband's ill-health. It may be the case that a wife will increase her market-time in order to pay for costly medical care for the husband. Alternatively, it may be because substitution in home production by the husband may lower the opportunity cost of the wife's work (Coile, 2004), or she may find that leisure time with her husband is less pleasurable (Siegel, 2006). On the other hand, Siegel finds that as a husband's selfassessed health status declines (or a stroke is suffered) the wife significantly decreases her hours of work. Thus, she may desire to spend more time at home caring for her 
husband or to make more out of the decreased life expectancy of the husband. More importantly, however, Siegel (2006) finds that the impact of the husband's health on a wife's labor market outcome will vary across alternative measures for health - an indicator for a work-limitation, self-assessed health, a health conditions index, and a physical functioning index - and that, when husband's earnings are treated as endogenous in a model for women's hours of work, the magnitude of the impact will vary. ${ }^{81}$ Although, whether instruments for these earnings are included, the direction of impact is the same.

While Siegel's findings were somewhat inconsistent with findings in earlier studies, the earlier studies did not control for the endogeneity of a wife's unearned income and therefore their results are generally not directly comparable (Siegel, 2006, p. 581). Despite this non-comparability I will review these studies. Parsons (1977) investigated the effects of family structure on men's health, hours of work, and earnings using data from the National Longitudinal Survey of Older Men and a self-assessed measure of health (excellent, good, fair, or poor). Parsons finds that despite poor health sharply decreasing the hours of work and therefore the earnings of men, there was no significant increase in the hours of work by other family members. He explains that an increase in transfer payments to the household may have offset the negative income effect of exiting the labor force. Conversely, using an alternative data set from the Productive American Survey, Parsons finds that a husband's poor health leads to a small

\footnotetext{
${ }^{81}$ Hausman tests revealed that she could not reject the hypothesis that husband's earnings were exogenous to women's labor force participation while they were endogenous to women's hours of work; potentially biasing the regression coefficients on hours.
} 
but insignificant decrease in the wife's productive work within the home and a significant increase in her market time.

Berger (1983) and Berger and Fleischer (1984) use the same data and also control for the effect of transfer payments on a wife's labor market response to the husband's poor health. Health was measured by self-reports of a work-limiting health condition. They find only a slight increase in a wife's hours of work and no significant effect on her labor force participation. Bartel and Taubman (1986) found that a husband's mental illness increased the likelihood of the wife's labor force participation. Haurin (1989) also found an impact of a husband's poor health on the wife's labor force decision.

Johnson and Favreault (2001) use three indicators for health - three or more functional impairments, more than five impairments, and a self-assessed measure - from HRS (1992-1998) data and find that a wife is less likely to retire with her spouse if he quits working due to poor health; particularly if he does not yet qualify for social security payments. ${ }^{82}$ Blau (1998) and Blau and Riphahn (1999) study joint retirement behavior in the United States and Germany, respectively. Cross-spouse, health effects are mainly small in both. However, Blau (1998) indicates that when the husband is not employed, the wife is less likely to retire in response to poor health of the husband, suggesting that ESI may be valuable. Poor health of the wife decreases the probability that the husband enters the workforce from non-employment. In contrast to Blau (1998), but possibly due to important differences between the German public pension system and similar U.S. institutions, Blau and Riphahn (1999) find that wives are more likely to exit the workforce and less likely to enter if the husband has a chronic condition and has left the

\footnotetext{
${ }^{82}$ The literature discussion so far was borrowed from Siegel's (2006) literature review, from which she draws comparisons for her results.
} 
workforce. The opposite effects are indicated for husbands with a chronic condition that remain employed. Independent of the wife's labor force status, the husband is less likely to exit employment and less likely to enter employment if the wife has a health condition.

Some studies have used longitudinal data to focus on the effect of a shock to a spouse's health on their spouse's labor supply, rather than the contemporary health status of the spouse. Although, this study will investigate only the latter relationship, Giertz (2000) provides evidence that the impact of spousal health did not require a health "event" (or shock) to significantly impact the household's economic decisions. He found that declines in health before and after an "event" correlated with declining incomes. Charles (1999) examines the effect of health shocks on spousal labor supply using two years of HRS longitudinal data. His focus was on the endogeneity and mismeasurement of health when using self-assessed measures or self-reported work limitations. Similar to Stern (1989) and Bound (1991), he uses objective indicators for physical functioning as instruments to account for measurement bias of dichotomous indicators and uses a twostage procedure along with fixed effects techniques to control for endogeneity bias of these measures. He finds that both the probability of a wife's labor force participation and her hours of work increase in response to a husband's diminished health. O'Hara (2004) uses longitudinal data [Survey of Income and Program Participation (1995)] with a medical expenditure approach to measuring health status to estimate the effect of a husband's ill health on mothers' labor force participation. He finds that the probability of a wife's labor force participation increases by eight percent when the spouse's health falls from excellent to poor. 
Coile (2004) uses time-series data from HRS (1992-2002) to investigate the labor supply responses between older husbands and wives when the other experiences an exogenous health shock in the previous period. Three types of health shocks are examined: acute health events, onset of new chronic illness, and accidental injuries or falls. The differences in impacts due to the severity of these events is also examined by interacting these shocks with an indicator for large changes in Activities of Daily Living (ADL) functioning and by using an indicator for a significant change in the self-assessed mortality experience by the individuals. Coile finds that a wife's health shock exhibits only a small and statistically insignificant decrease in the probability of her husband's exit from the labor force and an increase in hours worked - a statistically significant effect on hours was found when replacing the separate indicators for shocks with an indicator for any shock. The severity of the shock - associated with a decrease in physical functioning - had no additional impact. Likewise, for women, a shock to husband's health results in only a small and insignificant increase in labor supply. However, when the impact is severe, a negative and significant impact was found on the women's participation; no additional effect was found on hours.

Despite the lack of strong effects in Coile's study, the effect of a shock to a spouse's health seems to differ generally across men and women. She suggests that this may be explained by differing characteristics. For example, men have traditionally exhibited stronger "complementarity of leisure" effects than women - a wife's presence is viewed as a complement to men's leisure time - but a wife's severe health shock can weaken this effect thereby providing a greater incentive for the husband to maintain or increase labor market time. Conversely, if a shock to one's health requires assistance and 
the family prefers to have the spouse provide this care, it may be the case that the shock will increase the complementarity effect for women, for example because women are more likely to take on additional household responsibilities when a husband falls into ill health (Coile, 2004). For further example, Coiles' estimates also show evidence that a husband increases his labor supply in response to a shock in wife's health when substitute caregivers are available. To the extent that spouses tend to retire together, a husband's retirement decision is relatively more responsive to a wife's financial incentives for retirement. Lastly, similar to Parsons (1977), Berger (1983), and Berger and Fleischer (1984), Coile looks to the possibility that employer or publicly provided benefits may crowd out any increase in market time that would otherwise occur by spouses when faced with a negative shock to household income. She finds that husbands tend to reduce labor supply when wives have access to retiree health insurance or private pension benefits and wives reduce their labor supply when husbands have access to disability insurance benefits. ${ }^{83}$ Moreover, the extant of the crowding out effect does not appear to be consistent across men and women.

The former studies seem to focus on the labor market decisions of wives relative to their husband's health status because, despite women's increased role in the labor market over past decades, they tend to remain the primary caregivers in households (Siegel, 2006). Furthermore, women tend to marry men older than themselves and frequently witness declining health in their husbands (Siegel, 2006). It may also be due to the fact that husbands have traditionally shown little labor supply responsiveness with respect to their spouse's wages; wives have traditionally been the secondary earner (Blau

\footnotetext{
${ }^{83}$ Buchmueller and Valletta (1999) find a strong negative effect of husband's health insurance coverage on wives' work hours.
} 
and Kahn, 2007). Interestingly, though, Blau and Kahn (2007) find that from 1980 to 2000, women's cross-wage elasticity has continued a long-term trend by falling 38\%$47 \%$ in absolute value, while men's have stayed strongly the same. ${ }^{84}$ Due to the continual rise in female participation rates fewer women find themselves on the margin between participation and non-participation. Increased divorce rates and increasing career orientation of married women are also expected to decrease the sensitivity of women's labor supply to their own and their husband's wages. As a result, married women's labor supply elasticities are continually becoming more and more like those of married men (Blau and Kahn, 2007). It may be the case that the same forces that have led to increasing similarities of labor supply functions between husbands and wives can also alter their roles within the average household. Differences in characteristics that define husbands and wives' labor market responses to the health status of the other may be shrinking. Thus, older women who have worked throughout the 1980's and 1990's may respond to their husband's ill health differently than the responses which have been previously estimated by Siegel (2006) using 1992 data. ${ }^{85}$ So, this study will revisit Siegel's (2006) analysis to investigate the impact of husbands' health status on older women's labor supply, but similar to Coile (2004), it will also investigate the symmetry in the relationships between husbands and wives' labor supply relative to the other's

\footnotetext{
${ }^{84}$ This trend was more pronounced in the 1980's than in the 1990's.

${ }^{85}$ With respect to footnote 85 , it may still be the case that these characteristics of men and women workers have continually changed since 1992 . For one, it may be the case that older women who have established themselves in the workforce have experienced increased income or workplace benefits due to experience and tenure or have experienced stronger work commitments in the same respect. Furthermore, labor force participation among this cohort has continued to increase in the 1990's even if not in the same magnitude witnessed in previous decades. From 1992 to 2000 labor force participation rates of married women have increased from $56.3 \%$ to $59.6 \%$. Married men's has increased only slightly ( $74 \%$ to $75 \%$ ). The percent of the total population of women between 45 and 64 years of age that are married and employed increased by 11 percentage points from 1992 to 2006 . The equivalent statistic for men decreased by 6.6 percentage points (obtained from the BLS based on CPS data).
} 
health status. With respect to Coile (2004), it may be the case that men and women exhibit a relatively more symmetrical relationship than previously thought to exist once we control for the possible endogeneity of spousal earnings. Of course, this study's results will not be directly comparable with Coile's results since it will not be longitudinal and it will contain measures of health status derived from fundamentally different means.

This study will also provide further insight on the impact of health on labor market participation by utilizing various health measures that are similar to those found in Siegel's study, as well as a more global health measure - the Physical Component Summary (PCS) - found in MEPS. The use of PCS eliminates concerns of endogeneity associated with self-assessed measures. To the extent that it weights more heavily more severe conditions that limit one's capacity or willingness for productive or nonproductive work, and because it is continuous, it will be less susceptible to the measurement error. ${ }^{86}$ Besides, I am not aware of any study that has utilized MEPS to specifically investigate the impact of spousal health on the labor supply of men or women.

\section{Framework}

While this study replicates Siegel's (2006) methodology, differences in content and design between the HRS data and MEPS prevent exact replication of Siegel's (2006) analysis. Differences between Siegel's study and this study will be alluded to in the

\footnotetext{
${ }^{86}$ See chapter 1 for the discussion of concerns over measurement error. Baker et al (2004) find that there is less measurement error in objective reports of health when the condition is more serious (Coile, 2004, p. $11 \mathrm{n} 14)$. Other authors are often concerned with measurement bias resulting from non-continuous indicators for health.
} 
discussion of the empirical model. The following section will summarize the framework laid out by Siegel (2006).

We assume that each person faces a given wage rate, $\mathrm{W}$, at which he or she can choose to work any number of hours, or none. Suppose they are unwilling to work at all for less than some wage rate $\mathrm{W}^{*}$, referred to as the reservation wage. If $\mathrm{W}$ rises above $\mathrm{W}^{*}$, the hours that the person works will, at least initially, rise as $\mathrm{W}$ rises, provided the utility function is strictly quasi-concave and twice differentiable (Layard et al., 1980).

Let $\mathrm{L}^{*}$ equal an individual's desired hours of work, which is a function of his or her reservation wage, $\mathrm{W}^{*}$, and potential wage, $\mathrm{W}$. The reservation wage is determined by factors such as his or her spouse's health, own taste for leisure, and unearned income (partly made up of their spouse's income). The potential wage is determined by human capital including own-health status, other personal traits, and labor force experience. Unearned income equals the married couple's total income net of his or her own earnings. An individual's desired hours of work will be positive when their potential wage exceeds their reservation wage. Let $\mathrm{L}$ be dichotomous variable indicating an individual's labor force participation decision. L equals one when $L^{*}>0$ and equals zero otherwise.

Thus, $L^{*}$ is a function of unearned income, $Y$, a spouse's health, $H$, and other characteristics that affect the reservation wage and potential wage, $X$. Using $X$ in place of $\mathrm{W}$ and $\mathrm{W}^{*}$, the we represent an individual's desired hours of work as:

$$
L^{*}=g_{L}(Y, H, X)
$$

And $\mathrm{L}$ is determined by $L^{*}$ :

$$
L=1 \text { when } L^{*}>0
$$




$$
L=0 \text { when } L^{*} \leq 0
$$

The individual's unearned income, $Y$, includes their spouse's earnings, which is a function of their spouse's health, $H$, and other characteristics, $S$ :

$$
Y=f(H, Z)
$$

Therefore,

$$
L^{*}=g_{L}(f(H, S), H, X)
$$

By controlling for unearned income, we are controlling for the income effect associated with the spouse's health. Thus, holding all else constant, the coefficient on $H$ in the function, $L^{*}$, will reflect the impact of the spouse's health on the reservation wage of the individual.

There are reasons to believe, however, that a spouse's earnings are endogenous with the other's labor force decisions, thereby potentially biasing the coefficients on spousal earnings and health. For a couple nearing retirement, spousal labor market decisions are often coordinated and made jointly (Hurd, 1990; Blau, 1998; Blau and Riphahn, 1999; Maestas, 2001). There is also evidence of "assortive mating" - the tendency for individuals to marry those with similar preferences over work and leisure (Blau and Riphahn, 1999). Contoyannis and Jones (2004) show that a number of lifestyle variables are correlated between spouses. Thus, there is likely to be unobserved differences in tastes for work between low earning and high earning couples. I instrument the spouse's earnings with variables that are correlated with the ability to afford leisure but are not correlated with the tastes for leisure. 


\section{Data}

I estimated the effect of a spouse's health on an individual's labor supply using data from MEPS panels five (2001) through eleven (2007). ${ }^{87}$ The sample was restricted to couples in which the spouse whose labor supply is in question is between 50 and 61 years of age. Couples for which the health or employment status was not reported were dropped from the sample. Also, I dropped all couples in which at least one spouse is selfemployed because there are likely to be inaccuracies in reported hours worked and because wages were not reported for these individuals. ${ }^{88}$ This resulted in a total of 8,267 spousal pairs, or 3,877 couples in which the female's labor response to their husband's health is analyzed (2,120 in which the wife is employed) and 4,390 for males $(2,831$ in which the husband is employed).

The dependent variables for the three equations estimated below are the wife and husband's labor force participation, their wage, and their hours of work per week. Labor force participation is equal to one if the wife is working for pay, and it equals zero

otherwise. A spouse's hourly wage is calculated from his or her current weekly income divided by reported hours of work per week, or was directly reported by the individual. All demographic, human capital, employment, and employment-related measures used to predict labor outcomes are collected in round three of each panel. All regressors in the

\footnotetext{
${ }^{87}$ MEPS is constructed from a complex survey design, so, each observation is weighted by the respective person-level weight and some computationally intensive steps are needed in order to correctly estimate the variance-covariance matrices. The model was estimated using STATA's Survey procedures (StataCorp., 2007: p. 156).

${ }^{88}$ This resulted in 1,140 couples being dropped from the sample (712 male spouses were self-employed and 428 female spouses were self-employed). Siegel (2006) also dropped self-employed couples for the same reason but re-estimated her model including them to check for robustness. All estimates remained unchanged. Also, the previous chapter suggests that wives with less healthy husbands may select into selfemployment due to the flexible work schedule and environment it may afford. Siegel finds, however, that "husbands of self-employed wives were no more nor less healthy than the husbands of other employed wives across four measures for health."
} 
equations are identified in the Appendix and will be discussed further in the next section.

A discussion of the specification of health will follow that section.

The individual's labor force participation and hours of work are modeled as

functions of his or her total unearned income. Unearned income includes both their spouse's earnings and other unearned income. Spouses' earnings are calculated as their hourly wage reported in the current period multiplied by their usual hours of work per week. ${ }^{89}$ A dummy variable indicates whether a spouse is employed (working for pay and not self-employed) to control for spouses who are not working. The sum of the couples' yearly wage-earnings in the year prior to round three was subtracted from the total household income of that year in order to calculate the individual's other unearned income. $^{90}$

\section{Empirical Model}

This section discusses my empirical model. The objective of the analysis is to obtain consistent estimates for the impact of a spouse's health on an older individual's labor supply decisions while controlling for any indirect effects of spousal health through household income. In this regard, the discussion goes on to highlight the methods used to

\footnotetext{
${ }^{89}$ A small amount of individuals refused to provide information regarding wage earnings. In these cases their wage earnings for the year were imputed using information obtained from questionnaires regarding their current employment which includes information regarding hourly wage and hours worked per week. All imputations were conducted by MEPS - documentation can be found at http://meps.ahrq.gov/mepsweb/data_stats/download data files.jsp.

${ }^{90}$ Potential interview dates for round three questioning are within a span of quarter 3 of year one and quarter 2 of year two. Thus, some fraction of the sample may have been interviewed near the end of the year in which spousal earnings and household income was obtained while the remaining fraction was sampled after that year was completed. With this in mind, I assume little confounding effects on the estimates since I suspect that the decision-making individual has nearly full information regarding the total earnings of the household for a year which is nearly completed.
} 
account for possibly endogenous earnings variables. The following section discusses briefly the manner in which health measures are incorporated into the model.

Since the MEPS survey is at the household level and because we expect that most budgetary and care giving decisions are jointly made by spouses we cannot assume that the observations for wives and husbands within the full sample are independent. Therefore, separate analyses are conducted for wives and then husbands. However, in order to quantify the differences in labor supply responses between wives and husbands, a third round of estimates is conducted which assumes independence of the observations and combines the two sub-samples. A dummy equal to one if the respondent is male (zero otherwise) is included in the model and interacted with the health variables for both spouses. The coefficient on the interaction term represents the extent to which the impact of a partner's health on husbands' labor supply differs from its effect on women's labor supply. A check for the reliability of the latter estimates reveals similar results for the direct impact of health and spousal health for both males and females when each group is sampled separately and when they are combined to form one large sample - using a dummy variable to distinguish between the impacts of health by gender. This suggests that if there is any correlation between the observations for each husband and wife pairing it is probably not substantial enough to bias estimates on the combined sample. ${ }^{91}$ The results from these estimations can be found in Tables A11 through A19 located in the Appendix.

\footnotetext{
${ }^{91}$ Due to the age restriction on the individual and not the spouse, not every husband has a wife who was also sampled and vice versa. Additionally, an alternative way of testing the statistical difference between estimates on husbands and wives would be to estimate a seemingly unrelated regressions model then test the hypothesis that the difference between the similar coefficients across the equations for husbands and wives are statistically significant. However, I would also assume that the observations for husbands and wives are independent and therefore I would expect similar results from hypothesis tests.
} 
Labor force participation is estimated using probit regressions of the following empirical model:

$$
\operatorname{Pr}(L=1)=\alpha+\beta W^{*}+\gamma W+\delta Y+\varepsilon
$$

The individual is classified as participating in work $(L=1)$ if the person is working for pay and is not self-employed. Participation depends upon the individual's total unearned income, $Y$, and other factors that determine the reservation wage, $W^{*}$, as well as his or her potential wage, $W$. An individual's reservation wage, $W^{*}$, is determined by the value they place on non-market time. In my model, $W^{*}$ is a function of own-health, spouse's health, the number of children under 18 and age 18 and older usually living in the home, and his or her race. Potential wage, $W$, is a function of human capital which is dependent upon schooling and experience, as well as age and own health. Unfortunately, MEPS does not provide information pertaining to periods prior to which the individuals are interviewed, therefore we cannot observe the individual's work history. Instead, a proxy for years of labor experience is defined by [Age - Years of Schooling - 6] (Borjas, 1986). Since the sample is restricted to a relatively short span of ages [50-61], the proxy for experience is highly collinear with an individual's age and therefore the age variable is dropped from all regressions. ${ }^{92}$ Unearned income is composed of the spouse's earnings, controlling for his or her labor force participation, and other household income. A dummy variable indicates whether the individual receives pension benefits from a past or current job or currently collects returns from an IRA or 401-k. Additional dummy variables for census region, MSA status, and years are included to control for differences in labor demand across regions and time.

\footnotetext{
${ }^{92}$ I also re-estimate the models substituting age and age squared for experience and experience squared. There was no substantial change in the coefficients on health or their standard errors.
} 
Work hours are also modeled as a function of the reservation wage, potential

wage, and unearned income.

$$
L^{*}=\alpha+\beta W^{*}+\gamma W+\delta Y+\varepsilon
$$

The specification for reservation wage and unearned income remains the same as above except for the exclusion of the dummy for receipt of pension benefits. Potential wage is measured by the individual's predicted wage (see below) and whether, on the current job, he or she receives pension benefits, health insurance, and whether a choice of health insurance plans is available from the employer. I also control for whether the current job is affiliated with a union and whether paid sick leave is offered. ${ }^{93}$ Yearly dummies are also included in the model. Since this analysis is restricted to only those individuals who work, we correct for sample-selection bias by estimating hours of work with labor force participation using maximum likelihood estimation of a bivariate sample selection model. $^{94}$

The individual's predicted wage value is substituted for actual wage because their observed wage is endogenous (Siegel, 2006, p.583). The predicted wage is estimated as a function of human capital (schooling and the proxy for work experience), race, own health status, as well as the characteristics of the current job - whether it is white collar

\footnotetext{
${ }^{93}$ Siegel's model includes controls for whether, on the current job, the individual can choose to reduce or increase his or her hours of work. They are significant predictors of hours of work. This variable was not offered in MEPS. I assume that indicators for whether one or more health insurance plans is offered, the job is union, and it offers paid sick leave will capture the effects of a "good job" and possibly control for the heterogeneity associated with the ability to increase or decrease hours of work. These variables were not included in Siegel's model.

${ }^{94}$ This model is analogous to using the Heckman Correction, a two-step procedure. STATA does not allow Heckman's two-step procedure when using survey data. While the inverse mills ratio is not involved in the estimation, I follow Siegel's (2006) example - who also uses maximum likelihood estimation of a bivariate sample selection model - and report the equivalent of the coefficient on the inverse mills ratio had we used the two step procedure, $\lambda$ (this is simply equal to the multiplication of the estimated standard error for the hours equation, $\sigma$, and the correlation coefficient from the bivariate normal distribution, $\rho$ ).
} 
and union, years of tenure, a dummy for less than one year on the job, and the industrial sector (Government, Agriculture and Construction, FIRE, Sales, or Other). Controls for census region, MSA, and time period are also included. As with hours of work, we only observe the actual wage for those who are working therefore I also estimate predicted wage using maximum likelihood estimation of the bivariate sample selection model. Since the distribution of wages is skewed to the right, the natural log of the individual's wage was used as the dependent variable. Estimates for predicted wages are reported in Tables A5 through A7 located in the Appendix.

\subsection{Instrumenting Spouses' Earnings}

To control for the possible endogeneity of the spouses' earnings I follow Siegel's (2006) approach by using two-stage probit (least-squares) estimation for the participation (hours) equation. I estimate both the labor force participation and hours worked equation with and without instrumenting for the spouse's earnings and proceed to assess whether they are endogenous. The integrity of this analysis depends on the validity of the instruments; they must be highly correlated with spouse's earnings, and orthogonal to the disturbance in the participation equation. The instruments used to model a spouse's earnings are factors which affect the supply and demand for his or her labor: whether they are white-collar, years of tenure at the current job, whether the job is in the sales industry, the size of the firm that employs him or her (less than 100 employees, between 100 and 499 , or 500 or more), and whether the firm has more than one location. ${ }^{95}$ While

\footnotetext{
95 Other industries were included as instruments in the model initially. However they did not prove to be statistically significant in predicting the spouse's earnings and a few of the indicators did not pass tests for
} 
they may be somewhat influenced by individual preferences, I argue that these

instruments are likely to be orthogonal to their partner's current labor supply since (1) the

first three instruments listed are primarily determined by human capital attainment made

much earlier in one's career and therefore are exogenous to current decisions by their

spouse, or (2) all of the instruments (especially whether they are in sales, and those for

the size of the firm) are determined by the available jobs in the occupation the spouse has

chosen and trained for, in the region in which the spouse resides, and in the year in which

the spouse is observed.

Since MEPS utilizes a "complex survey design" standard statistical procedures for

hypothesis tests which assume simple random samples are invalid (this includes all

likelihood-ratio based tests and the Hausman test for exogeneity) (Eltinge and Sribney,

1996). A common approach to linear hypothesis testing in a survey design setting is to

use the "adjusted Wald Test" ${ }^{96}$ for testing the significance of individual and joint

orthogonality. The only industry dummy that was consistently significant across all specifications, and passed orthogonality tests was one that distinguishes sales from the other categories.

Alternative specifications for predicting spouse's earnings were exhaustively searched for and tests for validity narrowed the choice of instruments to the six listed above. The argument for the theoretical validity of my instruments follows Siegel's argument for her choice of instruments - industry classification and firm size; they "may be somewhat influenced by his [or her] preferences, but are primarily determined by" available jobs in the individual's occupation and region.

Siegel also models a husband's earnings as a function of his labor supply factors and human capital (schooling, work experience, and age). She argues that although they are highly correlated with the characteristics of the wife and therefore are excluded from the second stage equations, they are included in the first stage in order to improve the efficiency of the estimates. Formal tests for validity rejected the inclusion of these characteristics in my first stage estimates. However, the standard procedure for two-stage least squares (Wooldridge, 2002) requires that all exogenous variables in the model be included in the first stage estimates - which includes the covariates used to predict the "primary" spouses reservation and predicted wages in the second stages - and, since these are correlated with the similar characteristics of the spouse (if not the same for the household-related variables), I argue that little efficiency will be lost by excluding these in the model for spouse's earnings.

${ }^{96}$ Stata 10 carries out the adjusted Wald-test as $(\mathrm{d}-\mathrm{k}+1) \mathrm{W} /(\mathrm{kd})$ distributed $\mathrm{F}(\mathrm{k}, \mathrm{d}-\mathrm{k}+1)$, where $\mathrm{W}$ is the non-adjusted Wald test statistic, $\mathrm{k}$ is the number of terms being excluded from the model, $\mathrm{d}$ is the total number of sampled PSUs minus the total number of strata, and $\mathrm{F}(\mathrm{k}, \mathrm{d}-\mathrm{k}+1)$ is an $\mathrm{F}$ distribution with $\mathrm{k}$ numerator degrees of freedom and $\mathrm{d}-\mathrm{k}+1$ denominator degrees of freedom (StataCorp., 2007). 
coefficients. ${ }^{97}$ So, in order to test formally the empirical validity of the instruments I rely on statistical tests which, in a non-survey design setting, can be carried out using a simple F-test (Wald test) and therefore can be adjusted in a manner appropriate to the complex survey design.

An F-test is used to test the joint significance of the instruments in the spouse's earnings equation (prob $>\mathrm{F}=0.00$ for both men and women). To test that the instruments are orthogonal to men and women's labor supply decisions (i.e. test for "overidentifying restrictions") I use two alternatives. The first is the simplest procedure outlined by Bollen, Guilkey, and Mroz (1995). It involves the inclusion of all but one of the theoretically excluded instruments in the structural equation, where, if the restrictions are valid, then these variables should not be significant predictors of the labor outcome after controlling for spouse's earnings. The second test conducted was Sargan's test for overidentifying restrictions, a useful variant of the Hausman test for overidentification, outlined in Wooldridge (2002, p. 123). If the instruments are truly exogenous, then they should be uncorrelated with the residuals of the IV regression. Thus, we simply estimate an OLS regression of the 2SLS residuals on all exogenous variables, then, noting that $N \cdot R_{u}^{2} \stackrel{a}{\rightarrow} \chi_{r}^{2}$ where $N$ is the number of observations and $r(=5)$ is the number of overidentifying restrictions, we test the null hypothesis that the instruments are uncorrelated with the residuals. ${ }^{98}$ All tests for overidentifying restrictions did not reject

\footnotetext{
${ }^{97}$ The reader may refer to Korn and Graubard (1990) for a summary and further reference regarding the construction and validity of the adjusted Wald tests on complex survey data.

${ }^{98}$ For the two-stage probit estimates of the participation model this test was conducted on (1) the generalized probit residuals, and (2) the residuals obtained from estimating the binary outcome using 2SLS. The latter method is suggested in Cameron and Trivedi (2009, p.471). For the hours equations, this test was conducted without the sample-selection correction, which I argue is a more conservative approach, i.e. I will accept the null hypothesis more often.
} 
the null hypothesis - that the instruments for spouses' earnings are orthogonal to their partner's labor force participation and hours of work decisions - at the ten percent level across both male and female samples and across all specifications for health. Thus, these results will not be reported in the remainder of this paper.

To test for exogeneity of spouse's earnings I use two variants of the Hausman test outlined in Wooldridge (2002, pp. 118-120). The first test is a regression based form of the test which is asymptotically equivalent to the original form of the Hausman test and can be extended to non-linear models. We test the null hypothesis that spouse's earnings is exogenous by simply including the residuals of the first stage equation in the second stage estimation and conducting a t-test (adjusted Wald test) on its coefficient. The second test for exogeneity proved to be nearly equivalent to the latter test in all cases. Wooldridge (2002, p.120) shows that we may test the null hypothesis of exogeneity by comparing just the estimates of the parameter of interest - the coefficient on spouse's earnings with and without instrumenting - by using a t-test (adjusted Wald test) on the difference between the two coefficients. The outcomes of these tests will be reported in the results section.

\section{The Specification of Health}

Another methodological issue regards the treatment of health in the empirical models for labor supply. One complication is due to the possible endogeneity and measurement error of the variables for health - see chapter one, section three, for a discussion. ${ }^{99}$ In order to address these issues and remain consistent with Siegel's 
methodology, this model will follow the suggestions of Bound (1991) and rely upon the findings of Dwyer and Mitchell (1999) to justify the use of both health measures considered to be more subjective and likely to suffer from endogeneity and objective and likely to suffer from measurement error. Bound (1991) suggests that by treating all measures as exogenous and using both types of measures to compute estimates, we can obtain a range for the relative importance of health and income in these models.

To proxy for men's and women's health we use two, more subjective measures a work-limiting health condition and self-assessed health (Excellent/Very Good/Good/Fair-Poor) - and three, more objective measures - a summary index for selfreported physician-diagnosed health conditions, a summary index of physical functioning limitations, and the PCS. All health variables were observed contemporaneously with the labor outcome, except for PCS, which was constructed from responses to a SelfAdministered Questionnaire administered in round two of the survey period. ${ }^{100}$ All measures for health are described further in Table 1.

\footnotetext{
${ }^{99}$ To reiterate, endogeneity is a concern when the measures for own and spousal health are likely to be functions of one's underlying health, income, and other economic variables tied to employment decisions; the extent to which the measure of health is not correlated with the willingness or capacity to care for themselves will determine the degree of measurement error that is likely to result here.

${ }^{100}$ Unlike the other measures used in the models, the observed PCS is not contemporary to the period in which individuals report the labor market status (PCS was obtained only in rounds 2 and 4 of MEPS). Consequently, measurement error may bias estimates for the parameters on PCS. I assume, however, that labor decisions made between rounds two and three will be based upon the health status that is reflected by the PCS score constructed from round two responses. Although negative shocks to health which may have occurred between these two periods could result in an immediate labor force response, there is no way to observe this behavior and the expected fraction of individuals who experienced such a shock is probably small. The latter suspicion was confirmed by an examination on the relative changes in PCS between period two and period four. Besides, the correlations between PCS observed in round two and the alternative health measures observed in round three were strong. Overall, for models which incorporated PCS, I assume that for a majority of the sample, health will depreciate (improve) relatively gradually over the four to six month period between rounds two and three, and any labor force responses by either spouse will be highly correlated with the round two health status - similarly, Bound et. al. (1999) and Bound et al (2008) assume an AR(1) process for individual health status over time. Alternatively, I assume that labor force responses to unpredictable shocks to health will be less immediate due to job-search costs combined
} 


\section{Table 1. Description of health variables used in the analysis}

\begin{tabular}{|c|c|}
\hline Work-Limitation & $\begin{array}{l}\text { Dummy }=1 \text { if responds yes to question: "Is [person] limited in } \\
\text { any way in the ability to work at a job because of an impairment } \\
\text { or a physical or mental health problem?"; Dummy }=0 \text { otherwise }\end{array}$ \\
\hline Self Assessed Health Status & $\begin{array}{l}\text { A set of dummies [Excellent, Very Good, Good, Fair/Poor] is } \\
\text { defined based on the response to question: "In general, compared } \\
\text { to other people of [person]'s age, would you say that [person]'s } \\
\text { health is excellent, very good, good, fair, or poor?" }\end{array}$ \\
\hline Health Conditions Index & $\begin{array}{l}\text { Number of following conditions which respondent experienced } \\
\text { over lifetime: arthritis, asthma, emphysema, diabetes, cancer, } \\
\text { heart problems (including angina and congestive heart failure), } \\
\text { hypertension, psychological condition, stroke. }\end{array}$ \\
\hline Functional Limitation Index & $\begin{array}{l}\text { Number of restrictions on the following measures of physical } \\
\text { functioning: lifting } 10 \mathrm{lbs} \text {., walking up } 10 \text { steps, walking } 3 \\
\text { blocks, walking a mile, standing } 20 \text { minutes, bending or stooping, } \\
\text { reaching overhead, using fingers to grasp. }\end{array}$ \\
\hline $\begin{array}{l}\text { Physical Component } \\
\text { Summary }^{101}\end{array}$ & $\begin{array}{l}\text { Formulated using Principal Component Analysis on the following } \\
\text { SF-12 }{ }^{\odot} \text { questionnaire, which was designed outside of the MEPS } \\
\text { survey and is well documented. The underlying conception is } \\
\text { that overall health is composed of a physical and a mental } \\
\text { component for which PCS and its counterpart, the Mental } \\
\text { Component Summary, represent. The physical component } \\
\text { weights more heavily on the following five questions: (1) General } \\
\text { health today; (2) during a typical day, limitations in moderate } \\
\text { activities; (3) During a typical day, limitations in climbing several } \\
\text { flights of stairs; (4) During past } 4 \text { weeks, as result of physical } \\
\text { health, accomplished less than would like; (5) during past } 4 \\
\text { weeks, as a result of physical health, limited in kind of work or } \\
\text { other activities. The mental component weights more heavily on } \\
\text { the remaining questions: (6) During past } 4 \text { weeks, as result of } \\
\text { mental problems, accomplished less than you would like; (7) } \\
\text { During past } 4 \text { weeks, as result of mental problems, limited in kind } \\
\text { of work or other activities; (8)) During past } 4 \text { weeks, pain } \\
\text { interfered with normal work outside the home and homework; (9) } \\
\text { During past } 4 \text { weeks, felt calm and peaceful; (10) During past } 4 \\
\text { weeks, had a lot of energy; (11) During past } 4 \text { weeks, felt } \\
\text { downhearted and depressed; (12) During past } 4 \text { weeks, physical } \\
\text { health or emotional problems interfered with social activities. }\end{array}$ \\
\hline
\end{tabular}

with the lower likelihood that a spouse may alter their hours of work as desired at their place of employment, or since disability compensation or unemployment insurance is likely to lessen any short-term shock to household income. Thus, any bias due to an unobservable shock to health status and immediate labor force responses by the spouse is expected to be inconsequential.

${ }^{101}$ The Mental Component Summary was not included in the analysis since I am not focusing on the effects of a spouse's physical health versus (or holding constant) their mental health. The PCS does incorporate the effects to the last six questions listed but is correlated with mental health to a lesser extent than MCS. Notice that the other variables also incorporate a mental component to a limited degree as well. I do not believe this to lead to any substantive change in the interpretation of our results. 
The objective measures will likely be particularly appropriate for this study since we wish to model the individual's allocation of time with respect to the need to care for an ailing spouse (Siegel, 2006, p. 583). Chapter 1, section 3, discusses how the subjective measures tend to be plagued by endogeneity when they are used to model own labor supply. Bound (1991) suggests that when self-assessed health is used in the context of these models, the downward bias deriving from measurement error may, to some extent, cancel out the upward bias associated with its endogeneity. Though, this may or may not be true when considering the effect of a spouse's self-assessed health on the other spouse's labor supply (Siegel, 2006, p. 587). ${ }^{102}$ Furthermore, the work-limit measure may also suffer from an "error-in-variables" problem. The work-limit measure is more of a proxy for an individual's capacity to work than it is a proxy for one's overall physically functioning status. Hence, it would be a reasonable measure for estimating the effect of a spouse's ill health on a partner's labor supply through its effect on unearned income (Siegel, 2006). However, we include a measure for the spouse's employment income thereby holding household income constant. So, the work-limit measure may not be appropriate for measuring the effects of ill health attributable to that spouse's need for health care at home, or through the individual's preference for spending time together (Siegel, 2006, p. 585).

\footnotetext{
${ }^{102}$ To summarize, endogeneity is a concern when the measures for one's own (spouse's) health are also functions of one's (spouse's) income or other economic variables tied to employment decisions. The extent to which the measure of health is not correlated with the willingness or capacity to care for themselves will determine the degree of measurement error that is likely to result. Estimates on the indicator for a worklimiting condition may reflect more than just the individual's capacity for productive activity but also their desire to participate in the workforce or their preference to be labeled as 'work- limited' - whether "justified" by legal or social reasons; see chapter one for this discussion. Self-assessed health may be plagued by similar "justification" bias. Also, see chapter 1 for the discussion of the "error-in-variables" problem.
} 
The objective index used in this study which was not in Siegel's analysis arguably better captures a spouse's "overall" state of health. PCS is a continuous index constructed using principal component analysis on a series of questions designed for the specific purpose of comparing relative health status across the population. By construction, the use of the PCS eliminates concerns over subjectivity and measurement error. It can be viewed as a global measure of health status with greater "comparability" across individuals regarding the severity of the present conditions. ${ }^{103}$ In order to provide a meaningful interpretation of the estimates for an index, I observe each individual's deviation from the PCS sample mean relative to the overall standard deviation (or " $\mathrm{z}$ score") instead of the nominal value of the index. Thus, we interpret the coefficient on the z-score of spousal PCS to represent the marginal impact of one positive standard deviation from the sample's mean level of health on the spouse's labor supply decisions, holding all else constant.

Dwyer and Mitchell (1999) use the four measures found in Siegel (2006) - self assessed health status, work-limit, the health conditions index, and the functional limitations index - and find no evidence to suggest that they are endogenous in labor supply models nor correlated with compensation variables. They do, however, find evidence for measurement error on the objective indicators for health, but, as Siegel points out, this is probably because when the more objective health measures are used in models of own labor supply they will suffer from an "error-in-variables" problem since they are likely to measure health status rather than work capacity. Dwyer and Mitchell (1999) also find that self-rated health and work-limiting conditions are not substitutes in

\footnotetext{
${ }^{103}$ Chapter one, section 3, also discusses the advantages of constructed health indices and presents references regarding the validity and construction of PCS.
} 
models of labor force participation, but complements. The former measures disease while the latter measures functional status. Thus, they can both be included in the same model to test the effects of disease versus functional status. Likewise, the two more objective summary measures that can be treated in a similar manner.

The first two models that will be reported for both labor force participation and hours of work will include the two more subjective measures and the two more objective measures, respectively, thereby estimating the impact of the spouse's health condition on labor supply holding his or her functional status constant, or vice versa. To be thorough, four separate models for each of the four measures were also estimated and will be reported in the Appendix.

Siegel (2006) argues that, a priori, the physical function index is the most preferred health measure for estimating the effect of the spouse's health on the need for the other spouse's care or preference for spending time together since it is less likely to be endogenous than the subjective ones and it is "measured sufficiently finely" to avoid measurement error. ${ }^{104}$ This author argues, however, that PCS may also be a suitable measure for such effects. It is both objective and less likely to be plagued by measurement error to the extent that it is used as a tool for the comparison of the overall physical health across a given sample of individuals and not to proxy for only specific dimensions of health status. It is equally correlated with both objective indices (therefore accounting for disease and functioning), and, by construction, accounts for all morbidities and their severity across individuals (e.g. it will account for morbidities not specifically defined by the summary indices, and, a person who cannot bend or stoop and has or has

\footnotetext{
${ }^{104}$ My physical functioning index has a smaller range than Siegel's physical functioning index - it sums over only eight functional limitations while her index sums over 16 limitations.
} 
had cancer will tend to score differently than a person who cannot grasp and has or has had hypertension). Hence, the third model reported is one in which only PCS ("zzscored") will be included, since it may be regarded as a comprehensive health measure which reflects the severities of both disease and functional status when comparing individuals in a sample.

\section{Descriptive Statistics}

Table 2a presents the mean values of spouse's health measures for women and men. Table $2 \mathrm{~b}$ presents the mean values of own-health measures for women and men. A comparison of Tables $2 \mathrm{a}$ and $2 \mathrm{~b}$ shows that women's spouses tend to be less healthy than men's spouses while women, themselves, tend to be less healthy than men. For instance, nearly ten percent of the spouses of women and seven percent of the spouses of men report a work-limiting health condition (Table 2a) while nearly ten percent of women, themselves, and seven percent of men report a work-limiting condition (Table 2b). A slightly greater percentage of men's spouses report being in Excellent or Very good health ( $57 \%$ compared to $52 \%$ for women's spouses) and a smaller percentage report Fair or Poor health (13\% compared to $17 \%)$. The contrast is not as great when we compare men and women's own self-reported health status. Women's spouses, and women themselves, also report a greater number of health conditions and physical limitations than do men's spouses, and men themselves. A comparison of spouses' PCS and ownPCS between men and women show a similar pattern.

While these results may seem somewhat counterintuitive, they are probably due to the age restriction (50-61 years old) placed on the sample of individuals while no 
Table 2a. Means of spouses' health variables (standard errors)

\begin{tabular}{|c|c|c|c|c|c|c|c|}
\hline Variable & $\begin{array}{c}\text { Total } \\
\text { (8267) }\end{array}$ & $\begin{array}{c}\text { Women } \\
(3877)\end{array}$ & $\begin{array}{c}\text { Women } \\
\text { Employed } \\
(2120)\end{array}$ & $\begin{array}{c}\text { Women Non- } \\
\text { Employed } \\
(1757)\end{array}$ & $\begin{array}{c}\text { Men } \\
(4390) \\
\end{array}$ & $\begin{array}{c}\text { Men } \\
\text { Employed } \\
(2831)\end{array}$ & $\begin{array}{c}\text { Men Non- } \\
\text { Employed } \\
(1559) \\
\end{array}$ \\
\hline \multirow[t]{2}{*}{ Spouse Work-limit } & 0.084 & 0.097 & 0.088 & 0.110 & 0.072 & 0.069 & 0.079 \\
\hline & $(0.003)$ & $(0.005)$ & $(0.006)$ & $(0.008)$ & $(0.004)$ & $(0.006)$ & $(0.007)$ \\
\hline \multirow[t]{2}{*}{ Spouse Excellent } & 0.211 & 0.205 & 0.218 & 0.185 & 0.217 & 0.211 & 0.228 \\
\hline & $(0.006)$ & $(0.007)$ & $(0.010)$ & $(0.011)$ & $(0.008)$ & $(0.009)$ & $(0.014)$ \\
\hline \multirow[t]{2}{*}{ Spouse Very Good } & 0.336 & 0.318 & 0.319 & 0.316 & 0.351 & 0.362 & 0.330 \\
\hline & $(0.007)$ & $(0.009)$ & $(0.013)$ & $(0.014)$ & $(0.009)$ & $(0.012)$ & $(0.014)$ \\
\hline \multirow[t]{2}{*}{ Spouse Good } & 0.303 & 0.309 & 0.315 & 0.300 & 0.298 & 0.301 & 0.292 \\
\hline & $(0.007)$ & $(0.009)$ & $(0.012)$ & $(0.013)$ & $(0.009)$ & $(0.010)$ & $(0.015)$ \\
\hline \multirow[t]{2}{*}{ Spouse Fair } & 0.110 & 0.119 & 0.107 & 0.137 & 0.101 & 0.095 & 0.115 \\
\hline & $(0.004)$ & $(0.006)$ & $(0.007)$ & $(0.010)$ & $(0.006)$ & $(0.007)$ & $(0.009)$ \\
\hline \multirow[t]{2}{*}{ Spouse Poor } & 0.040 & 0.049 & 0.040 & 0.061 & 0.032 & 0.031 & 0.035 \\
\hline & $(0.003)$ & $(0.004)$ & $(0.005)$ & $(0.006)$ & $(0.003)$ & $(0.004)$ & $(0.005)$ \\
\hline \multirow[t]{2}{*}{ Spouse \# of Conditions } & 0.925 & 1.024 & 0.980 & 1.086 & 0.841 & 0.828 & 0.865 \\
\hline & $(0.014)$ & $(0.019)$ & $(0.027)$ & $(0.033)$ & $(0.017)$ & $(0.020)$ & $(0.032)$ \\
\hline \multirow[t]{2}{*}{ Spouse \# of Func. Limits } & 0.607 & 0.630 & 0.547 & 0.746 & 0.588 & 0.543 & 0.673 \\
\hline & $(0.021)$ & $(0.031)$ & $(0.038)$ & $(0.053)$ & $(0.028)$ & $(0.037)$ & $(0.051)$ \\
\hline \multirow[t]{2}{*}{ Spouse PCS* } & 47.975 & 47.678 & 48.214 & 46.952 & 48.231 & 48.604 & 47.510 \\
\hline & $(0.163)$ & $(0.208)$ & $(0.265)$ & $(0.344)$ & $(0.191)$ & $(0.235)$ & $(0.367)$ \\
\hline
\end{tabular}

* Minimum Spouse PCS reported in sample for women $=4.56 ;$ Max $=69.83$

Minimum Spouse PCS reported in sample for $\operatorname{men}=6.08$; $\operatorname{Max}=67.14$. 
Table 2b. Means of own-health variables (standard errors)

\begin{tabular}{|c|c|c|c|c|c|c|c|}
\hline Variable & $\begin{array}{c}\text { Total } \\
\text { (8267) }\end{array}$ & $\begin{array}{c}\text { Women } \\
\text { (3877) }\end{array}$ & $\begin{array}{c}\text { Women } \\
\text { Employed } \\
(2120)\end{array}$ & $\begin{array}{c}\text { Women Non- } \\
\text { Employed } \\
(1757)\end{array}$ & $\begin{array}{c}\text { Men } \\
(4390)\end{array}$ & $\begin{array}{c}\text { Men } \\
\text { Employed } \\
\text { (2831) }\end{array}$ & $\begin{array}{c}\text { Men Non- } \\
\text { Employed } \\
(1559)\end{array}$ \\
\hline Work-limit & $\begin{array}{c}0.083 \\
(0.004)\end{array}$ & $\begin{array}{c}0.092 \\
(0.006)\end{array}$ & $\begin{array}{c}0.022 \\
(0.004)\end{array}$ & $\begin{array}{c}0.190 \\
(0.012)\end{array}$ & $\begin{array}{c}0.075 \\
(0.004)\end{array}$ & $\begin{array}{c}0.016 \\
(0.002)\end{array}$ & $\begin{array}{c}0.188 \\
(0.010)\end{array}$ \\
\hline Excellent & $\begin{array}{c}0.212 \\
(0.006)\end{array}$ & $\begin{array}{c}0.202 \\
(0.008)\end{array}$ & $\begin{array}{c}0.232 \\
(0.011)\end{array}$ & $\begin{array}{c}0.160 \\
(0.012)\end{array}$ & $\begin{array}{c}0.220 \\
(0.007)\end{array}$ & $\begin{array}{c}0.234 \\
(0.009)\end{array}$ & $\begin{array}{c}0.192 \\
(0.011)\end{array}$ \\
\hline Very Good & $\begin{array}{c}0.334 \\
(0.008)\end{array}$ & $\begin{array}{c}0.338 \\
(0.011)\end{array}$ & $\begin{array}{c}0.371 \\
(0.013)\end{array}$ & $\begin{array}{c}0.291 \\
(0.016)\end{array}$ & $\begin{array}{c}0.331 \\
(0.008)\end{array}$ & $\begin{array}{c}0.352 \\
(0.011)\end{array}$ & $\begin{array}{c}0.290 \\
(0.012)\end{array}$ \\
\hline Good & $\begin{array}{c}0.308 \\
(0.007)\end{array}$ & $\begin{array}{c}0.307 \\
(0.009)\end{array}$ & $\begin{array}{c}0.314 \\
(0.013)\end{array}$ & $\begin{array}{c}0.299 \\
(0.014)\end{array}$ & $\begin{array}{c}0.309 \\
(0.008)\end{array}$ & $\begin{array}{c}0.324 \\
(0.010)\end{array}$ & $\begin{array}{c}0.279 \\
(0.013)\end{array}$ \\
\hline Fair & $\begin{array}{c}0.103 \\
(0.004)\end{array}$ & $\begin{array}{c}0.106 \\
(0.005)\end{array}$ & $\begin{array}{c}0.067 \\
(0.006)\end{array}$ & $\begin{array}{c}0.161 \\
(0.010)\end{array}$ & $\begin{array}{c}0.100 \\
(0.005)\end{array}$ & $\begin{array}{c}0.076 \\
(0.006)\end{array}$ & $\begin{array}{c}0.148 \\
(0.009)\end{array}$ \\
\hline Poor & $\begin{array}{c}0.042 \\
(0.003)\end{array}$ & $\begin{array}{c}0.045 \\
(0.004)\end{array}$ & $\begin{array}{c}0.016 \\
(0.003)\end{array}$ & $\begin{array}{c}0.087 \\
(0.008)\end{array}$ & $\begin{array}{c}0.040 \\
(0.003)\end{array}$ & $\begin{array}{c}0.014 \\
(0.003)\end{array}$ & $\begin{array}{c}0.089 \\
(0.008)\end{array}$ \\
\hline \# of Conditions & $\begin{array}{c}0.910 \\
(0.014)\end{array}$ & $\begin{array}{c}0.942 \\
(0.022)\end{array}$ & $\begin{array}{c}0.784 \\
(0.026)\end{array}$ & $\begin{array}{c}1.163 \\
(0.034)\end{array}$ & $\begin{array}{c}0.884 \\
(0.016)\end{array}$ & $\begin{array}{c}0.777 \\
(0.020)\end{array}$ & $\begin{array}{c}1.090 \\
(0.034)\end{array}$ \\
\hline \# of Func. Limits & $\begin{array}{c}0.589 \\
(0.021)\end{array}$ & $\begin{array}{c}0.721 \\
(0.035)\end{array}$ & $\begin{array}{c}0.339 \\
(0.030)\end{array}$ & $\begin{array}{c}1.256 \\
(0.075)\end{array}$ & $\begin{array}{c}0.476 \\
(0.024)\end{array}$ & $\begin{array}{c}0.199 \\
(0.020)\end{array}$ & $\begin{array}{c}1.011 \\
(0.062)\end{array}$ \\
\hline $\mathrm{PCS}^{* *}$ & $\begin{array}{l}48.149 \\
(0.150)\end{array}$ & $\begin{array}{l}47.515 \\
(0.218)\end{array}$ & $\begin{array}{l}49.879 \\
(0.245)\end{array}$ & $\begin{array}{l}44.314 \\
(0.442)\end{array}$ & $\begin{array}{l}48.696 \\
(0.181)\end{array}$ & $\begin{array}{l}50.422 \\
(0.187)\end{array}$ & $\begin{array}{l}45.362 \\
(0.388)\end{array}$ \\
\hline PCS observations & 7355 & 3450 & 1867 & 1583 & 3905 & 2516 & 1389 \\
\hline
\end{tabular}

** Minimum PCS reported in sample for women $=6.08 ; \operatorname{Max}=67.14$.

Minimum PCS reported in sample for $\operatorname{men}=4.56 ; \operatorname{Max}=66.42$. 
restrictions were placed on their spouse's age. Since women tend to marry older men and men tend to experience serious illnesses and disabilities at younger ages than women, older women will be more likely to witness the declining health of their spouses than older men (Simonsick, 1993; Siegel, 2006). Moreover, some studies have found that controlling for age, older women are more likely to report significantly poorer health than men (Ross and Bird, 1994), greater disability and somewhat greater use of personal assistance (Penning and Strain, 1994), and more acute and chronic health conditions (Verbrugge, 1984). The means of the non-health variables used throughout this study can be found in Table A1 in the Appendix. One comparison of note in the table is that the average age of a spouse is 57 for women and 52 for men.

Table 2a also shows that husbands and wives of non-employed individuals are more likely to be in poorer health than those of employed individuals. This relationship is also exhibited in Table 3, which shows the means for own-health conditional on spouses' employment status. Alternatively, it can be seen from Table 4 that healthier individuals are more likely to be employed themselves and to have employed spouses. These comparisons suggest that a spouse's poor health may be associated with a reduction in the individual's labor force participation for both men and women. However, it is likely that the health of a husband and wife within a given household are correlated. ${ }^{105}$ Thus, a multivariate analysis is needed to control for the health of the individual in order to distinguish between the direct effect of the spouse's health on the other's desire to work and the effect of own health (which may be correlated with a

\footnotetext{
${ }^{105}$ Estimated correlation between spouses' health measures: Work-limit $=0.20$; Excellent $=0.38$; Very Good $=0.33$; Good $=0.27$; Fair/Poor $=0.31$; No. of Conditions $=0.184$; No. of Function limits $=0.14$; PCS (and $\mathrm{z}$-score $)=0.26$.
} 
spouse's health) on the individual's capacity to work. ${ }^{106}$ The strengths of the two effects may differ between older men and women.

Table 3. Means of own-health variables by spouse's employment status (standard errors)

\begin{tabular}{|c|c|c|c|c|}
\hline \multirow[b]{2}{*}{ Health measures } & \multicolumn{2}{|c|}{ Women } & \multicolumn{2}{|c|}{ Men } \\
\hline & $\begin{array}{c}\text { Spouse } \\
\text { Employed } \\
(2593)\end{array}$ & $\begin{array}{c}\text { Spouse } \\
\text { Non-Emp. } \\
(1284)\end{array}$ & $\begin{array}{c}\text { Spouse } \\
\text { Employed } \\
(2796)\end{array}$ & $\begin{array}{c}\text { Spouse } \\
\text { Non-Emp. } \\
(1594)\end{array}$ \\
\hline Excellent & $\begin{array}{c}0.212 \\
(0.011)\end{array}$ & $\begin{array}{c}0.178 \\
(0.013)\end{array}$ & $\begin{array}{c}0.226 \\
(0.009)\end{array}$ & $\begin{array}{c}0.208 \\
(0.012)\end{array}$ \\
\hline Very Good & $\begin{array}{c}0.359 \\
(0.013)\end{array}$ & $\begin{array}{c}0.289 \\
(0.016)\end{array}$ & $\begin{array}{c}0.331 \\
(0.010)\end{array}$ & $\begin{array}{c}0.330 \\
(0.014)\end{array}$ \\
\hline Good & $\begin{array}{c}0.299 \\
(0.011)\end{array}$ & $\begin{array}{c}0.328 \\
(0.017)\end{array}$ & $\begin{array}{c}0.314 \\
(0.010)\end{array}$ & $\begin{array}{c}0.297 \\
(0.014)\end{array}$ \\
\hline Fair & $\begin{array}{c}0.095 \\
(0.006)\end{array}$ & $\begin{array}{c}0.132 \\
(0.010)\end{array}$ & $\begin{array}{c}0.097 \\
(0.006)\end{array}$ & $\begin{array}{c}0.107 \\
(0.010)\end{array}$ \\
\hline Poor & $\begin{array}{c}0.035 \\
(0.004)\end{array}$ & $\begin{array}{c}0.070 \\
(0.008)\end{array}$ & $\begin{array}{c}0.031 \\
(0.003)\end{array}$ & $\begin{array}{c}0.058 \\
(0.006)\end{array}$ \\
\hline Work-limit & $\begin{array}{c}0.078 \\
(0.006)\end{array}$ & $\begin{array}{c}0.125 \\
(0.012)\end{array}$ & $\begin{array}{c}0.069 \\
(0.005)\end{array}$ & $\begin{array}{c}0.087 \\
(0.008)\end{array}$ \\
\hline \# of Conditions & $\begin{array}{c}0.911 \\
(0.026)\end{array}$ & $\begin{array}{c}1.014 \\
(0.035)\end{array}$ & $\begin{array}{c}0.863 \\
(0.021)\end{array}$ & $\begin{array}{c}0.927 \\
(0.030)\end{array}$ \\
\hline \# of Functional Limitations & $\begin{array}{c}0.647 \\
(0.042)\end{array}$ & $\begin{array}{c}0.895 \\
(0.066)\end{array}$ & $\begin{array}{c}0.442 \\
(0.029)\end{array}$ & $\begin{array}{c}0.547 \\
(0.044)\end{array}$ \\
\hline PCS & $\begin{array}{c}48.193 \\
0.236\end{array}$ & $\begin{array}{c}45.952 \\
0.409\end{array}$ & $\begin{array}{c}48.991 \\
0.222\end{array}$ & $\begin{array}{c}48.101 \\
0.346\end{array}$ \\
\hline
\end{tabular}

\footnotetext{
${ }^{106}$ Additionally, although each of the health measures tend to be strongly correlated with the other health measures, they are not perfectly correlated. For instance, only $68 \%$ of women in poor health report a worklimiting condition and $33 \%$ of women who report a work-limiting condition report that they are in poor health (not reported). Each measure may capture some dimension of health unique to the other measures. Therefore, the models which incorporate two subjective measures and two more objective measures may prove more valuable than the PCS index to the extent that we can distinguish between the direct effects of the need for health maintenance - the Self-assessed measure and conditions index - or the direct effects of limitations to physical functioning - the work-limit indicator and the functional limitations index - holding the other constant.
} 
Table 4. Employment status by subjective own-health measures* (standard errors)

\begin{tabular}{|c|c|c|c|c|c|c|}
\hline \multirow[b]{2}{*}{ Status } & \multicolumn{6}{|c|}{ Women } \\
\hline & $\begin{array}{c}\text { Excellent } \\
\text { (682) }\end{array}$ & $\begin{array}{c}\text { Very } \\
\text { Good } \\
(1220)\end{array}$ & $\begin{array}{c}\text { Good } \\
(1223) \\
\end{array}$ & $\begin{array}{l}\text { Fair } \\
(538) \\
\end{array}$ & $\begin{array}{l}\text { Poor } \\
\text { (207) } \\
\end{array}$ & $\begin{array}{c}\text { Work-limit } \\
(414)\end{array}$ \\
\hline Employed & $\begin{array}{c}0.781 \\
(0.018)\end{array}$ & $\begin{array}{c}0.732 \\
(0.016)\end{array}$ & $\begin{array}{c}0.661 \\
(0.016)\end{array}$ & $\begin{array}{c}0.422 \\
(0.027)\end{array}$ & $\begin{array}{c}0.264 \\
(0.039)\end{array}$ & $\begin{array}{c}0.201 \\
(0.027)\end{array}$ \\
\hline Spouse Employed & $\begin{array}{c}0.736 \\
(0.019)\end{array}$ & $\begin{array}{c}0.744 \\
(0.015)\end{array}$ & $\begin{array}{c}0.68 \\
(0.016)\end{array}$ & $\begin{array}{c}0.627 \\
(0.026)\end{array}$ & $\begin{array}{c}0.54 \\
(0.040)\end{array}$ & $\begin{array}{c}0.594 \\
(0.030)\end{array}$ \\
\hline & \multicolumn{6}{|c|}{ Men } \\
\hline Status & $\begin{array}{c}\text { Excellent } \\
\text { (868) }\end{array}$ & $\begin{array}{c}\text { Very } \\
\text { Good } \\
(1367) \\
\end{array}$ & $\begin{array}{c}\text { Good } \\
(1410) \\
\end{array}$ & $\begin{array}{c}\text { Fair } \\
(526) \\
\end{array}$ & $\begin{array}{l}\text { Poor } \\
(215) \\
\end{array}$ & $\begin{array}{l}\text { Work } \\
\text { Limit } \\
(395) \\
\end{array}$ \\
\hline Employed & $\begin{array}{c}0.911 \\
(0.011)\end{array}$ & $\begin{array}{c}0.891 \\
(0.009)\end{array}$ & $\begin{array}{c}0.846 \\
(0.011)\end{array}$ & $\begin{array}{c}0.616 \\
(0.025)\end{array}$ & $\begin{array}{c}0.294 \\
(0.039)\end{array}$ & $\begin{array}{c}0.196 \\
(0.023)\end{array}$ \\
\hline Spouse Employed & $\begin{array}{c}0.696 \\
(0.017)\end{array}$ & $\begin{array}{c}0.679 \\
(0.015)\end{array}$ & $\begin{array}{c}0.69 \\
(0.015)\end{array}$ & $\begin{array}{c}0.657 \\
(0.028)\end{array}$ & $\begin{array}{c}0.525 \\
(0.039)\end{array}$ & $\begin{array}{c}0.682 \\
(0.029)\end{array}$ \\
\hline
\end{tabular}

\footnotetext{
* The means of employment status were only calculated conditional on the subjective health measures since these were categorical and the objective health measures were ordinal or continuous.
}

From Table A1 we see that women and men are on average 55 years old with no significant difference in age between those who work and those who do not. There is no significant difference in years of schooling between men and women and only a slightly lower average number of years for those who are non-employed. Women have significantly larger unearned incomes compared to men, and husbands' earnings account for a much larger percentage of women's total unearned income than does wives' earnings. Fifty-four percent of women are employed compared to 64.5 percent of men while 70 percent of their husbands are employed compared to 67 percent of wives. Both husbands and wives are more likely to be employed when the other spouse is also employed which likely explains why spouse's earnings account for a larger share of their 
total unearned income. ${ }^{107}$ Women who are employed work on average about 37 hours per week at a wage of $\$ 16.88$ per hour compared to 43.5 hours per week at $\$ 22.82$ per hour by men. Thus, as compared with older men, older women who are employed are less likely to hold full-time wage employment. The average tenure of a woman at her current job is 2.5 years less than that of men - 11 years compared to 13.5 years - and 74 percent of working men hold employer provided health insurance through their current job compared to only 53 percent of women. The bottom of Table A1 presents the means of the variables used to instrument for spouses' earnings. Seventy-seven percent of wives and 55 percent of husbands hold white-collar jobs, where approximately 12 percent of wives and 10 percent of husbands work in a sales industry, and a majority of both wives and husbands are employed by firms with less than 100 employees and more than one location. $^{108}$

\section{Regression Results}

The following subsections present the results of the regressions for the labor force participation by older women and men and for the hours of work by older women and men who are employed, respectively. Each subsection is divided into two parts. The first part discusses the estimates of the impact of spouses' health on their partners' reservation wage and concludes with a brief discussion regarding the other covariates in the model.

\footnotetext{
${ }^{107}$ Siegel (2006, p. 588) also notes this relationship in her discussion of the means.

108 The proportions of husbands working at small, mid-size, and large firms differ drastically from those found by Siegel. However, MEPS provides, and I include, the indicator for whether there is more than one location of the firm. The number of employees of the firm reported here may pertain to the number of employees at a particular location while, Siegel, using HRS (1992) data, may have a somewhat different construction for her variables.
} 
The second part discusses the extent to which asymmetry is exhibited between husbands and wives regarding this relationship.

The table in the body of each subsection has been limited to the presentation of the marginal effects of the spouses' health and the individuals' own health on the respective outcomes. Both tables juxtapose the results from the three models discussed in section 6 above. The first model models spouses' health and own health using the two more subjective measures - work limit and self-assessed health - the second, models health using the two more objective measures - the Health Conditions index and Functional Limitation index - and the third, models health using the z-score of the PCS. In order to facilitate a comparison of the findings across the three specifications of health above another table presents the results from regressions on four additional combinations of the five health measures. Estimates for the marginal effects of the remaining (nonhealth) variables and all other regressions highlighted in the section below are located in the Appendix. The results for the regressions which were used to predict the women and men's wages can also be found in the Appendix. All tables present the results with and without instrumenting for spouses' earnings. For the purposes of this section, all marginal effects are deemed "statistically insignificant" if they do not surpass the threshold of 10 percent level of significance using a two-sided t-test.

\subsection{Labor Force Participation}

I use the two variants of the Hausman test discussed in section 5.1 to test whether spouses' earnings are endogenous to their partner's labor force participation decision. I could not reject the hypothesis that husband's earnings are exogenous to women's labor 
force participation, across all specifications for health (Prob $>$ F ranged from 0.56 to 0.99 ).

On the other hand, the tests do reject this hypothesis for wives' earnings across all specifications for health (Prob $>\mathrm{F}$ ranged from 0.01 to 0.03 ). ${ }^{109}$ However, the results below are robust to whether the husband or wife's earnings are instrumented. ${ }^{110}$

The results in Table 5 indicate that a spouse's ill-health is estimated to lead to an increase in both older men and women's probabilities of employment when measured by an indicator for a work-limitation, the Health Conditions index, and the z-score of PCS. The effect associated with a spouse's movement from excellent to good or from excellent to fair/poor health is only statistically significant for males (at the 5 percent level). The same results are obtained when each of the four subjective and objective measures for health are included in the model alone (Table A2).

One noteworthy result is that my estimates contrast with Siegel's (2006) earlier results for women and their husbands. Siegel finds that of the subjective and objective measures (models 1 and 2 in Table 5) only the estimates on the index for functional limitations are statistically significant, whereas this study finds that, for women, the spouse's index for functional limitations is found to be statistically insignificant while the work-limit indicator and health conditions index are statistically significant at the 1

\footnotetext{
109 The exogeneity of husband's earnings agrees with Siegel's earlier findings for women but she did not assess the relationship between men and their wives.

110 A Two Staged Probit Regression (P2SLS) was used to instrument for spouses' earnings, robust standard errors are obtained using the survey procedures provided in STATA 10. Asymptotically correct standard errors for the P2SLS were not calculated, instead I rely on the following passage from Bollen, Guilkey, and Mroz (1995), page 115: "The Monte Carlo results of Guilkey, Mroz, and Taylor (1992) show that the asymptotically correct standard errors are no more effective in large finite samples than the conditional standard errors, which do not take into account the estimation error in the right-hand-side predicted variables. Thus, to date, the Monte Carlo evidence does not reveal any gain in calculating the more complex adjusted standard errors."
} 
Table 5. Estimates of women and men's labor force participation as a function of spouse's health measures with and without instrumenting for spouse's earnings

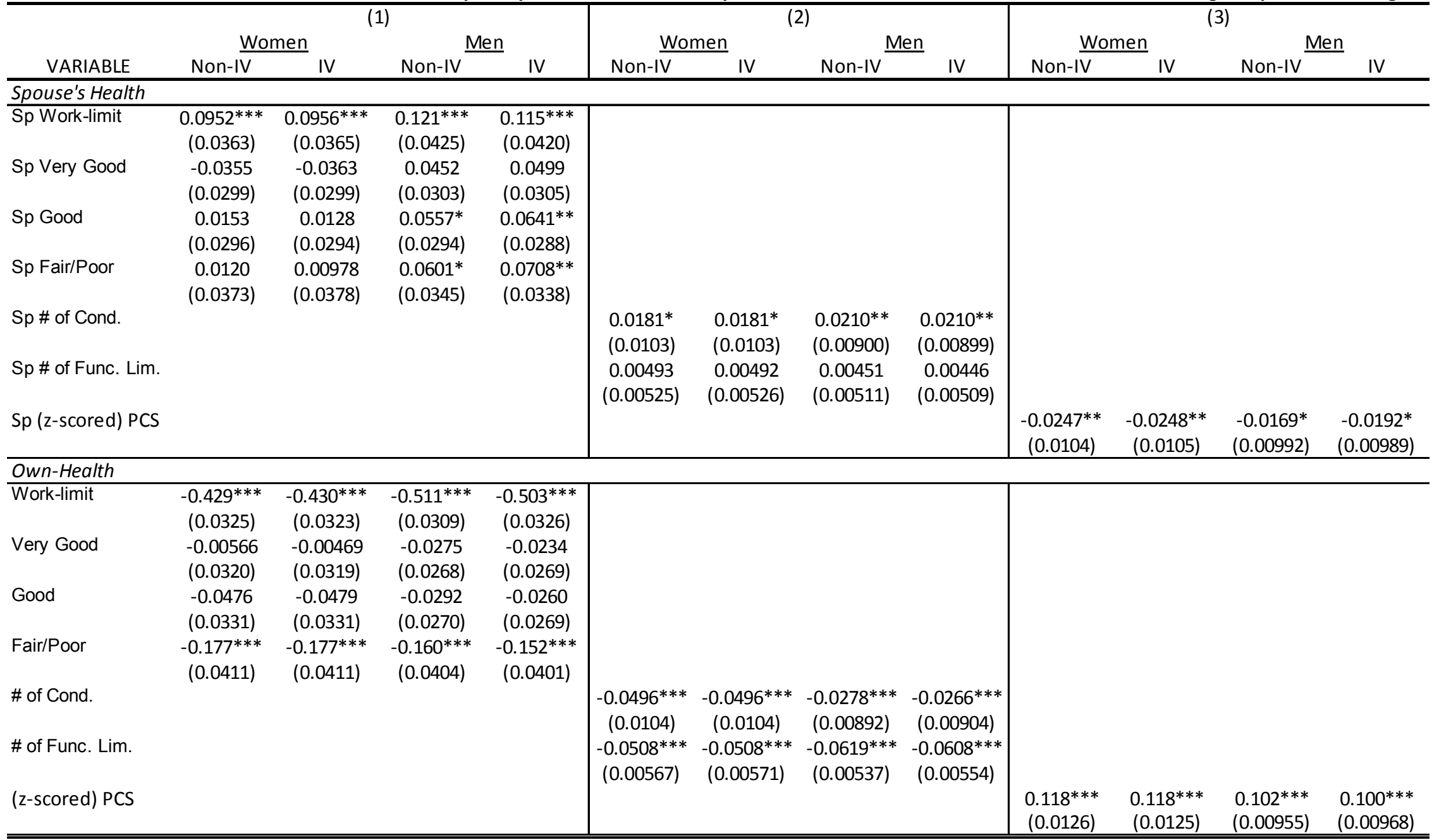

Note: Standard errors in parentheses; all tests are two-sided against the null hypothesis that the marginal effect is $=0 ;{ }^{* * *} p<0.01,{ }^{* *} p<0.05,{ }^{*} p<0.1$

Note: Probit regressions with robust standard errors, using MEPS Panels 5 through 7. Marginal Effects of the probit regression are reported - the coefficients are normalized to represent the derivative of the probability of employment with respect to a change in the explanatory variable. 
percent and 10 percent levels, respectively. ${ }^{111}$ Nonetheless, taken as a whole, the results reflect the importance of using a variety of health measures to assess the "range of importance" of a spouse's health on an older individual's labor supply.

Turning our attention to the coefficients on the indicator for a work-limiting condition in model 1 of Table 5, models 5, 6, and 7 in Table 6 below, and in Table A2, the impact of a spouse's work-limiting condition increases the probability of labor-force participation of women and men somewhere between 9.5 and 13 percentage points depending on the specification for health in the model. This result holds whether the indicator is included individually (Table A2), jointly with self-assessed health (model 1), or jointly with all other variables in the model (models 5, 6, and 7). Our models control for an individual's unearned income, including the spouse's earnings, thereby holding the effect of the spouse's ill-health on the family income constant. Therefore, it is unlikely that a decrease in earnings due to a spouse's functional limitations to work is driving the increase in the probability of the other spouse's employment (Siegel, 2006). Thus, it is more likely that the presence of a limitation to work by a spouse increases a partner's propensity for employment by decreasing the partner's reservation wage.

A priori, the subjective 'work-limit' measure captures functional status. However the regression results conflict with estimates on the more objective measures in which the index for functional status is statistically insignificant (model 2 and Table A2). It may be the case that, rather than functioning as a proxy for overall functional status, the worklimit indicator may suffer from an "error-in-variables" problem, as discussed earlier. To

\footnotetext{
${ }^{111}$ Note, however, that Siegel's physical functioning index has a range of $[0,16]$ while mine has a range of $[0,8]$. This may result in the measurement error on this index which Siegel claims is less likely to be present given that her index is measured "sufficiently finely".
} 
Table 6. Estimates of women and men's labor force participation as a function of spouse's health measures with and without instrumenting for spouse's earnings

\begin{tabular}{|c|c|c|c|c|c|c|c|c|c|c|c|c|c|c|c|c|}
\hline \multirow[b]{3}{*}{ VARIABLE } & \multicolumn{4}{|c|}{ (4) } & \multicolumn{4}{|c|}{ (5) } & \multicolumn{4}{|c|}{ (6) } & \multicolumn{4}{|c|}{ (7) } \\
\hline & \multicolumn{2}{|c|}{ Women } & \multicolumn{2}{|c|}{ Men } & \multicolumn{2}{|c|}{ Women } & \multicolumn{2}{|c|}{ Men } & \multicolumn{2}{|c|}{ Women } & \multicolumn{2}{|c|}{ Men } & \multicolumn{2}{|c|}{ Women } & \multicolumn{2}{|c|}{ Men } \\
\hline & Non-IV & IV & Non-IV & IV & Non-IV & IV & Non-IV & IV & Non-IV & IV & Non-IV & IV & Non-IV & IV & Non-IV & IV \\
\hline \multicolumn{17}{|l|}{ Spouse's Health } \\
\hline Sp Work-limit & & & & & $\begin{array}{c}0.104^{* * *} \\
(0.0400)\end{array}$ & $\begin{array}{c}0.106^{* * *} \\
(0.0400)\end{array}$ & $\begin{array}{l}0.124^{* * *} \\
(0.0435)\end{array}$ & $\begin{array}{c}0.119 * * * \\
(0.0427)\end{array}$ & $\begin{array}{c}0.124^{* *} \\
(0.0483)\end{array}$ & $\begin{array}{c}0.124^{* *} \\
(0.0484)\end{array}$ & $\begin{array}{c}0.119^{* *} \\
(0.0522)\end{array}$ & $\begin{array}{l}0.115^{* *} \\
(0.0516)\end{array}$ & $\begin{array}{l}0.118^{* *} \\
(0.0465)\end{array}$ & $\begin{array}{l}0.118^{* *} \\
(0.0465)\end{array}$ & $\begin{array}{c}0.130^{* *} \\
(0.0517)\end{array}$ & $\begin{array}{l}0.125^{* *} \\
(0.0514)\end{array}$ \\
\hline \multirow{2}{*}{ Sp Very Good } & & & & & & & & & -0.0471 & -0.0477 & $0.0535^{*}$ & $0.0546^{*}$ & -0.0416 & -0.0425 & 0.0426 & 0.0476 \\
\hline & & & & & & & & & $(0.0298)$ & $(0.0297)$ & $(0.0298)$ & (0.0299) & $(0.0296)$ & $(0.0296)$ & (0.0302) & (0.0305) \\
\hline \multirow[t]{2}{*}{ Sp Good } & & & & & & & & & -0.00397 & -0.00649 & $0.0555^{*}$ & $0.0598 * *$ & 0.00233 & -0.000326 & $0.0491^{*}$ & $0.0580^{* *}$ \\
\hline & & & & & & & & & $(0.0318)$ & $(0.0310)$ & $(0.0305)$ & $(0.0302)$ & $(0.0296)$ & $(0.0293)$ & $(0.0294)$ & $(0.0289)$ \\
\hline \multirow[t]{2}{*}{ Sp Fair/Poor } & & & & & & & & & -0.00283 & -0.00492 & 0.0513 & 0.0565 & -0.00788 & -0.0107 & 0.0505 & $0.0623^{*}$ \\
\hline & & & & & & & & & $(0.0460)$ & $(0.0460)$ & $(0.0420)$ & $(0.0414)$ & $(0.0400)$ & $(0.0405)$ & (0.0347) & (0.0341) \\
\hline \multirow[t]{2}{*}{$\mathrm{Sp} \#$ of Cond. } & 0.0162 & 0.0163 & $0.0221^{* *}$ & $0.0212^{* *}$ & & & & & 0.0122 & 0.0129 & $0.0195^{*}$ & $0.0184^{*}$ & 0.0145 & 0.0150 & 0.0163 & 0.0153 \\
\hline & $(0.0111)$ & (0.0111) & $(0.00952)$ & $(0.00953)$ & & & & & $(0.0118)$ & $(0.0117)$ & $(0.0104)$ & $(0.0104)$ & (0.0111) & $(0.0111)$ & $(0.00993)$ & (0.00996) \\
\hline \multirow[t]{2}{*}{ Sp \# of Func. Lim. } & 0.00296 & 0.00302 & 0.00692 & 0.00634 & & & & & -0.00801 & -0.00764 & 0.000676 & 0.000373 & -0.00667 & -0.00661 & -0.00493 & -0.00515 \\
\hline & $(0.00641)$ & $(0.00637)$ & $(0.00595)$ & $(0.00593)$ & & & & & $(0.00783)$ & (0.00782) & (0.00696) & $(0.00698)$ & $(0.00694)$ & (0.00694) & $(0.00667)$ & $(0.00670)$ \\
\hline \multirow[t]{2}{*}{ Sp (z-scored) PCS } & -0.0160 & -0.0157 & -0.00240 & -0.00542 & -0.0109 & -0.00942 & -0.00415 & -0.00683 & -0.00897 & -0.00747 & 0.00758 & 0.00550 & & & & \\
\hline & $(0.0133)$ & $(0.0134)$ & $(0.0120)$ & $(0.0119)$ & $(0.0125)$ & $(0.0126)$ & $(0.0113)$ & $(0.0111)$ & $(0.0144)$ & $(0.0144)$ & $(0.0135)$ & $(0.0135)$ & & & & \\
\hline \multicolumn{17}{|l|}{ Own-Health } \\
\hline \multirow[t]{2}{*}{ Work-limit } & & & & & $-0.446^{* * *}$ & $-0.447^{* * *}$ & $-0.523^{* * *}$ & $-0.518^{* * *}$ & $-0.430^{* * *}$ & $-0.430^{* * *}$ & $-0.488 * * *$ & $-0.484^{* * *}$ & $-0.396 * * *$ & $-0.397 * * *$ & $-0.484^{* * *}$ & $-0.476^{* * *}$ \\
\hline & & & & & $(0.0307)$ & $(0.0305)$ & $(0.0327)$ & $(0.0335)$ & (0.0399) & $(0.0401)$ & $(0.0438)$ & $(0.0442)$ & $(0.0419)$ & $(0.0416)$ & $(0.0416)$ & $(0.0427)$ \\
\hline \multirow[t]{2}{*}{ Very Good } & & & & & & & & & 0.0166 & 0.0174 & -0.0115 & -0.00741 & 0.00622 & 0.00717 & -0.0265 & -0.0225 \\
\hline & & & & & & & & & $(0.0320)$ & $(0.0319)$ & $(0.0267)$ & $(0.0267)$ & $(0.0316)$ & $(0.0315)$ & $(0.0266)$ & (0.0268) \\
\hline \multirow[t]{2}{*}{ Good } & & & & & & & & & 0.00855 & 0.00823 & -0.00768 & -0.00325 & -0.0243 & -0.0245 & -0.0282 & -0.0251 \\
\hline & & & & & & & & & $(0.0362)$ & $(0.0360)$ & $(0.0303)$ & $(0.0303)$ & $(0.0334)$ & $(0.0334)$ & $(0.0272)$ & $(0.0272)$ \\
\hline Fair/Poor & & & & & & & & & -0.0642 & -0.0638 & $-0.105^{* *}$ & $-0.0993^{* *}$ & $-0.132^{* * *}$ & $-0.131^{* * *}$ & $-0.150^{* * *}$ & $-0.143^{* * *}$ \\
\hline & & & & & & & & & $(0.0469)$ & $(0.0468)$ & $(0.0433)$ & $(0.0432)$ & $(0.0439)$ & $(0.0440)$ & $(0.0402)$ & (0.0398) \\
\hline \# of Cond. & $-0.0362^{* * *}$ & $-0.0362 * * *$ & $-0.0170^{*}$ & $-0.0159 *$ & & & & & $-0.0276^{* *}$ & $-0.0274^{* *}$ & 0.00282 & 0.00325 & $-0.0314 * * *$ & $-0.0314^{* * *}$ & 0.00247 & 0.00265 \\
\hline & (0.0119) & (0.0119) & $(0.00960)$ & $(0.00961)$ & & & & & $(0.0117)$ & $(0.0117)$ & $(0.0102)$ & $(0.0102)$ & $(0.0107)$ & $(0.0107)$ & $(0.00934)$ & $(0.00943)$ \\
\hline \# of Func. Lim. & $-0.0354^{* * *}$ & $-0.0355^{* * *}$ & $-0.0486^{* * *}$ & $-0.0481^{* * *}$ & & & & & 0.00429 & 0.00402 & -0.00797 & -0.00793 & -0.00712 & -0.00729 & -0.0118 & -0.0118 \\
\hline & $(0.00646)$ & $(0.00656)$ & $(0.00699)$ & $(0.00705)$ & & & & & $(0.00785)$ & $(0.00795)$ & $(0.00913)$ & $(0.00913)$ & $(0.00716)$ & $(0.00719)$ & $(0.00770)$ & $(0.00766)$ \\
\hline (z-scored) PCS & $0.0729 * * *$ & $0.0729 * * *$ & $0.0556 * * *$ & $0.0546^{* * *}$ & $0.0669 * * *$ & $0.0669 * * *$ & $0.0371 * * *$ & $0.0360 * * *$ & $0.0529 * * *$ & $0.0528^{* * *}$ & $0.0229 *$ & $0.0228^{*}$ & & & & \\
\hline & $(0.0150)$ & $(0.0150)$ & $(0.0114)$ & $(0.0113)$ & $(0.0133)$ & $(0.0134)$ & (0.0119) & $(0.0117)$ & $(0.0149)$ & $(0.0149)$ & $(0.0135)$ & $(0.0135)$ & & & & \\
\hline
\end{tabular}

Note: Probit regressions with robust standard errors, using MEPS Panels 5 through 7 . Marginal Effects of the probit regression are reported - the coefficients are normalized to represent the derivative of

the probability of employment with respect to a change in the explanatory variable. 
explore further, I estimated a regression of both women and men's labor force participation where health is modeled by an indicator for a limitation to work and the objective health conditions index and functional limitation index (results not shown but can be provided upon request). Only a slightly larger marginal effect of the 'work-limit' measures than what was presented in model 1 was revealed for both men and women ( 0.116 for women; 0.123 for men) and both objective indices were insignificant for women while the conditions index remained statistically significant ( 5 percent level) for men. Interactions of the objective measures with spouse's 'work-limit' were also insignificant, for both men and women, whether or not we control for the other objective index (results not shown but available on request). Suspecting that the work-limit indicator may be correlated with the spouse's type of work I also estimated models which (1) control for whether the spouse is "white collar", (2) include an interaction between 'work-limit' and 'white collar', and (3) include the interaction between 'work-limit' and an indicator for whether the spouse is employed (not shown but available on request). All coefficients on the new covariates were insignificant while the marginal impact of the 'work-limit' indicator remained robust across estimates for both men and women. These findings suggest that the 'work-limit' measure is not necessarily plagued by the "error-invariables" problem (at least, it does not suffer from any conceivable omitted variable bias). Instead, it may simply be measuring aspects of the spouse's health that are not captured by the alternative measures, but do impact the husband's or wife's labor decision.

Regarding the self-assessed measure for health, holding work-limiting conditions constant, the results show no statistically significant effect for women but a marginal 
impact on the probability of men's employment of 6 and 7 percent as a wife moves from excellent health to good and fair/poor health, respectively. While it may be the case that an asymmetry exists between men and women's probability of employment with respect to their counterpart's ill-health, the discontinuity between older men and women's reports of health status by age (Ross and Bird, 1994; Penning and Strain, 1994; Verbrugge, 1984) and the greater likelihood of measurement error due to its subjectivity suggests that we should look to the more objective indicators as our preferred measures for the effect of a spouse's health on the need for an individual's care or his or her preference for spending time together.

We find that the probability of women's and men's employment increases by 1.85 (10 percent level of significance) and 2.1 percent (5 percent level of significance), respectively, for every additional health condition reported by their spouse. No statistically significant effect on the functional limitation index was estimated. The effects remained the same, in magnitude and significance, when we instrumented for spouses' earnings. PCS proxies for overall health without limiting its scope to particular diseases or function, and is also more likely to reflect the severity of an individual's underlying conditions. To better interpret its coefficient we used each observation's 'zscore' of the normally distributed PCS index in the final model. Hence, we interpret the coefficients to mean that every positive standard deviation from the mean PCS of the sample of men and women is associated with a 2.5 percent decline in the probability of employment for women, and a 1.9 percent decline for men.

Table 6 presents estimates for the regressions of labor force participation on various combinations of the five health variables used in the analysis above. Model 4 
includes the two objective, summary indexes with the z-score of the PCS. We see that, for women, all marginal effects on spouses' health become statistically insignificant, despite the statistical significance of the health conditions index in model 2 (Table 5) and the z-score of the PCS in model 3 (Table 5). However, an adjusted Wald-test indicates that the three indexes are jointly significant at the ten percent level (Prob $>F=.0623)$. For men, we see that the marginal effect of the health conditions index remains statistically significant at the five percent level (compared to model 2) but the z-score of the PCS is no longer statistically significant (compared to model 3). An adjusted Waldtest indicates that the three indexes are jointly significant at the one percent level (Prob $>\mathrm{F}=.0017$ ). This evidence may suggest that PCS does tend to capture the effects captured by the health conditions index and functional limitations index when used alone and that it may be more appropriate to use the combination of the health conditions index and the functional limitation index interchangeably with the PCS measure rather than include all three objective indexes in one model. ${ }^{112}$ Moreover, it may be the case that PCS is an objective measure for health which can account for both disease status and functional status. Since it is also more likely than the other, summary, indexes to reflect the severity of the underlying conditions, it may offer a more accurate "comparability" of the health status across a sample of individuals (see chapter 1 for further discussion).

\footnotetext{
${ }^{112}$ On the other hand, it was reported above that when the work limit measures was combined with the two objective indexes the statistical significance of a wife's health conditions remained at the level found in model 2 of Table 5 for men. Model 5 in Table 6 shows that, when combined with worklimit, the PCS measure becomes statistically insignificant for both men and women despite its statistical significance in model 3. Model 6 in Table 6 combines all health variables used in the analysis and the health conditions index remains statistically significant, although only at the ten percent level. The statistical significance no longer remains when PCS is not incorporated with all other variables as in model 7 of Table 6 . This suggests that either PCS does not fully capture those effects captured by the health conditions index or that the health conditions index may be biased, to some extent, due to measurement error while the PCS may not be (as discussed in section 6).
} 
Turning our attention to models 6 and 7 in Table 6 , it appears that the estimates for the marginal effects of the more subjective measures - work limit and self-assessed health status - remain somewhat steady, whether included with or without the other more objective measures (model 1 versus models 6 and 7). On the other hand, the estimates on the more objective measures do not (model 2 versus models 6 and 7). This suggests that all measures capture some aspect of health not fully captured by the other measures. However, it does not preclude the possibility that the objective measures suffer from biasedness due to their subjectivity or due to an "error-in-variables" (omitted variable bias) problem.

Taken together or separately, the signs and magnitudes on all health measures indicate that both husbands and wives are more likely to participate in the labor market as their spouses' health diminishes. Although, estimates on the more objective measures suggest that both men's and women's probability of employment may be more responsive to the presence of disease rather than to functional limitations on the spouse. This finding is in contrast to Siegel's (2006) findings, on women, when she uses similar measures (excluding the PCS index) but 1992 data from the Health and Retirement Survey. However, noting that both our models hold the effect of a spouse's ill-health on the family income constant, the interpretation of the effects of a spouse's ill-health need not differ greatly between this study and Siegel's study. It may be the case that, while less attributable to functional limitations but more to physical health (or "disease"), a spouse's ill-health may require unusually high expenditures on health care. Thus an individual may increase their labor force participation to either obtain health insurance or to purchase health care or other health-related goods or services for his or her spouse. An 
alternative explanation is that he or she simply prefers to spend less time together (Siegel, 2006). ${ }^{113}$

The remaining covariates in the model impact the propensity for employment as expected (see Table A3). A strong, positive relationship between an individual's own health and employment is consistently exhibited across all specifications for health. The presence of one's own children in the home influences the tastes for work. Children less than 18 years reduce a wife's probability of work but significantly increase a husband's probability. This is most likely due to women traditionally being the care-givers in the home (Siegel, 2006) and men's traditional role as the primary earner (Blau and Kahn, 2007), or, possibly some aversion to the presence of children on the part of men. Children aged 18 or older increase the probability of men and women's employment since they could serve as substitute caregivers or help maintain the household (Coile, 2004; Siegel, 2006). Higher unearned income - indicated by household income, spouse's earnings, or pension from a previous job - reduces labor force participation. Both husbands and wives are more likely to work themselves when their spouse is employed as found by Siegel (2006) and Johnson and Favreault (2001).

The coefficients on education and the experience proxy did not necessarily behave in accordance with my expectations. For women, education consistently exhibited a positive but small and statistically insignificant marginal impact on the probability of employment. For men, after controlling for endogeneity of wives'

\footnotetext{
${ }^{113}$ Siegel notes that, "a wife may be especially likely to enter the labor market in response to a husband's function status if a substitute caregiver, such as a child aged 18 or over, is present in the household". Thus, she interacted the husband's functional status with the presence of adult children, but finds no statistical

significance. The interaction of the spouse's health conditions status with the presence of adult children as also insignificant here (results not shown but available on request). This contrasts with the findings of Coile (2004).
} 
earnings, its impact was consistently negative and statistically significant. It may be the case that higher-skilled men are more likely to retire earlier than lower-skilled men thereby causing the negative effect of human capital attainment on their probability of being employed at older ages. Early retirement may not be a significant factor for older women's labor decisions. Moreover, the coefficient on education in estimates for men and women's wages (Tables A5 through A7) was consistently positive and significant for both men and women who work. Therefore, the positive effects of educational attainment on men's potential earnings may be offset by its positive effect on higher earnings over one's career and therefore their likelihood of an earlier exit from the labor force.

The experience proxy, on the other hand, was much less stable across the specifications for health, rarely having any statistically significant effects on the estimates. This is probably due to the construction of the experience proxy [age-years of education-6]. As noted earlier, tests for multi-collinearity found age to be highly collinear with the proxy while education levels were not. I suspect that age strongly influences the estimated coefficient on experience and that the proxy does not serve its purpose well. I re-estimated the models substituting experience and experience squared with age and age squared and found that the estimated coefficients on the various specifications for health remained fairly stable and always with the same signs and significance levels. Age and age squared were always highly insignificant, which was expected since the age of everyone sampled was no more than 11 years apart. Thus, I suspect that the experience proxy is more reflective of the individual's age than actual work experience which is why it is highly insignificant in the model for participation. 
Moreover, the coefficient on experience in estimates for men and women's wages

(Tables A5 through A7) was fairly stable across the various specifications for health and consistently negative for both men and women who work. It was only highly significant for women - the negative effect may be due to its correlation with age and a possibly negative relationship, on average, between age and earnings among older women.

Hence, when used as a predictor of potential wages in the participation model we see that the sign on the coefficient for experience is consistently negative (although insignificant) for women while insignificant and less stable for men. Overall, I argue that the use of education and the experience proxy, jointly, along with own-health and race, is sufficient to control for potential wage and thus provides reliable results regarding the estimation of the coefficients on spouses' health.

\subsubsection{Symmetry of Husbands and Wives Regarding Labor Force Participation}

Another noteworthy result is that there appears to be no substantial difference between the marginal impacts of a spouse's ill-health on men and women's propensity for employment when measured by the preferred, objective measures for disease and physical functioning or the 'work-limit' measure. ${ }^{114}$ Nor do we find a statistical difference between the genders when we model men and women jointly and observe the

\footnotetext{
${ }^{114}$ For the models that include work-limit individually (see Table A11) there is an apparent difference in estimates for men and women. However, the interaction effect in the joint-sample of men and women is statistically insignificant, suggesting that no statistical difference exists. The differences that are apparent when it is included individually may be due to correlation with self-assessed health which does exhibit a somewhat weak statistical difference between men and women which explains why the difference disappears when we hold self-assessed health constant.
} 
coefficients on the interaction between health status and gender (see Table A12). These results hold even after we control for the endogeneity of spouses' earnings. ${ }^{115}$

A wife's self-assessment of good or fair/poor health status, on the other hand, seems to impact the husband's probability of employment when conditional on the more subjective measures while the opposite relationship does not hold. Estimating women and men jointly, we find that the statistical difference between the good and fair/poor categories is rejected, but, instead, we find that men are nearly 9 percent more likely than women to be employed when their spouse reports very good health as opposed to excellent health. These mixed results may be due to the subjective nature of the measure, as discussed above, since any asymmetry between the other, more objective, measures is not apparent. So, to explore further, I substituted self-assessed health with the two objective summary indices and find a similar pattern. For women, holding a spouse's work-limitation constant, the statistical significance on the spouse's conditions index disappeared, while, for men, the magnitude and statistical significance of the marginal impact remained the same as when we did not control for a work-limitation (results not shown but available on request). The results seem to show support for some degree of asymmetry in the relationship between husbands' and wives' propensity for employment and their spouses' disease status. Yet, the evidence still remains mixed since reestimating the latter model using the joint-sample of men and women revealed no statistical difference between the marginal impacts of the husbands' and wives' reported number of health conditions. Overall, we can conclude that, when using the more

\footnotetext{
${ }^{115}$ For the joint sample of men and women, tests for exogeneity reject the hypothesis at the $5 \%$ level for specifications that do not include the work-limit measure. For specifications that do include the work-limit measure, the hypothesis cannot be rejected.
} 
subjective self-assessed health measure, there is only weak evidence for asymmetry in the relationship between husbands and wives propensity for employment and their spouses' ill-health. There is no evidence for asymmetry when using the more objective measures for health.

\subsection{Hours of Work}

We now investigate whether men and women who are working are likely to increase or decrease their hours of work per week with respect to their spouse's ill health. As with the model for labor force participation, tests for exogeneity could not reject the hypothesis that husbands' earnings are exogenous across all specifications for health (Prob $>$ F ranged from 0.694 to 0.90 ) while they do reject the hypothesis for wife's earnings across all specifications for health (Prob $>$ F ranged from 0.01 to 0.04). ${ }^{116}$

The results reported in Table 7 show that a spouse's ill-health does not appear to lead to any substantial changes in the hours worked per week by women and men. Across all specifications for health, only having a wife with self-reported good health rather than excellent health leads to a statistically significant decrease of approximately two hours of work per week by husbands. An adjusted Wald-test shows that all measures of a spouse's self-assessed health are jointly significant, at the five percent level, for the sample of men $($ Prob $>F=.0379)$. The coefficients and their interpretations change little when all measures are included in the model individually (Table A8).

Despite the insignificance and small magnitudes of the coefficients on the objective measures for spouses' health, their signs suggest that older men and women are

\footnotetext{
116 The exogeneity of husband's earnings differs from Siegel's earlier findings for women but she did not assess the relationship between men and their wives.
} 
Table 7. Estimates of women and men's hours per week as a function of spouse's health measures with and without instrumenting for spouse's earnings

\begin{tabular}{|c|c|c|c|c|c|c|c|c|c|c|c|c|}
\hline \multirow[b]{3}{*}{ VARIABLE } & \multicolumn{4}{|c|}{ (1) } & \multicolumn{4}{|c|}{ (2) } & \multicolumn{4}{|c|}{ (3) } \\
\hline & \multicolumn{2}{|c|}{ Women } & \multicolumn{2}{|c|}{ Men } & \multicolumn{2}{|c|}{ Women } & \multicolumn{2}{|c|}{ Men } & \multicolumn{2}{|c|}{ Women } & \multicolumn{2}{|c|}{ Men } \\
\hline & Non-IV & IV & Non-IV & IV & Non-IV & IV & Non-IV & IV & Non-IV & IV & Non-IV & IV \\
\hline \multicolumn{13}{|l|}{ Spouse's Health } \\
\hline Spouse Work-limit & $\begin{array}{c}0.519 \\
(0.979)\end{array}$ & $\begin{array}{c}0.435 \\
(0.986)\end{array}$ & $\begin{array}{c}0.598 \\
(1.127)\end{array}$ & $\begin{array}{c}0.737 \\
(1.134)\end{array}$ & & & & & & & & \\
\hline Spouse Very Good & $\begin{array}{l}-0.309 \\
(0.671)\end{array}$ & $\begin{array}{l}-0.301 \\
(0.667)\end{array}$ & $\begin{array}{l}-0.957 \\
(0.654)\end{array}$ & $\begin{array}{r}-1.065 \\
(0.647)\end{array}$ & & & & & & & & \\
\hline Spouse Good & $\begin{array}{c}0.333 \\
(0.578)\end{array}$ & $\begin{array}{c}0.285 \\
(0.594)\end{array}$ & $\begin{array}{c}-1.677^{* *} \\
(0.678)\end{array}$ & $\begin{array}{c}-1.853^{* * *} \\
(0.678)\end{array}$ & & & & & & & & \\
\hline Spouse Fair/Poor & $\begin{array}{c}0.175 \\
(0.802)\end{array}$ & $\begin{array}{c}0.127 \\
(0.803)\end{array}$ & $\begin{array}{r}-0.250 \\
(0.841)\end{array}$ & $\begin{array}{l}-0.573 \\
(0.847)\end{array}$ & & & & & & & & \\
\hline Spouse \# of Conditions & & & & & $\begin{array}{c}0.211 \\
(0.229)\end{array}$ & $\begin{array}{c}0.200 \\
(0.229)\end{array}$ & $\begin{array}{c}0.166 \\
(0.233)\end{array}$ & $\begin{array}{c}0.156 \\
(0.232)\end{array}$ & & & & \\
\hline Spouse \# of Func. Limits & & & & & $\begin{array}{l}0.0976 \\
(0.151)\end{array}$ & $\begin{array}{l}0.0961 \\
(0.151)\end{array}$ & $\begin{array}{c}0.175 \\
(0.187)\end{array}$ & $\begin{array}{c}0.171 \\
(0.187)\end{array}$ & & & & \\
\hline Spouse (z-scored) PCS & & & & & & & & & $\begin{array}{r}-0.196 \\
(0.245) \\
\end{array}$ & $\begin{array}{r}-0.142 \\
(0.256) \\
\end{array}$ & $\begin{array}{r}-0.171 \\
(0.229) \\
\end{array}$ & $\begin{array}{r}-0.104 \\
(0.229) \\
\end{array}$ \\
\hline \multicolumn{13}{|l|}{ Own Health } \\
\hline Work-limit & $\begin{array}{c}-0.00748 \\
(1.806)\end{array}$ & $\begin{array}{c}0.431 \\
(1.816)\end{array}$ & $\begin{array}{c}-0.0449 \\
(1.723)\end{array}$ & $\begin{array}{l}-0.0179 \\
(1.710)\end{array}$ & & & & & & & & \\
\hline Very Good & $\begin{array}{l}-0.565 \\
(0.581)\end{array}$ & $\begin{array}{l}-0.538 \\
(0.586)\end{array}$ & $\begin{array}{c}0.669 \\
(0.567)\end{array}$ & $\begin{array}{c}0.567 \\
(0.572)\end{array}$ & & & & & & & & \\
\hline Good & $\begin{array}{c}0.191 \\
(0.609)\end{array}$ & $\begin{array}{c}0.210 \\
(0.614)\end{array}$ & $\begin{array}{l}-0.180 \\
(0.636)\end{array}$ & $\begin{array}{l}-0.243 \\
(0.640)\end{array}$ & & & & & & & & \\
\hline Fair/Poor & $\begin{array}{r}-0.563 \\
(0.991)\end{array}$ & $\begin{array}{l}-0.421 \\
(0.996)\end{array}$ & $\begin{array}{l}-0.178 \\
(1.009)\end{array}$ & $\begin{array}{l}-0.341 \\
(0.976)\end{array}$ & & & & & & & & \\
\hline \# of Conditions & & & & & $\begin{array}{l}-0.192 \\
(0.264)\end{array}$ & $\begin{array}{l}-0.150 \\
(0.266)\end{array}$ & $\begin{array}{l}-0.0606 \\
(0.284)\end{array}$ & $\begin{array}{l}-0.0765 \\
(0.285)\end{array}$ & & & & \\
\hline \# of Functional Limitations & & & & & $\begin{array}{c}0.184 \\
(0.160)\end{array}$ & $\begin{array}{c}0.223 \\
(0.166)\end{array}$ & $\begin{array}{l}0.0871 \\
(0.253)\end{array}$ & $\begin{array}{l}0.0766 \\
(0.252)\end{array}$ & & & & \\
\hline (z-scored) PCS & & & & & & & & & $\begin{array}{l}-0.0842 \\
(0.333) \\
\end{array}$ & $\begin{array}{r}-0.245 \\
(0.364) \\
\end{array}$ & $\begin{array}{l}0.643^{*} \\
(0.365) \\
\end{array}$ & $\begin{array}{l}0.750 * * \\
(0.353) \\
\end{array}$ \\
\hline
\end{tabular}

Note: Maximum Likelihood estimates of regression models with selection using MEPS (panels 5 through 11). Rho is the correlation between the residuals of the hours and

labor force participation equations, sigma is the standard error of the residual in the hours equation, and lambda is the product of rho and sigma. 
more likely to work a somewhat greater number of hours per week as the health of their spouse deteriorates. The coefficient on the indicator for a work-limitation also agrees with these findings. This supports the conclusion from the previous model. Whether in the context of labor market participation or hours of work of the employed, we find evidence for a negative relationship between the labor supply of older individuals and the health status of a spouse. It may be the case that an individual increases their time in productive activity in order to pay for unusually high medically related expenses, or simply because they desire to spend less time with their spouse at home.

Males increase their hours of work by an average of only 45 minutes per week for every standard deviation above the mean of (own) PCS (refer to Table A9). Otherwise, the estimates reveal no significant effects of men and women's own-health on their hours of work; which is consistent with Siegel's findings regarding women. Women whose husbands are employed tend to work fewer hours per week (between 1.6 and 1.89 fewer hours depending on the specification for health). The effect of wives' employment on men's hours is also negative but becomes smaller and insignificant once we control for the endogeneity of wives' earnings. Likewise, the effect of wives' earnings moves from positive, and insignificant, to negative and only sometimes significant at the 10 percent level, depending on the specification for health. Husbands' earnings and their own predicted wages have no statistically significant effect on women's hours of work. Men with higher predicted earnings work longer hours only after controlling for the endogeneity of their spouses earnings, though, the magnitude and levels of significance also vary across the specifications for health. Variation across the estimates for wives' 
employment and earnings as well as men's predicted wages is an expected finding since wives' earnings are endogenous in the model for men's hours of work.

Other unearned income has only a small, negative effect on women's work hours; a decrease of only one hour per week for approximately every $\$ 33,300$ in unearned income. It has no significant effect on men's hours. White males tend to work more hours than non-white males and, although statistically insignificant, the negative sign on the coefficient suggests that white females tend to work fewer hours on average than nonwhite females. The coefficients on the job characteristics remain fairly stable with and without instrumenting and across the specifications for health. On average, women work an additional 3 to 5 hours per week, and men work an additional 1 to 2 hours per week, at jobs that offer additional compensation in the form of a pension or $401 \mathrm{k}$ plan, health insurance, or paid sick leave. Male or female union participants work 2 fewer hours per week, on average, than non-union workers. Finally, to control for sample selectivity we estimated the model jointly with labor force participation. The coefficient on the inverse mills ratio, $\lambda$, reveals the impact of selection bias on the estimation results. For women, $\lambda$ was significant at the 10 percent level only when we modeled health with the functional limitations index, with or without the health conditions index. For men, we find that selection bias does impact the estimates when we model health with the more objective measures; $\lambda$ was statistically significant at the 5 percent level when measured with the objective indices, and at the 10 percent level when we included both the subjective worklimit measure and the objective PCS measure. ${ }^{117}$

\footnotetext{
${ }^{117}$ This may be evidence that the indicator for a limitation to work adequately controls for the sample selection bias. It may be a large determinant in deciding whether an older individual works and is therefore included in the sample for hours, or doesn't work and is excluded from the sample. Following Siegel's
} 


\subsubsection{Symmetry of Husbands and Wives Regarding Hours of Work}

The findings above reiterate the importance of using a variety of health measures to assess the full range of the impact of a spouse's health on labor market outcomes of his or her counterpart. When the health of the spouse is measured by their self-reported health status I find no statistically significant effect of husbands' health on their wives' hours of work. This neither supports nor conflicts with the conclusions drawn from the more objective measures. ${ }^{118}$ On the other hand, for men, when health is proxied with a self-assessed measure instead of more objective measures (model 1 in Table 7) we observe a negative rather than a positive relationship between spouses' ill health and men's labor supply. Moreover, we observe some degree of asymmetry between husbands' and wives' labor supply responses to their spouses' self-assessed health that is not apparent when using the more objective measures. Arguably, though, the evidence for this asymmetric relationship is weak since only the coefficient on the category of a wife's "good" health is statistically significant and distinguishable from that of a husband's "good" health on women's labor hours (see estimates for 'Male* Spouse Good' in Table A9). Furthermore, the more objective measures may be preferable to the selfassessed measure since they may be less susceptible to any measurement error attributable to subjectivity or possible endogeneity of self-assessments. It may be argued that the objective indexes that register only the predefined health conditions described in

example, I did not control for an own-health related work-limitation in the participation model when it is not featured in the specification of the spouse's health.

${ }^{118}$ Siegel (2006) found self-assessed health to be the only significant measure of health on a sample of women and their husbands. Thus, as with the participation model, my findings conflict with Siegel's in this regard. However, similar to the results reported here, she finds a negative relationship between husbands' self-assessed health and women's hours but a positive and statistically insignificant relationship between hours and the other measures, including a work-limitation. 
Table 1 may suffer from measurement error themselves; though, the PCS index is designed to be a more comprehensive assessment of one's relative health and no asymmetry between men and women was detected when it was included.

Nonetheless, it may still be the case that the labor market responses to a spouse's ill health do not differ between men and women according to real differences in 'complementarity of leisure' or propensities to care for their spouse. Instead, since men are more often married to women younger than themselves, it may be the case that a selfdiagnosis of poorer health by their younger spouse may increase the expected amount of total household medical expenditures that will be incurred before they reach the age of Medicare eligibility and therefore men respond by increasing hours of work. However, when we include spouse's age in the model or interact the spouse's age with self-assessed health, the coefficients on spouse's age and the interaction term are insignificant and the magnitudes and significance of spouse's self-assessed health are not affected (results not shown but available on request).

\section{Conclusion}

Using a more recent data set, this study used the framework laid out by Siegel (2006) which analyzes the impact of a husband's ill-health on an older wife's labor supply. It was extended to also analyze the impact of a wife's ill health on a husband's labor supply in order to assess the extent to which men and women may respond differently in this regard. Similar to Siegel's findings, I found that the estimated effect of a spouse's ill-health on the other's labor supply depends on the measurement used to proxy for their health status. I also found that, although the direction of impact does not 
change, the magnitudes of the coefficients on these health measures depend on whether we control for the possible endogeneity of the spouse's earnings in these models. However, while Siegel found that the exogeneity assumption of husbands' earnings could not be rejected when modeling women's labor force participation but should rejected when modeling their hours of work, I use slightly different (but equally valid) instruments for spouses' earnings to determine that husbands' earnings could be treated as exogenous in our models for both the participation and hours of work of wives, while the exogeneity assumption on wives' earnings should be rejected when modeling both the participation and hours of work of men.

I find that the ill-health of a spouse is estimated to increase the propensity for older women and older men to be employed when health is measured by a more objective measure for disease status - a health conditions index - and a more comprehensive objective measure of health, the PCS. I also found this relationship holds when we use an indicator for a work-limitation to proxy for the functional status of the spouse. Moreover, the magnitude of the marginal impact of the work-limit measure (9.5 - 13 percent across men and women) was quite large in comparison to the other measures, and it remained fairly steady over these specifications for health and across some extensions of the model that were used to test for the possibility of the "error-in-variables" problem. This suggests that the more subjective work-limit measure may reflect some dimension of a spouse's health status that the other measures included in our model do not measure, and this dimension of health is an important determinant to the other spouse's labor supply decision. By extension, this implies that the more objective measures may suffer from 
some degree of measurement error when used to proxy for a spouse's need for assistance or caregiving in the home.

I controlled for a spouse's earnings and its possible endogeneity in the model, thereby controlling for the negative impact that a spouse's ill-health may have household income and the according labor market response by the other spouse. I also control for the employment status of the spouse. Thus, we conclude that a spouse's ill-health must decrease men and women's reservation wages, and this may be in order to pay for unusually high medically-related expenses or to obtain or retain health insurance often tied to employment. It may also be the case that the ill-health of a spouse decreases the extent to which the presence of a spouse complements the other's leisure-time.

Furthermore, when I compared the estimated marginal impacts of a spouse's health between men and women's propensity for employment (by either comparing the similar coefficients across models for men and women, or by estimating the sample of men and women jointly and using an interaction between spousal health and a gender variable) I found only weak evidence that men are more responsive to their wives' poor health than are women to their husband's ill-health. The more subjective, and therefore possibly endogenous, self-assessed measure for wives' health was significant only in the model for men's labor force participation, while the coefficients for all other measures were statistically indistinguishable between men and women.

When I modeled the individuals' hours of work as a function of their spouses' health I found no statistically significant effects when health was measured by an indicator for a work-limitation and the other more objective indices. Although statistically insignificant, the signs on the coefficients show that both men and women 
tend to work a greater number of hours per week when their spouse reports a poorer health status. On the other hand, as in the model for labor force participation, I found a statistically significant marginal impact of wives' self-assessed health on husbands' hours of work. However, the sign of the coefficient on the measure indicates that an older husband tends to decrease, rather than increase, his hours of work as his wife moves from excellent health to a lower health status. It remained statistically distinguishable from the effect of husbands' self-assessed health on women's hours of work when we modeled men and women's hours of work jointly. Again, I find evidence for some degree of asymmetry between the men and women's labor supply responses to their spouse's illhealth when measured using self-assessed health, but no evidence when we use the other measures included in our model. It may be the case that husbands are less-likely than wives to take on the role of caregiver when their spouse falls into ill-health and more likely to respond through the provision of formal care or maintenance. Or, it may be that the complementarity effect of a wife's presence during a husband's leisure time tends to decrease as her health decreases, and that this does not occur to the same extent for women.

No matter the measure used to proxy for health status, my findings regarding the direction of the relationships between the participation and hours of women with respect to their husbands' health status generally agree with those of Siegel (2006). However, while she finds that only her objective measure for a husband's physical functioning exhibits any statistically significant effect on women's participation I find that my index for physical functioning is not significant but, instead, the index for health conditions (diseases) and the work-limitation variable are statistically significant. I also find a 
significant impact on the added PCS measure, but this may only be encompassing the same effects of disease status that the conditions index reflects.

Also, while Siegel (2006) finds that husbands' self-assessed health exhibits a statistically significant impact on women's hours of work, I find that none of the measures exhibit a statistically significant effect. Any disparities, however, may be due to a number of the differences alluded to in the discussion of my empirical model. Alternatively, some of the difference may be attributable to changes in the structure of the labor market for older women over the period from when her data was collected (1992) and mine was collected [2000-2007]. For instance, female participation rates have continually risen from 1980 to 2000 and the elasticity of women's labor supply with respect to their spouse's wage has become more and more like men's over that period (Blau and Kahn, 2007). These changes were concomitant with rising prices in the health care market over this period. Hence, it may be the case that chronic or acute illnesses warrant more costly care than in prior periods and women are in better position to enter or remain in the labor market in order to afford such care. Moreover, the negative impact on the household budget may, to some extent, offset any propensity by women to substitute their labor market time with caregiving at home or with spending more quality time with their husbands.

One deficiency of my model for the labor force participation of older individuals is that I could not observe their prior work experience using MEPS. For instance, I was forced to use a constructed proxy for work experience that was highly correlated with the age of the individual and therefore it is likely captured the effects of age on my outcomes instead of work experience. This analysis could be improved by using an alternative, 
longitudinal data set, such as the Health and Retirement Survey, which was used by Siegel and is often found in the retirement literature. This would also allow me to exploit its longitudinal structure to differentiate the impacts of a shock to a spouse's disease status and functional status from the effects of their overall, underlying health status. While MEPS is somewhat longitudinal it only provides detailed information obtained within a two-year window. On the other hand, MEPS does provide detailed information regarding expenditures on medical care during this period. It may be useful for future work in that I may be able to distinguish the budgetary effect of a spouse's ill health, which gives a spouse greater incentive to increase their labor supply, from the complementarity of leisure effects or the propensity of one spouse to give care to the other, which offsets this budgetary incentive.

Finally, I agree with Siegel's conclusion that "additional work is needed to unravel the interpretation of the various health measures used." The most ideal set of health measures for assessing the effect of a spouse's health on another's labor supply would include measures that proxy for not only the physical capacity to perform productive activities at work and at home but also ones that more accurately reflect the need for another person's assistance in caring for themselves (Siegel, 2006). While, admittedly, much of this work is the responsibility of the user, one practical suggestion for those who collect and provide health-related data to the research community is to expand upon the line of questioning regarding the specific physical and mental limitations on activity at work, home, and school. For example, it may be useful to extract further information from individuals who indicate that they feel limited in their activities on whether those limitations are due to the specific chronic or acute physical 
and mental conditions which are already reported in most data sets. Conversely, one could follow up on reports of specific physician diagnosed conditions to ask whether the individuals feel that each condition limits work, home, or school activity and to what extent. ${ }^{119}$ Such additional information may facilitate users in their efforts to attenuate some of the concerns regarding the endogenous nature and measurement error of some of the most commonly used measures in the research on health and labor outcomes.

\footnotetext{
${ }^{119}$ Note that these suggestions are put forth with some caution. Although I am not aware of any contemporary surveys that offer such information, my exposure to the available data sets may simply be limited.
} 


\section{Appendix}

\subsection{List of Variables Used in the Regressions}

Spouses' earnings: equal to spouse's wage level times the spouse's usual hours worked per week at the time of the observation (in hundreds)

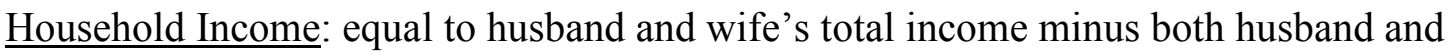
wife's wage income for the year prior to observation (in hundreds) Spouse employed: dummy equal to one if person's spouse is employed

$\#$ of children $<18$ : the number of own-children in the household less than 18 years of age $\#$ of children $>=18$ : the number of own-children in the household greater than or equal to 18 years of age

White: dummy equals one if person is white, no other race

Age: person's age in years

Male: dummy equals one if person is male

Education: years of education attained by person

Education missing: dummy equal to one if years of education was not reported

Experience: Years of work experience is proxied by [Age - years of education -6]

Midwest: dummy equal to one if person resides in Midwest Census region (Northeast Census region is excluded)

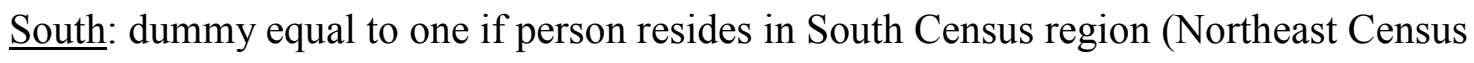
region is excluded)

West: dummy equal to one if person resides in West Census region (Northeast Census region is excluded)

MSA: dummy equals one if person resides within a Census metropolitan statistical area 
Pension/IRA: dummy equal to one if person is currently receiving pension or IRA benefits from a previous job

Panel 6: dummy equal to one if person is surveyed in round three of panel 6 (2002), (dummy for panel 5 is excluded).

Panel 7: equal to one if person is surveyed in round three of panel 6 (2003)

Panel 8: equal to one if person is surveyed in round three of panel 6 (2004)

Panel 9: equal to one if person is surveyed in round three of panel 6 (2005)

Panel 10: equal to one if person is surveyed in round three of panel 6 (2006)

Panel 11: equal to one if person is surveyed in round three of panel 6 (2007)

Predicted Wage: log of hourly wage calculated for working individuals using estimates found in Tables A5 through A7

Tenure: the number of years a person has been employed at their present job if employed $\leq 1$ yr. tenure: dummy equal to one if Tenure is less than one year if employed Tenure missing: dummy equal to one if tenure information is missing but employed Union: dummy equal to one if employed person is affiliated with a union White collar: dummy equal to one if person is employed in white collar occupation Paid sick leave: dummy equal to one if job includes paid sick leave Retirement/Pension plan: dummy equal to one if person's job includes pension plan Choice of H.I. Plans: dummy equal to one if person's job offers choice between more than one type of health insurance plan $>1$ location for firm: dummy equal to one if person is employed at firm with more than one location of business 
Industry: Ag./Const.: dummy equals one if employed in agricultural, construction, or natural resources industries (Industry: Gov't is excluded industry category) Industry: FIRE: dummy equals one if employed in Finance, Insurance, or Real Estate industries (Industry: Gov't is excluded industry category) Industry: Sales: equals one if employed in Sales/Retail industries (Industry: Gov't is excluded industry category) Industry: Other: dummy equal to one if not employed in $\mathrm{Ag} / \mathrm{Con}$, FIRE, Sales industries, or by a Government

Spouse tenure: the number of years a person's spouse has been employed at their present job if spouse is employed

Spouse white collar: dummy equal to one if person's spouse is employed with a white collar occupation

Spouse Industry: Sales: dummy equal to one if person's spouse is employed in the Sales/Retail industry as opposed to Government, $\mathrm{Ag} /$ Const, FIRE, or Other Spouse $>1$ location of firm: dummy equal to one if spouse is employed at a firm with more than one location of business Spouse: midsize firm: dummy equal to one if spouse is employed at firm with 100 or more employees but less than 500 employees (Spouse: small firm $[<100$ employees] is the excluded category) Spouse: large firm: dummy equal to one if spouse is employed at firm with 500 or more employees (Spouse: small firm [ $<100$ employees] is the excluded category) 


\subsection{List of Tables Found in the Appendix}

Table A1: Means of non-health variables used in regressions

Table A2: Estimates for labor force participation - health variables included singularly

Table A3: Estimates for labor force participation - models (1), (2), and (3)

Table A4: Estimates for labor force participation - models (4), (5), (6), and (7)

Table A5: Estimates for predicting wages - health variables included singularly

Table A6: Estimates for predicting wages - models (1), (2), and (3)

Table A7: Estimates for predicting wages - models (4), (5), (6), and (7)

Table A8: Estimates for hours of work - health variables included singularly

Table A9: Estimates for hours of work - models (1), (2), and (3)

Table A10: Estimates for hours of work - models (4), (5), (6), and (7)

Table A11: Joint-sample of men and women: estimates for labor force participation health variables included singularly

Table A12: Joint-sample of men and women: estimates for labor force participation models (1), (2), (3), and (4)

Table A13: Joint-sample of men and women: estimates for labor force participation models (5), (6), and (7)

Table A14: Joint-sample of men and women: estimates for predicting wages - health variables included singularly

Table A15: Joint-sample of men and women: estimates for predicting wages - models $(1),(2),(3)$, and (4)

Table A16: Joint-sample of men and women: estimates for predicting wages - models $(5),(6)$, and (7) 
Table A17: Joint-sample of men and women: estimates for hours of work - health variables included singularly

Table A18: Joint-sample of men and women: estimates for hours of work - models (1), (2), (3), and (4)

Table A19: Joint-sample of men and women: estimates for hours of work - models (5), (6), and (7) 
Table A1. Means of non-health variables used in regresssions (standard errors)

\begin{tabular}{|c|c|c|c|c|c|c|c|}
\hline Variable & $\begin{array}{c}\text { Total } \\
(8267) \\
\end{array}$ & $\begin{array}{c}\text { Women } \\
(3877) \\
\end{array}$ & $\begin{array}{c}\text { Women } \\
\text { Employed } \\
(2120) \\
\end{array}$ & $\begin{array}{c}\text { Women Non- } \\
\text { Employed } \\
(1757)\end{array}$ & $\begin{array}{c}\text { Men } \\
(4390)\end{array}$ & $\begin{array}{c}\text { Men } \\
\text { Employed } \\
(2831) \\
\end{array}$ & $\begin{array}{c}\text { Men Non- } \\
\text { Employed } \\
(1559) \\
\end{array}$ \\
\hline Spouse's Earnings (\$/week) & $\begin{array}{c}584 \\
(10.68)\end{array}$ & $\begin{array}{c}743 \\
(8.11)\end{array}$ & $\begin{array}{c}769 \\
(20.69)\end{array}$ & $\begin{array}{c}706 \\
(24.85)\end{array}$ & $\begin{array}{c}449 \\
(10.28)\end{array}$ & $\begin{array}{c}463 \\
(11.00)\end{array}$ & $\begin{array}{c}422 \\
(19.76)\end{array}$ \\
\hline Household Income (\$/year) & $\begin{array}{c}9,583 \\
(325.60)\end{array}$ & $\begin{array}{c}10,841 \\
(403.10)\end{array}$ & $\begin{array}{c}8,540 \\
(479.80)\end{array}$ & $\begin{array}{c}14,060 \\
(718.80)\end{array}$ & $\begin{array}{c}8,507 \\
(351.90)\end{array}$ & $\begin{array}{c}5,454 \\
(304.40)\end{array}$ & $\begin{array}{c}14,400 \\
(738.30)\end{array}$ \\
\hline Spouse Employed & $\begin{array}{c}0.683 \\
(0.007)\end{array}$ & $\begin{array}{c}0.697 \\
(0.009)\end{array}$ & $\begin{array}{c}0.745 \\
(0.010)\end{array}$ & $\begin{array}{c}0.629 \\
(0.013)\end{array}$ & $\begin{array}{c}0.671 \\
(0.009)\end{array}$ & $\begin{array}{c}0.706 \\
(0.010)\end{array}$ & $\begin{array}{c}0.604 \\
(0.015)\end{array}$ \\
\hline \# Children $<18$ years old & $\begin{array}{c}0.204 \\
(0.010)\end{array}$ & $\begin{array}{c}0.131 \\
(0.009)\end{array}$ & $\begin{array}{c}0.149 \\
(0.010)\end{array}$ & $\begin{array}{c}0.106 \\
(0.013)\end{array}$ & $\begin{array}{c}0.266 \\
(0.013)\end{array}$ & $\begin{array}{c}0.322 \\
(0.016)\end{array}$ & $\begin{array}{c}0.158 \\
(0.015)\end{array}$ \\
\hline \# Children $>=18$ years old & $\begin{array}{c}0.319 \\
(0.011)\end{array}$ & $\begin{array}{c}0.290 \\
(0.012)\end{array}$ & $\begin{array}{c}0.363 \\
(0.017)\end{array}$ & $\begin{array}{c}0.186 \\
(0.013)\end{array}$ & $\begin{array}{c}0.344 \\
(0.013)\end{array}$ & $\begin{array}{c}0.418 \\
(0.017)\end{array}$ & $\begin{array}{c}0.201 \\
(0.014)\end{array}$ \\
\hline White & $\begin{array}{c}0.744 \\
(0.007)\end{array}$ & $\begin{array}{c}0.747 \\
(0.008)\end{array}$ & $\begin{array}{c}0.757 \\
(0.010)\end{array}$ & $\begin{array}{c}0.732 \\
(0.012)\end{array}$ & $\begin{array}{c}0.742 \\
(0.008)\end{array}$ & $\begin{array}{c}0.743 \\
(0.008)\end{array}$ & $\begin{array}{c}0.739 \\
(0.014)\end{array}$ \\
\hline Spouse's Age & $\begin{array}{l}54.39 \\
0.086\end{array}$ & $\begin{array}{l}57.18 \\
0.121\end{array}$ & $\begin{array}{l}56.34 \\
0.150\end{array}$ & $\begin{array}{l}58.35 \\
0.196\end{array}$ & $\begin{array}{l}52.01 \\
0.100\end{array}$ & $\begin{array}{l}51.69 \\
0.119\end{array}$ & $\begin{array}{l}52.63 \\
0.178\end{array}$ \\
\hline Education (yrs.) & $\begin{array}{c}13.20 \\
(0.054)\end{array}$ & $\begin{array}{c}13.04 \\
(0.065)\end{array}$ & $\begin{array}{c}13.42 \\
(0.076)\end{array}$ & $\begin{array}{c}12.51 \\
(0.096)\end{array}$ & $\begin{array}{c}13.34 \\
(0.057)\end{array}$ & $\begin{array}{c}13.39 \\
(0.074)\end{array}$ & $\begin{array}{c}13.24 \\
(0.084)\end{array}$ \\
\hline Experience Proxy & $\begin{array}{c}35.80 \\
(0.075)\end{array}$ & $\begin{array}{c}35.94 \\
(0.092)\end{array}$ & $\begin{array}{c}35.02 \\
(0.111)\end{array}$ & $\begin{array}{c}37.23 \\
(0.128)\end{array}$ & $\begin{array}{c}35.68 \\
(0.082)\end{array}$ & $\begin{array}{c}35.25 \\
(0.103)\end{array}$ & $\begin{array}{c}36.52 \\
(0.115)\end{array}$ \\
\hline Northeast Census Region & $\begin{array}{c}0.195 \\
(0.011)\end{array}$ & $\begin{array}{c}0.187 \\
(0.012)\end{array}$ & $\begin{array}{c}0.206 \\
(0.015)\end{array}$ & $\begin{array}{c}0.159 \\
(0.012)\end{array}$ & $\begin{array}{c}0.203 \\
(0.012)\end{array}$ & $\begin{array}{c}0.201 \\
(0.013)\end{array}$ & $\begin{array}{c}0.207 \\
(0.014)\end{array}$ \\
\hline Midwest Census Region & $\begin{array}{c}0.225 \\
(0.012)\end{array}$ & $\begin{array}{c}0.228 \\
(0.012)\end{array}$ & $\begin{array}{c}0.243 \\
(0.015)\end{array}$ & $\begin{array}{c}0.206 \\
(0.014)\end{array}$ & $\begin{array}{c}0.222 \\
(0.012)\end{array}$ & $\begin{array}{c}0.232 \\
(0.013)\end{array}$ & $\begin{array}{c}0.203 \\
(0.015)\end{array}$ \\
\hline South Census Region & $\begin{array}{c}0.362 \\
(0.016)\end{array}$ & $\begin{array}{c}0.362 \\
(0.016)\end{array}$ & $\begin{array}{c}0.342 \\
(0.019)\end{array}$ & $\begin{array}{c}0.389 \\
(0.017)\end{array}$ & $\begin{array}{c}0.362 \\
(0.017)\end{array}$ & $\begin{array}{c}0.353 \\
(0.017)\end{array}$ & $\begin{array}{c}0.378 \\
(0.021)\end{array}$ \\
\hline
\end{tabular}


Table A1 (CONTINUED). Means of non-health variables used in regresssions (standard errors)

\begin{tabular}{|c|c|c|c|c|c|c|c|}
\hline Variable & $\begin{array}{c}\text { Total } \\
(8267) \\
\end{array}$ & $\begin{array}{c}\text { Women } \\
\text { (3877) }\end{array}$ & $\begin{array}{c}\text { Women } \\
\text { Employed } \\
(2120)\end{array}$ & $\begin{array}{c}\text { Women Non- } \\
\text { Employed } \\
(1757)\end{array}$ & $\begin{array}{c}\text { Men } \\
(4390) \\
\end{array}$ & $\begin{array}{c}\text { Men } \\
\text { Employed } \\
(2831) \\
\end{array}$ & $\begin{array}{c}\text { Men Non- } \\
\text { Employed } \\
(1559) \\
\end{array}$ \\
\hline \multirow[t]{2}{*}{ West Census Region } & 0.218 & 0.223 & 0.208 & 0.245 & 0.214 & 0.215 & 0.211 \\
\hline & $(0.014)$ & $(0.014)$ & $(0.018)$ & $(0.014)$ & $(0.014)$ & $(0.015)$ & $(0.017)$ \\
\hline \multirow[t]{2}{*}{ MSA } & 0.806 & 0.807 & 0.822 & 0.785 & 0.805 & 0.813 & 0.789 \\
\hline & $(0.010)$ & $(0.011)$ & $(0.012)$ & $(0.015)$ & $(0.010)$ & $(0.011)$ & $(0.015)$ \\
\hline \multirow[t]{2}{*}{ Pension/IRA } & 0.191 & 0.228 & 0.197 & 0.272 & 0.160 & 0.133 & 0.211 \\
\hline & $(0.008)$ & $(0.009)$ & $(0.011)$ & $(0.013)$ & $(0.008)$ & $(0.010)$ & $(0.012)$ \\
\hline \multirow[t]{2}{*}{ Panel 5 (2001) } & 0.130 & 0.127 & 0.134 & 0.117 & 0.133 & 0.132 & 0.135 \\
\hline & $(0.011)$ & $(0.012)$ & $(0.014)$ & $(0.013)$ & $(0.012)$ & $(0.013)$ & $(0.015)$ \\
\hline \multirow[t]{2}{*}{ Panel 6 (2002) } & 0.140 & 0.136 & 0.129 & 0.146 & 0.144 & 0.140 & 0.150 \\
\hline & $(0.005)$ & $(0.005)$ & $(0.007)$ & $(0.009)$ & $(0.005)$ & $(0.006)$ & $(0.010)$ \\
\hline \multirow[t]{2}{*}{ Panel 7 (2003) } & 0.140 & 0.139 & 0.135 & 0.145 & 0.140 & 0.135 & 0.150 \\
\hline & $(0.006)$ & $(0.007)$ & $(0.008)$ & $(0.011)$ & $(0.006)$ & $(0.007)$ & $(0.010)$ \\
\hline \multirow[t]{2}{*}{ Panel 8 (2004) } & 0.144 & 0.146 & 0.146 & 0.146 & 0.141 & 0.139 & 0.146 \\
\hline & $(0.005)$ & $(0.007)$ & $(0.009)$ & $(0.010)$ & $(0.006)$ & $(0.007)$ & $(0.010)$ \\
\hline \multirow[t]{2}{*}{ Panel 9 (2005) } & 0.144 & 0.146 & 0.141 & 0.153 & 0.143 & 0.144 & 0.140 \\
\hline & $(0.006)$ & $(0.006)$ & $(0.008)$ & $(0.010)$ & $(0.006)$ & $(0.007)$ & $(0.010)$ \\
\hline \multirow[t]{2}{*}{ Panel 10 (2006) } & 0.151 & 0.154 & 0.159 & 0.147 & 0.148 & 0.153 & 0.138 \\
\hline & $(0.005)$ & $(0.007)$ & $(0.010)$ & $(0.010)$ & $(0.006)$ & $(0.007)$ & $(0.011)$ \\
\hline \multirow[t]{2}{*}{ Panel 11 (2007) } & 0.151 & 0.152 & 0.156 & 0.147 & 0.151 & 0.156 & 0.141 \\
\hline & $(0.005)$ & $(0.006)$ & $(0.008)$ & $(0.009)$ & $(0.006)$ & $(0.007)$ & $(0.010)$ \\
\hline Hourly Wage & -- & -- & $\begin{array}{c}16.88 \\
(0.249)\end{array}$ & -- & -- & $\begin{array}{c}22.82 \\
(0.316)\end{array}$ & -- \\
\hline Hours per Week & -- & -- & $\begin{array}{c}37.08 \\
(0.263)\end{array}$ & -- & -- & $\begin{array}{c}43.51 \\
(0.216)\end{array}$ & -- \\
\hline Tenure (yrs.) & -- & -- & $\begin{array}{c}11.17 \\
(0.225)\end{array}$ & -- & -- & $\begin{array}{c}13.53 \\
(0.285)\end{array}$ & -- \\
\hline
\end{tabular}


Table A1 (CONTINUED). Means of non-health variables used in regresssions (standard errors)

\begin{tabular}{|c|c|c|c|c|c|c|c|}
\hline Variable & $\begin{array}{c}\text { Total } \\
(8267) \\
\end{array}$ & $\begin{array}{c}\text { Women } \\
(3877) \\
\end{array}$ & $\begin{array}{c}\text { Women } \\
\text { Employed } \\
(2120)\end{array}$ & $\begin{array}{c}\text { Women Non- } \\
\text { Employed } \\
(1757)\end{array}$ & $\begin{array}{c}\text { Men } \\
(4390) \\
\end{array}$ & $\begin{array}{c}\text { Men } \\
\text { Employed } \\
(2831) \\
\end{array}$ & $\begin{array}{c}\text { Men Non- } \\
\text { Employed } \\
(1559) \\
\end{array}$ \\
\hline$<1 \mathrm{yr}$. Tenure & -- & -- & $\begin{array}{c}0.028 \\
(0.004)\end{array}$ & -- & -- & $\begin{array}{c}0.034 \\
(0.004)\end{array}$ & -- \\
\hline Union & -- & -- & $\begin{array}{c}0.173 \\
(0.011)\end{array}$ & -- & -- & $\begin{array}{c}0.221 \\
(0.010)\end{array}$ & -- \\
\hline White Collar & -- & -- & $\begin{array}{c}0.762 \\
(0.010)\end{array}$ & -- & -- & $\begin{array}{c}0.516 \\
(0.011)\end{array}$ & -- \\
\hline Paid Sick Leave & -- & -- & $\begin{array}{c}0.722 \\
(0.010)\end{array}$ & -- & -- & $\begin{array}{c}0.719 \\
(0.009)\end{array}$ & -- \\
\hline Retirement/Pension Plan & -- & -- & $\begin{array}{c}0.637 \\
(0.011)\end{array}$ & -- & -- & $\begin{array}{c}0.708 \\
(0.010)\end{array}$ & -- \\
\hline Holds ESI & -- & -- & $\begin{array}{c}0.533 \\
(0.014)\end{array}$ & -- & -- & $\begin{array}{c}0.738 \\
(0.011)\end{array}$ & -- \\
\hline Choice of Health Ins. Plans & -- & -- & $\begin{array}{c}0.395 \\
(0.013)\end{array}$ & -- & -- & $\begin{array}{c}0.441 \\
(0.012)\end{array}$ & -- \\
\hline >1 Location for Firm & -- & -- & $\begin{array}{c}0.681 \\
(0.012)\end{array}$ & -- & -- & $\begin{array}{c}0.696 \\
(0.011)\end{array}$ & -- \\
\hline Industry: Government & -- & -- & $\begin{array}{c}0.075 \\
(0.006)\end{array}$ & -- & -- & $\begin{array}{c}0.080 \\
(0.006)\end{array}$ & -- \\
\hline Industry: Ag./Const. & -- & -- & $\begin{array}{c}0.015 \\
(0.003)\end{array}$ & -- & -- & $\begin{array}{c}0.100 \\
(0.007)\end{array}$ & -- \\
\hline Industry: FIRE & -- & -- & $\begin{array}{c}0.073 \\
(0.007)\end{array}$ & -- & -- & $\begin{array}{c}0.047 \\
(0.004)\end{array}$ & -- \\
\hline Industry: Sales & -- & -- & $\begin{array}{c}0.113 \\
(0.008)\end{array}$ & -- & -- & $\begin{array}{c}0.120 \\
(0.007)\end{array}$ & -- \\
\hline
\end{tabular}


Table A1 (CONTINUED). Means of non-health variables used in regresssions (standard errors)

\begin{tabular}{|c|c|c|c|c|c|c|c|}
\hline Variable & $\begin{array}{c}\text { Total } \\
(8267) \\
\end{array}$ & $\begin{array}{c}\text { Women } \\
(3877)\end{array}$ & $\begin{array}{c}\text { Women } \\
\text { Employed } \\
(2120) \\
\end{array}$ & $\begin{array}{c}\text { Women Non- } \\
\text { Employed } \\
(1757) \\
\end{array}$ & $\begin{array}{c}\text { Men } \\
(4390) \\
\end{array}$ & $\begin{array}{c}\text { Men } \\
\text { Employed } \\
(2831) \\
\end{array}$ & $\begin{array}{c}\text { Men Non- } \\
\text { Employed } \\
(1559) \\
\end{array}$ \\
\hline Industry: Other & -- & -- & $\begin{array}{c}0.724 \\
(0.011)\end{array}$ & -- & -- & $\begin{array}{c}0.653 \\
(0.012)\end{array}$ & -- \\
\hline \multicolumn{8}{|l|}{ Instrumenting Variable* } \\
\hline Spouse Tenure (yrs.) & -- & $\begin{array}{c}13.35 \\
(0.272)\end{array}$ & -- & -- & $\begin{array}{c}10.65 \\
(0.198)\end{array}$ & -- & -- \\
\hline Spouse White Collar & -- & $\begin{array}{c}0.550 \\
(0.012)\end{array}$ & -- & -- & $\begin{array}{c}0.773 \\
(0.010)\end{array}$ & -- & -- \\
\hline Spouse Industry: Sales & -- & $\begin{array}{c}0.126 \\
(0.008)\end{array}$ & -- & -- & $\begin{array}{c}0.108 \\
(0.007)\end{array}$ & -- & -- \\
\hline Spouse: >1 Location for Firm & -- & $\begin{array}{c}0.695 \\
(0.011)\end{array}$ & -- & -- & $\begin{array}{c}0.676 \\
(0.011)\end{array}$ & -- & -- \\
\hline Spouse: Small Firm $(<100)$ & -- & $\begin{array}{c}0.475 \\
(0.012)\end{array}$ & -- & -- & $\begin{array}{c}0.551 \\
(0.011)\end{array}$ & -- & -- \\
\hline Spouse: Midsize Firm (<499) & -- & $\begin{array}{c}0.238 \\
(0.010)\end{array}$ & -- & -- & $\begin{array}{c}0.211 \\
(0.008)\end{array}$ & -- & -- \\
\hline Spouse: Large Firm $(<=500)$ & -- & $\begin{array}{c}0.195 \\
(0.011)\end{array}$ & -- & -- & $\begin{array}{c}0.197 \\
(0.009)\end{array}$ & -- & -- \\
\hline
\end{tabular}

* Instruments only observed for currently employed spouses (2593 husbands and 2796 wives) 
Table A2. Estimates of women and men's labor force participation as a function of selected spouse's health measures with and without instrumenting for spouse's earnings

\begin{tabular}{|c|c|c|c|c|c|c|c|c|c|c|c|c|c|c|c|c|}
\hline \multirow[b]{2}{*}{ VARIABLE } & \multicolumn{2}{|c|}{ Women } & \multicolumn{2}{|c|}{ Men } & \multicolumn{2}{|c|}{ Women } & \multicolumn{2}{|c|}{ Men } & \multicolumn{2}{|c|}{ Women } & \multicolumn{2}{|c|}{ Men } & \multicolumn{2}{|c|}{ Women } & \multicolumn{2}{|c|}{ Men } \\
\hline & Non-IV & IV & Non-IV & IV & Non-IV & IV & Non-IV & IV & Non-IV & IV & Non-IV & IV & Non-IV & IV & Non-IV & IV \\
\hline \multicolumn{17}{|c|}{ Reservation Wage Indicators } \\
\hline Sp Work-limit & $\begin{array}{c}0.0968^{* * *} \\
(0.0330)\end{array}$ & $\begin{array}{c}0.0966^{* * *} \\
(0.0330)\end{array}$ & $\begin{array}{c}0.344^{* * *} \\
(0.108)\end{array}$ & $\begin{array}{c}0.125 * * * \\
(0.0392)\end{array}$ & & & & & & & & & & & & \\
\hline Sp Very Good & & & & & $\begin{array}{l}-0.0255 \\
(0.0297)\end{array}$ & $\begin{array}{l}-0.0255 \\
(0.0298)\end{array}$ & $\begin{array}{l}0.0497^{*} \\
(0.0289)\end{array}$ & $\begin{array}{l}0.0544^{*} \\
(0.0292)\end{array}$ & & & & & & & & \\
\hline Sp Good & & & & & $\begin{array}{c}0.0307 \\
(0.0291)\end{array}$ & $\begin{array}{c}0.0307 \\
(0.0289)\end{array}$ & $\begin{array}{l}0.0693 * * \\
(0.0276)\end{array}$ & $\begin{array}{c}0.0774^{* * *} \\
(0.0271)\end{array}$ & & & & & & & & \\
\hline Sp Fair/Poor & & & & & $\begin{array}{l}0.0579^{*} \\
(0.0331)\end{array}$ & $\begin{array}{l}0.0579 * \\
(0.0332)\end{array}$ & $\begin{array}{c}0.0995^{* * *} \\
(0.0276)\end{array}$ & $\begin{array}{c}0.108^{* * *} \\
(0.0271)\end{array}$ & & & & & & & & \\
\hline Sp \# of Cond. & & & & & & & & & $\begin{array}{c}0.0158^{*} \\
(0.00932)\end{array}$ & $\begin{array}{c}0.0158^{*} \\
(0.00934)\end{array}$ & $\begin{array}{l}0.0220^{* *} \\
(0.00859)\end{array}$ & $\begin{array}{l}0.0220^{* *} \\
(0.00863)\end{array}$ & & & & \\
\hline $\mathrm{Sp} \#$ of Func. Lim. & & & & & & & & & & & & & $\begin{array}{c}0.00765 \\
(0.00498)\end{array}$ & $\begin{array}{c}0.00765 \\
(0.00499)\end{array}$ & $\begin{array}{c}0.00711 \\
(0.00506)\end{array}$ & $\begin{array}{c}0.00712 \\
(0.00507)\end{array}$ \\
\hline Work-limit & $\begin{array}{c}-0.488^{* * *} \\
(0.0258)\end{array}$ & $\begin{array}{c}-0.489^{* * *} \\
(0.0256)\end{array}$ & $\begin{array}{c}-1.573^{* * *} \\
(0.103)\end{array}$ & $\begin{array}{c}-0.556^{* * *} \\
(0.0250)\end{array}$ & & & & & & & & & & & & \\
\hline Very Good & & & & & $\begin{array}{l}-0.0156 \\
(0.0316)\end{array}$ & $\begin{array}{l}-0.0156 \\
(0.0315)\end{array}$ & $\begin{array}{l}-0.0308 \\
(0.0263)\end{array}$ & $\begin{array}{c}-0.0267 \\
(0.0265)\end{array}$ & & & & & & & & \\
\hline Good & & & & & $\begin{array}{c}-0.0793^{* *} \\
(0.0336)\end{array}$ & $\begin{array}{c}-0.0793^{* *} \\
(0.0336)\end{array}$ & $\begin{array}{c}-0.0551^{* *} \\
(0.0263)\end{array}$ & $\begin{array}{l}-0.0514^{*} \\
(0.0262)\end{array}$ & & & & & & & & \\
\hline Fair/Poor & & & & & $\begin{array}{c}-0.344^{* * *} \\
(0.0351)\end{array}$ & $\begin{array}{c}-0.344^{* * *} \\
(0.0352)\end{array}$ & $\begin{array}{c}-0.313^{* * *} \\
(0.0346)\end{array}$ & $\begin{array}{c}-0.302^{* * *} \\
(0.0352)\end{array}$ & & & & & & & & \\
\hline \# of Cond. & & & & & & & & & $\begin{array}{c}-0.0755^{* * *} \\
(0.00975)\end{array}$ & $\begin{array}{c}-0.0755^{* * *} \\
(0.00972)\end{array}$ & $\begin{array}{c}-0.0544^{* * *} \\
(0.00852)\end{array}$ & $\begin{array}{c}-0.0525 * * * \\
(0.00875)\end{array}$ & & & & \\
\hline \# of Func. Lim. & & & & & & & & & & & & & $\begin{array}{c}-0.0579 * * * \\
(0.00545)\end{array}$ & $\begin{array}{c}-0.0580^{* * *} \\
(0.00549)\end{array}$ & $\begin{array}{c}-0.0664^{* * *} \\
(0.00542)\end{array}$ & $\begin{array}{c}-0.0650^{* * *} \\
(0.00565)\end{array}$ \\
\hline \# Children $<18$ & $\begin{array}{l}-0.0490^{*} \\
(0.0267)\end{array}$ & $\begin{array}{l}-0.0496 * \\
(0.0267)\end{array}$ & $\begin{array}{c}0.146^{* * *} \\
(0.0387)\end{array}$ & $\begin{array}{c}0.0532 * * * \\
(0.0140)\end{array}$ & $\begin{array}{l}-0.0356 \\
(0.0273)\end{array}$ & $\begin{array}{c}-0.0356 \\
(0.0273)\end{array}$ & $\begin{array}{c}0.0557^{* * *} \\
(0.0145)\end{array}$ & $\begin{array}{c}0.0541^{* * *} \\
(0.0143)\end{array}$ & $\begin{array}{l}-0.0381 \\
(0.0268)\end{array}$ & $\begin{array}{l}-0.0380 \\
(0.0269)\end{array}$ & $\begin{array}{c}0.0588^{* * *} \\
(0.0151)\end{array}$ & $\begin{array}{c}0.0571^{* * *} \\
(0.0150)\end{array}$ & $\begin{array}{c}-0.0506^{*} \\
(0.0260)\end{array}$ & $\begin{array}{l}-0.0506^{*} \\
(0.0260)\end{array}$ & $\begin{array}{c}0.0536 * * * \\
(0.0151)\end{array}$ & $\begin{array}{c}0.0520^{* * *} \\
(0.0150)\end{array}$ \\
\hline \# Children >=18 & $\begin{array}{c}0.0828^{* * *} \\
(0.0170)\end{array}$ & $\begin{array}{c}0.0829 * * * \\
(0.0170)\end{array}$ & $\begin{array}{c}0.263^{* * *} \\
(0.0414)\end{array}$ & $\begin{array}{c}0.0954^{* * *} \\
(0.0150)\end{array}$ & $\begin{array}{c}0.0943^{* * *} \\
(0.0165)\end{array}$ & $\begin{array}{c}0.0943^{* * *} \\
(0.0166)\end{array}$ & $\begin{array}{c}0.0986 * * * \\
(0.0149)\end{array}$ & $\begin{array}{c}0.0978^{* * *} \\
(0.0149)\end{array}$ & $\begin{array}{c}0.0928^{* * *} \\
(0.0162)\end{array}$ & $\begin{array}{c}0.0928^{* * *} \\
(0.0163)\end{array}$ & $\begin{array}{c}0.0971^{* * *} \\
(0.0146)\end{array}$ & $\begin{array}{c}0.0963^{* * *} \\
(0.0147)\end{array}$ & $\begin{array}{c}0.0863^{* * *} \\
(0.0164)\end{array}$ & $\begin{array}{c}0.0863^{* * *} \\
(0.0164)\end{array}$ & $\begin{array}{c}0.0980^{* * * *} \\
(0.0148)\end{array}$ & $\begin{array}{c}0.0974 * * * \\
(0.0149)\end{array}$ \\
\hline White & $\begin{array}{c}0.0438 \\
(0.0289)\end{array}$ & $\begin{array}{c}0.0452 \\
(0.0287)\end{array}$ & $\begin{array}{c}0.0999 \\
(0.0711)\end{array}$ & $\begin{array}{c}0.0367 \\
(0.0263)\end{array}$ & $\begin{array}{c}0.0413 \\
(0.0293)\end{array}$ & $\begin{array}{c}0.0412 \\
(0.0290)\end{array}$ & $\begin{array}{c}0.0318 \\
(0.0262)\end{array}$ & $\begin{array}{c}0.0338 \\
(0.0261)\end{array}$ & $\begin{array}{l}0.0585^{* *} \\
(0.0285)\end{array}$ & $\begin{array}{l}0.0583^{* *} \\
(0.0283)\end{array}$ & $\begin{array}{c}0.0377 \\
(0.0249)\end{array}$ & $\begin{array}{c}0.0385 \\
(0.0248)\end{array}$ & $\begin{array}{c}0.0477 \\
(0.0293)\end{array}$ & $\begin{array}{c}0.0479 \\
(0.0291)\end{array}$ & $\begin{array}{l}0.0444^{*} \\
(0.0249)\end{array}$ & $\begin{array}{l}0.0453^{*} \\
(0.0249)\end{array}$ \\
\hline
\end{tabular}


Table A2 (continued). Estimates of women and men's labor force participation as a function of selected spouse's health measures with and without instrumenting for spouse's earnings

\begin{tabular}{|c|c|c|c|c|c|c|c|c|c|c|c|c|c|c|c|c|}
\hline \multirow[b]{2}{*}{ VARIABLE } & \multicolumn{2}{|c|}{ Women } & \multicolumn{2}{|c|}{ Men } & \multicolumn{2}{|c|}{ Women } & \multicolumn{2}{|c|}{ Men } & \multicolumn{2}{|c|}{ Women } & \multicolumn{2}{|c|}{ Men } & \multicolumn{2}{|c|}{ Women } & \multicolumn{2}{|c|}{ Men } \\
\hline & Non-IV & IV & Non-IV & IV & Non-IV & IV & Non-IV & IV & Non-IV & IV & Non-IV & IV & Non-IV & IV & Non-IV & IV \\
\hline \multicolumn{17}{|c|}{ Potential Wage Indicators } \\
\hline \multirow[t]{2}{*}{ Educ. (yrs.) } & $0.0110^{* *}$ & $0.0121^{* *}$ & -0.0171 & -0.00622 & 0.00604 & 0.00604 & -0.00533 & $-0.00900 * *$ & $0.0125 * * *$ & $0.0124^{* *}$ & -0.000820 & -0.00521 & $.0107^{* *}$ & $0.0108^{* *}$ & -0.00464 & $-0.00862^{* *}$ \\
\hline & $(0.00463)$ & $(0.00537)$ & $(0.0114)$ & $(0.00413)$ & $(0.00451)$ & $(0.00525)$ & $(0.00413)$ & $(0.00423)$ & (0.00449) & $(0.00524)$ & $(0.00413)$ & $(0.00423)$ & $(0.00449)$ & $(0.00528)$ & $(0.00410)$ & $(0.00428)$ \\
\hline \multirow[t]{2}{*}{ Educ.missing } & $0.326 * * *$ & $0.327 * * *$ & $0.514^{*}$ & $0.161^{* *}$ & $0.299 * * *$ & $0.299 * * *$ & $0.183^{* * *}$ & $0.169^{* * *}$ & $0.319 * * *$ & $0.319 * * *$ & $0.200^{* * *}$ & $0.184^{* * *}$ & $0.316 * * *$ & $0.316^{* * *}$ & $0.178^{* * *}$ & $0.161^{* *}$ \\
\hline & $(0.0602)$ & $(0.0601)$ & $(0.263)$ & $(0.0677)$ & $(0.0688)$ & $(0.0690)$ & $(0.0616)$ & (0.0648) & (0.0569) & $(0.0573)$ & $(0.0548)$ & $(0.0591)$ & (0.0614) & $(0.0616)$ & $(0.0635)$ & $(0.0675)$ \\
\hline \multirow[t]{2}{*}{ Exper. } & $-0.0436 *$ & $-0.0460 *$ & -0.0150 & -0.00546 & -0.0366 & -0.0366 & 0.000197 & 0.00254 & -0.0314 & -0.0310 & 0.00231 & 0.00526 & -0.0387 & -0.0390 & -0.00482 & -0.00196 \\
\hline & $(0.0255)$ & $(0.0259)$ & $(0.0579)$ & $(0.0210)$ & $(0.0254)$ & $(0.0259)$ & $(0.0203)$ & $(0.0204)$ & $(0.0251)$ & $(0.0255)$ & $(0.0207)$ & $(0.0208)$ & $(0.0256)$ & $(0.0261)$ & $(0.0211)$ & $(0.0212)$ \\
\hline \multirow[t]{2}{*}{ Exper. Sq. } & 0.000288 & 0.000319 & -0.000229 & $-8.31 e-05$ & 0.000186 & 0.000186 & -0.000157 & -0.000194 & 0.000143 & 0.000138 & -0.000177 & -0.000223 & 0.000224 & 0.000227 & $-8.88 \mathrm{e}-05$ & -0.000133 \\
\hline & (0.000341) & $(0.000347)$ & $(0.000788)$ & $(0.000286)$ & (0.000339) & $(0.000344)$ & $(0.000274)$ & $(0.000275)$ & (0.000334) & $(0.000338)$ & $(0.000281)$ & $(0.000282)$ & (0.000342) & $(0.000348)$ & $(0.000287)$ & $(0.000288)$ \\
\hline \multicolumn{17}{|l|}{ Unearned Income } \\
\hline \multirow[t]{2}{*}{ Sp Earnings ( $\$ 100 /$ wk.) } & $-0.0113^{* * *}$ & $-0.0134^{* * *}$ & $-0.0197^{* * *}$ & $-0.00717^{* * *}$ & $-0.0107^{* * *}$ & $-0.0107^{* *}$ & $-0.00620^{* *}$ & 0.00637 & $-0.0104^{* * *}$ & $-0.0100^{* *}$ & $-0.00590^{* *}$ & 0.00747 & $-0.0109^{* * *}$ & $-0.0111^{* *}$ & -0.0063 & 0.00608 \\
\hline & $(0.0$ & $(0.00429)$ & $(0.00688)$ & $(0.00250)$ & (0.00149) & $(0.00436)$ & $(0.00241)$ & $(0.00545)$ & $(0.00149)$ & $(0.00440)$ & $(0.00246)$ & $(0.00549)$ & $(0.00151)$ & 10.0 & & $(0.00561)$ \\
\hline \multirow[t]{2}{*}{ HH Income (\$100/yr.) } & $-0.000283^{* * *}$ & $-0.000284^{* * *}$ & $-0.00121^{* * *}$ & $-0.000441^{* *}$ & $0.000273^{* * *}$ & $-0.000273^{* * *}$ & $-0.000467 * * *$ & $-0.000455^{* * *}$ & $0.000264^{* * *}$ & $0.000264 * * *$ & $0.000483^{* * *}$ & $* 0.000470 * *$ & $0.000273^{* * *}$ & $0.000273 * * *$ & ${ }^{*}-0.000469 * *$ & $* 0.000458 * *$ \\
\hline & $(5.96 e-05)$ & $(5.95 e-05)$ & $(0.000129)$ & $(4.70 e-05)$ & $(5.78 e-05)$ & $(5.80 \mathrm{e}-05)$ & $(4.85 e-05)$ & $(4.95 e-05)$ & $(5.88 \mathrm{e}-05)$ & (5.90e-05) & $(4.90 \mathrm{e}-05)$ & $(5.01 \mathrm{e}-05)$ & $(5.93 e-05)$ & $(5.95 e-05)$ & $(4.82 \mathrm{e}-05)$ & (4.94e-05) \\
\hline \multirow[t]{2}{*}{ Sp Employed } & $0.137^{* * *}$ & $0.157^{* * *}$ & $0.342^{* * *}$ & $0.126^{* * *}$ & $0.114^{* * *}$ & $0.114^{* *}$ & $0.103^{* * *}$ & 0.0202 & $0.122^{* * *}$ & $0.118^{* *}$ & $0.0994^{* * *}$ & 0.0105 & $0.122^{* * *}$ & $0.124^{* *}$ & $0.105^{* * *}$ & 0.0219 \\
\hline & 275) & $(0.0495)$ & $(0.0683)$ & $(0.0257)$ & $(0.0256)$ & $(0.0483)$ & $(0.0236)$ & $(0.0400)$ & $(0.0257)$ & $(0.0498)$ & $(0.0240)$ & 5) & $(0.0254)$ & $(0.0$ & (0.0243) & $(0.0$ \\
\hline \multirow[t]{2}{*}{ Pension/IRA } & -0.0287 & -0.0304 & -0.00800 & -0.00291 & -0.0304 & -0.0304 & -0.0108 & -0.0126 & -0.0279 & -0.0277 & -0.00345 & -0.00561 & -0.0339 & -0.0341 & 0.000833 & -0.00118 \\
\hline & $(0.0279)$ & $(0.0282)$ & $(0.0747)$ & $(0.0272)$ & $(0.0269)$ & $(0.0272)$ & $(0.0264)$ & $(0.0266)$ & $(0.0270)$ & $(0.0271)$ & $(0.0263)$ & $(0.0265)$ & $(0.0277)$ & $(0.0280)$ & $(0.0275)$ & $(0.0277)$ \\
\hline \multicolumn{17}{|c|}{ Control for Region and Time } \\
\hline \multirow[t]{2}{*}{ Midwest } & -0.0106 & -0.0118 & $0.159 * *$ & $0.0565 * *$ & -0.0138 & -0.0138 & $0.0482^{* *}$ & $0.0524 * *$ & -0.00994 & -0.00976 & $0.0506^{* *}$ & $0.0555^{* *}$ & -0.00753 & -0.00765 & $0.0477^{*}$ & $0.0523 * *$ \\
\hline & (0.0339) & $(0.0339)$ & (0.0718) & $(0.0250)$ & $(0.0315)$ & $(0.0315)$ & $(0.0235)$ & $(0.0230)$ & $(0.0329)$ & $(0.0330)$ & $(0.0241)$ & $(0.0235)$ & $(0.0320)$ & $(0.0320)$ & $(0.0251)$ & $(0.0246)$ \\
\hline \multirow[t]{2}{*}{ South } & $-0.0555^{*}$ & $-0.0559 *$ & 0.0879 & 0.0317 & $\begin{array}{l}-0.0531 * * \\
\end{array}$ & $-0.0531^{* *}$ & 0.0231 & 0.0268 & $-0.0655 * *$ & $-0.0654^{* *}$ & 0.0241 & 0.0286 & $-0.0511 *$ & $-0.0511^{*}$ & 0.0273 & 0.0314 \\
\hline & & & $(0.0664)$ & $(0.0238)$ & $(0.0263)$ & $(0.0264)$ & $(0.0226)$ & $(0.0223)$ & $(0.0282)$ & & $(0.0232)$ & (0.0229) & $(0.0277)$ & (0.0278) & $(0.0236)$ & \\
\hline \multirow[t]{2}{*}{ West } & $-0.0940^{* * *}$ & $-0.0940 * * *$ & 0.0541 & 0.0195 & $-0.0890 * * *$ & $-0.0890 * * *$ & 0.0185 & 0.0219 & $-0.0948 * * *$ & $-0.0948 * * *$ & 0.0191 & 0.0233 & $-0.0959 * * *$ & $-0.0959 * * *$ & 0.0168 & 0.0207 \\
\hline & $(0.0332)$ & $(0.0330)$ & $(0.0674)$ & $(0.0241)$ & $(0.0294)$ & $(0.0294)$ & $(0.0227)$ & $(0.0224)$ & $(0.0307)$ & $(0.0308)$ & $(0.0235)$ & $(0.0233)$ & $(0.0310)$ & (0.0310) & $(0.0236)$ & $(0.0235)$ \\
\hline \multirow[t]{2}{*}{ MSA } & 0.0327 & 0.0351 & 0.00377 & 0.00137 & 0.0383 & 0.0383 & 0.00723 & -0.00123 & $0.0441 *$ & $0.0437^{*}$ & 0.0123 & 0.00271 & 0.0372 & 0.0374 & 0.00670 & -0.00234 \\
\hline & (0.0251) & $(0.0253)$ & $(0.0586)$ & $(0.0213)$ & $(0.0247)$ & $(0.0249)$ & (0.0209) & $(0.0211)$ & $(0.0254)$ & $(0.0256)$ & $(0.0203)$ & $(0.0206)$ & $(0.0251)$ & $(0.0253)$ & $(0.0211)$ & $(0.0212)$ \\
\hline
\end{tabular}


Table A2 (continued). Estimates of women and men's labor force participation as a function of selected spouse's health measures with and without instrumenting for spouse's earnings

\begin{tabular}{|c|c|c|c|c|c|c|c|c|c|c|c|c|c|c|c|c|}
\hline \multirow[b]{2}{*}{ VARIABLE } & \multicolumn{2}{|c|}{ Women } & \multicolumn{2}{|c|}{ Men } & \multicolumn{2}{|c|}{ Women } & \multicolumn{2}{|c|}{ Men } & \multicolumn{2}{|c|}{ Women } & \multicolumn{2}{|c|}{ Men } & \multicolumn{2}{|c|}{ Women } & \multicolumn{2}{|c|}{ Men } \\
\hline & Non-IV & IV & Non-IV & IV & Non-IV & IV & Non-IV & IV & Non-IV & IV & Non-IV & IV & Non-IV & IV & Non-IV & IV \\
\hline Panel 6 (2002) & $\begin{array}{l}-0.00568 \\
(0.0470)\end{array}$ & $\begin{array}{l}-0.00453 \\
(0.0469)\end{array}$ & $\begin{array}{l}0.0523 \\
(0.117)\end{array}$ & $\begin{array}{c}0.0188 \\
(0.0418)\end{array}$ & $\begin{array}{l}-0.0118 \\
(0.0483)\end{array}$ & $\begin{array}{l}-0.0118 \\
(0.0482)\end{array}$ & $\begin{array}{c}0.0261 \\
(0.0413)\end{array}$ & $\begin{array}{c}0.0258 \\
(0.0417)\end{array}$ & $\begin{array}{c}0.0130 \\
(0.0463)\end{array}$ & $\begin{array}{c}0.0128 \\
(0.0462)\end{array}$ & $\begin{array}{c}0.0300 \\
(0.0395)\end{array}$ & $\begin{array}{c}0.0283 \\
(0.0398)\end{array}$ & $\begin{array}{l}-0.00382 \\
(0.0472)\end{array}$ & $\begin{array}{l}-0.00371 \\
(0.0471)\end{array}$ & $\begin{array}{c}0.0377 \\
(0.0396)\end{array}$ & $\begin{array}{c}0.0363 \\
(0.0400)\end{array}$ \\
\hline Panel 7 (2003) & $\begin{array}{l}-0.0279 \\
(0.0411)\end{array}$ & $\begin{array}{l}-0.0282 \\
(0.0411)\end{array}$ & $\begin{array}{l}-0.0822 \\
(0.0922)\end{array}$ & $\begin{array}{l}-0.0302 \\
(0.0343)\end{array}$ & $\begin{array}{l}-0.0408 \\
(0.0402)\end{array}$ & $\begin{array}{c}-0.0408 \\
(0.0403)\end{array}$ & $\begin{array}{l}-0.00761 \\
(0.0344)\end{array}$ & $\begin{array}{c}-0.00790 \\
(0.0347)\end{array}$ & $\begin{array}{c}-0.0263 \\
(0.0400)\end{array}$ & $\begin{array}{l}-0.0262 \\
(0.0402)\end{array}$ & $\begin{array}{l}-0.0102 \\
(0.0328)\end{array}$ & $\begin{array}{l}-0.0107 \\
(0.0331)\end{array}$ & $\begin{array}{l}-0.0362 \\
(0.0404)\end{array}$ & $\begin{array}{c}-0.0363 \\
(0.0405)\end{array}$ & $\begin{array}{l}-0.00396 \\
(0.0333)\end{array}$ & $\begin{array}{l}-0.00425 \\
(0.0335)\end{array}$ \\
\hline Panel 8 (2004) & $\begin{array}{l}-0.00484 \\
(0.0392)\end{array}$ & $\begin{array}{l}-0.00448 \\
(0.0390)\end{array}$ & $\begin{array}{c}0.0158 \\
(0.0966)\end{array}$ & $\begin{array}{l}0.00572 \\
(0.0349)\end{array}$ & $\begin{array}{l}-0.00868 \\
(0.0376)\end{array}$ & $\begin{array}{l}-0.00868 \\
(0.0375)\end{array}$ & $\begin{array}{l}0.00478 \\
(0.0338)\end{array}$ & $\begin{array}{c}-0.000986 \\
(0.0339)\end{array}$ & $\begin{array}{l}-0.00118 \\
(0.0372)\end{array}$ & $\begin{array}{l}-0.00124 \\
(0.0372)\end{array}$ & $\begin{array}{c}-0.000348 \\
(0.0335)\end{array}$ & $\begin{array}{l}-0.00652 \\
(0.0336)\end{array}$ & $\begin{array}{l}-0.00547 \\
(0.0384)\end{array}$ & $\begin{array}{l}-0.00543 \\
(0.0383)\end{array}$ & $\begin{array}{c}0.0156 \\
(0.0331)\end{array}$ & $\begin{array}{l}0.00995 \\
(0.0335)\end{array}$ \\
\hline Panel 9 (2005) & $\begin{array}{l}-0.0214 \\
(0.0370)\end{array}$ & $\begin{array}{l}-0.0201 \\
(0.0370)\end{array}$ & $\begin{array}{c}0.0561 \\
(0.0937)\end{array}$ & $\begin{array}{c}0.0202 \\
(0.0334)\end{array}$ & $\begin{array}{l}-0.0174 \\
(0.0391)\end{array}$ & $\begin{array}{c}-0.0174 \\
(0.0392)\end{array}$ & $\begin{array}{c}0.0187 \\
(0.0342)\end{array}$ & $\begin{array}{c}0.0137 \\
(0.0346)\end{array}$ & $\begin{array}{l}-0.0156 \\
(0.0375)\end{array}$ & $\begin{array}{l}-0.0158 \\
(0.0376)\end{array}$ & $\begin{array}{c}0.0197 \\
(0.0326)\end{array}$ & $\begin{array}{c}0.0144 \\
(0.0331)\end{array}$ & $\begin{array}{l}-0.0192 \\
(0.0372)\end{array}$ & $\begin{array}{l}-0.0190 \\
(0.0373)\end{array}$ & $\begin{array}{c}0.0234 \\
(0.0324)\end{array}$ & $\begin{array}{c}0.0184 \\
(0.0330)\end{array}$ \\
\hline Panel 10 (2006) & $\begin{array}{l}0.00621 \\
(0.0402)\end{array}$ & $\begin{array}{l}0.00705 \\
(0.0398)\end{array}$ & $\begin{array}{c}0.105 \\
(0.106)\end{array}$ & $\begin{array}{c}0.0374 \\
(0.0373)\end{array}$ & $\begin{array}{l}0.00475 \\
(0.0405)\end{array}$ & $\begin{array}{l}0.00474 \\
(0.0403)\end{array}$ & $\begin{array}{c}0.0409 \\
(0.0365)\end{array}$ & $\begin{array}{c}0.0337 \\
(0.0376)\end{array}$ & $\begin{array}{c}0.0191 \\
(0.0402)\end{array}$ & $\begin{array}{c}0.0190 \\
(0.0399)\end{array}$ & $\begin{array}{c}0.0369 \\
(0.0366)\end{array}$ & $\begin{array}{c}0.0295 \\
(0.0378)\end{array}$ & $\begin{array}{l}0.00425 \\
(0.0403)\end{array}$ & $\begin{array}{l}0.00433 \\
(0.0400)\end{array}$ & $\begin{array}{c}0.0411 \\
(0.0358)\end{array}$ & $\begin{array}{c}0.0343 \\
(0.0370)\end{array}$ \\
\hline Panel 11 (2007) & $\begin{array}{c}0.0134 \\
(0.0365)\end{array}$ & $\begin{array}{c}0.0150 \\
(0.0364)\end{array}$ & $\begin{array}{c}0.0689 \\
(0.0879)\end{array}$ & $\begin{array}{c}0.0248 \\
(0.0312)\end{array}$ & $\begin{array}{c}0.0177 \\
(0.0369)\end{array}$ & $\begin{array}{c}0.0177 \\
(0.0368)\end{array}$ & $\begin{array}{c}0.0294 \\
(0.0303)\end{array}$ & $\begin{array}{c}0.0157 \\
(0.0318)\end{array}$ & $\begin{array}{c}0.0234 \\
(0.0362)\end{array}$ & $\begin{array}{c}0.0231 \\
(0.0360)\end{array}$ & $\begin{array}{c}0.0261 \\
(0.0295)\end{array}$ & $\begin{array}{c}0.0114 \\
(0.0309)\end{array}$ & $\begin{array}{c}0.0143 \\
(0.0357)\end{array}$ & $\begin{array}{c}0.0145 \\
(0.0356)\end{array}$ & $\begin{array}{c}0.0372 \\
(0.0299)\end{array}$ & $\begin{array}{c}0.0235 \\
(0.0317)\end{array}$ \\
\hline
\end{tabular}

Note: Standard errors in parentheses; all tests are two-sided against the null hypothesis that the marginal effect is $=0 ; \quad{ }^{* * *} p<0.01, * * p<0.05,{ }^{*} p<0.1$

Note: Probit regressions with robust standard errors, using MEPS Panels 5 through 7. Marginal Effects of the probit regression are reported - the coefficients are normalized to represent the derivative of the probability of employment with respect to a change in the explanatory variable. 
Table A3. Estimates of women and men's labor force participation as a function of spouse's health measures with and without instrumenting for spouse's earnings

\begin{tabular}{|c|c|c|c|c|c|c|c|c|c|c|c|c|}
\hline \multirow[b]{3}{*}{ VARIABLE } & \multicolumn{4}{|c|}{ (1) } & \multicolumn{4}{|c|}{ (2) } & \multicolumn{4}{|c|}{ (3) } \\
\hline & \multicolumn{2}{|c|}{ Women } & \multicolumn{2}{|c|}{ Men } & \multicolumn{2}{|c|}{ Women } & \multicolumn{2}{|c|}{ Men } & \multicolumn{2}{|c|}{ Women } & \multicolumn{2}{|c|}{ Men } \\
\hline & Non-IV & IV & Non-IV & IV & Non-IV & IV & Non-IV & IV & Non-IV & IV & Non-IV & IV \\
\hline \multicolumn{13}{|c|}{ Reservation Wage Indicators } \\
\hline Spouse Work-limit & $\begin{array}{c}0.0952^{* * *} \\
(0.0363)\end{array}$ & $\begin{array}{c}0.0956 * * * \\
(0.0365)\end{array}$ & $\begin{array}{l}0.121^{* * *} \\
(0.0425)\end{array}$ & $\begin{array}{c}0.115^{* * *} \\
(0.0420)\end{array}$ & & & & & & & & \\
\hline Spouse Very Good & $\begin{array}{l}-0.0355 \\
(0.0299)\end{array}$ & $\begin{array}{r}-0.0363 \\
(0.0299)\end{array}$ & $\begin{array}{c}0.0452 \\
(0.0303)\end{array}$ & $\begin{array}{c}0.0499 \\
(0.0305)\end{array}$ & & & & & & & & \\
\hline Spouse Good & $\begin{array}{c}0.0153 \\
(0.0296)\end{array}$ & $\begin{array}{c}0.0128 \\
(0.0294)\end{array}$ & $\begin{array}{c}0.0557^{*} \\
(0.0294)\end{array}$ & $\begin{array}{c}0.0641^{* *} \\
(0.0288)\end{array}$ & & & & & & & & \\
\hline Spouse Fair/Poor & $\begin{array}{c}0.0120 \\
(0.0373)\end{array}$ & $\begin{array}{l}0.00978 \\
(0.0378)\end{array}$ & $\begin{array}{l}0.0601^{*} \\
(0.0345)\end{array}$ & $\begin{array}{l}0.0708^{* *} \\
(0.0338)\end{array}$ & & & & & & & & \\
\hline Spouse \# of Conditions & & & & & $\begin{array}{l}0.0181^{*} \\
(0.0103)\end{array}$ & $\begin{array}{l}0.0181^{*} \\
(0.0103)\end{array}$ & $\begin{array}{l}0.0210^{* *} \\
(0.00900)\end{array}$ & $\begin{array}{l}0.0210^{* *} \\
(0.00899)\end{array}$ & & & & \\
\hline Spouse \# of Func. Limits & & & & & $\begin{array}{c}0.00493 \\
(0.00525)\end{array}$ & $\begin{array}{c}0.00492 \\
(0.00526)\end{array}$ & $\begin{array}{c}0.00451 \\
(0.00511)\end{array}$ & $\begin{array}{c}0.00446 \\
(0.00509)\end{array}$ & & & & \\
\hline Spouse (z-scored) PCS & & & & & & & & & $\begin{array}{c}-0.0247^{* *} \\
(0.0104)\end{array}$ & $\begin{array}{c}-0.0248^{* *} \\
(0.0105)\end{array}$ & $\begin{array}{l}-0.0169 * \\
(0.00992)\end{array}$ & $\begin{array}{c}-0.0192^{*} \\
(0.00989)\end{array}$ \\
\hline Work-limit & $\begin{array}{c}-0.429 * * * \\
(0.0325)\end{array}$ & $\begin{array}{c}-0.430 * * * \\
(0.0323)\end{array}$ & $\begin{array}{c}-0.511^{* * *} \\
(0.0309)\end{array}$ & $\begin{array}{c}-0.503^{* * *} \\
(0.0326)\end{array}$ & & & & & & & & \\
\hline Very Good & $\begin{array}{c}-0.00566 \\
(0.0320)\end{array}$ & $\begin{array}{c}-0.00469 \\
(0.0319)\end{array}$ & $\begin{array}{r}-0.0275 \\
(0.0268)\end{array}$ & $\begin{array}{r}-0.0234 \\
(0.0269)\end{array}$ & & & & & & & & \\
\hline Good & $\begin{array}{l}-0.0476 \\
(0.0331)\end{array}$ & $\begin{array}{r}-0.0479 \\
(0.0331)\end{array}$ & $\begin{array}{l}-0.0292 \\
(0.0270)\end{array}$ & $\begin{array}{r}-0.0260 \\
(0.0269)\end{array}$ & & & & & & & & \\
\hline Fair/Poor & $\begin{array}{c}-0.177^{* * *} \\
(0.0411)\end{array}$ & $\begin{array}{c}-0.177^{* * *} \\
(0.0411)\end{array}$ & $\begin{array}{c}-0.160 * * * \\
(0.0404)\end{array}$ & $\begin{array}{c}-0.152^{* * *} \\
(0.0401)\end{array}$ & & & & & & & & \\
\hline \# of Conditions & & & & & $\begin{array}{c}-0.0496^{* * *} \\
(0.0104)\end{array}$ & $\begin{array}{c}-0.0496 * * * \\
(0.0104)\end{array}$ & $\begin{array}{c}-0.0278^{* * *} \\
(0.00892)\end{array}$ & $\begin{array}{c}-0.0266^{* * *} \\
(0.00904)\end{array}$ & & & & \\
\hline \# of Functional Limitations & & & & & $\begin{array}{c}-0.0508^{* * *} \\
(0.00567)\end{array}$ & $\begin{array}{c}-0.0508^{* * *} \\
(0.00571)\end{array}$ & $\begin{array}{c}-0.0619 * * * \\
(0.00537)\end{array}$ & $\begin{array}{c}-0.0608^{* * *} \\
(0.00554)\end{array}$ & & & & \\
\hline (z-scored) PCS & & & & & & & & & $\begin{array}{l}0.118^{* * *} \\
(0.0126)\end{array}$ & $\begin{array}{l}0.118^{* * *} \\
(0.0125)\end{array}$ & $\begin{array}{l}0.102^{* * *} \\
(0.00955)\end{array}$ & $\begin{array}{l}0.100^{* * *} \\
(0.00968)\end{array}$ \\
\hline
\end{tabular}


Table A3 (continued). Estimates of women and men's labor force participation as a function of spouse's health measures with and without instrumenting for spouse's earnings

\begin{tabular}{|c|c|c|c|c|c|c|c|c|c|c|c|c|}
\hline \multirow[b]{3}{*}{ VARIABLE } & \multicolumn{4}{|c|}{ (1) } & \multicolumn{4}{|c|}{ (2) } & \multicolumn{4}{|c|}{ (3) } \\
\hline & \multicolumn{2}{|c|}{ Women } & \multicolumn{2}{|c|}{ Men } & \multicolumn{2}{|c|}{ Women } & \multicolumn{2}{|c|}{ Men } & \multicolumn{2}{|c|}{ Women } & \multicolumn{2}{|c|}{ Men } \\
\hline & Non-IV & IV & Non-IV & IV & Non-IV & IV & Non-IV & IV & Non-IV & IV & Non-IV & IV \\
\hline$\#$ Children $<18$ years old & $-0.0469^{*}$ & $-0.0476^{*}$ & $0.0524^{* * *}$ & $0.0507^{* * *}$ & $-0.0510^{*}$ & $-0.0510^{*}$ & $0.0546 * * *$ & $0.0530^{* * *}$ & -0.0440 & -0.0439 & $0.0547^{* * *}$ & $0.0544^{* * *}$ \\
\hline & $(0.0272)$ & $(0.0272)$ & $(0.0138)$ & $(0.0138)$ & $(0.0264)$ & $(0.0264)$ & $(0.0154)$ & $(0.0153)$ & $(0.0324)$ & $(0.0323)$ & $(0.0169)$ & $(0.0168)$ \\
\hline \# Children $>=18$ years old & $\begin{array}{c}0.0843^{* * *} \\
(0.0172)\end{array}$ & $\begin{array}{c}0.0844^{* * *} \\
(0.0172)\end{array}$ & $\begin{array}{c}0.0955^{* * *} \\
(0.0151)\end{array}$ & $\begin{array}{c}0.0948^{* * *} \\
(0.0151)\end{array}$ & $\begin{array}{c}0.0851^{* * *} \\
(0.0164)\end{array}$ & $\begin{array}{c}0.0851^{* * *} \\
(0.0165)\end{array}$ & $\begin{array}{c}0.0973^{* * *} \\
(0.0148)\end{array}$ & $\begin{array}{c}0.0967^{* * *} \\
(0.0148)\end{array}$ & $\begin{array}{c}0.0889 * * * \\
(0.0178)\end{array}$ & $\begin{array}{c}0.0889 * * * \\
(0.0178)\end{array}$ & $\begin{array}{c}0.0996 * * * \\
(0.0157)\end{array}$ & $\begin{array}{c}0.0991^{* * *} \\
(0.0157)\end{array}$ \\
\hline White & $\begin{array}{c}0.0384 \\
(0.0293)\end{array}$ & $\begin{array}{c}0.0396 \\
(0.0291)\end{array}$ & $\begin{array}{c}0.0331 \\
(0.0277)\end{array}$ & $\begin{array}{c}0.0353 \\
(0.0277)\end{array}$ & $\begin{array}{c}0.0522^{*} \\
(0.0290)\end{array}$ & $\begin{array}{l}0.0524^{*} \\
(0.0288)\end{array}$ & $\begin{array}{l}0.0419^{*} \\
(0.0252)\end{array}$ & $\begin{array}{l}0.0428^{*} \\
(0.0251)\end{array}$ & $\begin{array}{l}0.0578^{*} \\
(0.0310)\end{array}$ & $\begin{array}{l}0.0577^{*} \\
(0.0311)\end{array}$ & $\begin{array}{c}0.0320 \\
(0.0277)\end{array}$ & $\begin{array}{c}0.0322 \\
(0.0275)\end{array}$ \\
\hline Potential Wage Indicators & & & & & & & & & & & & \\
\hline Education (yrs.) & $\begin{array}{l}0.00773^{*} \\
(0.00467)\end{array}$ & $\begin{array}{c}0.00879 \\
(0.00538)\end{array}$ & $\begin{array}{l}-0.00721^{*} \\
(0.00421)\end{array}$ & $\begin{array}{c}-0.0108 * * \\
(0.00437)\end{array}$ & $\begin{array}{l}0.0102^{* *} \\
(0.00450)\end{array}$ & $\begin{array}{c}0.0103^{*} \\
(0.00528)\end{array}$ & $\begin{array}{c}-0.00401 \\
(0.00411)\end{array}$ & $\begin{array}{l}-0.00815^{*} \\
(0.00428)\end{array}$ & $\begin{array}{l}0.00916 * \\
(0.00486)\end{array}$ & $\begin{array}{c}0.00909 \\
(0.00564)\end{array}$ & $\begin{array}{c}-0.00929^{* *} \\
(0.00456)\end{array}$ & $\begin{array}{c}-0.0127^{* * *} \\
(0.00473)\end{array}$ \\
\hline Education missing & $\begin{array}{c}0.308^{* * *} \\
(0.0699)\end{array}$ & $\begin{array}{l}0.309 * * * \\
(0.0698)\end{array}$ & $\begin{array}{c}0.152^{* *} \\
(0.0708)\end{array}$ & $\begin{array}{c}0.136^{*} \\
(0.0737)\end{array}$ & $\begin{array}{l}0.308^{* * *} \\
(0.0645)\end{array}$ & $\begin{array}{l}0.308^{* * *} \\
(0.0648)\end{array}$ & $\begin{array}{c}0.175 * * * \\
(0.0635)\end{array}$ & $\begin{array}{l}0.157^{* *} \\
(0.0675)\end{array}$ & $\begin{array}{l}0.309 * * * \\
(0.0720)\end{array}$ & $\begin{array}{l}0.309 * * * \\
(0.0723)\end{array}$ & $\begin{array}{c}0.142^{*} \\
(0.0824)\end{array}$ & $\begin{array}{c}0.127 \\
(0.0851)\end{array}$ \\
\hline Experience & $\begin{array}{c}-0.0446^{*} \\
(0.0257)\end{array}$ & $\begin{array}{l}-0.0469 * \\
(0.0261)\end{array}$ & $\begin{array}{l}-0.00423 \\
(0.0209)\end{array}$ & $\begin{array}{l}-0.00187 \\
(0.0211)\end{array}$ & $\begin{array}{l}-0.0383 \\
(0.0257)\end{array}$ & $\begin{array}{l}-0.0386 \\
(0.0261)\end{array}$ & $\begin{array}{l}-0.00180 \\
(0.0212)\end{array}$ & $\begin{array}{l}0.00105 \\
(0.0213)\end{array}$ & $\begin{array}{l}-0.0445^{*} \\
(0.0257)\end{array}$ & $\begin{array}{l}-0.0444^{*} \\
(0.0260)\end{array}$ & $\begin{array}{l}0.00742 \\
(0.0222)\end{array}$ & $\begin{array}{l}0.00965 \\
(0.0222)\end{array}$ \\
\hline Experience squared & $\begin{array}{c}0.000296 \\
(0.000344)\end{array}$ & $\begin{array}{c}0.000326 \\
(0.000349)\end{array}$ & $\begin{array}{c}-9.58 \mathrm{e}-05 \\
(0.000284)\end{array}$ & $\begin{array}{c}-0.000133 \\
(0.000286)\end{array}$ & $\begin{array}{c}0.000222 \\
(0.000342)\end{array}$ & $\begin{array}{c}0.000226 \\
(0.000348)\end{array}$ & $\begin{array}{c}-0.000123 \\
(0.000289)\end{array}$ & $\begin{array}{l}-0.000168 \\
(0.000289)\end{array}$ & $\begin{array}{c}0.000307 \\
(0.000346)\end{array}$ & $\begin{array}{c}0.000305 \\
(0.000349)\end{array}$ & $\begin{array}{c}-0.000253 \\
(0.000301)\end{array}$ & $\begin{array}{c}-0.000289 \\
(0.000301)\end{array}$ \\
\hline Spouse's Earnings ( $\$ 100 /$ week) & $\begin{array}{c}-0.0115^{* * *} \\
(0.00153)\end{array}$ & $\begin{array}{c}-0.0135 * * * \\
(0.00431)\end{array}$ & $\begin{array}{c}-0.00719 * * * \\
(0.00245)\end{array}$ & $\begin{array}{c}0.00535 \\
(0.00572)\end{array}$ & $\begin{array}{c}-0.0112^{* * *} \\
(0.00152)\end{array}$ & $\begin{array}{c}-0.0114^{* *} \\
(0.00448)\end{array}$ & $\begin{array}{c}-0.00646 * * * \\
(0.00243)\end{array}$ & $\begin{array}{c}0.00642 \\
(0.00560)\end{array}$ & $\begin{array}{c}-0.0114^{* * *} \\
(0.00167)\end{array}$ & $\begin{array}{l}-0.0113^{* *} \\
(0.00475)\end{array}$ & $\begin{array}{l}-0.00329 \\
(0.00255)\end{array}$ & $\begin{array}{c}0.00771 \\
(0.00557)\end{array}$ \\
\hline Household Income (\$100/year) & $\begin{array}{c}-0.000285 * * * \\
(5.90 \mathrm{e}-05)\end{array}$ & $\begin{array}{c}-0.000286^{* * *} \\
(5.89 \mathrm{e}-05)\end{array}$ & $\begin{array}{c}-0.000437^{* * *} \\
(4.71 \mathrm{e}-05)\end{array}$ & $\begin{array}{c}-0.000426 * * * \\
(4.82 \mathrm{e}-05)\end{array}$ & $\begin{array}{c}-0.000269 * * * \\
(5.94 e-05)\end{array}$ & $\begin{array}{c}-0.000269 * * * \\
(5.95 \mathrm{e}-05)\end{array}$ & $\begin{array}{c}-0.000468 * * * \\
(4.83 \mathrm{e}-05)\end{array}$ & $\begin{array}{c}-0.000456^{* * *} \\
(4.95 \mathrm{e}-05)\end{array}$ & $\begin{array}{c}-0.000291^{* * *} \\
(6.14 \mathrm{e}-05)\end{array}$ & $\begin{array}{c}-0.000291^{* * *} \\
(6.17 \mathrm{e}-05)\end{array}$ & $\begin{array}{c}-0.000485^{* * *} \\
(5.15 \mathrm{e}-05)\end{array}$ & $\begin{array}{c}-0.000475 * * * \\
(5.21 \mathrm{e}-05)\end{array}$ \\
\hline Spouse Employed & $\begin{array}{l}0.138^{* * *} \\
(0.0275)\end{array}$ & $\begin{array}{l}0.158^{* * *} \\
(0.0490)\end{array}$ & $\begin{array}{l}0.130 * * * \\
(0.0256)\end{array}$ & $\begin{array}{c}0.0463 \\
(0.0423)\end{array}$ & $\begin{array}{l}0.134^{* * *} \\
(0.0258)\end{array}$ & $\begin{array}{l}0.136^{* * *} \\
(0.0499)\end{array}$ & $\begin{array}{l}0.111^{* * *} \\
(0.0245)\end{array}$ & $\begin{array}{c}0.0247 \\
(0.0412)\end{array}$ & $\begin{array}{l}0.120^{* * *} \\
(0.0275)\end{array}$ & $\begin{array}{l}0.118^{* *} \\
(0.0516)\end{array}$ & $\begin{array}{c}0.0813^{* * *} \\
(0.0253)\end{array}$ & $\begin{array}{c}0.0110 \\
(0.0405)\end{array}$ \\
\hline Pension/IRA & $\begin{array}{l}-0.0294 \\
(0.0279)\end{array}$ & $\begin{array}{l}-0.0312 \\
(0.0282)\end{array}$ & $\begin{array}{c}-0.00386 \\
(0.0273)\end{array}$ & $\begin{array}{c}-0.00581 \\
(0.0275)\end{array}$ & $\begin{array}{l}-0.0349 \\
(0.0277)\end{array}$ & $\begin{array}{l}-0.0351 \\
(0.0279)\end{array}$ & $\begin{array}{l}0.00303 \\
(0.0277)\end{array}$ & $\begin{array}{c}0.000833 \\
(0.0279)\end{array}$ & $\begin{array}{l}-0.0474^{*} \\
(0.0286)\end{array}$ & $\begin{array}{c}-0.0472 \\
(0.0289)\end{array}$ & $\begin{array}{c}-0.00687 \\
(0.0283)\end{array}$ & $\begin{array}{c}-0.00748 \\
(0.0286)\end{array}$ \\
\hline
\end{tabular}


Table A3 (continued). Estimates of women and men's labor force participation as a function of spouse's health measures with and without instrumenting for spouse's earnings

\begin{tabular}{|c|c|c|c|c|c|c|c|c|c|c|c|c|}
\hline \multirow[b]{3}{*}{ VARIABLE } & \multicolumn{4}{|c|}{ (1) } & \multicolumn{4}{|c|}{ (2) } & \multicolumn{4}{|c|}{ (3) } \\
\hline & \multicolumn{2}{|c|}{ Women } & \multicolumn{2}{|c|}{ Men } & \multicolumn{2}{|c|}{ Women } & \multicolumn{2}{|c|}{ Men } & \multicolumn{2}{|c|}{ Women } & \multicolumn{2}{|c|}{ Men } \\
\hline & Non-IV & IV & Non-IV & IV & Non-IV & IV & Non-IV & IV & Non-IV & IV & Non-IV & IV \\
\hline Control for Region and Time & & & & & & & & & & & & \\
\hline Midwest Census Region & $\begin{array}{l}-0.00776 \\
(0.0330)\end{array}$ & $\begin{array}{l}-0.00912 \\
(0.0330)\end{array}$ & $\begin{array}{c}0.0538^{* *} \\
(0.0245)\end{array}$ & $\begin{array}{c}0.0583^{* *} \\
(0.0239)\end{array}$ & $\begin{array}{l}-0.00356 \\
(0.0321)\end{array}$ & $\begin{array}{l}-0.00369 \\
(0.0322)\end{array}$ & $\begin{array}{l}0.0471^{*} \\
(0.0248)\end{array}$ & $\begin{array}{c}0.0519 * * \\
(0.0243)\end{array}$ & $\begin{array}{l}-0.00516 \\
(0.0367)\end{array}$ & $\begin{array}{c}-0.00508 \\
(0.0367)\end{array}$ & $\begin{array}{c}0.0562^{* *} \\
(0.0256)\end{array}$ & $\begin{array}{l}0.0593^{* *} \\
(0.0255)\end{array}$ \\
\hline South Census Region & $\begin{array}{c}-0.0487^{*} \\
(0.0285)\end{array}$ & $\begin{array}{l}-0.0491^{*} \\
(0.0286)\end{array}$ & $\begin{array}{c}0.0305 \\
(0.0233)\end{array}$ & $\begin{array}{c}0.0343 \\
(0.0231)\end{array}$ & $\begin{array}{l}-0.0506^{*} \\
(0.0276)\end{array}$ & $\begin{array}{l}-0.0507^{*} \\
(0.0277)\end{array}$ & $\begin{array}{c}0.0285 \\
(0.0232)\end{array}$ & $\begin{array}{c}0.0327 \\
(0.0230)\end{array}$ & $\begin{array}{r}-0.0489 \\
(0.0307)\end{array}$ & $\begin{array}{l}-0.0489 \\
(0.0307)\end{array}$ & $\begin{array}{c}0.0347 \\
(0.0259)\end{array}$ & $\begin{array}{c}0.0372 \\
(0.0258)\end{array}$ \\
\hline West Census Region & $\begin{array}{c}-0.0910^{* * *} \\
(0.0320)\end{array}$ & $\begin{array}{c}-0.0912^{* * *} \\
(0.0318)\end{array}$ & $\begin{array}{c}0.0188 \\
(0.0235)\end{array}$ & $\begin{array}{c}0.0224 \\
(0.0234)\end{array}$ & $\begin{array}{c}-0.0976^{* * *} \\
(0.0313)\end{array}$ & $\begin{array}{c}-0.0976 * * * \\
(0.0313)\end{array}$ & $\begin{array}{c}0.0180 \\
(0.0233)\end{array}$ & $\begin{array}{c}0.0221 \\
(0.0232)\end{array}$ & $\begin{array}{c}-0.0776^{* *} \\
(0.0347)\end{array}$ & $\begin{array}{c}-0.0776^{* *} \\
(0.0348)\end{array}$ & $\begin{array}{c}0.0175 \\
(0.0263)\end{array}$ & $\begin{array}{c}0.0205 \\
(0.0263)\end{array}$ \\
\hline MSA & $\begin{array}{c}0.0336 \\
(0.0250)\end{array}$ & $\begin{array}{c}0.0358 \\
(0.0253)\end{array}$ & $\begin{array}{r}-0.00174 \\
(0.0216)\end{array}$ & $\begin{array}{c}-0.0102 \\
(0.0217)\end{array}$ & $\begin{array}{c}0.0395 \\
(0.0252)\end{array}$ & $\begin{array}{c}0.0398 \\
(0.0254)\end{array}$ & $\begin{array}{l}0.00396 \\
(0.0210)\end{array}$ & $\begin{array}{r}-0.00523 \\
(0.0212)\end{array}$ & $\begin{array}{c}0.0438^{*} \\
(0.0253)\end{array}$ & $\begin{array}{c}0.0437^{*} \\
(0.0256)\end{array}$ & $\begin{array}{l}0.00237 \\
(0.0207)\end{array}$ & $\begin{array}{l}-0.00479 \\
(0.0214)\end{array}$ \\
\hline Panel 6 (2002) & $\begin{array}{l}-0.0120 \\
(0.0483)\end{array}$ & $\begin{array}{c}-0.0112 \\
(0.0483)\end{array}$ & $\begin{array}{c}0.0148 \\
(0.0432)\end{array}$ & $\begin{array}{c}0.0148 \\
(0.0434)\end{array}$ & $\begin{array}{l}0.00620 \\
(0.0470)\end{array}$ & $\begin{array}{l}0.00634 \\
(0.0469)\end{array}$ & $\begin{array}{c}0.0309 \\
(0.0399)\end{array}$ & $\begin{array}{c}0.0295 \\
(0.0402)\end{array}$ & $\begin{array}{l}0.00939 \\
(0.0524)\end{array}$ & $\begin{array}{l}0.00931 \\
(0.0523)\end{array}$ & $\begin{array}{c}-0.0228 \\
(0.0428)\end{array}$ & $\begin{array}{l}-0.0241 \\
(0.0427)\end{array}$ \\
\hline Panel 7 (2003) & $\begin{array}{r}-0.0290 \\
(0.0412)\end{array}$ & $\begin{array}{l}-0.0295 \\
(0.0411)\end{array}$ & $\begin{array}{r}-0.0286 \\
(0.0352)\end{array}$ & $\begin{array}{r}-0.0283 \\
(0.0355)\end{array}$ & $\begin{array}{c}-0.0244 \\
(0.0404)\end{array}$ & $\begin{array}{l}-0.0244 \\
(0.0405)\end{array}$ & $\begin{array}{l}-0.00910 \\
(0.0333)\end{array}$ & $\begin{array}{r}-0.00942 \\
(0.0336)\end{array}$ & $\begin{array}{r}-0.0229 \\
(0.0429)\end{array}$ & $\begin{array}{l}-0.0229 \\
(0.0432)\end{array}$ & $\begin{array}{c}-0.0672^{* *} \\
(0.0336)\end{array}$ & $\begin{array}{l}-0.0655^{*} \\
(0.0335)\end{array}$ \\
\hline Panel 8 (2004) & $\begin{array}{l}-0.00336 \\
(0.0392)\end{array}$ & $\begin{array}{r}-0.00307 \\
(0.0391)\end{array}$ & $\begin{array}{l}0.00642 \\
(0.0348)\end{array}$ & $\begin{array}{l}0.00104 \\
(0.0352)\end{array}$ & $\begin{array}{l}0.00627 \\
(0.0380)\end{array}$ & $\begin{array}{l}0.00632 \\
(0.0379)\end{array}$ & $\begin{array}{c}0.0112 \\
(0.0330)\end{array}$ & $\begin{array}{l}0.00531 \\
(0.0334)\end{array}$ & $\begin{array}{c}-0.0181 \\
(0.0414)\end{array}$ & $\begin{array}{r}-0.0181 \\
(0.0413)\end{array}$ & $\begin{array}{c}-0.0234 \\
(0.0326)\end{array}$ & $\begin{array}{l}-0.0276 \\
(0.0324)\end{array}$ \\
\hline Panel 9 (2005) & $\begin{array}{c}-0.0172 \\
(0.0382)\end{array}$ & $\begin{array}{c}-0.0161 \\
(0.0382)\end{array}$ & $\begin{array}{c}0.0187 \\
(0.0344)\end{array}$ & $\begin{array}{c}0.0136 \\
(0.0350)\end{array}$ & $\begin{array}{c}-0.00909 \\
(0.0371)\end{array}$ & $\begin{array}{c}-0.00893 \\
(0.0372)\end{array}$ & $\begin{array}{c}0.0201 \\
(0.0327)\end{array}$ & $\begin{array}{c}0.0148 \\
(0.0334)\end{array}$ & $\begin{array}{c}-0.0185 \\
(0.0416)\end{array}$ & $\begin{array}{r}-0.0186 \\
(0.0418)\end{array}$ & $\begin{array}{c}-0.0280 \\
(0.0324)\end{array}$ & $\begin{array}{l}-0.0317 \\
(0.0327)\end{array}$ \\
\hline Panel 10 (2006) & $\begin{array}{l}0.00581 \\
(0.0406)\end{array}$ & $\begin{array}{l}0.00664 \\
(0.0402)\end{array}$ & $\begin{array}{c}0.0391 \\
(0.0377)\end{array}$ & $\begin{array}{c}0.0318 \\
(0.0390)\end{array}$ & $\begin{array}{c}0.0163 \\
(0.0405)\end{array}$ & $\begin{array}{c}0.0164 \\
(0.0402)\end{array}$ & $\begin{array}{c}0.0386 \\
(0.0363)\end{array}$ & $\begin{array}{c}0.0315 \\
(0.0375)\end{array}$ & $\begin{array}{l}0.00461 \\
(0.0426)\end{array}$ & $\begin{array}{l}0.00455 \\
(0.0424)\end{array}$ & $\begin{array}{l}0.000658 \\
(0.0351)\end{array}$ & $\begin{array}{l}-0.00268 \\
(0.0352)\end{array}$ \\
\hline Panel 11 (2007) & $\begin{array}{c}0.0174 \\
(0.0373)\end{array}$ & $\begin{array}{c}0.0190 \\
(0.0371)\end{array}$ & $\begin{array}{c}0.0249 \\
(0.0314)\end{array}$ & $\begin{array}{c}0.0111 \\
(0.0333)\end{array}$ & $\begin{array}{c}0.0262 \\
(0.0360)\end{array}$ & $\begin{array}{c}0.0264 \\
(0.0359)\end{array}$ & $\begin{array}{c}0.0324 \\
(0.0300)\end{array}$ & $\begin{array}{c}0.0181 \\
(0.0318)\end{array}$ & $\begin{array}{c}0.0307 \\
(0.0392)\end{array}$ & $\begin{array}{c}0.0307 \\
(0.0390)\end{array}$ & $\begin{array}{c}-0.00308 \\
(0.0311)\end{array}$ & $\begin{array}{l}-0.0131 \\
(0.0323)\end{array}$ \\
\hline
\end{tabular}

Note: Standard errors in parentheses; all tests are two-sided against the null hypothesis that the marginal effect is $=0 ; \quad * * * p<0.01, * * p<0.05, * p<0.1$

Note: Probit regressions with robust standard errors, using MEPS Panels 5 through 7. Marginal Effects of the probit regression are reported - the coefficients are normalized to represent the

derivative of the probability of employment with respect to a change in the explanatory variable. 
Table A4. Estimates of women and men's labor force participation as a function of spouse's health measures with and without instrumenting for spouse's earnings

\begin{tabular}{|c|c|c|c|c|c|c|c|c|c|c|c|c|c|c|c|c|}
\hline \multirow[b]{3}{*}{ VARIABLE } & \multicolumn{4}{|c|}{ (4) } & \multicolumn{4}{|c|}{ (5) } & \multicolumn{4}{|c|}{ (6) } & \multicolumn{4}{|c|}{ (7) } \\
\hline & \multicolumn{2}{|c|}{ Women } & \multicolumn{2}{|c|}{ Men } & \multicolumn{2}{|c|}{ Women } & \multicolumn{2}{|c|}{ Men } & \multicolumn{2}{|c|}{ Women } & \multicolumn{2}{|c|}{ Men } & \multicolumn{2}{|c|}{ Women } & \multicolumn{2}{|c|}{ Men } \\
\hline & Non-IV & IV & Non-IV & IV & Non-IV & IV & Non-IV & IV & Non-IV & IV & Non-IV & IV & Non-IV & IV & Non-IV & IV \\
\hline \multicolumn{5}{|c|}{ Reservation Wage Indicators } & & & & & & & & & & & & \\
\hline \multirow[t]{2}{*}{ Sp Work-limit } & & & & & $0.104^{* * *}$ & $0.106^{* * *}$ & $0.124^{* * *}$ & $0.119^{* * *}$ & $0.124^{* *}$ & $0.124^{* *}$ & $0.119^{* *}$ & $0.115^{* *}$ & $0.118^{* *}$ & $0.118^{* *}$ & $0.130^{* *}$ & $0.125^{* *}$ \\
\hline & & & & & $(0.0400)$ & $(0.0400)$ & $(0.0435)$ & $(0.0427)$ & $(0.0483)$ & $(0.0484)$ & $(0.0522)$ & $(0.0516)$ & $(0.0465)$ & $(0.0465)$ & $(0.0517)$ & $(0.0514)$ \\
\hline \multirow[t]{2}{*}{ Sp Very Good } & & & & & & & & & -0.0471 & -0.0477 & $0.0535^{*}$ & $0.0546^{*}$ & -0.0416 & -0.0425 & 0.0426 & 0.0476 \\
\hline & & & & & & & & & $(0.0298)$ & $(0.0297)$ & $(0.0298)$ & $(0.0299)$ & $(0.0296)$ & $(0.0296)$ & $(0.0302)$ & $(0.0305)$ \\
\hline \multirow[t]{2}{*}{ Sp Good } & & & & & & & & & -0.00397 & -0.00649 & $0.0555 *$ & $0.0598^{* *}$ & 0.00233 & -0.000326 & $0.0491^{*}$ & $0.0580^{* *}$ \\
\hline & & & & & & & & & $(0.0318)$ & $(0.0310)$ & $(0.0305)$ & $(0.0302)$ & $(0.0296)$ & $(0.0293)$ & (0.0294) & $(0.0289)$ \\
\hline \multirow[t]{2}{*}{ Sp Fair/Poor } & & & & & & & & & -0.00283 & -0.00492 & 0.0513 & 0.0565 & -0.00788 & -0.0107 & 0.0505 & $0.0623^{*}$ \\
\hline & & & & & & & & & $(0.0460)$ & $(0.0460)$ & $(0.0420)$ & $(0.0414)$ & $(0.0400)$ & $(0.0405)$ & $(0.0347)$ & $(0.0341)$ \\
\hline \multirow[t]{2}{*}{ Sp \# of Cond. } & 0.0162 & 0.0163 & $0.0221^{* *}$ & $0.0212^{* *}$ & & & & & 0.0122 & 0.0129 & $0.0195^{*}$ & $0.0184^{*}$ & 0.0145 & 0.0150 & 0.0163 & 0.0153 \\
\hline & $(0.0111)$ & $(0.0111)$ & $(0.00952)$ & $(0.00953)$ & & & & & $(0.0118)$ & $(0.0117)$ & $(0.0104)$ & $(0.0104)$ & $(0.0111)$ & $(0.0111)$ & (0.00993) & $(0.00996)$ \\
\hline \multirow[t]{2}{*}{ Sp \# of Func. Lim. } & 0.00296 & 0.00302 & 0.00692 & 0.00634 & & & & & -0.00801 & -0.00764 & 0.000676 & 0.000373 & -0.00667 & -0.00661 & -0.00493 & -0.00515 \\
\hline & $(0.00641)$ & $(0.00637)$ & $(0.00595)$ & $(0.00593)$ & & & & & $(0.00783)$ & $(0.00782)$ & $(0.00696)$ & (0.00698) & $(0.00694)$ & $(0.00694)$ & $(0.00667)$ & $(0.00670)$ \\
\hline \multirow[t]{2}{*}{ Sp (z-scored) PCS } & -0.0160 & -0.0157 & -0.00240 & -0.00542 & -0.0109 & -0.00942 & -0.00415 & -0.00683 & -0.00897 & -0.00747 & 0.00758 & 0.00550 & & & & \\
\hline & $(0.0133)$ & $(0.0134)$ & $(0.0120)$ & $(0.0119)$ & $(0.0125)$ & $(0.0126)$ & $(0.0113)$ & $(0.0111)$ & $(0.0144)$ & $(0.0144)$ & $(0.0135)$ & $(0.0135)$ & & & & \\
\hline \multirow[t]{2}{*}{ Work-limit } & & & & & $-0.446 * * *$ & $-0.447^{* * *}$ & $-0.523^{* * *}$ & $-0.518^{* * *}$ & $-0.430 * * *$ & $-0.430^{* * *}$ & $-0.488^{* * *}$ & $-0.484 * * *$ & $-0.396 * * *$ & $-0.397^{* * *}$ & $-0.484^{* * *}$ & $-0.476 * * *$ \\
\hline & & & & & $(0.0307)$ & $(0.0305)$ & $(0.0327)$ & $(0.0335)$ & $(0.0399)$ & $(0.0401)$ & $(0.0438)$ & $(0.0442)$ & $(0.0419)$ & $(0.0416)$ & $(0.0416)$ & $(0.0427)$ \\
\hline \multirow[t]{2}{*}{ Very Good } & & & & & & & & & 0.0166 & 0.0174 & -0.0115 & -0.00741 & 0.00622 & 0.00717 & -0.0265 & -0.0225 \\
\hline & & & & & & & & & $(0.0320)$ & $(0.0319)$ & $(0.0267)$ & $(0.0267)$ & $(0.0316)$ & $(0.0315)$ & $(0.0266)$ & $(0.0268)$ \\
\hline \multirow[t]{2}{*}{ Good } & & & & & & & & & 0.00855 & 0.00823 & -0.00768 & -0.00325 & -0.0243 & -0.0245 & -0.0282 & -0.0251 \\
\hline & & & & & & & & & $(0.0362)$ & $(0.0360)$ & $(0.0303)$ & $(0.0303)$ & $(0.0334)$ & $(0.0334)$ & $(0.0272)$ & $(0.0272)$ \\
\hline \multirow[t]{2}{*}{ Fair/Poor } & & & & & & & & & -0.0642 & -0.0638 & $-0.105^{* *}$ & $-0.0993^{* *}$ & $-0.132^{* * *}$ & $-0.131^{* * *}$ & $-0.150 * * *$ & $-0.143^{* * *}$ \\
\hline & & & & & & & & & $(0.0469)$ & $(0.0468)$ & $(0.0433)$ & $(0.0432)$ & $(0.0439)$ & $(0.0440)$ & $(0.0402)$ & $(0.0398)$ \\
\hline \# of Cond. & $-0.0362^{* * *}$ & $-0.0362^{* * *}$ & $-0.0170^{*}$ & $-0.0159^{*}$ & & & & & $-0.0276^{* *}$ & $-0.0274^{* *}$ & 0.00282 & 0.00325 & $-0.0314^{* * *}$ & $-0.0314^{* * *}$ & 0.00247 & 0.00265 \\
\hline & $(0.0119)$ & $(0.0119)$ & $(0.00960)$ & $(0.00961)$ & & & & & $(0.0117)$ & $(0.0117)$ & $(0.0102)$ & $(0.0102)$ & $(0.0107)$ & $(0.0107)$ & $(0.00934)$ & $(0.00943)$ \\
\hline \# of Func. Lim. & $-0.0354^{* * *}$ & $-0.0355^{* * *}$ & $-0.0486 * * *$ & $-0.0481^{* * *}$ & & & & & 0.00429 & 0.00402 & -0.00797 & -0.00793 & -0.00712 & -0.00729 & -0.0118 & -0.0118 \\
\hline & $(0.00646)$ & $(0.00656)$ & $(0.00699)$ & $(0.00705)$ & & & & & $(0.00785)$ & $(0.00795)$ & $(0.00913)$ & $(0.00913)$ & $(0.00716)$ & $(0.00719)$ & $(0.00770)$ & $(0.00766)$ \\
\hline (z-scored) PCS & $0.0729^{* * *}$ & $0.0729 * * *$ & $0.0556^{* * *}$ & $0.0546^{* * *}$ & $0.0669 * * *$ & $0.0669 * * *$ & $0.0371^{* * *}$ & $0.0360^{* * *}$ & $0.0529 * * *$ & $0.0528^{* * *}$ & $0.0229 *$ & $0.0228^{*}$ & & & & \\
\hline & $(0.0150)$ & $(0.0150)$ & $(0.0114)$ & $(0.0113)$ & $(0.0133)$ & $(0.0134)$ & $(0.0119)$ & $(0.0117)$ & $(0.0149)$ & $(0.0149)$ & $(0.0135)$ & $(0.0135)$ & & & & \\
\hline
\end{tabular}


Table A4. (continued) Estimates of women and men's labor force participation as a function of spouse's health measures with and without instrumenting for spouse's earnings

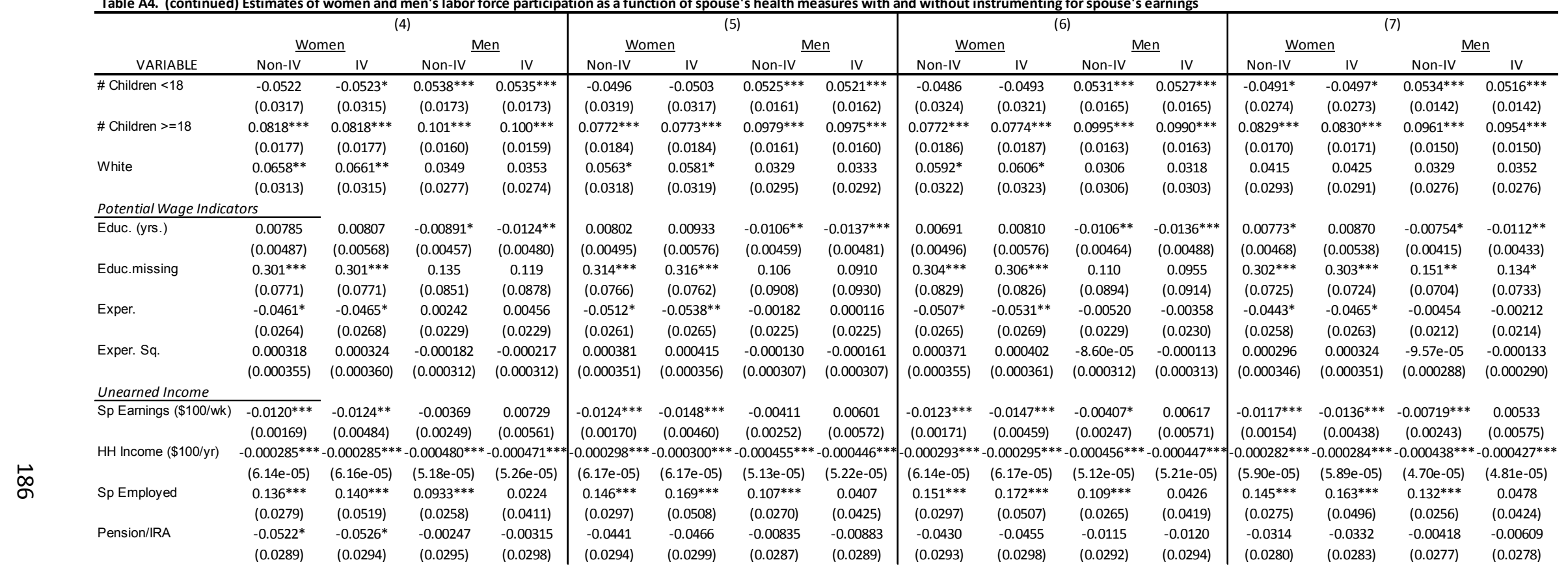


Table A4. (continued) Estimates of women and men's labor force participation as a function of spouse's health measures with and without instrumenting for spouse's earnings

\begin{tabular}{|c|c|c|c|c|c|c|c|c|c|c|c|c|c|c|c|c|}
\hline \multirow[b]{3}{*}{ VARIABLE } & \multicolumn{4}{|c|}{ (4) } & \multicolumn{4}{|c|}{ (5) } & \multicolumn{4}{|c|}{ (6) } & \multicolumn{4}{|c|}{ (7) } \\
\hline & \multicolumn{2}{|c|}{ Women } & \multicolumn{2}{|c|}{ Men } & \multicolumn{2}{|c|}{ Women } & \multicolumn{2}{|c|}{ Men } & \multicolumn{2}{|c|}{ Women } & \multicolumn{2}{|c|}{ Men } & \multicolumn{2}{|c|}{ Women } & \multicolumn{2}{|c|}{ Men } \\
\hline & Non-IV & IV & Non-IV & IV & Non-IV & IV & Non-IV & IV & Non-IV & IV & Non-IV & IV & Non-IV & IV & Non-IV & IV \\
\hline \multicolumn{17}{|c|}{ Control for Region and Time } \\
\hline Midwest & $\begin{array}{l}-0.00109 \\
(0.0363)\end{array}$ & $\begin{array}{l}-0.00134 \\
(0.0363)\end{array}$ & $\begin{array}{l}0.0521^{* *} \\
(0.0260)\end{array}$ & $\begin{array}{l}0.0554^{* *} \\
(0.0260)\end{array}$ & $\begin{array}{l}-0.00220 \\
(0.0368)\end{array}$ & $\begin{array}{l}-0.00374 \\
(0.0367)\end{array}$ & $\begin{array}{l}0.0609 * * \\
(0.0264)\end{array}$ & $\begin{array}{l}0.0640^{* *} \\
(0.0262)\end{array}$ & $\begin{array}{l}0.00429 \\
(0.0368)\end{array}$ & $\begin{array}{l}0.00270 \\
(0.0367)\end{array}$ & $\begin{array}{l}0.0578^{* *} \\
(0.0268)\end{array}$ & $\begin{array}{l}0.0609 * * \\
(0.0266)\end{array}$ & $\begin{array}{l}-0.00367 \\
(0.0331)\end{array}$ & $\begin{array}{l}-0.00490 \\
(0.0331)\end{array}$ & $\begin{array}{l}0.0523 * * \\
(0.0247)\end{array}$ & $\begin{array}{l}0.0569 * * \\
(0.0242)\end{array}$ \\
\hline South & $\begin{array}{l}-0.0419 \\
(0.0300)\end{array}$ & $\begin{array}{l}-0.0420 \\
(0.0300)\end{array}$ & $\begin{array}{c}0.0350 \\
(0.0255)\end{array}$ & $\begin{array}{c}0.0377 \\
(0.0255)\end{array}$ & $\begin{array}{l}-0.0396 \\
(0.0310)\end{array}$ & $\begin{array}{l}-0.0400 \\
(0.0309)\end{array}$ & $\begin{array}{c}0.0372 \\
(0.0261)\end{array}$ & $\begin{array}{c}0.0397 \\
(0.0261)\end{array}$ & $\begin{array}{l}-0.0357 \\
(0.0304)\end{array}$ & $\begin{array}{l}-0.0362 \\
(0.0304)\end{array}$ & $\begin{array}{c}0.0358 \\
(0.0258)\end{array}$ & $\begin{array}{c}0.0382 \\
(0.0258)\end{array}$ & $\begin{array}{l}-0.0467 \\
(0.0284)\end{array}$ & $\begin{array}{c}-0.0471^{*} \\
(0.0285)\end{array}$ & $\begin{array}{c}0.0316 \\
(0.0231)\end{array}$ & $\begin{array}{c}0.0354 \\
(0.0230)\end{array}$ \\
\hline West & $\begin{array}{c}(0.0830) \\
-0.080^{* *} \\
(0.0353)\end{array}$ & $\begin{array}{c}-0.0830 * * \\
(0.0352)\end{array}$ & $\begin{array}{c}0.0165 \\
(0.0255)\end{array}$ & $\begin{array}{c}0.0195 \\
(0.0256)\end{array}$ & $\begin{array}{c}-0.0773^{* *} \\
(0.0360)\end{array}$ & $\begin{array}{c}-0.0774^{* *} \\
(0.0358)\end{array}$ & $\begin{array}{c}0.0165 \\
(0.0269)\end{array}$ & $\begin{array}{c}0.0192 \\
(0.0269)\end{array}$ & $\begin{array}{c}-0.0741^{* *} \\
(0.0357)\end{array}$ & $\begin{array}{c}-0.0743^{* *} \\
(0.0356)\end{array}$ & $\begin{array}{c}0.0186 \\
(0.0264)\end{array}$ & $\begin{array}{c}0.0211 \\
(0.0265)\end{array}$ & $\begin{array}{c}-0.0919^{* * *} \\
(0.0322)\end{array}$ & $\begin{array}{c}-0.0920^{* * *} \\
(0.0321)\end{array}$ & $\begin{array}{c}0.0205 \\
(0.0234)\end{array}$ & $\begin{array}{c}0.0240 \\
(0.0234)\end{array}$ \\
\hline MSA & $\begin{array}{l}0.0442^{*} \\
(0.0255)\end{array}$ & $\begin{array}{l}0.0446^{*} \\
(0.0258)\end{array}$ & $\begin{array}{c}-0.000638 \\
(0.0212)\end{array}$ & $\begin{array}{l}-0.00788 \\
(0.0219)\end{array}$ & $\begin{array}{c}0.0367 \\
(0.0256)\end{array}$ & $\begin{array}{c}0.0391 \\
(0.0258)\end{array}$ & $\begin{array}{l}-0.00184 \\
(0.0216)\end{array}$ & $\begin{array}{l}-0.00857 \\
(0.0222)\end{array}$ & $\begin{array}{c}0.0385 \\
(0.0256)\end{array}$ & $\begin{array}{c}0.0408 \\
(0.0259)\end{array}$ & $\begin{array}{c}-0.00380 \\
(0.0221)\end{array}$ & $\begin{array}{l}-0.0103 \\
(0.0227)\end{array}$ & $\begin{array}{c}0.0349 \\
(0.0250)\end{array}$ & $\begin{array}{c}0.0371 \\
(0.0253)\end{array}$ & $\begin{array}{l}-0.00276 \\
(0.0216)\end{array}$ & $\begin{array}{l}-0.0111 \\
(0.0218)\end{array}$ \\
\hline Panel 6 (2002) & $\begin{array}{c}0.0197 \\
(0.0528)\end{array}$ & $\begin{array}{c}0.0199 \\
(0.0528)\end{array}$ & $\begin{array}{l}-0.0226 \\
(0.0428)\end{array}$ & $\begin{array}{l}-0.0237 \\
(0.0427)\end{array}$ & $\begin{array}{l}0.00803 \\
(0.0527)\end{array}$ & $\begin{array}{l}0.00931 \\
(0.0526)\end{array}$ & $\begin{array}{l}-0.0324 \\
(0.0440)\end{array}$ & $\begin{array}{l}-0.0334 \\
(0.0438)\end{array}$ & $\begin{array}{c}0.0127 \\
(0.0537)\end{array}$ & $\begin{array}{c}0.0134 \\
(0.0538)\end{array}$ & $\begin{array}{l}-0.0387 \\
(0.0453)\end{array}$ & $\begin{array}{l}-0.0388 \\
(0.0452)\end{array}$ & $\begin{array}{l}-0.00468 \\
(0.0483)\end{array}$ & $\begin{array}{l}-0.00399 \\
(0.0482)\end{array}$ & $\begin{array}{c}0.0121 \\
(0.0430)\end{array}$ & $\begin{array}{c}0.0124 \\
(0.0433)\end{array}$ \\
\hline Panel 7 (2003) & $\begin{array}{l}-0.00668 \\
(0.0434)\end{array}$ & $\begin{array}{l}-0.00682 \\
(0.0436)\end{array}$ & $\begin{array}{l}-0.0672^{*} \\
(0.0345)\end{array}$ & $\begin{array}{c}-0.0652^{*} \\
(0.0344)\end{array}$ & $\begin{array}{l}-0.00776 \\
(0.0441)\end{array}$ & $\begin{array}{l}-0.00836 \\
(0.0441)\end{array}$ & $\begin{array}{c}-0.0870^{* *} \\
(0.0342)\end{array}$ & $\begin{array}{c}-0.0851^{* *} \\
(0.0339)\end{array}$ & $\begin{array}{l}0.000685 \\
(0.0441)\end{array}$ & $\begin{array}{c}-0.000149 \\
(0.0441)\end{array}$ & $\begin{array}{c}-0.0908 * * \\
(0.0354)\end{array}$ & $\begin{array}{c}-0.0885^{* *} \\
(0.0356)\end{array}$ & $\begin{array}{l}-0.0211 \\
(0.0410)\end{array}$ & $\begin{array}{l}-0.0216 \\
(0.0410)\end{array}$ & $\begin{array}{l}-0.0312 \\
(0.0350)\end{array}$ & $\begin{array}{l}-0.0306 \\
(0.0353)\end{array}$ \\
\hline Panel 8 (2004) & $\begin{array}{c}-7.25 e-05 \\
(0.0416)\end{array}$ & $\begin{array}{c}-9.11 e-06 \\
(0.0415)\end{array}$ & $\begin{array}{l}-0.0214 \\
(0.0323)\end{array}$ & $\begin{array}{l}-0.0252 \\
(0.0322)\end{array}$ & $\begin{array}{l}-0.00917 \\
(0.0429)\end{array}$ & $\begin{array}{l}-0.00872 \\
(0.0425)\end{array}$ & $\begin{array}{l}-0.0251 \\
(0.0334)\end{array}$ & $\begin{array}{l}-0.0287 \\
(0.0334)\end{array}$ & $\begin{array}{c}-0.00100 \\
(0.109)\end{array}$ & $\begin{array}{c}-0.000743 \\
(0.0424)\end{array}$ & $\begin{array}{l}-0.0282 \\
(0.0336)\end{array}$ & $\begin{array}{l}-0.0317 \\
(0.0337)\end{array}$ & $\begin{array}{l}0.00579 \\
(0.0388)\end{array}$ & $\begin{array}{l}0.00605 \\
(0.0387)\end{array}$ & $\begin{array}{l}0.00556 \\
(0.0346)\end{array}$ & $\begin{array}{l}0.000437 \\
(0.0350)\end{array}$ \\
\hline Panel 9 (2005) & $\begin{array}{l}-0.00276 \\
(0.0404)\end{array}$ & $\begin{array}{l}-0.00255 \\
(0.0406)\end{array}$ & $\begin{array}{l}-0.0300 \\
(0.0328)\end{array}$ & $\begin{array}{l}-0.0335 \\
(0.0332)\end{array}$ & $\begin{array}{l}-0.0102 \\
(0.0407)\end{array}$ & $\begin{array}{l}-0.00892 \\
(0.0407)\end{array}$ & $\begin{array}{l}-0.0287 \\
(0.0326)\end{array}$ & $\begin{array}{l}-0.0320 \\
(0.0329)\end{array}$ & $\begin{array}{l}-0.00148 \\
(0.0412)\end{array}$ & $\begin{array}{c}-0.000515 \\
(0.0411)\end{array}$ & $\begin{array}{l}-0.0364 \\
(0.0341)\end{array}$ & $\begin{array}{l}-0.0397 \\
(0.0345)\end{array}$ & $\begin{array}{l}-0.0104 \\
(0.0378)\end{array}$ & $\begin{array}{l}-0.00933 \\
(0.0378)\end{array}$ & $\begin{array}{c}0.0161 \\
(0.0344)\end{array}$ & $\begin{array}{c}0.0112 \\
(0.0351)\end{array}$ \\
\hline Panel 10 (2006) & $\begin{array}{c}0.0204 \\
(0.0434)\end{array}$ & $\begin{array}{c}0.0205 \\
(0.0432)\end{array}$ & $\begin{array}{l}0.00355 \\
(0.0355)\end{array}$ & $\begin{array}{l}0.000348 \\
(0.0356)\end{array}$ & $\begin{array}{c}0.0106 \\
(0.0427)\end{array}$ & $\begin{array}{c}0.0117 \\
(0.0422)\end{array}$ & $\begin{array}{l}0.00332 \\
(0.0362)\end{array}$ & $\begin{array}{l}0.000142 \\
(0.0364)\end{array}$ & $\begin{array}{c}0.0210 \\
(0.0434)\end{array}$ & $\begin{array}{c}0.0218 \\
(0.0430)\end{array}$ & $\begin{array}{l}0.000263 \\
(0.0373)\end{array}$ & $\begin{array}{l}-0.00305 \\
(0.0375)\end{array}$ & $\begin{array}{c}0.0141 \\
(0.0407)\end{array}$ & $\begin{array}{c}0.0148 \\
(0.0403)\end{array}$ & $\begin{array}{c}0.0366 \\
(0.0379)\end{array}$ & $\begin{array}{c}0.0295 \\
(0.0392)\end{array}$ \\
\hline Panel 11 (2007) & $\begin{array}{c}0.0459 \\
(0.0396)\end{array}$ & $\begin{array}{c}0.0461 \\
(0.0394)\end{array}$ & $\begin{array}{l}-0.00215 \\
(0.0319)\end{array}$ & $\begin{array}{l}-0.0119 \\
(0.0332)\end{array}$ & $\begin{array}{c}0.0341 \\
(0.0403)\end{array}$ & $\begin{array}{c}0.0352 \\
(0.0400)\end{array}$ & $\begin{array}{l}-0.00694 \\
(0.0326)\end{array}$ & $\begin{array}{l}-0.0162 \\
(0.0340)\end{array}$ & $\begin{array}{c}0.0455 \\
(0.0408)\end{array}$ & $\begin{array}{c}0.0463 \\
(0.0408)\end{array}$ & $\begin{array}{l}-0.0100 \\
(0.0334)\end{array}$ & $\begin{array}{l}-0.0191 \\
(0.0348)\end{array}$ & $\begin{array}{c}0.0251 \\
(0.0373)\end{array}$ & $\begin{array}{c}0.0266 \\
(0.0371)\end{array}$ & $\begin{array}{c}0.0232 \\
(0.0315)\end{array}$ & $\begin{array}{l}0.00962 \\
(0.0334)\end{array}$ \\
\hline
\end{tabular}

Note: Probit regressions with robust standard errors, using MEPS Panels 5 through 7 . Marginal Effects of the probit regression are reported - the coefficients are normalized to represent the derivative of the probability of

employment with respect to a change in the explanatory variable. 
Table A5. Estimates of women and men's wages with and without instrumenting for spouse's earnings

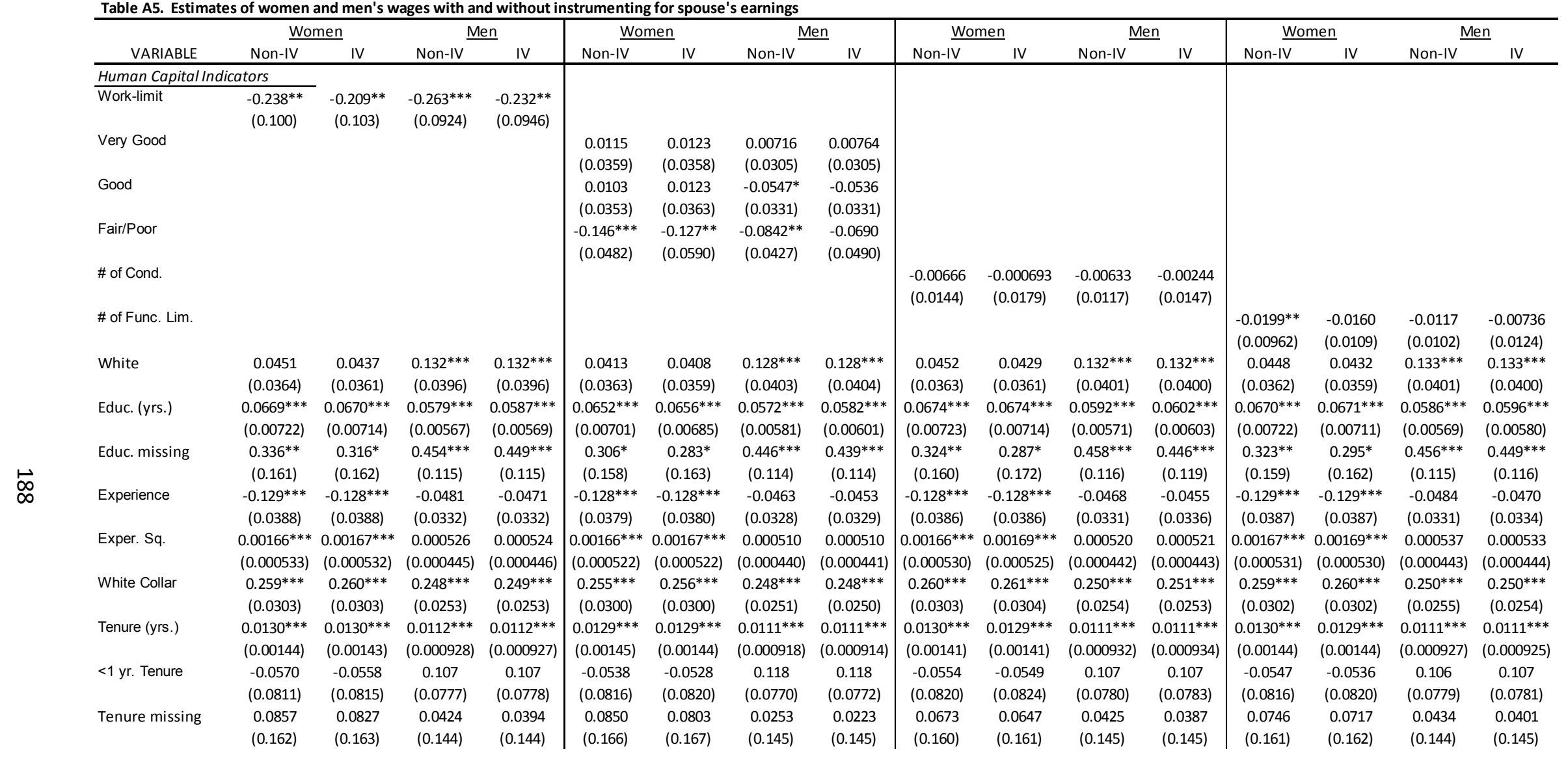


Table A5. (continued) Estimates of women and men's wages with and without instrumenting for spouse's earnings

\begin{tabular}{|c|c|c|c|c|c|c|c|c|c|c|c|c|c|c|c|c|}
\hline \multirow[b]{2}{*}{ VARIABLE } & \multicolumn{2}{|c|}{ Women } & \multicolumn{2}{|c|}{ Men } & \multicolumn{2}{|c|}{ Women } & \multicolumn{2}{|c|}{ Men } & \multicolumn{2}{|c|}{ Women } & \multicolumn{2}{|c|}{ Men } & \multicolumn{2}{|c|}{ Women } & \multicolumn{2}{|c|}{ Men } \\
\hline & Non-IV & IV & Non-IV & IV & Non-IV & IV & Non-IV & IV & Non-IV & IV & Non-IV & IV & Non-IV & IV & Non-IV & IV \\
\hline \multicolumn{2}{|c|}{ Labor Demand Indicators } & & & & & & & & & & & & & & & \\
\hline Industry: Ag./Const. & $\begin{array}{l}-0.199 \\
(0.149)\end{array}$ & $\begin{array}{l}-0.199 \\
(0.148)\end{array}$ & $\begin{array}{c}0.0166 \\
(0.0457)\end{array}$ & $\begin{array}{c}0.0168 \\
(0.0458)\end{array}$ & $\begin{array}{l}-0.198 \\
(0.150)\end{array}$ & $\begin{array}{l}-0.198 \\
(0.149)\end{array}$ & $\begin{array}{c}0.0125 \\
(0.0459)\end{array}$ & $\begin{array}{c}0.0121 \\
(0.0460)\end{array}$ & $\begin{array}{l}-0.196 \\
(0.150)\end{array}$ & $\begin{array}{l}-0.196 \\
(0.149)\end{array}$ & $\begin{array}{c}0.0131 \\
(0.0457)\end{array}$ & $\begin{array}{c}0.0125 \\
(0.0459)\end{array}$ & $\begin{array}{l}-0.201 \\
(0.149)\end{array}$ & $\begin{array}{l}-0.200 \\
(0.149)\end{array}$ & $\begin{array}{c}0.0132 \\
(0.0458)\end{array}$ & $\begin{array}{c}0.0131 \\
(0.0459)\end{array}$ \\
\hline Industry: FIRE & $\begin{array}{l}-0.0622 \\
(0.0641)\end{array}$ & $\begin{array}{l}-0.0622 \\
(0.0642)\end{array}$ & $\begin{array}{l}-0.0892 \\
(0.0574)\end{array}$ & $\begin{array}{l}-0.0896 \\
(0.0575)\end{array}$ & $\begin{array}{l}-0.0558 \\
(0.0649)\end{array}$ & $\begin{array}{l}-0.0555 \\
(0.0650)\end{array}$ & $\begin{array}{l}-0.0942 \\
(0.0585)\end{array}$ & $\begin{array}{l}-0.0951 \\
(0.0586)\end{array}$ & $\begin{array}{l}-0.0561 \\
(0.0647)\end{array}$ & $\begin{array}{l}-0.0557 \\
(0.0648)\end{array}$ & $\begin{array}{l}-0.0925 \\
(0.0585)\end{array}$ & $\begin{array}{l}-0.0931 \\
(0.0587)\end{array}$ & $\begin{array}{l}-0.0543 \\
(0.0651)\end{array}$ & $\begin{array}{l}-0.0537 \\
(0.0652)\end{array}$ & $\begin{array}{l}-0.0919 \\
(0.0585)\end{array}$ & $\begin{array}{l}-0.0924 \\
(0.0587)\end{array}$ \\
\hline Industry: Sales & $\begin{array}{c}-0.204^{* * *} \\
(0.0604)\end{array}$ & $\begin{array}{c}-0.205^{* * *} \\
(0.0605)\end{array}$ & $\begin{array}{c}-0.216 * * * \\
(0.0484)\end{array}$ & $\begin{array}{c}-0.216^{* * *} \\
(0.0484)\end{array}$ & $\begin{array}{c}-0.204^{* * *} \\
(0.0607)\end{array}$ & $\begin{array}{c}-0.204^{* * *} \\
(0.0608)\end{array}$ & $\begin{array}{c}-0.214 * * * \\
(0.0484)\end{array}$ & $\begin{array}{c}-0.215^{* * *} \\
(0.0485)\end{array}$ & $\begin{array}{c}-0.201^{* * *} \\
(0.0603)\end{array}$ & $\begin{array}{c}-0.201^{* * *} \\
(0.0604)\end{array}$ & $\begin{array}{c}-0.216 * * * \\
(0.0485)\end{array}$ & $\begin{array}{c}-0.217^{* * *} \\
(0.0487)\end{array}$ & $\begin{array}{c}-0.203^{* * *} \\
(0.0609)\end{array}$ & $\begin{array}{c}-0.204^{* * *} \\
(0.0610)\end{array}$ & $\begin{array}{c}-0.216 * * * \\
(0.0486)\end{array}$ & $\begin{array}{c}-0.217^{* * *} \\
(0.0487)\end{array}$ \\
\hline Industry: Other & $\begin{array}{l}-0.0355 \\
(0.0488)\end{array}$ & $\begin{array}{l}-0.0357 \\
(0.0488)\end{array}$ & $\begin{array}{c}-0.0801^{* *} \\
(0.0322)\end{array}$ & $\begin{array}{c}-0.0796^{* *} \\
(0.0324)\end{array}$ & $\begin{array}{l}-0.0346 \\
(0.0489)\end{array}$ & $\begin{array}{l}-0.0349 \\
(0.0488)\end{array}$ & $\begin{array}{c}-0.0816^{* *} \\
(0.0325)\end{array}$ & $\begin{array}{c}-0.0816^{* *} \\
(0.0327)\end{array}$ & $\begin{array}{l}-0.0324 \\
(0.0491)\end{array}$ & $\begin{array}{l}-0.0326 \\
(0.0490)\end{array}$ & $\begin{array}{c}-0.0823 * * \\
(0.0325)\end{array}$ & $\begin{array}{c}-0.0820^{* *} \\
(0.0328)\end{array}$ & $\begin{array}{l}-0.0339 \\
(0.0490)\end{array}$ & $\begin{array}{l}-0.0340 \\
(0.0491)\end{array}$ & $\begin{array}{c}-0.0824 * * \\
(0.0326)\end{array}$ & $\begin{array}{c}-0.0819 * * \\
(0.0329)\end{array}$ \\
\hline Union & $\begin{array}{c}0.0886^{* * *} \\
(0.0303)\end{array}$ & $\begin{array}{c}0.0889 * * * \\
(0.0304)\end{array}$ & $\begin{array}{c}0.0931^{* * *} \\
(0.0275)\end{array}$ & $\begin{array}{c}0.0939 * * * \\
(0.0275)\end{array}$ & $\begin{array}{c}0.0904^{* * *} \\
(0.0303)\end{array}$ & $\begin{array}{c}0.0910 * * * \\
(0.0306)\end{array}$ & $\begin{array}{c}0.0919 * * * \\
(0.0274)\end{array}$ & $\begin{array}{c}0.0926 * * * \\
(0.0274)\end{array}$ & $\begin{array}{c}0.0900^{* * *} \\
(0.0307)\end{array}$ & $\begin{array}{c}0.0906^{* * *} \\
(0.0311)\end{array}$ & $\begin{array}{c}0.0930^{* * *} \\
(0.0276)\end{array}$ & $\begin{array}{c}0.0936 * * * \\
(0.0275)\end{array}$ & $\begin{array}{c}0.0885^{* * *} \\
(0.0303)\end{array}$ & $\begin{array}{c}0.0889 * * * \\
(0.0305)\end{array}$ & $\begin{array}{c}0.0932^{* * *} \\
(0.0275)\end{array}$ & $\begin{array}{c}0.0939 * * * \\
(0.0275)\end{array}$ \\
\hline Midwest & $\begin{array}{l}-0.0296 \\
(0.0425)\end{array}$ & $\begin{array}{l}-0.0294 \\
(0.0425)\end{array}$ & $\begin{array}{c}-0.0711^{* *} \\
(0.0302)\end{array}$ & $\begin{array}{c}-0.0733^{* *} \\
(0.0303)\end{array}$ & $\begin{array}{l}-0.0310 \\
(0.0428)\end{array}$ & $\begin{array}{l}-0.0299 \\
(0.0430)\end{array}$ & $\begin{array}{c}-0.0760^{* *} \\
(0.0297)\end{array}$ & $\begin{array}{c}-0.0780^{* * *} \\
(0.0299)\end{array}$ & $\begin{array}{l}-0.0293 \\
(0.0431)\end{array}$ & $\begin{array}{l}-0.0285 \\
(0.0433)\end{array}$ & $\begin{array}{c}-0.0741^{* *} \\
(0.0303)\end{array}$ & $\begin{array}{c}-0.0770^{* *} \\
(0.0312)\end{array}$ & $\begin{array}{l}-0.0280 \\
(0.0429)\end{array}$ & $\begin{array}{l}-0.0277 \\
(0.0428)\end{array}$ & $\begin{array}{c}-0.0738^{* *} \\
(0.0303)\end{array}$ & $\begin{array}{c}-0.0760^{* *} \\
(0.0304)\end{array}$ \\
\hline South & $\begin{array}{l}-0.0243 \\
(0.0394)\end{array}$ & $\begin{array}{l}-0.0222 \\
(0.0402)\end{array}$ & $\begin{array}{c}-0.0810^{* * *} \\
(0.0308)\end{array}$ & $\begin{array}{c}-0.0813^{* * *} \\
(0.0307)\end{array}$ & $\begin{array}{l}-0.0207 \\
(0.0392)\end{array}$ & $\begin{array}{l}-0.0173 \\
(0.0409)\end{array}$ & $\begin{array}{c}-0.0804^{* * *} \\
(0.0309)\end{array}$ & $\begin{array}{c}-0.0802^{* * *} \\
(0.0307)\end{array}$ & $\begin{array}{l}-0.0252 \\
(0.0399)\end{array}$ & $\begin{array}{l}-0.0197 \\
(0.0443)\end{array}$ & $\begin{array}{c}-0.0810^{* * *} \\
(0.0310)\end{array}$ & $\begin{array}{c}-0.0807^{* * *} \\
(0.0308)\end{array}$ & $\begin{array}{l}-0.0215 \\
(0.0399)\end{array}$ & $\begin{array}{l}-0.0182 \\
(0.0415)\end{array}$ & $\begin{array}{c}-0.0812 * * * \\
(0.0311)\end{array}$ & $\begin{array}{c}-0.0812^{* * *} \\
(0.0310)\end{array}$ \\
\hline West & $\begin{array}{l}0.00802 \\
(0.0420)\end{array}$ & $\begin{array}{c}0.0122 \\
(0.0430)\end{array}$ & $\begin{array}{l}-0.0351 \\
(0.0338)\end{array}$ & $\begin{array}{l}-0.0353 \\
(0.0338)\end{array}$ & $\begin{array}{l}0.00901 \\
(0.0416)\end{array}$ & $\begin{array}{c}0.0147 \\
(0.0437)\end{array}$ & $\begin{array}{l}-0.0382 \\
(0.0341)\end{array}$ & $\begin{array}{l}-0.0383 \\
(0.0340)\end{array}$ & $\begin{array}{l}0.00856 \\
(0.0420)\end{array}$ & $\begin{array}{c}0.0165 \\
(0.0473)\end{array}$ & $\begin{array}{c}-0.0371 \\
(0.0342)\end{array}$ & $\begin{array}{l}-0.0371 \\
(0.0340)\end{array}$ & $\begin{array}{l}0.00905 \\
(0.0420)\end{array}$ & $\begin{array}{c}0.0153 \\
(0.0444)\end{array}$ & $\begin{array}{l}-0.0372 \\
(0.0342)\end{array}$ & $\begin{array}{l}-0.0372 \\
(0.0341)\end{array}$ \\
\hline MSA & $\begin{array}{l}0.205^{* * *} \\
(0.0296)\end{array}$ & $\begin{array}{l}0.204^{* * *} \\
(0.0293)\end{array}$ & $\begin{array}{l}0.115^{* * *} \\
(0.0241)\end{array}$ & $\begin{array}{c}0.115^{* * *} \\
(0.0241)\end{array}$ & $\begin{array}{l}0.204^{* * *} \\
(0.0296)\end{array}$ & $\begin{array}{l}0.202 * * * \\
(0.0292)\end{array}$ & $\begin{array}{l}0.114^{* * *} \\
(0.0241)\end{array}$ & $\begin{array}{l}0.113^{* * *} \\
(0.0241)\end{array}$ & $\begin{array}{l}0.207^{* * *} \\
(0.0301)\end{array}$ & $\begin{array}{c}0.203^{* * *} \\
(0.0299)\end{array}$ & $\begin{array}{l}0.117^{* * *} \\
(0.0245)\end{array}$ & $\begin{array}{c}0.116^{* * *} \\
(0.0245)\end{array}$ & $\begin{array}{l}0.205^{* * *} \\
(0.0297)\end{array}$ & $\begin{array}{l}0.203 * * * \\
(0.0293)\end{array}$ & $\begin{array}{l}0.117^{* * *} \\
(0.0246)\end{array}$ & $\begin{array}{l}0.116^{* * *} \\
(0.0246)\end{array}$ \\
\hline Panel 6 (2002) & $\begin{array}{l}0.00940 \\
(0.0500)\end{array}$ & $\begin{array}{c}0.0104 \\
(0.0499)\end{array}$ & $\begin{array}{l}0.166 * * * \\
(0.0626)\end{array}$ & $\begin{array}{c}0.167^{* * *} \\
(0.0626)\end{array}$ & $\begin{array}{l}0.00918 \\
(0.0499)\end{array}$ & $\begin{array}{c}0.0116 \\
(0.0500)\end{array}$ & $\begin{array}{l}0.168^{* * *} \\
(0.0635)\end{array}$ & $\begin{array}{l}0.169 * * * \\
(0.0637)\end{array}$ & $\begin{array}{c}0.0104 \\
(0.0498)\end{array}$ & $\begin{array}{c}0.0115 \\
(0.0498)\end{array}$ & $\begin{array}{l}0.171^{* * *} \\
(0.0631)\end{array}$ & $\begin{array}{c}0.171^{* * *} \\
(0.0632)\end{array}$ & $\begin{array}{l}0.00898 \\
(0.0498)\end{array}$ & $\begin{array}{c}0.0107 \\
(0.0498)\end{array}$ & $\begin{array}{l}0.172^{* * *} \\
(0.0629)\end{array}$ & $\begin{array}{l}0.172^{* * *} \\
(0.0628)\end{array}$ \\
\hline Panel 7 (2003) & $\begin{array}{l}0.00582 \\
(0.0579)\end{array}$ & $\begin{array}{l}0.00767 \\
(0.0576)\end{array}$ & $\begin{array}{l}0.00877 \\
(0.0522)\end{array}$ & $\begin{array}{c}0.0102 \\
(0.0524)\end{array}$ & $\begin{array}{l}0.00344 \\
(0.0580)\end{array}$ & $\begin{array}{l}0.00632 \\
(0.0576)\end{array}$ & $\begin{array}{c}0.0128 \\
(0.0519)\end{array}$ & $\begin{array}{c}0.0139 \\
(0.0522)\end{array}$ & $\begin{array}{l}0.00367 \\
(0.0579)\end{array}$ & $\begin{array}{l}0.00606 \\
(0.0574)\end{array}$ & $\begin{array}{c}0.0159 \\
(0.0521)\end{array}$ & $\begin{array}{c}0.0172 \\
(0.0525)\end{array}$ & $\begin{array}{l}0.00366 \\
(0.0581)\end{array}$ & $\begin{array}{l}0.00643 \\
(0.0577)\end{array}$ & $\begin{array}{c}0.0160 \\
(0.0520)\end{array}$ & $\begin{array}{c}0.0170 \\
(0.0521)\end{array}$ \\
\hline Panel 8 (2004) & $\begin{array}{l}0.0807^{*} \\
(0.0457)\end{array}$ & $\begin{array}{l}0.0813^{*} \\
(0.0455)\end{array}$ & $\begin{array}{l}0.0872^{*} \\
(0.0504)\end{array}$ & $\begin{array}{l}0.0870^{*} \\
(0.0502)\end{array}$ & $\begin{array}{l}0.0798^{*} \\
(0.0454)\end{array}$ & $\begin{array}{l}0.0806^{*} \\
(0.0451)\end{array}$ & $\begin{array}{l}0.0872^{*} \\
(0.0494)\end{array}$ & $\begin{array}{l}0.0872^{*} \\
(0.0492)\end{array}$ & $\begin{array}{l}0.0775^{*} \\
(0.0448)\end{array}$ & $\begin{array}{l}0.0777^{*} \\
(0.0446)\end{array}$ & $\begin{array}{l}0.0890^{*} \\
(0.0498)\end{array}$ & $\begin{array}{l}0.0891^{*} \\
(0.0496)\end{array}$ & $\begin{array}{l}0.0785^{*} \\
(0.0457)\end{array}$ & $\begin{array}{l}0.0792^{*} \\
(0.0455)\end{array}$ & $\begin{array}{l}0.0912^{*} \\
(0.0500)\end{array}$ & $\begin{array}{l}0.0905^{*} \\
(0.0496)\end{array}$ \\
\hline Panel 9 (2005) & $\begin{array}{c}0.0576 \\
(0.0512)\end{array}$ & $\begin{array}{c}0.0594 \\
(0.0510)\end{array}$ & $\begin{array}{l}0.123^{* *} \\
(0.0526)\end{array}$ & $\begin{array}{l}0.122^{* *} \\
(0.0525)\end{array}$ & $\begin{array}{c}0.0615 \\
(0.0506)\end{array}$ & $\begin{array}{c}0.0634 \\
(0.0504)\end{array}$ & $\begin{array}{l}0.121^{* *} \\
(0.0518)\end{array}$ & $\begin{array}{l}0.120^{* *} \\
(0.0516)\end{array}$ & $\begin{array}{c}0.0582 \\
(0.0501)\end{array}$ & $\begin{array}{c}0.0602 \\
(0.0498)\end{array}$ & $\begin{array}{l}0.123^{* *} \\
(0.0529)\end{array}$ & $\begin{array}{l}0.122^{* *} \\
(0.0526)\end{array}$ & $\begin{array}{c}0.0591 \\
(0.0509)\end{array}$ & $\begin{array}{c}0.0612 \\
(0.0507)\end{array}$ & $\begin{array}{l}0.124 * * \\
(0.0529)\end{array}$ & $\begin{array}{l}0.123^{* *} \\
(0.0528)\end{array}$ \\
\hline Panel 10 (2006) & $\begin{array}{l}0.173 * * * \\
(0.0446)\end{array}$ & $\begin{array}{c}0.173^{* * *} \\
(0.0446)\end{array}$ & $\begin{array}{l}0.127^{* *} \\
(0.0497)\end{array}$ & $\begin{array}{l}0.126 * * \\
(0.0496)\end{array}$ & $\begin{array}{l}0.177^{* * *} \\
(0.0445)\end{array}$ & $\begin{array}{l}0.177 * * * \\
(0.0445)\end{array}$ & $\begin{array}{l}0.126 * * \\
(0.0494)\end{array}$ & $\begin{array}{l}0.124 * * \\
(0.0491)\end{array}$ & $\begin{array}{l}0.173^{* * *} \\
(0.0436)\end{array}$ & $\begin{array}{c}0.172^{* * *} \\
(0.0438)\end{array}$ & $\begin{array}{l}0.127^{* *} \\
(0.0498)\end{array}$ & $\begin{array}{l}0.125^{* *} \\
(0.0495)\end{array}$ & $\begin{array}{l}0.172^{* * *} \\
(0.0445)\end{array}$ & $\begin{array}{l}0.173 * * * \\
(0.0446)\end{array}$ & $\begin{array}{l}0.128 * * \\
(0.0498)\end{array}$ & $\begin{array}{l}0.126^{* *} \\
(0.0497)\end{array}$ \\
\hline Panel 11 (2007) & $\begin{array}{l}0.179 * * * \\
(0.0479)\end{array}$ & $\begin{array}{l}0.179 * * * \\
(0.0478)\end{array}$ & $\begin{array}{l}0.173 * * * \\
(0.0481)\end{array}$ & $\begin{array}{c}0.172^{* * *} \\
(0.0479)\end{array}$ & $\begin{array}{l}0.183^{* * *} \\
(0.0473)\end{array}$ & $\begin{array}{l}0.182 * * * \\
(0.0472)\end{array}$ & $\begin{array}{l}0.176^{* * * *} \\
(0.0471)\end{array}$ & $\begin{array}{l}0.174^{* * *} \\
(0.0466)\end{array}$ & $\begin{array}{l}0.179 * * * \\
(0.0475)\end{array}$ & $\begin{array}{l}0.178^{* * *} \\
(0.0475)\end{array}$ & $\begin{array}{l}0.177 * * * \\
(0.0477)\end{array}$ & $\begin{array}{c}0.175^{* * *} \\
(0.0470)\end{array}$ & $\begin{array}{l}0.179 * * * \\
(0.0477)\end{array}$ & $\begin{array}{l}0.179 * * * \\
(0.0476)\end{array}$ & $\begin{array}{l}0.179 * * * \\
(0.0480)\end{array}$ & $\begin{array}{l}0.177^{* * *} \\
(0.0475)\end{array}$ \\
\hline
\end{tabular}


Table A5. (continued) Estimates of women and men's wages with and without instrumenting for spouse's earnings

\begin{tabular}{|c|c|c|c|c|c|c|c|c|c|c|c|c|c|c|c|c|}
\hline \multirow[b]{2}{*}{ VARIABLE } & \multicolumn{2}{|c|}{ Women } & \multicolumn{2}{|c|}{ Men } & \multicolumn{2}{|c|}{ Women } & \multicolumn{2}{|c|}{ Men } & \multicolumn{2}{|c|}{ Women } & \multicolumn{2}{|c|}{ Men } & \multicolumn{2}{|c|}{ Women } & \multicolumn{2}{|c|}{ Men } \\
\hline & Non-IV & IV & Non-IV & IV & Non-IV & IV & Non-IV & IV & Non-IV & IV & Non-IV & IV & Non-IV & IV & Non-IV & IV \\
\hline Constant & $\begin{array}{c}3.598^{* * *} \\
(0.714)\end{array}$ & $\begin{array}{c}3.586 * * * \\
(0.715)\end{array}$ & $\begin{array}{l}2.731^{* * *} \\
(0.601)\end{array}$ & $\begin{array}{c}2.703^{* * *} \\
(0.601)\end{array}$ & $\begin{array}{c}3.627^{* * *} \\
(0.707)\end{array}$ & $\begin{array}{c}3.607^{* * *} \\
(0.708)\end{array}$ & $\begin{array}{l}2.736^{* * *} \\
(0.594)\end{array}$ & $\begin{array}{c}2.704^{* * *} \\
(0.597)\end{array}$ & $\begin{array}{c}3.571^{* * *} \\
(0.715)\end{array}$ & $\begin{array}{c}3.568^{* * *} \\
(0.716)\end{array}$ & $\begin{array}{l}2.688^{* * *} \\
(0.598)\end{array}$ & $\begin{array}{l}2.653^{* * *} \\
(0.612)\end{array}$ & $\begin{array}{c}3.600^{* * *} \\
(0.713)\end{array}$ & $\begin{array}{c}3.585 * * * \\
(0.715)\end{array}$ & $\begin{array}{c}2.724^{* * *} \\
(0.599)\end{array}$ & $\begin{array}{c}2.688^{* * *} \\
(0.605)\end{array}$ \\
\hline$\rho$ & $\begin{array}{c}0.139 \\
(0.0601)\end{array}$ & $\begin{array}{c}0.075 \\
(0.0911)\end{array}$ & $\begin{array}{c}0.119 \\
(0.0729)\end{array}$ & $\begin{array}{c}0.056 \\
(0.0962)\end{array}$ & $\begin{array}{c}0.121 \\
(0.0643)\end{array}$ & $\begin{array}{c}0.038 \\
(0.1352)\end{array}$ & $\begin{array}{c}0.078 \\
(0.1013)\end{array}$ & $\begin{array}{c}0.002 \\
(0.1748)\end{array}$ & $\begin{array}{c}0.118 \\
(0.0648)\end{array}$ & $\begin{array}{c}0.005 \\
(0.2198)\end{array}$ & $\begin{array}{c}0.058 \\
(0.0995)\end{array}$ & $\begin{array}{c}-0.043 \\
(0.2659)\end{array}$ & $\begin{array}{c}0.123 \\
(0.0619)\end{array}$ & $\begin{array}{c}0.031 \\
(0.1388)\end{array}$ & $\begin{array}{c}0.084 \\
(0.0901)\end{array}$ & $\begin{array}{c}0.003 \\
(0.1597)\end{array}$ \\
\hline$\sigma$ & $\begin{array}{c}0.483 \\
(0.0187)\end{array}$ & $\begin{array}{c}0.481 \\
(0.0187)\end{array}$ & $\begin{array}{c}0.496 \\
(0.0144)\end{array}$ & $\begin{array}{c}0.495 \\
(0.0143)\end{array}$ & $\begin{array}{c}0.482 \\
(0.0186)\end{array}$ & $\begin{array}{c}0.480 \\
(0.0187)\end{array}$ & $\begin{array}{c}0.495 \\
(0.0144)\end{array}$ & $\begin{array}{c}0.495 \\
(0.0144)\end{array}$ & $\begin{array}{c}0.483 \\
(0.0187)\end{array}$ & $\begin{array}{c}0.481 \\
(0.0189)\end{array}$ & $\begin{array}{c}0.496 \\
(0.0143)\end{array}$ & $\begin{array}{c}0.496 \\
(0.0148)\end{array}$ & $\begin{array}{c}0.483 \\
(0.0187)\end{array}$ & $\begin{array}{c}0.481 \\
(0.0188)\end{array}$ & $\begin{array}{c}0.496 \\
(0.0144)\end{array}$ & $\begin{array}{c}0.495 \\
(0.0143)\end{array}$ \\
\hline$\lambda$ & $\begin{array}{c}0.067 \\
(0.0290)\end{array}$ & $\begin{array}{c}0.036 \\
(0.0438)\end{array}$ & $\begin{array}{c}0.059 \\
(0.0363)\end{array}$ & $\begin{array}{c}0.028 \\
(0.0476)\end{array}$ & $\begin{array}{c}0.058 \\
(0.0308)\end{array}$ & $\begin{array}{c}0.018 \\
(0.0649)\end{array}$ & $\begin{array}{c}0.039 \\
(0.0503)\end{array}$ & $\begin{array}{c}0.001 \\
(0.0864)\end{array}$ & $\begin{array}{c}0.057 \\
(0.0312)\end{array}$ & $\begin{array}{c}0.002 \\
(0.1058)\end{array}$ & $\begin{array}{c}0.029 \\
(0.0494)\end{array}$ & $\begin{array}{c}-0.021 \\
(0.1320)\end{array}$ & $\begin{array}{c}0.059 \\
(0.0297)\end{array}$ & $\begin{array}{c}0.015 \\
(0.0667)\end{array}$ & $\begin{array}{c}0.042 \\
(0.0448)\end{array}$ & $\begin{array}{c}0.002 \\
(0.0791)\end{array}$ \\
\hline
\end{tabular}

Note: Standard errors in parentheses; all tests are two-sided against the null hypothesis that the marginal effect is $=0 ; *^{* * *} p<0.01,{ }^{* *} p<0.05,{ }^{*} p<0.1$

Note: Maximum Likelihood estimates of regression models with selection using MEPS (panels 5 through 11). Rho is the correlation between the residuals of the wage and labor force participation equations, sigma is the standard error of the residual in the wage equation, and lambda the product of rho and sigma. 
Table A6. Estimates of women and men's wages with and without instrumenting for spouse's earnings

\begin{tabular}{|c|c|c|c|c|c|c|c|c|c|c|c|c|}
\hline \multirow[b]{3}{*}{ VARIABLE } & \multicolumn{4}{|c|}{ (1) } & \multicolumn{4}{|c|}{ (2) } & \multicolumn{4}{|c|}{ (3) } \\
\hline & \multicolumn{2}{|c|}{ Women } & \multicolumn{2}{|c|}{ Men } & \multicolumn{2}{|c|}{ Women } & \multicolumn{2}{|c|}{ Men } & \multicolumn{2}{|c|}{ Women } & \multicolumn{2}{|c|}{ Men } \\
\hline & Non-IV & IV & Non-IV & IV & Non-IV & IV & Non-IV & IV & Non-IV & IV & Non-IV & IV \\
\hline \multicolumn{13}{|l|}{ Human Capital Indicators } \\
\hline \multirow[t]{2}{*}{ Work-limit } & $-0.178^{*}$ & -0.154 & $-0.234^{* *}$ & $-0.205^{* *}$ & & & & & & & & \\
\hline & $(0.0941)$ & $(0.0971)$ & $(0.0902)$ & $(0.0928)$ & & & & & & & & \\
\hline \multirow[t]{2}{*}{ Very Good } & 0.0136 & 0.0140 & 0.00696 & 0.00743 & & & & & & & & \\
\hline & (0.0359) & $(0.0357)$ & $(0.0306)$ & $(0.0305)$ & & & & & & & & \\
\hline \multirow[t]{2}{*}{ Good } & 0.0145 & 0.0148 & -0.0512 & -0.0511 & & & & & & & & \\
\hline & $(0.0351)$ & $(0.0354)$ & $(0.0335)$ & $(0.0333)$ & & & & & & & & \\
\hline \multirow[t]{2}{*}{ Fair/Poor } & $-0.113^{* * *}$ & $-0.107^{* *}$ & $-0.0664^{*}$ & -0.0606 & & & & & & & & \\
\hline & $(0.0413)$ & $(0.0429)$ & $(0.0402)$ & $(0.0403)$ & & & & & & & & \\
\hline \multirow[t]{2}{*}{ \# of Conditions } & & & & & -0.00160 & 0.00152 & -0.00444 & -0.00280 & & & & \\
\hline & & & & & $(0.0140)$ & $(0.0144)$ & $(0.0115)$ & $(0.0117)$ & & & & \\
\hline \multirow[t]{2}{*}{ \# of Functional Limitations } & & & & & $-0.0196 * *$ & -0.0161 & -0.0106 & -0.00623 & & & & \\
\hline & & & & & (0.00958) & $(0.0106)$ & (0.0103) & $(0.0131)$ & & & & \\
\hline \multirow[t]{2}{*}{ (z-scored) PCS } & & & & & & & & & $0.0430^{* * *}$ & $0.0388^{* * *}$ & $0.0555^{* * *}$ & -0.0259 \\
\hline & & & & & & & & & $(0.0140)$ & $(0.0142)$ & $(0.0176)$ & $(0.0217)$ \\
\hline \multirow[t]{2}{*}{ White } & 0.0428 & 0.0418 & $0.128^{* * *}$ & $0.129 * * *$ & 0.0449 & 0.0431 & $0.133^{* * *}$ & $0.133^{* * *}$ & 0.0155 & 0.0143 & $0.126^{* * *}$ & $0.129 * * *$ \\
\hline & $(0.0364)$ & $(0.0361)$ & $(0.0400)$ & $(0.0400)$ & $(0.0362)$ & $(0.0358)$ & $(0.0400)$ & (0.0399) & $(0.0364)$ & $(0.0362)$ & $(0.0439)$ & $(0.0462)$ \\
\hline \multirow[t]{2}{*}{ Education (yrs.) } & $0.0653^{* * *}$ & $0.0655^{* * *}$ & $0.0566^{* * *}$ & $0.0575^{* * *}$ & $0.0670^{* * *}$ & $0.0671^{* * *}$ & $0.0588^{* * *}$ & $0.0598 * * *$ & $0.0612^{* * *}$ & $0.0613^{* * *}$ & $0.0578^{* * *}$ & $0.0748 * * *$ \\
\hline & $(0.00704)$ & $(0.00693)$ & $(0.00576)$ & $(0.00582)$ & $(0.00723)$ & $(0.00712)$ & $(0.00570)$ & $(0.00585)$ & $(0.00782)$ & $(0.00772)$ & $(0.00662)$ & $(0.00703)$ \\
\hline \multirow[t]{2}{*}{ Education missing } & $0.318^{* *}$ & $0.300^{*}$ & $0.443^{* * *}$ & $0.439^{* * *}$ & $0.324^{* *}$ & $0.296 *$ & $0.455^{* * *}$ & $0.448^{* * *}$ & $0.296 *$ & 0.281 & $0.377^{* * *}$ & $0.314^{* *}$ \\
\hline & $(0.160)$ & (0.161) & $(0.114)$ & $(0.114)$ & (0.159) & (0.162) & $(0.115)$ & $(0.116)$ & $(0.172)$ & (0.173) & $(0.122)$ & $(0.140)$ \\
\hline \multirow[t]{2}{*}{ Experience } & $-0.129 * * *$ & $-0.128^{* * *}$ & -0.0465 & -0.0456 & $-0.129 * * *$ & $-0.129 * * *$ & -0.0475 & -0.0462 & $-0.120^{* * *}$ & $-0.120^{* * *}$ & $-0.0557^{*}$ & -0.0434 \\
\hline & $(0.0380)$ & $(0.0381)$ & $(0.0330)$ & $(0.0330)$ & $(0.0385)$ & $(0.0386)$ & $(0.0332)$ & $(0.0334)$ & $(0.0394)$ & $(0.0395)$ & $(0.0335)$ & $(0.0355)$ \\
\hline \multirow[t]{2}{*}{ Experience squared } & $0.00166 * * *$ & $0.00167^{* * *}$ & 0.000506 & 0.000506 & $0.00167^{* * *}$ & $0.00169 * * *$ & 0.000527 & 0.000526 & $0.00156 * * *$ & $0.00156^{* * *}$ & 0.000653 & 0.000691 \\
\hline & $(0.000523)$ & $(0.000523)$ & $(0.000443)$ & $(0.000444)$ & $(0.000529)$ & $(0.000527)$ & $(0.000444)$ & $(0.000445)$ & $(0.000543)$ & $(0.000544)$ & $(0.000453)$ & $(0.000491)$ \\
\hline \multirow[t]{2}{*}{ White Collar } & $0.256 * * *$ & $0.257^{* * *}$ & $0.246^{* * *}$ & $0.247^{* * *}$ & $0.259 * * *$ & $0.260^{* * *}$ & $0.249 * * *$ & $0.250^{* * *}$ & $0.285^{* * *}$ & $0.286 * * *$ & $0.249 * * *$ & $0.255^{* * *}$ \\
\hline & $(0.0301)$ & $(0.0300)$ & $(0.0251)$ & $(0.0250)$ & $(0.0303)$ & $(0.0302)$ & $(0.0255)$ & $(0.0254)$ & $(0.0325)$ & $(0.0325)$ & $(0.0271)$ & $(0.0245)$ \\
\hline \multirow[t]{2}{*}{ Tenure (yrs.) } & $0.0130^{* * *}$ & $0.0129 * * *$ & $0.0112^{* * *}$ & $0.0111^{* * *}$ & $0.0130^{* * *}$ & $0.0129 * * *$ & $0.0111^{* * *}$ & $0.0111 * * *$ & $0.0139 * * *$ & $0.0138^{* * *}$ & $0.0119 * * *$ & $0.0105^{* * *}$ \\
\hline & $(0.00145)$ & $(0.00145)$ & $(0.000920)$ & $(0.000918)$ & $(0.00141)$ & $(0.00141)$ & $(0.000931)$ & (0.000929) & $(0.00141)$ & $(0.00141)$ & $(0.000996)$ & (0.000997) \\
\hline$<1 \mathrm{yr}$. Tenure & -0.0561 & -0.0545 & 0.117 & 0.117 & -0.0541 & -0.0532 & 0.106 & 0.107 & -0.102 & -0.101 & $0.162^{*}$ & $0.173 * *$ \\
\hline & $(0.0810)$ & $(0.0814)$ & (0.0769) & $(0.0770)$ & $(0.0816)$ & $(0.0819)$ & (0.0779) & $(0.0781)$ & (0.0738) & $(0.0739)$ & $(0.0841)$ & $(0.0798)$ \\
\hline Tenure missing & 0.0968 & 0.0929 & 0.0254 & 0.0226 & 0.0734 & 0.0710 & 0.0421 & 0.0389 & 0.125 & 0.120 & 0.0117 & 0.00657 \\
\hline & (0.168) & (0.169) & (0.145) & $(0.145)$ & (0.161) & (0.162) & (0.144) & $(0.145)$ & $(0.228)$ & (0.229) & (0.179) & (0.148) \\
\hline
\end{tabular}


Table A6 (continued). Estimates of women and men's wages with and without instrumenting for spouse's earnings

\begin{tabular}{|c|c|c|c|c|c|c|c|c|c|c|c|c|}
\hline \multirow[b]{3}{*}{ VARIABLE } & \multicolumn{4}{|c|}{ (1) } & \multicolumn{4}{|c|}{ (2) } & \multicolumn{4}{|c|}{ (3) } \\
\hline & \multicolumn{2}{|c|}{ Women } & \multicolumn{2}{|c|}{ Men } & \multicolumn{2}{|c|}{ Women } & \multicolumn{2}{|c|}{ Men } & \multicolumn{2}{|c|}{$\underline{\text { Women }}$} & \multicolumn{2}{|c|}{ Men } \\
\hline & Non-IV & IV & Non-IV & IV & Non-IV & IV & Non-IV & IV & Non-IV & IV & Non-IV & IV \\
\hline \multicolumn{13}{|l|}{ Labor Demand Indicators } \\
\hline \multirow[t]{2}{*}{ Industry: Ag./Const. } & -0.201 & -0.200 & 0.0149 & 0.0150 & -0.200 & -0.199 & 0.0128 & 0.0126 & -0.200 & -0.199 & 0.0484 & 0.0373 \\
\hline & $(0.150)$ & (0.149) & $(0.0457)$ & $(0.0458)$ & $(0.150)$ & (0.149) & $(0.0456)$ & $(0.0458)$ & $(0.153)$ & (0.152) & $(0.0473)$ & $(0.0490)$ \\
\hline \multirow[t]{2}{*}{ Industry: FIRE } & -0.0605 & -0.0604 & -0.0913 & -0.0920 & -0.0543 & -0.0537 & -0.0922 & -0.0926 & -0.0815 & -0.0821 & -0.0759 & -0.0960 \\
\hline & $(0.0641)$ & $(0.0642)$ & $(0.0572)$ & $(0.0573)$ & $(0.0649)$ & $(0.0651)$ & $(0.0584)$ & $(0.0585)$ & $(0.0648)$ & $(0.0651)$ & $(0.0644)$ & $(0.0678)$ \\
\hline \multirow[t]{2}{*}{ Industry: Sales } & $-0.206^{* * *}$ & $-0.207^{* * *}$ & $-0.214^{* * *}$ & $-0.214^{* * *}$ & $-0.203^{* * *}$ & $-0.203^{* * *}$ & $-0.216^{* * *}$ & $-0.217^{* * *}$ & $-0.221 * * *$ & $-0.222^{* * *}$ & $-0.187^{* * *}$ & $-0.184 * * *$ \\
\hline & $(0.0601)$ & $(0.0602)$ & $(0.0483)$ & $(0.0484)$ & $(0.0604)$ & (0.0604) & $(0.0486)$ & $(0.0487)$ & $(0.0652)$ & $(0.0653)$ & $(0.0518)$ & $(0.0561)$ \\
\hline \multirow[t]{2}{*}{ Industry: Other } & -0.0369 & -0.0370 & $-0.0799 * *$ & $-0.0795 * *$ & -0.0338 & -0.0340 & $-0.0826^{* *}$ & $-0.0821 * *$ & -0.0381 & -0.0385 & $-0.0729 * *$ & -0.0636 \\
\hline & $(0.0485)$ & $(0.0485)$ & $(0.0320)$ & $(0.0322)$ & $(0.0491)$ & $(0.0491)$ & $(0.0324)$ & $(0.0327)$ & $(0.0540)$ & $(0.0541)$ & $(0.0356)$ & $(0.0400)$ \\
\hline \multirow[t]{2}{*}{ Union } & $0.0894^{* * *}$ & $0.0898 * * *$ & $0.0925^{* * *}$ & $0.0933^{* * *}$ & $0.0881 * * *$ & $0.0885 * * *$ & $0.0934^{* * *}$ & $0.0940 * * *$ & $0.0886 * * *$ & $0.0889 * * *$ & $0.101^{* * *}$ & $0.0995 * * *$ \\
\hline & (0.0301) & $(0.0303)$ & $(0.0274)$ & $(0.0274)$ & $(0.0305)$ & $(0.0307)$ & $(0.0276)$ & $(0.0276)$ & $(0.0327)$ & $(0.0328)$ & (0.0298) & (0.0299) \\
\hline \multirow[t]{2}{*}{ Midwest Census Region } & -0.0304 & -0.0301 & $-0.0736^{* *}$ & $-0.0757^{* *}$ & -0.0277 & -0.0277 & $-0.0739 * *$ & $-0.0762^{* *}$ & 0.00480 & 0.00471 & $-0.0623^{*}$ & $-0.0886^{* *}$ \\
\hline & $(0.0424)$ & $(0.0424)$ & $(0.0297)$ & $(0.0297)$ & $(0.0429)$ & $(0.0427)$ & $(0.0303)$ & $(0.0304)$ & $(0.0473)$ & $(0.0471)$ & $(0.0350)$ & $(0.0383)$ \\
\hline \multirow[t]{2}{*}{ South Census Region } & -0.0207 & -0.0188 & $-0.0803^{* * *}$ & $-0.0806^{* * *}$ & -0.0215 & -0.0183 & $-0.0810^{* * *}$ & $-0.0811^{* * *}$ & 0.00127 & 0.00247 & $-0.0827^{* *}$ & $-0.0863^{* *}$ \\
\hline & $(0.0389)$ & $(0.0397)$ & $(0.0306)$ & $(0.0306)$ & $(0.0398)$ & $(0.0414)$ & $(0.0311)$ & $(0.0310)$ & $(0.0439)$ & $(0.0445)$ & $(0.0359)$ & $(0.0389)$ \\
\hline \multirow[t]{2}{*}{ West Census Region } & 0.00833 & 0.0124 & -0.0367 & -0.0369 & 0.00861 & 0.0152 & -0.0372 & -0.0371 & 0.0589 & 0.0616 & -0.0487 & -0.0489 \\
\hline & $(0.0418)$ & $(0.0429)$ & $(0.0337)$ & $(0.0336)$ & $(0.0422)$ & $(0.0448)$ & $(0.0342)$ & $(0.0340)$ & $(0.0438)$ & $(0.0444)$ & $(0.0400)$ & $(0.0426)$ \\
\hline \multirow[t]{2}{*}{ MSA } & $0.204^{* * *}$ & $0.203^{* * *}$ & $0.113^{* * *}$ & $0.113^{* * *}$ & $0.205^{* * *}$ & $0.203^{* * *}$ & $0.116^{* * *}$ & $0.116^{* * *}$ & $0.224^{* * *}$ & $0.222^{* * *}$ & $0.112^{* * *}$ & $0.106^{* * *}$ \\
\hline & $(0.0293)$ & $(0.0290)$ & $(0.0238)$ & $(0.0238)$ & $(0.0298)$ & (0.0294) & $(0.0245)$ & $(0.0245)$ & $(0.0307)$ & $(0.0302)$ & $(0.0255)$ & $(0.0299)$ \\
\hline \multirow[t]{2}{*}{ Panel 6 (2002) } & 0.0101 & 0.0113 & $0.164^{* * *}$ & $0.165^{* * *}$ & 0.00897 & 0.0102 & $0.172^{* * *}$ & $0.172^{* * *}$ & -0.0473 & -0.0464 & $0.172^{* *}$ & $0.217^{* * *}$ \\
\hline & $(0.0495)$ & $(0.0494)$ & $(0.0629)$ & $(0.0631)$ & $(0.0494)$ & $(0.0493)$ & $(0.0629)$ & (0.0629) & $(0.0481)$ & $(0.0481)$ & $(0.0705)$ & $(0.0736)$ \\
\hline \multirow[t]{2}{*}{ Panel 7 (2003) } & 0.00587 & 0.00777 & 0.00734 & 0.00870 & 0.00396 & 0.00607 & 0.0164 & 0.0174 & -0.0230 & -0.0213 & 0.00799 & 0.0616 \\
\hline & $(0.0576)$ & $(0.0573)$ & $(0.0522)$ & $(0.0524)$ & $(0.0577)$ & $(0.0573)$ & $(0.0521)$ & $(0.0523)$ & $(0.0561)$ & $(0.0560)$ & $(0.0540)$ & $(0.0581)$ \\
\hline
\end{tabular}


Table A6 (continued). Estimates of women and men's wages with and without instrumenting for spouse's earnings

\begin{tabular}{|c|c|c|c|c|c|c|c|c|c|c|c|c|}
\hline \multirow[b]{3}{*}{ VARIABLE } & \multicolumn{4}{|c|}{ (1) } & \multicolumn{4}{|c|}{ (2) } & \multicolumn{4}{|c|}{ (3) } \\
\hline & \multicolumn{2}{|c|}{ Women } & \multicolumn{2}{|c|}{ Men } & \multicolumn{2}{|c|}{ Women } & \multicolumn{2}{|c|}{$\underline{\text { Men }}$} & \multicolumn{2}{|c|}{ Women } & \multicolumn{2}{|c|}{ Men } \\
\hline & Non-IV & IV & Non-IV & IV & Non-IV & IV & Non-IV & IV & Non-IV & IV & Non-IV & IV \\
\hline Panel 8 (2004) & $\begin{array}{l}0.0827^{*} \\
(0.0454)\end{array}$ & $\begin{array}{l}0.0831^{*} \\
(0.0452)\end{array}$ & $\begin{array}{l}0.0863^{*} \\
(0.0498)\end{array}$ & $\begin{array}{l}0.0860^{*} \\
(0.0496)\end{array}$ & $\begin{array}{c}0.0788^{*} \\
(0.0449)\end{array}$ & $\begin{array}{l}0.0788^{*} \\
(0.0447)\end{array}$ & $\begin{array}{c}0.0914^{*} \\
(0.0499)\end{array}$ & $\begin{array}{c}0.0907^{*} \\
(0.0495)\end{array}$ & $\begin{array}{c}0.0484 \\
(0.0381)\end{array}$ & $\begin{array}{c}0.0497 \\
(0.0378)\end{array}$ & $\begin{array}{l}0.0901 * \\
(0.0524)\end{array}$ & $\begin{array}{l}0.110^{* *} \\
(0.0529)\end{array}$ \\
\hline Panel 9 (2005) & $\begin{array}{c}0.0613 \\
(0.0507)\end{array}$ & $\begin{array}{c}0.0629 \\
(0.0505)\end{array}$ & $\begin{array}{l}0.121^{* *} \\
(0.0515)\end{array}$ & $\begin{array}{l}0.120^{* *} \\
(0.0515)\end{array}$ & $\begin{array}{c}0.0591 \\
(0.0500)\end{array}$ & $\begin{array}{c}0.0607 \\
(0.0497)\end{array}$ & $\begin{array}{l}0.124^{* *} \\
(0.0529)\end{array}$ & $\begin{array}{l}0.123^{* *} \\
(0.0527)\end{array}$ & $\begin{array}{c}0.0226 \\
(0.0459)\end{array}$ & $\begin{array}{c}0.0240 \\
(0.0456)\end{array}$ & $\begin{array}{l}0.113^{* *} \\
(0.0534)\end{array}$ & $\begin{array}{l}0.132^{* *} \\
(0.0575)\end{array}$ \\
\hline Panel 10 (2006) & $\begin{array}{c}0.177^{* * *} \\
(0.0446)\end{array}$ & $\begin{array}{l}0.178^{* * *} \\
(0.0445)\end{array}$ & $\begin{array}{l}0.126^{* *} \\
(0.0492)\end{array}$ & $\begin{array}{l}0.125 * * \\
(0.0491)\end{array}$ & $\begin{array}{l}0.173^{* * *} \\
(0.0437)\end{array}$ & $\begin{array}{l}0.172^{* * *} \\
(0.0439)\end{array}$ & $\begin{array}{l}0.128^{* *} \\
(0.0498)\end{array}$ & $\begin{array}{l}0.126^{* *} \\
(0.0495)\end{array}$ & $\begin{array}{c}0.124^{* * *} \\
(0.0390)\end{array}$ & $\begin{array}{c}0.124^{* * *} \\
(0.0388)\end{array}$ & $\begin{array}{l}0.119^{* *} \\
(0.0516)\end{array}$ & $\begin{array}{l}0.123^{* *} \\
(0.0553)\end{array}$ \\
\hline Panel 11 (2007) & $\begin{array}{c}0.183^{* * *} \\
(0.0473)\end{array}$ & $\begin{array}{l}0.183 * * * \\
(0.0472)\end{array}$ & $\begin{array}{l}0.172 * * * \\
(0.0474)\end{array}$ & $\begin{array}{l}0.171^{* * *} \\
(0.0472)\end{array}$ & $\begin{array}{l}0.180^{* * *} \\
(0.0474)\end{array}$ & $\begin{array}{l}0.179 * * * \\
(0.0474)\end{array}$ & $\begin{array}{c}0.179 * * * \\
(0.0478)\end{array}$ & $\begin{array}{c}0.176^{* * *} \\
(0.0472)\end{array}$ & $\begin{array}{c}0.130^{* * * *} \\
(0.0421)\end{array}$ & $\begin{array}{c}0.130^{* * *} \\
(0.0418)\end{array}$ & $\begin{array}{l}0.174 * * * \\
(0.0505)\end{array}$ & $\begin{array}{l}0.171^{* * *} \\
(0.0507)\end{array}$ \\
\hline Constant & $\begin{array}{c}3.632^{* * *} \\
(0.707)\end{array}$ & $\begin{array}{c}3.616 * * * \\
(0.708)\end{array}$ & $\begin{array}{c}2.746 * * * \\
(0.597)\end{array}$ & $\begin{array}{c}2.719^{* * *} \\
(0.596)\end{array}$ & $\begin{array}{c}3.597 * * * \\
(0.713)\end{array}$ & $\begin{array}{c}3.588^{* * *} \\
(0.714)\end{array}$ & $\begin{array}{c}2.705^{* * *} \\
(0.601)\end{array}$ & $\begin{array}{c}2.671^{* * *} \\
(0.608)\end{array}$ & $\begin{array}{c}3.484^{* * *} \\
(0.738)\end{array}$ & $\begin{array}{c}3.475^{* * *} \\
(0.739)\end{array}$ & $\begin{array}{c}2.834 * * * \\
(0.598)\end{array}$ & $\begin{array}{c}2.391 * * * \\
(0.618)\end{array}$ \\
\hline$\rho$ & $\begin{array}{c}0.140 \\
(0.0612)\end{array}$ & $\begin{array}{c}0.077 \\
(0.0945)\end{array}$ & $\begin{array}{c}0.114 \\
(0.0805)\end{array}$ & $\begin{array}{c}0.051 \\
(0.1087)\end{array}$ & $\begin{array}{c}0.128 \\
(0.0635)\end{array}$ & $\begin{array}{c}0.033 \\
(0.1412)\end{array}$ & $\begin{array}{c}0.051 \\
(0.1087)\end{array}$ & $\begin{array}{c}-0.011 \\
(0.1831)\end{array}$ & $\begin{array}{c}0.162 \\
(0.0687)\end{array}$ & $\begin{array}{c}0.110 \\
(0.0991)\end{array}$ & $\begin{array}{c}0.022 \\
(0.1445)\end{array}$ & $\begin{array}{c}-0.824 \\
(0.0485)\end{array}$ \\
\hline$\sigma$ & $\begin{array}{c}0.482 \\
(0.0187)\end{array}$ & $\begin{array}{c}0.480 \\
(0.0187)\end{array}$ & $\begin{array}{c}0.495 \\
(0.0144)\end{array}$ & $\begin{array}{c}0.494 \\
(0.0144)\end{array}$ & $\begin{array}{c}0.483 \\
(0.0188)\end{array}$ & $\begin{array}{c}0.481 \\
(0.0188)\end{array}$ & $\begin{array}{c}0.494 \\
(0.0144)\end{array}$ & $\begin{array}{c}0.495 \\
(0.0144)\end{array}$ & $\begin{array}{c}0.473 \\
(0.0175)\end{array}$ & $\begin{array}{c}0.472 \\
(0.0176)\end{array}$ & $\begin{array}{c}0.495 \\
(0.0156)\end{array}$ & $\begin{array}{c}0.596 \\
(0.0306)\end{array}$ \\
\hline$\lambda$ & $\begin{array}{c}0.067 \\
(0.0296)\end{array}$ & $\begin{array}{c}0.037 \\
(0.0454)\end{array}$ & $\begin{array}{c}0.057 \\
(0.0400)\end{array}$ & $\begin{array}{c}0.025 \\
(0.0537)\end{array}$ & $\begin{array}{c}0.062 \\
(0.0306)\end{array}$ & $\begin{array}{c}0.016 \\
(0.0679)\end{array}$ & $\begin{array}{c}0.025 \\
(0.0537)\end{array}$ & $\begin{array}{c}-0.005 \\
(0.0907)\end{array}$ & $\begin{array}{c}0.077 \\
(0.0322)\end{array}$ & $\begin{array}{c}0.052 \\
(0.0466)\end{array}$ & $\begin{array}{c}0.011 \\
(0.0715)\end{array}$ & $\begin{array}{c}-0.491 \\
(0.0527)\end{array}$ \\
\hline
\end{tabular}

Note : Standard errors in parentheses; all tests are two-sided against the null hypothesis that the marginal effect is $=0 ;{ }^{* * *} p<0.01,{ }^{* *} p<0.05,{ }^{*} p<0.1$

Note: Maximum Likelihood estimates of regression models with selection using MEPS (panels 5 through 11). Rho is the correlation between the residuals of the wage and labor force participation equations, sigma is the standard error of the residual in the wage equation, and lambda is the product of rho and sigma. 
Table A7. Estimates of women and men's wages with and without instrumenting for spouse's earnings

\begin{tabular}{|c|c|c|c|c|c|c|c|c|c|c|c|c|c|c|c|c|}
\hline \multirow[b]{3}{*}{ VARIABLE } & \multicolumn{4}{|c|}{ (4) } & \multicolumn{4}{|c|}{ (5) } & \multicolumn{4}{|c|}{ (6) } & \multicolumn{4}{|c|}{ (7) } \\
\hline & \multicolumn{2}{|c|}{ Women } & \multicolumn{2}{|c|}{ Men } & \multicolumn{2}{|c|}{ Women } & \multicolumn{2}{|c|}{ Men } & \multicolumn{2}{|c|}{ Women } & \multicolumn{2}{|c|}{ Men } & \multicolumn{2}{|c|}{ Women } & \multicolumn{2}{|c|}{ Men } \\
\hline & Non-IV & IV & Non-IV & IV & Non-IV & IV & Non-IV & IV & Non-IV & IV & Non-IV & IV & Non-IV & IV & Non-IV & IV \\
\hline \multicolumn{5}{|c|}{ Human Capital Indicators } & & & & & & & & & & & & \\
\hline \multirow[t]{2}{*}{ Work-limit } & & & & & $-0.211 *$ & -0.189 & $-0.177 *$ & -0.154 & -0.155 & -0.127 & $-0.198 * *$ & $-0.174 *$ & $-0.169 *$ & -0.121 & $-0.248 * *$ & $-0.217^{*}$ \\
\hline & & & & & $(0.122)$ & $(0.123)$ & $(0.0933)$ & $(0.0960)$ & (0.119) & $(0.121)$ & $(0.0975)$ & $(0.104)$ & $(0.0937)$ & $(0.122)$ & (0.0974) & $(0.110)$ \\
\hline \multirow[t]{2}{*}{ Very Good } & & & & & & & & & 0.0203 & 0.0201 & 0.0182 & 0.0178 & 0.0125 & 0.0152 & 0.00481 & 0.00980 \\
\hline & & & & & & & & & $(0.0378)$ & $(0.0375)$ & $(0.0357)$ & $(0.0357)$ & $(0.0362)$ & $(0.0379)$ & $(0.0310)$ & $(0.0355)$ \\
\hline \multirow[t]{2}{*}{ Good } & & & & & & & & & 0.0389 & 0.0369 & -0.0356 & -0.0368 & 0.0124 & 0.0251 & $-0.0578^{*}$ & -0.0570 \\
\hline & & & & & & & & & $(0.0368)$ & $(0.0363)$ & $(0.0385)$ & $(0.0386)$ & $(0.0362)$ & $(0.0359)$ & $(0.0350)$ & $(0.0374)$ \\
\hline \multirow[t]{2}{*}{ Fair/Poor } & & & & & & & & & $-0.0826^{*}$ & $-0.0813^{*}$ & -0.0337 & -0.0308 & $-0.115 * * *$ & $-0.104^{* *}$ & $-0.0821^{*}$ & -0.0727 \\
\hline & & & & & & & & & $(0.0456)$ & $(0.0460)$ & $(0.0506)$ & $(0.0506)$ & $(0.0416)$ & $(0.0447)$ & $(0.0440)$ & $(0.0483)$ \\
\hline \multirow[t]{2}{*}{ \# of Cond. } & 0.00356 & 0.00501 & 0.00740 & 0.00821 & & & & & 0.00641 & 0.00751 & 0.0139 & 0.0139 & 0.00606 & 0.00556 & 0.0102 & 0.00888 \\
\hline & $(0.0151)$ & (0.0149) & (0.0117) & $(0.0122)$ & & & & & $(0.0155)$ & $(0.0153)$ & $(0.0122)$ & $(0.0122)$ & $(0.0142)$ & $(0.0155)$ & (0.0119) & $(0.0123)$ \\
\hline \multirow[t]{2}{*}{ \# of Func. Lim. } & -0.0163 & -0.0147 & 0.0142 & 0.0176 & & & & & -0.00283 & -0.00337 & $0.0217^{*}$ & $0.0219^{*}$ & -0.00286 & -0.00705 & 0.00641 & 0.0124 \\
\hline & (0.0109) & $(0.0110)$ & $(0.0119)$ & $(0.0207)$ & & & & & (0.00997) & $(0.00989)$ & (0.0114) & (0.0114) & $(0.00840)$ & $(0.00937)$ & $(0.0107)$ & $(0.0114)$ \\
\hline \multirow[t]{2}{*}{ (z-scored) PCS } & $0.0317^{* *}$ & $0.0287^{* *}$ & $0.0646 * * *$ & $0.0608^{* *}$ & $0.0313^{* *}$ & $0.0291 * *$ & $0.0497 * * *$ & $0.0483^{* * *}$ & $0.0248 *$ & 0.0223 & $0.0523 * * *$ & $0.0511^{* * *}$ & & & & \\
\hline & $(0.0143)$ & $(0.0142)$ & $(0.0164)$ & $(0.0234)$ & $(0.0136)$ & $(0.0135)$ & $(0.0146)$ & $(0.0147)$ & (0.0149) & $(0.0146)$ & $(0.0165)$ & $(0.0168)$ & & & & \\
\hline \multirow[t]{2}{*}{ White } & 0.0173 & 0.0157 & $0.125 * * *$ & $0.125^{* * *}$ & 0.0175 & 0.0160 & $0.126^{* * *}$ & $0.126^{* * *}$ & 0.0188 & 0.0171 & $0.122^{* * *}$ & $0.122^{* * *}$ & 0.0421 & 0.0190 & $0.128^{* * *}$ & $0.123^{* * *}$ \\
\hline & $(0.0364)$ & $(0.0362)$ & $(0.0436)$ & $(0.0436)$ & $(0.0368)$ & $(0.0365)$ & $(0.0436)$ & $(0.0436)$ & $(0.0361)$ & $(0.0359)$ & $(0.0439)$ & $(0.0439)$ & $(0.0362)$ & $(0.0360)$ & $(0.0398)$ & $(0.0442)$ \\
\hline \multirow[t]{2}{*}{ Education (yrs.) } & $0.0612^{* * *}$ & $0.0613^{* * *}$ & $0.0573^{* * *}$ & $0.0585 * * *$ & $0.0609 * * *$ & $0.0610^{* * *}$ & $0.0568 * * *$ & $0.0575^{* * *}$ & $0.0601 * * *$ & $0.0603^{* * *}$ & $0.0558 * * *$ & $0.0566 * * *$ & $0.0653^{* * *}$ & $0.0606^{* * *}$ & $0.0562^{* * *}$ & $0.0572 * * *$ \\
\hline & $(0.00781)$ & $(0.00770)$ & $(0.00661)$ & $(0.00840)$ & $(0.00778)$ & $(0.00768)$ & $(0.00651)$ & $(0.00657)$ & $(0.00754)$ & $(0.00743)$ & $(0.00680)$ & $(0.00699)$ & $(0.00705)$ & $(0.00741)$ & $(0.00582)$ & (0.00704) \\
\hline Educ. missing & $0.294^{*}$ & 0.276 & $0.378^{* * *}$ & $0.374^{* * *}$ & $0.304^{*}$ & $0.289 *$ & $0.375^{* * *}$ & $0.374 * * *$ & $0.290^{*}$ & 0.273 & $0.379^{* * *}$ & $0.377^{* * *}$ & $0.318^{* *}$ & 0.269 & $0.441 * * *$ & $0.389^{* * *}$ \\
\hline & $(0.172)$ & (0.174) & $(0.122)$ & $(0.123)$ & (0.174) & (0.174) & $(0.122)$ & $(0.122)$ & (0.172) & (0.174) & $(0.122)$ & $(0.122)$ & $(0.160)$ & $(0.176)$ & (0.114) & $(0.122)$ \\
\hline Experience & $-0.121^{* * *}$ & $-0.121^{* * *}$ & $-0.0557^{*}$ & -0.0545 & $-0.120^{* * *}$ & $-0.119 * * *$ & $-0.0570^{*}$ & $-0.0562^{*}$ & $-0.122^{* * *}$ & $-0.121 * * *$ & $-0.0563^{*}$ & -0.0553 & $-0.130 * * *$ & $-0.122^{* * *}$ & -0.0476 & $-0.0571 *$ \\
\hline & $(0.0393)$ & (0.0394) & $(0.0337)$ & $(0.0346)$ & $(0.0397)$ & $(0.0398)$ & $(0.0336)$ & $(0.0337)$ & $(0.0388)$ & $(0.0389)$ & (0.0338) & $(0.0339)$ & $(0.0380)$ & $(0.0395)$ & $(0.0332)$ & $(0.0339)$ \\
\hline Exper. Sq. & $0.00157^{* * *}$ & $0.00158^{* * *}$ & 0.000648 & 0.000647 & $0.00155^{* * *}$ & $0.00155^{* * *}$ & 0.000659 & 0.000657 & $0.00157 * * *$ & $0.00157^{* * *}$ & 0.000645 & 0.000642 & $0.00167 * * *$ & $0.00159 * * *$ & 0.000518 & 0.000661 \\
\hline & $(0.000543)$ & $(0.000543)$ & $(0.000456)$ & $(0.000458)$ & $(0.000548)$ & $(0.000548)$ & $(0.000455)$ & $(0.000456)$ & $(0.000536)$ & $(0.000536)$ & $(0.000459)$ & $(0.000460)$ & $(0.000521)$ & $(0.000542)$ & $(0.000446)$ & $(0.000460)$ \\
\hline White Collar & $0.285^{* * *}$ & $0.286 * * *$ & $0.250^{* * *}$ & $0.250^{* * *}$ & $0.286^{* * *}$ & $0.287^{* * *}$ & $0.248^{* * *}$ & $0.248^{* * *}$ & $0.282^{* * *}$ & $0.283^{* * *}$ & $0.248^{* * *}$ & $0.248^{* * *}$ & $0.255^{* * *}$ & $0.284^{* * *}$ & $0.246^{* * *}$ & $0.250^{* * *}$ \\
\hline & $(0.0327)$ & $(0.0326)$ & $(0.0273)$ & $(0.0275)$ & $(0.0327)$ & $(0.0327)$ & $(0.0270)$ & $(0.0270)$ & $(0.0326)$ & $(0.0326)$ & $(0.0269)$ & $(0.0269)$ & $(0.0302)$ & $(0.0329)$ & $(0.0251)$ & $(0.0268)$ \\
\hline Tenure (yrs.) & $0.0139 * * *$ & $0.0139 * * *$ & $0.0119 * * *$ & $0.0119 * * *$ & $0.0139 * * *$ & $0.0138^{* * *}$ & $0.0120^{* * *}$ & $0.0119^{* * *}$ & $0.0140^{* * *}$ & $0.0139 * * *$ & $0.0119^{* * *}$ & $0.0119 * * *$ & $0.0130^{* * *}$ & $0.0140^{* * *}$ & $0.0112^{* * *}$ & $0.0119 * * *$ \\
\hline & $(0.00139)$ & $(0.00139)$ & $(0.00100)$ & (0.000992) & $(0.00141)$ & $(0.00141)$ & $(0.00100)$ & $(0.000998)$ & $(0.00139)$ & $(0.00140)$ & $(0.000997)$ & $(0.000992)$ & $(0.00142)$ & $(0.00140)$ & $(0.000922)$ & $(0.000990)$ \\
\hline$<1 \mathrm{yr}$. Tenure & -0.0980 & -0.0971 & $0.162^{*}$ & $0.163^{*}$ & -0.102 & -0.101 & $0.161^{*}$ & $0.162^{*}$ & -0.0996 & -0.0981 & $0.169 * *$ & $0.170^{* *}$ & -0.0540 & -0.0923 & 0.118 & $0.170^{* *}$ \\
\hline & (0.0739) & $(0.0740)$ & $(0.0845)$ & (0.0849) & $(0.0736)$ & $(0.0736)$ & $(0.0838)$ & $(0.0838)$ & (0.0741) & $(0.0742)$ & $(0.0833)$ & (0.0834) & $(0.0811)$ & $(0.0741)$ & (0.0769) & $(0.0812)$ \\
\hline Tenure missing & 0.129 & 0.125 & 0.0152 & 0.0127 & 0.144 & 0.140 & 0.0108 & 0.00914 & 0.167 & 0.162 & 0.00396 & 0.00232 & 0.0928 & 0.155 & 0.0254 & -0.00665 \\
\hline & (0.229) & $(0.230)$ & (0.179) & (0.179) & (0.230) & $(0.231)$ & (0.179) & (0.179) & $(0.235)$ & $(0.236)$ & (0.179) & (0.179) & (0.169) & $(0.236)$ & (0.144) & $(0.179)$ \\
\hline
\end{tabular}


Table A7. (continued) Estimates of women and men's wages with and without instrumenting for spouse's earnings

\begin{tabular}{|c|c|c|c|c|c|c|c|c|c|c|c|c|c|c|c|c|}
\hline \multirow[b]{3}{*}{ VARIABLE } & \multicolumn{4}{|c|}{ (4) } & \multicolumn{4}{|c|}{ (5) } & \multicolumn{4}{|c|}{ (6) } & \multicolumn{4}{|c|}{ (7) } \\
\hline & \multicolumn{2}{|c|}{ Women } & \multicolumn{2}{|c|}{ Men } & \multicolumn{2}{|c|}{ Women } & \multicolumn{2}{|c|}{ Men } & \multicolumn{2}{|c|}{ Women } & \multicolumn{2}{|c|}{ Men } & \multicolumn{2}{|c|}{ Women } & \multicolumn{2}{|c|}{ Men } \\
\hline & Non-IV & IV & Non-IV & IV & Non-IV & IV & Non-IV & IV & Non-IV & IV & Non-IV & IV & Non-IV & IV & Non-IV & IV \\
\hline \multicolumn{17}{|c|}{ Labor Demand Indicators } \\
\hline Industry: Ag./Const. & $\begin{array}{l}-0.201 \\
(0.153)\end{array}$ & $\begin{array}{l}-0.201 \\
(0.152)\end{array}$ & $\begin{array}{c}0.0513 \\
(0.0469)\end{array}$ & $\begin{array}{c}0.0507 \\
(0.0472)\end{array}$ & $\begin{array}{l}-0.202 \\
(0.153)\end{array}$ & $\begin{array}{l}-0.201 \\
(0.152)\end{array}$ & $\begin{array}{c}0.0500 \\
(0.0471)\end{array}$ & $\begin{array}{c}0.0499 \\
(0.0472)\end{array}$ & $\begin{array}{l}-0.200 \\
(0.154)\end{array}$ & $\begin{array}{l}-0.200 \\
(0.153)\end{array}$ & $\begin{array}{c}0.0526 \\
(0.0472)\end{array}$ & $\begin{array}{c}0.0521 \\
(0.0473)\end{array}$ & $\begin{array}{l}-0.199 \\
(0.150)\end{array}$ & $\begin{array}{l}-0.199 \\
(0.154)\end{array}$ & $\begin{array}{c}0.0174 \\
(0.0458)\end{array}$ & $\begin{array}{c}0.0505 \\
(0.0479)\end{array}$ \\
\hline Industry: FIRE & $\begin{array}{l}-0.0797 \\
(0.0652)\end{array}$ & $\begin{array}{l}-0.0802 \\
(0.0655)\end{array}$ & $\begin{array}{l}-0.0766 \\
(0.0643)\end{array}$ & $\begin{array}{l}-0.0773 \\
(0.0647)\end{array}$ & $\begin{array}{l}-0.0853 \\
(0.0641)\end{array}$ & $\begin{array}{l}-0.0862 \\
(0.0644)\end{array}$ & $\begin{array}{l}-0.0730 \\
(0.0634)\end{array}$ & $\begin{array}{l}-0.0734 \\
(0.0635)\end{array}$ & $\begin{array}{l}-0.0836 \\
(0.0642)\end{array}$ & $\begin{array}{l}-0.0842 \\
(0.0645)\end{array}$ & $\begin{array}{l}-0.0769 \\
(0.0637)\end{array}$ & $\begin{array}{l}-0.0777 \\
(0.0638)\end{array}$ & $\begin{array}{l}-0.0596 \\
(0.0641)\end{array}$ & $\begin{array}{l}-0.0808 \\
(0.0648)\end{array}$ & $\begin{array}{l}-0.0914 \\
(0.0574)\end{array}$ & $\begin{array}{l}-0.0762 \\
(0.0652)\end{array}$ \\
\hline Industry: Sales & $\begin{array}{c}-0.222^{* * *} \\
(0.0648)\end{array}$ & $\begin{array}{c}-0.223 * * * \\
(0.0649)\end{array}$ & $\begin{array}{c}-0.186 * * * \\
(0.0514)\end{array}$ & $\begin{array}{c}-0.187^{* * *} \\
(0.0515)\end{array}$ & $\begin{array}{c}-0.223 * * * \\
(0.0646)\end{array}$ & $\begin{array}{c}-0.224^{* * *} \\
(0.0647)\end{array}$ & $\begin{array}{c}-0.187^{* * *} \\
(0.0516)\end{array}$ & $\begin{array}{c}-0.187^{* * *} \\
(0.0517)\end{array}$ & $\begin{array}{c}-0.224^{* * * *} \\
(0.0644)\end{array}$ & $\begin{array}{c}-0.225^{* * *} \\
(0.0645)\end{array}$ & $\begin{array}{c}-0.185^{* * *} \\
(0.0513)\end{array}$ & $\begin{array}{c}-0.185^{* * *} \\
(0.0513)\end{array}$ & $\begin{array}{c}-0.205 * * * \\
(0.0595)\end{array}$ & $\begin{array}{c}-0.222^{* * *} \\
(0.0646)\end{array}$ & $\begin{array}{c}-0.213^{* * *} \\
(0.0482)\end{array}$ & $\begin{array}{c}-0.187^{* * *} \\
(0.0518)\end{array}$ \\
\hline Industry: Other & $\begin{array}{l}-0.0389 \\
(0.0541)\end{array}$ & $\begin{array}{c}-0.0393 \\
(0.0541)\end{array}$ & $\begin{array}{c}-0.0716^{* *} \\
(0.0353)\end{array}$ & $\begin{array}{c}-0.0711^{* *} \\
(0.0357)\end{array}$ & $\begin{array}{r}-0.0405 \\
(0.0535)\end{array}$ & $\begin{array}{c}-0.0409 \\
(0.0536)\end{array}$ & $\begin{array}{c}-0.0716^{* *} \\
(0.0351)\end{array}$ & $\begin{array}{c}-0.0713^{* *} \\
(0.0353)\end{array}$ & $\begin{array}{l}-0.0424 \\
(0.0533)\end{array}$ & $\begin{array}{l}-0.0429 \\
(0.0534)\end{array}$ & $\begin{array}{l}-0.0687^{*} \\
(0.0352)\end{array}$ & $\begin{array}{c}-0.0686^{*} \\
(0.0353)\end{array}$ & $\begin{array}{l}-0.0367 \\
(0.0485)\end{array}$ & $\begin{array}{l}-0.0415 \\
(0.0535)\end{array}$ & $\begin{array}{c}-0.0786^{* *} \\
(0.0320)\end{array}$ & $\begin{array}{c}-0.0681^{*} \\
(0.0360)\end{array}$ \\
\hline Union & $\begin{array}{c}0.0864^{* * *} \\
(0.0328)\end{array}$ & $\begin{array}{c}0.0866^{* * * *} \\
(0.0329)\end{array}$ & $\begin{array}{l}0.100^{* * *} \\
(0.0297)\end{array}$ & $\begin{array}{l}0.101^{* * *} \\
(0.0298)\end{array}$ & $\begin{array}{c}0.0884^{* * *} \\
(0.0325)\end{array}$ & $\begin{array}{c}0.0887^{* * * *} \\
(0.0327)\end{array}$ & $\begin{array}{c}0.100^{* * *} \\
(0.0297)\end{array}$ & $\begin{array}{c}0.101^{* * *} \\
(0.0297)\end{array}$ & $\begin{array}{c}0.0878^{* * *} \\
(0.0326)\end{array}$ & $\begin{array}{c}0.0881^{* * *} \\
(0.0328)\end{array}$ & $\begin{array}{c}0.0976^{* * *} \\
(0.0295)\end{array}$ & $\begin{array}{c}0.0979 * * * \\
(0.0295)\end{array}$ & $\begin{array}{c}0.0881^{* * *} \\
(0.0302)\end{array}$ & $\begin{array}{c}0.0883^{* * *} * \\
(0.0328)\end{array}$ & $\begin{array}{c}0.0917^{* * *} \\
(0.0273)\end{array}$ & $\begin{array}{c}0.0944^{* * *} \\
(0.0293)\end{array}$ \\
\hline Midwest & $\begin{array}{l}0.00537 \\
(0.0470)\end{array}$ & $\begin{array}{l}0.00508 \\
(0.0467)\end{array}$ & $\begin{array}{c}-0.0624^{*} \\
(0.0351)\end{array}$ & $\begin{array}{c}-0.0646^{*} \\
(0.0373)\end{array}$ & $\begin{array}{l}0.00646 \\
(0.0469)\end{array}$ & $\begin{array}{l}0.00614 \\
(0.0467)\end{array}$ & $\begin{array}{c}-0.0593^{*} \\
(0.0349)\end{array}$ & $\begin{array}{l}-0.0610^{*} \\
(0.0350)\end{array}$ & $\begin{array}{l}0.00733 \\
(0.0470)\end{array}$ & $\begin{array}{l}0.00693 \\
(0.0468)\end{array}$ & $\begin{array}{l}-0.0636^{*} \\
(0.0347)\end{array}$ & $\begin{array}{c}-0.0655^{*} \\
(0.0350)\end{array}$ & $\begin{array}{l}-0.0302 \\
(0.0424)\end{array}$ & $\begin{array}{l}0.00565 \\
(0.0467)\end{array}$ & $\begin{array}{c}-0.0743^{* *} \\
(0.0298)\end{array}$ & $\begin{array}{c}-0.0668^{*} \\
(0.0350)\end{array}$ \\
\hline South & $\begin{array}{l}0.00376 \\
(0.0438)\end{array}$ & $\begin{array}{l}0.00508 \\
(0.0444)\end{array}$ & $\begin{array}{c}-0.0825^{* *} \\
(0.0360)\end{array}$ & $\begin{array}{c}-0.0830^{* *} \\
(0.0361)\end{array}$ & $\begin{array}{l}0.00440 \\
(0.0437)\end{array}$ & $\begin{array}{l}0.00509 \\
(0.0441)\end{array}$ & $\begin{array}{c}-0.0828^{* *} \\
(0.0358)\end{array}$ & $\begin{array}{c}-0.0832^{* *} \\
(0.0357)\end{array}$ & $\begin{array}{l}0.00765 \\
(0.0430)\end{array}$ & $\begin{array}{l}0.00876 \\
(0.0435)\end{array}$ & $\begin{array}{c}-0.0842^{* *} \\
(0.0354)\end{array}$ & $\begin{array}{c}-0.0847^{* *} \\
(0.0354)\end{array}$ & $\begin{array}{l}-0.0201 \\
(0.0389)\end{array}$ & $\begin{array}{l}0.00819 \\
(0.0435)\end{array}$ & $\begin{array}{c}-0.0804 * * * \\
(0.0306)\end{array}$ & $\begin{array}{c}-0.0872^{* *} \\
(0.0354)\end{array}$ \\
\hline West & $\begin{array}{c}0.0591 \\
(0.0439)\end{array}$ & $\begin{array}{c}0.0627 \\
(0.0447)\end{array}$ & $\begin{array}{l}-0.0483 \\
(0.0400)\end{array}$ & $\begin{array}{l}-0.0481 \\
(0.0398)\end{array}$ & $\begin{array}{c}0.0616 \\
(0.0440)\end{array}$ & $\begin{array}{c}0.0642 \\
(0.0445)\end{array}$ & $\begin{array}{l}-0.0481 \\
(0.0397)\end{array}$ & $\begin{array}{l}-0.0482 \\
(0.0397)\end{array}$ & $\begin{array}{c}0.0629 \\
(0.0436)\end{array}$ & $\begin{array}{c}0.0661 \\
(0.0442)\end{array}$ & $\begin{array}{l}-0.0504 \\
(0.0395)\end{array}$ & $\begin{array}{l}-0.0504 \\
(0.0395)\end{array}$ & $\begin{array}{l}0.00860 \\
(0.0419)\end{array}$ & $\begin{array}{c}0.0666 \\
(0.0445)\end{array}$ & $\begin{array}{l}-0.0364 \\
(0.0337)\end{array}$ & $\begin{array}{l}-0.0528 \\
(0.0397)\end{array}$ \\
\hline MSA & $\begin{array}{c}0.222^{* * *} \\
(0.0305)\end{array}$ & $\begin{array}{c}0.220^{* * *} \\
(0.0300)\end{array}$ & $\begin{array}{l}0.112 * * * \\
(0.0255)\end{array}$ & $\begin{array}{c}0.112^{* * *} \\
(0.0256)\end{array}$ & $\begin{array}{c}0.221^{* * *} \\
(0.0301)\end{array}$ & $\begin{array}{c}0.220^{* * *} \\
(0.0297)\end{array}$ & $\begin{array}{c}0.112^{* * *} \\
(0.0254)\end{array}$ & $\begin{array}{c}0.112^{* * *} \\
(0.0254)\end{array}$ & $\begin{array}{c}0.221^{* * *} \\
(0.0299)\end{array}$ & $\begin{array}{c}0.220^{* * *} \\
(0.0295)\end{array}$ & $\begin{array}{l}0.112^{* * *} \\
(0.0253)\end{array}$ & $\begin{array}{c}0.112^{* * *} \\
(0.0253)\end{array}$ & $\begin{array}{l}0.204^{* * *} \\
(0.0294)\end{array}$ & $\begin{array}{c}0.219 * * * \\
(0.0297)\end{array}$ & $\begin{array}{l}0.113^{* * *} \\
(0.0238)\end{array}$ & $\begin{array}{l}0.115 * * * \\
(0.0253)\end{array}$ \\
\hline Panel 6 (2002) & $\begin{array}{l}-0.0459 \\
(0.0474)\end{array}$ & $\begin{array}{l}-0.0453 \\
(0.0473)\end{array}$ & $\begin{array}{l}0.169 * * \\
(0.0705)\end{array}$ & $\begin{array}{l}0.172^{* *} \\
(0.0749)\end{array}$ & $\begin{array}{l}-0.0457 \\
(0.0482)\end{array}$ & $\begin{array}{c}-0.0451 \\
(0.0481)\end{array}$ & $\begin{array}{l}0.168^{* *} \\
(0.0698)\end{array}$ & $\begin{array}{l}0.170^{* *} \\
(0.0702)\end{array}$ & $\begin{array}{l}-0.0435 \\
(0.0482)\end{array}$ & $\begin{array}{l}-0.0430 \\
(0.0481)\end{array}$ & $\begin{array}{l}0.163^{* *} \\
(0.0711)\end{array}$ & $\begin{array}{l}0.166^{* *} \\
(0.0721)\end{array}$ & $\begin{array}{l}0.00814 \\
(0.0488)\end{array}$ & $\begin{array}{l}-0.0410 \\
(0.0483)\end{array}$ & $\begin{array}{l}0.163^{* *} \\
(0.0629)\end{array}$ & $\begin{array}{l}0.169 * * \\
(0.0725)\end{array}$ \\
\hline Panel 7 (2003) & $\begin{array}{l}-0.0218 \\
(0.0554)\end{array}$ & $\begin{array}{c}-0.0208 \\
(0.0551)\end{array}$ & $\begin{array}{l}0.00395 \\
(0.0539)\end{array}$ & $\begin{array}{l}0.00793 \\
(0.0579)\end{array}$ & $\begin{array}{c}-0.0198 \\
(0.0556)\end{array}$ & $\begin{array}{l}-0.0186 \\
(0.0554)\end{array}$ & $\begin{array}{l}0.00190 \\
(0.0538)\end{array}$ & $\begin{array}{l}0.00466 \\
(0.0543)\end{array}$ & $\begin{array}{l}-0.0202 \\
(0.0552)\end{array}$ & $\begin{array}{l}-0.0193 \\
(0.0549)\end{array}$ & $\begin{array}{l}-0.00395 \\
(0.0543)\end{array}$ & $\begin{array}{c}-0.000975 \\
(0.0554)\end{array}$ & $\begin{array}{l}0.00471 \\
(0.0570)\end{array}$ & $\begin{array}{l}-0.0172 \\
(0.0551)\end{array}$ & $\begin{array}{l}0.00528 \\
(0.0522)\end{array}$ & $\begin{array}{l}0.00268 \\
(0.0563)\end{array}$ \\
\hline
\end{tabular}


Table A7. (continued) Estimates of women and men's wages with and without instrumenting for spouse's earnings

\begin{tabular}{|c|c|c|c|c|c|c|c|c|c|c|c|c|c|c|c|c|}
\hline \multirow[b]{3}{*}{ VARIABLE } & \multicolumn{4}{|c|}{ (4) } & \multicolumn{4}{|c|}{ (5) } & \multicolumn{4}{|c|}{ (6) } & \multicolumn{4}{|c|}{ (7) } \\
\hline & \multicolumn{2}{|c|}{ Women } & \multicolumn{2}{|c|}{ Men } & \multicolumn{2}{|c|}{ Women } & \multicolumn{2}{|c|}{ Men } & \multicolumn{2}{|c|}{ Women } & \multicolumn{2}{|c|}{ Men } & \multicolumn{2}{|c|}{ Women } & \multicolumn{2}{|c|}{ Men } \\
\hline & Non-IV & IV & Non-IV & IV & Non-IV & IV & Non-IV & IV & Non-IV & IV & Non-IV & IV & Non-IV & IV & Non-IV & IV \\
\hline Panel 8 (2004) & $\begin{array}{c}0.0506 \\
(0.0374)\end{array}$ & $\begin{array}{c}0.0510 \\
(0.0370)\end{array}$ & $\begin{array}{c}0.0847 \\
(0.0521)\end{array}$ & $\begin{array}{c}0.0857 \\
(0.0528)\end{array}$ & $\begin{array}{c}0.0512 \\
(0.0385)\end{array}$ & $\begin{array}{c}0.0520 \\
(0.0381)\end{array}$ & $\begin{array}{l}0.0882^{*} \\
(0.0526)\end{array}$ & $\begin{array}{l}0.0889 * \\
(0.0526)\end{array}$ & $\begin{array}{c}0.0527 \\
(0.0379)\end{array}$ & $\begin{array}{c}0.0531 \\
(0.0374)\end{array}$ & $\begin{array}{c}0.0792 \\
(0.0519)\end{array}$ & $\begin{array}{c}0.0800 \\
(0.0520)\end{array}$ & $\begin{array}{l}0.0812^{*} \\
(0.0446)\end{array}$ & $\begin{array}{c}0.0559 \\
(0.0373)\end{array}$ & $\begin{array}{l}0.0827^{*} \\
(0.0495)\end{array}$ & $\begin{array}{c}0.0793 \\
(0.0527)\end{array}$ \\
\hline Panel 9 (2005) & $\begin{array}{c}0.0250 \\
(0.0445)\end{array}$ & $\begin{array}{c}0.0259 \\
(0.0441)\end{array}$ & $\begin{array}{l}0.110^{* *} \\
(0.0534)\end{array}$ & $\begin{array}{l}0.111^{* *} \\
(0.0545)\end{array}$ & $\begin{array}{c}0.0250 \\
(0.0458)\end{array}$ & $\begin{array}{c}0.0262 \\
(0.0455)\end{array}$ & $\begin{array}{l}0.112^{* *} \\
(0.0531)\end{array}$ & $\begin{array}{l}0.113^{* *} \\
(0.0532)\end{array}$ & $\begin{array}{c}0.0277 \\
(0.0449)\end{array}$ & $\begin{array}{c}0.0286 \\
(0.0445)\end{array}$ & $\begin{array}{l}0.107^{* *} \\
(0.0529)\end{array}$ & $\begin{array}{l}0.108^{* *} \\
(0.0532)\end{array}$ & $\begin{array}{c}0.0598 \\
(0.0497)\end{array}$ & $\begin{array}{c}0.0320 \\
(0.0441)\end{array}$ & $\begin{array}{l}0.120^{* *} \\
(0.0516)\end{array}$ & $\begin{array}{l}0.109 * * \\
(0.0535)\end{array}$ \\
\hline Panel 10 (2006) & $\begin{array}{l}0.125 * * * \\
(0.0383)\end{array}$ & $\begin{array}{l}0.125 * * * \\
(0.0381)\end{array}$ & $\begin{array}{l}0.115^{* *} \\
(0.0516)\end{array}$ & $\begin{array}{l}0.115^{* *} \\
(0.0517)\end{array}$ & $\begin{array}{l}0.126^{* * *} \\
(0.0390)\end{array}$ & $\begin{array}{l}0.126 * * * \\
(0.0388)\end{array}$ & $\begin{array}{l}0.119 * * \\
(0.0513)\end{array}$ & $\begin{array}{l}0.119^{* *} \\
(0.0514)\end{array}$ & $\begin{array}{l}0.128^{* * *} \\
(0.0382)\end{array}$ & $\begin{array}{l}0.128 * * * \\
(0.0380)\end{array}$ & $\begin{array}{l}0.111^{* *} \\
(0.0511)\end{array}$ & $\begin{array}{l}0.111^{* *} \\
(0.0511)\end{array}$ & $\begin{array}{l}0.176^{* * *} \\
(0.0437)\end{array}$ & $\begin{array}{l}0.132 * * * \\
(0.0381)\end{array}$ & $\begin{array}{l}0.124^{* *} \\
(0.0492)\end{array}$ & $\begin{array}{l}0.115 * * \\
(0.0513)\end{array}$ \\
\hline Panel 11 (2007) & $\begin{array}{l}0.132^{* * *} \\
(0.0409)\end{array}$ & $\begin{array}{l}0.131^{* * *} \\
(0.0406)\end{array}$ & $\begin{array}{l}0.171^{* * *} \\
(0.0503)\end{array}$ & $\begin{array}{c}0.171^{* * *} \\
(0.0498)\end{array}$ & $\begin{array}{l}0.132^{* * *} \\
(0.0418)\end{array}$ & $\begin{array}{l}0.131^{* * *} \\
(0.0416)\end{array}$ & $\begin{array}{l}0.172^{* * *} \\
(0.0506)\end{array}$ & $\begin{array}{c}0.172^{* * *} \\
(0.0505)\end{array}$ & $\begin{array}{l}0.137^{* * *} \\
(0.0404)\end{array}$ & $\begin{array}{l}0.135 * * * \\
(0.0401)\end{array}$ & $\begin{array}{l}0.167^{* * *} \\
(0.0500)\end{array}$ & $\begin{array}{l}0.166^{* * *} \\
(0.0499)\end{array}$ & $\begin{array}{l}0.182^{* * *} \\
(0.0467)\end{array}$ & $\begin{array}{l}0.138^{* * *} \\
(0.0407)\end{array}$ & $\begin{array}{l}0.170^{* * *} \\
(0.0473)\end{array}$ & $\begin{array}{c}0.168^{* * *} \\
(0.0499)\end{array}$ \\
\hline Constant & $\begin{array}{c}3.505^{* * *} \\
(0.738)\end{array}$ & $\begin{array}{c}3.494^{* * *} \\
(0.739)\end{array}$ & $\begin{array}{c}2.839 * * * \\
(0.602)\end{array}$ & $\begin{array}{c}2.800^{* * *} \\
(0.638)\end{array}$ & $\begin{array}{c}3.491 * * * \\
(0.740)\end{array}$ & $\begin{array}{c}3.477^{* * *} \\
(0.742)\end{array}$ & $\begin{array}{c}2.878^{* * *} \\
(0.599)\end{array}$ & $\begin{array}{c}2.854^{* * *} \\
(0.600)\end{array}$ & $\begin{array}{c}3.525^{* * *} \\
(0.734)\end{array}$ & $\begin{array}{c}3.511^{* * *} \\
(0.736)\end{array}$ & $\begin{array}{c}2.891^{* * *} \\
(0.602)\end{array}$ & $\begin{array}{c}2.862^{* * *} \\
(0.604)\end{array}$ & $\begin{array}{c}3.644^{* * *} \\
(0.707)\end{array}$ & $\begin{array}{c}3.527 * * * \\
(0.745)\end{array}$ & $\begin{array}{c}2.776^{* * *} \\
(0.604)\end{array}$ & $\begin{array}{c}2.918^{* * *} \\
(0.607)\end{array}$ \\
\hline$\rho$ & $\begin{array}{c}0.150 \\
(0.0705)\end{array}$ & $\begin{array}{c}0.086 \\
(0.1086)\end{array}$ & $\begin{array}{c}0.030 \\
(0.1311)\end{array}$ & $\begin{array}{c}-0.0562955 \\
0.426\end{array}$ & $\begin{array}{c}0.159 \\
(0.0662)\end{array}$ & $\begin{array}{c}0.106 \\
(0.0886)\end{array}$ & $\begin{array}{c}0.084 \\
(0.0909)\end{array}$ & $\begin{array}{c}0.037 \\
(0.1143)\end{array}$ & $\begin{array}{c}0.145 \\
(0.0672)\end{array}$ & $\begin{array}{c}0.080 \\
(0.0979)\end{array}$ & $\begin{array}{c}0.054 \\
(0.1107)\end{array}$ & $\begin{array}{c}0.000 \\
0.1601731\end{array}$ & $\begin{array}{c}0.136 \\
(0.0628)\end{array}$ & $\begin{array}{c}0.064 \\
(0.1052)\end{array}$ & $\begin{array}{c}0.105 \\
(0.0828)\end{array}$ & $\begin{array}{c}-0.011 \\
(0.1783)\end{array}$ \\
\hline$\sigma$ & $\begin{array}{c}0.473 \\
(0.0174)\end{array}$ & $\begin{array}{c}0.471 \\
(0.0175)\end{array}$ & $\begin{array}{c}0.495 \\
(0.0155)\end{array}$ & $\begin{array}{c}(0.4952) \\
0.017\end{array}$ & $\begin{array}{c}0.473 \\
(0.0172)\end{array}$ & $\begin{array}{c}0.471 \\
(0.0173)\end{array}$ & $\begin{array}{c}0.496 \\
(0.0156)\end{array}$ & $\begin{array}{c}0.495 \\
(0.0156)\end{array}$ & $\begin{array}{c}0.471 \\
(0.0172)\end{array}$ & $\begin{array}{c}0.470 \\
(0.0173)\end{array}$ & $\begin{array}{c}0.494 \\
(0.0155)\end{array}$ & $\begin{array}{l}0.4938941 \\
0.0156024\end{array}$ & $\begin{array}{c}0.482 \\
(0.0188)\end{array}$ & $\begin{array}{c}0.469 \\
(0.0173)\end{array}$ & $\begin{array}{c}0.495 \\
(0.0144)\end{array}$ & $\begin{array}{c}0.495 \\
(0.0156)\end{array}$ \\
\hline$\lambda$ & $\begin{array}{c}0.071 \\
(0.0330)\end{array}$ & $\begin{array}{c}0.040 \\
(0.0510)\end{array}$ & $\begin{array}{c}0.015 \\
(0.0649)\end{array}$ & $\begin{array}{c}-(0.0279) \\
0.211\end{array}$ & $\begin{array}{c}0.075 \\
(0.0309)\end{array}$ & $\begin{array}{c}0.050 \\
(0.0415)\end{array}$ & $\begin{array}{c}0.042 \\
(0.0451)\end{array}$ & $\begin{array}{c}0.018 \\
(0.0566)\end{array}$ & $\begin{array}{c}0.068 \\
(0.0314)\end{array}$ & $\begin{array}{c}0.038 \\
(0.0458)\end{array}$ & $\begin{array}{c}0.027 \\
(0.0547)\end{array}$ & $\begin{array}{c}0.000 \\
0.0791086\end{array}$ & $\begin{array}{c}0.065 \\
(0.0304)\end{array}$ & $\begin{array}{c}0.030 \\
(0.0492)\end{array}$ & $\begin{array}{c}0.052 \\
(0.0411)\end{array}$ & $\begin{array}{c}-0.006 \\
(0.0883)\end{array}$ \\
\hline
\end{tabular}

Note: Standard errors in parentheses; all tests are two-sided against the null hypothesis that the marginal effect is $=0 ;{ }^{* * *} p<0.01,{ }^{* *} p<0.05,{ }^{*} p<0.1$

Note: Maximum Likelihood estimates of regression models with selection using MEPS (panels 5 through 11). Rho is the correlation between the residuals of the wage and labor force participation equations, sigma is the standard error of the residual in the wage equation, and lambda is the product of rho and sigma. 


\begin{tabular}{|c|c|c|c|c|c|c|c|c|c|c|c|c|c|c|c|c|}
\hline \multirow[b]{2}{*}{ VARIABLE } & \multicolumn{2}{|c|}{ Women } & \multicolumn{2}{|c|}{ Men } & \multicolumn{2}{|c|}{ Women } & \multicolumn{2}{|c|}{ Men } & \multicolumn{2}{|c|}{ Women } & \multicolumn{2}{|c|}{ Men } & \multicolumn{2}{|c|}{ Women } & \multicolumn{2}{|c|}{ Men } \\
\hline & Non-IV & IV & Non-IV & IV & Non-IV & IV & Non-IV & IV & Non-IV & IV & Non-IV & IV & Non-IV & IV & Non-IV & IV \\
\hline \multicolumn{17}{|c|}{ Reservation Wage Indicators } \\
\hline Sp Work-limit & $\begin{array}{c}0.540 \\
(0.875)\end{array}$ & $\begin{array}{c}0.438 \\
(0.878)\end{array}$ & $\begin{array}{c}0.774 \\
(1.090)\end{array}$ & $\begin{array}{c}0.779 \\
(1.096)\end{array}$ & & & & & & & & & & & & \\
\hline Sp Very Good & & & & & $\begin{array}{l}-0.323 \\
(0.674)\end{array}$ & $\begin{array}{l}-0.327 \\
(0.670)\end{array}$ & $\begin{array}{l}-0.948 \\
(0.657)\end{array}$ & $\begin{array}{l}-1.050 \\
(0.651)\end{array}$ & & & & & & & & \\
\hline Sp Good & & & & & $\begin{array}{c}0.363 \\
(0.583)\end{array}$ & $\begin{array}{c}0.302 \\
(0.597)\end{array}$ & $\begin{array}{c}-1.651^{* *} \\
(0.685)\end{array}$ & $\begin{array}{c}-1.816^{* * *} \\
(0.683)\end{array}$ & & & & & & & & \\
\hline Sp Fair/Poor & & & & & $\begin{array}{c}0.342 \\
(0.778)\end{array}$ & $\begin{array}{c}0.258 \\
(0.779)\end{array}$ & $\begin{array}{l}-0.0614 \\
(0.858)\end{array}$ & $\begin{array}{c}-0.332 \\
(0.862)\end{array}$ & & & & & & & & \\
\hline $\mathrm{Sp} \#$ of Cond. & & & & & & & & & $\begin{array}{c}0.276 \\
(0.213)\end{array}$ & $\begin{array}{c}0.269 \\
(0.213)\end{array}$ & $\begin{array}{c}0.253 \\
(0.238)\end{array}$ & $\begin{array}{c}0.241 \\
(0.238)\end{array}$ & & & & \\
\hline $\mathrm{Sp} \#$ of Func. Lim. & & & & & & & & & & & & & $\begin{array}{c}0.135 \\
(0.140)\end{array}$ & $\begin{array}{c}0.132 \\
(0.141)\end{array}$ & $\begin{array}{c}0.198 \\
(0.191)\end{array}$ & $\begin{array}{c}0.193 \\
(0.190)\end{array}$ \\
\hline Work-limit & $\begin{array}{l}0.0266 \\
(1.826)\end{array}$ & $\begin{array}{c}0.584 \\
(1.868)\end{array}$ & $\begin{array}{l}0.0624 \\
(1.778)\end{array}$ & $\begin{array}{l}0.0516 \\
(1.761)\end{array}$ & & & & & & & & & & & & \\
\hline Very Good & & & & & $\begin{array}{c}-0.564 \\
(0.579)\end{array}$ & $\begin{array}{l}-0.530 \\
(0.583)\end{array}$ & $\begin{array}{c}0.668 \\
(0.569)\end{array}$ & $\begin{array}{c}0.566 \\
(0.575)\end{array}$ & & & & & & & & \\
\hline Good & & & & & $\begin{array}{c}0.177 \\
(0.600)\end{array}$ & $\begin{array}{c}0.215 \\
(0.607)\end{array}$ & $\begin{array}{l}-0.177 \\
(0.637)\end{array}$ & $\begin{array}{l}-0.245 \\
(0.641)\end{array}$ & & & & & & & & \\
\hline Fair/Poor & & & & & $\begin{array}{l}-0.508 \\
(1.036)\end{array}$ & $\begin{array}{l}-0.232 \\
(1.080)\end{array}$ & $\begin{array}{l}-0.0701 \\
(1.003)\end{array}$ & $\begin{array}{l}-0.269 \\
(0.967)\end{array}$ & & & & & & & & \\
\hline \# of Cond. & & & & & & & & & $\begin{array}{l}-0.172 \\
(0.272)\end{array}$ & $\begin{array}{l}-0.116 \\
(0.276)\end{array}$ & $\begin{array}{l}-0.0139 \\
(0.294)\end{array}$ & $\begin{array}{l}-0.0350 \\
(0.295)\end{array}$ & & & & \\
\hline \# of Func. Lim. & & & & & & & & & & & & & $\begin{array}{c}0.187 \\
(0.174)\end{array}$ & $\begin{array}{c}0.240 \\
(0.185)\end{array}$ & $\begin{array}{l}0.0909 \\
(0.254)\end{array}$ & $\begin{array}{l}0.0768 \\
(0.253)\end{array}$ \\
\hline \# Children $<18$ & $\begin{array}{l}-0.607 \\
(0.554)\end{array}$ & $\begin{array}{l}-0.604 \\
(0.553)\end{array}$ & $\begin{array}{l}0.0221 \\
(0.228)\end{array}$ & $\begin{array}{l}0.0360 \\
(0.228)\end{array}$ & $\begin{array}{l}-0.588 \\
(0.564)\end{array}$ & $\begin{array}{l}-0.590 \\
(0.563)\end{array}$ & $\begin{array}{c}-0.00600 \\
(0.231)\end{array}$ & $\begin{array}{l}0.00955 \\
(0.231)\end{array}$ & $\begin{array}{l}-0.586 \\
(0.556)\end{array}$ & $\begin{array}{l}-0.585 \\
(0.555)\end{array}$ & $\begin{array}{l}0.0486 \\
(0.236)\end{array}$ & $\begin{array}{l}0.0604 \\
(0.234)\end{array}$ & $\begin{array}{l}-0.580 \\
(0.557)\end{array}$ & $\begin{array}{l}-0.576 \\
(0.556)\end{array}$ & $\begin{array}{l}0.0314 \\
(0.228)\end{array}$ & $\begin{array}{l}0.0469 \\
(0.227)\end{array}$ \\
\hline \# Children >=18 & $\begin{array}{c}0.702^{*} \\
(0.362)\end{array}$ & $\begin{array}{c}0.629^{*} \\
(0.366)\end{array}$ & $\begin{array}{l}-0.0557 \\
(0.280)\end{array}$ & $\begin{array}{l}-0.0933 \\
(0.284)\end{array}$ & $\begin{array}{l}0.739^{* *} \\
(0.364)\end{array}$ & $\begin{array}{l}0.670^{*} \\
(0.369)\end{array}$ & $\begin{array}{l}-0.0603 \\
(0.289)\end{array}$ & $\begin{array}{l}-0.0922 \\
(0.293)\end{array}$ & $\begin{array}{c}0.719^{*} \\
(0.367)\end{array}$ & $\begin{array}{l}0.654^{*} \\
(0.372)\end{array}$ & $\begin{array}{l}-0.0622 \\
(0.282)\end{array}$ & $\begin{array}{c}-0.101 \\
(0.286)\end{array}$ & $\begin{array}{c}0.673^{*} \\
(0.366)\end{array}$ & $\begin{array}{c}0.595 \\
(0.372)\end{array}$ & $\begin{array}{l}-0.0543 \\
(0.278)\end{array}$ & $\begin{array}{l}-0.0897 \\
(0.281)\end{array}$ \\
\hline White & $\begin{array}{l}-0.893 \\
(0.574)\end{array}$ & $\begin{array}{l}-0.928 \\
(0.571)\end{array}$ & $\begin{array}{c}1.961^{* * *} \\
(0.562)\end{array}$ & $\begin{array}{c}1.766^{* * *} \\
(0.553)\end{array}$ & $\begin{array}{l}-0.738 \\
(0.577)\end{array}$ & $\begin{array}{l}-0.773 \\
(0.572)\end{array}$ & $\begin{array}{c}1.872^{* * *} \\
(0.568)\end{array}$ & $\begin{array}{c}1.658^{* * *} \\
(0.563)\end{array}$ & $\begin{array}{l}-0.841 \\
(0.570)\end{array}$ & $\begin{array}{l}-0.883 \\
(0.567)\end{array}$ & $\begin{array}{c}1.947^{* * *} \\
(0.561)\end{array}$ & $\begin{array}{c}1.757^{* * *} \\
(0.551)\end{array}$ & $\begin{array}{c}-0.901 \\
(0.571)\end{array}$ & $\begin{array}{l}-0.941^{*} \\
(0.568)\end{array}$ & $\begin{array}{c}1.972^{* * *} \\
(0.565)\end{array}$ & $\begin{array}{c}1.780^{* * *} \\
(0.556)\end{array}$ \\
\hline
\end{tabular}


Table A8 (Continued). Estimates of women and men's hours per week as a function of spouses' selected health measures with and without instrumenting for spouses' earnings

\begin{tabular}{|c|c|c|c|c|c|c|c|c|c|c|c|c|c|c|c|c|}
\hline \multirow[b]{2}{*}{ VARIABLE } & \multicolumn{2}{|c|}{ Women } & \multicolumn{2}{|c|}{ Men } & \multicolumn{2}{|c|}{ Women } & \multicolumn{2}{|c|}{ Men } & \multicolumn{2}{|c|}{ Women } & \multicolumn{2}{|c|}{ Men } & \multicolumn{2}{|c|}{ Women } & \multicolumn{2}{|c|}{ Men } \\
\hline & Non-IV & IV & Non-IV & IV & Non-IV & IV & Non-IV & IV & Non-IV & IV & Non-IV & IV & Non-IV & IV & Non-IV & IV \\
\hline \multicolumn{17}{|l|}{ Potential Wage Indicators } \\
\hline Predicted Wage & $\begin{array}{l}0.0907 \\
(0.768)\end{array}$ & $\begin{array}{l}-0.0324 \\
(0.826)\end{array}$ & $\begin{array}{c}0.828 \\
(0.847)\end{array}$ & $\begin{array}{l}1.698^{* *} \\
(0.829)\end{array}$ & $\begin{array}{c}0.363 \\
(0.774)\end{array}$ & $\begin{array}{c}0.291 \\
(0.825)\end{array}$ & $\begin{array}{c}0.517 \\
(0.868)\end{array}$ & $\begin{array}{c}1.361 \\
(0.843)\end{array}$ & $\begin{array}{l}0.0914 \\
(0.775)\end{array}$ & $\begin{array}{c}-0.00531 \\
(0.825)\end{array}$ & $\begin{array}{c}0.816 \\
(0.847)\end{array}$ & $\begin{array}{l}1.667^{* *} \\
(0.834)\end{array}$ & $\begin{array}{l}0.0119 \\
(0.779)\end{array}$ & $\begin{array}{l}-0.108 \\
(0.836)\end{array}$ & $\begin{array}{c}0.816 \\
(0.838)\end{array}$ & $\begin{array}{l}1.686^{* *} \\
(0.826)\end{array}$ \\
\hline Union & $\begin{array}{c}-2.051^{* * *} \\
(0.524)\end{array}$ & $\begin{array}{c}-2.045^{* * *} \\
(0.522)\end{array}$ & $\begin{array}{c}-2.607^{* * *} \\
(0.501)\end{array}$ & $\begin{array}{c}-2.587^{* * *} \\
(0.502)\end{array}$ & $\begin{array}{c}-2.048^{* * *} \\
(0.524)\end{array}$ & $\begin{array}{c}-2.045^{* * *} \\
(0.522)\end{array}$ & $\begin{array}{c}-2.523^{* * *} \\
(0.499)\end{array}$ & $\begin{array}{c}-2.495^{* * *} \\
(0.499)\end{array}$ & $\begin{array}{c}-2.019^{* * *} \\
(0.531)\end{array}$ & $\begin{array}{c}-2.015^{* * *} \\
(0.528)\end{array}$ & $\begin{array}{c}-2.653^{* * *} \\
(0.502)\end{array}$ & $\begin{array}{c}-2.631^{* * *} \\
(0.503)\end{array}$ & $\begin{array}{c}-2.030 * * * \\
(0.525)\end{array}$ & $\begin{array}{c}-2.022^{* * *} \\
(0.523)\end{array}$ & $\begin{array}{c}-2.629 * * * \\
(0.502)\end{array}$ & $\begin{array}{c}-2.608^{* * *} \\
(0.502)\end{array}$ \\
\hline Ret./Pension Plan & $\begin{array}{c}3.374 * * * \\
(0.560)\end{array}$ & $\begin{array}{c}3.388^{* * *} \\
(0.562)\end{array}$ & $\begin{array}{c}1.819 * * * \\
(0.571)\end{array}$ & $\begin{array}{c}1.898^{* * *} \\
(0.569)\end{array}$ & $\begin{array}{c}3.331 * * * \\
(0.559)\end{array}$ & $\begin{array}{c}3.352^{* * *} \\
(0.561)\end{array}$ & $\begin{array}{c}1.832^{* * *} \\
(0.574)\end{array}$ & $\begin{array}{c}1.917^{* * *} \\
(0.573)\end{array}$ & $\begin{array}{c}3.373^{* * *} \\
(0.562)\end{array}$ & $\begin{array}{c}3.390 * * * \\
(0.564)\end{array}$ & $\begin{array}{c}1.837^{* * *} \\
(0.574)\end{array}$ & $\begin{array}{c}1.917^{* * * *} \\
(0.571)\end{array}$ & $\begin{array}{c}3.402^{* * *} \\
(0.561)\end{array}$ & $\begin{array}{c}3.413^{* * *} \\
(0.563)\end{array}$ & $\begin{array}{c}1.844^{* * *} \\
(0.573)\end{array}$ & $\begin{array}{c}1.925^{* * *} \\
(0.571)\end{array}$ \\
\hline Holds ESI & $\begin{array}{c}4.514^{* * *} \\
(0.514)\end{array}$ & $\begin{array}{c}4.451^{* * *} \\
(0.508)\end{array}$ & $\begin{array}{c}1.800^{* * *} \\
(0.617)\end{array}$ & $\begin{array}{l}1.549 * * \\
(0.626)\end{array}$ & $\begin{array}{c}4.545^{* * *} \\
(0.525)\end{array}$ & $\begin{array}{c}4.476 * * * \\
(0.517)\end{array}$ & $\begin{array}{c}1.824^{* * *} \\
(0.611)\end{array}$ & $\begin{array}{l}1.569^{* *} \\
(0.617)\end{array}$ & $\begin{array}{l}4.531^{* * *} \\
(0.515)\end{array}$ & $\begin{array}{c}4.474^{* * *} \\
(0.508)\end{array}$ & $\begin{array}{c}1.786 * * * \\
(0.609)\end{array}$ & $\begin{array}{l}1.539 * * \\
(0.620)\end{array}$ & $\begin{array}{c}4.527^{* * *} \\
(0.515)\end{array}$ & $\begin{array}{c}4.462 * * * \\
(0.510)\end{array}$ & $\begin{array}{c}1.803^{* * *} \\
(0.614)\end{array}$ & $\begin{array}{l}1.551^{* *} \\
(0.624)\end{array}$ \\
\hline Choice of HI Plans & $\begin{array}{l}1.144^{* *} \\
(0.486)\end{array}$ & $\begin{array}{l}1.151^{* *} \\
(0.486)\end{array}$ & $\begin{array}{l}-0.122 \\
(0.476)\end{array}$ & $\begin{array}{l}-0.113 \\
(0.478)\end{array}$ & $\begin{array}{l}1.063^{* *} \\
(0.482)\end{array}$ & $\begin{array}{l}1.074^{* *} \\
(0.482)\end{array}$ & $\begin{array}{l}-0.0832 \\
(0.473)\end{array}$ & $\begin{array}{l}-0.0807 \\
(0.475)\end{array}$ & $\begin{array}{l}1.179 * * \\
(0.480)\end{array}$ & $\begin{array}{l}1.186^{* *} \\
(0.480)\end{array}$ & $\begin{array}{l}-0.125 \\
(0.476)\end{array}$ & $\begin{array}{l}-0.114 \\
(0.479)\end{array}$ & $\begin{array}{l}1.144^{* *} \\
(0.483)\end{array}$ & $\begin{array}{l}1.151^{* *} \\
(0.484)\end{array}$ & $\begin{array}{l}-0.106 \\
(0.477)\end{array}$ & $\begin{array}{l}-0.0961 \\
(0.479)\end{array}$ \\
\hline Paid Sick Leave & $\begin{array}{c}5.074^{* * *} \\
(0.642)\end{array}$ & $\begin{array}{c}5.077^{* * *} \\
(0.646)\end{array}$ & $\begin{array}{l}1.024^{*} \\
(0.544)\end{array}$ & $\begin{array}{l}1.037^{*} \\
(0.544)\end{array}$ & $\begin{array}{c}5.061 * * * \\
(0.648)\end{array}$ & $\begin{array}{c}5.057^{* * *} \\
(0.651)\end{array}$ & $\begin{array}{l}0.962^{*} \\
(0.559)\end{array}$ & $\begin{array}{l}0.972^{*} \\
(0.557)\end{array}$ & $\begin{array}{c}5.042^{* * * *} \\
(0.644)\end{array}$ & $\begin{array}{c}5.043 * * * \\
(0.647)\end{array}$ & $\begin{array}{l}1.008^{*} \\
(0.546)\end{array}$ & $\begin{array}{l}1.022^{*} \\
(0.545)\end{array}$ & $\begin{array}{c}5.051^{* * *} \\
(0.641)\end{array}$ & $\begin{array}{c}5.053^{* * *} \\
(0.644)\end{array}$ & $\begin{array}{l}1.014^{*} \\
(0.545)\end{array}$ & $\begin{array}{l}1.028^{*} \\
(0.544)\end{array}$ \\
\hline Sp Earnings (\$100/wk.) & $\begin{array}{c}0.0734 \\
(0.0525)\end{array}$ & $\begin{array}{c}0.0604 \\
(0.0909)\end{array}$ & $\begin{array}{c}0.0566 \\
(0.0664)\end{array}$ & $\begin{array}{l}-0.261^{*} \\
(0.138)\end{array}$ & $\begin{array}{c}0.0734 \\
(0.0531)\end{array}$ & $\begin{array}{c}0.0527 \\
(0.0933)\end{array}$ & $\begin{array}{c}0.0531 \\
(0.0655)\end{array}$ & $\begin{array}{c}-0.277^{* *} \\
(0.137)\end{array}$ & $\begin{array}{c}0.0678 \\
(0.0521)\end{array}$ & $\begin{array}{c}0.0534 \\
(0.0906)\end{array}$ & $\begin{array}{c}0.0556 \\
(0.0665)\end{array}$ & $\begin{array}{l}-0.258^{*} \\
(0.138)\end{array}$ & $\begin{array}{c}0.0780 \\
(0.0530)\end{array}$ & $\begin{array}{c}0.0635 \\
(0.0923)\end{array}$ & $\begin{array}{c}0.0585 \\
(0.0663)\end{array}$ & $\begin{array}{l}-0.259^{*} \\
(0.138)\end{array}$ \\
\hline HH Income (\$100/yr) & $\begin{array}{l}-0.00329^{*} \\
(0.00169)\end{array}$ & $\begin{array}{c}-0.00301^{*} \\
(0.00173)\end{array}$ & $\begin{array}{l}-0.00106 \\
(0.00200)\end{array}$ & $\begin{array}{r}-0.00115 \\
(0.00199)\end{array}$ & $\begin{array}{c}-0.00343^{* *} \\
(0.00171)\end{array}$ & $\begin{array}{l}-0.00321^{*} \\
(0.00173)\end{array}$ & $\begin{array}{r}-0.00100 \\
(0.00201)\end{array}$ & $\begin{array}{c}-0.00113 \\
(0.00201)\end{array}$ & $\begin{array}{l}-0.00344^{* *} \\
(0.00171)\end{array}$ & $\begin{array}{l}-0.00324^{*} \\
(0.00174)\end{array}$ & $\begin{array}{l}-0.00109 \\
(0.00202)\end{array}$ & $\begin{array}{c}-0.00117 \\
(0.00201)\end{array}$ & $\begin{array}{c}-0.00312^{*} \\
(0.00170)\end{array}$ & $\begin{array}{c}-0.00284 \\
(0.00173)\end{array}$ & $\begin{array}{l}-0.000998 \\
(0.00201)\end{array}$ & $\begin{array}{c}-0.00111 \\
(0.00200)\end{array}$ \\
\hline Sp Employed & $\begin{array}{c}-1.968^{* * *} \\
(0.680)\end{array}$ & $\begin{array}{c}-1.919^{* *} \\
(0.936)\end{array}$ & $\begin{array}{c}-1.684^{* * *} \\
(0.645)\end{array}$ & $\begin{array}{c}0.357 \\
(1.121)\end{array}$ & $\begin{array}{c}-1.949 * * * \\
(0.620)\end{array}$ & $\begin{array}{c}-1.811^{* *} \\
(0.901)\end{array}$ & $\begin{array}{c}-1.702^{* *} \\
(0.666)\end{array}$ & $\begin{array}{c}0.385 \\
(1.128)\end{array}$ & $\begin{array}{c}-1.877^{* * *} \\
(0.631)\end{array}$ & $\begin{array}{c}-1.790^{* *} \\
(0.908)\end{array}$ & $\begin{array}{c}-1.700^{* *} \\
(0.667)\end{array}$ & $\begin{array}{c}0.311 \\
(1.126)\end{array}$ & $\begin{array}{c}-1.996^{* * * *} \\
(0.631)\end{array}$ & $\begin{array}{c}-1.917^{* *} \\
(0.921)\end{array}$ & $\begin{array}{c}-1.640^{* * *} \\
(0.623)\end{array}$ & $\begin{array}{c}0.398 \\
(1.109)\end{array}$ \\
\hline \multicolumn{17}{|l|}{ Yearly Dummies } \\
\hline Panel 6 (2002) & $\begin{array}{l}-0.0478 \\
(1.071)\end{array}$ & $\begin{array}{l}-0.0366 \\
(1.071)\end{array}$ & $\begin{array}{l}1.843^{*} \\
(0.940)\end{array}$ & $\begin{array}{l}1.672^{*} \\
(0.933)\end{array}$ & $\begin{array}{c}0.136 \\
(1.059)\end{array}$ & $\begin{array}{c}0.142 \\
(1.057)\end{array}$ & $\begin{array}{l}1.755^{*} \\
(0.953)\end{array}$ & $\begin{array}{l}1.572^{*} \\
(0.947)\end{array}$ & $\begin{array}{l}0.0156 \\
(1.077)\end{array}$ & $\begin{array}{l}0.00621 \\
(1.077)\end{array}$ & $\begin{array}{l}1.787^{*} \\
(0.937)\end{array}$ & $\begin{array}{l}1.623^{*} \\
(0.931)\end{array}$ & $\begin{array}{l}-0.0406 \\
(1.072)\end{array}$ & $\begin{array}{l}-0.0298 \\
(1.074)\end{array}$ & $\begin{array}{l}1.842^{*} \\
(0.946)\end{array}$ & $\begin{array}{l}1.674^{*} \\
(0.938)\end{array}$ \\
\hline Panel 7 (2003) & $\begin{array}{l}-0.134 \\
(0.944)\end{array}$ & $\begin{array}{l}-0.0927 \\
(0.947)\end{array}$ & $\begin{array}{l}-0.915 \\
(0.866)\end{array}$ & $\begin{array}{l}-0.916 \\
(0.857)\end{array}$ & $\begin{array}{l}-0.0791 \\
(0.930)\end{array}$ & $\begin{array}{l}-0.0362 \\
(0.931)\end{array}$ & $\begin{array}{l}-0.982 \\
(0.870)\end{array}$ & $\begin{array}{l}-0.981 \\
(0.860)\end{array}$ & $\begin{array}{l}-0.126 \\
(0.946)\end{array}$ & $\begin{array}{l}-0.0933 \\
(0.948)\end{array}$ & $\begin{array}{l}-0.963 \\
(0.871)\end{array}$ & $\begin{array}{l}-0.961 \\
(0.863)\end{array}$ & $\begin{array}{r}-0.136 \\
(0.941)\end{array}$ & $\begin{array}{l}-0.0840 \\
(0.945)\end{array}$ & $\begin{array}{l}-0.935 \\
(0.883)\end{array}$ & $\begin{array}{l}-0.935 \\
(0.873)\end{array}$ \\
\hline
\end{tabular}


Table A8 (Continued). Estimates of women and men's hours per week as a function of spouses' selected health measures with and without instrumenting for spouses' earnings

\begin{tabular}{|c|c|c|c|c|c|c|c|c|c|c|c|c|c|c|c|c|}
\hline \multirow[b]{2}{*}{ VARIABLE } & \multicolumn{2}{|c|}{ Women } & \multicolumn{2}{|c|}{ Men } & \multicolumn{2}{|c|}{ Women } & \multicolumn{2}{|c|}{ Men } & \multicolumn{2}{|c|}{ Women } & \multicolumn{2}{|c|}{ Men } & \multicolumn{2}{|c|}{ Women } & \multicolumn{2}{|c|}{ Men } \\
\hline & Non-IV & IV & Non-IV & IV & Non-IV & IV & Non-IV & IV & Non-IV & IV & Non-IV & IV & Non-IV & IV & Non-IV & IV \\
\hline Panel 8 (2004) & $\begin{array}{c}0.167 \\
(0.878)\end{array}$ & $\begin{array}{c}0.202 \\
(0.879)\end{array}$ & $\begin{array}{c}0.356 \\
(0.997)\end{array}$ & $\begin{array}{c}0.407 \\
(0.980)\end{array}$ & $\begin{array}{c}0.219 \\
(0.880)\end{array}$ & $\begin{array}{c}0.253 \\
(0.881)\end{array}$ & $\begin{array}{c}0.368 \\
(1.010)\end{array}$ & $\begin{array}{c}0.425 \\
(0.992)\end{array}$ & $\begin{array}{c}0.206 \\
(0.882)\end{array}$ & $\begin{array}{c}0.234 \\
(0.884)\end{array}$ & $\begin{array}{c}0.328 \\
(0.990)\end{array}$ & $\begin{array}{c}0.380 \\
(0.975)\end{array}$ & $\begin{array}{c}0.122 \\
(0.876)\end{array}$ & $\begin{array}{c}0.159 \\
(0.877)\end{array}$ & $\begin{array}{c}0.330 \\
(1.002)\end{array}$ & $\begin{array}{c}0.383 \\
(0.984)\end{array}$ \\
\hline Panel 9 (2005) & $\begin{array}{c}0.287 \\
(0.961)\end{array}$ & $\begin{array}{c}0.341 \\
(0.970)\end{array}$ & $\begin{array}{l}-0.660 \\
(0.815)\end{array}$ & $\begin{array}{c}-0.670 \\
(0.802)\end{array}$ & $\begin{array}{c}0.330 \\
(0.943)\end{array}$ & $\begin{array}{c}0.376 \\
(0.950)\end{array}$ & $\begin{array}{r}-0.660 \\
(0.806)\end{array}$ & $\begin{array}{c}-0.659 \\
(0.792)\end{array}$ & $\begin{array}{c}0.350 \\
(0.974)\end{array}$ & $\begin{array}{c}0.392 \\
(0.981)\end{array}$ & $\begin{array}{c}-0.683 \\
(0.821)\end{array}$ & $\begin{array}{c}-0.687 \\
(0.810)\end{array}$ & $\begin{array}{c}0.280 \\
(0.959)\end{array}$ & $\begin{array}{c}0.335 \\
(0.969)\end{array}$ & $\begin{array}{c}-0.695 \\
(0.829)\end{array}$ & $\begin{array}{c}-0.703 \\
(0.816)\end{array}$ \\
\hline Panel 10 (2006) & $\begin{array}{c}0.134 \\
(1.008)\end{array}$ & $\begin{array}{c}0.166 \\
(1.016)\end{array}$ & $\begin{array}{l}0.0720 \\
(0.866)\end{array}$ & $\begin{array}{c}0.132 \\
(0.847)\end{array}$ & $\begin{array}{c}0.164 \\
(0.996)\end{array}$ & $\begin{array}{c}0.189 \\
(1.005)\end{array}$ & $\begin{array}{l}0.0429 \\
(0.872)\end{array}$ & $\begin{array}{c}0.125 \\
(0.850)\end{array}$ & $\begin{array}{c}0.192 \\
(1.011)\end{array}$ & $\begin{array}{c}0.208 \\
(1.019)\end{array}$ & $\begin{array}{l}0.0395 \\
(0.861)\end{array}$ & $\begin{array}{c}0.106 \\
(0.844)\end{array}$ & $\begin{array}{c}0.145 \\
(1.011)\end{array}$ & $\begin{array}{c}0.181 \\
(1.020)\end{array}$ & $\begin{array}{l}0.0631 \\
(0.874)\end{array}$ & $\begin{array}{c}0.126 \\
(0.855)\end{array}$ \\
\hline Panel 11 (2007) & $\begin{array}{l}-0.385 \\
(0.890)\end{array}$ & $\begin{array}{c}-0.342 \\
(0.900)\end{array}$ & $\begin{array}{c}-0.794 \\
(0.803)\end{array}$ & $\begin{array}{c}-0.629 \\
(0.794)\end{array}$ & $\begin{array}{l}-0.390 \\
(0.882)\end{array}$ & $\begin{array}{c}-0.358 \\
(0.890)\end{array}$ & $\begin{array}{c}-0.768 \\
(0.806)\end{array}$ & $\begin{array}{c}-0.586 \\
(0.796)\end{array}$ & $\begin{array}{c}-0.380 \\
(0.895)\end{array}$ & $\begin{array}{l}-0.355 \\
(0.904)\end{array}$ & $\begin{array}{c}-0.838 \\
(0.805)\end{array}$ & $\begin{array}{l}-0.670 \\
(0.798)\end{array}$ & $\begin{array}{c}-0.385 \\
(0.890)\end{array}$ & $\begin{array}{c}-0.342 \\
(0.901)\end{array}$ & $\begin{array}{l}-0.819 \\
(0.818)\end{array}$ & $\begin{array}{c}-0.652 \\
(0.809)\end{array}$ \\
\hline Constant & $\begin{array}{c}31.00^{* * *} \\
(2.449)\end{array}$ & $\begin{array}{c}31.76^{* * *} \\
(2.600)\end{array}$ & $\begin{array}{c}38.25^{* * *} \\
(2.304)\end{array}$ & $\begin{array}{c}36.00 * * * \\
(2.309)\end{array}$ & $\begin{array}{c}30.08^{* * *} \\
(2.413)\end{array}$ & $\begin{array}{c}30.65 * * * \\
(2.485)\end{array}$ & $\begin{array}{c}39.98^{* * *} \\
(2.470)\end{array}$ & $\begin{array}{c}38.01 * * * \\
(2.455)\end{array}$ & $\begin{array}{c}30.68^{* * *} \\
(2.394)\end{array}$ & $\begin{array}{c}31.27^{* * *} \\
(2.485)\end{array}$ & $\begin{array}{c}38.21^{* * *} \\
(2.393)\end{array}$ & $\begin{array}{c}36.00 * * * \\
(2.394)\end{array}$ & $\begin{array}{c}31.29 * * * \\
(2.444)\end{array}$ & $\begin{array}{c}32.04^{* * * *} \\
(2.606)\end{array}$ & $\begin{array}{c}38.19 * * * \\
(2.322)\end{array}$ & $\begin{array}{c}35.92^{* * *} \\
(2.347)\end{array}$ \\
\hline$\rho$ & $\begin{array}{c}-0.163 \\
(0.1127)\end{array}$ & $\begin{array}{c}-0.236 \\
(0.1246)\end{array}$ & $\begin{array}{c}-0.086 \\
(0.0412)\end{array}$ & $\begin{array}{c}-0.087 \\
(0.0429)\end{array}$ & $\begin{array}{c}-0.110 \\
(0.1078)\end{array}$ & $\begin{array}{c}-0.173 \\
(0.1190)\end{array}$ & $\begin{array}{c}-0.077 \\
(0.0412)\end{array}$ & $\begin{array}{c}-0.076 \\
(0.0434)\end{array}$ & $\begin{array}{c}-0.131 \\
(0.1049)\end{array}$ & $\begin{array}{c}-0.188 \\
(0.1144)\end{array}$ & $\begin{array}{c}-0.080 \\
(0.0412)\end{array}$ & $\begin{array}{c}-0.082 \\
(0.0415)\end{array}$ & $\begin{array}{c}-0.194 \\
(0.1167)\end{array}$ & $\begin{array}{c}-0.267 \\
(0.1290)\end{array}$ & $\begin{array}{c}-0.091 \\
(0.0401)\end{array}$ & $\begin{array}{c}-0.090 \\
(0.0416)\end{array}$ \\
\hline$\sigma$ & $\begin{array}{c}8.853 \\
(0.2341)\end{array}$ & $\begin{array}{c}8.926 \\
(0.2441)\end{array}$ & $\begin{array}{c}9.487 \\
(0.3652)\end{array}$ & $\begin{array}{c}9.481 \\
(0.3628)\end{array}$ & $\begin{array}{c}8.809 \\
(0.2373)\end{array}$ & $\begin{array}{c}8.857 \\
(0.2468)\end{array}$ & $\begin{array}{c}9.457 \\
(0.3670)\end{array}$ & $\begin{array}{c}9.449 \\
(0.3651)\end{array}$ & $\begin{array}{c}8.828 \\
(0.2364)\end{array}$ & $\begin{array}{c}8.876 \\
(0.2446)\end{array}$ & $\begin{array}{c}9.485 \\
(0.3684)\end{array}$ & $\begin{array}{c}9.480 \\
(0.3660)\end{array}$ & $\begin{array}{c}8.881 \\
(0.2393)\end{array}$ & $\begin{array}{c}8.967 \\
(0.2539)\end{array}$ & $\begin{array}{c}9.487 \\
(0.3633)\end{array}$ & $\begin{array}{c}9.480 \\
(0.3607)\end{array}$ \\
\hline$\lambda$ & $\begin{array}{c}-1.443 \\
(1.0053)\end{array}$ & $\begin{array}{c}-2.103 \\
(1.1329)\end{array}$ & $\begin{array}{c}-0.813 \\
(0.3983)\end{array}$ & $\begin{array}{c}-0.820 \\
(0.4134)\end{array}$ & $\begin{array}{c}-0.967 \\
(0.9533)\end{array}$ & $\begin{array}{c}-1.532 \\
(1.0662)\end{array}$ & $\begin{array}{c}-0.732 \\
(0.3967)\end{array}$ & $\begin{array}{c}-0.714 \\
(0.4163)\end{array}$ & $\begin{array}{c}-1.152 \\
(0.9320)\end{array}$ & $\begin{array}{c}-1.668 \\
(1.0295)\end{array}$ & $\begin{array}{c}-0.758 \\
(0.4004)\end{array}$ & $\begin{array}{c}-0.776 \\
(0.4026)\end{array}$ & $\begin{array}{c}-1.727 \\
(1.0496)\end{array}$ & $\begin{array}{c}-2.393 \\
(1.1866)\end{array}$ & $\begin{array}{c}-0.862 \\
(0.3891)\end{array}$ & $\begin{array}{c}-0.854 \\
(0.4022)\end{array}$ \\
\hline
\end{tabular}

Note : Standard errors in parentheses; all tests are two-sided against the null hypothesis that the marginal effect is $=0 ; * * * p<0.01,{ }^{* *} p<0.05,{ }^{*} p<0.1$

Note: Maximum Likelihood estimates of regression models with selection using MEPS (panels 5 through 11). Rho is the correlation between the residuals of the hours and labor force partici pation equations, sigma is

the standard error of the residual in the hours equation, and lambda is the product of rho and sigma. 
Table A9. Estimates of women and men's hours per week as a function of spouse's health measures with and without instrumenting for spouse's earnings

\begin{tabular}{|c|c|c|c|c|c|c|c|c|c|c|c|c|}
\hline \multirow[b]{3}{*}{ VARIABLE } & \multicolumn{4}{|c|}{ (1) } & \multicolumn{4}{|c|}{$\overline{(2)}$} & \multicolumn{4}{|c|}{ (3) } \\
\hline & \multicolumn{2}{|c|}{ Women } & \multicolumn{2}{|c|}{ Men } & \multicolumn{2}{|c|}{ Women } & \multicolumn{2}{|c|}{ Men } & \multicolumn{2}{|c|}{ Women } & \multicolumn{2}{|c|}{ Men } \\
\hline & Non-IV & IV & Non-IV & IV & Non-IV & IV & Non-IV & IV & Non-IV & IV & Non-IV & IV \\
\hline Reservation Wage Indicators & & & & & & & & & & & & \\
\hline Spouse Work-limit & $\begin{array}{c}0.519 \\
(0.979)\end{array}$ & $\begin{array}{c}0.435 \\
(0.986)\end{array}$ & $\begin{array}{c}0.598 \\
(1.127)\end{array}$ & $\begin{array}{c}0.737 \\
(1.134)\end{array}$ & & & & & & & & \\
\hline Spouse Very Good & $\begin{array}{c}-0.309 \\
(0.671)\end{array}$ & $\begin{array}{l}-0.301 \\
(0.667)\end{array}$ & $\begin{array}{l}-0.957 \\
(0.654)\end{array}$ & $\begin{array}{l}-1.065 \\
(0.647)\end{array}$ & & & & & & & & \\
\hline Spouse Good & $\begin{array}{c}0.333 \\
(0.578)\end{array}$ & $\begin{array}{c}0.285 \\
(0.594)\end{array}$ & $\begin{array}{c}-1.677^{* *} \\
(0.678)\end{array}$ & $\begin{array}{c}-1.853^{* * *} \\
(0.678)\end{array}$ & & & & & & & & \\
\hline Spouse Fair/Poor & $\begin{array}{c}0.175 \\
(0.802)\end{array}$ & $\begin{array}{c}0.127 \\
(0.803)\end{array}$ & $\begin{array}{r}-0.250 \\
(0.841)\end{array}$ & $\begin{array}{r}-0.573 \\
(0.847)\end{array}$ & & & & & & & & \\
\hline Spouse \# of Conditions & & & & & $\begin{array}{c}0.211 \\
(0.229)\end{array}$ & $\begin{array}{c}0.200 \\
(0.229)\end{array}$ & $\begin{array}{c}0.166 \\
(0.233)\end{array}$ & $\begin{array}{c}0.156 \\
(0.232)\end{array}$ & & & & \\
\hline Spouse \# of Func. Limits & & & & & $\begin{array}{l}0.0976 \\
(0.151)\end{array}$ & $\begin{array}{l}0.0961 \\
(0.151)\end{array}$ & $\begin{array}{c}0.175 \\
(0.187)\end{array}$ & $\begin{array}{c}0.171 \\
(0.187)\end{array}$ & & & & \\
\hline Spouse (z-scored) PCS & & & & & & & & & $\begin{array}{l}-0.196 \\
(0.245)\end{array}$ & $\begin{array}{l}-0.142 \\
(0.256)\end{array}$ & $\begin{array}{l}-0.171 \\
(0.229)\end{array}$ & $\begin{array}{l}-0.104 \\
(0.229)\end{array}$ \\
\hline Work-limit & $\begin{array}{c}-0.00748 \\
(1.806)\end{array}$ & $\begin{array}{c}0.431 \\
(1.816)\end{array}$ & $\begin{array}{l}-0.0449 \\
(1.723)\end{array}$ & $\begin{array}{l}-0.0179 \\
(1.710)\end{array}$ & & & & & & & & \\
\hline Very Good & $\begin{array}{l}-0.565 \\
(0.581)\end{array}$ & $\begin{array}{l}-0.538 \\
(0.586)\end{array}$ & $\begin{array}{c}0.669 \\
(0.567)\end{array}$ & $\begin{array}{c}0.567 \\
(0.572)\end{array}$ & & & & & & & & \\
\hline Good & $\begin{array}{c}0.191 \\
(0.609)\end{array}$ & $\begin{array}{c}0.210 \\
(0.614)\end{array}$ & $\begin{array}{l}-0.180 \\
(0.636)\end{array}$ & $\begin{array}{l}-0.243 \\
(0.640)\end{array}$ & & & & & & & & \\
\hline Fair/Poor & $\begin{array}{r}-0.563 \\
(0.991)\end{array}$ & $\begin{array}{c}-0.421 \\
(0.996)\end{array}$ & $\begin{array}{c}-0.178 \\
(1.009)\end{array}$ & $\begin{array}{l}-0.341 \\
(0.976)\end{array}$ & & & & & & & & \\
\hline \# of Conditions & & & & & $\begin{array}{l}-0.192 \\
(0.264)\end{array}$ & $\begin{array}{r}-0.150 \\
(0.266)\end{array}$ & $\begin{array}{l}-0.0606 \\
(0.284)\end{array}$ & $\begin{array}{l}-0.0765 \\
(0.285)\end{array}$ & & & & \\
\hline \# of Functional Limitations & & & & & $\begin{array}{c}0.184 \\
(0.160)\end{array}$ & $\begin{array}{c}0.223 \\
(0.166)\end{array}$ & $\begin{array}{l}0.0871 \\
(0.253)\end{array}$ & $\begin{array}{l}0.0766 \\
(0.252)\end{array}$ & & & & \\
\hline (z-scored) PCS & & & & & & & & & $\begin{array}{l}-0.0842 \\
(0.333)\end{array}$ & $\begin{array}{l}-0.245 \\
(0.364)\end{array}$ & $\begin{array}{c}0.643^{*} \\
(0.365)\end{array}$ & $\begin{array}{l}0.750^{* *} \\
(0.353)\end{array}$ \\
\hline
\end{tabular}


Table A9. (continued) Estimates of women and men's hours per week as a function of spouse's health measures with and without instrumenting for spouse's earnings

\begin{tabular}{|c|c|c|c|c|c|c|c|c|c|c|c|c|}
\hline \multirow[b]{3}{*}{ VARIABLE } & \multicolumn{4}{|c|}{ (1) } & \multicolumn{4}{|c|}{ (2) } & \multicolumn{4}{|c|}{ (3) } \\
\hline & \multicolumn{2}{|c|}{ Women } & \multicolumn{2}{|c|}{ Men } & \multicolumn{2}{|c|}{ Women } & \multicolumn{2}{|c|}{ Men } & \multicolumn{2}{|c|}{ Women } & \multicolumn{2}{|c|}{ Men } \\
\hline & Non-IV & IV & Non-IV & IV & Non-IV & IV & Non-IV & IV & Non-IV & IV & Non-IV & IV \\
\hline \# Children $<18$ years old & $\begin{array}{c}-0.582 \\
(0.562)\end{array}$ & $\begin{array}{c}-0.577 \\
(0.561)\end{array}$ & $\begin{array}{c}0.0173 \\
(0.228)\end{array}$ & $\begin{array}{c}0.0328 \\
(0.227)\end{array}$ & $\begin{array}{c}-0.558 \\
(0.554)\end{array}$ & $\begin{array}{c}-0.552 \\
(0.554)\end{array}$ & $\begin{array}{l}0.0610 \\
(0.234)\end{array}$ & $\begin{array}{l}0.0732 \\
(0.233)\end{array}$ & $\begin{array}{l}-0.478 \\
(0.609)\end{array}$ & $\begin{array}{c}-0.492 \\
(0.606)\end{array}$ & $\begin{array}{l}0.00788 \\
(0.247)\end{array}$ & $\begin{array}{c}0.0182 \\
(0.248)\end{array}$ \\
\hline \# Children $>=18$ years old & $\begin{array}{l}0.725 * * \\
(0.356)\end{array}$ & $\begin{array}{l}0.659^{*} \\
(0.359)\end{array}$ & $\begin{array}{l}-0.0339 \\
(0.286)\end{array}$ & $\begin{array}{l}-0.0671 \\
(0.290)\end{array}$ & $\begin{array}{l}0.677^{*} \\
(0.358)\end{array}$ & $\begin{array}{l}0.610^{*} \\
(0.361)\end{array}$ & $\begin{array}{c}-0.0424 \\
(0.277)\end{array}$ & $\begin{array}{l}-0.0802 \\
(0.281)\end{array}$ & $\begin{array}{c}0.584 \\
(0.409)\end{array}$ & $\begin{array}{c}0.466 \\
(0.430)\end{array}$ & $\begin{array}{l}0.0524 \\
(0.321)\end{array}$ & $\begin{array}{l}0.0315 \\
(0.324)\end{array}$ \\
\hline $\begin{array}{l}\text { White } \\
\text { Potential Wage Indicators }\end{array}$ & $\begin{array}{l}-0.788 \\
(0.583)\end{array}$ & $\begin{array}{l}-0.823 \\
(0.578)\end{array}$ & $\begin{array}{c}1.867^{* * *} \\
(0.569)\end{array}$ & $\begin{array}{c}1.650^{* * *} \\
(0.563)\end{array}$ & $\begin{array}{c}-0.872 \\
(0.566)\end{array}$ & $\begin{array}{l}-0.913 \\
(0.563)\end{array}$ & $\begin{array}{c}1.960 * * * \\
(0.567)\end{array}$ & $\begin{array}{c}1.770^{* * *} \\
(0.557)\end{array}$ & $\begin{array}{l}-1.114^{*} \\
(0.642)\end{array}$ & $\begin{array}{l}-1.150^{*} \\
(0.641)\end{array}$ & $\begin{array}{c}2.182^{* * *} \\
(0.608)\end{array}$ & $\begin{array}{c}2.104^{* * *} \\
(0.603)\end{array}$ \\
\hline Individual's Predicted Wage & $\begin{array}{c}0.307 \\
(0.770)\end{array}$ & $\begin{array}{c}0.223 \\
(0.825)\end{array}$ & $\begin{array}{c}0.552 \\
(0.868)\end{array}$ & $\begin{array}{l}1.403^{*} \\
(0.841)\end{array}$ & $\begin{array}{c}-0.00763 \\
(0.768)\end{array}$ & $\begin{array}{l}-0.113 \\
(0.824)\end{array}$ & $\begin{array}{c}0.863 \\
(0.837)\end{array}$ & $\begin{array}{l}1.718^{* *} \\
(0.826)\end{array}$ & $\begin{array}{c}0.269 \\
(0.772)\end{array}$ & $\begin{array}{c}0.166 \\
(0.831)\end{array}$ & $\begin{array}{c}0.663 \\
(0.899)\end{array}$ & $\begin{array}{c}0.927 \\
(0.892)\end{array}$ \\
\hline Union & $\begin{array}{c}-2.040 * * * \\
(0.521)\end{array}$ & $\begin{array}{c}-2.036^{* * *} \\
(0.519)\end{array}$ & $\begin{array}{c}-2.515^{* * *} \\
(0.499)\end{array}$ & $\begin{array}{c}-2.488^{* * *} \\
(0.499)\end{array}$ & $\begin{array}{c}-1.992^{* * *} \\
(0.531)\end{array}$ & $\begin{array}{c}-1.985^{* * *} \\
(0.528)\end{array}$ & $\begin{array}{c}-2.654^{* * *} \\
(0.500)\end{array}$ & $\begin{array}{c}-2.631^{* * *} \\
(0.501)\end{array}$ & $\begin{array}{c}-2.386^{* * *} \\
(0.562)\end{array}$ & $\begin{array}{c}-2.379 * * * \\
(0.560)\end{array}$ & $\begin{array}{c}-2.686^{* * *} \\
(0.541)\end{array}$ & $\begin{array}{c}-2.633^{* * *} \\
(0.540)\end{array}$ \\
\hline Retirement/Pension Plan & $\begin{array}{c}3.329 * * * \\
(0.558)\end{array}$ & $\begin{array}{c}3.350 * * * \\
(0.561)\end{array}$ & $\begin{array}{c}1.817^{* * *} \\
(0.573)\end{array}$ & $\begin{array}{c}1.901^{* * *} \\
(0.572)\end{array}$ & $\begin{array}{c}3.389 * * * \\
(0.565)\end{array}$ & $\begin{array}{c}3.402^{* * *} \\
(0.567)\end{array}$ & $\begin{array}{c}1.844^{* * *} \\
(0.575)\end{array}$ & $\begin{array}{c}1.925^{* * *} \\
(0.573)\end{array}$ & $\begin{array}{c}3.408^{* * *} \\
(0.606)\end{array}$ & $\begin{array}{c}3.408^{* * *} \\
(0.608)\end{array}$ & $\begin{array}{c}1.902^{* * *} \\
(0.616)\end{array}$ & $\begin{array}{c}2.025^{* * *} \\
(0.613)\end{array}$ \\
\hline Holds ESI & $\begin{array}{c}4.526^{* * *} \\
(0.520)\end{array}$ & $\begin{array}{c}4.453^{* * *} \\
(0.512)\end{array}$ & $\begin{array}{c}1.816^{* * *} \\
(0.613)\end{array}$ & $\begin{array}{l}1.558^{* *} \\
(0.620)\end{array}$ & $\begin{array}{c}4.525^{* * *} \\
(0.514)\end{array}$ & $\begin{array}{c}4.464^{* * *} \\
(0.508)\end{array}$ & $\begin{array}{c}1.783^{* * *} \\
(0.606)\end{array}$ & $\begin{array}{l}1.534^{* *} \\
(0.618)\end{array}$ & $\begin{array}{c}4.908^{* * *} \\
(0.528)\end{array}$ & $\begin{array}{c}4.853^{* * *} \\
(0.520)\end{array}$ & $\begin{array}{c}1.801 * * * \\
(0.676)\end{array}$ & $\begin{array}{l}1.618^{* *} \\
(0.673)\end{array}$ \\
\hline Choice of Insurance Plans & $\begin{array}{l}1.069 * * \\
(0.486)\end{array}$ & $\begin{array}{l}1.080^{* *} \\
(0.486)\end{array}$ & $\begin{array}{l}-0.0910 \\
(0.472)\end{array}$ & $\begin{array}{l}-0.0894 \\
(0.473)\end{array}$ & $\begin{array}{l}1.185^{* *} \\
(0.480)\end{array}$ & $\begin{array}{l}1.191^{* *} \\
(0.480)\end{array}$ & $\begin{array}{l}-0.113 \\
(0.478)\end{array}$ & $\begin{array}{l}-0.103 \\
(0.481)\end{array}$ & $\begin{array}{l}1.033^{*} \\
(0.558)\end{array}$ & $\begin{array}{l}1.043^{*} \\
(0.558)\end{array}$ & $\begin{array}{c}-0.232 \\
(0.513)\end{array}$ & $\begin{array}{c}-0.202 \\
(0.515)\end{array}$ \\
\hline $\begin{array}{l}\text { Paid Sick Leave } \\
\text { Unearned Income }\end{array}$ & $\begin{array}{c}5.090 * * * \\
(0.645)\end{array}$ & $\begin{array}{c}5.088^{* * *} \\
(0.649)\end{array}$ & $\begin{array}{l}0.979^{*} \\
(0.554)\end{array}$ & $\begin{array}{c}0.990^{*} \\
(0.553)\end{array}$ & $\begin{array}{c}5.052^{* * *} \\
(0.641)\end{array}$ & $\begin{array}{c}5.053^{* * *} \\
(0.645)\end{array}$ & $\begin{array}{l}1.020^{*} \\
(0.546)\end{array}$ & $\begin{array}{l}1.033^{*} \\
(0.544)\end{array}$ & $\begin{array}{c}4.945^{* * *} \\
(0.678)\end{array}$ & $\begin{array}{c}4.943^{* * *} \\
(0.683)\end{array}$ & $\begin{array}{l}0.977^{*} \\
(0.588)\end{array}$ & $\begin{array}{c}1.049 * \\
(0.584)\end{array}$ \\
\hline Spouse's Earnings ( $\$ 100 /$ week) & $\begin{array}{c}0.0766 \\
(0.0530)\end{array}$ & $\begin{array}{c}0.0572 \\
(0.0934)\end{array}$ & $\begin{array}{c}0.0518 \\
(0.0656)\end{array}$ & $\begin{array}{c}-0.282^{* *} \\
(0.137)\end{array}$ & $\begin{array}{c}0.0762 \\
(0.0523)\end{array}$ & $\begin{array}{c}0.0632 \\
(0.0920)\end{array}$ & $\begin{array}{c}0.0574 \\
(0.0662)\end{array}$ & $\begin{array}{l}-0.258^{*} \\
(0.138)\end{array}$ & $\begin{array}{c}0.0548 \\
(0.0559)\end{array}$ & $\begin{array}{c}0.0238 \\
(0.0946)\end{array}$ & $\begin{array}{c}0.0435 \\
(0.0719)\end{array}$ & $\begin{array}{c}-0.199 \\
(0.145)\end{array}$ \\
\hline Household Income (\$100/year) & $\begin{array}{c}-0.00337^{* *} \\
(0.00169)\end{array}$ & $\begin{array}{c}-0.00312^{*} \\
(0.00171)\end{array}$ & $\begin{array}{r}-0.00110 \\
(0.00200)\end{array}$ & $\begin{array}{r}-0.00121 \\
(0.00199)\end{array}$ & $\begin{array}{c}-0.00319^{*} \\
(0.00169)\end{array}$ & $\begin{array}{l}-0.00295^{*} \\
(0.00172)\end{array}$ & $\begin{array}{r}-0.00108 \\
(0.00201)\end{array}$ & $\begin{array}{r}-0.00117 \\
(0.00200)\end{array}$ & $\begin{array}{c}-0.00349 * \\
(0.00184)\end{array}$ & $\begin{array}{c}-0.00302 \\
(0.00192)\end{array}$ & $\begin{array}{l}-0.000818 \\
(0.00227)\end{array}$ & $\begin{array}{l}-0.000930 \\
(0.00227)\end{array}$ \\
\hline Spouse Employed & $\begin{array}{c}-1.886 * * * \\
(0.668)\end{array}$ & $\begin{array}{c}-1.779 * \\
(0.931)\end{array}$ & $\begin{array}{c}-1.634^{* *} \\
(0.646)\end{array}$ & $\begin{array}{c}0.488 \\
(1.114)\end{array}$ & $\begin{array}{c}-1.890^{* * *} \\
(0.625)\end{array}$ & $\begin{array}{c}-1.823^{* *} \\
(0.920)\end{array}$ & $\begin{array}{c}-1.591^{* *} \\
(0.629)\end{array}$ & $\begin{array}{c}0.429 \\
(1.104)\end{array}$ & $\begin{array}{c}-1.605^{* *} \\
(0.680)\end{array}$ & $\begin{array}{l}-1.401 \\
(0.939)\end{array}$ & $\begin{array}{c}-1.756^{* *} \\
(0.715)\end{array}$ & $\begin{array}{c}-0.231 \\
(1.190)\end{array}$ \\
\hline
\end{tabular}


Table A9. (continued) Estimates of women and men's hours per week as a function of spouse's health measures with and without instrumenting for spouse's earnings

\begin{tabular}{|c|c|c|c|c|c|c|c|c|c|c|c|c|}
\hline \multirow[b]{3}{*}{ VARIABLE } & \multicolumn{4}{|c|}{ (1) } & \multicolumn{4}{|c|}{ (2) } & \multicolumn{4}{|c|}{ (3) } \\
\hline & \multicolumn{2}{|c|}{ Women } & \multicolumn{2}{|c|}{ Men } & \multicolumn{2}{|c|}{ Women } & \multicolumn{2}{|c|}{ Men } & \multicolumn{2}{|c|}{ Women } & \multicolumn{2}{|c|}{ Men } \\
\hline & Non-IV & IV & Non-IV & IV & Non-IV & IV & Non-IV & IV & Non-IV & IV & Non-IV & IV \\
\hline Yearly Dummies & & & & & & & & & & & & \\
\hline Panel 6 (2002) & $\begin{array}{c}0.114 \\
(1.057)\end{array}$ & $\begin{array}{c}0.120 \\
(1.054)\end{array}$ & $\begin{array}{l}1.748^{*} \\
(0.954)\end{array}$ & $\begin{array}{c}1.561 \\
(0.949)\end{array}$ & $\begin{array}{r}0.0255 \\
(1.076)\end{array}$ & $\begin{array}{r}0.0224 \\
(1.079)\end{array}$ & $\begin{array}{l}1.806^{*} \\
(0.942)\end{array}$ & $\begin{array}{c}1.641^{*} \\
(0.936)\end{array}$ & $\begin{array}{c}0.0834 \\
(1.142)\end{array}$ & $\begin{array}{c}0.113 \\
(1.142)\end{array}$ & $\begin{array}{c}2.425^{* *} \\
(0.981)\end{array}$ & $\begin{array}{c}2.343^{* *} \\
(0.981)\end{array}$ \\
\hline Panel 7 (2003) & $\begin{array}{r}-0.0410 \\
(0.937)\end{array}$ & $\begin{array}{c}-0.00520 \\
(0.939)\end{array}$ & $\begin{array}{c}-1.008 \\
(0.874)\end{array}$ & $\begin{array}{r}-1.010 \\
(0.864)\end{array}$ & $\begin{array}{c}-0.0944 \\
(0.951)\end{array}$ & $\begin{array}{c}-0.0583 \\
(0.955)\end{array}$ & $\begin{array}{l}-0.980 \\
(0.880)\end{array}$ & $\begin{array}{c}-0.977 \\
(0.872)\end{array}$ & $\begin{array}{c}0.184 \\
(0.973)\end{array}$ & $\begin{array}{c}0.229 \\
(0.978)\end{array}$ & $\begin{array}{r}-0.935 \\
(0.883)\end{array}$ & $\begin{array}{r}-0.988 \\
(0.873)\end{array}$ \\
\hline Panel 8 (2004) & $\begin{array}{c}0.222 \\
(0.870)\end{array}$ & $\begin{array}{c}0.251 \\
(0.872)\end{array}$ & $\begin{array}{c}0.343 \\
(0.999)\end{array}$ & $\begin{array}{c}0.400 \\
(0.980)\end{array}$ & $\begin{array}{c}0.172 \\
(0.873)\end{array}$ & $\begin{array}{c}0.195 \\
(0.875)\end{array}$ & $\begin{array}{c}0.298 \\
(0.991)\end{array}$ & $\begin{array}{c}0.353 \\
(0.975)\end{array}$ & $\begin{array}{c}0.454 \\
(0.975)\end{array}$ & $\begin{array}{c}0.510 \\
(0.981)\end{array}$ & $\begin{array}{c}0.573 \\
(1.042)\end{array}$ & $\begin{array}{c}0.610 \\
(1.026)\end{array}$ \\
\hline Panel 9 (2005) & $\begin{array}{c}0.340 \\
(0.941)\end{array}$ & $\begin{array}{c}0.387 \\
(0.948)\end{array}$ & $\begin{array}{r}-0.689 \\
(0.808)\end{array}$ & $\begin{array}{c}-0.692 \\
(0.794)\end{array}$ & $\begin{array}{c}0.347 \\
(0.972)\end{array}$ & $\begin{array}{c}0.387 \\
(0.981)\end{array}$ & $\begin{array}{l}-0.729 \\
(0.829)\end{array}$ & $\begin{array}{r}-0.733 \\
(0.817)\end{array}$ & $\begin{array}{c}0.374 \\
(1.032)\end{array}$ & $\begin{array}{c}0.448 \\
(1.049)\end{array}$ & $\begin{array}{r}-0.703 \\
(0.804)\end{array}$ & $\begin{array}{l}-0.690 \\
(0.790)\end{array}$ \\
\hline Panel 10 (2006) & $\begin{array}{c}0.166 \\
(0.994)\end{array}$ & $\begin{array}{c}0.191 \\
(1.003)\end{array}$ & $\begin{array}{l}0.0364 \\
(0.870)\end{array}$ & $\begin{array}{c}0.117 \\
(0.848)\end{array}$ & $\begin{array}{c}0.205 \\
(1.014)\end{array}$ & $\begin{array}{c}0.225 \\
(1.024)\end{array}$ & $\begin{array}{l}0.0342 \\
(0.868)\end{array}$ & $\begin{array}{c}0.101 \\
(0.850)\end{array}$ & $\begin{array}{c}0.135 \\
(1.083)\end{array}$ & $\begin{array}{c}0.177 \\
(1.095)\end{array}$ & $\begin{array}{c}0.00663 \\
(0.940)\end{array}$ & $\begin{array}{r}0.0711 \\
(0.926)\end{array}$ \\
\hline Panel 11 (2007) & $\begin{array}{r}-0.375 \\
(0.878)\end{array}$ & $\begin{array}{l}-0.341 \\
(0.886)\end{array}$ & $\begin{array}{l}-0.786 \\
(0.807)\end{array}$ & $\begin{array}{l}-0.603 \\
(0.796)\end{array}$ & $\begin{array}{c}-0.374 \\
(0.893)\end{array}$ & $\begin{array}{l}-0.348 \\
(0.902)\end{array}$ & $\begin{array}{l}-0.862 \\
(0.810)\end{array}$ & $\begin{array}{l}-0.693 \\
(0.803)\end{array}$ & $\begin{array}{l}-0.512 \\
(0.959)\end{array}$ & $\begin{array}{l}-0.485 \\
(0.964)\end{array}$ & $\begin{array}{l}-0.715 \\
(0.841)\end{array}$ & $\begin{array}{l}-0.568 \\
(0.829)\end{array}$ \\
\hline Constant & $\begin{array}{c}30.26 * * * \\
(2.437)\end{array}$ & $\begin{array}{c}30.90 * * * \\
(2.524)\end{array}$ & $\begin{array}{c}39.81^{* * *} \\
(2.464)\end{array}$ & $\begin{array}{c}37.84^{* * *} \\
(2.435)\end{array}$ & $\begin{array}{c}31.11^{* * *} \\
(2.355)\end{array}$ & $\begin{array}{c}31.76^{* * *} \\
(2.465)\end{array}$ & $\begin{array}{c}37.96 * * * \\
(2.374)\end{array}$ & $\begin{array}{c}35.75^{* * *} \\
(2.380)\end{array}$ & $\begin{array}{c}30.29 * * * \\
(2.641)\end{array}$ & $\begin{array}{c}31.28^{* * *} \\
(2.919)\end{array}$ & $\begin{array}{c}38.52 * * * \\
(2.453)\end{array}$ & $\begin{array}{c}37.54^{* * *} \\
(2.711)\end{array}$ \\
\hline$\rho$ & $\begin{array}{c}-0.136 \\
(0.1068)\end{array}$ & $\begin{array}{c}-0.204 \\
(0.1174)\end{array}$ & $\begin{array}{c}-0.072 \\
(0.0419)\end{array}$ & $\begin{array}{c}-0.071 \\
(0.0441)\end{array}$ & $\begin{array}{c}-0.186 \\
(0.1037)\end{array}$ & $\begin{array}{c}-0.251 \\
(0.1122)\end{array}$ & $\begin{array}{c}-0.084 \\
(0.0404)\end{array}$ & $\begin{array}{c}-0.084 \\
(0.0417)\end{array}$ & $\begin{array}{c}-0.159 \\
(0.1358)\end{array}$ & $\begin{array}{c}-0.271 \\
(0.1687)\end{array}$ & $\begin{array}{c}-0.093 \\
(0.0425)\end{array}$ & $\begin{array}{c}-0.090 \\
(0.0442)\end{array}$ \\
\hline$\sigma$ & $\begin{array}{c}8.820 \\
(0.2349)\end{array}$ & $\begin{array}{c}8.879 \\
(0.2431)\end{array}$ & $\begin{array}{c}9.453 \\
(0.3647)\end{array}$ & $\begin{array}{c}9.444 \\
(0.3626)\end{array}$ & $\begin{array}{c}8.866 \\
(0.2364)\end{array}$ & $\begin{array}{c}8.938 \\
(0.2442)\end{array}$ & $\begin{array}{c}9.482 \\
(0.3641)\end{array}$ & $\begin{array}{c}9.476 \\
(0.3615)\end{array}$ & $\begin{array}{c}8.790 \\
(0.2489)\end{array}$ & $\begin{array}{c}8.908 \\
(0.2916)\end{array}$ & $\begin{array}{c}9.540 \\
(0.3937)\end{array}$ & $\begin{array}{c}9.537 \\
(0.3910)\end{array}$ \\
\hline$\lambda$ & $\begin{array}{c}-1.197 \\
(0.9464)\end{array}$ & $\begin{array}{c}-1.809 \\
(1.0566)\end{array}$ & $\begin{array}{c}-0.676 \\
(0.4022)\end{array}$ & $\begin{array}{c}-0.672 \\
(0.4215)\end{array}$ & $\begin{array}{c}-1.651 \\
(0.9293)\end{array}$ & $\begin{array}{c}-2.240 \\
(1.0242)\end{array}$ & $\begin{array}{c}-0.793 \\
(0.3916)\end{array}$ & $\begin{array}{c}-0.793 \\
(0.4031)\end{array}$ & $\begin{array}{c}-1.400 \\
(1.2058)\end{array}$ & $\begin{array}{c}-2.412 \\
(1.5492)\end{array}$ & $\begin{array}{c}-0.883 \\
(0.4166)\end{array}$ & $\begin{array}{c}-0.856 \\
(0.4306)\end{array}$ \\
\hline
\end{tabular}

Note: Standard errors in parentheses; all tests are two-sided against the null hypothesis that the marginal effect is $=0 ; \quad * * * p<0.01, * * p<0.05,{ }^{*} p<0.1$

Note: Maximum Likelihood estimates of regression models with selection using MEPS (panels 5 through 11). Rho is the correlation between the residuals of the hours and labor force participation equations, sigma is the standard error of the residual in the hours equation, and lambda is the product of rho and sigma. 
Table A10. Estimates of women and men's hours per week as a function of spouse's health measures with and without instrumenting for spouse's earnings

\begin{tabular}{|c|c|c|c|c|c|c|c|c|c|c|c|c|c|c|c|c|}
\hline \multirow[b]{3}{*}{ VARIABLE } & \multicolumn{4}{|c|}{ (4) } & \multicolumn{4}{|c|}{ (5) } & \multicolumn{4}{|c|}{ (6) } & \multicolumn{4}{|c|}{ (7) } \\
\hline & \multicolumn{2}{|c|}{ Women } & \multicolumn{2}{|c|}{ Men } & \multicolumn{2}{|c|}{ Women } & \multicolumn{2}{|c|}{ Men } & \multicolumn{2}{|c|}{ Women } & \multicolumn{2}{|c|}{ Men } & \multicolumn{2}{|c|}{$\underline{\text { Women }}$} & \multicolumn{2}{|c|}{ Men } \\
\hline & Non-IV & IV & Non-IV & IV & Non-IV & IV & Non-IV & IV & Non-IV & IV & Non-IV & IV & Non-IV & IV & Non-IV & IV \\
\hline \multicolumn{17}{|c|}{ Reservation Wage Indicators } \\
\hline Sp Work-limit & & & & & $\begin{array}{c}0.139 \\
(0.976)\end{array}$ & $\begin{array}{l}-0.0388 \\
(0.979)\end{array}$ & $\begin{array}{c}0.445 \\
(1.221)\end{array}$ & $\begin{array}{c}0.546 \\
(1.219)\end{array}$ & $\begin{array}{l}-0.301 \\
(1.189)\end{array}$ & $\begin{array}{c}-0.518 \\
(1.190)\end{array}$ & $\begin{array}{l}-1.488 \\
(1.161)\end{array}$ & $\begin{array}{l}-1.396 \\
(1.159)\end{array}$ & $\begin{array}{l}-0.0185 \\
(1.118)\end{array}$ & $\begin{array}{l}-0.141 \\
(1.116)\end{array}$ & $\begin{array}{l}-0.586 \\
(1.311)\end{array}$ & $\begin{array}{l}-0.481 \\
(1.322)\end{array}$ \\
\hline Sp Very Good & & & & & & & & & $\begin{array}{l}-0.538 \\
(0.719)\end{array}$ & $\begin{array}{l}-0.496 \\
(0.718)\end{array}$ & $\begin{array}{c}-1.381^{* *} \\
(0.695)\end{array}$ & $\begin{array}{c}-1.385^{* *} \\
(0.697)\end{array}$ & $\begin{array}{l}-0.420 \\
(0.679)\end{array}$ & $\begin{array}{c}-0.412 \\
(0.674)\end{array}$ & $\begin{array}{l}-1.037 \\
(0.658)\end{array}$ & $\begin{array}{l}-1.151^{*} \\
(0.651)\end{array}$ \\
\hline Sp Good & & & & & & & & & $\begin{array}{c}0.121 \\
(0.710)\end{array}$ & $\begin{array}{l}0.0589 \\
(0.714)\end{array}$ & $\begin{array}{c}-2.128^{* * *} \\
(0.765)\end{array}$ & $\begin{array}{c}-2.193^{* * *} \\
(0.765)\end{array}$ & $\begin{array}{c}0.178 \\
(0.614)\end{array}$ & $\begin{array}{c}0.134 \\
(0.630)\end{array}$ & $\begin{array}{c}-1.874^{* * *} \\
(0.695)\end{array}$ & $\begin{array}{c}-2.057 * * * \\
(0.697)\end{array}$ \\
\hline Sp Fair/Poor & & & & & & & & & $\begin{array}{l}0.0987 \\
(1.050)\end{array}$ & $\begin{array}{l}0.0315 \\
(1.048)\end{array}$ & $\begin{array}{l}-0.791 \\
(1.050)\end{array}$ & $\begin{array}{l}-0.948 \\
(1.062)\end{array}$ & $\begin{array}{l}-0.180 \\
(0.931)\end{array}$ & $\begin{array}{l}-0.230 \\
(0.935)\end{array}$ & $\begin{array}{l}-0.744 \\
(0.894)\end{array}$ & $\begin{array}{l}-1.086 \\
(0.907)\end{array}$ \\
\hline Sp \# of Cond. & $\begin{array}{c}0.121 \\
(0.267)\end{array}$ & $\begin{array}{c}0.114 \\
(0.265)\end{array}$ & $\begin{array}{c}0.254 \\
(0.251)\end{array}$ & $\begin{array}{c}0.269 \\
(0.251)\end{array}$ & & & & & $\begin{array}{l}0.0891 \\
(0.283)\end{array}$ & $\begin{array}{c}0.0984 \\
(0.282)\end{array}$ & $\begin{array}{c}0.363 \\
(0.258)\end{array}$ & $\begin{array}{c}0.386 \\
(0.258)\end{array}$ & $\begin{array}{c}0.184 \\
(0.259)\end{array}$ & $\begin{array}{c}0.185 \\
(0.260)\end{array}$ & $\begin{array}{c}0.291 \\
(0.242)\end{array}$ & $\begin{array}{c}0.304 \\
(0.242)\end{array}$ \\
\hline Sp \# of Func. Lim. & $\begin{array}{c}0.125 \\
(0.166)\end{array}$ & $\begin{array}{c}0.127 \\
(0.168)\end{array}$ & $\begin{array}{c}0.218 \\
(0.230)\end{array}$ & $\begin{array}{c}0.229 \\
(0.230)\end{array}$ & & & & & $\begin{array}{c}0.131 \\
(0.207)\end{array}$ & $\begin{array}{c}0.154 \\
(0.208)\end{array}$ & $\begin{array}{c}0.300 \\
(0.250)\end{array}$ & $\begin{array}{c}0.308 \\
(0.249)\end{array}$ & $\begin{array}{c}0.108 \\
(0.192)\end{array}$ & $\begin{array}{c}0.120 \\
(0.192)\end{array}$ & $\begin{array}{c}0.223 \\
(0.230)\end{array}$ & $\begin{array}{c}0.228 \\
(0.230)\end{array}$ \\
\hline Sp (z-scored) PCS & $\begin{array}{l}-0.0332 \\
(0.291)\end{array}$ & $\begin{array}{l}0.0235 \\
(0.298)\end{array}$ & $\begin{array}{c}0.117 \\
(0.280)\end{array}$ & $\begin{array}{c}0.193 \\
(0.279)\end{array}$ & $\begin{array}{l}-0.187 \\
(0.270)\end{array}$ & $\begin{array}{l}-0.152 \\
(0.278)\end{array}$ & $\begin{array}{l}-0.119 \\
(0.241)\end{array}$ & $\begin{array}{l}-0.0465 \\
(0.239)\end{array}$ & $\begin{array}{l}-0.0263 \\
(0.314)\end{array}$ & $\begin{array}{l}0.0110 \\
(0.321)\end{array}$ & $\begin{array}{l}-0.0328 \\
(0.309)\end{array}$ & $\begin{array}{l}0.0224 \\
(0.306)\end{array}$ & & & & \\
\hline Work-limit & & & & & $\begin{array}{l}-1.682 \\
(1.974)\end{array}$ & $\begin{array}{l}-0.0388 \\
(0.979)\end{array}$ & $\begin{array}{c}1.511 \\
(1.908)\end{array}$ & $\begin{array}{c}1.464 \\
(1.891)\end{array}$ & $\begin{array}{l}-2.780 \\
(2.170)\end{array}$ & $\begin{array}{c}-2.022 \\
(2.243)\end{array}$ & $\begin{array}{c}0.142 \\
(1.920)\end{array}$ & $\begin{array}{c}0.109 \\
(1.911)\end{array}$ & $\begin{array}{l}-0.391 \\
(1.997)\end{array}$ & $\begin{array}{c}-0.00403 \\
(1.993)\end{array}$ & $\begin{array}{l}-0.550 \\
(1.807)\end{array}$ & $\begin{array}{l}-0.548 \\
(1.795)\end{array}$ \\
\hline Very Good & & & & & & & & & $\begin{array}{l}-0.696 \\
(0.666)\end{array}$ & $\begin{array}{l}-0.693 \\
(0.673)\end{array}$ & $\begin{array}{c}0.961 \\
(0.619)\end{array}$ & $\begin{array}{c}0.840 \\
(0.623)\end{array}$ & $\begin{array}{l}-0.478 \\
(0.601)\end{array}$ & $\begin{array}{l}-0.461 \\
(0.606)\end{array}$ & $\begin{array}{c}0.678 \\
(0.571)\end{array}$ & $\begin{array}{c}0.568 \\
(0.577)\end{array}$ \\
\hline Good & & & & & & & & & $\begin{array}{c}0.170 \\
(0.759)\end{array}$ & $\begin{array}{c}0.146 \\
(0.761)\end{array}$ & $\begin{array}{c}0.246 \\
(0.698)\end{array}$ & $\begin{array}{c}0.112 \\
(0.700)\end{array}$ & $\begin{array}{c}0.302 \\
(0.641)\end{array}$ & $\begin{array}{c}0.303 \\
(0.644)\end{array}$ & $\begin{array}{l}-0.206 \\
(0.625)\end{array}$ & $\begin{array}{l}-0.271 \\
(0.625)\end{array}$ \\
\hline Fair/Poor & & & & & & & & & $\begin{array}{l}-0.709 \\
(1.157)\end{array}$ & $\begin{array}{l}-0.585 \\
(1.161)\end{array}$ & $\begin{array}{c}0.435 \\
(1.372)\end{array}$ & $\begin{array}{c}0.222 \\
(1.330)\end{array}$ & $\begin{array}{l}-0.455 \\
(1.099)\end{array}$ & $\begin{array}{l}-0.349 \\
(1.105)\end{array}$ & $\begin{array}{l}-0.213 \\
(1.185)\end{array}$ & $\begin{array}{l}-0.393 \\
(1.151)\end{array}$ \\
\hline \# of Cond. & $\begin{array}{r}-0.230 \\
(0.290)\end{array}$ & $\begin{array}{l}-0.166 \\
(0.296)\end{array}$ & $\begin{array}{c}0.0342 \\
(0.334)\end{array}$ & $\begin{array}{l}0.0164 \\
(0.335)\end{array}$ & & & & & $\begin{array}{c}-0.272 \\
(0.295)\end{array}$ & $\begin{array}{r}-0.225 \\
(0.298)\end{array}$ & $\begin{array}{l}0.0350 \\
(0.347)\end{array}$ & $\begin{array}{l}0.0335 \\
(0.346)\end{array}$ & $\begin{array}{l}-0.253 \\
(0.274)\end{array}$ & $\begin{array}{c}-0.226 \\
(0.275)\end{array}$ & $\begin{array}{l}0.0258 \\
(0.310)\end{array}$ & $\begin{array}{l}0.0296 \\
(0.309)\end{array}$ \\
\hline \# of Func. Lim. & $\begin{array}{c}0.159 \\
(0.184)\end{array}$ & $\begin{array}{c}0.211 \\
(0.193)\end{array}$ & $\begin{array}{c}0.476^{*} \\
(0.279)\end{array}$ & $\begin{array}{c}0.456 \\
(0.277)\end{array}$ & & & & & $\begin{array}{c}0.276 \\
(0.218)\end{array}$ & $\begin{array}{c}0.259 \\
(0.220)\end{array}$ & $\begin{array}{c}0.431 \\
(0.283)\end{array}$ & $\begin{array}{c}0.419 \\
(0.282)\end{array}$ & $\begin{array}{c}0.160 \\
(0.186)\end{array}$ & $\begin{array}{c}0.159 \\
(0.186)\end{array}$ & $\begin{array}{c}0.116 \\
(0.264)\end{array}$ & $\begin{array}{c}0.114 \\
(0.266)\end{array}$ \\
\hline (z-scored) PCS & $\begin{array}{c}-0.0701 \\
(0.329)\end{array}$ & $\begin{array}{l}-0.167 \\
(0.337)\end{array}$ & $\begin{array}{c}0.909 * * \\
(0.425)\end{array}$ & $\begin{array}{l}0.898^{* *} \\
(0.424)\end{array}$ & $\begin{array}{l}-0.102 \\
(0.295)\end{array}$ & $\begin{array}{l}-0.190 \\
(0.303)\end{array}$ & $\begin{array}{l}0.766^{* *} \\
(0.362)\end{array}$ & $\begin{array}{l}0.760^{* *} \\
(0.362)\end{array}$ & $\begin{array}{c}-0.0214 \\
(0.333)\end{array}$ & $\begin{array}{l}-0.0766 \\
(0.337)\end{array}$ & $\begin{array}{c}0.854^{*} \\
(0.457)\end{array}$ & $\begin{array}{l}0.816^{*} \\
(0.455)\end{array}$ & & & & \\
\hline
\end{tabular}




\begin{tabular}{|c|c|c|c|c|c|c|c|c|c|c|c|c|c|c|c|c|}
\hline \multirow[b]{3}{*}{ VARIABLE } & \multicolumn{4}{|c|}{ (4) } & \multicolumn{4}{|c|}{ (5) } & \multicolumn{4}{|c|}{ (6) } & \multicolumn{4}{|c|}{ (7) } \\
\hline & \multicolumn{2}{|c|}{ Women } & \multicolumn{2}{|c|}{ Men } & \multicolumn{2}{|c|}{ Women } & \multicolumn{2}{|c|}{ Men } & \multicolumn{2}{|c|}{ Women } & \multicolumn{2}{|c|}{ Men } & \multicolumn{2}{|c|}{ Women } & \multicolumn{2}{|c|}{ Men } \\
\hline & Non-IV & IV & Non-IV & IV & Non-IV & IV & Non-IV & IV & Non-IV & IV & Non-IV & IV & Non-IV & IV & Non-IV & IV \\
\hline \multirow[t]{2}{*}{ \# Children $<18$} & -0.454 & -0.458 & 0.0789 & 0.0760 & -0.472 & -0.483 & 0.0194 & 0.0141 & -0.406 & -0.411 & 0.112 & 0.112 & -0.548 & -0.541 & 0.0835 & 0.101 \\
\hline & $(0.609)$ & $(0.608)$ & $(0.252)$ & $(0.252)$ & $(0.603)$ & $(0.600)$ & $(0.243)$ & $(0.244)$ & $(0.618)$ & $(0.615)$ & $(0.255)$ & $(0.254)$ & $(0.565)$ & $(0.563)$ & $(0.235)$ & $(0.233)$ \\
\hline \multirow[t]{2}{*}{ \# Children $>=18$} & 0.553 & 0.440 & 0.0911 & 0.0641 & 0.555 & 0.445 & 0.0697 & 0.0426 & 0.601 & 0.513 & 0.102 & 0.0810 & $0.726 * *$ & $0.668^{*}$ & -0.00732 & -0.0409 \\
\hline & $(0.400)$ & (0.413) & $(0.304)$ & $(0.307)$ & $(0.397)$ & $(0.410)$ & $(0.318)$ & $(0.321)$ & $(0.384)$ & (0.389) & $(0.315)$ & $(0.317)$ & $(0.349)$ & $(0.350)$ & $(0.281)$ & $(0.285)$ \\
\hline \multirow[t]{2}{*}{ White } & $-1.158^{*}$ & $-1.211^{*}$ & $2.103 * * *$ & $1.951^{* * *}$ & $-1.141^{*}$ & $-1.176^{*}$ & $2.169 * * *$ & $2.013^{* * *}$ & -1.014 & -1.048 & $2.025^{* * *}$ & $1.854^{* * *}$ & -0.780 & -0.813 & $1.830^{* * *}$ & $1.602^{* * *}$ \\
\hline & $(0.637)$ & $(0.638)$ & $(0.610)$ & $(0.604)$ & $(0.641)$ & $(0.641)$ & $(0.604)$ & (0.599) & $(0.638)$ & $(0.638)$ & $(0.621)$ & $(0.619)$ & $(0.578)$ & $(0.576)$ & $(0.576)$ & $(0.569)$ \\
\hline \multicolumn{17}{|c|}{ Potential Wage Indicators } \\
\hline Predicted Wage & $\begin{array}{c}0.122 \\
(0.783)\end{array}$ & $\begin{array}{l}0.00832 \\
(0.850)\end{array}$ & $\begin{array}{c}0.704 \\
(0.884)\end{array}$ & $\begin{array}{c}1.361 \\
(0.874)\end{array}$ & $\begin{array}{c}0.224 \\
(0.784)\end{array}$ & $\begin{array}{c}0.112 \\
(0.857)\end{array}$ & $\begin{array}{c}0.679 \\
(0.896)\end{array}$ & $\begin{array}{c}1.353 \\
(0.882)\end{array}$ & $\begin{array}{c}0.338 \\
(0.792)\end{array}$ & $\begin{array}{c}0.301 \\
(0.858)\end{array}$ & $\begin{array}{c}0.584 \\
(0.889)\end{array}$ & $\begin{array}{c}1.245 \\
(0.875)\end{array}$ & $\begin{array}{c}0.246 \\
(0.771)\end{array}$ & $\begin{array}{c}0.206 \\
(0.814)\end{array}$ & $\begin{array}{c}0.591 \\
(0.846)\end{array}$ & $\begin{array}{l}1.463^{*} \\
(0.817)\end{array}$ \\
\hline Union & $\begin{array}{c}-2.318^{* * *} \\
(0.569)\end{array}$ & $\begin{array}{c}-2.305^{* * *} \\
(0.567)\end{array}$ & $\begin{array}{c}-2.743^{* * *} \\
(0.538)\end{array}$ & $\begin{array}{c}-2.726 * * * \\
(0.539)\end{array}$ & $\begin{array}{c}-2.389 * * * \\
(0.559)\end{array}$ & $\begin{array}{c}-2.381 * * * \\
(0.557)\end{array}$ & $\begin{array}{c}-2.686^{* * *} \\
(0.539)\end{array}$ & $\begin{array}{c}-2.670^{* * *} \\
(0.541)\end{array}$ & $\begin{array}{c}-2.262^{* * *} \\
(0.571)\end{array}$ & $\begin{array}{c}-2.262 * * * \\
(0.568)\end{array}$ & $\begin{array}{c}-2.713^{* * *} \\
(0.534)\end{array}$ & $\begin{array}{c}-2.698^{* * *} \\
(0.534)\end{array}$ & $\begin{array}{c}-1.977^{* * *} \\
(0.526)\end{array}$ & $\begin{array}{c}-1.979 * * * \\
(0.521)\end{array}$ & $\begin{array}{c}-2.572^{* * *} \\
(0.497)\end{array}$ & $\begin{array}{c}-2.554 * * * \\
(0.497)\end{array}$ \\
\hline Ret./Pension Plan & $\begin{array}{c}3.413^{* * *} \\
(0.612)\end{array}$ & $\begin{array}{c}3.409^{* * *} \\
(0.613)\end{array}$ & $\begin{array}{c}1.979 * * * \\
(0.613)\end{array}$ & $\begin{array}{c}2.057^{* * *} \\
(0.611)\end{array}$ & $\begin{array}{c}3.398^{* * *} \\
(0.605)\end{array}$ & $\begin{array}{c}3.399 * * * \\
(0.607)\end{array}$ & $\begin{array}{c}1.906 * * * \\
(0.615)\end{array}$ & $\begin{array}{c}1.985^{* * *} \\
(0.612)\end{array}$ & $\begin{array}{c}3.353^{* * *} \\
(0.608)\end{array}$ & $\begin{array}{c}3.367 * * * \\
(0.611)\end{array}$ & $\begin{array}{c}1.948^{* * *} \\
(0.611)\end{array}$ & $\begin{array}{c}2.029 * * * \\
(0.609)\end{array}$ & $\begin{array}{c}3.337^{* * *} \\
(0.565)\end{array}$ & $\begin{array}{c}3.353^{* * *} \\
(0.570)\end{array}$ & $\begin{array}{l}1.832^{* * *} \\
(0.573)\end{array}$ & $\begin{array}{c}1.911^{* * *} \\
(0.570)\end{array}$ \\
\hline Holds ESI & $\begin{array}{c}4.923 * * * \\
(0.526)\end{array}$ & $\begin{array}{c}4.866 * * * \\
(0.519)\end{array}$ & $\begin{array}{c}1.738^{* * *} \\
(0.664)\end{array}$ & $\begin{array}{l}1.519^{* *} \\
(0.669)\end{array}$ & $\begin{array}{c}4.932^{* * *} \\
(0.527)\end{array}$ & $\begin{array}{c}4.870^{* * * *} \\
(0.521)\end{array}$ & $\begin{array}{c}1.794 * * * \\
(0.677)\end{array}$ & $\begin{array}{l}1.570^{* *} \\
(0.679)\end{array}$ & $\begin{array}{c}5.001 * * * \\
(0.528)\end{array}$ & $\begin{array}{c}4.929^{* * *} \\
(0.518)\end{array}$ & $\begin{array}{c}1.746 * * * \\
(0.662)\end{array}$ & $\begin{array}{l}1.523 * * \\
(0.664)\end{array}$ & $\begin{array}{c}4.533^{* * *} \\
(0.518)\end{array}$ & $\begin{array}{c}4.463^{* * *} \\
(0.510)\end{array}$ & $\begin{array}{l}1.797^{* * *} \\
(0.603)\end{array}$ & $\begin{array}{l}1.537^{* *} \\
(0.612)\end{array}$ \\
\hline Choice of H.I. Plans & $\begin{array}{l}1.071^{*} \\
(0.553)\end{array}$ & $\begin{array}{l}1.080^{*} \\
(0.552)\end{array}$ & $\begin{array}{l}-0.254 \\
(0.515)\end{array}$ & $\begin{array}{l}-0.247 \\
(0.517)\end{array}$ & $\begin{array}{l}1.007^{*} \\
(0.564)\end{array}$ & $\begin{array}{l}1.021^{*} \\
(0.563)\end{array}$ & $\begin{array}{l}-0.236 \\
(0.513)\end{array}$ & $\begin{array}{l}-0.230 \\
(0.515)\end{array}$ & $\begin{array}{l}0.944^{*} \\
(0.555)\end{array}$ & $\begin{array}{l}0.960^{*} \\
(0.554)\end{array}$ & $\begin{array}{l}-0.199 \\
(0.513)\end{array}$ & $\begin{array}{l}-0.201 \\
(0.514)\end{array}$ & $\begin{array}{l}1.105^{* *} \\
(0.481)\end{array}$ & $\begin{array}{l}1.112^{* *} \\
(0.481)\end{array}$ & $\begin{array}{l}-0.0969 \\
(0.475)\end{array}$ & $\begin{array}{l}-0.0940 \\
(0.476)\end{array}$ \\
\hline Paid Sick Leave & $\begin{array}{c}4.950^{* * *} \\
(0.677)\end{array}$ & $\begin{array}{c}4.946^{* * *} \\
(0.682)\end{array}$ & $\begin{array}{l}0.984^{*} \\
(0.584)\end{array}$ & $\begin{array}{l}1.006^{*} \\
(0.582)\end{array}$ & $\begin{array}{c}4.962^{* * *} \\
(0.678)\end{array}$ & $\begin{array}{c}4.957^{* * *} \\
(0.683)\end{array}$ & $\begin{array}{l}1.000^{*} \\
(0.586)\end{array}$ & $\begin{array}{l}1.021^{*} \\
(0.584)\end{array}$ & $\begin{array}{c}4.983 * * * \\
(0.681)\end{array}$ & $\begin{array}{c}4.977 * * * \\
(0.685)\end{array}$ & $\begin{array}{c}0.884 \\
(0.598)\end{array}$ & $\begin{array}{c}0.900 \\
(0.596)\end{array}$ & $\begin{array}{c}5.075 * * * \\
(0.646)\end{array}$ & $\begin{array}{c}5.065^{* * *} \\
(0.648)\end{array}$ & $\begin{array}{l}0.932^{*} \\
(0.557)\end{array}$ & $\begin{array}{l}0.941^{*} \\
(0.553)\end{array}$ \\
\hline Sp Earnings (\$100/wk.) & $\begin{array}{c}0.0603 \\
(0.0554)\end{array}$ & $\begin{array}{c}0.0334 \\
(0.0952)\end{array}$ & $\begin{array}{c}0.0403 \\
(0.0712)\end{array}$ & $\begin{array}{l}-0.223 \\
(0.141)\end{array}$ & $\begin{array}{c}0.0589 \\
(0.0556)\end{array}$ & $\begin{array}{c}0.0284 \\
(0.0942)\end{array}$ & $\begin{array}{c}0.0435 \\
(0.0718)\end{array}$ & $\begin{array}{l}-0.222 \\
(0.142)\end{array}$ & $\begin{array}{c}0.0624 \\
(0.0553)\end{array}$ & $\begin{array}{c}0.0196 \\
(0.0961)\end{array}$ & $\begin{array}{c}0.0380 \\
(0.0701)\end{array}$ & $\begin{array}{l}-0.237^{*} \\
(0.138)\end{array}$ & $\begin{array}{c}0.0765 \\
(0.0525)\end{array}$ & $\begin{array}{c}0.0577 \\
(0.0929)\end{array}$ & $\begin{array}{c}0.0501 \\
(0.0654)\end{array}$ & $\begin{array}{c}-0.290^{* *} \\
(0.136)\end{array}$ \\
\hline HH Income ( $\$ 100 / y r)$. & $\begin{array}{l}-0.00332 * \\
(0.00182)\end{array}$ & $\begin{array}{r}-0.00285 \\
(0.00189)\end{array}$ & $\begin{array}{l}-0.000948 \\
(0.00229)\end{array}$ & $\begin{array}{r}-0.00109 \\
(0.00229)\end{array}$ & $\begin{array}{l}-0.00345^{*} \\
(0.00182)\end{array}$ & $\begin{array}{r}-0.00294 \\
(0.00191)\end{array}$ & $\begin{array}{l}-0.000925 \\
(0.00226)\end{array}$ & $\begin{array}{l}-0.00107 \\
(0.00226)\end{array}$ & $\begin{array}{c}-0.00357^{* *} \\
(0.00181)\end{array}$ & $\begin{array}{l}-0.00318^{*} \\
(0.00187)\end{array}$ & $\begin{array}{r}-0.00103 \\
(0.00230)\end{array}$ & $\begin{array}{r}-0.00120 \\
(0.00230)\end{array}$ & $\begin{array}{c}-0.00338^{* *} \\
(0.00168)\end{array}$ & $\begin{array}{c}-0.00317^{*} \\
(0.00171)\end{array}$ & $\begin{array}{l}-0.00116 \\
(0.00202)\end{array}$ & $\begin{array}{c}-0.00127 \\
(0.00201)\end{array}$ \\
\hline Sp Employed & $\begin{array}{c}-1.544^{* *} \\
(0.675)\end{array}$ & $\begin{array}{l}-1.393 \\
(0.961)\end{array}$ & $\begin{array}{c}-1.602^{* *} \\
(0.673)\end{array}$ & $\begin{array}{l}0.0446 \\
(1.119)\end{array}$ & $\begin{array}{c}-1.610^{* *} \\
(0.729)\end{array}$ & $\begin{array}{l}-1.453 \\
(0.979)\end{array}$ & $\begin{array}{c}-1.719^{* *} \\
(0.681)\end{array}$ & $\begin{array}{l}-0.0573 \\
(1.142)\end{array}$ & $\begin{array}{c}-1.500^{* *} \\
(0.704)\end{array}$ & $\begin{array}{l}-1.218 \\
(0.970)\end{array}$ & $\begin{array}{c}-1.622 * * \\
(0.682)\end{array}$ & $\begin{array}{c}0.0961 \\
(1.110)\end{array}$ & $\begin{array}{c}-1.812^{* * *} \\
(0.659)\end{array}$ & $\begin{array}{l}-1.706^{*} \\
(0.930)\end{array}$ & $\begin{array}{c}-1.572^{* *} \\
(0.639)\end{array}$ & $\begin{array}{c}0.590 \\
(1.094)\end{array}$ \\
\hline
\end{tabular}


Table A10. (continued) Estimates of women and men's hours per week as a function of spouse's health measures with and without instrumenting for spouse's earnings

\begin{tabular}{|c|c|c|c|c|c|c|c|c|c|c|c|c|c|c|c|c|}
\hline \multirow[b]{3}{*}{ VARIABLE } & \multicolumn{4}{|c|}{ (4) } & \multicolumn{4}{|c|}{ (5) } & \multicolumn{4}{|c|}{ (6) } & \multicolumn{4}{|c|}{ (7) } \\
\hline & \multicolumn{2}{|c|}{ Women } & \multicolumn{2}{|c|}{ Men } & \multicolumn{2}{|c|}{ Women } & \multicolumn{2}{|c|}{ Men } & \multicolumn{2}{|c|}{ Women } & \multicolumn{2}{|c|}{ Men } & \multicolumn{2}{|c|}{ Women } & \multicolumn{2}{|c|}{ Men } \\
\hline & Non-IV & IV & Non-IV & IV & Non-IV & IV & Non-IV & IV & Non-IV & IV & Non-IV & IV & Non-IV & IV & Non-IV & IV \\
\hline Yearly Dummies & & & & & & & & & & & & & & & & \\
\hline Panel 6 (2002) & $\begin{array}{c}0.0510 \\
(1.143)\end{array}$ & $\begin{array}{l}0.0573 \\
(1.150)\end{array}$ & $\begin{array}{l}2.226^{* *} \\
(0.978)\end{array}$ & $\begin{array}{l}2.092^{* *} \\
(0.978)\end{array}$ & $\begin{array}{l}0.0637 \\
(1.143)\end{array}$ & $\begin{array}{c}0.100 \\
(1.147)\end{array}$ & $\begin{array}{l}2.426^{* *} \\
(0.979)\end{array}$ & $\begin{array}{l}2.293^{* *} \\
(0.978)\end{array}$ & $\begin{array}{c}0.242 \\
(1.121)\end{array}$ & $\begin{array}{c}0.261 \\
(1.122)\end{array}$ & $\begin{array}{c}2.119^{* *} \\
(0.987)\end{array}$ & $\begin{array}{l}1.970^{* *} \\
(0.990)\end{array}$ & $\begin{array}{c}0.171 \\
(1.057)\end{array}$ & $\begin{array}{c}0.178 \\
(1.056)\end{array}$ & $\begin{array}{l}1.631^{*} \\
(0.949)\end{array}$ & $\begin{array}{c}1.419 \\
(0.945)\end{array}$ \\
\hline Panel 7 (2003) & $\begin{array}{c}0.198 \\
(0.988)\end{array}$ & $\begin{array}{c}0.217 \\
(0.993)\end{array}$ & $\begin{array}{l}-1.171 \\
(0.915)\end{array}$ & $\begin{array}{l}-1.187 \\
(0.907)\end{array}$ & $\begin{array}{c}0.210 \\
(0.978)\end{array}$ & $\begin{array}{c}0.236 \\
(0.985)\end{array}$ & $\begin{array}{c}-0.930 \\
(0.889)\end{array}$ & $\begin{array}{l}-0.943 \\
(0.881)\end{array}$ & $\begin{array}{c}0.340 \\
(0.986)\end{array}$ & $\begin{array}{c}0.340 \\
(0.989)\end{array}$ & $\begin{array}{l}-1.238 \\
(0.917)\end{array}$ & $\begin{array}{c}-1.260 \\
(0.910)\end{array}$ & $\begin{array}{l}0.00994 \\
(0.948)\end{array}$ & $\begin{array}{l}0.0396 \\
(0.948)\end{array}$ & $\begin{array}{c}-1.141 \\
(0.878)\end{array}$ & $\begin{array}{c}-1.141 \\
(0.871)\end{array}$ \\
\hline Panel 8 (2004) & $\begin{array}{c}0.430 \\
(0.972)\end{array}$ & $\begin{array}{c}0.452 \\
(0.976)\end{array}$ & $\begin{array}{c}0.272 \\
(1.015)\end{array}$ & $\begin{array}{c}0.304 \\
(0.997)\end{array}$ & $\begin{array}{c}0.475 \\
(0.973)\end{array}$ & $\begin{array}{c}0.521 \\
(0.978)\end{array}$ & $\begin{array}{c}0.561 \\
(1.036)\end{array}$ & $\begin{array}{c}0.594 \\
(1.018)\end{array}$ & $\begin{array}{c}0.559 \\
(0.959)\end{array}$ & $\begin{array}{c}0.579 \\
(0.960)\end{array}$ & $\begin{array}{c}0.229 \\
(1.003)\end{array}$ & $\begin{array}{c}0.259 \\
(0.986)\end{array}$ & $\begin{array}{c}0.260 \\
(0.863)\end{array}$ & $\begin{array}{c}0.281 \\
(0.859)\end{array}$ & $\begin{array}{c}0.200 \\
(0.983)\end{array}$ & $\begin{array}{c}0.260 \\
(0.966)\end{array}$ \\
\hline Panel 9 (2005) & $\begin{array}{c}0.379 \\
(1.050)\end{array}$ & $\begin{array}{c}0.425 \\
(1.063)\end{array}$ & $\begin{array}{c}-0.922 \\
(0.822)\end{array}$ & $\begin{array}{c}-0.934 \\
(0.812)\end{array}$ & $\begin{array}{c}0.390 \\
(1.031)\end{array}$ & $\begin{array}{c}0.456 \\
(1.050)\end{array}$ & $\begin{array}{c}-0.731 \\
(0.810)\end{array}$ & $\begin{array}{c}-0.743 \\
(0.799)\end{array}$ & $\begin{array}{c}0.470 \\
(1.024)\end{array}$ & $\begin{array}{c}0.511 \\
(1.035)\end{array}$ & $\begin{array}{c}-0.967 \\
(0.817)\end{array}$ & $\begin{array}{c}-0.982 \\
(0.807)\end{array}$ & $\begin{array}{c}0.393 \\
(0.956)\end{array}$ & $\begin{array}{c}0.434 \\
(0.958)\end{array}$ & $\begin{array}{c}-0.812 \\
(0.817)\end{array}$ & $\begin{array}{c}-0.802 \\
(0.805)\end{array}$ \\
\hline Panel 10 (2006) & $\begin{array}{c}0.155 \\
(1.097)\end{array}$ & $\begin{array}{c}0.164 \\
(1.111)\end{array}$ & $\begin{array}{c}-0.204 \\
(0.927)\end{array}$ & $\begin{array}{c}-0.191 \\
(0.911)\end{array}$ & $\begin{array}{c}0.139 \\
(1.082)\end{array}$ & $\begin{array}{c}0.173 \\
(1.097)\end{array}$ & $\begin{array}{l}-0.0167 \\
(0.934)\end{array}$ & $\begin{array}{c}-0.00710 \\
(0.919)\end{array}$ & $\begin{array}{c}0.254 \\
(1.083)\end{array}$ & $\begin{array}{c}0.258 \\
(1.094)\end{array}$ & $\begin{array}{c}-0.271 \\
(0.925)\end{array}$ & $\begin{array}{c}-0.252 \\
(0.909)\end{array}$ & $\begin{array}{c}0.248 \\
(0.999)\end{array}$ & $\begin{array}{c}0.266 \\
(0.994)\end{array}$ & $\begin{array}{l}-0.0565 \\
(0.864)\end{array}$ & $\begin{array}{l}0.0347 \\
(0.845)\end{array}$ \\
\hline Panel 11 (2007) & $\begin{array}{c}-0.517 \\
(0.968)\end{array}$ & $\begin{array}{c}-0.518 \\
(0.972)\end{array}$ & $\begin{array}{l}-0.955 \\
(0.855)\end{array}$ & $\begin{array}{c}-0.855 \\
(0.846)\end{array}$ & $\begin{array}{c}-0.484 \\
(0.954)\end{array}$ & $\begin{array}{c}-0.460 \\
(0.961)\end{array}$ & $\begin{array}{c}-0.717 \\
(0.843)\end{array}$ & $\begin{array}{c}-0.617 \\
(0.834)\end{array}$ & $\begin{array}{c}-0.440 \\
(0.958)\end{array}$ & $\begin{array}{r}-0.440 \\
(0.961)\end{array}$ & $\begin{array}{c}-0.973 \\
(0.853)\end{array}$ & $\begin{array}{c}-0.869 \\
(0.844)\end{array}$ & $\begin{array}{l}-0.350 \\
(0.883)\end{array}$ & $\begin{array}{c}-0.325 \\
(0.882)\end{array}$ & $\begin{array}{c}-0.929 \\
(0.809)\end{array}$ & $\begin{array}{c}-0.744 \\
(0.798)\end{array}$ \\
\hline Constant & $\begin{array}{c}30.72^{* * *} \\
(2.607)\end{array}$ & $\begin{array}{c}31.74^{* * *} \\
(2.862)\end{array}$ & $\begin{array}{c}37.95 * * * \\
(2.468)\end{array}$ & $\begin{array}{c}36.24 * * * \\
(2.440)\end{array}$ & $\begin{array}{c}30.51^{* * *} \\
(2.678)\end{array}$ & $\begin{array}{c}31.59 * * * \\
(3.003)\end{array}$ & $\begin{array}{c}38.33 * * * \\
(2.424)\end{array}$ & $\begin{array}{c}36.59^{* * *} \\
(2.404)\end{array}$ & $\begin{array}{c}30.09 * * * \\
(2.670)\end{array}$ & $\begin{array}{c}30.86^{* * *} \\
(2.844)\end{array}$ & $\begin{array}{c}39.22^{* * *} \\
(2.539)\end{array}$ & $\begin{array}{c}37.67 * * * \\
(2.486)\end{array}$ & $\begin{array}{c}30.33^{* * *} \\
(2.380)\end{array}$ & $\begin{array}{c}30.82^{* * *} \\
(2.422)\end{array}$ & $\begin{array}{c}39.66^{* * *} \\
(2.455)\end{array}$ & $\begin{array}{c}37.62^{* * *} \\
(2.430)\end{array}$ \\
\hline$\rho$ & $\begin{array}{c}-0.202 \\
(0.1284)\end{array}$ & $\begin{array}{c}-0.318 \\
(0.1526)\end{array}$ & $\begin{array}{c}-0.082 \\
(0.0435)\end{array}$ & $\begin{array}{c}-0.077 \\
(0.0454)\end{array}$ & $\begin{array}{c}-0.186 \\
(0.1353)\end{array}$ & $\begin{array}{c}-0.307 \\
(0.1666)\end{array}$ & $\begin{array}{c}-0.087 \\
(0.0429)\end{array}$ & $\begin{array}{c}-0.082 \\
(0.0451)\end{array}$ & $\begin{array}{c}-0.152 \\
(0.1224)\end{array}$ & $\begin{array}{c}-0.258 \\
(0.1445)\end{array}$ & $\begin{array}{c}-0.073 \\
(0.0450)\end{array}$ & $\begin{array}{c}-0.069 \\
(0.0474)\end{array}$ & $\begin{array}{c}-0.140 \\
(0.0970)\end{array}$ & $\begin{array}{c}-0.202 \\
(0.1041)\end{array}$ & $\begin{array}{c}-0.071 \\
(0.0413)\end{array}$ & $\begin{array}{c}-0.071 \\
(0.0436)\end{array}$ \\
\hline$\sigma$ & $\begin{array}{c}8.818 \\
(0.2508)\end{array}$ & $\begin{array}{c}8.965 \\
(0.2898)\end{array}$ & $\begin{array}{c}9.517 \\
(0.3837)\end{array}$ & $\begin{array}{c}9.510 \\
(0.3812)\end{array}$ & $\begin{array}{c}8.799 \\
(0.2471)\end{array}$ & $\begin{array}{c}8.944 \\
(0.2928)\end{array}$ & $\begin{array}{c}9.536 \\
(0.3902)\end{array}$ & $\begin{array}{c}9.529 \\
(0.3881)\end{array}$ & $\begin{array}{c}8.744 \\
(0.2417)\end{array}$ & $\begin{array}{c}8.848 \\
(0.2631)\end{array}$ & $\begin{array}{c}9.480 \\
(0.3820)\end{array}$ & $\begin{array}{c}9.473 \\
(0.3800)\end{array}$ & $\begin{array}{c}8.815 \\
(0.2353)\end{array}$ & $\begin{array}{c}8.870 \\
(0.2411)\end{array}$ & $\begin{array}{c}9.444 \\
(0.3607)\end{array}$ & $\begin{array}{c}9.435 \\
(0.3584)\end{array}$ \\
\hline$\lambda$ & $\begin{array}{c}-1.783 \\
(1.1498)\end{array}$ & $\begin{array}{c}-2.852 \\
(1.4242)\end{array}$ & $\begin{array}{c}-0.779 \\
(0.4216)\end{array}$ & $\begin{array}{c}-0.735 \\
(0.4384)\end{array}$ & $\begin{array}{c}-1.634 \\
(1.2051)\end{array}$ & $\begin{array}{c}-2.749 \\
(1.5452)\end{array}$ & $\begin{array}{c}-0.828 \\
(0.4164)\end{array}$ & $\begin{array}{c}-0.784 \\
(0.4359)\end{array}$ & $\begin{array}{c}-1.331 \\
(1.0781)\end{array}$ & $\begin{array}{c}-2.280 \\
(1.3088)\end{array}$ & $\begin{array}{c}-0.695 \\
(0.4311)\end{array}$ & $\begin{array}{c}-0.655 \\
(0.4530)\end{array}$ & $\begin{array}{c}-1.237 \\
(0.8599)\end{array}$ & $\begin{array}{c}-1.795 \\
(0.9357)\end{array}$ & $\begin{array}{c}-0.674 \\
(0.3956)\end{array}$ & $\begin{array}{c}-0.670 \\
(0.4155)\end{array}$ \\
\hline
\end{tabular}

Note: Standard errors in parentheses; all tests are two-sided against the null hypothesis that the marginal effect is $=0 ;{ }^{* * *} p<0.01,{ }^{* *} p<0.05,{ }^{*} p<0.1$

Note: Maximum Likelihood estimates of regression models with selection using MEPS (panels 5 through 11). Rho is the correlation between the residuals of the hours and labor force participation equations, sigma is

the standard error of the residual in the hours equation, and lambda is the product of rho and sigma. 
Table A11. Estimates of labor force participation using the Joint-sample of men and women with and without instrumenting for spouse's earnings

\begin{tabular}{|c|c|c|c|c|c|c|c|c|}
\hline \multirow[b]{2}{*}{ VARIABLE } & \multicolumn{2}{|c|}{ (Work-limit) } & \multicolumn{2}{|c|}{ (SAH Status) } & \multicolumn{2}{|c|}{ (\# of Conditions) } & \multicolumn{2}{|c|}{ (\# of Func. Lim.) } \\
\hline & Non-IV & IV & Non-IV & IV & Non-IV & IV & Non-IV & IV \\
\hline Reservation Wage Indicators & & & & & & & & \\
\hline Male & $\begin{array}{c}0.0317^{* *} \\
(0.0156)\end{array}$ & $\begin{array}{c}0.0463^{* *} \\
(0.0182)\end{array}$ & $\begin{array}{l}-0.0409 \\
(0.0309)\end{array}$ & $\begin{array}{l}-0.0199 \\
(0.0348)\end{array}$ & $\begin{array}{l}0.00940 \\
(0.0225)\end{array}$ & $\begin{array}{c}0.0306 \\
(0.0245)\end{array}$ & $\begin{array}{c}0.0261 \\
(0.0160)\end{array}$ & $\begin{array}{c}0.0444^{* *} \\
(0.0185)\end{array}$ \\
\hline Spouse Work-limit & $\begin{array}{c}0.0994^{* * *} \\
(0.0297)\end{array}$ & $\begin{array}{c}0.106 * * * \\
(0.0298)\end{array}$ & -- & $\begin{array}{l}-- \\
--\end{array}$ & $\begin{array}{l}-- \\
--\end{array}$ & $\begin{array}{l}-- \\
--\end{array}$ & $\begin{array}{l}-- \\
--\end{array}$ & $\begin{array}{l}-- \\
--\end{array}$ \\
\hline Spouse Very Good & -- & $\begin{array}{l}-- \\
--\end{array}$ & $\begin{array}{l}-0.0318 \\
(0.0283)\end{array}$ & $\begin{array}{c}-0.0286 \\
(0.0286)\end{array}$ & $\begin{array}{l}-- \\
--\end{array}$ & -- & $\begin{array}{l}-- \\
--\end{array}$ & $\begin{array}{l}-- \\
--\end{array}$ \\
\hline Spouse Good & $\begin{array}{l}-- \\
--\end{array}$ & $\begin{array}{l}-- \\
--\end{array}$ & $\begin{array}{c}0.0225 \\
(0.0279)\end{array}$ & $\begin{array}{c}0.0313 \\
(0.0281)\end{array}$ & $\begin{array}{l}-- \\
--\end{array}$ & $\begin{array}{l}-- \\
--\end{array}$ & $\begin{array}{l}-- \\
--\end{array}$ & $\begin{array}{l}-- \\
--\end{array}$ \\
\hline Spouse Fair/Poor & $\begin{array}{l}-- \\
--\end{array}$ & $\begin{array}{l}-- \\
--\end{array}$ & $\begin{array}{c}0.0490 \\
(0.0304)\end{array}$ & $\begin{array}{l}0.0599 * \\
(0.0309)\end{array}$ & $\begin{array}{l}-- \\
--\end{array}$ & $\begin{array}{l}-- \\
--\end{array}$ & $\begin{array}{l}-- \\
--\end{array}$ & $\begin{array}{l}-- \\
--\end{array}$ \\
\hline Spouse \# of Conditions & $\begin{array}{l}-- \\
--\end{array}$ & $\begin{array}{l}-- \\
--\end{array}$ & $\begin{array}{l}-- \\
--\end{array}$ & $\begin{array}{l}-- \\
--\end{array}$ & $\begin{array}{c}0.0166^{*} \\
(0.00889)\end{array}$ & $\begin{array}{c}0.0174 * \\
(0.00888)\end{array}$ & $\begin{array}{l}-- \\
--\end{array}$ & $\begin{array}{l}-- \\
--\end{array}$ \\
\hline Spouse \# of Func. Limits & -- & -- & $\begin{array}{l}-- \\
--\end{array}$ & -- & -- & -- & $\begin{array}{c}0.00703 \\
(0.00478)\end{array}$ & $\begin{array}{c}0.00806 * \\
(0.00486)\end{array}$ \\
\hline Spouse (z-scored) PCS & $\begin{array}{l}-- \\
--\end{array}$ & $\begin{array}{l}-- \\
--\end{array}$ & -- & -- & -- & -- & -- & -- \\
\hline Male * Spouse Work-limit & $\begin{array}{c}0.0364 \\
(0.0443)\end{array}$ & $\begin{array}{c}0.0255 \\
(0.0448)\end{array}$ & $\begin{array}{l}-- \\
--\end{array}$ & $\begin{array}{l}-- \\
--\end{array}$ & $\begin{array}{l}-- \\
--\end{array}$ & $\begin{array}{l}-- \\
--\end{array}$ & $\begin{array}{l}-- \\
--\end{array}$ & $\begin{array}{l}-- \\
--\end{array}$ \\
\hline Male * Spouse Very Good & $\begin{array}{l}-- \\
--\end{array}$ & $\begin{array}{l}-- \\
--\end{array}$ & $\begin{array}{c}0.0844^{* *} \\
(0.0385)\end{array}$ & $\begin{array}{c}0.0828 * * \\
(0.0389)\end{array}$ & $\begin{array}{l}-- \\
--\end{array}$ & $\begin{array}{l}-- \\
--\end{array}$ & $\begin{array}{l}-- \\
--\end{array}$ & $\begin{array}{l}-- \\
--\end{array}$ \\
\hline Male * Spouse Good & $\begin{array}{l}-- \\
--\end{array}$ & $\begin{array}{l}-- \\
--\end{array}$ & $\begin{array}{c}0.0565 \\
(0.0386)\end{array}$ & $\begin{array}{c}0.0499 \\
(0.0386)\end{array}$ & $\begin{array}{l}-- \\
--\end{array}$ & $\begin{array}{l}-- \\
--\end{array}$ & $\begin{array}{l}-- \\
--\end{array}$ & $\begin{array}{l}-- \\
--\end{array}$ \\
\hline Male * Spouse Fair/Poor & $\begin{array}{l}-- \\
--\end{array}$ & $\begin{array}{l}-- \\
--\end{array}$ & $\begin{array}{l}0.0679 * \\
(0.0382)\end{array}$ & $\begin{array}{c}0.0572 \\
(0.0394)\end{array}$ & $\begin{array}{l}-- \\
--\end{array}$ & $\begin{array}{l}-- \\
--\end{array}$ & $\begin{array}{l}-- \\
--\end{array}$ & $\begin{array}{l}-- \\
--\end{array}$ \\
\hline Male * Spouse \# of Conditions & $\begin{array}{l}-- \\
--\end{array}$ & $\begin{array}{l}-- \\
--\end{array}$ & $\begin{array}{l}-- \\
--\end{array}$ & $\begin{array}{l}-- \\
--\end{array}$ & $\begin{array}{l}0.00741 \\
(0.0126)\end{array}$ & $\begin{array}{l}0.00543 \\
(0.0126)\end{array}$ & $\begin{array}{l}-- \\
--\end{array}$ & $\begin{array}{l}-- \\
--\end{array}$ \\
\hline Male * Spouse \# of Func. Limits & $\begin{array}{l}-- \\
--\end{array}$ & $\begin{array}{l}-- \\
--\end{array}$ & $\begin{array}{l}-- \\
--\end{array}$ & $\begin{array}{l}-- \\
--\end{array}$ & $\begin{array}{l}-- \\
--\end{array}$ & $\begin{array}{l}-- \\
--\end{array}$ & $\begin{array}{c}0.00148 \\
(0.00645)\end{array}$ & $\begin{array}{l}-0.000173 \\
(0.00650)\end{array}$ \\
\hline Male * Spouse (z-scored) PCS & $\begin{array}{l}-- \\
--\end{array}$ & $\begin{array}{l}-- \\
--\end{array}$ & $\begin{array}{l}-- \\
--\end{array}$ & $\begin{array}{l}-- \\
--\end{array}$ & $\begin{array}{l}-- \\
--\end{array}$ & $\begin{array}{l}-- \\
--\end{array}$ & $\begin{array}{l}-- \\
--\end{array}$ & $\begin{array}{l}-- \\
--\end{array}$ \\
\hline
\end{tabular}


Table A11. (conintued) Estimates of labor force participation using the Joint-sample of men and women with and without instrumenting for spouse's earnings

\begin{tabular}{|c|c|c|c|c|c|c|c|c|}
\hline \multirow[b]{2}{*}{ VARIABLE } & \multicolumn{2}{|c|}{ (Work-limit) } & \multicolumn{2}{|c|}{ (SAH Status) } & \multicolumn{2}{|c|}{ (\# of Conditions) } & \multicolumn{2}{|c|}{ (\# of Func. Lim.) } \\
\hline & Non-IV & IV & Non-IV & IV & Non-IV & IV & Non-IV & IV \\
\hline \multirow[t]{2}{*}{ Work-limit } & $-0.502 * * *$ & $-0.498 * * *$ & $\begin{array}{l}- \\
-\end{array}$ & & -- & -- & $\overline{--}$ & $\overline{--}$ \\
\hline & $(0.0284)$ & $(0.0285)$ & -- & & -- & -- & -- & -- \\
\hline \multirow[t]{2}{*}{ Very Good } & -- & -- & -0.0186 & -0.0212 & -- & -- & -- & -- \\
\hline & -- & -- & $(0.0307)$ & $(0.0307)$ & -- & -- & -- & -- \\
\hline \multirow[t]{2}{*}{ Good } & -- & -- & $-0.0877 * * *$ & $-0.0852 * *$ & -- & -- & -- & -- \\
\hline & -- & -- & $(0.0327)$ & $(0.0329)$ & -- & -- & -- & -- \\
\hline \multirow[t]{2}{*}{ Fair/Poor } & -- & -- & $-0.362^{* * *}$ & $-0.359 * * *$ & -- & -- & -- & -- \\
\hline & -- & -- & $(0.0353)$ & $(0.0355)$ & -- & -- & -- & -- \\
\hline \multirow[t]{2}{*}{ \# of Conditions } & -- & -- & -- & -- & $-0.0739 * * *$ & $-0.0725 * * *$ & -- & -- \\
\hline & -- & -- & -- & -- & $(0.00933)$ & $(0.00946)$ & -- & -- \\
\hline \multirow[t]{2}{*}{ \# of Functional Limitations } & -- & -- & -- & -- & -- & -- & $-0.0563 * * *$ & $-0.0552 * * *$ \\
\hline & -- & -- & -- & -- & -- & -- & $(0.00511)$ & $(0.00513)$ \\
\hline \multirow[t]{2}{*}{ (z-scored) PCS } & -- & -- & -- & -- & -- & -- & -- & -- \\
\hline & -- & -- & -- & -- & -- & -- & -- & -- \\
\hline \multirow[t]{2}{*}{ Male * Work-limit } & -0.0536 & -0.0581 & -- & -- & -- & -- & -- & -- \\
\hline & $(0.0572)$ & $(0.0568)$ & -- & -- & -- & -- & -- & -- \\
\hline \multirow[t]{2}{*}{ Male * Very Good } & -- & -- & -0.00587 & -0.00181 & -- & -- & -- & -- \\
\hline & -- & -- & $(0.0372)$ & $(0.0371)$ & -- & -- & -- & -- \\
\hline \multirow[t]{2}{*}{ Male * Good } & -- & -- & 0.0401 & 0.0391 & -- & -- & -- & -- \\
\hline & -- & -- & $(0.0406)$ & $(0.0411)$ & -- & -- & -- & -- \\
\hline \multirow[t]{2}{*}{ Male * Fair/Poor } & -- & -- & 0.0626 & 0.0616 & -- & -- & -- & -- \\
\hline & -- & -- & $(0.0427)$ & $(0.0428)$ & -- & -- & -- & -- \\
\hline \multirow[t]{2}{*}{ Male ${ }^{*} \#$ of Conditions } & -- & -- & -- & -- & 0.0189 & 0.0179 & -- & -- \\
\hline & -- & -- & -- & -- & $(0.0130)$ & $(0.0132)$ & -- & -- \\
\hline \multirow[t]{2}{*}{ Male * \# of Functional Limitations } & -- & -- & -- & -- & -- & -- & -0.0110 & -0.0118 \\
\hline & -- & -- & -- & -- & -- & -- & $(0.00817)$ & (0.00814) \\
\hline \multirow[t]{2}{*}{ Male * (z-scored) PCS } & -- & -- & -- & -- & -- & -- & -- & -- \\
\hline & -- & -- & -- & -- & -- & -- & -- & -- \\
\hline
\end{tabular}


Table A11. (continued) Estimates of labor force participation using the Joint-sample of men and women with and without instrumenting for spouse's earnings

\begin{tabular}{|c|c|c|c|c|c|c|c|c|}
\hline \multirow[b]{2}{*}{ VARIABLE } & \multicolumn{2}{|c|}{ (Work-limit) } & \multicolumn{2}{|c|}{ (SAH Status) } & \multicolumn{2}{|c|}{ (\# of Conditions) } & \multicolumn{2}{|c|}{ (\# of Func. Lim.) } \\
\hline & Non-IV & IV & Non-IV & IV & Non-IV & IV & Non-IV & IV \\
\hline \multirow[t]{2}{*}{ \# Children $<18$ years old } & $0.0271^{* *}$ & $0.0271^{* *}$ & $0.0327^{* *}$ & $0.0328^{* *}$ & $0.0348 * * *$ & $0.0348^{* * *}$ & $0.0275^{* *}$ & $0.0275^{* *}$ \\
\hline & $(0.0128)$ & $(0.0127)$ & $(0.0131)$ & $(0.0130)$ & $(0.0133)$ & $(0.0132)$ & $(0.0131)$ & $(0.0130)$ \\
\hline \multirow[t]{2}{*}{ \# Children $>=18$ years old } & $0.0909 * * *$ & $0.0906 * * *$ & $0.0972 * * *$ & $0.0965 * * *$ & $0.0958 * * *$ & $0.0952 * * *$ & $0.0935 * * *$ & $0.0931 * * *$ \\
\hline & (0.0109) & $(0.0109)$ & $(0.0108)$ & $(0.0108)$ & $(0.0105)$ & $(0.0105)$ & $(0.0107)$ & $(0.0107)$ \\
\hline \multirow[t]{2}{*}{ White } & $0.0361 *$ & $0.0344^{*}$ & $0.0329 *$ & $0.0314^{*}$ & $0.0435^{* *}$ & $0.0410 * *$ & $0.0423 * *$ & $0.0402 * *$ \\
\hline & $(0.0189)$ & $(0.0187)$ & $(0.0190)$ & $(0.0188)$ & $(0.0182)$ & $(0.0180)$ & $(0.0184)$ & $(0.0183)$ \\
\hline \multicolumn{9}{|l|}{ Potential Wage Indicators } \\
\hline \multirow[t]{2}{*}{ Education (yrs.) } & 0.00126 & -0.000650 & -0.000314 & -0.00269 & 0.00493 & 0.00219 & 0.00209 & -0.000322 \\
\hline & $(0.00324)$ & $(0.00355)$ & $(0.00325)$ & $(0.00352)$ & $(0.00334)$ & $(0.00362)$ & $(0.00320)$ & $(0.00351)$ \\
\hline \multirow[t]{2}{*}{ Education missing } & $0.240 * * *$ & $0.235^{* * *}$ & $0.235^{* * *}$ & $0.228 * * *$ & $0.254 * * *$ & $0.246 * * *$ & $0.243 * * *$ & $0.236 * * *$ \\
\hline & $(0.0436)$ & $(0.0458)$ & $(0.0425)$ & $(0.0446)$ & $(0.0370)$ & $(0.0397)$ & $(0.0409)$ & $(0.0433)$ \\
\hline \multirow[t]{2}{*}{ Experience } & -0.0182 & -0.0153 & -0.0131 & -0.00949 & -0.00945 & -0.00537 & -0.0158 & -0.0121 \\
\hline & $(0.0145)$ & $(0.0147)$ & $(0.0143)$ & $(0.0145)$ & $(0.0142)$ & $(0.0143)$ & $(0.0146)$ & $(0.0148)$ \\
\hline \multirow[t]{2}{*}{ Experience squared } & $2.90 \mathrm{e}-05$ & $-1.03 e-05$ & $-4.13 e-05$ & $-8.98 e-05$ & $-7.50 e-05$ & -0.000130 & $1.61 \mathrm{e}-07$ & $-4.98 \mathrm{e}-05$ \\
\hline & $(0.000197)$ & (0.000199) & $(0.000193)$ & (0.000195) & (0.000191) & $(0.000193)$ & $(0.000198)$ & $(0.000200)$ \\
\hline \multicolumn{9}{|l|}{ Unearned Income } \\
\hline \multirow[t]{2}{*}{ Spouse's Earnings (\$/week) } & $-0.00897^{* * *}$ & -0.00440 & $-0.00846^{* * *}$ & -0.00243 & $-0.00802 * * *$ & -0.00169 & $-0.00850 * * *$ & -0.00277 \\
\hline & $(0.00134)$ & $(0.00341)$ & $(0.00131)$ & $(0.00343)$ & $(0.00131)$ & $(0.00345)$ & $(0.00131)$ & $(0.00341)$ \\
\hline \multirow[t]{2}{*}{ Household Income (\$/year) } & $-0.000364^{* * *}$ & $-0.000359 * * *$ & $-0.000373 * * *$ & $-0.000366^{* * *}$ & $-0.000378 * * *$ & $-0.000371^{* * *}$ & $-0.000374 * * *$ & $-0.000367 * * *$ \\
\hline & (4.10e-05) & (4.19e-05) & $(4.14 \mathrm{e}-05)$ & $(4.25 e-05)$ & (4.19e-05) & $(4.30 \mathrm{e}-05)$ & (4.17e-05) & $(4.27 e-05)$ \\
\hline \multirow[t]{2}{*}{ Spouse Employed } & $0.127^{* * *}$ & $0.0907^{* * *}$ & $0.104^{* * *}$ & $0.0564^{*}$ & $0.105^{* * *}$ & $0.0533^{*}$ & $0.108 * * *$ & $0.0621 * *$ \\
\hline & $(0.0198)$ & $(0.0325)$ & $(0.0178)$ & $(0.0310)$ & (0.0184) & $(0.0319)$ & $(0.0184)$ & (0.0309) \\
\hline \multirow[t]{2}{*}{ Pension/IRA } & -0.0115 & -0.00927 & -0.0167 & -0.0135 & -0.0118 & -0.00876 & -0.0124 & -0.00962 \\
\hline & $(0.0206)$ & $(0.0207)$ & $(0.0200)$ & $(0.0201)$ & (0.0199) & (0.0199) & $(0.0208)$ & $(0.0209)$ \\
\hline
\end{tabular}


Table A11. (continued) Estimates of labor force participation using the Joint-sample of men and women with and without instrumenting for spouse's earnings

\begin{tabular}{|c|c|c|c|c|c|c|c|c|}
\hline \multirow[b]{2}{*}{ VARIABLE } & \multicolumn{2}{|c|}{ (Work-limit) } & \multicolumn{2}{|c|}{ (SAH Status) } & \multicolumn{2}{|c|}{ (\# of Conditions) } & \multicolumn{2}{|c|}{ (\# of Func. Lim.) } \\
\hline & Non-IV & IV & Non-IV & IV & Non-IV & IV & Non-IV & IV \\
\hline \multicolumn{9}{|c|}{ Control for Region and Time } \\
\hline \multirow[t]{2}{*}{ Midwest Census Region } & 0.0284 & 0.0307 & 0.0216 & 0.0247 & 0.0255 & 0.0285 & 0.0245 & 0.0273 \\
\hline & $(0.0193)$ & $(0.0192)$ & $(0.0183)$ & $(0.0181)$ & $(0.0187)$ & $(0.0186)$ & $(0.0187)$ & $(0.0185)$ \\
\hline \multirow[t]{2}{*}{ South Census Region } & -0.00650 & -0.00510 & -0.0105 & -0.00871 & -0.0149 & -0.0130 & -0.00701 & -0.00525 \\
\hline & (0.0183) & $(0.0183)$ & $(0.0167)$ & $(0.0168)$ & $(0.0174)$ & $(0.0175)$ & $(0.0172)$ & $(0.0173)$ \\
\hline \multirow[t]{2}{*}{ West Census Region } & -0.0312 & -0.0304 & $-0.0298 *$ & -0.0287 & $-0.0311^{*}$ & -0.0300 & $-0.0338^{*}$ & $-0.0327^{*}$ \\
\hline & $(0.0198)$ & $(0.0200)$ & $(0.0178)$ & $(0.0180)$ & $(0.0186)$ & (0.0189) & $(0.0186)$ & (0.0189) \\
\hline \multirow[t]{2}{*}{ MSA } & 0.0152 & 0.0109 & 0.0210 & 0.0154 & $0.0265^{*}$ & 0.0202 & 0.0202 & 0.0145 \\
\hline & $(0.0161)$ & $(0.0166)$ & $(0.0157)$ & $(0.0161)$ & $(0.0158)$ & $(0.0162)$ & $(0.0156)$ & $(0.0160)$ \\
\hline \multirow[t]{2}{*}{ Panel 6 (2002) } & 0.00377 & 0.00208 & 0.00618 & 0.00476 & 0.0187 & 0.0162 & 0.0152 & 0.0130 \\
\hline & $(0.0314)$ & $(0.0316)$ & $(0.0322)$ & $(0.0322)$ & $(0.0310)$ & $(0.0311)$ & $(0.0313)$ & $(0.0314)$ \\
\hline \multirow[t]{2}{*}{ Panel 7 (2003) } & -0.0316 & -0.0312 & -0.0248 & -0.0240 & -0.0206 & -0.0201 & -0.0218 & -0.0213 \\
\hline & $(0.0264)$ & $(0.0266)$ & $(0.0265)$ & $(0.0266)$ & $(0.0262)$ & $(0.0264)$ & $(0.0263)$ & $(0.0264)$ \\
\hline \multirow[t]{2}{*}{ Panel 8 (2004) } & 0.000249 & -0.00129 & -0.00188 & -0.00394 & -0.00217 & -0.00435 & 0.00462 & 0.00257 \\
\hline & (0.0248) & $(0.0250)$ & $(0.0238)$ & $(0.0238)$ & $(0.0239)$ & $(0.0240)$ & $(0.0237)$ & $(0.0238)$ \\
\hline \multirow[t]{2}{*}{ Panel 9 (2005) } & -0.000423 & -0.00292 & 0.00134 & -0.00161 & 0.00232 & -0.00104 & 0.00254 & -0.000617 \\
\hline & $(0.0262)$ & $(0.0266)$ & $(0.0277)$ & $(0.0280)$ & $(0.0265)$ & $(0.0268)$ & $(0.0260)$ & $(0.0264)$ \\
\hline \multirow[t]{2}{*}{ Panel 10 (2006) } & 0.0210 & 0.0187 & 0.0234 & 0.0203 & 0.0269 & 0.0238 & 0.0224 & 0.0196 \\
\hline & (0.0288) & $(0.0291)$ & $(0.0283)$ & $(0.0287)$ & $(0.0282)$ & $(0.0285)$ & $(0.0282)$ & $(0.0286)$ \\
\hline \multirow[t]{2}{*}{ Panel 11 (2007) } & 0.0172 & 0.0127 & 0.0229 & 0.0170 & 0.0230 & 0.0167 & 0.0246 & 0.0189 \\
\hline & $(0.0236)$ & (0.0239) & $(0.0235)$ & $(0.0238)$ & $(0.0234)$ & $(0.0236)$ & $(0.0234)$ & $(0.0237)$ \\
\hline
\end{tabular}

Note: Standard errors in parentheses; all tests are two-sided against the null hypothesis that the marginal effect is $=0 ; \quad * * * p<0.01, * * p<0.05, * p<0.1$

Note: Probit regressions with robust standard errors, using MEPS Panels 5 through 7 . Marginal Effects of the probit regression are reported - the coefficients are normalized to represent the derivative of the probability of employment with respect to a change in the explanatory variable. 
Table A12. Estimates of labor force participation using the Joint-sample of men and women with and without instrumenting for spouse's earnings

\begin{tabular}{|c|c|c|c|c|c|c|c|c|}
\hline \multirow[b]{2}{*}{ VARIABLE } & \multicolumn{2}{|c|}{ (1) } & \multicolumn{2}{|c|}{$(2)$} & \multicolumn{2}{|c|}{ (3) } & \multicolumn{2}{|c|}{ (4) } \\
\hline & Non-IV & IV & Non-IV & IV & Non-IV & IV & Non-IV & IV \\
\hline \multicolumn{9}{|l|}{ Reservation Wage Indicators } \\
\hline Male & $\begin{array}{l}-0.0392 \\
(0.0326)\end{array}$ & $\begin{array}{l}-0.0221 \\
(0.0362)\end{array}$ & $\begin{array}{l}0.00844 \\
(0.0230)\end{array}$ & $\begin{array}{c}0.0282 \\
(0.0248)\end{array}$ & $\begin{array}{c}0.0342^{* *} \\
(0.0153)\end{array}$ & $\begin{array}{c}0.0508 * * * \\
(0.0174)\end{array}$ & $\begin{array}{c}0.0196 \\
(0.0256)\end{array}$ & $\begin{array}{c}0.0355 \\
(0.0262)\end{array}$ \\
\hline Spouse Work-limit & $\begin{array}{l}0.107 * * * \\
(0.0333)\end{array}$ & $\begin{array}{l}0.111^{* * *} \\
(0.0331)\end{array}$ & $\begin{array}{l}-- \\
--\end{array}$ & $\begin{array}{l}-- \\
--\end{array}$ & $\begin{array}{l}-- \\
--\end{array}$ & $\begin{array}{l}-- \\
--\end{array}$ & $\begin{array}{l}-- \\
--\end{array}$ & $\begin{array}{l}-- \\
--\end{array}$ \\
\hline Spouse Very Good & $\begin{array}{l}-0.0414 \\
(0.0285)\end{array}$ & $\begin{array}{l}-0.0387 \\
(0.0288)\end{array}$ & $\begin{array}{l}-- \\
--\end{array}$ & $\begin{array}{l}-- \\
--\end{array}$ & $\begin{array}{l}-- \\
--\end{array}$ & $\begin{array}{l}-- \\
--\end{array}$ & $\begin{array}{l}-- \\
--\end{array}$ & $\begin{array}{l}-- \\
--\end{array}$ \\
\hline Spouse Good & $\begin{array}{l}0.00669 \\
(0.0285)\end{array}$ & $\begin{array}{c}0.0137 \\
(0.0287)\end{array}$ & $\begin{array}{l}-- \\
--\end{array}$ & $\begin{array}{l}-- \\
--\end{array}$ & $\begin{array}{l}-- \\
--\end{array}$ & $\begin{array}{l}-- \\
--\end{array}$ & $\begin{array}{l}-- \\
--\end{array}$ & $\begin{array}{l}-- \\
--\end{array}$ \\
\hline Spouse Fair/Poor & $\begin{array}{c}-0.00157 \\
(0.0350)\end{array}$ & $\begin{array}{l}0.00623 \\
(0.0352)\end{array}$ & -- & -- & $\begin{array}{l}-- \\
--\end{array}$ & -- & -- & -- \\
\hline Spouse \# of Conditions & $\begin{array}{l}-- \\
--\end{array}$ & $\begin{array}{l}-- \\
--\end{array}$ & $\begin{array}{c}0.0193 * \\
(0.00980)\end{array}$ & $\begin{array}{c}0.0194 * * \\
(0.00977)\end{array}$ & $\begin{array}{l}-- \\
--\end{array}$ & $\begin{array}{l}-- \\
--\end{array}$ & $\begin{array}{c}0.0173 \\
(0.0107)\end{array}$ & $\begin{array}{c}0.0166 \\
(0.0107)\end{array}$ \\
\hline Spouse \# of Func. Limits & -- & -- & $\begin{array}{c}0.00399 \\
(0.00504)\end{array}$ & $\begin{array}{c}0.00504 \\
(0.00511)\end{array}$ & $\begin{array}{l}-- \\
--\end{array}$ & -- & $\begin{array}{c}0.00318 \\
(0.00617)\end{array}$ & $\begin{array}{c}0.00269 \\
(0.00615)\end{array}$ \\
\hline Spouse (z-scored) PCS & $\begin{array}{l}-- \\
--\end{array}$ & $\begin{array}{l}-- \\
--\end{array}$ & $\begin{array}{l}-- \\
--\end{array}$ & $\begin{array}{l}-- \\
--\end{array}$ & $\begin{array}{l}-0.0231^{* *} \\
(0.00957)\end{array}$ & $\begin{array}{c}-0.0279 * * * \\
(0.00960)\end{array}$ & $\begin{array}{l}-0.0138 \\
(0.0126)\end{array}$ & $\begin{array}{l}-0.0192 \\
(0.0125)\end{array}$ \\
\hline Male * Spouse Work-limit & $\begin{array}{c}0.0140 \\
(0.0530)\end{array}$ & $\begin{array}{l}0.00503 \\
(0.0534)\end{array}$ & $\begin{array}{l}-- \\
--\end{array}$ & $\begin{array}{l}-- \\
--\end{array}$ & $\begin{array}{l}-- \\
--\end{array}$ & $\begin{array}{l}-- \\
--\end{array}$ & $\begin{array}{l}-- \\
--\end{array}$ & -- \\
\hline Male * Spouse Very Good & $\begin{array}{c}0.0905^{* *} \\
(0.0397)\end{array}$ & $\begin{array}{c}0.0892^{* *} \\
(0.0400)\end{array}$ & $\begin{array}{l}-- \\
--\end{array}$ & -- & $\begin{array}{l}-- \\
--\end{array}$ & $\begin{array}{l}-- \\
--\end{array}$ & -- & $\begin{array}{l}-- \\
--\end{array}$ \\
\hline Male * Spouse Good & $\begin{array}{c}0.0600 \\
(0.0400)\end{array}$ & $\begin{array}{c}0.0551 \\
(0.0401)\end{array}$ & $\begin{array}{l}-- \\
--\end{array}$ & $\begin{array}{l}-- \\
--\end{array}$ & $\begin{array}{l}-- \\
--\end{array}$ & $\begin{array}{l}-- \\
--\end{array}$ & $\begin{array}{l}-- \\
--\end{array}$ & $\begin{array}{l}-- \\
--\end{array}$ \\
\hline Male * Spouse Fair/Poor & $\begin{array}{l}0.0783^{*} \\
(0.0442)\end{array}$ & $\begin{array}{c}0.0729 \\
(0.0445)\end{array}$ & $\begin{array}{l}-- \\
--\end{array}$ & $\begin{array}{l}-- \\
--\end{array}$ & $\begin{array}{l}-- \\
--\end{array}$ & $\begin{array}{l}-- \\
--\end{array}$ & $\begin{array}{l}-- \\
--\end{array}$ & $\begin{array}{l}-- \\
--\end{array}$ \\
\hline Male * Spouse \# of Conditions & $\begin{array}{l}-- \\
--\end{array}$ & $\begin{array}{l}-- \\
--\end{array}$ & $\begin{array}{l}0.00301 \\
(0.0139)\end{array}$ & $\begin{array}{l}0.00224 \\
(0.0138)\end{array}$ & $\begin{array}{l}-- \\
--\end{array}$ & $\begin{array}{l}-- \\
--\end{array}$ & $\begin{array}{l}0.00521 \\
(0.0143)\end{array}$ & $\begin{array}{l}0.00505 \\
(0.0143)\end{array}$ \\
\hline Male * Spouse \# of Func. Limits & $\begin{array}{l}-- \\
--\end{array}$ & $\begin{array}{l}-- \\
--\end{array}$ & $\begin{array}{c}0.00171 \\
(0.00688)\end{array}$ & $\begin{array}{c}0.000136 \\
(0.00689)\end{array}$ & $\begin{array}{l}-- \\
--\end{array}$ & $\begin{array}{l}-- \\
--\end{array}$ & $\begin{array}{c}0.00413 \\
(0.00878)\end{array}$ & $\begin{array}{c}0.00415 \\
(0.00875)\end{array}$ \\
\hline Male * Spouse (z-scored) PCS & $\begin{array}{l}-- \\
--\end{array}$ & $\begin{array}{l}-- \\
--\end{array}$ & $\begin{array}{l}-- \\
--\end{array}$ & $\begin{array}{l}-- \\
--\end{array}$ & $\begin{array}{l}0.00326 \\
(0.0130)\end{array}$ & $\begin{array}{l}0.00821 \\
(0.0130)\end{array}$ & $\begin{array}{l}0.00901 \\
(0.0177)\end{array}$ & $\begin{array}{c}0.0138 \\
(0.0177)\end{array}$ \\
\hline
\end{tabular}


Table A12. (continued) Estimates of labor force participation using the Joint-sample of men and women with and without instrumenting for spouse's earnings

\begin{tabular}{|c|c|c|c|c|c|c|c|c|}
\hline \multirow[b]{2}{*}{ VARIABLE } & \multicolumn{2}{|c|}{ (1) } & \multicolumn{2}{|c|}{ (2) } & \multicolumn{2}{|c|}{ (3) } & \multicolumn{2}{|c|}{ (4) } \\
\hline & Non-IV & IV & Non-IV & IV & Non-IV & IV & Non-IV & IV \\
\hline \multirow[t]{2}{*}{ Work-limit } & $-0.428 * * *$ & $-0.423^{* * *}$ & $\overline{--}$ & $\overline{--}$ & $\begin{array}{l}- \\
\end{array}$ & $\overline{--}$ & $\overline{--}$ & -- \\
\hline & $(0.0356)$ & $(0.0357)$ & -- & -- & -- & -- & -- & -- \\
\hline \multirow[t]{2}{*}{ Very Good } & -0.00930 & -0.0115 & -- & -- & -- & -- & -- & -- \\
\hline & $(0.0311)$ & $(0.0310)$ & -- & -- & -- & -- & -- & -- \\
\hline \multirow[t]{2}{*}{ Good } & $-0.0587^{*}$ & $-0.0569^{*}$ & -- & -- & -- & -- & -- & -- \\
\hline & $(0.0320)$ & $(0.0322)$ & -- & -- & -- & -- & -- & -- \\
\hline \multirow[t]{2}{*}{ Fair/Poor } & $-0.202 * * *$ & $-0.201 * * *$ & -- & -- & -- & -- & -- & -- \\
\hline & $(0.0405)$ & $(0.0406)$ & -- & -- & -- & -- & -- & -- \\
\hline \multirow[t]{2}{*}{ \# of Conditions } & -- & -- & $-0.0488 * * *$ & $-0.0483^{* * *}$ & -- & -- & $-0.0343 * * *$ & $-0.0344 * * *$ \\
\hline & -- & -- & $(0.0100)$ & $(0.0101)$ & -- & -- & $(0.0113)$ & $(0.0114)$ \\
\hline \multirow[t]{2}{*}{ \# of Functional Limitations } & -- & -- & $-0.0492 * * *$ & $-0.0482 * * *$ & -- & -- & $-0.0327^{* * *}$ & $-0.0320 * * *$ \\
\hline & -- & -- & $(0.00535)$ & $(0.00537)$ & -- & -- & $(0.00610)$ & $(0.00608)$ \\
\hline \multirow[t]{2}{*}{ (z-scored) PCS } & -- & -- & -- & -- & $0.119 * * *$ & $0.118^{* * *}$ & $0.0770 * * *$ & $0.0762^{* * *}$ \\
\hline & -- & -- & -- & -- & $(0.0119)$ & $(0.0117)$ & $(0.0142)$ & (0.0139) \\
\hline \multirow[t]{2}{*}{ Male * Work-limit } & -0.0972 & -0.101 & -- & -- & -- & -- & -- & -- \\
\hline & $(0.0645)$ & $(0.0642)$ & -- & -- & -- & -- & -- & -- \\
\hline \multirow[t]{2}{*}{ Male * Very Good } & -0.0110 & -0.00759 & -- & -- & -- & -- & -- & -- \\
\hline & (0.0378) & $(0.0377)$ & -- & -- & -- & -- & -- & -- \\
\hline \multirow[t]{2}{*}{ Male * Good } & 0.0401 & 0.0393 & -- & -- & -- & -- & -- & -- \\
\hline & $(0.0414)$ & $(0.0417)$ & -- & -- & -- & -- & -- & -- \\
\hline \multirow[t]{2}{*}{ Male * Fair/Poor } & 0.0539 & 0.0543 & -- & -- & -- & -- & -- & -- \\
\hline & $(0.0485)$ & $(0.0484)$ & -- & -- & -- & -- & -- & -- \\
\hline \multirow[t]{2}{*}{ Male ${ }^{*}$ \# of Conditions } & -- & -- & 0.0210 & 0.0207 & -- & -- & 0.0162 & 0.0166 \\
\hline & -- & -- & $(0.0139)$ & $(0.0141)$ & -- & -- & $(0.0155)$ & $(0.0155)$ \\
\hline \multirow[t]{2}{*}{ Male * \# of Functional Limitations } & -- & -- & $-0.0138^{*}$ & $-0.0146^{*}$ & -- & -- & $-0.0185^{*}$ & $-0.0191^{*}$ \\
\hline & -- & -- & $(0.00831)$ & $(0.00827)$ & -- & -- & $(0.0106)$ & $(0.0105)$ \\
\hline \multirow[t]{2}{*}{ Male * (z-scored) PCS } & -- & -- & -- & -- & -0.0190 & -0.0177 & -0.0262 & -0.0254 \\
\hline & -- & -- & -- & -- & $(0.0142)$ & $(0.0142)$ & $(0.0178)$ & $(0.0178)$ \\
\hline \multirow[t]{2}{*}{ \# Children $<18$ years old } & $0.0268 * *$ & $0.0269 * *$ & $0.0282 * *$ & $0.0283 * *$ & $0.0309 * *$ & $0.0314 * *$ & $0.0280^{*}$ & $0.0284 *$ \\
\hline & $(0.0128)$ & $(0.0127)$ & $(0.0132)$ & $(0.0131)$ & $(0.0156)$ & $(0.0157)$ & $(0.0155)$ & $(0.0155)$ \\
\hline \multirow[t]{2}{*}{ \# Children >=18 years old } & $0.0915 * * *$ & $0.0911^{* * *}$ & $0.0927^{* * *}$ & $0.0923^{* * *}$ & $0.0950 * * *$ & $0.0945 * * *$ & $0.0929 * * *$ & $0.0924^{* * *}$ \\
\hline & $(0.0110)$ & $(0.0110)$ & $(0.0106)$ & $(0.0106)$ & $(0.0118)$ & $(0.0118)$ & $(0.0118)$ & $(0.0118)$ \\
\hline \multirow[t]{2}{*}{ White } & 0.0320 & 0.0307 & $0.0429 * *$ & $0.0406 * *$ & $0.0398 *$ & $0.0375^{*}$ & $0.0451 * *$ & $0.0429 * *$ \\
\hline & (0.0195) & $(0.0194)$ & $(0.0184)$ & $(0.0183)$ & $(0.0204)$ & $(0.0203)$ & $(0.0204)$ & $(0.0203)$ \\
\hline
\end{tabular}


Table A12. (continued) Estimates of labor force participation using the Joint-sample of men and women with and without instrumenting for spouse's earnings

\begin{tabular}{|c|c|c|c|c|c|c|c|c|}
\hline \multirow[b]{2}{*}{ VARIABLE } & \multicolumn{2}{|c|}{ (1) } & \multicolumn{2}{|c|}{$(2)$} & \multicolumn{2}{|c|}{ (3) } & \multicolumn{2}{|c|}{ (4) } \\
\hline & Non-IV & IV & Non-IV & IV & Non-IV & IV & Non-IV & IV \\
\hline \multicolumn{9}{|l|}{ Potential Wage Indicators } \\
\hline \multirow[t]{2}{*}{ Education (yrs.) } & -0.000631 & -0.00253 & 0.00218 & -0.000319 & -0.000756 & -0.00308 & -0.00102 & -0.00325 \\
\hline & $(0.00327)$ & $(0.00356)$ & $(0.00323)$ & $(0.00354)$ & $(0.00342)$ & $(0.00365)$ & (0.00339) & $(0.00366)$ \\
\hline \multirow[t]{2}{*}{ Education missing } & $0.224 * * *$ & $0.219 * * *$ & $0.236 * * *$ & $0.229 * * *$ & $0.221 * * *$ & $0.213^{* * *}$ & $0.212 * * *$ & $0.204^{* * *}$ \\
\hline & $(0.0478)$ & $(0.0497)$ & $(0.0421)$ & $(0.0446)$ & $(0.0533)$ & $(0.0561)$ & $(0.0555)$ & $(0.0582)$ \\
\hline \multirow[t]{2}{*}{ Experience } & -0.0183 & -0.0154 & -0.0139 & -0.0101 & -0.0129 & -0.00952 & -0.0154 & -0.0121 \\
\hline & $(0.0146)$ & $(0.0148)$ & $(0.0146)$ & $(0.0148)$ & $(0.0157)$ & $(0.0156)$ & $(0.0163)$ & $(0.0163)$ \\
\hline \multirow[t]{2}{*}{ Experience squared } & $3.06 e-05$ & $-8.44 e-06$ & $-2.04 e-05$ & $-7.19 e-05$ & $-3.53 e-05$ & $-8.12 e-05$ & $-3.40 e-06$ & $-4.70 e-05$ \\
\hline & $(0.000198)$ & $(0.000200)$ & (0.000198) & $(0.000200)$ & $(0.000214)$ & $(0.000213)$ & $(0.000222)$ & $(0.000222)$ \\
\hline \multicolumn{9}{|l|}{ Unearned Income } \\
\hline \multirow[t]{2}{*}{ Spouse's Earnings (\$/week) } & $-0.00917^{* * *}$ & -0.00432 & $-0.00865^{* * *}$ & -0.00273 & $-0.00781 * * *$ & -0.00212 & $-0.00831 * * *$ & -0.00287 \\
\hline & $(0.00134)$ & $(0.00342)$ & $(0.00131)$ & $(0.00344)$ & $(0.00140)$ & $(0.00343)$ & $(0.00138)$ & $(0.00344)$ \\
\hline \multirow[t]{2}{*}{ Household Income (\$/year) } & $-0.000364 * * *$ & $-0.000358^{* * *}$ & $-0.000373^{* * *}$ & $-0.000366^{* * *}$ & $-0.000388^{* * *}$ & $-0.000382 * * *$ & $-0.000384^{* * *}$ & $-0.000378 * * *$ \\
\hline & $(4.11 e-05)$ & (4.21e-05) & $(4.18 e-05)$ & $(4.28 \mathrm{e}-05)$ & $(4.38 \mathrm{e}-05)$ & $(4.44 \mathrm{e}-05)$ & $(4.40 e-05)$ & (4.47e-05) \\
\hline \multirow[t]{2}{*}{ Spouse Employed } & $0.131 * * *$ & $0.0928 * * *$ & $0.117 * * *$ & $0.0689 * *$ & $0.0983^{* * *}$ & $0.0548 *$ & $0.113 * * *$ & $0.0709 * *$ \\
\hline & $(0.0198)$ & $(0.0323)$ & $(0.0186)$ & $(0.0312)$ & (0.0199) & $(0.0323)$ & $(0.0205)$ & $(0.0319)$ \\
\hline \multirow[t]{2}{*}{ Pension/IRA } & -0.0124 & -0.00986 & -0.0118 & -0.00888 & -0.0225 & -0.0189 & -0.0221 & -0.0185 \\
\hline & $(0.0206)$ & $(0.0206)$ & $(0.0207)$ & $(0.0208)$ & $(0.0214)$ & $(0.0214)$ & $(0.0219)$ & $(0.0220)$ \\
\hline \multicolumn{9}{|l|}{ Control for Region and Time } \\
\hline \multirow[t]{2}{*}{ Midwest Census Region } & 0.0278 & 0.0304 & 0.0261 & 0.0290 & 0.0294 & 0.0320 & 0.0288 & 0.0313 \\
\hline & $(0.0190)$ & $(0.0188)$ & $(0.0188)$ & $(0.0187)$ & $(0.0200)$ & $(0.0200)$ & $(0.0201)$ & $(0.0201)$ \\
\hline \multirow[t]{2}{*}{ South Census Region } & -0.00436 & -0.00293 & -0.00622 & -0.00446 & -0.00325 & -0.00208 & -0.000298 & 0.000850 \\
\hline & $(0.0176)$ & $(0.0177)$ & $(0.0173)$ & $(0.0174)$ & $(0.0192)$ & $(0.0193)$ & $(0.0191)$ & $(0.0192)$ \\
\hline \multirow[t]{2}{*}{ West Census Region } & -0.0306 & -0.0296 & $-0.0336 *$ & $-0.0325^{*}$ & -0.0260 & -0.0251 & -0.0291 & -0.0282 \\
\hline & (0.0189) & $(0.0191)$ & $(0.0187)$ & $(0.0191)$ & $(0.0198)$ & $(0.0202)$ & $(0.0198)$ & $(0.0202)$ \\
\hline \multirow[t]{2}{*}{ MSA } & 0.0142 & 0.00979 & 0.0199 & 0.0141 & 0.0210 & 0.0162 & 0.0197 & 0.0150 \\
\hline & $(0.0162)$ & $(0.0167)$ & $(0.0156)$ & $(0.0160)$ & $(0.0162)$ & $(0.0166)$ & $(0.0160)$ & $(0.0164)$ \\
\hline
\end{tabular}


Table A12. (continued) Estimates of labor force participation using the Joint-sample of men and women with and without instrumenting for spouse's earnings

\begin{tabular}{|c|c|c|c|c|c|c|c|c|}
\hline \multirow[b]{2}{*}{ VARIABLE } & \multicolumn{2}{|c|}{ (1) } & \multicolumn{2}{|c|}{ (2) } & \multicolumn{2}{|c|}{ (3) } & \multicolumn{2}{|c|}{ (4) } \\
\hline & Non-IV & IV & Non-IV & IV & Non-IV & IV & Non-IV & IV \\
\hline Panel 6 (2002) & $\begin{array}{c}-0.000973 \\
(0.0321)\end{array}$ & $\begin{array}{c}-0.00209 \\
(0.0322)\end{array}$ & $\begin{array}{c}0.0160 \\
(0.0313)\end{array}$ & $\begin{array}{c}0.0137 \\
(0.0314)\end{array}$ & $\begin{array}{c}-0.0126 \\
(0.0341)\end{array}$ & $\begin{array}{c}-0.0146 \\
(0.0339)\end{array}$ & $\begin{array}{c}-0.00750 \\
(0.0338)\end{array}$ & $\begin{array}{l}-0.00921 \\
(0.0337)\end{array}$ \\
\hline Panel 7 (2003) & $\begin{array}{l}-0.0311 \\
(0.0266)\end{array}$ & $\begin{array}{c}-0.0304 \\
(0.0267)\end{array}$ & $\begin{array}{l}-0.0195 \\
(0.0264)\end{array}$ & $\begin{array}{l}-0.0189 \\
(0.0266)\end{array}$ & $\begin{array}{l}-0.0504^{*} \\
(0.0267)\end{array}$ & $\begin{array}{c}-0.0491^{*} \\
(0.0269)\end{array}$ & $\begin{array}{l}-0.0436 \\
(0.0272)\end{array}$ & $\begin{array}{c}-0.0421 \\
(0.0274)\end{array}$ \\
\hline Panel 8 (2004) & $\begin{array}{l}0.00150 \\
(0.0246)\end{array}$ & $\begin{array}{c}-6.21 e-05 \\
(0.0247)\end{array}$ & $\begin{array}{l}0.00752 \\
(0.0237)\end{array}$ & $\begin{array}{l}0.00541 \\
(0.0238)\end{array}$ & $\begin{array}{l}-0.0229 \\
(0.0239)\end{array}$ & $\begin{array}{l}-0.0247 \\
(0.0240)\end{array}$ & $\begin{array}{l}-0.0136 \\
(0.0236)\end{array}$ & $\begin{array}{l}-0.0151 \\
(0.0237)\end{array}$ \\
\hline Panel 9 (2005) & $\begin{array}{c}0.000448 \\
(0.0270)\end{array}$ & $\begin{array}{c}-0.00194 \\
(0.0273)\end{array}$ & $\begin{array}{l}0.00516 \\
(0.0260)\end{array}$ & $\begin{array}{l}0.00194 \\
(0.0263)\end{array}$ & $\begin{array}{l}-0.0262 \\
(0.0271)\end{array}$ & $\begin{array}{l}-0.0286 \\
(0.0273)\end{array}$ & $\begin{array}{l}-0.0204 \\
(0.0263)\end{array}$ & $\begin{array}{l}-0.0225 \\
(0.0265)\end{array}$ \\
\hline Panel 10 (2006) & $\begin{array}{c}0.0217 \\
(0.0290)\end{array}$ & $\begin{array}{c}0.0192 \\
(0.0294)\end{array}$ & $\begin{array}{c}0.0263 \\
(0.0283)\end{array}$ & $\begin{array}{c}0.0234 \\
(0.0286)\end{array}$ & $\begin{array}{r}-0.00185 \\
(0.0290)\end{array}$ & $\begin{array}{r}-0.00385 \\
(0.0292)\end{array}$ & $\begin{array}{l}0.00651 \\
(0.0290)\end{array}$ & $\begin{array}{l}0.00482 \\
(0.0292)\end{array}$ \\
\hline Panel 11 (2007) & $\begin{array}{c}0.0193 \\
(0.0237)\end{array}$ & $\begin{array}{c}0.0146 \\
(0.0241)\end{array}$ & $\begin{array}{c}0.0273 \\
(0.0237)\end{array}$ & $\begin{array}{c}0.0214 \\
(0.0240)\end{array}$ & $\begin{array}{l}0.00940 \\
(0.0253)\end{array}$ & $\begin{array}{l}0.00522 \\
(0.0253)\end{array}$ & $\begin{array}{c}0.0165 \\
(0.0255)\end{array}$ & $\begin{array}{c}0.0128 \\
(0.0256)\end{array}$ \\
\hline
\end{tabular}

Note: Standard errors in parentheses; all tests are two-sided against the null hypothesis that the marginal effect is $=0 ; \quad * * * p<0.01, * * p<0.05, * p<0.1$

Note: Probit regressions with robust standard errors, using MEPS Panels 5 through 7 . Marginal Effects of the probit regression are reported - the coefficients are normalized to represent the derivative of the probability of employment with respect to a change in the explanatory variable. 
Table A13. Estimates of labor force participation using the Joint-sample of men and women with and without instrumenting for spouse's earnings

\begin{tabular}{|c|c|c|c|c|c|c|}
\hline \multirow[b]{2}{*}{ VARIABLE } & \multicolumn{2}{|c|}{ (5) } & \multicolumn{2}{|c|}{ (6) } & \multicolumn{2}{|c|}{ (7) } \\
\hline & Non-IV & IV & Non-IV & IV & Non-IV & IV \\
\hline \multicolumn{7}{|l|}{ Reservation Wage Indicators } \\
\hline \multirow[t]{2}{*}{ Male } & $0.0443^{* *}$ & $0.0562 * * *$ & -0.0463 & -0.0341 & -0.0535 & -0.0361 \\
\hline & $(0.0173)$ & $(0.0187)$ & $(0.0400)$ & $(0.0410)$ & $(0.0347)$ & $(0.0378)$ \\
\hline \multirow[t]{2}{*}{ Spouse Work-limit } & $0.116^{* * *}$ & $0.117^{* * *}$ & $0.140 * * *$ & $0.143^{* * *}$ & $0.132^{* * *}$ & $0.136^{* * *}$ \\
\hline & $(0.0376)$ & $(0.0377)$ & $(0.0457)$ & $(0.0457)$ & $(0.0438)$ & $(0.0436)$ \\
\hline \multirow[t]{2}{*}{ Spouse Very Good } & -- & -- & $-0.0515^{*}$ & $-0.0500 *$ & $-0.0478^{*}$ & -0.0448 \\
\hline & -- & -- & $(0.0285)$ & $(0.0288)$ & $(0.0282)$ & $(0.0286)$ \\
\hline \multirow[t]{2}{*}{ Spouse Good } & -- & -- & -0.0123 & -0.00750 & -0.00707 & 0.000859 \\
\hline & -- & -- & $(0.0309)$ & $(0.0311)$ & $(0.0286)$ & $(0.0288)$ \\
\hline \multirow[t]{2}{*}{ Spouse Fair/Poor } & -- & -- & -0.0176 & -0.0133 & -0.0231 & -0.0136 \\
\hline & -- & -- & $(0.0438)$ & (0.0444) & $(0.0380)$ & $(0.0383)$ \\
\hline \multirow[t]{2}{*}{ Spouse \# of Conditions } & -- & -- & 0.0145 & 0.0135 & 0.0173 & 0.0163 \\
\hline & -- & -- & $(0.0113)$ & $(0.0113)$ & $(0.0107)$ & $(0.0107)$ \\
\hline \multirow[t]{2}{*}{ Spouse \# of Func. Limits } & -- & -- & -0.00884 & -0.00943 & -0.00790 & -0.00786 \\
\hline & -- & -- & $(0.00754)$ & $(0.00750)$ & $(0.00674)$ & $(0.00675)$ \\
\hline \multirow[t]{2}{*}{ Spouse (z-scored) PCS } & -0.00761 & -0.0109 & -0.00778 & -0.0111 & -- & -- \\
\hline & (0.0119) & $(0.0119)$ & $(0.0138)$ & (0.0138) & -- & -- \\
\hline \multirow[t]{2}{*}{ Male * Spouse Work-limit } & 0.0107 & 0.00657 & -0.0213 & -0.0273 & -0.000763 & -0.00937 \\
\hline & $(0.0545)$ & $(0.0545)$ & $(0.0705)$ & $(0.0705)$ & $(0.0668)$ & $(0.0674)$ \\
\hline \multirow[t]{2}{*}{ Male * Spouse Very Good } & -- & -- & $0.108 * * *$ & $0.107^{* * *}$ & $0.0940 * *$ & $0.0927^{* *}$ \\
\hline & -- & -- & $(0.0405)$ & $(0.0407)$ & $(0.0392)$ & $(0.0395)$ \\
\hline \multirow[t]{2}{*}{ Male * Spouse Good } & -- & -- & $0.0795^{*}$ & $0.0760^{*}$ & $0.0673^{*}$ & 0.0619 \\
\hline & -- & -- & $(0.0426)$ & $(0.0429)$ & $(0.0396)$ & $(0.0398)$ \\
\hline \multirow[t]{2}{*}{ Male * Spouse Fair/Poor } & -- & -- & 0.0871 & 0.0842 & $0.0889 * *$ & $0.0829 *$ \\
\hline & -- & -- & $(0.0552)$ & $(0.0558)$ & $(0.0446)$ & $(0.0453)$ \\
\hline \multirow[t]{2}{*}{ Male * Spouse \# of Conditions } & -- & -- & 0.00420 & 0.00453 & -0.00155 & -0.00112 \\
\hline & -- & -- & $(0.0153)$ & $(0.0154)$ & $(0.0149)$ & (0.0149) \\
\hline \multirow[t]{2}{*}{ Male * Spouse \# of Func. Limits } & -- & -- & 0.00939 & 0.00990 & 0.00301 & 0.00282 \\
\hline & -- & -- & $(0.0110)$ & $(0.0110)$ & $(0.00969)$ & $(0.00968)$ \\
\hline \multirow[t]{2}{*}{ Male * Spouse (z-scored) PCS } & 0.000642 & 0.00349 & 0.0161 & 0.0190 & -- & -- \\
\hline & $(0.0157)$ & $(0.0157)$ & $(0.0199)$ & (0.0199) & -- & -- \\
\hline
\end{tabular}


Table A13. (continued) Estimates of labor force participation using the Joint-sample of men and women with and without instrumenting for spouse's earnings

\begin{tabular}{|c|c|c|c|c|c|c|}
\hline \multirow[b]{2}{*}{ VARIABLE } & \multicolumn{2}{|c|}{ (5) } & \multicolumn{2}{|c|}{ (6) } & \multicolumn{2}{|c|}{ (7) } \\
\hline & Non-IV & IV & Non-IV & IV & Non-IV & IV \\
\hline \multirow[t]{2}{*}{ Work-limit } & $-0.454 * * *$ & $-0.451 * * *$ & $-0.435 * * *$ & $-0.433 * * *$ & $-0.395 * * *$ & $-0.392^{* * *}$ \\
\hline & (0.0339) & $(0.0336)$ & $(0.0428)$ & $(0.0428)$ & $(0.0450)$ & $(0.0452)$ \\
\hline \multirow[t]{2}{*}{ Very Good } & -- & -- & 0.0120 & 0.0104 & 0.00219 & -0.000222 \\
\hline & -- & -- & $(0.0306)$ & $(0.0305)$ & $(0.0306)$ & $(0.0305)$ \\
\hline \multirow[t]{2}{*}{ Good } & -- & -- & -0.00533 & -0.00424 & -0.0372 & -0.0357 \\
\hline & -- & -- & $(0.0346)$ & $(0.0348)$ & $(0.0322)$ & $(0.0324)$ \\
\hline \multirow[t]{2}{*}{ Fair/Poor } & -- & -- & $-0.0889 *$ & $-0.0888^{*}$ & $-0.159 * * *$ & $-0.159 * * *$ \\
\hline & -- & -- & $(0.0455)$ & $(0.0457)$ & $(0.0432)$ & (0.0429) \\
\hline \multirow[t]{2}{*}{ \# of Conditions } & -- & -- & $-0.0247^{* *}$ & $-0.0249 * *$ & $-0.0292 * * *$ & $-0.0291 * * *$ \\
\hline & -- & -- & $(0.0112)$ & $(0.0113)$ & $(0.0103)$ & $(0.0105)$ \\
\hline \multirow[t]{2}{*}{ \# of Functional Limitations } & -- & -- & 0.00554 & 0.00589 & -0.00609 & -0.00572 \\
\hline & -- & -- & $(0.00741)$ & $(0.00740)$ & $(0.00683)$ & $(0.00684)$ \\
\hline \multirow[t]{2}{*}{ (z-scored) PCS } & $0.0702 * * *$ & $0.0696 * * *$ & $0.0540 * * *$ & $0.0538^{* * *}$ & -- & -- \\
\hline & (0.0126) & $(0.0125)$ & $(0.0142)$ & $(0.0140)$ & -- & -- \\
\hline \multirow[t]{2}{*}{ Male * Work-limit } & -0.0805 & -0.0830 & -0.0559 & -0.0572 & -0.101 & -0.102 \\
\hline & $(0.0666)$ & $(0.0662)$ & $(0.0805)$ & $(0.0803)$ & $(0.0798)$ & $(0.0797)$ \\
\hline \multirow[t]{2}{*}{ Male * Very Good } & -- & -- & -0.0157 & -0.0128 & -0.0215 & -0.0179 \\
\hline & -- & -- & $(0.0386)$ & $(0.0384)$ & $(0.0372)$ & $(0.0369)$ \\
\hline \multirow[t]{2}{*}{ Male * Good } & -- & -- & 0.00985 & 0.0104 & 0.0208 & 0.0203 \\
\hline & -- & -- & $(0.0457)$ & $(0.0460)$ & $(0.0417)$ & $(0.0420)$ \\
\hline \multirow[t]{2}{*}{ Male * Fair/Poor } & -- & -- & -0.00416 & -0.00232 & 0.0241 & 0.0253 \\
\hline & -- & -- & $(0.0541)$ & $(0.0543)$ & $(0.0501)$ & (0.0499) \\
\hline \multirow[t]{2}{*}{ Male * \# of Conditions } & -- & -- & $0.0254^{*}$ & $0.0258^{*}$ & $0.0305^{* *}$ & $0.0304^{* *}$ \\
\hline & -- & -- & $(0.0153)$ & $(0.0154)$ & $(0.0142)$ & (0.0144) \\
\hline \multirow[t]{2}{*}{ Male * \# of Functional Limitations } & -- & -- & -0.0148 & -0.0152 & -0.00570 & -0.00615 \\
\hline & -- & -- & $(0.0133)$ & $(0.0133)$ & $(0.0113)$ & $(0.0114)$ \\
\hline \multirow[t]{2}{*}{ Male $^{*}($ z-scored) PCS } & $-0.0387^{* *}$ & $-0.0381 * *$ & $-0.0356^{*}$ & $-0.0351^{*}$ & -- & -- \\
\hline & $(0.0167)$ & $(0.0168)$ & $(0.0193)$ & $(0.0193)$ & -- & -- \\
\hline
\end{tabular}


Table A13. (continued) Estimates of labor force participation using the Joint-sample of men and women with and without instrumenting for spouse's earnings

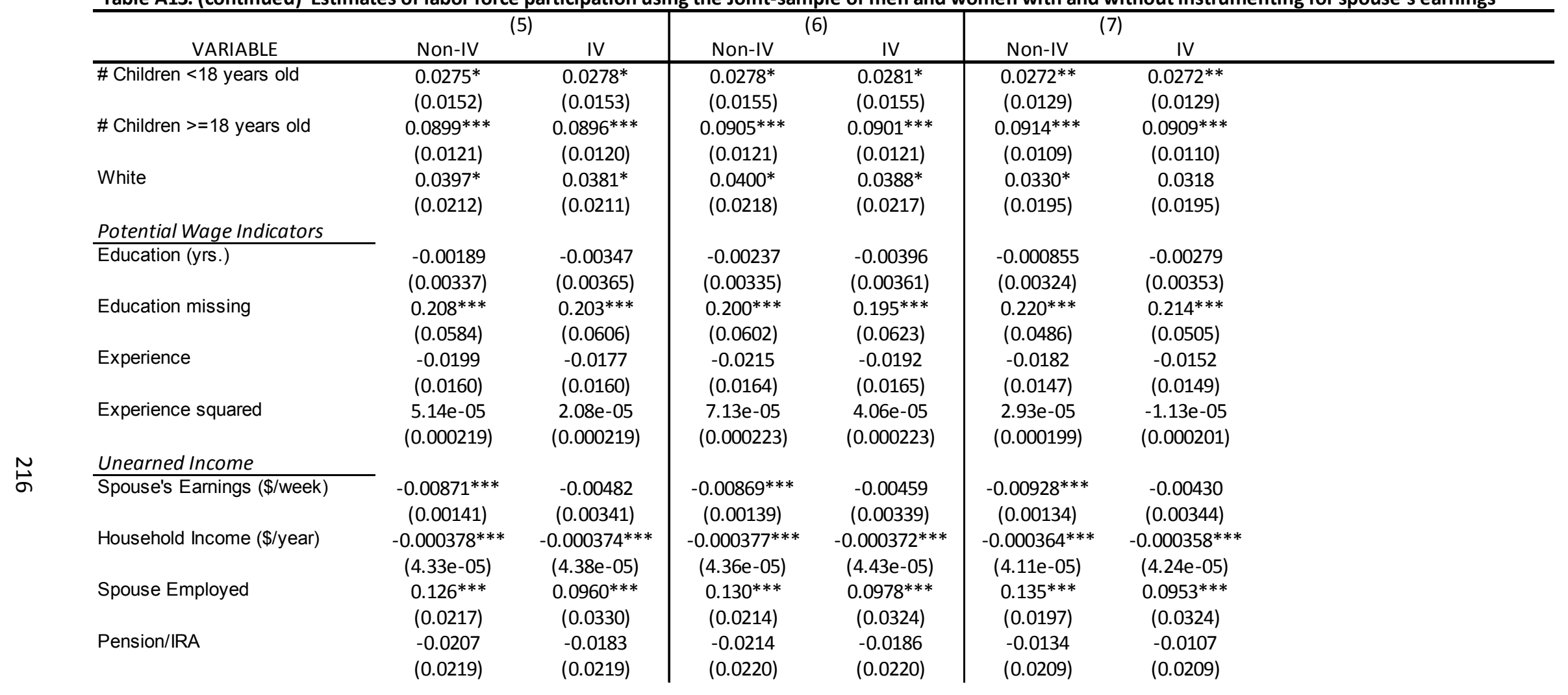


Table A13. (continued) Estimates of labor force participation using the Joint-sample of men and women with and without instrumenting for spouse's earnings

\begin{tabular}{|c|c|c|c|c|c|c|}
\hline \multirow[b]{2}{*}{ VARIABLE } & \multicolumn{2}{|c|}{ (5) } & \multicolumn{2}{|c|}{ (6) } & \multicolumn{2}{|c|}{ (7) } \\
\hline & Non-IV & IV & Non-IV & IV & Non-IV & IV \\
\hline \multicolumn{7}{|c|}{ Control for Region and Time } \\
\hline \multirow[t]{2}{*}{ Midwest Census Region } & $0.0338 *$ & $0.0357^{*}$ & $0.0345^{*}$ & $0.0366^{*}$ & 0.0290 & $0.0316^{*}$ \\
\hline & $(0.0204)$ & $(0.0202)$ & $(0.0204)$ & $(0.0202)$ & $(0.0191)$ & (0.0189) \\
\hline \multirow[t]{2}{*}{ South Census Region } & 0.00233 & 0.00316 & 0.00293 & 0.00381 & -0.00294 & -0.00148 \\
\hline & $(0.0197)$ & $(0.0197)$ & $(0.0195)$ & $(0.0195)$ & $(0.0176)$ & $(0.0176)$ \\
\hline \multirow[t]{2}{*}{ West Census Region } & -0.0264 & -0.0257 & -0.0239 & -0.0232 & -0.0299 & -0.0288 \\
\hline & $(0.0206)$ & $(0.0209)$ & $(0.0203)$ & $(0.0206)$ & $(0.0190)$ & $(0.0193)$ \\
\hline \multirow[t]{2}{*}{ MSA } & 0.0157 & 0.0124 & 0.0158 & 0.0124 & 0.0144 & 0.00987 \\
\hline & $(0.0168)$ & $(0.0172)$ & $(0.0168)$ & $(0.0172)$ & $(0.0161)$ & $(0.0166)$ \\
\hline \multirow{2}{*}{ Panel 6 (2002) } & -0.0181 & -0.0195 & -0.0187 & -0.0195 & 0.000735 & -0.000305 \\
\hline & (0.0337) & $(0.0336)$ & $(0.0341)$ & $(0.0341)$ & $(0.0322)$ & $(0.0323)$ \\
\hline \multirow[t]{2}{*}{ Panel 7 (2003) } & $-0.0539 * *$ & $-0.0530 *$ & $-0.0512^{*}$ & $-0.0499 *$ & -0.0291 & -0.0283 \\
\hline & $(0.0270)$ & $(0.0272)$ & $(0.0275)$ & $(0.0276)$ & $(0.0268)$ & $(0.0267)$ \\
\hline \multirow[t]{2}{*}{ Panel 8 (2004) } & -0.0191 & -0.0203 & -0.0166 & -0.0176 & 0.00511 & 0.00358 \\
\hline & $(0.0246)$ & $(0.0248)$ & $(0.0246)$ & $(0.0248)$ & $(0.0246)$ & $(0.0247)$ \\
\hline \multirow[t]{2}{*}{ Panel 9 (2005) } & -0.0232 & -0.0248 & -0.0232 & -0.0247 & 0.00210 & -0.000282 \\
\hline & $(0.0262)$ & $(0.0265)$ & $(0.0268)$ & $(0.0270)$ & $(0.0269)$ & $(0.0272)$ \\
\hline \multirow[t]{2}{*}{ Panel 10 (2006) } & 0.00202 & 0.000597 & 0.00528 & 0.00394 & 0.0240 & 0.0216 \\
\hline & (0.0293) & $(0.0294)$ & $(0.0296)$ & $(0.0297)$ & $(0.0290)$ & (0.0294) \\
\hline \multirow[t]{2}{*}{ Panel 11 (2007) } & 0.00862 & 0.00584 & 0.0126 & 0.00987 & 0.0218 & 0.0170 \\
\hline & $(0.0254)$ & $(0.0255)$ & $(0.0259)$ & $(0.0260)$ & $(0.0241)$ & $(0.0245)$ \\
\hline
\end{tabular}

Note: Standard errors in parentheses; all tests are two-sided against the null hypothesis that the marginal effect is $=0$; ${ }^{* * *} p<0.01,{ }^{* *} p<0.05, * p<0.1$

Note: Probit regressions with robust standard errors, using MEPS Panels 5 through 7 . Marginal Effects of the probit regression are reported - the coefficients are normalized to represent the derivative of the probability of employment with respect to a change in the explanatory variable. 
Table A14. Estimates of wages using the Joint sample of men and women with and without instrumenting for spouse's earnings

\begin{tabular}{|c|c|c|c|c|c|c|c|c|}
\hline \multirow[b]{2}{*}{ VARIABLE } & \multicolumn{2}{|c|}{ (Work-limit) } & \multicolumn{2}{|c|}{ (SAH Status) } & \multicolumn{2}{|c|}{ (\# of Conditions) } & \multicolumn{2}{|c|}{ (\# of Func. Lim.) } \\
\hline & Non-IV & IV & Non-IV & IV & Non-IV & IV & Non-IV & IV \\
\hline Male & $\begin{array}{c}0.340 * * * \\
(0.0162)\end{array}$ & $\begin{array}{c}0.338 * * * \\
(0.0165)\end{array}$ & $\begin{array}{c}0.354^{* * *} \\
(0.0370)\end{array}$ & $\begin{array}{c}0.352^{* * *} \\
(0.0366)\end{array}$ & $\begin{array}{c}0.340 * * * \\
(0.0212)\end{array}$ & $\begin{array}{c}0.336 * * * \\
(0.0217)\end{array}$ & $\begin{array}{c}0.336 * * * \\
(0.0172)\end{array}$ & $\begin{array}{c}0.333^{* * *} \\
(0.0178)\end{array}$ \\
\hline Work-limit & $\begin{array}{c}-0.245^{* *} \\
(0.0996)\end{array}$ & $\begin{array}{c}-0.221^{* *} \\
(0.100)\end{array}$ & $\begin{array}{l}-- \\
--\end{array}$ & $\begin{array}{l}-- \\
--\end{array}$ & $\begin{array}{l}-- \\
--\end{array}$ & $\begin{array}{l}-- \\
--\end{array}$ & $\begin{array}{l}-- \\
--\end{array}$ & $\begin{array}{l}-- \\
--\end{array}$ \\
\hline Very Good & $\begin{array}{l}-- \\
--\end{array}$ & $\begin{array}{l}-- \\
--\end{array}$ & $\begin{array}{c}0.0122 \\
(0.0359)\end{array}$ & $\begin{array}{c}0.0130 \\
(0.0358)\end{array}$ & $\begin{array}{l}-- \\
--\end{array}$ & $\begin{array}{l}-- \\
--\end{array}$ & $\begin{array}{l}-- \\
--\end{array}$ & $\begin{array}{l}-- \\
--\end{array}$ \\
\hline Good & $\begin{array}{l}-- \\
--\end{array}$ & $\begin{array}{l}-- \\
--\end{array}$ & $\begin{array}{l}0.00706 \\
(0.0349)\end{array}$ & $\begin{array}{l}0.00950 \\
(0.0356)\end{array}$ & $\begin{array}{l}-- \\
--\end{array}$ & $\begin{array}{l}-- \\
--\end{array}$ & $\begin{array}{l}-- \\
--\end{array}$ & $\begin{array}{l}-- \\
--\end{array}$ \\
\hline Fair/Poor & $\begin{array}{l}-- \\
--\end{array}$ & $\begin{array}{l}-- \\
--\end{array}$ & $\begin{array}{c}-0.151^{* * *} \\
(0.0462)\end{array}$ & $\begin{array}{c}-0.133^{* * *} \\
(0.0507)\end{array}$ & $\begin{array}{l}-- \\
--\end{array}$ & $\begin{array}{l}-- \\
--\end{array}$ & -- & $\begin{array}{l}-- \\
--\end{array}$ \\
\hline \# of Conditions & $\begin{array}{l}-- \\
--\end{array}$ & $\begin{array}{l}-- \\
--\end{array}$ & $\begin{array}{l}-- \\
--\end{array}$ & $\begin{array}{l}-- \\
--\end{array}$ & $\begin{array}{l}-0.00685 \\
(0.0145)\end{array}$ & $\begin{array}{l}-0.00186 \\
(0.0153)\end{array}$ & $\begin{array}{l}-- \\
--\end{array}$ & $\begin{array}{l}-- \\
--\end{array}$ \\
\hline \# of Functional Limitations & $\begin{array}{l}-- \\
--\end{array}$ & $\begin{array}{l}-- \\
--\end{array}$ & -- & $\begin{array}{l}-- \\
--\end{array}$ & $\begin{array}{l}-- \\
--\end{array}$ & $\begin{array}{l}-- \\
--\end{array}$ & $\begin{array}{c}-0.0201 * * \\
(0.00952)\end{array}$ & $\begin{array}{c}-0.0169 * \\
(0.00973)\end{array}$ \\
\hline (z-scored) PCS & -- & $\begin{array}{l}-- \\
--\end{array}$ & -- & -- & -- & -- & -- & $\begin{array}{l}-- \\
--\end{array}$ \\
\hline Male * Work-limit & $\begin{array}{l}-0.0247 \\
(0.125)\end{array}$ & $\begin{array}{c}-0.0232 \\
(0.124)\end{array}$ & $\begin{array}{l}-- \\
--\end{array}$ & $\begin{array}{l}-- \\
--\end{array}$ & $\begin{array}{l}-- \\
--\end{array}$ & $\begin{array}{l}-- \\
--\end{array}$ & $\begin{array}{l}-- \\
--\end{array}$ & $\begin{array}{l}-- \\
--\end{array}$ \\
\hline Male * Very Good & $\begin{array}{l}-- \\
--\end{array}$ & $\begin{array}{l}-- \\
--\end{array}$ & $\begin{array}{l}-0.00396 \\
(0.0475)\end{array}$ & $\begin{array}{c}-0.00463 \\
(0.0474)\end{array}$ & $\begin{array}{l}-- \\
--\end{array}$ & $\begin{array}{l}-- \\
--\end{array}$ & $\begin{array}{l}-- \\
--\end{array}$ & $\begin{array}{l}-- \\
--\end{array}$ \\
\hline Male * Good & $\begin{array}{l}-- \\
--\end{array}$ & -- & $\begin{array}{l}-0.0582 \\
(0.0471)\end{array}$ & $\begin{array}{c}-0.0603 \\
(0.0473)\end{array}$ & $\begin{array}{l}-- \\
--\end{array}$ & $\begin{array}{l}-- \\
--\end{array}$ & -- & $\begin{array}{l}-- \\
--\end{array}$ \\
\hline Male * Fair/Poor & $\begin{array}{l}-- \\
--\end{array}$ & $\begin{array}{l}-- \\
--\end{array}$ & $\begin{array}{c}0.0709 \\
(0.0590)\end{array}$ & $\begin{array}{c}0.0665 \\
(0.0595)\end{array}$ & -- & -- & -- & $\begin{array}{l}-- \\
--\end{array}$ \\
\hline Male * \# of Conditions & $\begin{array}{l}-- \\
--\end{array}$ & $\begin{array}{l}-- \\
--\end{array}$ & $\begin{array}{l}-- \\
--\end{array}$ & $\begin{array}{l}-- \\
--\end{array}$ & $\begin{array}{c}-0.000618 \\
(0.0165)\end{array}$ & $\begin{array}{l}-0.00226 \\
(0.0164)\end{array}$ & $\begin{array}{l}-- \\
--\end{array}$ & $\begin{array}{l}-- \\
--\end{array}$ \\
\hline Male * \# of Functional Limitations & $\begin{array}{l}-- \\
--\end{array}$ & $\begin{array}{l}-- \\
--\end{array}$ & -- & $\begin{array}{l}-- \\
--\end{array}$ & $\begin{array}{l}-- \\
--\end{array}$ & $\begin{array}{l}-- \\
--\end{array}$ & $\begin{array}{l}0.00740 \\
(0.0136)\end{array}$ & $\begin{array}{l}0.00798 \\
(0.0134)\end{array}$ \\
\hline
\end{tabular}


Table A14. (continued) Estimates of wages using the Joint sample of men and women with and without instrumenting for spouse's earnings

\begin{tabular}{|c|c|c|c|c|c|c|c|c|}
\hline \multirow[b]{2}{*}{ VARIABLE } & \multicolumn{2}{|c|}{ (Work-limit) } & \multicolumn{2}{|c|}{ (SAH Status) } & \multicolumn{2}{|c|}{ (\# of Conditions) } & \multicolumn{2}{|c|}{ (\# of Func. Lim.) } \\
\hline & Non-IV & IV & Non-IV & IV & Non-IV & IV & Non-IV & IV \\
\hline White & $\begin{array}{c}0.0942^{* * *} \\
(0.0296)\end{array}$ & $\begin{array}{c}0.0937^{* * *} \\
(0.0295)\end{array}$ & $\begin{array}{c}0.0899^{* * *} \\
(0.0299)\end{array}$ & $\begin{array}{c}0.0900 * * * \\
(0.0299)\end{array}$ & $\begin{array}{c}0.0944^{* * *} \\
(0.0298)\end{array}$ & $\begin{array}{c}0.0937^{* * *} \\
(0.0295)\end{array}$ & $\begin{array}{c}0.0948^{* * *} \\
(0.0297)\end{array}$ & $\begin{array}{c}0.0942^{* * *} \\
(0.0295)\end{array}$ \\
\hline Education (yrs.) & $\begin{array}{c}0.0620 * * * \\
(0.00464)\end{array}$ & $\begin{array}{c}0.0624^{* * *} \\
(0.00458)\end{array}$ & $\begin{array}{c}0.0608 * * * \\
(0.00467)\end{array}$ & $\begin{array}{c}0.0615^{* * *} \\
(0.00460)\end{array}$ & $\begin{array}{c}0.0629 * * * \\
(0.00466)\end{array}$ & $\begin{array}{c}0.0634^{* * *} \\
(0.00458)\end{array}$ & $\begin{array}{l}0.0624 * * * \\
(0.00467)\end{array}$ & $\begin{array}{c}0.0629 * * * \\
(0.00460)\end{array}$ \\
\hline Education missing & $\begin{array}{l}0.441 * * * \\
(0.0903)\end{array}$ & $\begin{array}{l}0.431^{* * *} \\
(0.0902)\end{array}$ & $\begin{array}{c}0.426 * * * \\
(0.0898)\end{array}$ & $\begin{array}{l}0.414 * * * \\
(0.0901)\end{array}$ & $\begin{array}{c}0.439 * * * \\
(0.0905)\end{array}$ & $\begin{array}{c}0.420^{* * *} \\
(0.0919)\end{array}$ & $\begin{array}{c}0.438^{* * *} \\
(0.0897)\end{array}$ & $\begin{array}{c}0.425^{* * *} \\
(0.0898)\end{array}$ \\
\hline Experience & $\begin{array}{c}-0.0845^{* * *} \\
(0.0246)\end{array}$ & $\begin{array}{c}-0.0838^{* * *} \\
(0.0246)\end{array}$ & $\begin{array}{c}-0.0837^{* * *} \\
(0.0241)\end{array}$ & $\begin{array}{c}-0.0828 * * * \\
(0.0240)\end{array}$ & $\begin{array}{c}-0.0835^{* * *} \\
(0.0245)\end{array}$ & $\begin{array}{c}-0.0827^{* * *} \\
(0.0246)\end{array}$ & $\begin{array}{c}-0.0848^{* * *} \\
(0.0245)\end{array}$ & $\begin{array}{c}-0.0839 * * * \\
(0.0246)\end{array}$ \\
\hline Experience squared & $\begin{array}{c}0.00103^{* * *} \\
(0.000330)\end{array}$ & $\begin{array}{c}0.00103 * * * \\
(0.000330)\end{array}$ & $\begin{array}{l}0.00102^{* * *} \\
(0.000324)\end{array}$ & $\begin{array}{c}0.00103^{* * *} \\
(0.000326)\end{array}$ & $\begin{array}{c}0.00103^{* * *} \\
(0.000329)\end{array}$ & $\begin{array}{l}0.00104^{* * *} \\
(0.000330)\end{array}$ & $\begin{array}{c}0.00104^{* * *} \\
(0.000329)\end{array}$ & $\begin{array}{c}0.00104^{* * *} \\
(0.000330)\end{array}$ \\
\hline White Collar & $\begin{array}{l}0.246^{* * *} \\
(0.0191)\end{array}$ & $\begin{array}{c}0.247^{* * *} \\
(0.0191)\end{array}$ & $\begin{array}{c}0.245^{* * *} \\
(0.0190)\end{array}$ & $\begin{array}{l}0.246^{* * *} \\
(0.0189)\end{array}$ & $\begin{array}{l}0.248^{* * *} \\
(0.0191)\end{array}$ & $\begin{array}{c}0.249 * * * \\
(0.0191)\end{array}$ & $\begin{array}{c}0.247 * * * \\
(0.0192)\end{array}$ & $\begin{array}{c}0.248^{* * *} \\
(0.0192)\end{array}$ \\
\hline Tenure (yrs.) & $\begin{array}{c}0.0119 * * * \\
(0.000770)\end{array}$ & $\begin{array}{c}0.0119 * * * \\
(0.000770)\end{array}$ & $\begin{array}{l}0.0119 * * * \\
(0.000776)\end{array}$ & $\begin{array}{c}0.0119 * * * \\
(0.000775)\end{array}$ & $\begin{array}{c}0.0119 * * * \\
(0.000768)\end{array}$ & $\begin{array}{l}0.0119 * * * \\
(0.000767)\end{array}$ & $\begin{array}{l}0.0119 * * * \\
(0.000771)\end{array}$ & $\begin{array}{c}0.0119 * * * \\
(0.000770)\end{array}$ \\
\hline$<1 \mathrm{yr}$. Tenure & $\begin{array}{c}0.0404 \\
(0.0564)\end{array}$ & $\begin{array}{c}0.0411 \\
(0.0565)\end{array}$ & $\begin{array}{c}0.0477 \\
(0.0566)\end{array}$ & $\begin{array}{c}0.0480 \\
(0.0567)\end{array}$ & $\begin{array}{c}0.0406 \\
(0.0566)\end{array}$ & $\begin{array}{c}0.0409 \\
(0.0567)\end{array}$ & $\begin{array}{c}0.0406 \\
(0.0564)\end{array}$ & $\begin{array}{c}0.0411 \\
(0.0565)\end{array}$ \\
\hline Tenure missing & $\begin{array}{l}0.0787 \\
(0.117)\end{array}$ & $\begin{array}{r}0.0759 \\
(0.117)\end{array}$ & $\begin{array}{l}0.0688 \\
(0.119)\end{array}$ & $\begin{array}{l}0.0657 \\
(0.119)\end{array}$ & $\begin{array}{r}0.0731 \\
(0.117)\end{array}$ & $\begin{array}{r}0.0706 \\
(0.117)\end{array}$ & $\begin{array}{r}0.0761 \\
(0.117)\end{array}$ & $\begin{array}{l}0.0735 \\
(0.117)\end{array}$ \\
\hline Industry: Ag./Const. & $\begin{array}{l}0.00861 \\
(0.0421)\end{array}$ & $\begin{array}{l}0.00908 \\
(0.0420)\end{array}$ & $\begin{array}{l}0.00543 \\
(0.0420)\end{array}$ & $\begin{array}{l}0.00555 \\
(0.0420)\end{array}$ & $\begin{array}{l}0.00748 \\
(0.0416)\end{array}$ & $\begin{array}{l}0.00739 \\
(0.0415)\end{array}$ & $\begin{array}{l}0.00628 \\
(0.0418)\end{array}$ & $\begin{array}{l}0.00662 \\
(0.0417)\end{array}$ \\
\hline Industry: FIRE & $\begin{array}{c}-0.0722 * \\
(0.0391)\end{array}$ & $\begin{array}{c}-0.0724^{*} \\
(0.0392)\end{array}$ & $\begin{array}{c}-0.0710^{*} \\
(0.0394)\end{array}$ & $\begin{array}{c}-0.0712^{*} \\
(0.0395)\end{array}$ & $\begin{array}{c}-0.0710^{*} \\
(0.0394)\end{array}$ & $\begin{array}{c}-0.0711^{*} \\
(0.0395)\end{array}$ & $\begin{array}{c}-0.0694^{*} \\
(0.0395)\end{array}$ & $\begin{array}{c}-0.0694^{*} \\
(0.0396)\end{array}$ \\
\hline Industry: Sales & $\begin{array}{c}-0.213^{* * *} \\
(0.0326)\end{array}$ & $\begin{array}{c}-0.213^{* * *} \\
(0.0327)\end{array}$ & $\begin{array}{c}-0.212 * * * \\
(0.0329)\end{array}$ & $\begin{array}{c}-0.212^{* * *} \\
(0.0330)\end{array}$ & $\begin{array}{c}-0.212^{* * *} \\
(0.0326)\end{array}$ & $\begin{array}{c}-0.212 * * * \\
(0.0327)\end{array}$ & $\begin{array}{c}-0.213^{* * *} \\
(0.0327)\end{array}$ & $\begin{array}{c}-0.213^{* * *} \\
(0.0328)\end{array}$ \\
\hline Industry: Other & $\begin{array}{c}-0.0630 * * * \\
(0.0239)\end{array}$ & $\begin{array}{c}-0.0627^{* * *} \\
(0.0239)\end{array}$ & $\begin{array}{c}-0.0633^{* * *} \\
(0.0238)\end{array}$ & $\begin{array}{c}-0.0632^{* * *} \\
(0.0238)\end{array}$ & $\begin{array}{c}-0.0628^{* * *} \\
(0.0236)\end{array}$ & $\begin{array}{c}-0.0627^{* * *} \\
(0.0237)\end{array}$ & $\begin{array}{c}-0.0637^{* * *} \\
(0.0237)\end{array}$ & $\begin{array}{c}-0.0634 * * * \\
(0.0238)\end{array}$ \\
\hline Union & $\begin{array}{c}0.0952^{* * *} \\
(0.0208)\end{array}$ & $\begin{array}{c}0.0958^{* * *} \\
(0.0208)\end{array}$ & $\begin{array}{c}0.0951^{* * *} \\
(0.0206)\end{array}$ & $\begin{array}{c}0.0958 * * * \\
(0.0207)\end{array}$ & $\begin{array}{c}0.0957^{* * *} \\
(0.0209)\end{array}$ & $\begin{array}{c}0.0964^{* * *} \\
(0.0209)\end{array}$ & $\begin{array}{c}0.0950 * * * \\
(0.0208)\end{array}$ & $\begin{array}{c}0.0956^{* * *} \\
(0.0209)\end{array}$ \\
\hline
\end{tabular}


Table A14. (continued) Estimates of wages using the Joint sample of men and women with and without instrumenting for spouse's earnings

\begin{tabular}{|c|c|c|c|c|c|c|c|c|}
\hline \multirow[b]{2}{*}{ VARIABLE } & \multicolumn{2}{|c|}{ (Work-limit) } & \multicolumn{2}{|c|}{ (SAH Status) } & \multicolumn{2}{|c|}{ (\# of Conditions) } & \multicolumn{2}{|c|}{ (\# of Func. Lim.) } \\
\hline & Non-IV & IV & Non-IV & IV & Non-IV & IV & Non-IV & IV \\
\hline Midwest Census Region & $\begin{array}{c}-0.0540 * * \\
(0.0270)\end{array}$ & $\begin{array}{c}-0.0550^{* *} \\
(0.0269)\end{array}$ & $\begin{array}{c}-0.0574^{* *} \\
(0.0272)\end{array}$ & $\begin{array}{c}-0.0580^{* *} \\
(0.0271)\end{array}$ & $\begin{array}{c}-0.0554^{* *} \\
(0.0276)\end{array}$ & $\begin{array}{c}-0.0565^{* *} \\
(0.0272)\end{array}$ & $\begin{array}{c}-0.0547^{* *} \\
(0.0275)\end{array}$ & $\begin{array}{c}-0.0556^{* *} \\
(0.0272)\end{array}$ \\
\hline South Census Region & $\begin{array}{c}-0.0571 * * \\
(0.0266)\end{array}$ & $\begin{array}{c}-0.0565^{* *} \\
(0.0266)\end{array}$ & $\begin{array}{c}-0.0552^{* *} \\
(0.0271)\end{array}$ & $\begin{array}{c}-0.0538^{*} \\
(0.0273)\end{array}$ & $\begin{array}{c}-0.0572^{* *} \\
(0.0274)\end{array}$ & $\begin{array}{c}-0.0550^{* *} \\
(0.0278)\end{array}$ & $\begin{array}{c}-0.0558^{* *} \\
(0.0273)\end{array}$ & $\begin{array}{c}-0.0547^{* *} \\
(0.0274)\end{array}$ \\
\hline West Census Region & $\begin{array}{l}-0.0184 \\
(0.0285)\end{array}$ & $\begin{array}{l}-0.0169 \\
(0.0286)\end{array}$ & $\begin{array}{l}-0.0196 \\
(0.0291)\end{array}$ & $\begin{array}{c}-0.0174 \\
(0.0294)\end{array}$ & $\begin{array}{l}-0.0185 \\
(0.0290)\end{array}$ & $\begin{array}{l}-0.0155 \\
(0.0295)\end{array}$ & $\begin{array}{l}-0.0188 \\
(0.0290)\end{array}$ & $\begin{array}{c}-0.0166 \\
(0.0292)\end{array}$ \\
\hline MSA & $\begin{array}{l}0.152 * * * \\
(0.0206)\end{array}$ & $\begin{array}{c}0.151^{* * *} \\
(0.0206)\end{array}$ & $\begin{array}{l}0.152 * * * \\
(0.0205)\end{array}$ & $\begin{array}{c}0.150^{* * *} \\
(0.0204)\end{array}$ & $\begin{array}{c}0.154^{* * *} \\
(0.0209)\end{array}$ & $\begin{array}{c}0.152^{* * *} \\
(0.0207)\end{array}$ & $\begin{array}{c}0.153^{* * *} \\
(0.0211)\end{array}$ & $\begin{array}{c}0.152^{* * *} \\
(0.0210)\end{array}$ \\
\hline Panel 6 (2002) & $\begin{array}{l}0.0971^{* *} \\
(0.0464)\end{array}$ & $\begin{array}{c}0.0981 * * \\
(0.0465)\end{array}$ & $\begin{array}{l}0.0978 * * \\
(0.0470)\end{array}$ & $\begin{array}{l}0.0995^{* *} \\
(0.0474)\end{array}$ & $\begin{array}{l}0.101^{* *} \\
(0.0468)\end{array}$ & $\begin{array}{l}0.102^{* *} \\
(0.0470)\end{array}$ & $\begin{array}{l}0.100 * * \\
(0.0464)\end{array}$ & $\begin{array}{l}0.101^{* *} \\
(0.0466)\end{array}$ \\
\hline Panel 7 (2003) & $\begin{array}{l}0.00213 \\
(0.0410)\end{array}$ & $\begin{array}{l}0.00347 \\
(0.0411)\end{array}$ & $\begin{array}{l}0.00348 \\
(0.0411)\end{array}$ & $\begin{array}{l}0.00512 \\
(0.0412)\end{array}$ & $\begin{array}{l}0.00549 \\
(0.0411)\end{array}$ & $\begin{array}{l}0.00706 \\
(0.0411)\end{array}$ & $\begin{array}{l}0.00538 \\
(0.0410)\end{array}$ & $\begin{array}{l}0.00681 \\
(0.0411)\end{array}$ \\
\hline Panel 8 (2004) & $\begin{array}{l}0.0801^{* *} \\
(0.0360)\end{array}$ & $\begin{array}{l}0.0802 * * \\
(0.0359)\end{array}$ & $\begin{array}{l}0.0796 * * \\
(0.0361)\end{array}$ & $\begin{array}{l}0.0798^{* *} \\
(0.0360)\end{array}$ & $\begin{array}{c}0.0797^{* *} \\
(0.0356)\end{array}$ & $\begin{array}{c}0.0798 * * \\
(0.0354)\end{array}$ & $\begin{array}{c}0.0812^{* *} \\
(0.0360)\end{array}$ & $\begin{array}{l}0.0811^{* *} \\
(0.0358)\end{array}$ \\
\hline Panel 9 (2005) & $\begin{array}{l}0.0932 * * \\
(0.0384)\end{array}$ & $\begin{array}{c}0.0933 * * \\
(0.0385)\end{array}$ & $\begin{array}{l}0.0939 * * \\
(0.0380)\end{array}$ & $\begin{array}{c}0.0941 * * \\
(0.0381)\end{array}$ & $\begin{array}{c}0.0940 * * \\
(0.0381)\end{array}$ & $\begin{array}{c}0.0940 * * \\
(0.0383)\end{array}$ & $\begin{array}{c}0.0946 * * \\
(0.0383)\end{array}$ & $\begin{array}{c}0.0946 * * \\
(0.0384)\end{array}$ \\
\hline Panel 10 (2006) & $\begin{array}{l}0.146 * * * \\
(0.0380)\end{array}$ & $\begin{array}{c}0.145^{* * *} \\
(0.0381)\end{array}$ & $\begin{array}{l}0.147^{* * *} \\
(0.0382)\end{array}$ & $\begin{array}{l}0.146 * * * \\
(0.0383)\end{array}$ & $\begin{array}{c}0.146 * * * \\
(0.0379)\end{array}$ & $\begin{array}{c}0.145^{* * *} \\
(0.0381)\end{array}$ & $\begin{array}{c}0.146 * * * \\
(0.0382)\end{array}$ & $\begin{array}{c}0.145^{* * *} \\
(0.0383)\end{array}$ \\
\hline Panel 11 (2007) & $\begin{array}{l}0.176 * * * \\
(0.0381)\end{array}$ & $\begin{array}{c}0.175^{* * *} \\
(0.0382)\end{array}$ & $\begin{array}{l}0.179 * * * \\
(0.0376)\end{array}$ & $\begin{array}{l}0.178^{* * *} \\
(0.0376)\end{array}$ & $\begin{array}{c}0.178^{* * *} \\
(0.0381)\end{array}$ & $\begin{array}{c}0.177^{* * *} \\
(0.0380)\end{array}$ & $\begin{array}{c}0.179 * * * \\
(0.0382)\end{array}$ & $\begin{array}{c}0.178 * * * \\
(0.0382)\end{array}$ \\
\hline Constant & $\begin{array}{c}2.953^{* * *} \\
(0.458)\end{array}$ & $\begin{array}{c}2.935^{* * *} \\
(0.457)\end{array}$ & $\begin{array}{c}2.961^{* * *} \\
(0.458)\end{array}$ & $\begin{array}{c}2.935^{* * *} \\
(0.456)\end{array}$ & $\begin{array}{c}2.915^{* * *} \\
(0.459)\end{array}$ & $\begin{array}{c}2.894^{* * *} \\
(0.460)\end{array}$ & $\begin{array}{c}2.950 * * * \\
(0.458)\end{array}$ & $\begin{array}{c}2.926 * * * \\
(0.457)\end{array}$ \\
\hline$\rho$ & $\begin{array}{c}0.142 \\
(0.0483)\end{array}$ & $\begin{array}{c}0.090 \\
(0.0629)\end{array}$ & $\begin{array}{c}0.115 \\
(0.0565)\end{array}$ & $\begin{array}{c}0.044 \\
(0.0944)\end{array}$ & $\begin{array}{c}0.099 \\
(0.0576)\end{array}$ & $\begin{array}{c}0.008 \\
(0.1217)\end{array}$ & $\begin{array}{c}0.119 \\
(0.0528)\end{array}$ & $\begin{array}{c}0.048 \\
(0.0851)\end{array}$ \\
\hline$\sigma$ & $\begin{array}{c}0.493 \\
(0.0118)\end{array}$ & $\begin{array}{c}0.492 \\
(0.0118)\end{array}$ & $\begin{array}{c}0.492 \\
(0.0119)\end{array}$ & $\begin{array}{c}0.491 \\
(0.0119)\end{array}$ & $\begin{array}{c}0.493 \\
(0.0118)\end{array}$ & $\begin{array}{c}0.491 \\
(0.0120)\end{array}$ & $\begin{array}{c}0.493 \\
(0.0119)\end{array}$ & $\begin{array}{c}0.492 \\
(0.0119)\end{array}$ \\
\hline$\lambda$ & $\begin{array}{c}0.070 \\
(0.0237)\end{array}$ & $\begin{array}{c}0.044 \\
(0.0308)\end{array}$ & $\begin{array}{c}0.057 \\
(0.0277)\end{array}$ & $\begin{array}{c}0.022 \\
(0.0463)\end{array}$ & $\begin{array}{c}0.049 \\
(0.0283)\end{array}$ & $\begin{array}{c}0.004 \\
(0.0598)\end{array}$ & $\begin{array}{c}0.059 \\
(0.0259)\end{array}$ & $\begin{array}{c}0.024 \\
(0.0418)\end{array}$ \\
\hline
\end{tabular}

Note: Maximum Likelihood estimates of regression models with selection using MEPS (panels 5 through 11). Rho is the correlation between the residuals of the wage and labor force participation equations, sigma is the standard error of the residual in the wage equation, and lambda is the product of rho and sigma. 
Table A15. Estimates of wages using the Joint sample of men and women with and without instrumenting for spouse's earnings

\begin{tabular}{|c|c|c|c|c|c|c|c|c|}
\hline \multirow[b]{2}{*}{ VARIABLE } & \multicolumn{2}{|c|}{ (1) } & \multicolumn{2}{|c|}{ (2) } & \multicolumn{2}{|c|}{ (3) } & \multicolumn{2}{|c|}{ (4) } \\
\hline & Non-IV & IV & Non-IV & IV & Non-IV & IV & Non-IV & IV \\
\hline Male & $\begin{array}{c}0.356 * * * \\
(0.0372)\end{array}$ & $\begin{array}{c}0.354^{* * *} \\
(0.0369)\end{array}$ & $\begin{array}{c}0.338^{* * *} \\
(0.0215)\end{array}$ & $\begin{array}{c}0.335^{* * *} \\
(0.0218)\end{array}$ & $\begin{array}{c}0.340^{* * *} \\
(0.0170)\end{array}$ & $\begin{array}{c}0.337 * * * \\
(0.0176)\end{array}$ & $\begin{array}{c}0.329 * * * \\
(0.0234)\end{array}$ & $\begin{array}{c}0.326 * * * \\
(0.0239)\end{array}$ \\
\hline \multirow[t]{2}{*}{ Work-limit } & $-0.181^{*}$ & $-0.159^{*}$ & -- & -- & -- & -- & -- & -- \\
\hline & $(0.0940)$ & $(0.0947)$ & -- & -- & -- & -- & -- & -- \\
\hline \multirow[t]{2}{*}{ Very Good } & 0.0142 & 0.0145 & -- & -- & -- & -- & -- & -- \\
\hline & $(0.0359)$ & $(0.0357)$ & -- & -- & -- & -- & -- & -- \\
\hline \multirow[t]{2}{*}{ Good } & 0.0105 & 0.0114 & -- & -- & -- & -- & -- & -- \\
\hline & $(0.0347)$ & $(0.0349)$ & -- & -- & -- & -- & -- & -- \\
\hline \multirow[t]{2}{*}{ Fair/Poor } & $-0.120 * * *$ & $-0.114 * * *$ & -- & -- & -- & -- & -- & -- \\
\hline & $(0.0411)$ & $(0.0417)$ & -- & -- & -- & -- & -- & -- \\
\hline \multirow[t]{2}{*}{ \# of Conditions } & -- & -- & -0.00234 & 0.000297 & -- & -- & 0.00459 & 0.00605 \\
\hline & -- & -- & (0.0141) & $(0.0142)$ & -- & -- & $(0.0151)$ & (0.0151) \\
\hline \multirow[t]{2}{*}{ \# of Functional Limitations } & -- & -- & $-0.0194 * *$ & $-0.0165^{*}$ & -- & -- & -0.0164 & -0.0148 \\
\hline & -- & -- & $(0.00942)$ & $(0.00965)$ & -- & -- & $(0.0104)$ & $(0.0105)$ \\
\hline \multirow[t]{2}{*}{ (z-scored) PCS } & -- & -- & -- & -- & $0.0403 * * *$ & $0.0352^{* *}$ & $0.0303^{* *}$ & $0.0269 *$ \\
\hline & -- & -- & -- & -- & $(0.0141)$ & $(0.0144)$ & $(0.0141)$ & $(0.0142)$ \\
\hline \multirow[t]{2}{*}{ Male * Work-limit } & -0.0645 & -0.0610 & -- & -- & -- & -- & -- & -- \\
\hline & $(0.121)$ & $(0.120)$ & -- & -- & -- & -- & -- & -- \\
\hline \multirow[t]{2}{*}{ Male * Very Good } & -0.00556 & -0.00579 & -- & -- & -- & -- & -- & -- \\
\hline & $(0.0476)$ & $(0.0474)$ & -- & -- & -- & -- & -- & -- \\
\hline \multirow[t]{2}{*}{ Male * Good } & -0.0570 & -0.0583 & -- & -- & -- & -- & -- & -- \\
\hline & $(0.0472)$ & $(0.0472)$ & -- & -- & -- & -- & -- & -- \\
\hline \multirow[t]{2}{*}{ Male * Fair/Poor } & 0.0637 & 0.0614 & -- & -- & -- & -- & -- & -- \\
\hline & $(0.0559)$ & $(0.0560)$ & -- & -- & -- & -- & -- & -- \\
\hline \multirow[t]{2}{*}{ Male * \# of Conditions } & -- & -- & -0.00249 & -0.00382 & -- & -- & 0.00153 & 0.000658 \\
\hline & -- & -- & $(0.0165)$ & $(0.0164)$ & -- & -- & $(0.0174)$ & $(0.0173)$ \\
\hline \multirow[t]{2}{*}{ Male ${ }^{*}$ \# of Functional Limitations } & -- & -- & 0.00768 & 0.00852 & -- & -- & $0.0276^{*}$ & $0.0285^{*}$ \\
\hline & -- & -- & $(0.0137)$ & $(0.0135)$ & -- & -- & $(0.0158)$ & $(0.0156)$ \\
\hline \multirow[t]{2}{*}{ Male * (z-scored) PCS } & -- & -- & -- & -- & 0.0191 & 0.0199 & 0.0344 & 0.0354 \\
\hline & -- & -- & -- & -- & $(0.0204)$ & $(0.0204)$ & $(0.0219)$ & $(0.0220)$ \\
\hline
\end{tabular}


Table A15. (continued) Estimates of wages using the Joint sample of men and women with and without instrumenting for spouse's earnings

\begin{tabular}{|c|c|c|c|c|c|c|c|c|}
\hline \multirow[b]{2}{*}{ VARIABLE } & \multicolumn{2}{|c|}{ (1) } & \multicolumn{2}{|c|}{ (2) } & \multicolumn{2}{|c|}{ (3) } & \multicolumn{2}{|c|}{ (4) } \\
\hline & Non-IV & IV & Non-IV & IV & Non-IV & IV & Non-IV & IV \\
\hline White & $\begin{array}{c}0.0907^{* * *} \\
(0.0299)\end{array}$ & $\begin{array}{c}0.0905^{* * * *} \\
(0.0298)\end{array}$ & $\begin{array}{c}0.0948 * * * \\
(0.0297)\end{array}$ & $\begin{array}{c}0.0941^{* * *} \\
(0.0295)\end{array}$ & $\begin{array}{l}0.0794 * * \\
(0.0318)\end{array}$ & $\begin{array}{l}0.0792^{* *} \\
(0.0318)\end{array}$ & $\begin{array}{l}0.0798^{* *} \\
(0.0319)\end{array}$ & $\begin{array}{l}0.0792^{* *} \\
(0.0318)\end{array}$ \\
\hline Education (yrs.) & $\begin{array}{c}0.0606 * * * \\
(0.00464)\end{array}$ & $\begin{array}{l}0.0611^{* * *} \\
(0.00458)\end{array}$ & $\begin{array}{l}0.0625^{* * *} \\
(0.00464)\end{array}$ & $\begin{array}{l}0.0630 * * * \\
(0.00457)\end{array}$ & $\begin{array}{l}0.0588^{* * *} \\
(0.00502)\end{array}$ & $\begin{array}{c}0.0594^{* * *} \\
(0.00495)\end{array}$ & $\begin{array}{l}0.0587^{* * *} \\
(0.00502)\end{array}$ & $\begin{array}{c}0.0592 * * * \\
(0.00494)\end{array}$ \\
\hline Education missing & $\begin{array}{l}0.427 * * * \\
(0.0898)\end{array}$ & $\begin{array}{l}0.419 * * * \\
(0.0898)\end{array}$ & $\begin{array}{l}0.437 * * * \\
(0.0898)\end{array}$ & $\begin{array}{l}0.424 * * * \\
(0.0900)\end{array}$ & $\begin{array}{l}0.375^{* * *} \\
(0.0936)\end{array}$ & $\begin{array}{l}0.367 * * * \\
(0.0937)\end{array}$ & $\begin{array}{l}0.376^{* * *} \\
(0.0935)\end{array}$ & $\begin{array}{l}0.367 * * * \\
(0.0937)\end{array}$ \\
\hline Experience & $\begin{array}{c}-0.0839 * * * \\
(0.0241)\end{array}$ & $\begin{array}{c}-0.0832 * * * \\
(0.0241)\end{array}$ & $\begin{array}{c}-0.0842^{* * *} \\
(0.0244)\end{array}$ & $\begin{array}{c}-0.0834^{* * *} \\
(0.0245)\end{array}$ & $\begin{array}{c}-0.0852^{* * *} \\
(0.0243)\end{array}$ & $\begin{array}{c}-0.0845^{* * *} \\
(0.0244)\end{array}$ & $\begin{array}{c}-0.0856^{* * *} \\
(0.0242)\end{array}$ & $\begin{array}{c}-0.0849 * * * \\
(0.0243)\end{array}$ \\
\hline Experience squared & $\begin{array}{l}0.00102 * * * \\
(0.000324)\end{array}$ & $\begin{array}{l}0.00103 * * * \\
(0.000325)\end{array}$ & $\begin{array}{l}0.00104 * * * \\
(0.000328)\end{array}$ & $\begin{array}{c}0.00104 * * * \\
(0.000329)\end{array}$ & $\begin{array}{l}0.00105^{* * *} \\
(0.000329)\end{array}$ & $\begin{array}{l}0.00106 * * * \\
(0.000331)\end{array}$ & $\begin{array}{l}0.00106 * * * \\
(0.000328)\end{array}$ & $\begin{array}{l}0.00106 * * * \\
(0.000330)\end{array}$ \\
\hline White Collar & $\begin{array}{l}0.244^{* * *} \\
(0.0189)\end{array}$ & $\begin{array}{l}0.245^{* * *} \\
(0.0189)\end{array}$ & $\begin{array}{l}0.247^{* * * *} \\
(0.0192)\end{array}$ & $\begin{array}{l}0.248^{* * *} \\
(0.0191)\end{array}$ & $\begin{array}{l}0.257^{* * * *} \\
(0.0204)\end{array}$ & $\begin{array}{l}0.257^{* * *} \\
(0.0204)\end{array}$ & $\begin{array}{l}0.257^{* * *} \\
(0.0204)\end{array}$ & $\begin{array}{l}0.258^{* * *} \\
(0.0204)\end{array}$ \\
\hline Tenure (yrs.) & $\begin{array}{l}0.0119 * * * \\
(0.000774)\end{array}$ & $\begin{array}{l}0.0119 * * * \\
(0.000773)\end{array}$ & $\begin{array}{l}0.0119 * * * \\
(0.000768)\end{array}$ & $\begin{array}{c}0.0119 * * * \\
(0.000768)\end{array}$ & $\begin{array}{c}0.0127 * * * \\
(0.000792)\end{array}$ & $\begin{array}{l}0.0127^{* * *} \\
(0.000792)\end{array}$ & $\begin{array}{c}0.0128 * * * \\
(0.000794)\end{array}$ & $\begin{array}{c}0.0127^{* * *} \\
(0.000794)\end{array}$ \\
\hline$<1 \mathrm{yr}$. Tenure & $\begin{array}{c}0.0464 \\
(0.0565)\end{array}$ & $\begin{array}{c}0.0472 \\
(0.0566)\end{array}$ & $\begin{array}{c}0.0410 \\
(0.0565)\end{array}$ & $\begin{array}{c}0.0415 \\
(0.0566)\end{array}$ & $\begin{array}{c}0.0529 \\
(0.0566)\end{array}$ & $\begin{array}{c}0.0535 \\
(0.0567)\end{array}$ & $\begin{array}{c}0.0548 \\
(0.0568)\end{array}$ & $\begin{array}{c}0.0554 \\
(0.0568)\end{array}$ \\
\hline Tenure missing & $\begin{array}{l}0.0725 \\
(0.119)\end{array}$ & $\begin{array}{l}0.0695 \\
(0.119)\end{array}$ & $\begin{array}{l}0.0750 \\
(0.117)\end{array}$ & $\begin{array}{l}0.0725 \\
(0.117)\end{array}$ & $\begin{array}{l}0.0909 \\
(0.152)\end{array}$ & $\begin{array}{l}0.0881 \\
(0.152)\end{array}$ & $\begin{array}{l}0.0946 \\
(0.152)\end{array}$ & $\begin{array}{l}0.0922 \\
(0.152)\end{array}$ \\
\hline Industry: Ag./Const. & $\begin{array}{l}0.00642 \\
(0.0422)\end{array}$ & $\begin{array}{l}0.00682 \\
(0.0421)\end{array}$ & $\begin{array}{l}0.00622 \\
(0.0415)\end{array}$ & $\begin{array}{l}0.00639 \\
(0.0415)\end{array}$ & $\begin{array}{c}0.0290 \\
(0.0442)\end{array}$ & $\begin{array}{c}0.0292 \\
(0.0442)\end{array}$ & $\begin{array}{c}0.0312 \\
(0.0438)\end{array}$ & $\begin{array}{c}0.0312 \\
(0.0438)\end{array}$ \\
\hline Industry: FIRE & $\begin{array}{l}-0.0717^{*} \\
(0.0389)\end{array}$ & $\begin{array}{l}-0.0720^{*} \\
(0.0390)\end{array}$ & $\begin{array}{l}-0.0695^{*} \\
(0.0394)\end{array}$ & $\begin{array}{l}-0.0695^{*} \\
(0.0395)\end{array}$ & $\begin{array}{l}-0.0720^{*} \\
(0.0404)\end{array}$ & $\begin{array}{l}-0.0724^{*} \\
(0.0406)\end{array}$ & $\begin{array}{l}-0.0708^{*} \\
(0.0405)\end{array}$ & $\begin{array}{l}-0.0713^{*} \\
(0.0406)\end{array}$ \\
\hline Industry: Sales & $\begin{array}{c}-0.213^{* * *} \\
(0.0327)\end{array}$ & $\begin{array}{l}-0.213^{* * *} \\
(0.0328)\end{array}$ & $\begin{array}{c}-0.213^{* * *} \\
(0.0326)\end{array}$ & $\begin{array}{c}-0.213^{* * *} \\
(0.0327)\end{array}$ & $\begin{array}{c}-0.205^{* * *} \\
(0.0345)\end{array}$ & $\begin{array}{c}-0.205^{* * *} \\
(0.0346)\end{array}$ & $\begin{array}{c}-0.205^{* * *} \\
(0.0342)\end{array}$ & $\begin{array}{c}-0.205^{* * *} \\
(0.0343)\end{array}$ \\
\hline Industry: Other & $\begin{array}{c}-0.0633^{* * * *} \\
(0.0238)\end{array}$ & $\begin{array}{c}-0.0630 * * * \\
(0.0238)\end{array}$ & $\begin{array}{c}-0.0638^{* * *} \\
(0.0235)\end{array}$ & $\begin{array}{c}-0.0635^{* * *} \\
(0.0236)\end{array}$ & $\begin{array}{c}-0.0617^{* *} \\
(0.0261)\end{array}$ & $\begin{array}{c}-0.0616^{* *} \\
(0.0261)\end{array}$ & $\begin{array}{c}-0.0612^{* *} \\
(0.0258)\end{array}$ & $\begin{array}{c}-0.0611^{* *} \\
(0.0259)\end{array}$ \\
\hline Union & $\begin{array}{c}0.0952 * * * \\
(0.0206)\end{array}$ & $\begin{array}{c}0.0958^{* * *} \\
(0.0206)\end{array}$ & $\begin{array}{c}0.0951 * * * \\
(0.0209)\end{array}$ & $\begin{array}{c}0.0957^{* * *} \\
(0.0209)\end{array}$ & $\begin{array}{l}0.100 * * * \\
(0.0232)\end{array}$ & $\begin{array}{l}0.101^{* * *} \\
(0.0233)\end{array}$ & $\begin{array}{c}0.0988 * * * \\
(0.0233)\end{array}$ & $\begin{array}{c}0.0993 * * * \\
(0.0233)\end{array}$ \\
\hline
\end{tabular}


Table A15. (continued) Estimates of wages using the Joint sample of men and women with and without instrumenting for spouse's earnings

\begin{tabular}{|c|c|c|c|c|c|c|c|c|}
\hline \multirow[b]{2}{*}{ VARIABLE } & \multicolumn{2}{|c|}{ (1) } & \multicolumn{2}{|c|}{ (2) } & \multicolumn{2}{|c|}{ (3) } & \multicolumn{2}{|c|}{ (4) } \\
\hline & Non-IV & IV & Non-IV & IV & Non-IV & IV & Non-IV & IV \\
\hline \multirow[t]{2}{*}{ Midwest Census Region } & $-0.0559 * *$ & $-0.0567 * *$ & $-0.0546 * *$ & $-0.0556^{* *}$ & -0.0332 & -0.0341 & -0.0332 & -0.0342 \\
\hline & $(0.0268)$ & $(0.0267)$ & $(0.0275)$ & $(0.0272)$ & $(0.0309)$ & $(0.0307)$ & (0.0309) & $(0.0306)$ \\
\hline \multirow[t]{2}{*}{ South Census Region } & $-0.0551 * *$ & $-0.0546 * *$ & $-0.0555 * *$ & $-0.0544 * *$ & -0.0452 & -0.0445 & -0.0440 & -0.0434 \\
\hline & $(0.0265)$ & $(0.0265)$ & $(0.0273)$ & $(0.0274)$ & $(0.0309)$ & $(0.0310)$ & $(0.0308)$ & $(0.0307)$ \\
\hline \multirow[t]{2}{*}{ West Census Region } & -0.0193 & -0.0178 & -0.0188 & -0.0163 & -0.00213 & -0.000621 & -0.00196 & -0.000194 \\
\hline & $(0.0286)$ & $(0.0288)$ & $(0.0289)$ & $(0.0292)$ & $(0.0326)$ & $(0.0327)$ & $(0.0324)$ & $(0.0326)$ \\
\hline \multirow[t]{2}{*}{ MSA } & $0.151^{* * *}$ & $0.150 * * *$ & $0.153^{* * *}$ & $0.152^{* * *}$ & $0.158^{* * *}$ & $0.157 * * *$ & $0.157 * * *$ & $0.156 * * *$ \\
\hline & $(0.0203)$ & $(0.0203)$ & $(0.0210)$ & $(0.0209)$ & $(0.0210)$ & $(0.0210)$ & $(0.0210)$ & $(0.0209)$ \\
\hline \multirow[t]{2}{*}{ Panel 6 (2002) } & $0.0958 * *$ & $0.0970 * *$ & $0.100 * *$ & $0.101^{* *}$ & 0.0744 & 0.0765 & 0.0735 & 0.0753 \\
\hline & $(0.0466)$ & $(0.0467)$ & $(0.0464)$ & $(0.0466)$ & (0.0499) & (0.0504) & (0.0497) & $(0.0501)$ \\
\hline \multirow[t]{2}{*}{ Panel 7 (2003) } & 0.00120 & 0.00259 & 0.00589 & 0.00711 & -0.0147 & -0.0124 & -0.0161 & -0.0142 \\
\hline & $(0.0410)$ & $(0.0411)$ & $(0.0409)$ & $(0.0410)$ & $(0.0413)$ & (0.0415) & (0.0409) & $(0.0411)$ \\
\hline \multirow[t]{2}{*}{ Panel 8 (2004) } & $0.0804^{* *}$ & $0.0804 * *$ & $0.0816^{* *}$ & $0.0812^{* *}$ & $0.0643^{*}$ & $0.0653^{*}$ & $0.0624^{*}$ & $0.0628 *$ \\
\hline & $(0.0362)$ & $(0.0360)$ & $(0.0356)$ & $(0.0355)$ & $(0.0362)$ & $(0.0361)$ & $(0.0358)$ & $(0.0356)$ \\
\hline \multirow[t]{2}{*}{ Panel 9 (2005) } & $0.0937^{* *}$ & $0.0938 * *$ & $0.0948^{* *}$ & $0.0946 * *$ & $0.0690^{*}$ & 0.0699* & $0.0687^{*}$ & $0.0692^{*}$ \\
\hline & $(0.0380)$ & $(0.0381)$ & $(0.0380)$ & $(0.0382)$ & $(0.0384)$ & (0.0384) & $(0.0380)$ & $(0.0380)$ \\
\hline \multirow[t]{2}{*}{ Panel 10 (2006) } & $0.147^{* * *}$ & $0.146 * * *$ & $0.146 * * *$ & $0.145^{* * *}$ & $0.115^{* * *}$ & $0.116^{* * *}$ & $0.114^{* * *}$ & $0.114^{* * *}$ \\
\hline & $(0.0380)$ & $(0.0380)$ & $(0.0378)$ & $(0.0379)$ & $(0.0387)$ & $(0.0387)$ & $(0.0382)$ & $(0.0382)$ \\
\hline \multirow[t]{2}{*}{ Panel 11 (2007) } & $0.177^{* * *}$ & $0.176 * * *$ & $0.179 * * *$ & $0.178 * * *$ & $0.154^{* * *}$ & $0.153^{* * *}$ & $0.153^{* * *}$ & $0.152^{* * *}$ \\
\hline & $(0.0376)$ & $(0.0376)$ & $(0.0379)$ & $(0.0379)$ & (0.0394) & (0.0393) & $(0.0387)$ & $(0.0386)$ \\
\hline \multirow[t]{2}{*}{ Constant } & $2.968 * * *$ & $2.948 * * *$ & $2.936 * * *$ & $2.915^{* * *}$ & $2.973 * * *$ & $2.955^{* * *}$ & $2.988 * * *$ & $2.968 * * *$ \\
\hline & $(0.458)$ & $(0.457)$ & $(0.457)$ & $(0.457)$ & $(0.457)$ & $(0.457)$ & $(0.457)$ & $(0.456)$ \\
\hline \multirow[t]{2}{*}{$\rho$} & 0.141 & 0.086 & 0.116 & 0.040 & 0.117 & 0.059 & 0.113 & 0.050 \\
\hline & (0.0505) & $(0.0691)$ & $(0.0547)$ & $(0.0925)$ & $(0.0602)$ & (0.0864) & $(0.0606)$ & $(0.0905)$ \\
\hline \multirow[t]{2}{*}{$\sigma$} & 0.492 & 0.491 & 0.493 & 0.491 & 0.489 & 0.488 & 0.489 & 0.487 \\
\hline & (0.0118) & (0.0118) & $(0.0118)$ & (0.0119) & $(0.0121)$ & $(0.0121)$ & $(0.0120)$ & $(0.0121)$ \\
\hline \multirow[t]{2}{*}{$\lambda$} & 0.069 & 0.042 & 0.057 & 0.020 & 0.057 & 0.029 & 0.055 & 0.024 \\
\hline & $(0.0248)$ & (0.0339) & $(0.0269)$ & (0.0454) & $(0.0293)$ & $(0.0421)$ & (0.0294) & $(0.0440)$ \\
\hline
\end{tabular}

Note: Standard errors in parentheses; all tests are two-sided against the null hypothesis that the marginal effect is $=0 ; * * * p<0.01, * * p<0.05, * p<0.1$

Note: Maximum Likelihood estimates of regression models with selection using MEPS (panels 5 through 11). Rho is the correlation between the residuals of the

wage and labor force participation equations, sigma is the standard error of the residual in the wage equation, and lambda is the product of rho and sigma. 
Table A16. Estimates of wages using the Joint sample of men and women with and without instrumenting for spouse's earnings

\begin{tabular}{|c|c|c|c|c|c|c|}
\hline \multirow[b]{2}{*}{ VARIABLE } & \multicolumn{2}{|c|}{ (5) } & \multicolumn{2}{|c|}{$(6)$} & \multicolumn{2}{|c|}{ (7) } \\
\hline & Non-IV & IV & Non-IV & IV & Non-IV & IV \\
\hline Male & $\begin{array}{c}0.341^{* * *} \\
(0.0165)\end{array}$ & $\begin{array}{c}0.339 * * * \\
(0.0168)\end{array}$ & $\begin{array}{c}0.347^{* * *} \\
(0.0432)\end{array}$ & $\begin{array}{c}0.345^{* * *} \\
(0.0429)\end{array}$ & $\begin{array}{c}0.354^{* * *} \\
(0.0379)\end{array}$ & $\begin{array}{c}0.353 * * * \\
(0.0376)\end{array}$ \\
\hline Work-limit & $\begin{array}{l}-0.214^{*} \\
(0.124)\end{array}$ & $\begin{array}{l}-0.193 \\
(0.124)\end{array}$ & $\begin{array}{l}-0.150 \\
(0.124)\end{array}$ & $\begin{array}{l}-0.126 \\
(0.125)\end{array}$ & $\begin{array}{l}-0.171^{*} \\
(0.0942)\end{array}$ & $\begin{array}{c}-0.149 \\
(0.0958)\end{array}$ \\
\hline Very Good & $\begin{array}{l}-- \\
--\end{array}$ & -- & $\begin{array}{c}0.0208 \\
(0.0381)\end{array}$ & $\begin{array}{c}0.0204 \\
(0.0379)\end{array}$ & $\begin{array}{c}0.0132 \\
(0.0362)\end{array}$ & $\begin{array}{c}0.0133 \\
(0.0360)\end{array}$ \\
\hline Good & $\begin{array}{l}-- \\
--\end{array}$ & $\begin{array}{l}-- \\
--\end{array}$ & $\begin{array}{c}0.0361 \\
(0.0369)\end{array}$ & $\begin{array}{c}0.0350 \\
(0.0367)\end{array}$ & $\begin{array}{l}0.00860 \\
(0.0360)\end{array}$ & $\begin{array}{l}0.00884 \\
(0.0361)\end{array}$ \\
\hline Fair/Poor & $\begin{array}{l}-- \\
--\end{array}$ & $\begin{array}{l}-- \\
--\end{array}$ & $\begin{array}{l}-0.0873 * \\
(0.0465)\end{array}$ & $\begin{array}{c}-0.0851^{*} \\
(0.0467)\end{array}$ & $\begin{array}{c}-0.122^{* * *} \\
(0.0418)\end{array}$ & $\begin{array}{c}-0.116^{* * *} \\
(0.0425)\end{array}$ \\
\hline \# of Conditions & $\begin{array}{l}-- \\
--\end{array}$ & $\begin{array}{l}-- \\
--\end{array}$ & $\begin{array}{l}0.00750 \\
(0.0155)\end{array}$ & $\begin{array}{l}0.00845 \\
(0.0154)\end{array}$ & $\begin{array}{l}0.00568 \\
(0.0144)\end{array}$ & $\begin{array}{l}0.00689 \\
(0.0143)\end{array}$ \\
\hline \# of Functional Limitations & $\begin{array}{l}-- \\
--\end{array}$ & $\begin{array}{l}-- \\
--\end{array}$ & $\begin{array}{c}-0.00338 \\
(0.00975)\end{array}$ & $\begin{array}{r}-0.00381 \\
(0.00966)\end{array}$ & $\begin{array}{l}-0.00256 \\
(0.00842)\end{array}$ & $\begin{array}{r}-0.00240 \\
(0.00833)\end{array}$ \\
\hline (z-scored) PCS & $\begin{array}{c}0.0309 * * \\
(0.0133)\end{array}$ & $\begin{array}{c}0.0286^{* *} \\
(0.0132)\end{array}$ & $\begin{array}{c}0.0236 \\
(0.0147)\end{array}$ & $\begin{array}{c}0.0212 \\
(0.0145)\end{array}$ & $\begin{array}{l}-- \\
--\end{array}$ & $\begin{array}{l}-- \\
--\end{array}$ \\
\hline Male * Work-limit & $\begin{array}{l}0.00961 \\
(0.142)\end{array}$ & $\begin{array}{l}0.0117 \\
(0.141)\end{array}$ & $\begin{array}{c}-0.0771 \\
(0.146)\end{array}$ & $\begin{array}{c}-0.0764 \\
(0.146)\end{array}$ & $\begin{array}{l}-0.0883 \\
(0.132)\end{array}$ & $\begin{array}{r}-0.0849 \\
(0.131)\end{array}$ \\
\hline Male * Very Good & $\begin{array}{l}-- \\
--\end{array}$ & $\begin{array}{l}-- \\
--\end{array}$ & $\begin{array}{c}-0.000640 \\
(0.0523)\end{array}$ & $\begin{array}{c}-0.000885 \\
(0.0523)\end{array}$ & $\begin{array}{l}-0.00665 \\
(0.0479)\end{array}$ & $\begin{array}{c}-0.00662 \\
(0.0476)\end{array}$ \\
\hline Male * Good & $\begin{array}{l}-- \\
--\end{array}$ & -- & $\begin{array}{l}-0.0652 \\
(0.0521)\end{array}$ & $\begin{array}{l}-0.0658 \\
(0.0522)\end{array}$ & $\begin{array}{l}-0.0611 \\
(0.0484)\end{array}$ & $\begin{array}{l}-0.0619 \\
(0.0484)\end{array}$ \\
\hline Male * Fair/Poor & $\begin{array}{l}-- \\
--\end{array}$ & $\begin{array}{l}-- \\
--\end{array}$ & $\begin{array}{c}0.0608 \\
(0.0683)\end{array}$ & $\begin{array}{c}0.0612 \\
(0.0685)\end{array}$ & $\begin{array}{c}0.0505 \\
(0.0603)\end{array}$ & $\begin{array}{c}0.0492 \\
(0.0605)\end{array}$ \\
\hline Male ${ }^{*} \#$ of Conditions & $\begin{array}{l}-- \\
--\end{array}$ & $\begin{array}{l}-- \\
--\end{array}$ & $\begin{array}{l}0.00504 \\
(0.0181)\end{array}$ & $\begin{array}{l}0.00410 \\
(0.0181)\end{array}$ & $\begin{array}{l}0.00347 \\
(0.0176)\end{array}$ & $\begin{array}{l}0.00228 \\
(0.0175)\end{array}$ \\
\hline Male * \# of Functional Limitations & -- & -- & $\begin{array}{c}0.0247 \\
(0.0158)\end{array}$ & $\begin{array}{c}0.0255 \\
(0.0157)\end{array}$ & $\begin{array}{l}0.00867 \\
(0.0145)\end{array}$ & $\begin{array}{l}0.00900 \\
(0.0144)\end{array}$ \\
\hline Male * (z-scored) PCS & $\begin{array}{c}0.0166 \\
(0.0201)\end{array}$ & $\begin{array}{c}0.0177 \\
(0.0201)\end{array}$ & $\begin{array}{c}0.0275 \\
(0.0222)\end{array}$ & $\begin{array}{c}0.0289 \\
(0.0223)\end{array}$ & $\begin{array}{l}-- \\
--\end{array}$ & $\begin{array}{l}-- \\
--\end{array}$ \\
\hline
\end{tabular}


Table A16. (continued) Estimates of wages using the Joint sample of men and women with and without instrumenting for spouse's earnings

\begin{tabular}{|c|c|c|c|c|c|c|}
\hline \multirow{2}{*}{ VARIABLE } & \multicolumn{2}{|c|}{ (5) } & \multicolumn{2}{|c|}{ (6) } & \multicolumn{2}{|c|}{ (7) } \\
\hline & Non-IV & IV & Non-IV & IV & Non-IV & IV \\
\hline \multirow[t]{2}{*}{ White } & $0.0804^{* *}$ & $0.0799 * *$ & $0.0784^{* *}$ & $0.0778^{* *}$ & $0.0900 * * *$ & $0.0896^{* * *}$ \\
\hline & $(0.0320)$ & $(0.0319)$ & $(0.0322)$ & $(0.0320)$ & $(0.0298)$ & $(0.0297)$ \\
\hline \multirow[t]{2}{*}{ Education (yrs.) } & $0.0584^{* * *}$ & $0.0589 * * *$ & $0.0575 * * *$ & $0.0581 * * *$ & $0.0604 * * *$ & $0.0609 * * *$ \\
\hline & $(0.00501)$ & $(0.00495)$ & $(0.00505)$ & $(0.00500)$ & $(0.00466)$ & $(0.00460)$ \\
\hline \multirow[t]{2}{*}{ Education missing } & $0.377 * * *$ & $0.370 * * *$ & $0.374 * * *$ & $0.366 * * *$ & $0.426 * * *$ & $0.417^{* * *}$ \\
\hline & $(0.0935)$ & $(0.0933)$ & $(0.0932)$ & $(0.0932)$ & $(0.0898)$ & $(0.0898)$ \\
\hline \multirow[t]{2}{*}{ Experience } & $-0.0859 * * *$ & $-0.0851 * * *$ & $-0.0862 * * *$ & $-0.0853 * * *$ & $-0.0848 * * *$ & $-0.0841 * * *$ \\
\hline & $(0.0244)$ & $(0.0245)$ & $(0.0242)$ & $(0.0242)$ & $(0.0242)$ & $(0.0242)$ \\
\hline \multirow[t]{2}{*}{ Experience squared } & $0.00106 * * *$ & $0.00106^{* * *}$ & $0.00106 * * *$ & $0.00106 * * *$ & $0.00103 * * *$ & $0.00104 * * *$ \\
\hline & $(0.000331)$ & $(0.000332)$ & $(0.000327)$ & (0.000329) & $(0.000325)$ & (0.000326) \\
\hline \multirow[t]{2}{*}{ White Collar } & $0.256 * * *$ & $0.257^{* * *}$ & $0.255^{* * *}$ & $0.256 * * *$ & $0.244 * * *$ & $0.245^{* * *}$ \\
\hline & $(0.0204)$ & $(0.0204)$ & $(0.0202)$ & $(0.0202)$ & $(0.0189)$ & (0.0188) \\
\hline \multirow{2}{*}{ Tenure (yrs.) } & $0.0127 * * *$ & $0.0127^{* * *}$ & $0.0128^{* * *}$ & $0.0128 * * *$ & $0.0119 * * *$ & $0.0119 * * *$ \\
\hline & $(0.000792)$ & $(0.000792)$ & $(0.000795)$ & $(0.000795)$ & $(0.000774)$ & (0.000774) \\
\hline \multirow[t]{2}{*}{$<1 \mathrm{yr}$. Tenure } & 0.0531 & 0.0538 & 0.0585 & 0.0592 & 0.0478 & 0.0486 \\
\hline & $(0.0565)$ & $(0.0565)$ & $(0.0571)$ & $(0.0571)$ & $(0.0567)$ & $(0.0567)$ \\
\hline \multirow[t]{2}{*}{ Tenure missing } & 0.0963 & 0.0935 & 0.101 & 0.0977 & 0.0714 & 0.0686 \\
\hline & $(0.152)$ & (0.153) & (0.154) & (0.154) & (0.119) & (0.119) \\
\hline \multirow[t]{2}{*}{ Industry: Ag./Const. } & 0.0291 & 0.0293 & 0.0309 & 0.0307 & 0.00873 & 0.00901 \\
\hline & $(0.0443)$ & $(0.0443)$ & $(0.0442)$ & $(0.0442)$ & $(0.0421)$ & $(0.0420)$ \\
\hline \multirow[t]{2}{*}{ Industry: FIRE } & $-0.0723^{*}$ & $-0.0730^{*}$ & $-0.0720 *$ & $-0.0729^{*}$ & $-0.0712^{*}$ & $-0.0715^{*}$ \\
\hline & $(0.0401)$ & $(0.0402)$ & $(0.0402)$ & $(0.0403)$ & $(0.0390)$ & $(0.0391)$ \\
\hline \multirow[t]{2}{*}{ Industry: Sales } & $-0.205^{* * *}$ & $-0.206 * * *$ & $-0.204^{* * *}$ & $-0.205^{* * *}$ & $-0.212^{* * *}$ & $-0.212^{* * *}$ \\
\hline & $(0.0342)$ & $(0.0343)$ & $(0.0343)$ & $(0.0344)$ & $(0.0325)$ & $(0.0326)$ \\
\hline \multirow[t]{2}{*}{ Industry: Other } & $-0.0619 * *$ & $-0.0618^{* *}$ & $-0.0608 * *$ & $-0.0608 * *$ & $-0.0625^{* * *}$ & $-0.0622 * * *$ \\
\hline & $(0.0260)$ & $(0.0261)$ & $(0.0260)$ & $(0.0260)$ & $(0.0237)$ & $(0.0238)$ \\
\hline \multirow[t]{2}{*}{ Union } & $0.0997^{* * *}$ & $0.100 * * *$ & $0.0980 * * *$ & $0.0985^{* * *}$ & $0.0943 * * *$ & $0.0949 * * *$ \\
\hline & $(0.0231)$ & $(0.0231)$ & $(0.0228)$ & $(0.0229)$ & $(0.0205)$ & $(0.0205)$ \\
\hline
\end{tabular}


Table A16. (continued) Estimates of wages using the Joint sample of men and women with and without instrumenting for spouse's earnings

\begin{tabular}{|c|c|c|c|c|c|c|}
\hline \multirow[b]{2}{*}{ VARIABLE } & \multicolumn{2}{|c|}{ (5) } & \multicolumn{2}{|c|}{ (6) } & \multicolumn{2}{|c|}{ (7) } \\
\hline & Non-IV & IV & Non-IV & IV & Non-IV & IV \\
\hline \multirow[t]{2}{*}{ Midwest Census Region } & -0.0312 & -0.0323 & -0.0331 & -0.0343 & $-0.0561 * *$ & $-0.0570 * *$ \\
\hline & $(0.0308)$ & $(0.0306)$ & (0.0306) & (0.0304) & $(0.0269)$ & $(0.0268)$ \\
\hline \multirow[t]{2}{*}{ South Census Region } & -0.0442 & -0.0441 & -0.0434 & -0.0431 & $-0.0548 * *$ & $-0.0542 * *$ \\
\hline & $(0.0305)$ & $(0.0305)$ & (0.0299) & (0.0299) & $(0.0264)$ & $(0.0264)$ \\
\hline \multirow[t]{2}{*}{ West Census Region } & -0.00117 & -0.000128 & -0.00156 & -0.000192 & -0.0188 & -0.0171 \\
\hline & $(0.0324)$ & $(0.0325)$ & $(0.0321)$ & $(0.0322)$ & $(0.0286)$ & $(0.0288)$ \\
\hline \multirow[t]{2}{*}{ MSA } & $0.157^{* * *}$ & $0.156^{* * *}$ & $0.157^{* * *}$ & $0.156^{* * *}$ & $0.151^{* * *}$ & $0.150 * * *$ \\
\hline & $(0.0209)$ & $(0.0208)$ & $(0.0206)$ & $(0.0206)$ & $(0.0203)$ & $(0.0202)$ \\
\hline \multirow[t]{2}{*}{ Panel 6 (2002) } & 0.0733 & 0.0750 & 0.0712 & 0.0731 & $0.0942 * *$ & $0.0954^{* *}$ \\
\hline & $(0.0498)$ & $(0.0501)$ & $(0.0503)$ & $(0.0507)$ & $(0.0463)$ & $(0.0465)$ \\
\hline \multirow[t]{2}{*}{ Panel 7 (2003) } & -0.0159 & -0.0141 & -0.0195 & -0.0175 & -0.000268 & 0.00105 \\
\hline & $(0.0412)$ & (0.0414) & (0.0410) & $(0.0412)$ & $(0.0408)$ & (0.0408) \\
\hline \multirow[t]{2}{*}{ Panel 8 (2004) } & $0.0650 *$ & $0.0656^{*}$ & $0.0606^{*}$ & $0.0611^{*}$ & $0.0779 * *$ & $0.0777^{* *}$ \\
\hline & $(0.0365)$ & $(0.0364)$ & $(0.0362)$ & $(0.0360)$ & (0.0356) & $(0.0355)$ \\
\hline \multirow[t]{2}{*}{ Panel 9 (2005) } & $0.0703^{*}$ & $0.0708^{*}$ & $0.0683^{*}$ & $0.0689^{*}$ & $0.0923 * *$ & $0.0923^{* *}$ \\
\hline & $(0.0384)$ & $(0.0384)$ & $(0.0382)$ & $(0.0382)$ & (0.0377) & $(0.0378)$ \\
\hline \multirow[t]{2}{*}{ Panel 10 (2006) } & $0.116^{* * *}$ & $0.116^{* * *}$ & $0.113^{* * *}$ & $0.113^{* * *}$ & $0.145^{* * *}$ & $0.144^{* * *}$ \\
\hline & $(0.0385)$ & $(0.0385)$ & $(0.0380)$ & $(0.0380)$ & $(0.0375)$ & $(0.0376)$ \\
\hline \multirow[t]{2}{*}{ Panel 11 (2007) } & $0.154^{* * *}$ & $0.153^{* * *}$ & $0.153^{* * *}$ & $0.152^{* * *}$ & $0.176 * * *$ & $0.175^{* * *}$ \\
\hline & $(0.0392)$ & (0.0392) & $(0.0382)$ & $(0.0381)$ & $(0.0372)$ & $(0.0372)$ \\
\hline \multirow[t]{2}{*}{ Constant } & $2.999 * * *$ & $2.979 * * *$ & $3.015^{* * *}$ & $2.991 * * *$ & $2.989 * * *$ & $2.968 * * *$ \\
\hline & $(0.459)$ & $(0.458)$ & $(0.461)$ & $(0.460)$ & $(0.461)$ & $(0.460)$ \\
\hline \multirow[t]{2}{*}{$\rho$} & 0.139 & 0.091 & 0.118 & 0.059 & 0.133 & 0.074 \\
\hline & $(0.0540)$ & $(0.0675)$ & $(0.0577)$ & $(0.0813)$ & $(0.0512)$ & $(0.0727)$ \\
\hline \multirow[t]{2}{*}{$\sigma$} & 0.489 & 0.488 & 0.488 & 0.487 & 0.492 & 0.491 \\
\hline & $(0.0120)$ & $(0.0120)$ & (0.0119) & $(0.0120)$ & $(0.0118)$ & $(0.0118)$ \\
\hline \multirow[t]{2}{*}{$\lambda$} & 0.068 & 0.044 & 0.057 & 0.029 & 0.066 & 0.036 \\
\hline & $(0.0262)$ & $(0.0328)$ & (0.0279) & (0.0394) & (0.0251) & $(0.0356)$ \\
\hline
\end{tabular}

Note: Standard errors in parentheses; all tests are two-sided against the null hypothesis that the marginal effect is $=0 ; \quad * * * p<0.01, * * p<0.05, * p<0.1$

Note: Maximum Likelihood estimates of regression models with selection using MEPS (panels 5 through 11). Rho is the correlation between the residuals of the

wage and labor force participation equations, sigma is the standard error of the residual in the wage equation, and lambda is the product of rho and sigma. 
Table A17. Estimates of hours of work using the Joint sample of men and women with and without instrumenting for spouse's earnings

\begin{tabular}{|c|c|c|c|c|c|c|c|c|}
\hline \multirow[b]{2}{*}{ VARIABLE } & \multicolumn{2}{|c|}{ (Work-limit) } & \multicolumn{2}{|c|}{ (SAH Status) } & \multicolumn{2}{|c|}{ (\# of Conditions) } & \multicolumn{2}{|c|}{ (\# of Func. Lim.) } \\
\hline & Non-IV & IV & Non-IV & IV & Non-IV & IV & Non-IV & IV \\
\hline Male & $\begin{array}{c}5.470 * * * \\
(0.417)\end{array}$ & $\begin{array}{c}5.074 * * * \\
(0.494)\end{array}$ & $\begin{array}{c}5.949 * * * \\
(0.837)\end{array}$ & $\begin{array}{c}5.493 * * * \\
(0.857)\end{array}$ & $\begin{array}{c}5.491 * * * \\
(0.614)\end{array}$ & $\begin{array}{c}5.077 * * * \\
(0.665)\end{array}$ & $\begin{array}{c}5.478^{* * *} \\
(0.424)\end{array}$ & $\begin{array}{c}5.076^{* * *} \\
(0.503)\end{array}$ \\
\hline Spouse Work-limit & $\begin{array}{r}0.0180 \\
(0.820)\end{array}$ & $\begin{array}{c}-0.184 \\
(0.817)\end{array}$ & $\begin{array}{l}-- \\
--\end{array}$ & $\begin{array}{l}-- \\
--\end{array}$ & $\begin{array}{l}-- \\
--\end{array}$ & $\begin{array}{l}-- \\
--\end{array}$ & $\begin{array}{l}-- \\
--\end{array}$ & $\begin{array}{l}-- \\
--\end{array}$ \\
\hline Spouse Very Good & -- & $\begin{array}{l}-- \\
--\end{array}$ & $\begin{array}{l}-0.380 \\
(0.689)\end{array}$ & $\begin{array}{c}-0.447 \\
(0.676)\end{array}$ & $\begin{array}{l}-- \\
--\end{array}$ & -- & $\begin{array}{l}-- \\
--\end{array}$ & $\begin{array}{l}-- \\
--\end{array}$ \\
\hline Spouse Good & -- & $\begin{array}{l}-- \\
--\end{array}$ & $\begin{array}{c}0.274 \\
(0.601)\end{array}$ & $\begin{array}{c}0.105 \\
(0.605)\end{array}$ & $\begin{array}{l}-- \\
--\end{array}$ & -- & $\begin{array}{l}-- \\
--\end{array}$ & $\begin{array}{l}-- \\
--\end{array}$ \\
\hline Spouse Fair/Poor & $\begin{array}{l}-- \\
--\end{array}$ & $\begin{array}{l}-- \\
--\end{array}$ & $\begin{array}{l}0.0393 \\
(0.764)\end{array}$ & $\begin{array}{r}-0.195 \\
(0.772)\end{array}$ & $\begin{array}{l}-- \\
--\end{array}$ & $\begin{array}{l}-- \\
--\end{array}$ & $\begin{array}{l}-- \\
--\end{array}$ & $\begin{array}{l}-- \\
--\end{array}$ \\
\hline Spouse \# of Conditions & -- & $\begin{array}{l}-- \\
--\end{array}$ & -- & $\begin{array}{l}-- \\
--\end{array}$ & $\begin{array}{c}0.233 \\
(0.219)\end{array}$ & $\begin{array}{c}0.209 \\
(0.221)\end{array}$ & -- & -- \\
\hline Spouse \# of Func. Limits & $\begin{array}{l}-- \\
--\end{array}$ & $\begin{array}{l}-- \\
--\end{array}$ & $\begin{array}{l}-- \\
--\end{array}$ & $\begin{array}{l}-- \\
--\end{array}$ & $\begin{array}{l}-- \\
--\end{array}$ & $\begin{array}{l}-- \\
--\end{array}$ & $\begin{array}{l}0.0478 \\
(0.136)\end{array}$ & $\begin{array}{l}0.0239 \\
(0.135)\end{array}$ \\
\hline Spouse (z-scored) PCS & $\begin{array}{l}-- \\
--\end{array}$ & $\begin{array}{l}-- \\
--\end{array}$ & -- & $\begin{array}{l}-- \\
--\end{array}$ & $\begin{array}{l}-- \\
--\end{array}$ & $\begin{array}{l}-- \\
--\end{array}$ & $\begin{array}{l}-- \\
--\end{array}$ & $\begin{array}{l}-- \\
--\end{array}$ \\
\hline Male * Spouse Work-limit & $\begin{array}{c}0.909 \\
(1.413)\end{array}$ & $\begin{array}{c}1.142 \\
(1.409)\end{array}$ & $\begin{array}{l}-- \\
--\end{array}$ & $\begin{array}{l}-- \\
--\end{array}$ & -- & $\begin{array}{l}-- \\
--\end{array}$ & -- & -- \\
\hline Male * Spouse Very Good & $\begin{array}{l}-- \\
--\end{array}$ & $\begin{array}{l}-- \\
--\end{array}$ & $\begin{array}{l}-0.505 \\
(0.974)\end{array}$ & $\begin{array}{r}-0.471 \\
(0.968)\end{array}$ & $\begin{array}{l}-- \\
--\end{array}$ & $\begin{array}{l}-- \\
--\end{array}$ & $\begin{array}{l}-- \\
--\end{array}$ & $\begin{array}{l}-- \\
--\end{array}$ \\
\hline Male * Spouse Good & -- & -- & $\begin{array}{c}-1.929 * * \\
(0.879)\end{array}$ & $\begin{array}{c}-1.799 * * \\
(0.880)\end{array}$ & -- & $\begin{array}{l}-- \\
--\end{array}$ & -- & $\begin{array}{l}-- \\
--\end{array}$ \\
\hline Male * Spouse Fair/Poor & $\begin{array}{l}-- \\
--\end{array}$ & $\begin{array}{l}-- \\
--\end{array}$ & $\begin{array}{c}0.148 \\
(1.147)\end{array}$ & $\begin{array}{c}0.335 \\
(1.158)\end{array}$ & $\begin{array}{l}-- \\
--\end{array}$ & $\begin{array}{l}-- \\
--\end{array}$ & $\begin{array}{l}-- \\
--\end{array}$ & $\begin{array}{l}-- \\
--\end{array}$ \\
\hline Male * Spouse \# of Conditions & -- & $\begin{array}{l}-- \\
--\end{array}$ & $\begin{array}{l}-- \\
--\end{array}$ & $\begin{array}{l}-- \\
--\end{array}$ & $\begin{array}{l}-0.0159 \\
(0.323)\end{array}$ & $\begin{array}{l}0.0165 \\
(0.324)\end{array}$ & $\begin{array}{l}-- \\
--\end{array}$ & $\begin{array}{l}-- \\
--\end{array}$ \\
\hline Male * Spouse \# of Func. Limits & $\begin{array}{l}-- \\
--\end{array}$ & $\begin{array}{l}-- \\
--\end{array}$ & $\begin{array}{l}-- \\
--\end{array}$ & $\begin{array}{l}-- \\
--\end{array}$ & $\begin{array}{l}-- \\
--\end{array}$ & $\begin{array}{l}-- \\
--\end{array}$ & $\begin{array}{c}0.167 \\
(0.249)\end{array}$ & $\begin{array}{c}0.197 \\
(0.250)\end{array}$ \\
\hline Male * Spouse (z-scored) PCS & -- & $\begin{array}{l}-- \\
--\end{array}$ & $\begin{array}{l}-- \\
--\end{array}$ & $\begin{array}{l}-- \\
--\end{array}$ & $\begin{array}{l}-- \\
--\end{array}$ & $\begin{array}{l}-- \\
--\end{array}$ & $\begin{array}{l}-- \\
--\end{array}$ & $\begin{array}{l}-- \\
--\end{array}$ \\
\hline
\end{tabular}


Table A17. (continued) Estimates of hours of work using the Joint sample of men and women with and without instrumenting for spouse's earnings

\begin{tabular}{|c|c|c|c|c|c|c|c|c|}
\hline \multirow[b]{2}{*}{ VARIABLE } & \multicolumn{2}{|c|}{ (Work-limit) } & \multicolumn{2}{|c|}{ (SAH Status) } & \multicolumn{2}{|c|}{ (\# of Conditions) } & \multicolumn{2}{|c|}{ (\# of Func. Lim.) } \\
\hline & Non-IV & IV & Non-IV & IV & Non-IV & IV & Non-IV & IV \\
\hline \multirow[t]{2}{*}{ Work-limit } & -0.0403 & 0.125 & -- & -- & -- & -- & -- & -- \\
\hline & $(1.821)$ & $(1.818)$ & -- & -- & -- & -- & -- & -- \\
\hline \multirow[t]{2}{*}{ Very Good } & -- & -- & -0.640 & -0.601 & -- & -- & -- & -- \\
\hline & -- & -- & $(0.602)$ & $(0.604)$ & -- & -- & -- & -- \\
\hline \multirow[t]{2}{*}{ Good } & -- & -- & 0.156 & 0.118 & -- & -- & -- & -- \\
\hline & -- & -- & $(0.616)$ & $(0.622)$ & -- & -- & -- & -- \\
\hline \multirow[t]{2}{*}{ Fair/Poor } & -- & -- & -0.770 & -0.661 & -- & -- & -- & -- \\
\hline & -- & -- & $(0.976)$ & $(0.979)$ & -- & -- & -- & -- \\
\hline \multirow[t]{2}{*}{ \# of Conditions } & -- & -- & -- & -- & -0.141 & -0.135 & -- & -- \\
\hline & -- & -- & -- & -- & $(0.281)$ & $(0.282)$ & -- & -- \\
\hline \multirow[t]{2}{*}{ \# of Functional Limitations } & -- & -- & -- & -- & -- & -- & 0.147 & 0.152 \\
\hline & -- & -- & -- & -- & -- & -- & $(0.158)$ & $(0.160)$ \\
\hline \multirow{2}{*}{ (z-scored) PCS } & -- & -- & -- & -- & -- & -- & -- & -- \\
\hline & -- & -- & -- & -- & -- & -- & -- & -- \\
\hline \multirow[t]{2}{*}{ Male * Work-limit } & 1.020 & 1.106 & -- & -- & -- & -- & -- & -- \\
\hline & $(2.724)$ & $(2.727)$ & -- & -- & -- & -- & -- & -- \\
\hline \multirow[t]{2}{*}{ Male * Very Good } & -- & -- & 1.169 & 1.114 & -- & -- & -- & -- \\
\hline & -- & -- & $(0.853)$ & $(0.865)$ & -- & -- & -- & -- \\
\hline \multirow[t]{2}{*}{ Male * Good } & -- & -- & -0.321 & -0.283 & -- & -- & -- & -- \\
\hline & -- & -- & $(0.850)$ & $(0.863)$ & -- & -- & -- & -- \\
\hline \multirow[t]{2}{*}{ Male * Fair/Poor } & -- & -- & 1.203 & 1.150 & -- & -- & -- & -- \\
\hline & -- & -- & $(1.373)$ & $(1.372)$ & -- & -- & -- & -- \\
\hline \multirow[t]{2}{*}{ Male ${ }^{*}$ \# of Conditions } & -- & -- & -- & -- & 0.164 & 0.169 & -- & -- \\
\hline & -- & -- & -- & -- & $(0.410)$ & $(0.411)$ & -- & -- \\
\hline \multirow[t]{2}{*}{ Male * \# of Functional Limitations } & -- & -- & -- & -- & -- & -- & 0.0330 & 0.0531 \\
\hline & -- & -- & -- & -- & -- & -- & $(0.299)$ & $(0.300)$ \\
\hline \multirow[t]{2}{*}{ Male * (z-scored) PCS } & -- & -- & -- & -- & -- & -- & -- & -- \\
\hline & -- & -- & -- & -- & -- & -- & -- & -- \\
\hline
\end{tabular}


Table A17. (continued) Estimates of hours of work using the Joint sample of men and women with and without instrumenting for spouse's earnings

\begin{tabular}{|c|c|c|c|c|c|c|c|c|}
\hline \multirow[b]{2}{*}{ VARIABLE } & \multicolumn{2}{|c|}{ (Work-limit) } & \multicolumn{2}{|c|}{ (SAH Status) } & \multicolumn{2}{|c|}{ (\# of Conditions) } & \multicolumn{2}{|c|}{ (\# of Func. Lim.) } \\
\hline & Non-IV & IV & Non-IV & IV & Non-IV & IV & Non-IV & IV \\
\hline \# Children <18 years old & $\begin{array}{c}-0.232 \\
(0.210)\end{array}$ & $\begin{array}{l}-0.240 \\
(0.213)\end{array}$ & $\begin{array}{l}-0.243 \\
(0.214)\end{array}$ & $\begin{array}{l}-0.250 \\
(0.217)\end{array}$ & $\begin{array}{l}-0.213 \\
(0.217)\end{array}$ & $\begin{array}{l}-0.217 \\
(0.220)\end{array}$ & $\begin{array}{c}-0.228 \\
(0.209)\end{array}$ & $\begin{array}{l}-0.235 \\
(0.213)\end{array}$ \\
\hline \multirow[t]{2}{*}{ \# Children $>=18$ years old } & 0.184 & 0.155 & 0.193 & 0.169 & 0.182 & 0.157 & 0.174 & 0.147 \\
\hline & (0.219) & $(0.221)$ & $(0.223)$ & $(0.225)$ & $(0.218)$ & $(0.220)$ & $(0.216)$ & $(0.218)$ \\
\hline \multirow[t]{2}{*}{ White } & 0.681 & 0.657 & 0.670 & 0.636 & $0.686^{*}$ & 0.662 & 0.679 & 0.654 \\
\hline & $(0.417)$ & $(0.417)$ & $(0.430)$ & $(0.429)$ & $(0.415)$ & $(0.415)$ & $(0.420)$ & $(0.420)$ \\
\hline \multicolumn{9}{|l|}{ Potential Wage Indicators } \\
\hline \multirow[t]{2}{*}{ Individual's Predicted Wage } & 0.283 & 0.611 & 0.185 & 0.514 & 0.244 & 0.580 & 0.257 & 0.591 \\
\hline & $(0.566)$ & $(0.586)$ & $(0.578)$ & $(0.592)$ & $(0.564)$ & $(0.585)$ & $(0.566)$ & $(0.586)$ \\
\hline \multirow[t]{2}{*}{ Union } & $-2.283 * * *$ & $-2.285^{* * *}$ & $-2.215^{* * *}$ & $-2.217^{* * *}$ & $-2.294 * * *$ & $-2.297 * * *$ & $-2.291 * * *$ & $-2.294 * * *$ \\
\hline & $(0.364)$ & $(0.365)$ & $(0.365)$ & $(0.367)$ & $(0.369)$ & $(0.370)$ & $(0.365)$ & $(0.367)$ \\
\hline \multirow[t]{2}{*}{ Retirement/Pension Plan } & $2.604 * * *$ & $2.630 * * *$ & $2.596 * * *$ & $2.628 * * *$ & $2.617^{* * *}$ & $2.646^{* * *}$ & $2.629 * * *$ & $2.656 * * *$ \\
\hline & $(0.389)$ & $(0.391)$ & $(0.391)$ & $(0.393)$ & $(0.389)$ & $(0.391)$ & $(0.389)$ & $(0.391)$ \\
\hline \multirow[t]{2}{*}{ Holds ESI } & $3.306 * * *$ & $3.194 * * *$ & $3.333^{* * *}$ & $3.214^{* * *}$ & $3.299 * * *$ & $3.183^{* * *}$ & $3.307^{* * *}$ & $3.192 * * *$ \\
\hline & $(0.406)$ & $(0.400)$ & $(0.407)$ & $(0.400)$ & $(0.401)$ & $(0.396)$ & $(0.404)$ & $(0.398)$ \\
\hline \multirow[t]{2}{*}{ Choice of Insurance Plans } & 0.399 & 0.407 & 0.403 & 0.414 & 0.418 & 0.429 & 0.411 & 0.420 \\
\hline & $(0.343)$ & $(0.345)$ & $(0.346)$ & $(0.347)$ & $(0.342)$ & $(0.343)$ & $(0.343)$ & $(0.345)$ \\
\hline \multirow[t]{2}{*}{ Paid Sick Leave } & $2.821 * * *$ & $2.815^{* * *}$ & $2.778^{* * *}$ & $2.769 * * *$ & $2.799 * * *$ & $2.793 * * *$ & $2.801^{* * *}$ & $2.795^{* * *}$ \\
\hline & $(0.451)$ & $(0.452)$ & $(0.460)$ & $(0.461)$ & $(0.453)$ & $(0.454)$ & $(0.453)$ & $(0.454)$ \\
\hline \multicolumn{9}{|l|}{ Unearned Income } \\
\hline \multirow[t]{2}{*}{ Spouse's Earnings ( $\$ 100 /$ week) } & 0.0680 & -0.0284 & 0.0706 & -0.0320 & 0.0666 & -0.0331 & 0.0701 & -0.0288 \\
\hline & $(0.0441)$ & $(0.0774)$ & $(0.0445)$ & $(0.0776)$ & $(0.0441)$ & $(0.0773)$ & $(0.0443)$ & $(0.0774)$ \\
\hline \multirow[t]{2}{*}{ Household Income (\$100/year) } & -0.00204 & -0.00203 & -0.00207 & -0.00209 & -0.00213 & -0.00214 & -0.00191 & -0.00191 \\
\hline & $(0.00142)$ & $(0.00144)$ & $(0.00143)$ & $(0.00144)$ & $(0.00142)$ & $(0.00144)$ & $(0.00143)$ & $(0.00145)$ \\
\hline \multirow[t]{2}{*}{ Spouse Employed } & $-1.874 * * *$ & -1.168 & $-1.861 * * *$ & -1.106 & $-1.834 * * *$ & -1.082 & $-1.844 * * *$ & -1.108 \\
\hline & $(0.495)$ & $(0.724)$ & $(0.496)$ & $(0.719)$ & (0.505) & $(0.724)$ & $(0.481)$ & $(0.717)$ \\
\hline
\end{tabular}


Table A17. (continued) Estimates of hours of work using the Joint sample of men and women with and without instrumenting for spouse's earnings

\begin{tabular}{|c|c|c|c|c|c|c|c|c|}
\hline \multirow[b]{2}{*}{ VARIABLE } & \multicolumn{2}{|c|}{ (Work-limit) } & \multicolumn{2}{|c|}{$\overline{\text { (SAH Status) }}$} & \multicolumn{2}{|c|}{ (\# of Conditions) } & \multicolumn{2}{|c|}{ (\# of Func. Lim.) } \\
\hline & Non-IV & IV & Non-IV & IV & Non-IV & IV & Non-IV & IV \\
\hline \multicolumn{9}{|l|}{ Yearly Dummies } \\
\hline \multirow[t]{2}{*}{ Panel 6 (2002) } & 1.127 & 1.119 & 1.119 & 1.097 & 1.122 & 1.110 & 1.115 & 1.104 \\
\hline & $(0.770)$ & $(0.775)$ & (0.777) & $(0.781)$ & $(0.769)$ & $(0.773)$ & $(0.776)$ & $(0.781)$ \\
\hline \multirow[t]{2}{*}{ Panel 7 (2003) } & -0.492 & -0.494 & -0.499 & -0.507 & -0.504 & -0.510 & -0.516 & -0.520 \\
\hline & $(0.681)$ & $(0.684)$ & (0.672) & $(0.674)$ & (0.681) & $(0.684)$ & (0.690) & $(0.693)$ \\
\hline \multirow[t]{2}{*}{ Panel 8 (2004) } & 0.382 & 0.394 & 0.420 & 0.431 & 0.389 & 0.401 & 0.343 & 0.355 \\
\hline & $(0.672)$ & $(0.673)$ & (0.677) & $(0.677)$ & $(0.673)$ & (0.674) & $(0.680)$ & $(0.681)$ \\
\hline \multirow[t]{2}{*}{ Panel 9 (2005) } & -0.244 & -0.232 & -0.212 & -0.204 & -0.216 & -0.203 & -0.272 & -0.258 \\
\hline & $(0.678)$ & $(0.680)$ & $(0.662)$ & $(0.664)$ & $(0.684)$ & $(0.687)$ & $(0.683)$ & $(0.686)$ \\
\hline \multirow[t]{2}{*}{ Panel 10 (2006) } & 0.287 & 0.273 & 0.303 & 0.291 & 0.303 & 0.289 & 0.276 & 0.262 \\
\hline & $(0.732)$ & $(0.738)$ & $(0.726)$ & $(0.732)$ & $(0.734)$ & $(0.740)$ & (0.739) & $(0.746)$ \\
\hline \multirow{2}{*}{ Panel 11 (2007) } & -0.545 & -0.512 & -0.527 & -0.495 & -0.559 & -0.527 & -0.574 & -0.542 \\
\hline & $(0.630)$ & (0.639) & (0.625) & $(0.632)$ & $(0.636)$ & (0.644) & $(0.637)$ & $(0.646)$ \\
\hline \multirow[t]{2}{*}{ Constant } & $32.33^{* * *}$ & $31.92 * * *$ & $32.75^{* * *}$ & $32.42 * * *$ & $32.26 * * *$ & $31.79 * * *$ & $32.39 * * *$ & $31.94 * * *$ \\
\hline & $(1.382)$ & $(1.441)$ & (1.508) & $(1.536)$ & (1.394) & $(1.444)$ & (1.389) & $(1.453)$ \\
\hline \multirow[t]{2}{*}{$\rho$} & -0.142 & -0.168 & -0.123 & -0.144 & -0.129 & -0.149 & -0.156 & -0.178 \\
\hline & $(0.0368)$ & $(0.0362)$ & $(0.0358)$ & (0.0359) & $(0.0343)$ & $(0.0340)$ & $(0.0353)$ & (0.0349) \\
\hline \multirow[t]{2}{*}{$\sigma$} & 9.395 & 9.417 & 9.362 & 9.380 & 9.387 & 9.404 & 9.404 & 9.426 \\
\hline & $(0.2416)$ & $(0.2435)$ & $(0.2433)$ & $(0.2452)$ & $(0.2442)$ & $(0.2460)$ & $(0.2405)$ & $(0.2422)$ \\
\hline \multirow[t]{2}{*}{$\lambda$} & -1.337 & -1.579 & -1.151 & -1.352 & -1.209 & -1.403 & -1.466 & -1.682 \\
\hline & $(0.3518)$ & $(0.3487)$ & $(0.3403)$ & $(0.3437)$ & $(0.3296)$ & $(0.3289)$ & (0.3389) & $(0.3379)$ \\
\hline
\end{tabular}

Note: Standard errors in parentheses; all tests are two-sided against the null hypothesis that the marginal effect is $=0 ; \quad * * * p<0.01, * * p<0.05,{ }^{*} p<0.1$

Note: Maximum Likelihood estimates of regression models with selection using MEPS (panels 5 through 11). Rho is the correlation between the residuals of the wage and labor force participation equations, sigma is the standard error of the residual in the wage equation, and lambda is the product of rho and sigma. 
Table A18. Estimates of hours of work using the Joint sample of men and women with and without instrumenting for spouse's earnings

\begin{tabular}{|c|c|c|c|c|c|c|c|c|}
\hline \multirow[b]{2}{*}{ VARIABLE } & \multicolumn{2}{|c|}{ (1) } & \multicolumn{2}{|c|}{$(2)$} & \multicolumn{2}{|c|}{ (3) } & \multicolumn{2}{|c|}{ (4) } \\
\hline & Non-IV & IV & Non-IV & IV & Non-IV & IV & Non-IV & IV \\
\hline Male & $\begin{array}{c}5.928 * * * \\
(0.841)\end{array}$ & $\begin{array}{c}5.471^{* * *} \\
(0.859)\end{array}$ & $\begin{array}{c}5.488 * * * \\
(0.614)\end{array}$ & $\begin{array}{c}5.080^{* * *} \\
(0.665)\end{array}$ & $\begin{array}{c}5.680 * * * \\
(0.442)\end{array}$ & $\begin{array}{c}5.359 * * * \\
(0.507)\end{array}$ & $\begin{array}{c}5.165^{* * *} \\
(0.764)\end{array}$ & $\begin{array}{c}4.860^{* * *} \\
(0.784)\end{array}$ \\
\hline Spouse Work-limit & $\begin{array}{c}0.0174 \\
(0.952)\end{array}$ & $\begin{array}{c}-0.129 \\
(0.949)\end{array}$ & $\begin{array}{l}-- \\
--\end{array}$ & -- & -- & -- & -- & -- \\
\hline Spouse Very Good & $\begin{array}{c}-0.372 \\
(0.685)\end{array}$ & $\begin{array}{c}-0.432 \\
(0.671)\end{array}$ & $\begin{array}{l}-- \\
--\end{array}$ & $\begin{array}{l}-- \\
--\end{array}$ & $\begin{array}{l}-- \\
--\end{array}$ & $\begin{array}{l}-- \\
--\end{array}$ & -- & -- \\
\hline Spouse Good & $\begin{array}{c}0.280 \\
(0.592)\end{array}$ & $\begin{array}{c}0.122 \\
(0.597)\end{array}$ & -- & -- & -- & $\begin{array}{l}-- \\
--\end{array}$ & -- & $\begin{array}{l}-- \\
--\end{array}$ \\
\hline Spouse Fair/Poor & $\begin{array}{l}0.0549 \\
(0.802)\end{array}$ & $\begin{array}{c}-0.124 \\
(0.812)\end{array}$ & $\begin{array}{l}-- \\
--\end{array}$ & $\begin{array}{l}-- \\
--\end{array}$ & $\begin{array}{l}-- \\
--\end{array}$ & $\begin{array}{l}-- \\
--\end{array}$ & $\begin{array}{l}-- \\
--\end{array}$ & $\begin{array}{l}-- \\
--\end{array}$ \\
\hline Spouse \# of Conditions & $\begin{array}{l}-- \\
--\end{array}$ & -- & $\begin{array}{c}0.228 \\
(0.238)\end{array}$ & $\begin{array}{c}0.216 \\
(0.238)\end{array}$ & -- & $\begin{array}{l}-- \\
--\end{array}$ & $\begin{array}{c}0.118 \\
(0.279)\end{array}$ & $\begin{array}{c}0.121 \\
(0.278)\end{array}$ \\
\hline Spouse \# of Func. Limits & -- & $\begin{array}{l}-- \\
--\end{array}$ & $\begin{array}{c}0.00417 \\
(0.148)\end{array}$ & $\begin{array}{c}-0.0172 \\
(0.147)\end{array}$ & $\begin{array}{l}-- \\
--\end{array}$ & $\begin{array}{l}-- \\
--\end{array}$ & $\begin{array}{l}0.0207 \\
(0.167)\end{array}$ & $\begin{array}{l}0.0238 \\
(0.167)\end{array}$ \\
\hline Spouse (z-scored) PCS & -- & -- & -- & -- & $\begin{array}{c}-0.0927 \\
(0.242)\end{array}$ & $\begin{array}{c}-0.0141 \\
(0.244)\end{array}$ & $\begin{array}{c}-0.0482 \\
(0.291)\end{array}$ & $\begin{array}{c}0.0337 \\
(0.292)\end{array}$ \\
\hline Male * Spouse Work-limit & $\begin{array}{c}0.634 \\
(1.517)\end{array}$ & $\begin{array}{c}0.835 \\
(1.504)\end{array}$ & -- & $\begin{array}{l}-- \\
--\end{array}$ & $\begin{array}{l}-- \\
--\end{array}$ & $\begin{array}{l}-- \\
--\end{array}$ & $\begin{array}{l}-- \\
--\end{array}$ & $\begin{array}{l}-- \\
--\end{array}$ \\
\hline Male * Spouse Very Good & $\begin{array}{r}-0.523 \\
(0.970)\end{array}$ & $\begin{array}{r}-0.500 \\
(0.964)\end{array}$ & -- & -- & $\begin{array}{l}-- \\
--\end{array}$ & -- & $\begin{array}{l}-- \\
--\end{array}$ & $\begin{array}{l}-- \\
--\end{array}$ \\
\hline Male * Spouse Good & $\begin{array}{c}-1.962^{* *} \\
(0.875)\end{array}$ & $\begin{array}{c}-1.848^{* *} \\
(0.876)\end{array}$ & -- & -- & -- & -- & $\begin{array}{l}-- \\
--\end{array}$ & $\begin{array}{l}-- \\
--\end{array}$ \\
\hline Male * Spouse Fair/Poor & $\begin{array}{l}-0.0819 \\
(1.165)\end{array}$ & $\begin{array}{r}0.0218 \\
(1.170)\end{array}$ & $\begin{array}{l}-- \\
--\end{array}$ & $\begin{array}{l}-- \\
--\end{array}$ & $\begin{array}{l}-- \\
--\end{array}$ & $\begin{array}{l}-- \\
--\end{array}$ & $\begin{array}{l}-- \\
--\end{array}$ & $\begin{array}{l}-- \\
--\end{array}$ \\
\hline Male * Spouse \# of Conditions & $\begin{array}{l}-- \\
--\end{array}$ & $\begin{array}{l}-- \\
--\end{array}$ & $\begin{array}{c}-0.124 \\
(0.335)\end{array}$ & $\begin{array}{r}-0.108 \\
(0.335)\end{array}$ & $\begin{array}{l}-- \\
--\end{array}$ & $\begin{array}{l}-- \\
--\end{array}$ & $\begin{array}{l}0.0824 \\
(0.373)\end{array}$ & $\begin{array}{l}0.0847 \\
(0.373)\end{array}$ \\
\hline Male * Spouse \# of Func. Limits & $\begin{array}{l}-- \\
--\end{array}$ & $\begin{array}{l}-- \\
--\end{array}$ & $\begin{array}{c}0.199 \\
(0.255)\end{array}$ & $\begin{array}{c}0.224 \\
(0.256)\end{array}$ & -- & $\begin{array}{l}-- \\
--\end{array}$ & $\begin{array}{c}0.243 \\
(0.314)\end{array}$ & $\begin{array}{c}0.244 \\
(0.314)\end{array}$ \\
\hline Male * Spouse (z-scored) PCS & $\begin{array}{l}-- \\
--\end{array}$ & $\begin{array}{l}-- \\
--\end{array}$ & $\begin{array}{l}-- \\
--\end{array}$ & $\begin{array}{l}-- \\
--\end{array}$ & $\begin{array}{r}-0.0595 \\
(0.317)\end{array}$ & $\begin{array}{l}-0.131 \\
(0.323)\end{array}$ & $\begin{array}{c}0.215 \\
(0.391)\end{array}$ & $\begin{array}{c}0.146 \\
(0.396)\end{array}$ \\
\hline
\end{tabular}


Table A18. (continued) Estimates of hours of work using the Joint sample of men and women with and without instrumenting for spouse's earnings

\begin{tabular}{|c|c|c|c|c|c|c|c|c|}
\hline \multirow[b]{2}{*}{ VARIABLE } & \multicolumn{2}{|c|}{ (1) } & \multicolumn{2}{|c|}{ (2) } & \multicolumn{2}{|c|}{ (3) } & \multicolumn{2}{|c|}{ (4) } \\
\hline & Non-IV & IV & Non-IV & IV & Non-IV & IV & Non-IV & IV \\
\hline \multirow[t]{2}{*}{ Work-limit } & 0.0953 & 0.222 & -- & -- & -- & -- & -- & $\overline{--}$ \\
\hline & (1.829) & $(1.822)$ & -- & -- & -- & -- & -- & -- \\
\hline \multirow[t]{2}{*}{ Very Good } & -0.647 & -0.610 & -- & -- & -- & -- & -- & -- \\
\hline & $(0.603)$ & $(0.605)$ & -- & -- & -- & -- & -- & -- \\
\hline \multirow[t]{2}{*}{ Good } & 0.131 & 0.0884 & -- & -- & -- & -- & -- & -- \\
\hline & $(0.622)$ & $(0.628)$ & -- & -- & -- & -- & -- & -- \\
\hline \multirow[t]{2}{*}{ Fair/Poor } & -0.941 & -0.857 & -- & -- & -- & -- & -- & -- \\
\hline & $(0.966)$ & $(0.965)$ & -- & -- & -- & -- & -- & -- \\
\hline \multirow[t]{2}{*}{ \# of Conditions } & -- & -- & -0.183 & -0.177 & -- & -- & -0.215 & -0.200 \\
\hline & -- & -- & $(0.277)$ & $(0.278)$ & -- & -- & $(0.306)$ & $(0.306)$ \\
\hline \multirow[t]{2}{*}{ \# of Functional Limitations } & -- & -- & 0.144 & 0.147 & -- & -- & 0.116 & 0.119 \\
\hline & -- & -- & $(0.153)$ & $(0.154)$ & -- & -- & $(0.181)$ & $(0.182)$ \\
\hline \multirow[t]{2}{*}{ (z-scored) PCS } & -- & -- & -- & -- & -0.0473 & -0.0568 & 0.00439 & -0.000488 \\
\hline & -- & -- & -- & -- & $(0.264)$ & $(0.267)$ & $(0.289)$ & $(0.290)$ \\
\hline \multirow[t]{2}{*}{ Male * Work-limit } & 0.662 & 0.760 & -- & -- & -- & -- & -- & -- \\
\hline & $(2.627)$ & $(2.625)$ & -- & -- & -- & -- & -- & -- \\
\hline \multirow[t]{2}{*}{ Male * Very Good } & 1.173 & 1.121 & -- & -- & -- & -- & -- & -- \\
\hline & $(0.854)$ & $(0.866)$ & -- & -- & -- & -- & -- & -- \\
\hline \multirow[t]{2}{*}{ Male * Good } & -0.319 & -0.280 & -- & -- & -- & -- & -- & -- \\
\hline & $(0.861)$ & $(0.874)$ & -- & -- & -- & -- & -- & -- \\
\hline \multirow[t]{2}{*}{ Male * Fair/Poor } & 1.159 & 1.097 & -- & -- & -- & -- & -- & -- \\
\hline & (1.314) & (1.309) & -- & -- & -- & -- & -- & -- \\
\hline \multirow[t]{2}{*}{ Male ${ }^{*}$ \# of Conditions } & -- & -- & 0.142 & 0.139 & -- & -- & 0.236 & 0.221 \\
\hline & -- & -- & $(0.407)$ & $(0.408)$ & -- & -- & $(0.454)$ & $(0.456)$ \\
\hline \multirow[t]{2}{*}{ Male * \# of Functional Limitations } & -- & -- & 0.0260 & 0.0459 & -- & -- & 0.389 & 0.398 \\
\hline & -- & -- & $(0.302)$ & $(0.303)$ & -- & -- & $(0.328)$ & $(0.328)$ \\
\hline \multirow[t]{2}{*}{ Male * (z-scored) PCS } & -- & -- & -- & -- & 0.499 & 0.470 & 0.726 & 0.702 \\
\hline & -- & -- & -- & -- & $(0.437)$ & $(0.436)$ & $(0.489)$ & $(0.489)$ \\
\hline
\end{tabular}


Table A18. (continued) Estimates of hours of work using the Joint sample of men and women with and without instrumenting for spouse's earnings

\begin{tabular}{|c|c|c|c|c|c|c|c|c|}
\hline \multirow[b]{2}{*}{ VARIABLE } & \multicolumn{2}{|c|}{ (1) } & \multicolumn{2}{|c|}{ (2) } & \multicolumn{2}{|c|}{ (3) } & \multicolumn{2}{|c|}{ (4) } \\
\hline & Non-IV & IV & Non-IV & IV & Non-IV & IV & Non-IV & IV \\
\hline \# Children $<18$ years old & $\begin{array}{c}-0.223 \\
(0.211)\end{array}$ & $\begin{array}{r}-0.231 \\
(0.214)\end{array}$ & $\begin{array}{l}-0.205 \\
(0.216)\end{array}$ & $\begin{array}{l}-0.210 \\
(0.219)\end{array}$ & $\begin{array}{l}-0.218 \\
(0.225)\end{array}$ & $\begin{array}{l}-0.229 \\
(0.228)\end{array}$ & $\begin{array}{l}-0.169 \\
(0.228)\end{array}$ & $\begin{array}{c}-0.179 \\
(0.231)\end{array}$ \\
\hline \# Children $>=18$ years old & $\begin{array}{c}0.209 \\
(0.221)\end{array}$ & $\begin{array}{c}0.183 \\
(0.223)\end{array}$ & $\begin{array}{c}0.185 \\
(0.215)\end{array}$ & $\begin{array}{c}0.159 \\
(0.217)\end{array}$ & $\begin{array}{c}0.184 \\
(0.244)\end{array}$ & $\begin{array}{c}0.164 \\
(0.246)\end{array}$ & $\begin{array}{c}0.207 \\
(0.234)\end{array}$ & $\begin{array}{c}0.185 \\
(0.237)\end{array}$ \\
\hline White & $\begin{array}{c}0.659 \\
(0.430)\end{array}$ & $\begin{array}{c}0.626 \\
(0.430)\end{array}$ & $\begin{array}{c}0.689 \\
(0.419)\end{array}$ & $\begin{array}{c}0.664 \\
(0.419)\end{array}$ & $\begin{array}{l}0.754^{*} \\
(0.456)\end{array}$ & $\begin{array}{c}0.744 \\
(0.457)\end{array}$ & $\begin{array}{c}0.709 \\
(0.455)\end{array}$ & $\begin{array}{c}0.696 \\
(0.456)\end{array}$ \\
\hline Potential Wage Indicators & & & & & & & & \\
\hline Individual's Predicted Wage & $\begin{array}{c}0.207 \\
(0.577)\end{array}$ & $\begin{array}{c}0.536 \\
(0.589)\end{array}$ & $\begin{array}{c}0.274 \\
(0.563)\end{array}$ & $\begin{array}{c}0.606 \\
(0.582)\end{array}$ & $\begin{array}{c}0.209 \\
(0.622)\end{array}$ & $\begin{array}{c}0.484 \\
(0.636)\end{array}$ & $\begin{array}{c}0.207 \\
(0.611)\end{array}$ & $\begin{array}{c}0.469 \\
(0.626)\end{array}$ \\
\hline Union & $\begin{array}{c}-2.213^{* * *} \\
(0.364)\end{array}$ & $\begin{array}{c}-2.214^{* * *} \\
(0.365)\end{array}$ & $\begin{array}{c}-2.291^{* * *} \\
(0.366)\end{array}$ & $\begin{array}{c}-2.295^{* * *} \\
(0.368)\end{array}$ & $\begin{array}{c}-2.451^{* * *} \\
(0.391)\end{array}$ & $\begin{array}{c}-2.454^{* * *} \\
(0.393)\end{array}$ & $\begin{array}{c}-2.465^{* * *} \\
(0.390)\end{array}$ & $\begin{array}{c}-2.468^{* * *} \\
(0.393)\end{array}$ \\
\hline Retirement/Pension Plan & $\begin{array}{c}2.586^{* * *} \\
(0.392)\end{array}$ & $\begin{array}{c}2.616^{* * *} \\
(0.394)\end{array}$ & $\begin{array}{c}2.623^{* * *} \\
(0.390)\end{array}$ & $\begin{array}{c}2.650^{* * *} \\
(0.392)\end{array}$ & $\begin{array}{c}2.683^{* * *} \\
(0.435)\end{array}$ & $\begin{array}{c}2.710^{* * *} \\
(0.438)\end{array}$ & $\begin{array}{c}2.727^{* * *} \\
(0.436)\end{array}$ & $\begin{array}{c}2.754^{* * *} \\
(0.440)\end{array}$ \\
\hline Holds ESI & $\begin{array}{c}3.325^{* * *} \\
(0.407)\end{array}$ & $\begin{array}{c}3.207^{* * *} \\
(0.400)\end{array}$ & $\begin{array}{c}3.294^{* * *} \\
(0.399)\end{array}$ & $\begin{array}{c}3.181^{* * * *} \\
(0.394)\end{array}$ & $\begin{array}{c}3.489 * * * \\
(0.427)\end{array}$ & $\begin{array}{c}3.391 * * * \\
(0.417)\end{array}$ & $\begin{array}{c}3.453^{* * *} \\
(0.423)\end{array}$ & $\begin{array}{c}3.358^{* * *} \\
(0.413)\end{array}$ \\
\hline Choice of Insurance Plans & $\begin{array}{c}0.396 \\
(0.346)\end{array}$ & $\begin{array}{c}0.405 \\
(0.348)\end{array}$ & $\begin{array}{c}0.425 \\
(0.343)\end{array}$ & $\begin{array}{c}0.435 \\
(0.344)\end{array}$ & $\begin{array}{c}0.269 \\
(0.372)\end{array}$ & $\begin{array}{c}0.275 \\
(0.373)\end{array}$ & $\begin{array}{c}0.273 \\
(0.372)\end{array}$ & $\begin{array}{c}0.279 \\
(0.373)\end{array}$ \\
\hline $\begin{array}{l}\text { Paid Sick Leave } \\
\text { Unearned Income }\end{array}$ & $\begin{array}{c}2.800 * * * \\
(0.458)\end{array}$ & $\begin{array}{c}2.793 * * * \\
(0.459)\end{array}$ & $\begin{array}{c}2.808 * * * \\
(0.453)\end{array}$ & $\begin{array}{c}2.801^{* * *} \\
(0.454)\end{array}$ & $\begin{array}{c}2.752^{* * *} \\
(0.492)\end{array}$ & $\begin{array}{c}2.748^{* * *} \\
(0.492)\end{array}$ & $\begin{array}{c}2.769 * * * \\
(0.488)\end{array}$ & $\begin{array}{c}2.766 * * * \\
(0.488)\end{array}$ \\
\hline Spouse's Earnings (\$100/week) & $\begin{array}{c}0.0705 \\
(0.0443)\end{array}$ & $\begin{array}{l}-0.0316 \\
(0.0775)\end{array}$ & $\begin{array}{c}0.0690 \\
(0.0442)\end{array}$ & $\begin{array}{l}-0.0291 \\
(0.0773)\end{array}$ & $\begin{array}{c}0.0571 \\
(0.0487)\end{array}$ & $\begin{array}{l}-0.0299 \\
(0.0810)\end{array}$ & $\begin{array}{c}0.0561 \\
(0.0487)\end{array}$ & $\begin{array}{c}-0.0283 \\
(0.0806)\end{array}$ \\
\hline Household Income (\$100/year) & $\begin{array}{c}-0.00211 \\
(0.00143)\end{array}$ & $\begin{array}{c}-0.00211 \\
(0.00144)\end{array}$ & $\begin{array}{c}-0.00200 \\
(0.00143)\end{array}$ & $\begin{array}{l}-0.00200 \\
(0.00144)\end{array}$ & $\begin{array}{c}-0.00219 \\
(0.00163)\end{array}$ & $\begin{array}{c}-0.00219 \\
(0.00165)\end{array}$ & $\begin{array}{r}-0.00220 \\
(0.00163)\end{array}$ & $\begin{array}{c}-0.00219 \\
(0.00165)\end{array}$ \\
\hline Spouse Employed & $\begin{array}{c}-1.829 * * * \\
(0.495)\end{array}$ & $\begin{array}{r}-1.090 \\
(0.719)\end{array}$ & $\begin{array}{c}-1.780 * * * \\
(0.486)\end{array}$ & $\begin{array}{r}-1.050 \\
(0.715)\end{array}$ & $\begin{array}{c}-1.791^{* * *} \\
(0.525)\end{array}$ & $\begin{array}{l}-1.169 \\
(0.752)\end{array}$ & $\begin{array}{c}-1.676^{* * *} \\
(0.506)\end{array}$ & $\begin{array}{c}-1.073 \\
(0.732)\end{array}$ \\
\hline
\end{tabular}


Table A18. (continued) Estimates of hours of work using the Joint sample of men and women with and without instrumenting for spouse's earnings

\begin{tabular}{|c|c|c|c|c|c|c|c|c|}
\hline \multirow[b]{2}{*}{ VARIABLE } & \multicolumn{2}{|c|}{ (1) } & \multicolumn{2}{|c|}{$(2)$} & \multicolumn{2}{|c|}{ (3) } & \multicolumn{2}{|c|}{ (4) } \\
\hline & Non-IV & IV & Non-IV & IV & Non-IV & IV & Non-IV & IV \\
\hline \multicolumn{9}{|l|}{ Yearly Dummies } \\
\hline \multirow[t]{2}{*}{ Panel 6 (2002) } & 1.115 & 1.095 & 1.135 & 1.123 & $1.539 *$ & $1.547^{*}$ & $1.436^{*}$ & $1.439 *$ \\
\hline & $(0.774)$ & $(0.778)$ & $(0.775)$ & $(0.780)$ & $(0.808)$ & $(0.814)$ & $(0.806)$ & $(0.812)$ \\
\hline \multirow[t]{2}{*}{ Panel 7 (2003) } & -0.505 & -0.512 & -0.514 & -0.520 & -0.410 & -0.409 & -0.532 & -0.534 \\
\hline & $(0.677)$ & $(0.680)$ & $(0.691)$ & (0.694) & $(0.682)$ & $(0.685)$ & $(0.703)$ & $(0.706)$ \\
\hline \multirow[t]{2}{*}{ Panel 8 (2004) } & 0.405 & 0.414 & 0.354 & 0.365 & 0.581 & 0.599 & 0.407 & 0.421 \\
\hline & $(0.668)$ & $(0.668)$ & $(0.676)$ & $(0.677)$ & $(0.744)$ & $(0.746)$ & $(0.736)$ & $(0.738)$ \\
\hline \multirow[t]{2}{*}{ Panel 9 (2005) } & -0.231 & -0.224 & -0.254 & -0.242 & -0.260 & -0.242 & -0.377 & -0.363 \\
\hline & $(0.663)$ & $(0.665)$ & $(0.689)$ & $(0.691)$ & $(0.678)$ & $(0.683)$ & $(0.692)$ & $(0.696)$ \\
\hline \multirow[t]{2}{*}{ Panel 10 (2006) } & 0.296 & 0.283 & 0.292 & 0.277 & 0.193 & 0.187 & 0.0858 & 0.0756 \\
\hline & $(0.724)$ & $(0.731)$ & $(0.741)$ & $(0.748)$ & $(0.784)$ & $(0.789)$ & $(0.785)$ & (0.789) \\
\hline \multirow[t]{2}{*}{ Panel 11 (2007) } & -0.533 & -0.501 & -0.584 & -0.553 & -0.596 & -0.578 & -0.730 & -0.717 \\
\hline & $(0.623)$ & $(0.631)$ & $(0.638)$ & $(0.647)$ & $(0.671)$ & (0.679) & $(0.680)$ & $(0.687)$ \\
\hline \multirow[t]{2}{*}{ Constant } & $32.68 * * *$ & $32.38 * * *$ & $32.18 * * *$ & $31.73 * * *$ & $32.21 * * *$ & $31.84 * * *$ & $32.23 * * *$ & $31.88 * * *$ \\
\hline & $(1.524)$ & (1.548) & $(1.401)$ & $(1.451)$ & $(1.451)$ & $(1.516)$ & (1.502) & $(1.563)$ \\
\hline \multirow[t]{2}{*}{$\rho$} & -0.125 & -0.150 & -0.147 & -0.168 & -0.149 & -0.168 & -0.150 & -0.170 \\
\hline & $(0.0363)$ & $(0.0358)$ & $(0.0338)$ & $(0.0335)$ & $(0.0387)$ & $(0.0380)$ & $(0.0372)$ & $(0.0367)$ \\
\hline \multirow[t]{2}{*}{$\sigma$} & 9.361 & 9.381 & 9.394 & 9.414 & 9.418 & 9.434 & 9.404 & 9.422 \\
\hline & $(0.2419)$ & $(0.2440)$ & $(0.2415)$ & $(0.2434)$ & $(0.2619)$ & $(0.2639)$ & $(0.2560)$ & $(0.2584)$ \\
\hline \multirow[t]{2}{*}{$\lambda$} & -1.171 & -1.408 & -1.381 & -1.586 & -1.406 & -1.581 & -1.407 & -1.605 \\
\hline & $(0.3447)$ & $(0.3433)$ & $(0.3251)$ & $(0.3252)$ & $(0.3727)$ & $(0.3692)$ & $(0.3578)$ & $(0.3567)$ \\
\hline
\end{tabular}

Note : Standard errors in parentheses; all tests are two-sided against the null hypothesis that the marginal effect is $=0 ; \quad * * * p<0.01, * * p<0.05, * p<0.1$

Note: Maximum Likelihood estimates of regression models with selection using MEPS (panels 5 through 11). Rho is the correlation between the residuals of the wage and labor force participation equations, sigma is the standard error of the residual in the wage equation, and lambda is the product of rho and sigma. 
Table A19. Estimates of hours of work using the Joint sample of men and women with and without instrumenting for spouse's earnings

\begin{tabular}{|c|c|c|c|c|c|c|}
\hline \multirow[b]{2}{*}{ VARIABLE } & \multicolumn{2}{|c|}{ (5) } & \multicolumn{2}{|c|}{ (6) } & \multicolumn{2}{|c|}{ (7) } \\
\hline & Non-IV & IV & Non-IV & IV & Non-IV & IV \\
\hline Male & $\begin{array}{c}5.457 * * * \\
(0.460)\end{array}$ & $\begin{array}{c}5.125 * * * \\
(0.521)\end{array}$ & $\begin{array}{c}5.441^{* * *} \\
(1.081)\end{array}$ & $\begin{array}{c}5.113 * * * \\
(1.066)\end{array}$ & $\begin{array}{c}5.837 * * * \\
(0.897)\end{array}$ & $\begin{array}{c}5.388^{* * *} \\
(0.912)\end{array}$ \\
\hline Spouse Work-limit & $\begin{array}{r}-0.498 \\
(0.950)\end{array}$ & $\begin{array}{r}-0.570 \\
(0.948)\end{array}$ & $\begin{array}{l}-0.726 \\
(1.158)\end{array}$ & $\begin{array}{r}-0.850 \\
(1.160)\end{array}$ & $\begin{array}{r}-0.324 \\
(1.092)\end{array}$ & $\begin{array}{l}-0.481 \\
(1.089)\end{array}$ \\
\hline Spouse Very Good & $\begin{array}{l}-- \\
--\end{array}$ & $\begin{array}{l}-- \\
--\end{array}$ & $\begin{array}{l}-0.527 \\
(0.746)\end{array}$ & $\begin{array}{l}-0.554 \\
(0.736)\end{array}$ & $\begin{array}{l}-0.480 \\
(0.695)\end{array}$ & $\begin{array}{c}-0.542 \\
(0.679)\end{array}$ \\
\hline Spouse Good & $\begin{array}{l}-- \\
--\end{array}$ & $\begin{array}{l}-- \\
--\end{array}$ & $\begin{array}{l}0.0869 \\
(0.729)\end{array}$ & $\begin{array}{l}-0.0263 \\
(0.724)\end{array}$ & $\begin{array}{c}0.123 \\
(0.631)\end{array}$ & $\begin{array}{l}-0.0432 \\
(0.635)\end{array}$ \\
\hline Spouse Fair/Poor & $\begin{array}{l}-- \\
--\end{array}$ & $\begin{array}{l}-- \\
--\end{array}$ & $\begin{array}{l}0.0251 \\
(1.073)\end{array}$ & $\begin{array}{c}-0.0881 \\
(1.067)\end{array}$ & $\begin{array}{l}-0.271 \\
(0.941)\end{array}$ & $\begin{array}{l}-0.468 \\
(0.948)\end{array}$ \\
\hline Spouse \# of Conditions & $\begin{array}{l}-- \\
--\end{array}$ & $\begin{array}{l}-- \\
--\end{array}$ & $\begin{array}{l}0.0983 \\
(0.297)\end{array}$ & $\begin{array}{c}0.114 \\
(0.297)\end{array}$ & $\begin{array}{c}0.214 \\
(0.267)\end{array}$ & $\begin{array}{c}0.228 \\
(0.267)\end{array}$ \\
\hline Spouse \# of Func. Limits & $\begin{array}{l}-- \\
--\end{array}$ & $\begin{array}{l}-- \\
--\end{array}$ & $\begin{array}{l}0.0714 \\
(0.210)\end{array}$ & $\begin{array}{r}0.0851 \\
(0.211)\end{array}$ & $\begin{array}{l}0.0487 \\
(0.196)\end{array}$ & $\begin{array}{r}0.0499 \\
(0.196)\end{array}$ \\
\hline Spouse (z-scored) PCS & $\begin{array}{c}-0.192 \\
(0.281)\end{array}$ & $\begin{array}{r}-0.123 \\
(0.284)\end{array}$ & $\begin{array}{c}-0.0649 \\
(0.322)\end{array}$ & $\begin{array}{c}-0.00214 \\
(0.321)\end{array}$ & $\begin{array}{l}-- \\
--\end{array}$ & $\begin{array}{l}-- \\
--\end{array}$ \\
\hline Male * Spouse Work-limit & $\begin{array}{c}1.234 \\
(1.739)\end{array}$ & $\begin{array}{c}1.330 \\
(1.736)\end{array}$ & $\begin{array}{l}-0.549 \\
(1.541)\end{array}$ & $\begin{array}{r}-0.406 \\
(1.544)\end{array}$ & $\begin{array}{l}-0.107 \\
(1.619)\end{array}$ & $\begin{array}{r}0.0815 \\
(1.604)\end{array}$ \\
\hline Male * Spouse Very Good & $\begin{array}{l}-- \\
--\end{array}$ & $\begin{array}{l}-- \\
--\end{array}$ & $\begin{array}{r}-0.750 \\
(1.033)\end{array}$ & $\begin{array}{r}-0.746 \\
(1.029)\end{array}$ & $\begin{array}{c}-0.481 \\
(0.990)\end{array}$ & $\begin{array}{l}-0.459 \\
(0.982)\end{array}$ \\
\hline Male * Spouse Good & $\begin{array}{l}-- \\
--\end{array}$ & $\begin{array}{l}-- \\
--\end{array}$ & $\begin{array}{l}-2.072^{*} \\
(1.054)\end{array}$ & $\begin{array}{l}-1.990^{*} \\
(1.048)\end{array}$ & $\begin{array}{c}-1.969 * * \\
(0.927)\end{array}$ & $\begin{array}{c}-1.851^{* *} \\
(0.927)\end{array}$ \\
\hline Male * Spouse Fair/Poor & $\begin{array}{l}-- \\
--\end{array}$ & $\begin{array}{l}-- \\
--\end{array}$ & $\begin{array}{r}-0.386 \\
(1.469)\end{array}$ & $\begin{array}{r}-0.333 \\
(1.469)\end{array}$ & $\begin{array}{c}-0.172 \\
(1.308)\end{array}$ & $\begin{array}{l}-0.0615 \\
(1.312)\end{array}$ \\
\hline Male * Spouse \# of Conditions & $\begin{array}{l}-- \\
--\end{array}$ & $\begin{array}{l}-- \\
--\end{array}$ & $\begin{array}{c}0.187 \\
(0.396)\end{array}$ & $\begin{array}{c}0.178 \\
(0.397)\end{array}$ & $\begin{array}{c}-0.00401 \\
(0.371)\end{array}$ & $\begin{array}{r}-0.0107 \\
(0.372)\end{array}$ \\
\hline Male * Spouse \# of Func. Limits & $\begin{array}{l}-- \\
--\end{array}$ & $\begin{array}{l}-- \\
--\end{array}$ & $\begin{array}{c}0.242 \\
(0.331)\end{array}$ & $\begin{array}{c}0.230 \\
(0.331)\end{array}$ & $\begin{array}{c}0.169 \\
(0.311)\end{array}$ & $\begin{array}{c}0.171 \\
(0.312)\end{array}$ \\
\hline Male * Spouse (z-scored) PCS & $\begin{array}{c}0.134 \\
(0.364)\end{array}$ & $\begin{array}{r}0.0779 \\
(0.371)\end{array}$ & $\begin{array}{c}0.132 \\
(0.444)\end{array}$ & $\begin{array}{r}0.0766 \\
(0.447)\end{array}$ & $\begin{array}{l}-- \\
--\end{array}$ & $\begin{array}{l}-- \\
--\end{array}$ \\
\hline
\end{tabular}


Table A19. (continued) Estimates of hours of work using the Joint sample of men and women with and without instrumenting for spouse's earnings

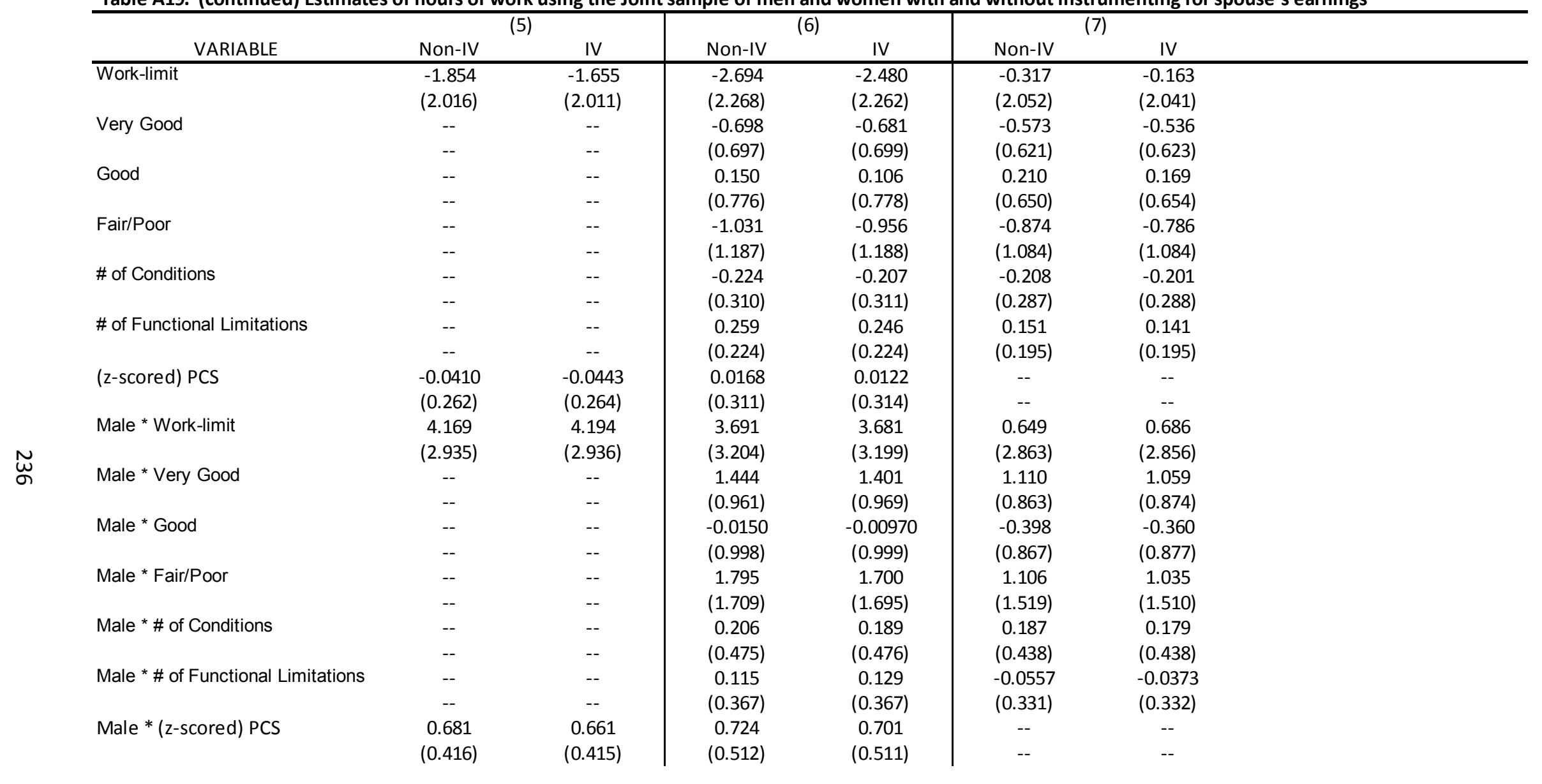


Table A19. (continued) Estimates of hours of work using the Joint sample of men and women with and without instrumenting for spouse's earnings

\begin{tabular}{|c|c|c|c|c|c|c|}
\hline \multirow[b]{2}{*}{ VARIABLE } & \multicolumn{2}{|c|}{ (5) } & \multicolumn{2}{|c|}{ (6) } & \multicolumn{2}{|c|}{ (7) } \\
\hline & Non-IV & IV & Non-IV & IV & Non-IV & IV \\
\hline \multirow[t]{2}{*}{ \# Children $<18$ years old } & -0.206 & -0.220 & -0.132 & -0.145 & -0.177 & -0.183 \\
\hline & $(0.222)$ & $(0.225)$ & $(0.228)$ & $(0.232)$ & $(0.216)$ & $(0.220)$ \\
\hline \multirow[t]{2}{*}{ \# Children $>=18$ years old } & 0.193 & 0.167 & 0.233 & 0.209 & 0.227 & 0.202 \\
\hline & $(0.240)$ & $(0.243)$ & $(0.237)$ & (0.239) & $(0.216)$ & $(0.219)$ \\
\hline \multirow[t]{2}{*}{ White } & $0.750^{*}$ & 0.736 & 0.716 & 0.693 & 0.649 & 0.614 \\
\hline & (0.451) & $(0.452)$ & $(0.461)$ & $(0.462)$ & $(0.433)$ & $(0.432)$ \\
\hline \multicolumn{7}{|l|}{ Potential Wage Indicators } \\
\hline \multirow{2}{*}{ Individual's Predicted Wage } & 0.216 & 0.483 & 0.197 & 0.457 & 0.215 & 0.543 \\
\hline & $(0.621)$ & $(0.634)$ & $(0.621)$ & $(0.634)$ & $(0.564)$ & $(0.580)$ \\
\hline \multirow[t]{2}{*}{ Union } & $-2.455 * * *$ & $-2.456 * * *$ & $-2.412^{* * *}$ & $-2.414^{* * *}$ & $-2.221 * * *$ & $-2.223 * * *$ \\
\hline & $(0.387)$ & $(0.390)$ & $(0.389)$ & $(0.391)$ & $(0.364)$ & $(0.365)$ \\
\hline \multirow[t]{2}{*}{ Retirement/Pension Plan } & $2.685 * * *$ & $2.712 * * *$ & $2.686 * * *$ & $2.719 * * *$ & $2.594 * * *$ & $2.624 * * *$ \\
\hline & $(0.433)$ & $(0.436)$ & $(0.438)$ & $(0.441)$ & $(0.392)$ & $(0.395)$ \\
\hline \multirow[t]{2}{*}{ Holds ESI } & $3.498 * * *$ & $3.399 * * *$ & $3.509 * * *$ & $3.405^{* * *}$ & $3.316^{* * *}$ & $3.199 * * *$ \\
\hline & $(0.430)$ & $(0.420)$ & $(0.424)$ & $(0.413)$ & $(0.399)$ & $(0.393)$ \\
\hline \multirow[t]{2}{*}{ Choice of Insurance Plans } & 0.250 & 0.257 & 0.261 & 0.268 & 0.409 & 0.419 \\
\hline & $(0.373)$ & $(0.374)$ & $(0.376)$ & $(0.377)$ & $(0.347)$ & $(0.348)$ \\
\hline \multirow[t]{2}{*}{ Paid Sick Leave } & $2.779 * * *$ & $2.776 * * *$ & $2.737^{* * *}$ & $2.733^{* * *}$ & $2.777^{* * *}$ & $2.768^{* * *}$ \\
\hline & $(0.490)$ & $(0.490)$ & $(0.495)$ & $(0.495)$ & $(0.458)$ & $(0.459)$ \\
\hline \multicolumn{7}{|l|}{ Unearned Income } \\
\hline \multirow[t]{2}{*}{ Spouse's Earnings (\$100/week) } & 0.0573 & -0.0285 & 0.0594 & -0.0294 & 0.0693 & -0.0327 \\
\hline & $(0.0486)$ & $(0.0812)$ & $(0.0484)$ & $(0.0800)$ & $(0.0442)$ & $(0.0772)$ \\
\hline \multirow[t]{2}{*}{ Household Income (\$100/year) } & -0.00225 & -0.00222 & -0.00235 & -0.00233 & -0.00216 & -0.00217 \\
\hline & $(0.00164)$ & $(0.00166)$ & $(0.00165)$ & $(0.00167)$ & $(0.00143)$ & $(0.00144)$ \\
\hline \multirow[t]{2}{*}{ Spouse Employed } & $-1.782 * * *$ & -1.178 & $-1.703 * * *$ & -1.080 & $-1.766^{* * *}$ & -1.026 \\
\hline & $(0.510)$ & $(0.745)$ & $(0.513)$ & $(0.735)$ & $(0.495)$ & $(0.712)$ \\
\hline
\end{tabular}


Table A19. (continued) Estimates of hours of work using the Joint sample of men and women with and without instrumenting for spouse's earnings

\begin{tabular}{|c|c|c|c|c|c|c|}
\hline \multirow[b]{2}{*}{ VARIABLE } & \multicolumn{2}{|c|}{ (5) } & \multicolumn{2}{|c|}{ (6) } & \multicolumn{2}{|c|}{ (7) } \\
\hline & Non-IV & IV & Non-IV & IV & Non-IV & IV \\
\hline \multicolumn{7}{|l|}{ Yearly Dummies } \\
\hline \multirow[t]{2}{*}{ Panel 6 (2002) } & $1.543 *$ & $1.553^{*}$ & $1.445^{*}$ & $1.443 *$ & 1.089 & 1.066 \\
\hline & $(0.803)$ & $(0.810)$ & $(0.802)$ & $(0.806)$ & $(0.775)$ & $(0.779)$ \\
\hline \multirow[t]{2}{*}{ Panel 7 (2003) } & -0.404 & -0.399 & -0.505 & -0.507 & -0.544 & -0.554 \\
\hline & $(0.685)$ & $(0.688)$ & $(0.697)$ & $(0.699)$ & $(0.685)$ & $(0.688)$ \\
\hline \multirow[t]{2}{*}{ Panel 8 (2004) } & 0.576 & 0.595 & 0.454 & 0.468 & 0.359 & 0.365 \\
\hline & $(0.737)$ & $(0.740)$ & $(0.724)$ & $(0.726)$ & $(0.669)$ & $(0.669)$ \\
\hline \multirow{2}{*}{ Panel 9 (2005) } & -0.277 & -0.259 & -0.346 & -0.334 & -0.266 & -0.260 \\
\hline & (0.679) & $(0.683)$ & (0.679) & $(0.682)$ & $(0.674)$ & $(0.676)$ \\
\hline \multirow[t]{2}{*}{ Panel 10 (2006) } & 0.176 & 0.169 & 0.108 & 0.0990 & 0.288 & 0.273 \\
\hline & $(0.776)$ & $(0.781)$ & $(0.769)$ & $(0.774)$ & $(0.730)$ & $(0.737)$ \\
\hline \multirow[t]{2}{*}{ Panel 11 (2007) } & -0.588 & -0.569 & -0.698 & -0.684 & -0.589 & -0.560 \\
\hline & $(0.670)$ & $(0.677)$ & $(0.670)$ & $(0.677)$ & $(0.629)$ & $(0.636)$ \\
\hline \multirow[t]{2}{*}{ Constant } & $32.22 * * *$ & $31.92 * * *$ & $32.60 * * *$ & $32.37 * * *$ & $32.64 * * *$ & $32.33 * * *$ \\
\hline & (1.470) & (1.536) & (1.644) & (1.686) & (1.508) & (1.537) \\
\hline \multirow[t]{2}{*}{$\rho$} & -0.149 & -0.174 & -0.130 & -0.156 & -0.124 & -0.148 \\
\hline & (0.0389) & (0.0379) & $(0.0384)$ & $(0.0376)$ & $(0.0346)$ & $(0.0345)$ \\
\hline \multirow[t]{2}{*}{$\sigma$} & 9.410 & 9.431 & 9.360 & 9.380 & 9.354 & 9.374 \\
\hline & $(0.2593)$ & $(0.2615)$ & $(0.2547)$ & $(0.2574)$ & $(0.2398)$ & $(0.2420)$ \\
\hline \multirow[t]{2}{*}{$\lambda$} & -1.399 & -1.637 & -1.217 & -1.464 & -1.155 & -1.389 \\
\hline & $(0.3730)$ & $(0.3663)$ & $(0.3640)$ & $(0.3605)$ & $(0.3289)$ & (0.3307) \\
\hline
\end{tabular}

Note: Standard errors in parentheses; all tests are two-sided against the null hypothesis that the marginal effect is $=0 ; \quad * * * p<0.01, * * p<0.05, * p<0.1$

Note: Maximum Likelihood estimates of regression models with selection using MEPS (panels 5 through 11). Rho is the correlation between the residuals of the wage and labor force participation equations, sigma is the standard error of the residual in the wage equation, and lambda is the product of rho and sigma. 


\section{References}

Baker, M., M. Stabile, and C. Deri (2004) "What Do Self-Reported, Objective, Measures of Health Measure?” The Journal of Human Resources, 39(4), PP. 1067-1093.

Bartel, A. and P. Taubman (1986) "Some Economic and Demographic Consequences of Mental Illness," Journal of Labor Economics, 4, PP. 243-256.

Berger, M.C. (1983) “Labor Supply and Spouse's Health: the Effects of Illness, Disability, and Mortality," Social Science Quarterly, 64, pp. 494-509.

Berger, M.C. and B.M. Fleisher (1984) "Husband's Health and Wife's Labor Supply," Journal of Health Economics, 3, pp. 63-75.

Blau, D.M. (1998) "Labor Force Dynamics of Older Married Couples," Journal of Labor Economics, 16(3), pp. 595-629.

Blau, D.M. and R.T. Riphahn (1999) "Labor Force Transitions of Older Married Couples in Germany." Labour Economics, 6, pp. 229-251.

Blau, F.D. and L.M. Kahn (2007) "Changes in Labor Supply Behavior of Married Women: 1980-2000,” Journal of Labor Economics, 25(3), pp. 393-438.

Bollen, K.A., D.K. Guilkey, and T.A. Mroz (1995) "Binary Outcomes and Endogenous Explanatory Variables: Tests and Solutions with an Application to the Demand for Contraceptive Use in Tunisia," Demography, 32(1), pp. 111-131.

Borjas, G.J. (1986) “The Self-Employment Experience of Immigrants,” The Journal of Human Resources, 21(4), pp. 485-506.

Bound, J. (1991) "Self-Reported Versus Objective Measures of Health in Retirement Models," The Journal of Human Resources, 26(1), pp. 106-138.

Bound, J., M.Schoenbaum, T. Stinebrickner, and T. Waidmann (1999) “The Dynamic Effects of Health on the Labor Force Transitions of Older Workers," Labour Economics, 6, pp. 179-202.

Bound, J., T. Stinebrickner, and T. Waidmann (2008) "Health, Economic Resources and the Work Decisions of Older Men," Population Studies Center Research Report 07-630. University of Michigan Institute for Social Research: Ann Arbor, MI.

Buchmueller, T.C. and R.G. Valletta (1999) "The Effect of Health Insurance on Married Female Labor Supply,” The Journal of Human Resources, 34(1), pp. 42-70. 
Cameron, A.C. and P.K. Trivedi (2007) Microeconometrics Using Stata. StataCorp LP: College Station, TX.

Charles, K.K. (1999) "Sickness in the Family: Health Shocks and Spousal Labor Supply," Working Paper 00-011. Ford School of Public Policy Working Paper Series, University of Michigan: MI.

Coile, C.C. (2004) "Health Shocks and Couples' Labor Supply Decisions," NBER Working Paper 10810. National Bureau of Economic Research: Cambridge, MA.

Contoyannis, P. and A. Jones (2004) "Socio-economic Status, Health and Lifestyle," Journal of Health Economics, 23, pp. 965-995.

Dwyer, D.S. and O.S. Mitchell (1999) "Health Problems as Determinants of Retirement: Are Self-rated Measures Endogenous?" Journal of Health Economics, 18, pp. 173-193.

Eltinge, J.L. and W.M. Sribney (1996) "svy5: Estimates of Linear Combinations and Hypothesis Tests for Survey Data," Stata Technical Bulletin, 31, pp. 31-42.

Giertz, S. (2000) "Spouse's Labor Supply Response of Low-Income Households to IncomeLosses from Disability," Industrial and Labor Relations Review, 29, pp. 85-96.

Huarin, D. (1989) “Women's Labor Market Reactions to Family Disruptions," The Review of Economics and Statistics, 71, pp. 54-61.

Hurd, M.D. (1990) “The Joint Retirement Decisions of Husbands and Wives," in D.A. Wise, ed., Issues in the Economics of Aging. University of Chicago Press for the National Bureau of Economic Research: Chicago, IL. pp. 231-254.

Johnson, R.W. and M.M. Favreault (2001) "Retiring Together or Working Alone: the Impact of Spousal Employment and Disability on Retirement Decisions," Working Paper 2001- 01. Center for Retirement Research at Boston College: Boston, MA.

Korn, E.L. and B. Graubard (1990) "Simultaneous Testing of Regression Coefficients with Complex Survey Data: Use of Bonferroni $t$ statistics," American Statistician, 44, pp. 270-276.

Layard, R., M. Barton and A. Zabalza (1980) "Married Women's Participation and Hours," Economica, 47, pp. 51-72.

Maestas, N. (2001) "Labor, Love and Leisure: Complementarity and the Timing of Retirement by Working Couples," Unpublished Manuscript. 
O’Hara, B. (2004) “Do Mothers Work to Support Ailing Husbands?” Journal of Family and Economic Issues, 25(2), pp. 179-198.

Parsons, D.O. (1977) "Health, Family Structure, and Labor Supply," The American Economic Review, 67(4), pp. 703-712.

Penning, M.J. and L.A. Strain (1994) "Gender Differences in Disability, Assistance, and Subjective Well-being in Later Life," Journal of Gerontology, 49(4), pp. S202-S208.

Ross, C.E. and C.E. Bird (1994) "Sex Stratification and Health Lifestyle: Consequence's for Men and Women's Perceived Health," Journal of Health and Social Behavior, 35(2), pp. 161-178.

Siegel, M.J. (2006) "Measuring the Effect of Husband's Health on Wife's Labor Supply," Health Economics, 15, pp. 579-601.

Simonsick, E. (1993) "Relationship Between Husband's Health Status and the Mental Health of Older Women," Journal of Aging and Health, 5(3), pp. 319-337.

StataCorp. (2007) Stata Statistical Software: Release 10 [SVY]. StataCorp LP: College Station, TX

Stern, S. (1989) "Measuring the Effect of Disability on Labor Force Participation," The Journal of Human Resources, 24(3), pp. 361-395.

Verbrugge, L. (1984) "A Health Profile of Older Women with Comparisons To Older Men," Research on Aging, 3(6), pp. 291-322.

Wooldridge, J.M. (2002) Econometric Analysis of Cross Section and Panel Data. The MIT Press: Cambridge, MA. 